PNL-8318

Ver. 2.0

INTEGRATED BASELINE SYSTEM (IBS)

Version 2.0

\title{
USER GUIDE
}
J. C. Bower ${ }^{(a)}$
E. E. Schrank
M. J. Burford
J. R. Williams
T. R. Downing
C. Winters
S. W. Matsumoto
B. M. Wood

March 1994

Prepared for the U.S. Army Nuclear and Chemical Agency under a Related Services Agreement with the U.S. Department of Energy Contract DE-AC06-76RLO 1830

Pacific Northwest Laboratory

Richland, Washington 99352

(a) Bower Software Services Kennewick, Washington 


\section{NOTICE}

The Integrated Baseline System (IBS) is an emergency planning, training, and response tool intended to supplement existing resources for emergency planning, training, and management. IBS results must NOT be used as the sole basis for a decision regarding public safety. Although IBS is operational, not all IBS software/models have been verified. The assumptions of the IBS software must be reviewed to assure its appropriateness for an intended use. 


\section{Preface}

The Integrated Baseline System (IBS) is an emergency management planning and analysis tool being developed under the direction of the Federal Emergency Management Agency. The following documents were developed to support system users. The audience for each is identified.

This IBS User Guide explains how to start and use the IBS program, which is designed to help civilian emergency management personnel to plan for and support their responses to a chemical-releasing event at a military chemical stockpile. (a) Audience: all users of the IBS, especially emergency management planners and analysts.

The IBS Utilities Guide explains how you can use IBS utility programs to manage and manipulate various kinds of IBS data. These programs include utilities for creating, editing, and displaying maps and other data that are referenced to geographic location. Audience: chiefly data managers but also system managers and some emergency management planners and analysts.

The IBS Models Guide summarizes the IBS use of several computer models for predicting the results of emergency situations. These include models for predicting dispersion/doses of airborne contaminants, traffic evacuation, explosion effects, heat radiation from a fire, and siren sound transmission. The guide references additional technical documentation on the models when such documentation is available from other sources. Audience: chiefly emergency management planners and analysts, but also data managers and system managers.

The IBS Data Management Guide provides the information needed to manage the data files and database used to support the administrative, userenvironment, database management, and operational capabilities of the IBS. Audience: chiefly database administrators and system managers, but also emergency management planners and analysts who want to know details of the emergency management data.

The IBS System Management Guide defines IBS hardware and software requirements and gives instructions for installing, upgrading, or transferring the IBS software package. Audience: system managers.

(a) The IBS program was developed as part of the U.S. Army's Chemical Stockpile Emergency Preparedness Program (CSEPP). 


\section{New in This Guide}

In response to user requests, the IBS Main Menu was changed shortly before the latest release. This addendum lists the changes made.

The following new options were added to the IBS Main Menu:

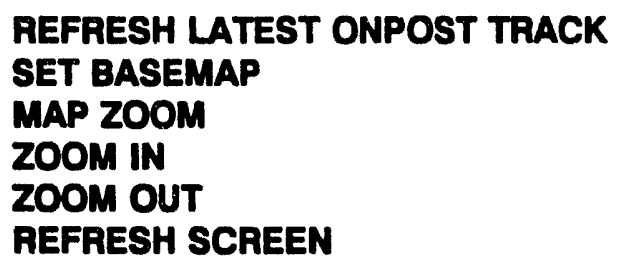

Not all of the samples of the Main Menu in this Guide will reflect the latest changes. This Preface has been updated as well as Section 1, Introduction and Overview.

REFRESH LATEST ONPOST TRACK is discussed in Section 7, along with the related function, SHOW LATEST ONPOST TRACK.

SET BASEMAP, MAP ZOOM, ZOOM IN, ZOOM OUT, and REFRESH SCREEN are discussed in Section 5, Map Analysis.

The following Main Menu options were renamed:
ANALYZE TRACK $\rightarrow$
CHANGE D2 TRACK CASE $\rightarrow$
ANALYZE D2 TRACK
REPORT CURRENT D2 DESCRIPTION $\rightarrow$

The functionality of these options were not changed. Although updates are in progress, you may still find these functions mentioned under their old names in this Guide. 
About thls Gulde

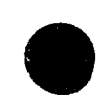




\section{About This Guide}

\section{Purpose}

This IBS User Guide explains how to start and use the Integrated Baseline System (IBS) program. IBS is an emergency management planning and analysis tool that is being developed under the direction of the U.S. Army Nuclear and Chemical Agency (USANCA). ${ }^{\text {(a) }}$

\section{Scope}

This document provides information for the general system user, and is the primary reference for the system features of the IBS. It is designed for persons who are familiar with general emergency management concepts, operations, and vocabulary.

Although the IBS manual set covers basic and advanced operations, it is not a complete reference document set. Emergency situation modeling software in the IBS is supported by additional technical documents. Some of the other IBS software is commercial software for which more complete docunentation is available. The IBS manuals reference such documentation where necessary.

General questions regarding IBS should be directed to the IBS Project Manager for the U.S. Army Nuclear and Chemical Agency (USANCA):

COL Lawrence Skelly

Chief, Chemical Division

U.S. Army Nuclear and Chemical Agency

7150 Heller Loop, Suite 101

Springfield, VA 22150-3198

Software use questions and problems should be addressed to the IBS Help Desk operated by Innovative Emergency Management (IEM):

(504) $767-1138$

Innovative Emergency Management

Suite E

Baton Rouge, LA 70808-4362

(a) The IBS is being developed by the Pacific Northwest Laboratory (PNL). PNL is operated for the U.S.

Department of Energy by Battelle Memorial Institute under Contract DE-ACO6-76RLO 1830. 
All references to IBS should be made through USANCA. If an emergency contact is necessary, and USANCA cannot be reached, a second source of information is the software developer, Pacific Northwest Laboratory:

Pacific Northwest Laboratory

Attn: Blanche M. Wood, K7-22

POB 999, MS K7-22

Richland, WA 99352

Phone (509) 375-2615

\section{Audience}

The primary audience for tnis document is composed of IBS general users, emergency planners and analysts, information managers, and geographic database administrators.

\section{Prerequisites}

Knowledge Requirements for Using the IBS. Users of the IBS software should receive training in the use of IBS capabilities for emergency management planning and operational tasks associated with CSEPP. For those users, this document is a reference guide to IBS capabilities. However, this document does not describe the overall context for using the IBS: it is expected that training and training materials will provide that context.

\section{Organization}

The chapters of this guide introduce IBS concepts and functions and explain how to navigate the menus and operate the various parts of the system.

\section{Section 1. Introduction and Overview}

A description of general system functions plus an introduction to the purpose and parts of the IBS and its use in developing emergency plans. Describes how to navigate the menu system, conventions for interacting with the IBS, and presents a series of exercises for the new user.

\section{Section 2. Message Board}

A reference guide to the IBS system functions and commands for the Message Board Main Menu function. 
Section 3. Status Board

A reference guide to the IBS system functions and commands for the Status Board Main Menu function.

\section{Section 4. Personnel Management}

A reference guide to the IBS system functions and commands for the Personnel Management Main Menu function.

Section 5. Map Analysis

A reference guide to the IBS system functions and commancis for the Map Analysis Main Menu function.

Section 6. Resource Management

A reference guide to the IBS system functions and commands for the Resource Management Main Menu function.

\section{Section 7. Show Latest Onpost Track and Refresh Latest Onpost Track}

A reference guide to the IBS system functions and commands for the Show Latest Onpost Track and Refresh Latest Onpost Track Main Menu Functions.

Sec a 8. Analyze D2 Track

A reference guide to the IBS system functions and commands for the Analyze D2 Track Main Menu function.

\section{Section 9. Change D2 Case}

A reference guide to the IBS system functions and commands for the Change D2 Case Main Menu function.

\section{Section 10. Show D2 Description}

A reference guide to the IBS system functions and commands for the Show D2 Description Main Menu function.

\section{Section 11. Emergency Activities}

A reference guide to the IBS system functions and commands for the Emergency Activities Main Menu function. 
Section 12. Setup

A reference guide to the IBS system functions and commands for the Setup Main Menu function.

Appendix A. IBS Graphic Menus

IBS Graphic Menus are illustrated in a series of pull-out reference pages.

Appendix B. Non-Graphic IBS

The use of the non-graphic IBS is summarized.

Appendix C. People Location

The People Location (LOCATE) program and its functions are described.

Appendix D. Onpost Simulator

The Onpost Simulator program and its functions are described.

Appendix E. IBS and Onpost EOC Reports

Descriptions of the formats for IBS and Onpost EOC reports.

Appendix F. System Icons

Descriptions and illustrations of the icons used in the graphic map display of IBS. 


\section{How to Use this Document}

This guide is organiz $d$ around the capabilities of the graphic IBS software. You will access most of these capabilities by picking them from menu listings on your terminal screen.

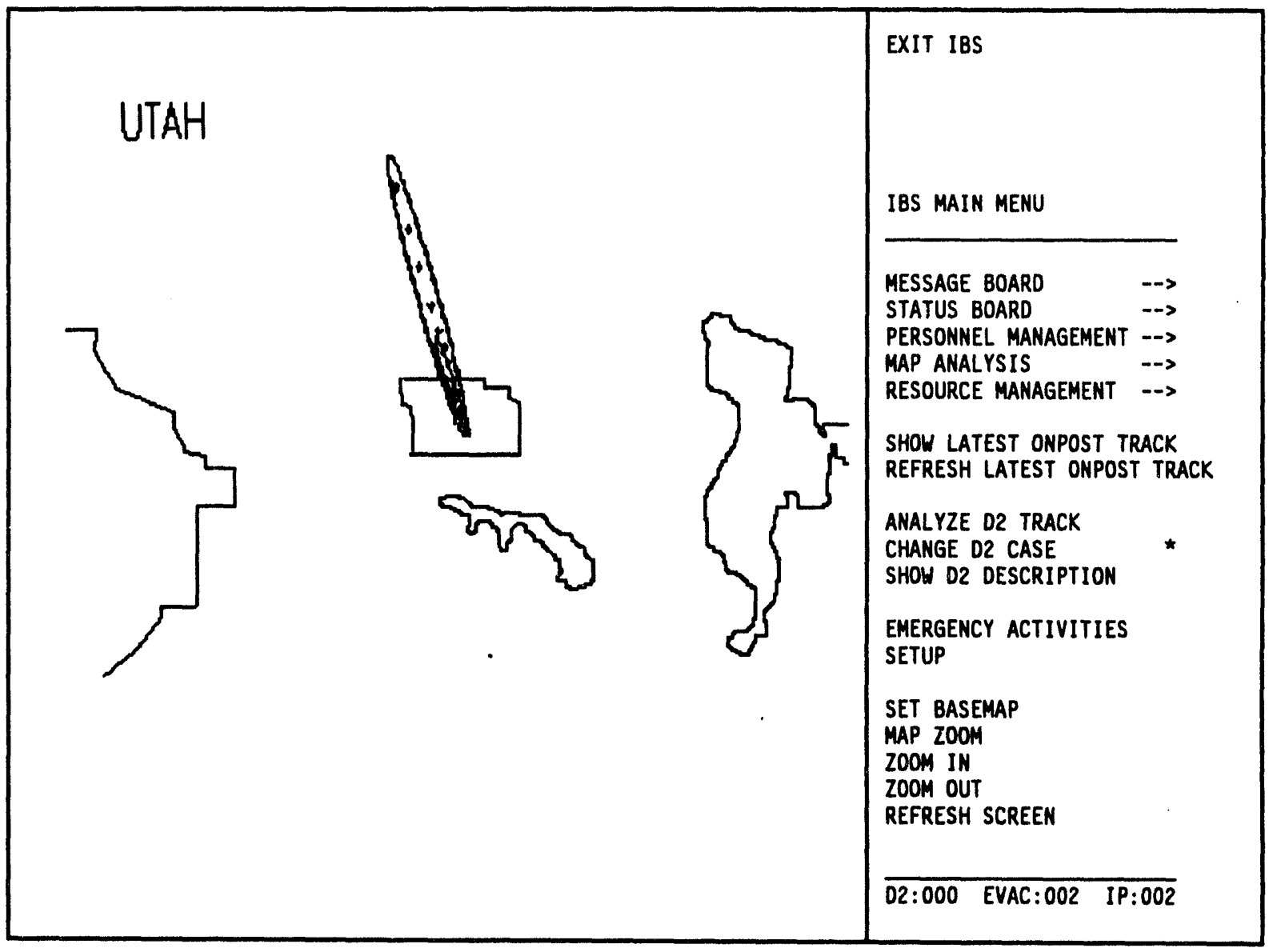

This is an illustration of the IBS main menu, which displays when you start the IBS. The screen display is split into two sections:

- Map display

- Menu display

The map display is on the left side of the screen, and is always visible except when you are in a report, a form, or other text function. The initial map display is the preset default established by the system manager. You can change the map display using the functions described in this guide. 
The menu display is on the right side of the screen. In this guide, the menu display is often shown without the accompanying map display, as in this example.

\begin{tabular}{|l|}
\hline EXIT IBS \\
\\
\\
IBS MAIN MENU \\
\hline \\
MESSAGE BOARD \\
STATUS BOARD \\
PERSONNEL MANAGEMENT \\
MAP ANALYSIS \\
RESOURCE MANAGEMENT \\
SHOW LATEST ONPOST TRACK \\
REFRESH LATEST ONPOST TRACK \\
ANALYZ D2 TRACK \\
CHANGE D2 CASE \\
SHOW D2 DESCRIPTION \\
EMERGENCY ACTIVITIES \\
SETUP \\
SET BASEMAP \\
MAP ZOOM \\
ZOOM IN \\
ZOOM OUT \\
REFRESH SCREEN \\
\hline
\end{tabular}

Each item on this menu represents a major category of capabilities. Picking items on this menu leads you to other menus (submenus) that list further capabilities.

Reference Sections. The sections following Section 1 comprise the reference sections of this guide. The sections are organized by major function in the order in which they appear on the main menu. Each section explains one function on the IBS main menu and is pagenumbered independently. Within each section, descriptions of submenu items are ordered alphabetically.

Page Headings in the Reference Sections. The menu/submenu item names appear at the top of each page so you can look up most IBS capabilities as in a dictionary.

Asterisks $\left(^{*}\right)$ in this Guide. Asterisks indicate IBS menu items that require special privileges. These items appear as blank lines on the menus of users who lack the required privileges.

\section{Visual Conventions in this Guide}

- Bold italics mark special terms (defined in the text).

- Menu items are upper case and bold: STATUS BOARD.

- Special headings mark the beginning of each menu item description: 
- MAIN MENU ITEMS

II SECOND-LEVEL MENU ITEMS

III THIRD-LEVEL MENU ITEMS

- Key Names. Keyboard key names are in upper-case letters. Special function key names are also in bold. Key combinations that require you to press keys simultaneously are hyphenated.

Examples: Instruction Meaning of Instruction

Press RETURN. Press the RETURN key once.

Press GOLD Z. Press the GOLD key once. Then press the $\mathrm{Z}$ key once.

Press CTRL-Z. Hold down the CTRL key and press the $\mathrm{Z}$ key once.

- Screen Text. Computer screen text appears in a different typeface than text that is typed in. Text that has been typed (or will be typed) at the keyboard is shown in bold.

Example: Enter the longitude > -112.3386

Enter the latitude $>\mathbf{4 0 . 2 6 7 9}$

- Data Input Forms. Some text screens are also forms that you will use for entering some system data. Forms in this guide are represented with the following graphic lines located before and after the text. Complete instructions for filling in IBS forms are presented in Section 1.

Example:

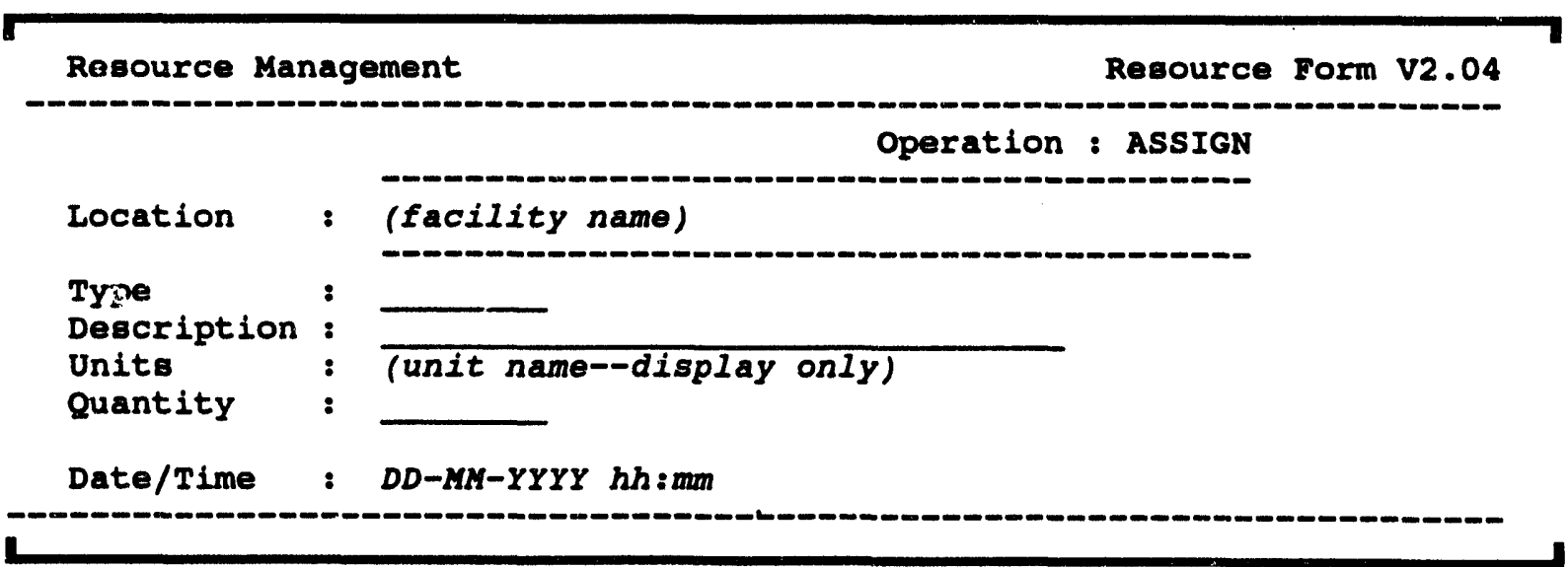


- Italics in screen displays indicate notes or variable items (examples on the screen above). 


\section{Contents}

Preface $\ldots \ldots \ldots \ldots \ldots \ldots \ldots \ldots \ldots \ldots \ldots \ldots \ldots \ldots \ldots \ldots$ ill

About This Guide $\ldots \ldots \ldots \ldots \ldots \ldots \ldots \ldots \ldots \ldots \ldots \ldots \ldots \ldots \ldots$

\section{Saction 1. Introduction and Overview}

Overview of System Use $\ldots \ldots \ldots \ldots \ldots \ldots \ldots \ldots \ldots \ldots \ldots \ldots \ldots . .2$

IBS Users . . . . . . . . . . . . . . . . . . . . . . . 1.4

Getting Started (and Getting Stopped) . . . . . . . . . . . . . . . 1.5

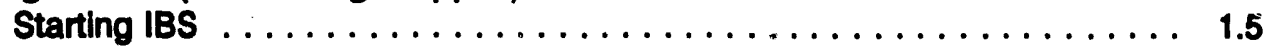

Using IBS menus ......................... 1.5

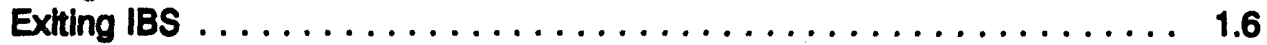

Conventions for Interacting with the IBS $\ldots \ldots \ldots \ldots \ldots \ldots \ldots \ldots \ldots 1.8$

Graphic Interactions $\ldots \ldots \ldots \ldots \ldots \ldots \ldots \ldots \ldots \ldots \ldots \ldots \ldots$

Using Tektronix Terminals $\ldots \ldots \ldots \ldots \ldots \ldots \ldots \ldots \ldots \ldots \ldots \ldots 1.11$

Using a VAXstation ......................... 1.11

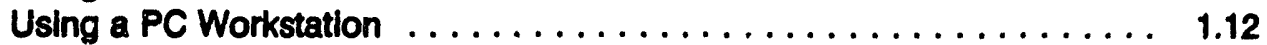

Defining Map Areas (Polygons) $\ldots \ldots \ldots \ldots \ldots \ldots \ldots \ldots \ldots \ldots .1 .12$

Stopping Map Redraws $\ldots \ldots \ldots \ldots \ldots \ldots \ldots \ldots \ldots \ldots \ldots \ldots \ldots \ldots$

Problems with Graphic Input $\ldots \ldots \ldots \ldots \ldots \ldots \ldots \ldots \ldots \ldots \ldots, 1.14$

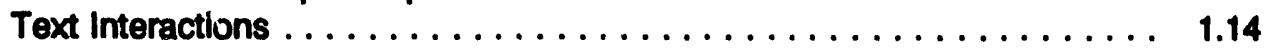

Viewing Text Dialog ......................... 1.15

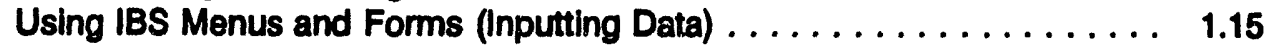

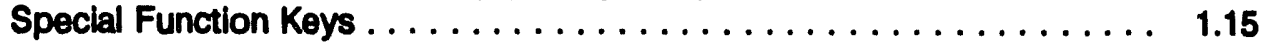

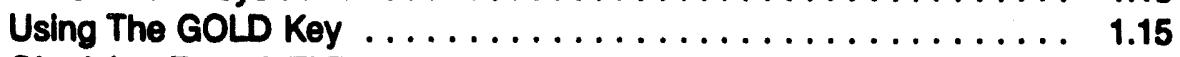

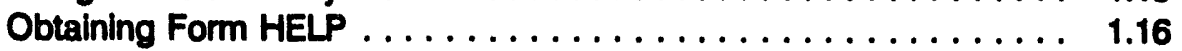

Selecting an Option from a Text Menu . . . . . . . . . . . . 1.18

To select an option from a text menu $\ldots \ldots \ldots \ldots \ldots \ldots \ldots .1 .18$

Selecting Multiple Items from a Lst . . . . . . . . . . . . . . . 1.19

Positioning the Input Cursor in a Form ............ 1.19

Entering Numeric Values in a Form .............. 1.19

Problems with Menus and Forms $\ldots \ldots \ldots \ldots \ldots \ldots \ldots \ldots . \ldots \ldots$

Overview of the IBS Main Menu ..................... 1.20

Asterisks $\left(^{*}\right)$ in this Document . . . . . . . . . . . . . . . . . 1.20

Order of the Reference Sections . . . . . . . . . . . . . . . . . . . 1.20

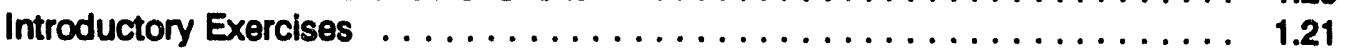

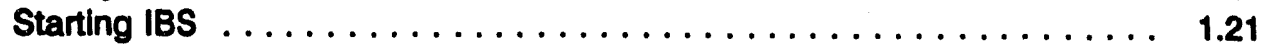

Exercise 1. Viewing the Onpost Work Plan .............. 1.23

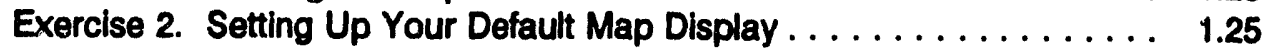

Exercise 3. Adjusting the Map Display ................. 1.29

Exercise 4. Using Emergency Activities . . . . . . . . . . . . . . . . . 1.34

\section{Section 2. Message Board}

Onpost Emergency Event Notfication $\ldots \ldots \ldots \ldots \ldots \ldots \ldots \ldots \ldots \ldots .2 .2$

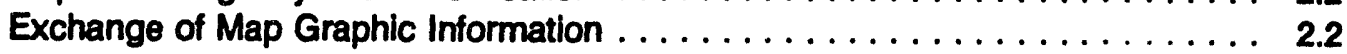

IBS Usor Guide - 2/23/94_xill 


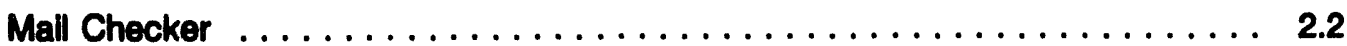

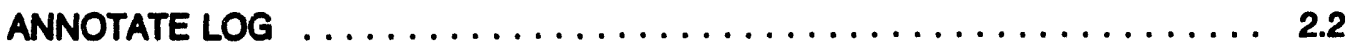

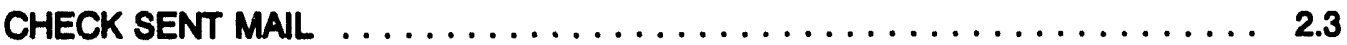

CREATE COMMON LOG REPORT and CREATE PRIVATE LOG REPORT $\ldots \ldots 2.4$

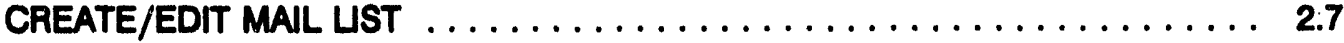

CREATE IBS $\rightarrow$ ONPOST RPT $\ldots \ldots \ldots \ldots \ldots \ldots \ldots \ldots \ldots \ldots \ldots$

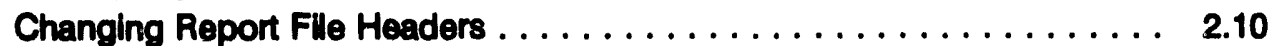

Exiting from the Data Input Forms $\ldots \ldots \ldots \ldots \ldots \ldots \ldots \ldots \ldots .11$

RESEND IBS->ONPOST RPT ${ }^{*} \ldots \ldots \ldots \ldots \ldots \ldots \ldots \ldots \ldots \ldots \ldots \ldots . \ldots \ldots$

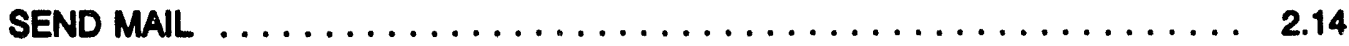

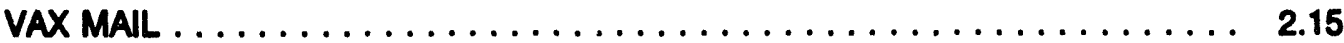

Adding Messages to the Common Log Report . . . . . . . . . . 2.16

VAX PHONE .................................... 2.17

VIEW COMMON LOG REPORT and VIEW PRIVATE LOG REPORT . . . . . 2.18

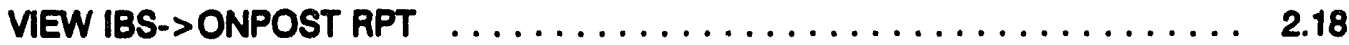

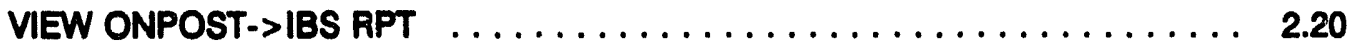

\section{Section 3. Status Board}

Understanding Implementing Procedures . . . . . . . . . . . . . . . . 3.2

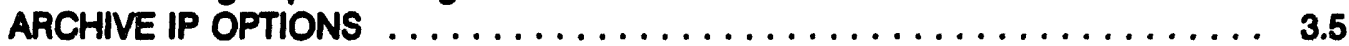

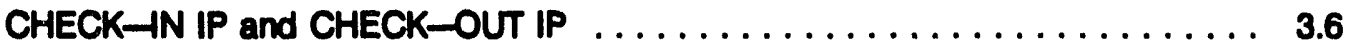

Renumbering an IP . . . . . . . . . . . . .

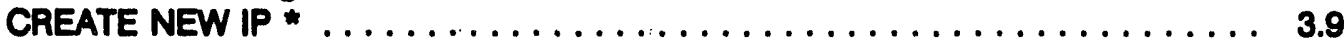

IMPLEMENTING PROCEDURES $\ldots \ldots \ldots \ldots \ldots \ldots \ldots \ldots \ldots \ldots \ldots .10 \ldots \ldots$

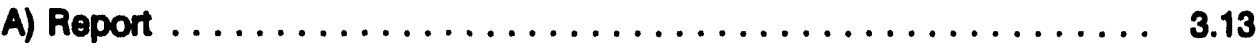

Sample IP Reports: ...................... 3.16

B) View IP Notes and Change IP Notes . . . . . . . . . . . . . . 3.17

C) Use Tasks $\ldots \ldots \ldots \ldots \ldots \ldots \ldots \ldots \ldots \ldots \ldots \ldots \ldots \ldots \ldots \ldots$

Lusting Overdue Tasks . . . . . . . . . . . . . . . . . . . 3.21

Lusting Tasks by Description $\ldots \ldots \ldots \ldots \ldots \ldots \ldots \ldots \ldots . \ldots \ldots$

Vlewing (and Changing) Task Actions .............. 3.23

Vlewing (and Changing) Task Resources ... . . . . . . . . . 3.24

Viewing (and Changing) Task/Action/Resource Notes . . . . . . . . 3.26

C) Change Tasks * ......................... 3.27

Changing Phases .......................... 3.28

Task Information Flelds . . . . . . . . . . . . . . 3.28

Editing Task Information . . . . . . . . . . . . . . 3.29

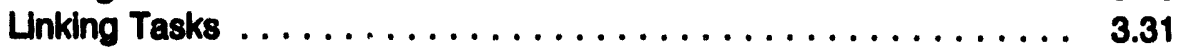

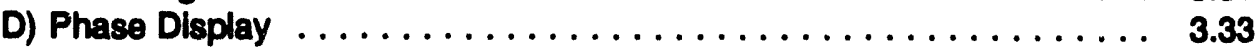

ONPOST EVENT STATUS $\ldots \ldots \ldots \ldots \ldots \ldots \ldots \ldots \ldots \ldots \ldots \ldots \ldots . \ldots \ldots . \ldots \ldots$

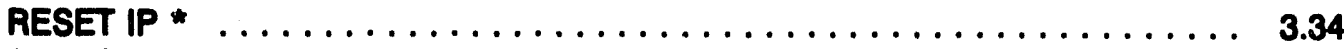

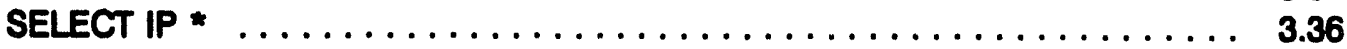

Selecting a New IP in Operational Mode .............. 3.36

Choose IP by NUMBER . . . . . . . . . . . . . . . 3.37

Choose Whether to Retain Completed Tasks from the Previous IP . 3.37

Set IP Base Time ......................... 3.38

Choose IP by SEARCH FOR IP CRITERIA . . . . . . . . . . 3.39

Choose Whether to Retain Completed Tasks from the Previous IP . 3.41

Selecting an IP in Planning Mode ................ 3.42

SELECT ONPOST ACTIVITY * and VIEW ONPOST ACTIVITY . . . . . . 3.42

Viewing an Onpost Acthity $\ldots \ldots \ldots \ldots \ldots \ldots \ldots \ldots \ldots . \ldots \ldots$ 
Selecting an Onpost Activity $\ldots \ldots \ldots \ldots \ldots \ldots \ldots \ldots \ldots . \ldots . \ldots . \ldots 3$

SHOW USER ENVIRONMENT $\ldots \ldots \ldots \ldots \ldots \ldots \ldots \ldots \ldots \ldots \ldots \ldots . \ldots \ldots$

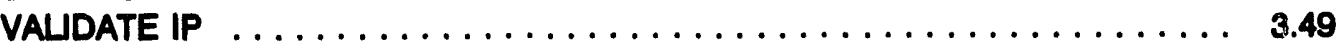

VIEW BATCH LOG $\ldots \ldots \ldots \ldots \ldots \ldots \ldots \ldots \ldots \ldots \ldots \ldots \ldots \ldots . \ldots \ldots$

VIEW ONPOST WORK PLAN $\ldots \ldots \ldots \ldots \ldots \ldots \ldots \ldots \ldots \ldots \ldots .5 . \ldots \ldots$

\section{Section 4. Personnel Management}

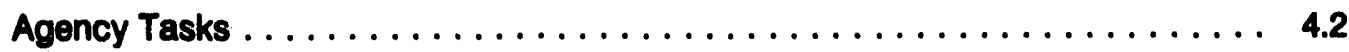

ADD AGENCIES ${ }^{2} \ldots \ldots \ldots \ldots \ldots \ldots \ldots \ldots \ldots \ldots \ldots \ldots \ldots .3$

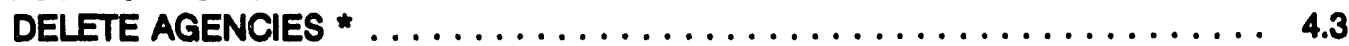

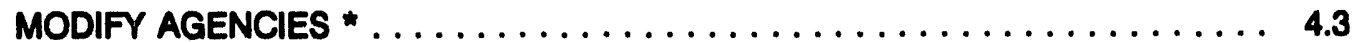

1. Speclfy Which Agency to Modify $\ldots \ldots \ldots \ldots \ldots \ldots \ldots \ldots \ldots, 4$

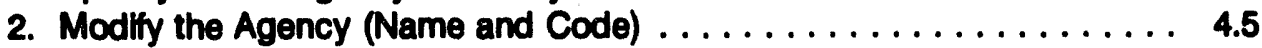

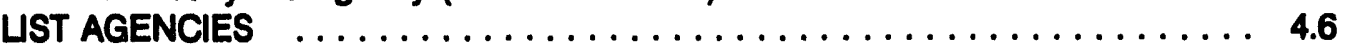

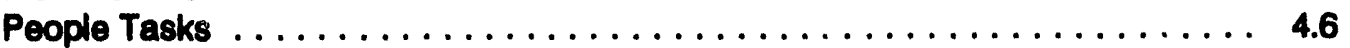

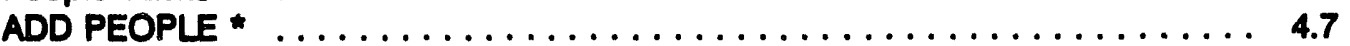

DELETE PEOPLE ${ }^{*} \ldots \ldots \ldots \ldots \ldots \ldots \ldots \ldots \ldots \ldots \ldots \ldots$

UST PEOPLE BY NAME...AGENCY...POSITION $\ldots \ldots \ldots \ldots \ldots \ldots \ldots \ldots 4.9$

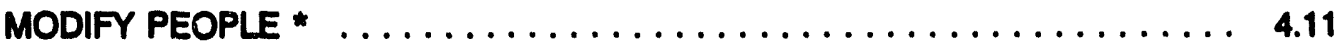

1. Speclfy Which Person to Modlfy .................. 4.11

2. Enter Now Information about the Person $\ldots \ldots \ldots \ldots \ldots \ldots \ldots \ldots 4.12$

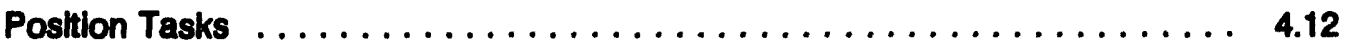

ADD POSITIONS ${ }^{2} \ldots \ldots \ldots \ldots \ldots \ldots \ldots \ldots \ldots \ldots \ldots \ldots \ldots . \ldots \ldots \ldots$

1. Speclfy Which Agency $\ldots \ldots \ldots \ldots \ldots \ldots \ldots \ldots \ldots \ldots \ldots .13$

2. Enter a New Position Name $\ldots \ldots \ldots \ldots \ldots \ldots \ldots \ldots \ldots . \ldots .15$

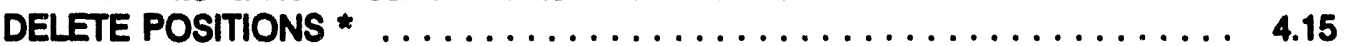

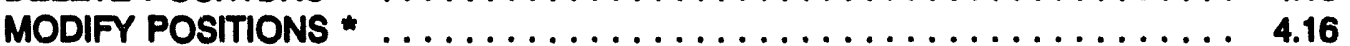

1. Specify Which Position to Modify ................. 4.16

2. Enter a New Name for the Position $\ldots \ldots \ldots \ldots \ldots \ldots \ldots \ldots .4 .17$

UST POSITIONS $\ldots \ldots \ldots \ldots \ldots \ldots \ldots \ldots \ldots \ldots \ldots \ldots \ldots \ldots .17$

\section{Section 5. Map Analysis}

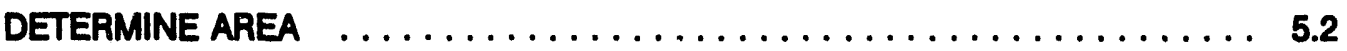

DISPLAY ICONS (TURN OFF ICONS) $\ldots \ldots \ldots \ldots \ldots \ldots \ldots \ldots \ldots \ldots .3$

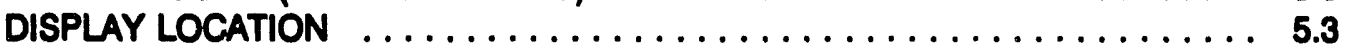

DISPLAY TEXT (TURN OFF TEXT) $\ldots \ldots \ldots \ldots \ldots \ldots \ldots \ldots \ldots \ldots \ldots .3$

ESTIMATE POPULATION $\ldots \ldots \ldots \ldots \ldots \ldots \ldots \ldots \ldots \ldots \ldots \ldots \ldots \ldots$

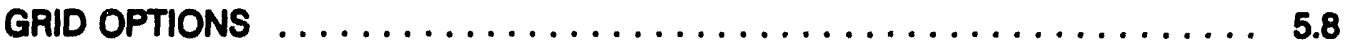

HIGHUGHT DATA $\ldots \ldots \ldots \ldots \ldots \ldots \ldots \ldots \ldots \ldots \ldots \ldots \ldots \ldots \ldots \ldots$

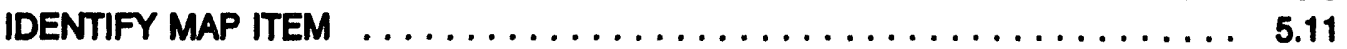

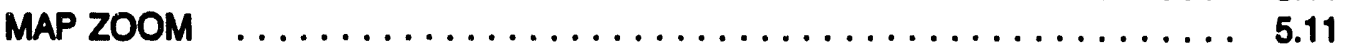

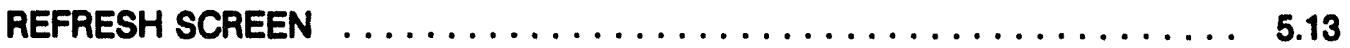

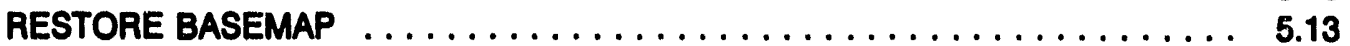

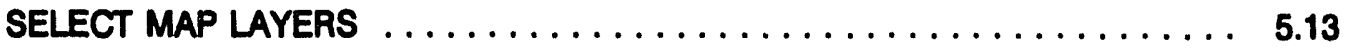

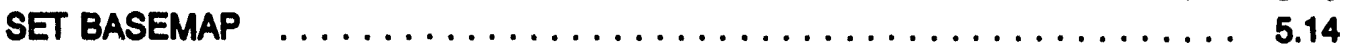

SUMMARIZE POINT DATA $\ldots \ldots \ldots \ldots \ldots \ldots \ldots \ldots \ldots \ldots \ldots \ldots .15$

TURN OFF ICONS (DISPLAY ICONS) $\ldots \ldots \ldots \ldots \ldots \ldots \ldots \ldots \ldots \ldots . \ldots \ldots .17$

TURN OFF TEXT (DISPLAY TEXT) $\ldots \ldots \ldots \ldots \ldots \ldots \ldots \ldots \ldots \ldots \ldots \ldots . \ldots \ldots .17$

UNHIGHUGHT DATA $\ldots \ldots \ldots \ldots \ldots \ldots \ldots \ldots \ldots \ldots \ldots \ldots \ldots \ldots \ldots$

IBS Uner Guide - 3/8/94 XV XV X 
ZOOM IN

ZOOM OUT

\section{Section 6. Resource Management}

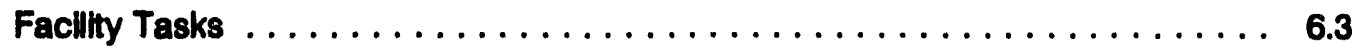

ADD FACILITIES ${ }^{*} \ldots \ldots \ldots \ldots \ldots \ldots \ldots \ldots \ldots \ldots \ldots \ldots \ldots . \ldots \ldots \ldots$

1. Speclfy a Facilly (Known Point) Location .............. 6.4

2. Enter a Facllty Description . . . . . . . . . . . . . . . . . 6.5

3. Enter Personnel Information about the Facility Contact Person . . . . . 6.6

DELETE FACILITIES ${ }^{\star} \ldots \ldots \ldots \ldots \ldots \ldots \ldots \ldots \ldots \ldots \ldots . \ldots \ldots$

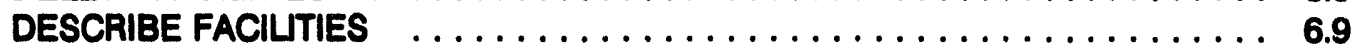

HIGHUGHT FACIUTIES $\ldots \ldots \ldots \ldots \ldots \ldots \ldots \ldots \ldots \ldots \ldots \ldots \ldots \ldots .6 \ldots \ldots$

1. Specify an Area of Interest $\ldots \ldots \ldots \ldots \ldots \ldots \ldots \ldots \ldots \ldots .11$

2. Select Which Resources to Locate . . . . . . . . . . . . . . . . . 6.12

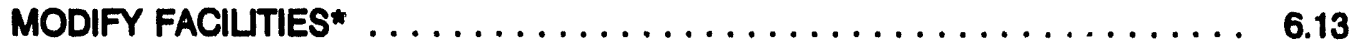

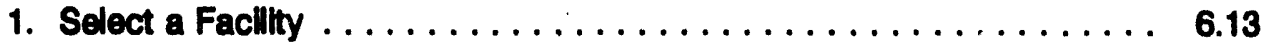

2. Modify the Facllity Description $\ldots \ldots \ldots \ldots \ldots \ldots \ldots \ldots \ldots .6 \ldots$

1. Select a Known Point ......................... 6.14

2. Modify the Known Point Location or Name . . . . . . . . . . . . . 6.14

Selecting a Facllty $\ldots \ldots \ldots \ldots \ldots \ldots \ldots \ldots \ldots \ldots \ldots \ldots \ldots . \ldots \ldots$

Resource Tasks ............................ 6.18

ASSIGN RESOURCES $\ldots \ldots \ldots \ldots \ldots \ldots \ldots \ldots \ldots \ldots \ldots \ldots \ldots \ldots .20$

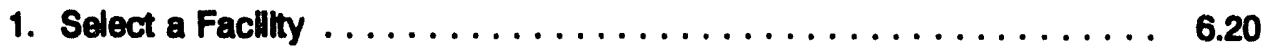

2. Enter the Resource Information .................. 6.20

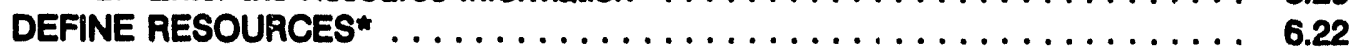

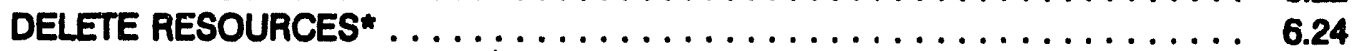

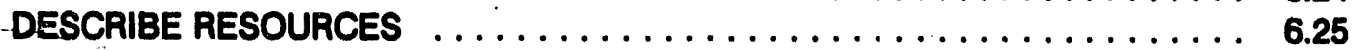

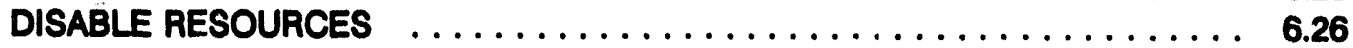

ENABLE RESOURCES $\ldots \ldots \ldots \ldots \ldots \ldots \ldots \ldots \ldots \ldots \ldots \ldots \ldots \ldots \ldots \ldots \ldots \ldots .27$

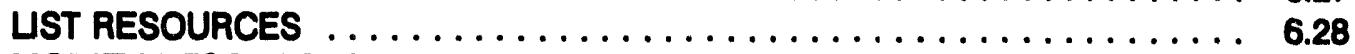

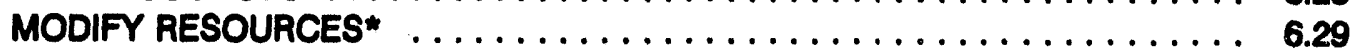

1. Select a Resource for Modifying . . . . . . . . . . . . . . . . 6.29

2. Modifying the Resource Information ................. 6.30

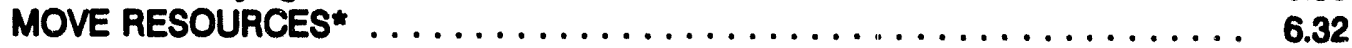

1. Select a Resource to Move ... . . . . . . . . . . . . . . . . 6.32

2. Specify an Amount of Resource to Move ............... 6.32

3. Select a Destination Facillty ...................... 6.33

Resource Form Use $\ldots \ldots \ldots \ldots \ldots \ldots \ldots \ldots \ldots \ldots \ldots \ldots \ldots \ldots .6 .34$

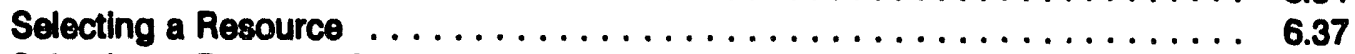

Selecting a Resource Type $\ldots \ldots \ldots \ldots \ldots \ldots \ldots \ldots \ldots \ldots \ldots \ldots . \ldots \ldots . .38$

SUMMARIZE RESOURCES $\ldots \ldots \ldots \ldots \ldots \ldots \ldots \ldots \ldots \ldots \ldots \ldots .6 \ldots \ldots \ldots$

1. Select an Area of Interest $\ldots \ldots \ldots \ldots \ldots \ldots \ldots \ldots \ldots \ldots .6 \ldots$

2. Select a Resource Type to be Summarked ............... 6.41

\section{Section 7. Show, Remove, and Refresh Latest Onpost Track}

Show (Remove) Latest Onpost Track . . . . . . . . . . . . . . 7.1

Refresh Latest Onpost Track . . . . . . . . . . . . . . . . . . . . . 7.1 


\section{Section 8. Analyze D2 Track}

ANIMATE D2 TRACK $\ldots \ldots \ldots \ldots \ldots \ldots \ldots \ldots \ldots \ldots \ldots \ldots .3$

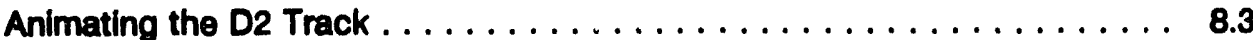

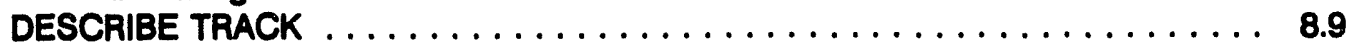

DOSE DETAILS $\ldots \ldots \ldots \ldots \ldots \ldots \ldots \ldots \ldots \ldots \ldots \ldots \ldots \ldots$

PRINT D2 REPORT $\ldots \ldots \ldots \ldots \ldots \ldots \ldots \ldots \ldots \ldots \ldots \ldots \ldots \ldots \ldots \ldots$

SHOW ELEVATION $\ldots \ldots \ldots \ldots \ldots \ldots \ldots \ldots \ldots \ldots \ldots \ldots \ldots \ldots .6 .11$

\section{Section 9. Change D2 Case}

Choosing a D2 Case by Case Number $\ldots \ldots \ldots \ldots \ldots \ldots \ldots \ldots \ldots .1$

Choosing a D2 Case by Searching for D2 Crtterla . . . . . . . . . . . 9.2

\section{Section 10. Show D2 Description}

SHOW D2 DESCRIPTION

Section 11. Emergency Activities

DAMAGE ASSESSMENT $\ldots \ldots \ldots \ldots \ldots \ldots \ldots \ldots \ldots \ldots \ldots \ldots \ldots$

DELETE CONTAMINATION AREA $\ldots \ldots \ldots \ldots \ldots \ldots \ldots \ldots$

DELETE NATIONAL DEFENSE AREA $\ldots \ldots \ldots \ldots \ldots \ldots \ldots \ldots$

DRAW CONTAMINATION AREA $\ldots \ldots \ldots \ldots \ldots \ldots \ldots \ldots \ldots \ldots \ldots$

DRAW NATIONAL DEFENSE AREA $\ldots \ldots \ldots \ldots \ldots \ldots \ldots \ldots \ldots \ldots$

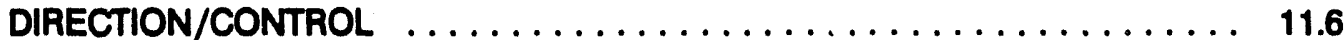

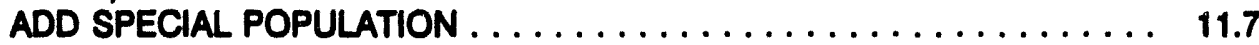

MODIFY FACIUTIES ${ }^{*} \ldots \ldots \ldots \ldots \ldots \ldots \ldots \ldots \ldots \ldots \ldots \ldots$

Modlfy the Facllty Description . . . . . . . . . . . . . . . . . . 11.9

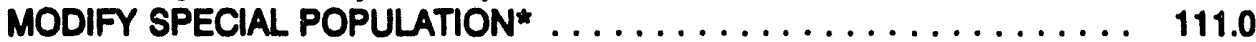

ESTIMATE POPULATION $\ldots \ldots \ldots \ldots \ldots \ldots \ldots \ldots \ldots \ldots \ldots \ldots \ldots$

RELEASE OVERLAYS $\ldots \ldots \ldots \ldots \ldots \ldots \ldots \ldots \ldots \ldots \ldots \ldots \ldots \ldots$

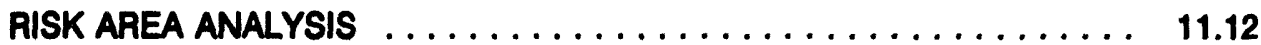

SAVE CURRENT RISK AREA $\ldots \ldots \ldots \ldots \ldots \ldots \ldots \ldots \ldots \ldots \ldots \ldots$

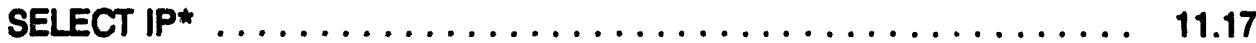

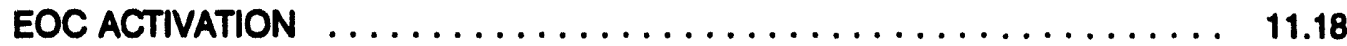

GENERATE CAL UST $\ldots \ldots \ldots \ldots \ldots \ldots \ldots \ldots \ldots \ldots \ldots \ldots, 11.19$

UST FIRST TASKS $\ldots \ldots \ldots \ldots \ldots \ldots \ldots \ldots \ldots \ldots \ldots \ldots \ldots \ldots \ldots$

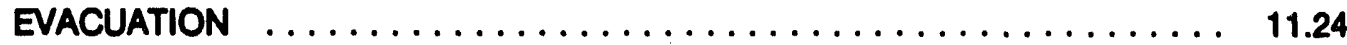

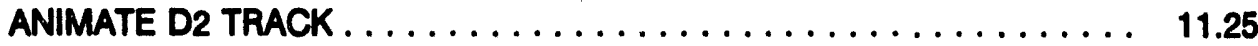

EVAC ROUTE OVERLAYS $\ldots \ldots \ldots \ldots \ldots \ldots \ldots \ldots \ldots \ldots \ldots \ldots$

DESCRIBE EVACUATION POINT $\ldots \ldots \ldots \ldots \ldots \ldots \ldots \ldots \ldots \ldots \ldots$

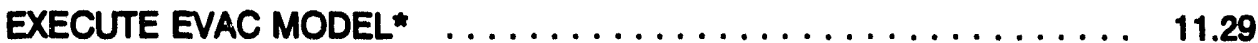

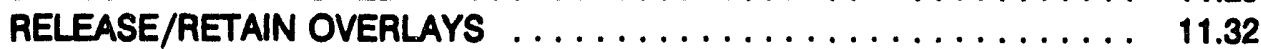

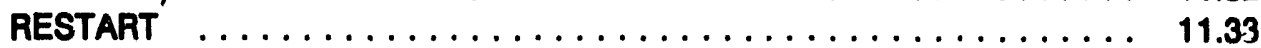

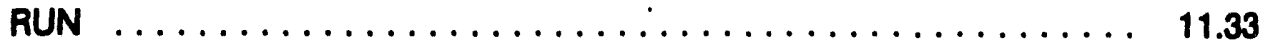

SELECT MODEL CASE* $\ldots \ldots \ldots \ldots \ldots \ldots \ldots \ldots \ldots \ldots \ldots \ldots \ldots$

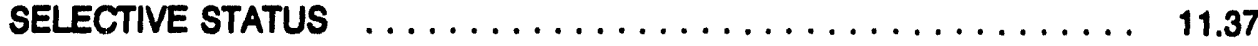

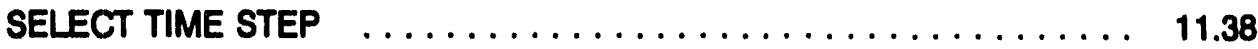

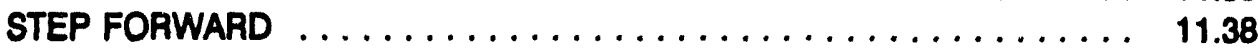

STEP BACKWARD $\ldots \ldots \ldots \ldots \ldots \ldots \ldots \ldots \ldots \ldots \ldots \ldots \ldots \ldots \ldots$

IBS User Guide - 3/8/84_ XVII 
HAZARD ANALYSIS $\ldots \ldots \ldots \ldots \ldots \ldots \ldots \ldots \ldots \ldots \ldots \ldots \ldots \ldots$

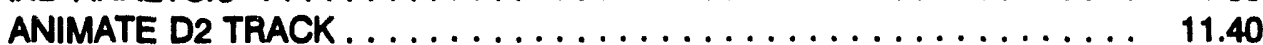

CHANGE TRACK CASE ${ }^{\star} \ldots \ldots \ldots \ldots \ldots \ldots \ldots \ldots \ldots \ldots \ldots \ldots$

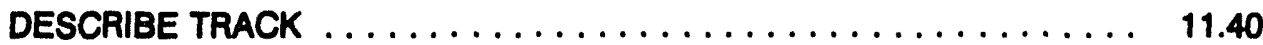

RELEASE/RETAIN OVERLAYS $\ldots \ldots \ldots \ldots \ldots \ldots \ldots \ldots \ldots \ldots 11.41$

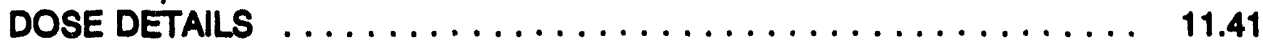

EXECUTE D2 ${ }^{*} \ldots \ldots \ldots \ldots \ldots \ldots \ldots \ldots \ldots \ldots \ldots \ldots \ldots \ldots \ldots \ldots$

Holds on Variables ........................ 11.45

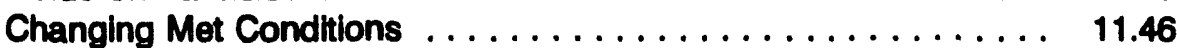

Summing Dosage Distrlbution ................. 11.46

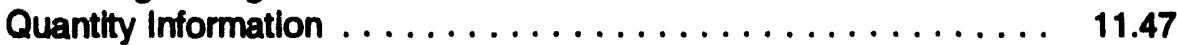

Two-Minute Correction .................... 11.47

Converting Units $\ldots \ldots \ldots \ldots \ldots \ldots \ldots \ldots \ldots \ldots \ldots \ldots, 11.47$

Time After Functioning $\ldots \ldots \ldots \ldots \ldots \ldots \ldots \ldots \ldots \ldots \ldots$

Latest Met .......................... 11.47

Additional Input $\ldots \ldots \ldots \ldots \ldots \ldots \ldots \ldots \ldots \ldots \ldots \ldots \ldots \ldots$

PRINT D2 REPORT $\ldots \ldots \ldots \ldots \ldots \ldots \ldots \ldots \ldots \ldots \ldots \ldots \ldots 11.55$

REPORT CURRENT D2 DESCRIPTION $\ldots \ldots \ldots \ldots \ldots \ldots \ldots \ldots, 11.55$

SHOW ELEVATION $\ldots \ldots \ldots \ldots \ldots \ldots \ldots \ldots \ldots \ldots \ldots \ldots \ldots \ldots$

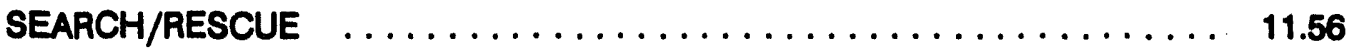

DRAW SEARCH AREAS $\ldots \ldots \ldots \ldots \ldots \ldots \ldots \ldots \ldots \ldots \ldots, 11.56$

DELETE SEARCH AREA $\ldots \ldots \ldots \ldots \ldots \ldots \ldots \ldots \ldots \ldots \ldots \ldots . \ldots \ldots$

RELEASE/RETAIN OVERLAYS $\ldots \ldots \ldots \ldots \ldots \ldots \ldots \ldots \ldots \ldots \ldots, 11.57$

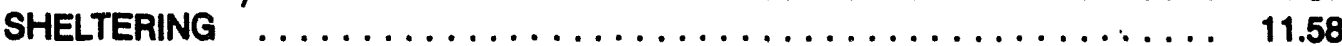

ADD FACIUTIES ${ }^{*} \ldots \ldots \ldots \ldots \ldots \ldots \ldots \ldots \ldots \ldots \ldots \ldots \ldots$

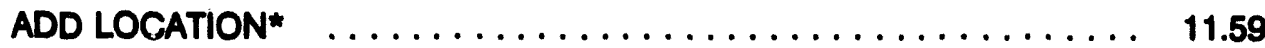

MODIFY FACILTIES* $\ldots \ldots \ldots \ldots \ldots \ldots \ldots \ldots \ldots \ldots \ldots \ldots, 11.59$

RELEASE/RETAIN OVERLAYS $\ldots \ldots \ldots \ldots \ldots \ldots \ldots \ldots \ldots \ldots 11.60$

SHELTER \& CENTER SUMMARY $\ldots \ldots \ldots \ldots \ldots \ldots \ldots \ldots \ldots \ldots, 11.60$

SHELTER OR CENTER INFO $\ldots \ldots \ldots \ldots \ldots \ldots \ldots \ldots \ldots \ldots \ldots, 11.61$

Section 12. Setup

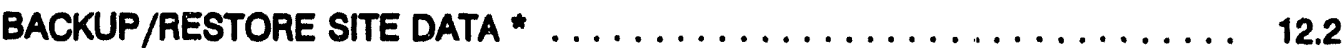

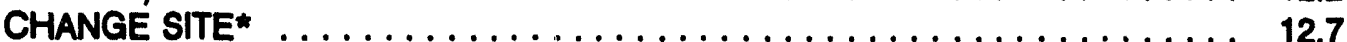

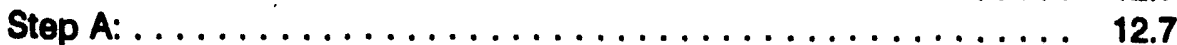

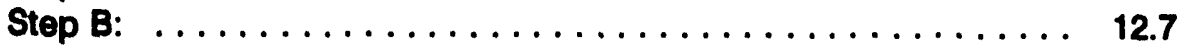

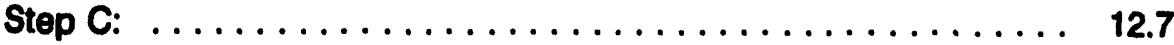

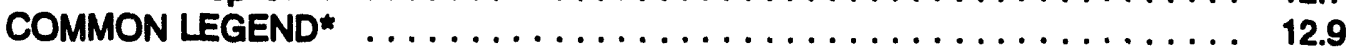

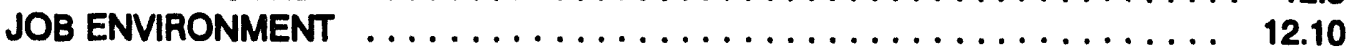

CHANGE MENU COLORS $\ldots \ldots \ldots \ldots \ldots \ldots \ldots \ldots \ldots \ldots \ldots \ldots, 12.11$

CHANGE SITE CHARACTERISTICS $\ldots \ldots \ldots \ldots \ldots \ldots \ldots \ldots \ldots \ldots, 12.12$

CHANGE TEXT COLORS $\ldots \ldots \ldots \ldots \ldots \ldots \ldots \ldots \ldots \ldots \ldots . \ldots \ldots$

COPY CASE OR SITE FILES $\star \ldots \ldots \ldots \ldots \ldots \ldots \ldots \ldots \ldots \ldots . \ldots \ldots$

Copying Ste or Case Data FROM Another IBS User . . . . . . . 12.17

Copying Site or Case Flles TO Another IBS User . . . . . . . . 12.19

Tracking Case Check-In and Check-out . . . . . . . . . . 12.19

Deleting a Site Database . . . . . . . . . . . . . . . . . . . . . 12.20

HARDWARE SETTINGS $\ldots \ldots \ldots \ldots \ldots \ldots \ldots \ldots \ldots \ldots \ldots \ldots \ldots, 12.23$

MISCELANEOUS SETTINGS $\ldots \ldots \ldots \ldots \ldots \ldots \ldots \ldots \ldots \ldots, 12.23$

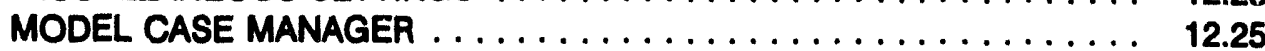

SET TO DEFAULT COLORS $\ldots \ldots \ldots \ldots \ldots \ldots \ldots \ldots \ldots \ldots \ldots \ldots .12 .27$ 
MAP LAYERS - BY ACTIVITY $\ldots \ldots \ldots \ldots \ldots \ldots \ldots \ldots \ldots \ldots \ldots \ldots$

MAP LAYERS - DEFAULT $\ldots \ldots \ldots \ldots \ldots \ldots \ldots \ldots \ldots \ldots \ldots \ldots \ldots$

Restricting Map Layers Based on Display Size . . . . . . . . . 12.30

\section{Appendix A. IBS Graphic Menus}

Example of a Submenu with Layered Menu Selections . . . . . . . . . A.2

Appendix B. Non-Graphic IBS

To Start NON-GRAPHIC IBS (IBS_NOGR) $\ldots \ldots \ldots \ldots \ldots \ldots \ldots$

Using IBS Shell to Run Non-Graphic IBS

\section{Appendix C. People Location}

To Start the LOCATE Program $\ldots \ldots \ldots \ldots \ldots \ldots \ldots \ldots \ldots \ldots$ C.1

PEOPLE LOCATION MENu $\ldots \ldots \ldots \ldots \ldots \ldots \ldots \ldots \ldots \ldots \ldots \ldots \ldots$. 2

Option A. Enter Persons $\ldots \ldots \ldots \ldots \ldots \ldots \ldots \ldots \ldots \ldots \ldots \ldots \ldots \ldots$ C.3

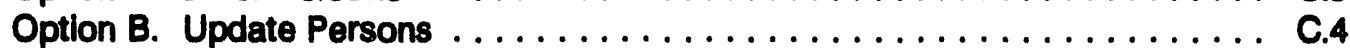

Option C. Search for Missing Persons $\ldots \ldots \ldots \ldots \ldots \ldots \ldots \ldots \ldots \ldots$ C.5

Option D. Enter Default Values for the Enter Persons Form . . . . . . . . . C.6

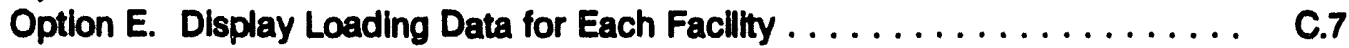

Option F. Select a Different Facllity

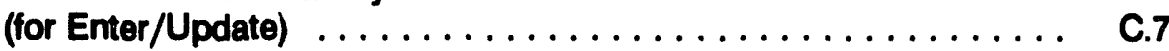

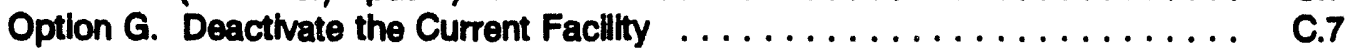

Option $X$. Exit, with Optional Facllity Deactivation $\ldots \ldots \ldots \ldots \ldots \ldots \ldots \ldots$ C.8

Using IBS Shell to Run People Location . . . . . . . . . . . . . . . C.8

\section{Appendix D. Onpost Simulator}

To Start the Onpost Simulator . . . . . . . . . . . . . . . . . . . . D.1

Using IBS Shell to Run the Onpost Simulator ............. D.4

\section{Appendix E. IBS and Onpost EOC Reports}

Reports from the IBS $\ldots \ldots \ldots \ldots \ldots \ldots \ldots \ldots \ldots \ldots \ldots \ldots$ E.2

CHANGE FILE HEADERS $\ldots \ldots \ldots \ldots \ldots \ldots \ldots \ldots \ldots \ldots \ldots \ldots$ E.3

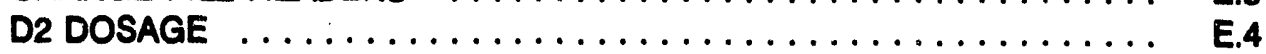

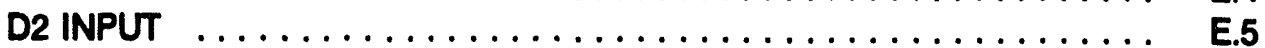

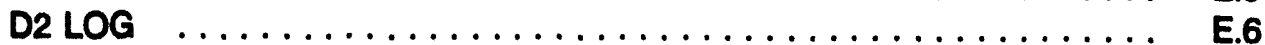

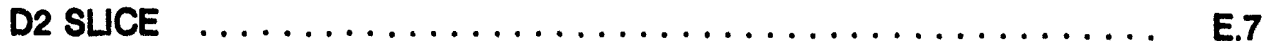

GENERIC GRAPHIC DATA $\ldots \ldots \ldots \ldots \ldots \ldots \ldots \ldots \ldots \ldots$ E.8

GENERIC TEXT DATA $\ldots \ldots \ldots \ldots \ldots \ldots \ldots \ldots \ldots \ldots \ldots \ldots$ E.9

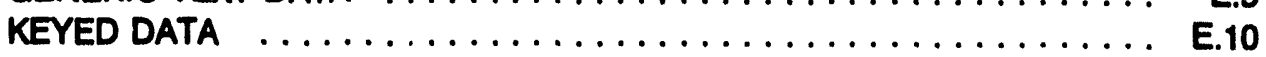

OFFPOST CASUALTY REPORT $\ldots \ldots \ldots \ldots \ldots \ldots \ldots \ldots \ldots \ldots \ldots$ E.11

OFFPOST EVACUATION ROUTES $\ldots \ldots \ldots \ldots \ldots \ldots \ldots \ldots \ldots \ldots \ldots$ E.12

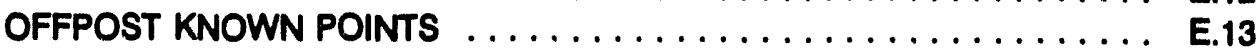

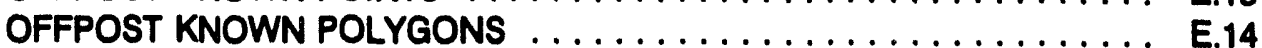

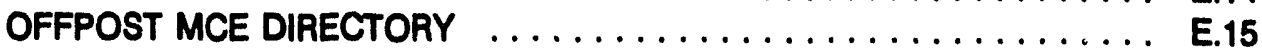

OFFPOST SHELTER REPORT $\ldots \ldots \ldots \ldots \ldots \ldots \ldots \ldots \ldots \ldots$ E.16

OFFPOST STATUS REPORT $\ldots \ldots \ldots \ldots \ldots \ldots \ldots \ldots \ldots \ldots \ldots .17$

IBS Uear Guide - 3/8/94 XIX 
PROTECTIVE ACTION REPORT $\ldots \ldots \ldots \ldots \ldots \ldots \ldots \ldots \ldots \ldots$ E.19

PROPOSED EVACUATION ROUTES $\ldots \ldots \ldots \ldots \ldots \ldots \ldots \ldots \ldots \ldots$ E.22

PROPOSED MILTARY ROUTES $\ldots \ldots \ldots \ldots \ldots \ldots \ldots \ldots \ldots \ldots$ E.23

RECEPTION CTR DIRECTORY $\ldots \ldots \ldots \ldots \ldots \ldots \ldots \ldots \ldots \ldots \ldots$ E.25

RECEPTION CTR REPORT $\ldots \ldots \ldots \ldots \ldots \ldots \ldots \ldots \ldots \ldots \ldots$ E.26

TRAFFIC CONTROL REPORT $\ldots \ldots \ldots \ldots \ldots \ldots \ldots \ldots \ldots \ldots \ldots$ E.27

Reports from the Onpost EOC System $\ldots \ldots \ldots \ldots \ldots \ldots \ldots \ldots \ldots \ldots$ E.28

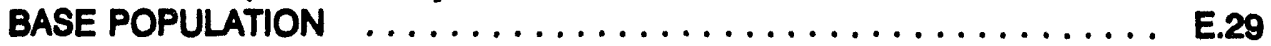

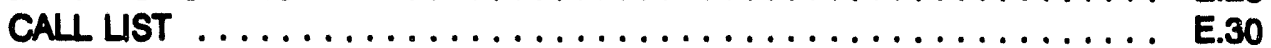

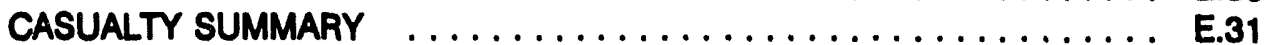

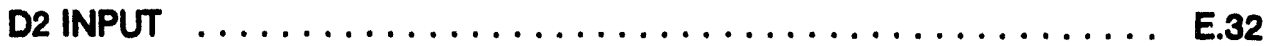

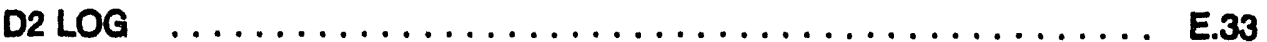

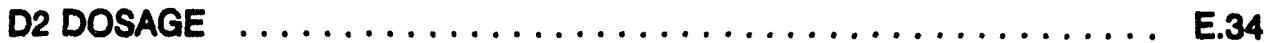

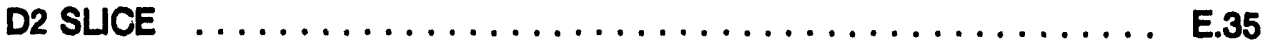

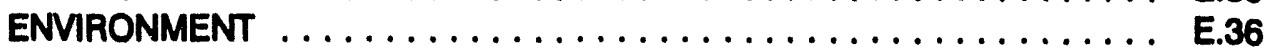

GENERIC GRAPHIC DATA $\ldots \ldots \ldots \ldots \ldots \ldots \ldots \ldots \ldots \ldots \ldots \ldots \ldots \ldots \ldots$

GENERIC TEXT DATA $\ldots \ldots \ldots \ldots \ldots \ldots \ldots \ldots \ldots \ldots \ldots \ldots \ldots \ldots$

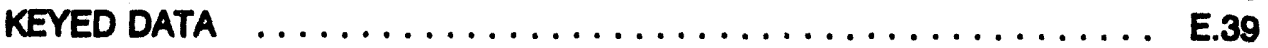

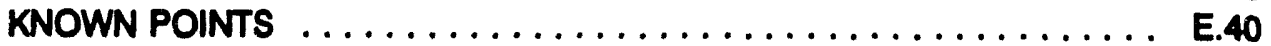

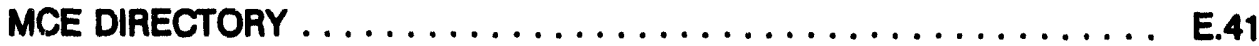

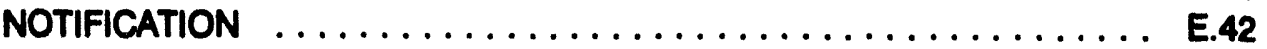

SIGNIFICANT EVENTS $\ldots \ldots \ldots \ldots \ldots \ldots \ldots \ldots \ldots \ldots \ldots \ldots . \ldots \ldots$ E.43

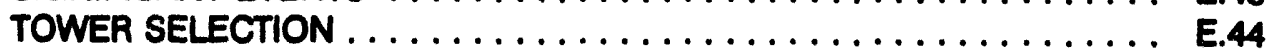

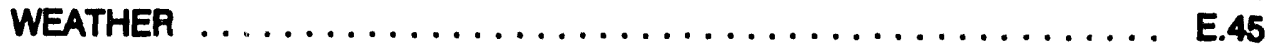

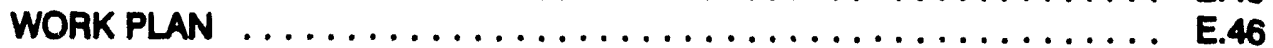

\section{Appendix F. IBS Icons}

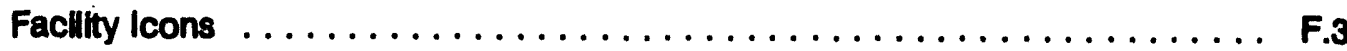

Resource Icons $\ldots \ldots \ldots \ldots \ldots \ldots \ldots \ldots \ldots \ldots \ldots \ldots \ldots \ldots$ F.13

Non-Facllity/Resource Icons . . . . . . . . . . . . . . . . . . F.19 



\section{Section 1 Introduction and Overview}

The fundamental function of the IBS is to provide tools that civilian emergency management personnel can use in developing emergency plans and in supporting emergency management activities to cope with a chemical-releasing event at a military chemical stockpile.

Emergency management planners can evaluate concepts and ideas using the IBS system. The results of that experience can then be factored into refining requirements and plans.

In this introduction you will find:

- Overview of System Use - system concepts and terms

- IBS Users - general descriptions of IBS users

- Getting Started (and Getting Stopped) - basic operating procedures

- Conventions for Interacting with the IBS - conventions for interacting with various terminals, map displays, menus, and forms.

- Overview of the IBS Main Menu - an overview of IBS Main Menu functions.

- Introductory Exercises - a series of exercises to familiarize the new user with basic IBS system functions, commands, and options. 


\section{Overview of System Use}

The storage, movement, or disposal of chemical weapons materials at a military stockpile require emergency preparedness by the military and the state and local governments. Systems are being implemented by both groups to support such preparedness by providing computerized data management, analysis, and monitoring tools that supplement traditional tools for emergency management.

The offpost system (IBS, in this case) is located at one or more Emergency Operations Centers (EOCs) that have primary responsibilities for preparedness and response from state and local authorities. The onpost system monitors ongoing chemical-related activities on the post.

The onpost and offpost systems exchange certain information so that the users of each kind of system are aware of both current conditions and planned activities. The Work Plan for current onpost activities (such as the transport or disposal of chemicals) is composed of data supplied by the onpost system. This data can include D2 runs and weather reports. Predefined reports of offpost emergency management activities are transmitted to the onpost system, especially after an actual event. Other offpost systems may also communicate with the IBS; for example, terminals and systems at some locations (such as hospitals or shelters) can update a people location database.

The IBS can help with many aspects of the Emergency Management Components illustrated in Figure 1.1. These components include

- Planning for an emergency

- Readiness/ dealing with an emergency

- Recovering from an emergency

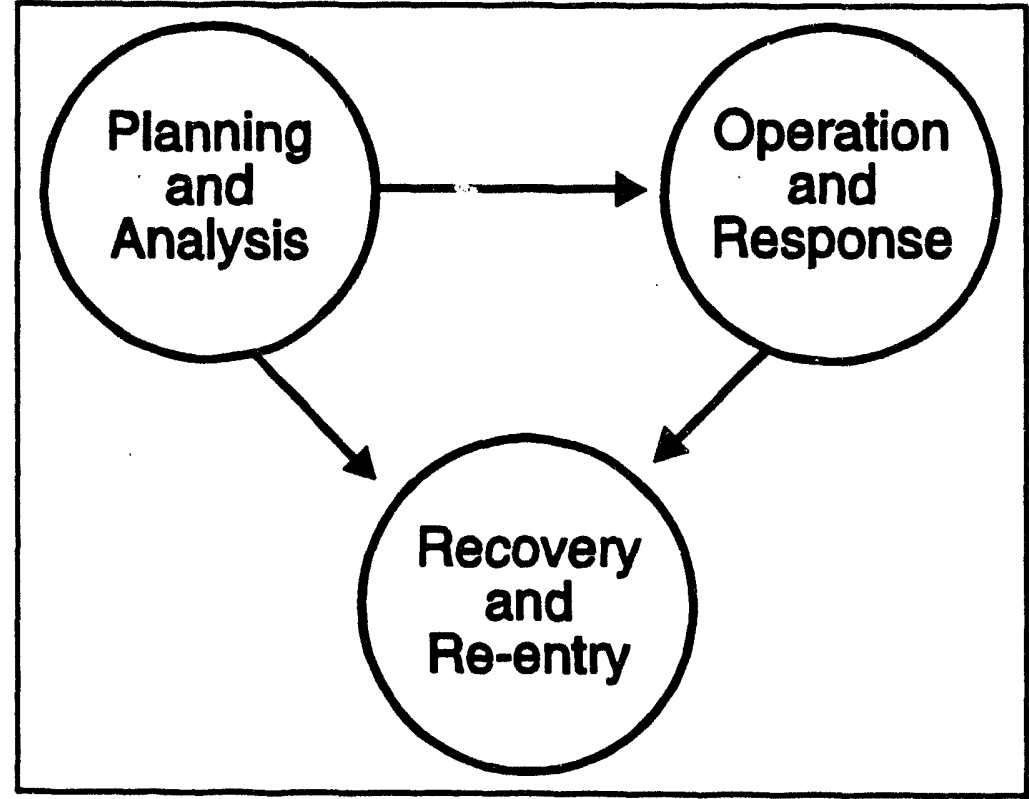

Figure 1.1. Relation of Emergency Management Components

Emergency management personnel at the offpost EOC routinely evaluate the pissible effects of the most likely event (chemical release), given the current onpost activities, weather situation, 
and population pattern (distribution of population around the post). Personnel at the EOC can use the IBS to build and maintain data that are related to particular chemical events and site conditions. At any specific time, a portion of that data is designated as the current operational site database- the operational data that would most probably apply if an event occurs.

Included in that operational site database is the current Implementing Procedure (IP) for managing a specific set of Emergency Functions for an event situation. An IP has a basic structure similar to the following example.

\section{Implementing Procedure}

1. Emergency Function

A. Task

Responsible agencies/personnel

Required resources

B. Task

Required actions

Responsible agencies/personnel

Required resources

Required actions

2. Emergency Function

A. Task

Responsible agencies/personnel

Required resources

B. Task

Required actions

Responsible agencies/personnel

Required resources

Required actions

For each Emergency Function, the IP includes anticipated tasks and links them with the responsible personnel and required resources. The IBS enables emergency managers and planners to assemble a set of IPs that represent preplanned tasks and task actions for different event situations.

Even before an event occurs, an Operational IP (OPIP) is in effect at the EOC. The OPIP is updated, based on changing activities in the Work Plan, the weather, and the time of day (which is related to population pattern). Because the OPIP is in effect before an event actually occurs, it may contain precautionary activities that must be carried out before the occurrence of an event in order to ensure public safety. 


\section{IBS Users}

Personnel at the EOC and other offpost locations will have assigned roles for using the IBS. By using different program modules and user privilege controls, the system presents different capabilities to each type of user. The principal categories of IBS users are the following:

1. View Only: General users include emergency management decision makers, agency representatives, etc., who use and act on the information that the IBS provides. Generally, they can view but not change data.

2. Information Managers: Exactly one person on the EOC staff has responsibilities as the IBS Information Manager. This person is responsible for maintaining shared site data (the "real data") during an exercise.

3. Analyst/Planners: Information analysts and emergency management planners can own and use wholly independent sets of site data. They can use the IBS to develop IPs, model cases, and supporting information during planning stages. They can modify the operational site database by bringing in their planning data. Analyst/planners have only general user privileges for viewing and using the operational site database.

4. General Users: Use and maintain the operational site database on a daily basis and use the IP.

5. Locators: Locators use only the LOCATE program to keep track of people at shelters, hospitals, and other special locations. Locators might be shelter managers, Red Cross volunteers, hospital personnel, or decontamination/reception center personnel. Although they can modify the people location database, locators have limited access to other IBS capabilities. 


\section{Getting Started (and Getting Stopped)}

The IBS is a multi-user system and can be operating on several computer terminals at once. Before starting the IBS at a terminal, you must be logged in to the computer system, and your terminal screen must be showing the VMS general system prompt, which is usually a dollar sign (\$).

\section{Starting IBS}

To start the main graphic IBS program, perform the following procedure.

1. At the general system prompt type IBS and press the Return key.

\section{\$ IBS}

The screen will clear and the following message will flash:

IBS Version 2.00

October 1, 1993

READING CONTROL

FILES PLEASE WAIT

After a few moments, the IBS will display a map of the site and the IBS main menu, as shown in Figure 1.2.

\section{Using IBS menus}

Picking menu options will initiate specific operations or result in the display of other menus (submenus) for further refining selection of a desired operation. Appendix A contains complete listings of the IBS graphic menus.

To pick a menu option, perform the following procedures.

1. Move the crosshairs displayed on the screen by pressing the joydisk or using a mouse. When using a joydisk, hold down the Shift key to speed up crosshair movement.

2. Place the crosshairs over the menu option you want.

3. Press the spacebar to finish picking the option. The system then performs the function you have requested.

In the actual operation of menus, some items will not be available to general users of the system. In particular, items that modify or update data will not appear on the menus of those who have no special privileges to modify information. 


\section{Exiting IBS}

To exit the IBS program, perform the following procedures.

1. If you are not currently at the main menu, return to the main menu by picking the IBS MAIN MENU option at the top of virtually all other menus.

2. Pick the EXIT IBS option at the top of the IBS main menu shown in Figure 1.2.

When you pick EXIT IBS, your screen returns to the general VMS system prompt. 


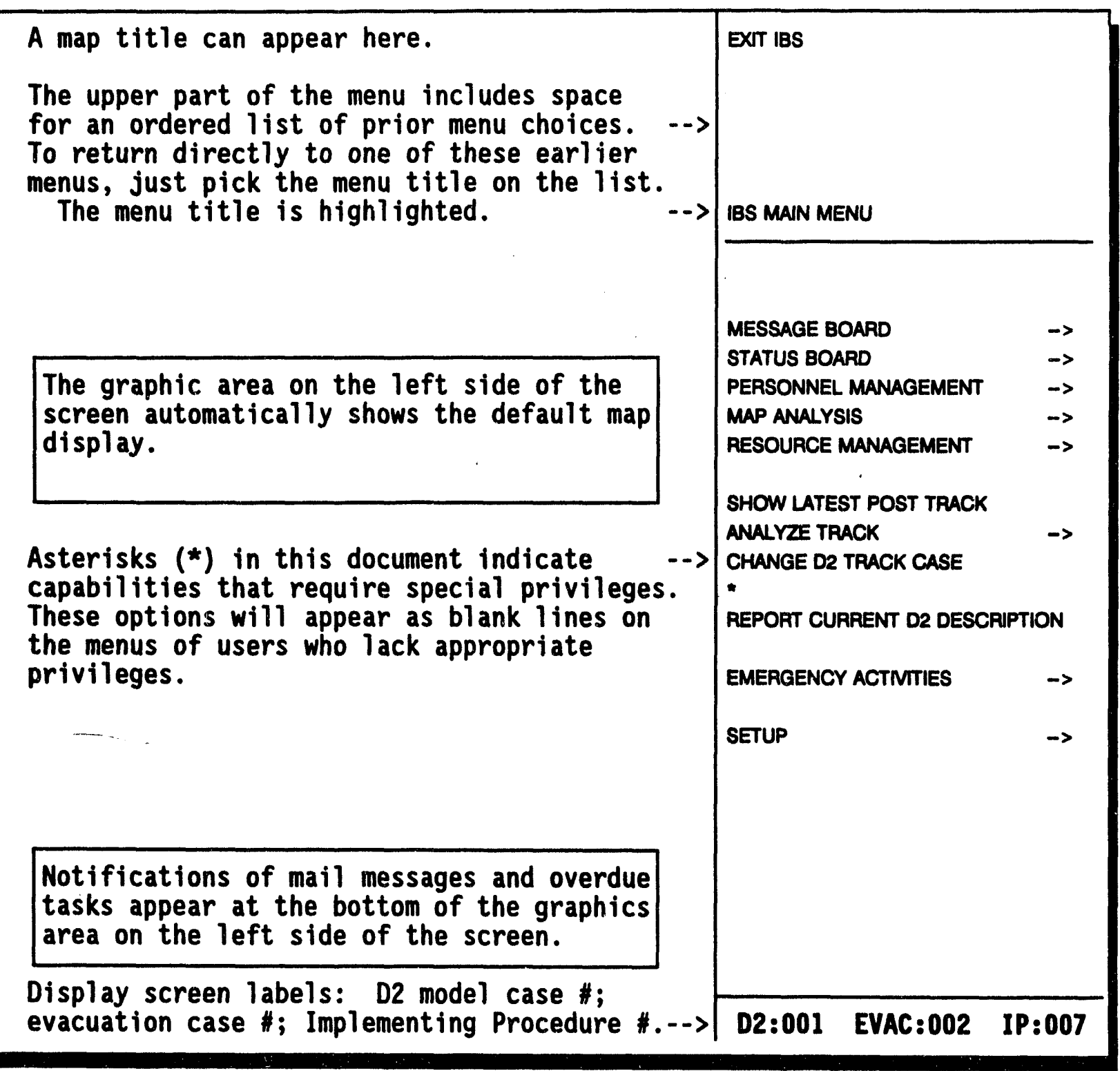

Figure 1.2. Map Display Screen and Main Menu of the Graphic IBS Software 


\section{Conventions for Interacting with the IBS}

In using the IBS, you will point at map locations, pick menu items, and fill in text forms, interacting with both graphic and text screen displays.

These interactions are described in the following sections. The IBS is designed to work on a VAX computer platform and is accessible through three types of devices for textual/graphic input and display:

- Tektronix graphics terminals (Models 4107, 4109, 4207, 4208, 4209 4211)

- VAXstations emulating a Tektronix graphics terminal (with terminal emulation software: Grafpoint TGRAF-X software for emulating a Tektronix 4107)

- PC workstations emulating a Tektronix graphics terminal(with terminal emulation software: Grafpoint TGRAF-07 software for emulating a Tektronix 4107).

When the hardware creates differences in interaction, the differences are noted.

\section{Graphic Interactions}

Except for file names and possibly some descriptive text, most input to the mapping and graphics software will be through your interaction with the menus and displays on the color graphics screen. Map graphics appear in a large display area on the left side of the screen, as shown in Figure 1.2. Menu options appear in the menu area on the right side of the screen.

In a typical interaction, you will use a graphics input device to select an option from a menu of options and then pick screen locations at which to perform the task. For example, to display the coordinates of a point on a map, you select DISPLAY LOCATION on the MAP ANALYSIS menu and then pick a screen location. 
The following conventions apply to graphic menu interactions:

- The title of the current menu is usually displayed in yellow (options are available for you to customize menu colors). The option items of the current menu are listed below the title.

- When you select a menu item, a submenu of further items can replace the current menu. The sequence of menu selections leading to this new menu is listed (in order) above the menu title.

- You can return to a previous menu in the sequence by picking any item that is listed above the current menu title: you will return directly to that level without seeing the intervening menus.

- Selected menu items display in a different color. If the selected menu item starts blinking, the program is expecting further input, either from the graphics input device or from the keyboard.

- Menu options for adding or updating data are restricted to users who have special privileges (such as Information Managers and planners using the system in planning mode). Comparable menus seen by other general users with view only' privileges will contain blank lines instead.

- Table 1.1 lists the locations of some standard menu items that occur on many IBS menus. 
Table 1.1. Location of Standard Items on the IBS Graphic Menus

Line

Number Menu Item or Line Use Notes on Use or Occurrence

1 IBS MAIN MENU Returns you to the IBS main menu.

2-6 Previous menu Selections leading to the current menu selections can be picked to return to a previous menu.

7 CURRENT MENU TITLE Current menu title is usually displayed in yellow.

8

Horizontal bar separates the title from the options of the current menu.

Usually a blank line.

10

CONTINUE

Needed by some menu items to complete an operation; occurs on menus only if needed-otherwise this line is blank.

MESSAGE BOARD

STATUS BOARD

13

PERSONNEl MANAGEMENT

Standard options

14

MAP ANALYSIS

15

RESOURCE MANAGEMENT

on most menus

28

MAP ZOOM

29

ZOON IN

30

ZOOM OUT

31

REFRESH SCREEN

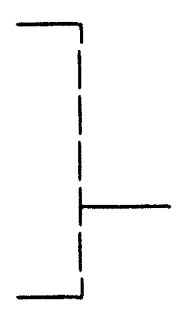

General display options on several menus

The following sections explain how to:

- Pick an item on a menu or a point on the screen with the different input devices 
- Define an area (polygon)

- Troubleshoot, if certain problems occur with graphic interactions

\section{Using Tektronix Terminals}

When IBS is ready to accept graphics input, a graphics cursor (cross hairs) appears on the Tektronix terminal screen. Perform the following procedures to:

- Move the cursor

- Point with the cursor

- Select screen points or menu options

1. Bit Pad: If you have a bit pad (graphics tablet) and mouse, move the mouse across the bit pad to move the cross hairs on the screen.

Joydisk: If you do not have a bit pad, press the sides of the joydisk located on the keyboard to move the cross hairs. Press the Shift key at the same time to move the cross hairs rapidly.

2. Move the cross hairs over the graphics menu until they cross over the lettering of the desired menu item (or over the desired point on a map).

3. Bit Pad: Tap the yellow mouse button to select the menu item or point.

Joydisk: Tap the space bar to select the menu item or point.

If you have picked an operation for which no further graphics input is necessary, the cursor disappears while the operation is completed.

Note: If the space bar does not seem to be selecting correctly, press Ctrl-Q.

Avoid pressing the Return key to select items. Although this can work, heavy computer use can slow the system's response to input, making it appear as if the input was not received. Pressing Return repeatedly could enter an inadvertent keyboard response to a system request for input.

\section{Using a VAXstation}

The chief difference for graphic interactions on the VAXstation is the workstation has no joydisk for moving the cursor on the graphics display screen. Instead, the VAXstation (with Tektronix emulator) uses a mouse to position the cursor. When you press the left mouse button, it selects a menu item or point location. 


\section{Using a PC Workstation}

Like the VAXstation, the PC workstation (with Tektronix emulator) generally uses a mouse to position the cursor (cross hairs); pressing the mouse button selects a menu item or point location.

If the PC workstation does not have a mouse (or other input device), perform the following procedures to move the cursor:

1. To move the cursor, press one of the arrow keys on the numeric keypad ( 2 = down, $4=$ left, $6=$ right, $8=u p$ ).

To increase the speed of cursor movement, hold down the Alt or Shift key while you press the arrow key. (The speed of keypad cursor movement is selectable through the emulation software-consult the TGRAF-07 software manual.)

2. Move the cursor until the center point of the cursor crosses over the desired menu item (or over the desired point on a map).

3. Press the space bar once to select the menu item (or point).

The same caution applies as for the Tektronix terminal: Avoid pressing the Return (Enter) key to select items. This will prevent an inadvertent response to other program interactions that require pressing Return (Enter).

\section{Defining Map Areas (Polygons)}

IBS sometimes prompts you to define an area of the map screen for use in an operation. For example, when you pick the ESTIMATE POPULATION option, the IBS prompts you to define the area in one of three ways:

Select Area of Interest Menu
0 : ExIT
$1:$ Current screen
$2:$ Select existing polygon
$3:$ Draw polygon
Menu Choice $(?=H e l p)=\infty$

After you define an area by one of these three methods, the operation (ESTIMATE POPULATION) is then based on data within that area. Your choices of methods are:

1. Current Screen: Uses all data within the current screen map area. 
2. Select existing Polygon: Uses all data within the area boundad by the chosen polygon. If you choose this option, the system prompts you to pick a polygon:

* * MSG: select a polygon. CONTINUE when done.

A. Pick any point on an existing polygon.

The polygon will blink in white to indicate a pick. If the wrong polygon is highlighted, pick again on the desired polygon until it blinks.

B. Pick CONTINUE from the menu to confirm the polygon selection.

3. Draw Polygon: Enables you to pick points to define a polygon around the desired area. The system prompts:

* kse: Draw a polygon. Continus when done.

A. Pick points that define the sides of a polygon.

Line segments are drawn from point to point.

B. Pick CONTINUE from the menu to complete the final side of the polygon.

The system completes the polygon by drawing the final line segment between the first and last points that you picked.

The operation (ESTIMATE POPULATION in the above example) is then completed, based on data within the area you have defined.

\section{Stopping Map Redrawis}

The IBS redraws the map display when you select menus and certain menu functions. Depending upon how many map layers you have turned on, these screen redraws can take time. You can halt a map redraw by performing the following procedure.

1. Press Ctrl-Z. The system will display the message:

* * MSG: Aborting the map redraw may cause some functions to

* * MSG: not perform as expected.

Really abort map redraw? $(Y / N<C t r l-z>=A b o r t)=\equiv$

2. Enter $\mathbf{Y}$ (yes) or $\mathbf{N}$ (no) to either stop the map redraw or escape from the function. Some functions can behave strangely due to the fact that map data has been partially loaded into memory, but is not visible on the screen. 
If data has been highlighted, you may need to stop the map redraw twice to complete the stop.

Stopping the map redraw is especially useful if you discover that a particular map layer is making screen redraws take too long. After stopping the redraw, you can then go to the Select Map Layers function under Map Analysis and turn off that map layer, or change its parameters.

\section{Problems with Graphic Input}

If you have problems with graphic screen interactions, try these suggested solutions:

- If the screen is static and the system does not accept input, press Ctrl-Q.

Press the Dialog key to see if there are any error messages (see the following section on textual interactions).

- If the system is entirely locked up, press Ctrl-Y to exit IBS if you are stuck in a form or text screen. Restart IBS by typing IBS at the system prompt.

If you are stuck in graphics mode, perform the following procedures.

1. Press the Setup button on your keyboard.

2. Type code ansi and press the Return key.

3. Type cancel and press the Return key.

4. Press the Setup button.

5. Press Ctrl-Y. The system prompt will display.

This method of interrupting the program can cause you to lose the contents of your session, so use it only for the most severe system lockups.

- Call your system manager if you continue to have difficulties. If you do not want to lose the contents of a work session, call your system manager before attempting any of the preceding procedures.

\section{Text Interactions}

The IBS usually prompts for text input through
- menus
- data forms 
A menu is a list from which you can select options. A data form is a collection of related data items displayed on the screen with an input field for each item of data.

Text interactions occur within full-screen or partial-screen windows that overlay the normal display of map graphics.

\section{Vlowing Text Dialog}

The IBS uses various mixes of graphics and text dialog. In some cases, the graphics and text may not appear on the screen of the Tektronix emulators exactly as they would appear on a Tektronix terminal. In other cases the dialog may disappear before you are through reading it. To toggle the text dialog on (or off), use the Dialog key:

- Tektronix terminals: You can press the Dialog key to view text that was replaced by graphics before you were through reading.

- VAXstations: Pick the D VIS (Dialog VISible) button in the row of on-screen buttons at the bottom of the TGRAF-X window.

- PC workstations: Press [ALT-Z]. (Refer to the TGRAF-07 reference manual for more information.)

\section{Using IBS Menus and Forms (Inputting Data)}

The menus and data forms generally used in the IBS contain blank spaces or fields in which you select options or enter data. Generally a blinking input cursor (pointer) on the screen indicates which field is ready to accept an entry. The keyboard conventions used for operating the menus and forms presented by the IBS are described in the following paragraph. Table 1.2 summarizes the data entry conventions for data forms.

\section{Special Function Keys}

The IBS uses two special function keys:

- Help key

- GOLD key

\section{Using The GOLD Key}

The GOLD key is used with other keys for completing and exiting data forms. See Table 1.2.

The identity and placement of the GOLD key on your keyboard depends on the type of workstation/emulator: 


\begin{tabular}{|c|c|}
\hline Terminal Type & GOLD Function Key \\
\hline $\begin{array}{l}\text { Tektronix 4107, } \\
\quad 4109,4208,4211\end{array}$ & $\begin{array}{l}\text { F5, Home } \\
\text { PF1 }\end{array}$ \\
\hline VAXstation & PF1 \\
\hline $\begin{array}{l}\text { PC } \\
\text { Workstation }{ }^{(0)}\end{array}$ & NumLock \\
\hline
\end{tabular}

\section{Obtaining Form HELP}

If you have a question about a particular item on a data form, you can press the Help key.

The identity and placement of the Help key on your keyboard depends on the type of workstation/emulator:

\begin{tabular}{cll} 
Terminal Type & HELP Function Key \\
\cline { 1 - 1 } Tektronix 4107, & Help, F6 \\
4109, 4208 & PF2 \\
VAXstation & Help \\
PC workstation & [Alt-ScrollLock]
\end{tabular}

On all types of keyboards you can also use the ? key (question mark) to get help information. Pressing Help yields two types of information.

- Eield Information: Pressing Help the first time produces specific help information pertaining to the current input field.

- Eorm/Menu Information: Pressing Help a second time produces general help information pertaining to the entire data form or menu.

In both cases, more than one page (screenful) of help information may be available. Press Return to page through the available information and return to the data form or menu.

\footnotetext{
(a) The setup mode of the TGRAP-07 soltware allows you to define the PC keybound's function keys. It might be helpful to assign function keys to a few IBS functions. Refer to the TGRAP-07 reference manual for details on function key definitions and how to aesign them.
} 
Table 12. Summary of Data Entry Conventions for Data Forms - Tektronix and [PC] Keypresses

Keypress(es) $\%$ RETURN

CTRL-D

CTRL-F

Up F1 [8]

Down F2 [2]

Left F3 [4]

Right F4 [6]

HELP, F6, PF2

?+RETURN and ??

[ALT-ScrollLock]
Cursor Movement

Advance past a scrolling block of items on a form

Move left one character without altering the text

Move right one character without altering the text

Move to preceding line

Move to next line

Backup horizontally to preceding field

Advance horizontally to next field

Eorm Editing or Operation In fields with Help, first press: Show information about the current field.

Second press: Show info about the current form or menu. In selected fields, ?? + RETURN will display a list of possible choices to enter in the field.

GOLD Z

Complete and exit one form:

[NumLock] [Z] Checks and accepts current entries in field and form; Signals completion of the current form;

Moves to the next form (in a set of forms); or Exits to the previous higher-level form or menu (from a single-page form)

GOLD Y

Exit from a form or set of forms:

[NumLock] [Y]

Restores the original contents of the current field;

Signals completion of the current set of forms;

Exits to the previous higher-level form or menu.

RETURN Accept the current neld entry and advance:

If the cursor is in the final field of a form, pressing RETURN acts like GOLD Z.

BACKSPACE Delete the previous character.

CTRL-E or CTRL-Z

Refresh the screen. Use these to redraw your screen. For example, after a broadcast message prints over your form, use CTRL-E to redraw the form. These keystrokes work only on forms, not menus. Some complex forms may not refresh completely. If you have trouble refreshing a form, exit the form by pressing GOLD Y and restart the form.

Delete character. 
CTRL-R Insert a blank. Inserts a blank character into the current field.

CTRL-W Provide an option to abort current field or form: A prompt at the bottom of the screen will ask you whether you want to abort the field (F), the whole form $(\mathrm{W})$, or nothing $(\mathrm{N})$.

- An F aborts the current entry and restores the original contents of the field-the contents before you started changing it.

- A W aborts the current form and restores the original contents of the form.

- An $\mathbf{N}$ enables you to continue without aborting.

CTRL-X Clear the current field. Clears the field you are currently working in of any characters.

\section{Selecting an Option from a Text Menu}

Text menus generally consist of a list of options and a single input field:

Highlight Data Menu

Highlight Data Menu
0 : ExIT
$2:$ Iist attributes for current screen
Menu Choice $(?=H e l p)=m$

\section{To select an option from a text menu}

Type the character corresponding to the desired option and press Return. If you need help, type a ? at the prompt and press the Return key. For the above menu, the following help screen will display.

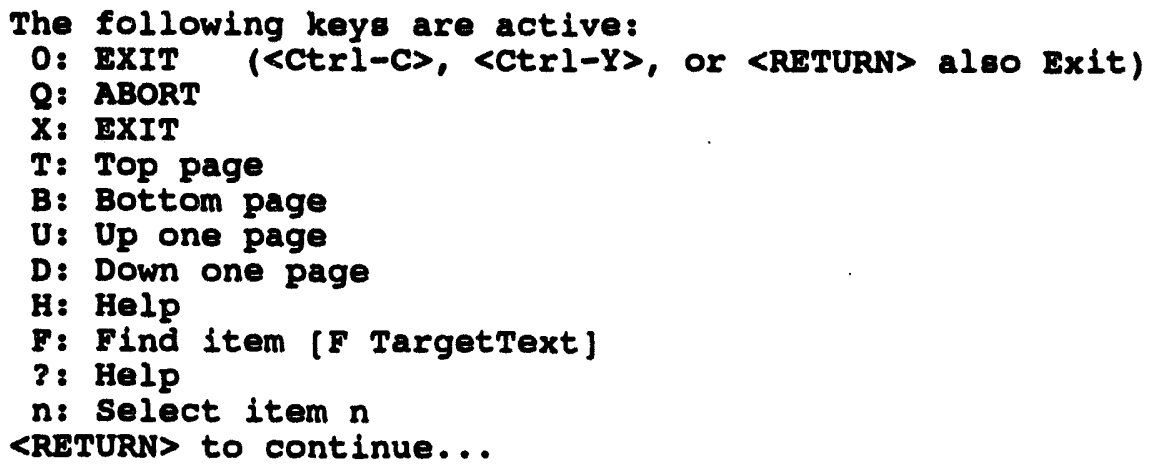




\section{Selecting Multiple Stems from a List}

Some menus are list menus and will enable you to select several items in a range. To do this, enter the beginning and ending numbers in the range separated by a + . For example, to select numbers 2 through 6 from a list, enter $2+6$ at the prompt. The system will select numbers $2,3,4,5$, and 6 for you. List menus can be recognised by the prompt List Choice (?=Help) $\Rightarrow$.

\section{Positioning the Input Cursor in a Form}

When the IBS first displays a data form, the input cursor is at the beginning of the first entry field. Use the arrow keys to move the cursor to the various fields of the form. When the cursor is at the beginning of a field, Return also advances the input cursor to the next field. These cursor movements do NOT affect any entries already in the entry fields unless you have started to make a new entry in the field where the cursor resides. When the form is not large enough to contain all the necessary items, some items may be scrolled several lines (one block) at a time to reveal more input fields. You can enter a percent (\%) symbol at the beginning of an entry field to advance the input cursor past the scrolling block area of the form.

\section{Entering Numeric Values in a Form}

The data forms accept floating point input in some cases. Type numeric values (positive or negative) to fit the entry fields. When you press Return or an arrow key to accept the numeric entry, the IBS rewrites the entry to fit the field, sometimes reformatting the value in scientific notation.

\section{Problems with Menus and Forms}

If you have one of the following problems with text menus or data forms, try the suggested solution(s):

- If the following messages display: "Input too long for this field." or "Value out of range for this field.", check your entry. Use the Delete key ([Backspace] on the PC) to delete the current value, and type your entry again. Press the Help key to get information about acceptable field values. If you are using a PC and the backspace key does not seem to work, try Ctrl-Backspace.

- If the screen is ratic and the system does not accept keyboard input, try pressing Ctrl-Q to free up the keyboard.

- If no system response follows a menu selection or completion of a form, try the following. If you pressed Return while the system was updating the display, you may need to press Return again to continue. 


\section{Overview of the IBS Main Menu}

\begin{tabular}{|l|}
\hline EXIT IBS \\
\\
IBS MAIN MENU \\
\hline \\
MESSAGE BOARD \\
STATUS BOARD \\
PERSONNEL MANAGEMENT \\
MAP ANALYSIS
\end{tabular}

The IBS combines emergency management planning and tracking capabilities with computerized map display and modeling of emergency events (such as the dispersion of a chemical agent or the evacuation of a population).

$<-$ View or send messages and reports.

<-- Plan or track Emergency Function tasks.

<-- Maintain database of EOC personnel.

<- Show and analyze graphic map information.

<-- Manage and track use of resources.

<-- Map computed time-release concentrations.

<- Show computed information about track.

$<-$ - Switch between track data sets.

<-- Show text description of current track.

<-- Carry out emergency support activities and computer modeling activities.

<-- Tailor various system features that are to be used as default conditions.

\section{Asterisks $\left(^{*}\right)$ in this Document}

In this document the asterisks on the graphic menus indicate options that require special privileges. These options will be blank lines on the menus of General Users.

\section{Order of the Reference Sections}

The reference sections of this guide are arranged in the same order as the major options appear on the main menu. Capabilities within each section are arranged in alphabetical order. 


\section{Introductory Exercises}

The following exercises have been developed to give you a practical introduction to the IBS. After performing these exercises, you will be able to:

- Start IBS

- Navigate the menu system

- Select options

- Set up default map layers

- View data

- Work with Emergency Planning Zones (EPZs)

- Change map displays

- Exit IBS

The exercises are not intended as a substitute for formal training. Formal training provides in-depth methodologies and procedures tailored for your work site.

To do the exercises, you must have a user account on the VAX computer system. You must be able to login with a username and password. If you do not have a user account, contact your system manager.

Note: The graphic displays shown in these exercises are examples included for instructional purposes. The map displays and system data included on your system can vary. Even though your map display may look different, the IBS commands still work in the same way.

\section{Starting IBS}

To do these exercises perform the following procedures.

1. Login to the VAX.

2. Start IBS by typing ibs at the system prompt and press the Return key. The system will display the following message:

READING CONTROL FILES

PLEASE WAIT. 
After a few moments, the IBS Main Menu and default map graphic displays as shown.

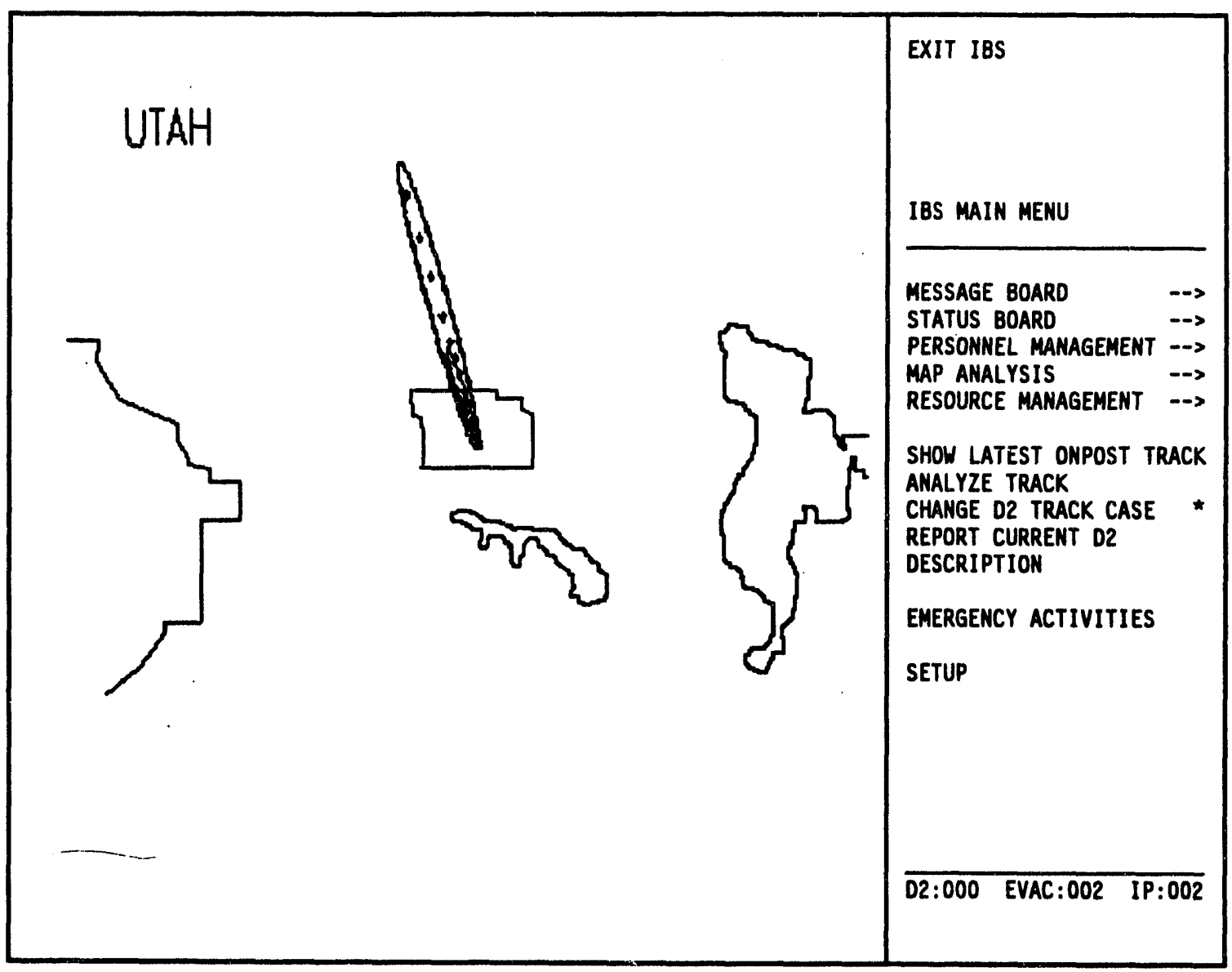

You are now ready to begin any of the following exercises.

1. Viewing the Onpost Work Plan

2. Setting Up Your Default Map Display

3. Adjusting the Map Display

4. Using Emergency Activities

For detailed information on pointing and selecting with the graphic cursor (cross hairs), and working with text displays and forms, see the preceding heading Getting Started and Conventions for Interacting with the IBS earlier in this section. 


\section{Exercise 1. Viewing the Onpost Work Plan}

To view the current Onpost Work Plan, perform the following procedures.

1. From the IBS Main Menu, select the Status Board command with the cross hairs and press the Space bar. The Status Buard menu displays as shown.

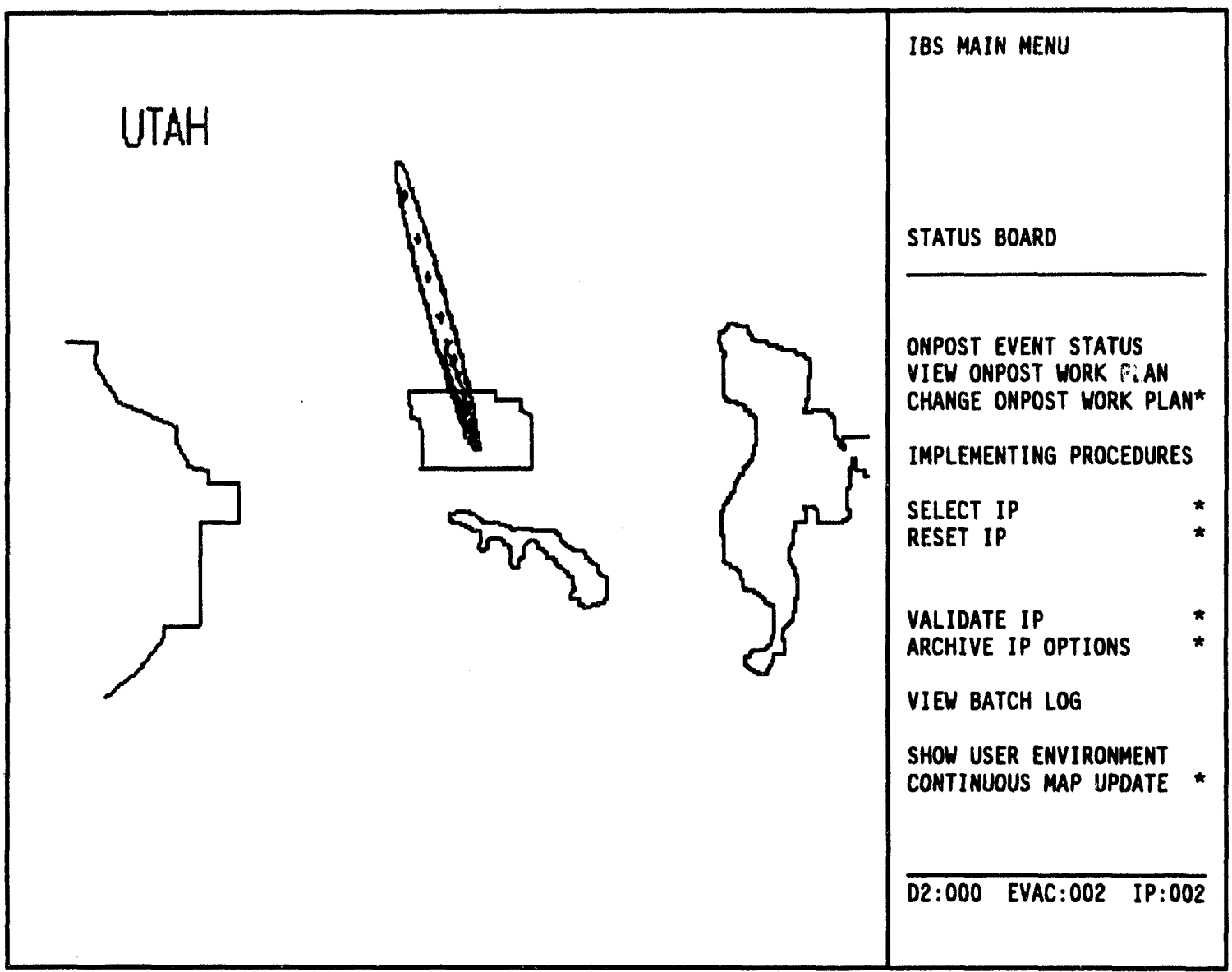


2. From the Status Board menu, select the View Onpost Work Plan command.

The Onpost Work Plan displays, as shown. This text screen overlays the graphic map display.

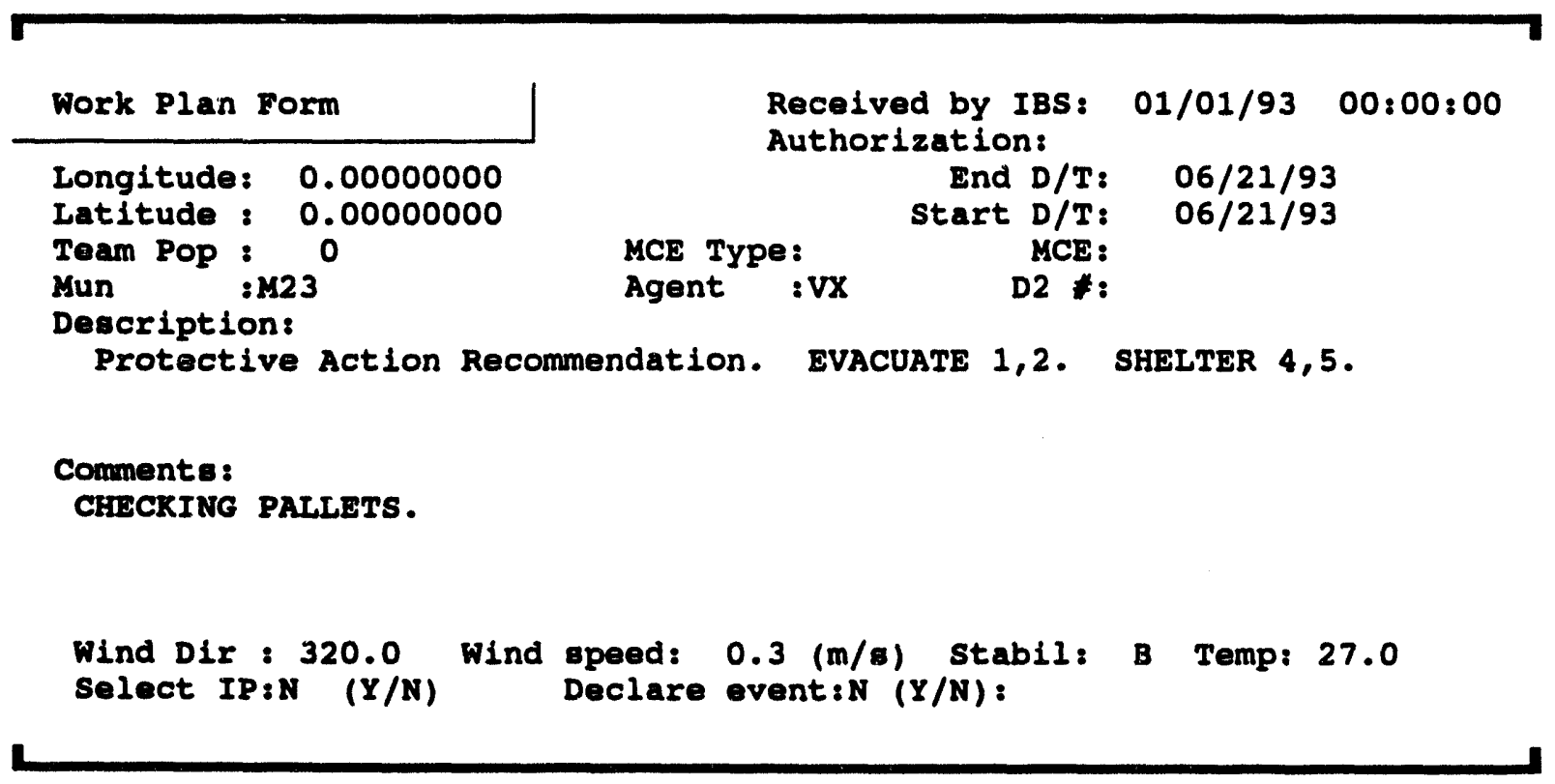

3. Exit the current Onpost Work Plan by pressing GOLD-Y. The Status Board menu displays.

4. From the top of the Status Board menu, select the IBS Main Menu command. The system returns you to the Main Menu.

For detailed information on the Onpost Work Plan and Implementing Procedures, see Section 3. 


\section{Exercise 2. Setting Up Your Default Map Display}

Each time you start IBS, you can set up the map display to show you the map layer infomation you want. To set up the map display, perform the following procedures.

1. From the IBS Main menu, select the Setup comand. The Setup menu will display as shown.

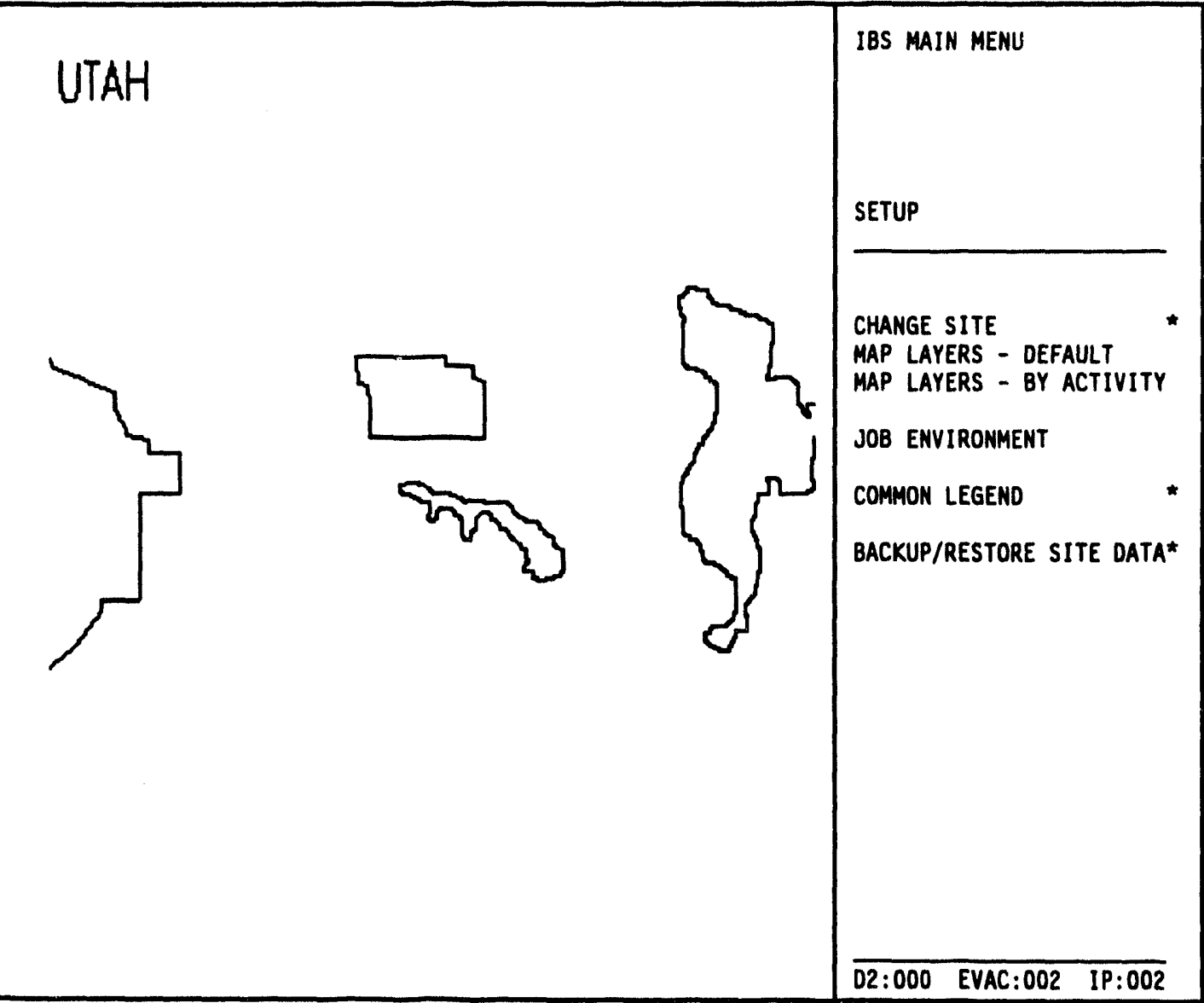

2. From the Setup menu, select the Map Layers - Default comand. The Change Default Map Layers msiu will display, as shown. 


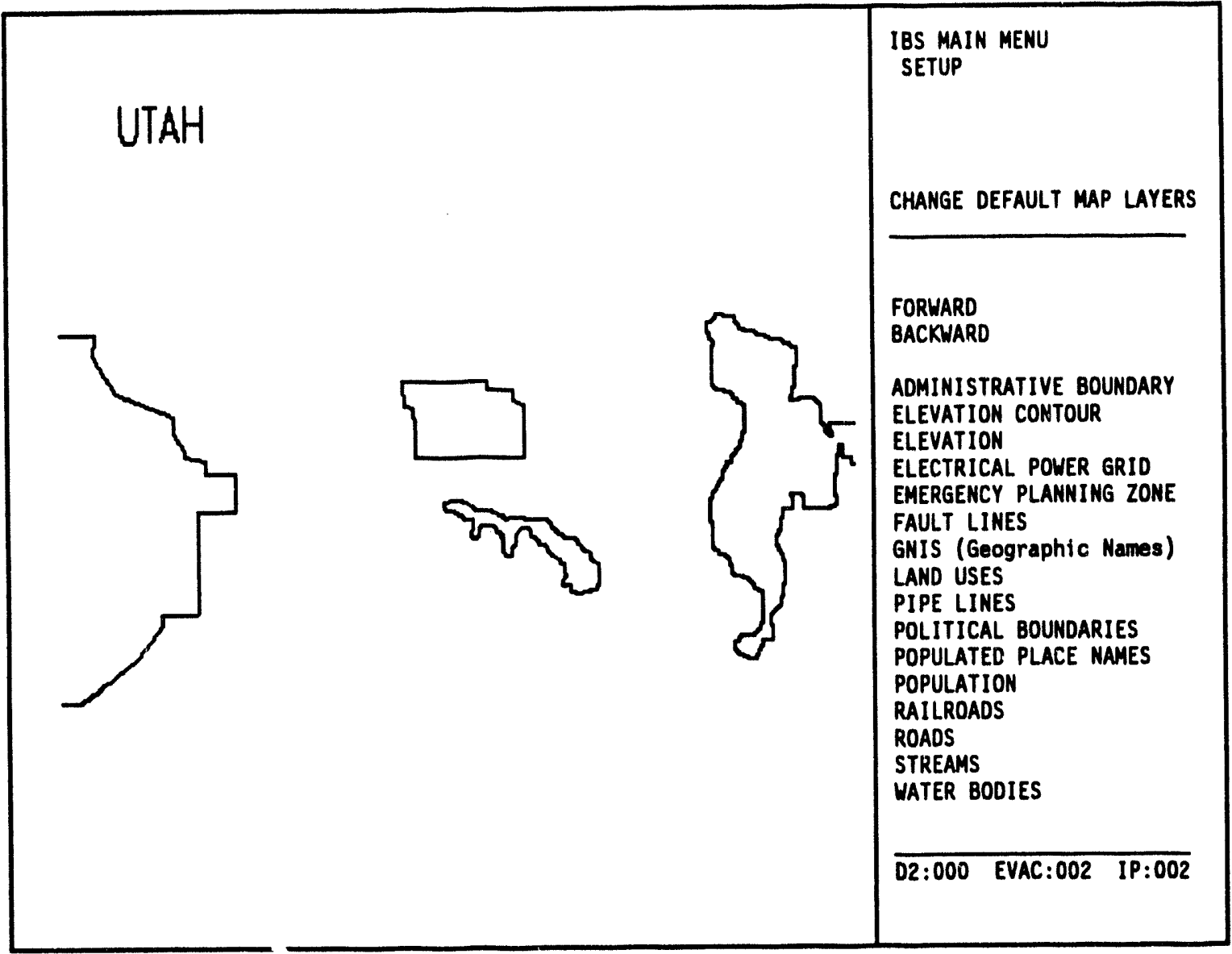

The Map Layers - Default menu consists of several lists of map layers from which you can pick the layers you want to view. For this exercise you will pick the following layers:

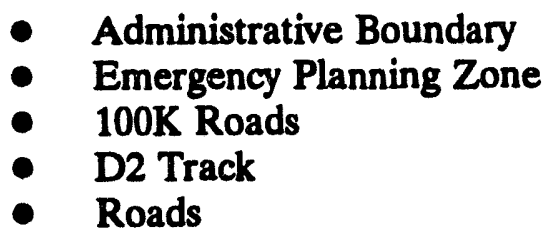

These map layers may not all be contained in the first map layer list.

Note: The user list of map layers supplied with your system can be slightly different from the examples shown.

3. Use the Forward command to page through the lists by selecting the command with the cursor (cross hairs).

4. Select the map layers when they display on the list. As you select the map layers, they will highlight in green. Keep paging through the list and picking map layers until all four listed map layers have been selected. 
Previously selected default map layers will display in green on the list. Lcave these as they are. After paging forward several times, you will eventually return to the first page of the list.

5. Select the Setup command to exit Select Default Map Layers. The Restrictions of Map Layers by Display Size menu will display, as shown.

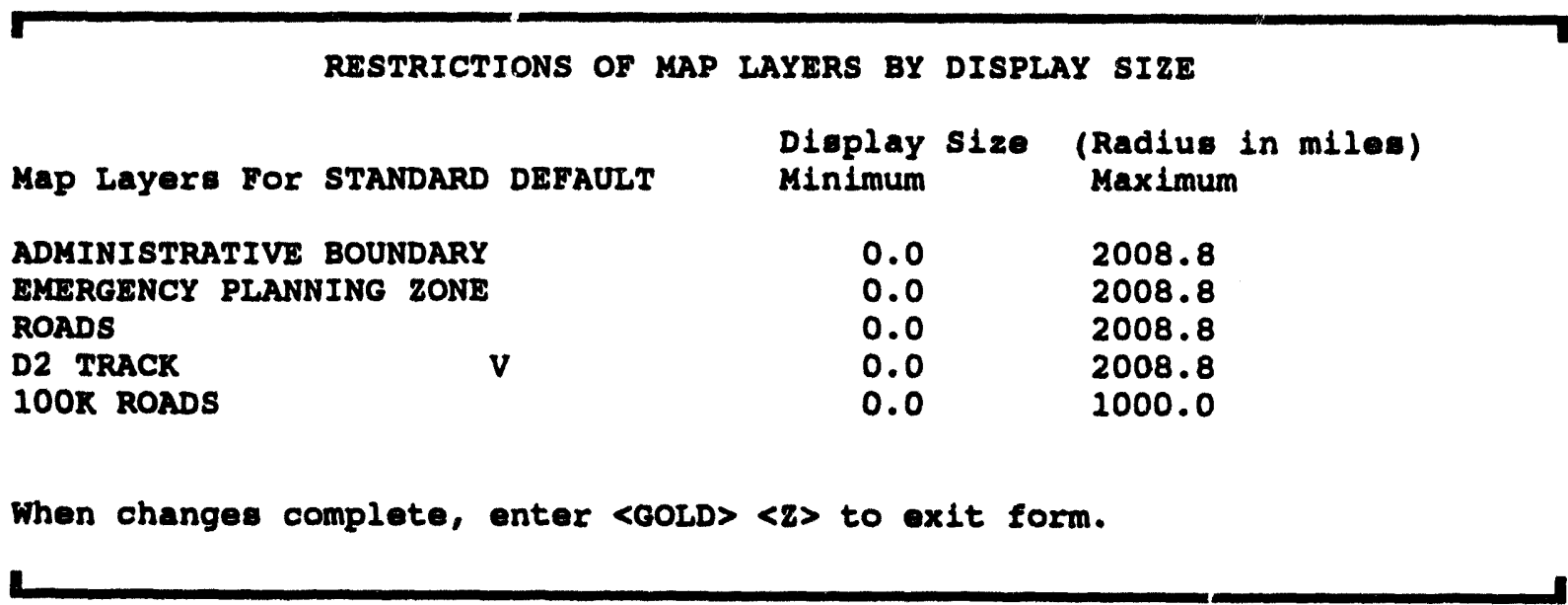

6. Use this menu to restrict the display of certain data-rich map layers. In many cases, the default setting is fine. In this exercise, you were instructed to turn on the display of both Roads and $100 \mathrm{~K}$ Roads. Use the Return key to move through the Minimum and Maximum fields and change the settings for $100 \mathrm{~K}$ Roads to the following:

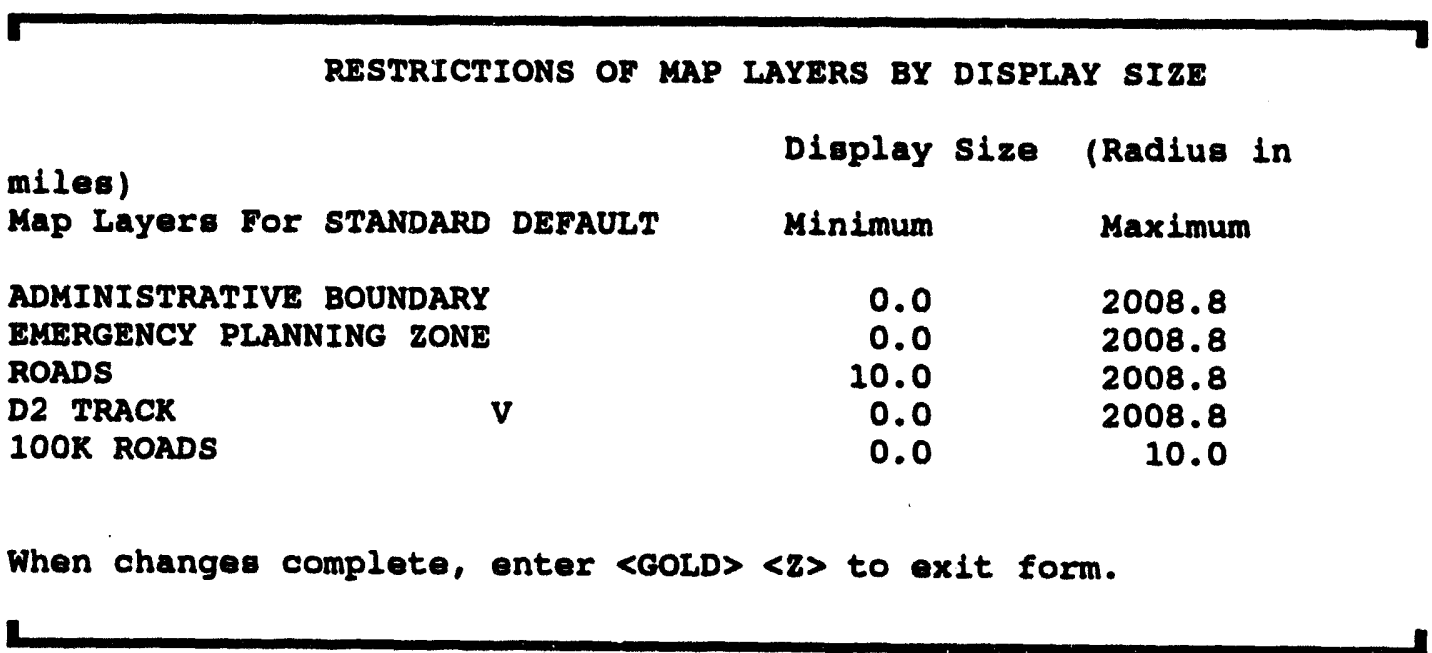

Notice that you have now restricted $100 \mathrm{~K}$ Roads so that they will display only when you have zoomed in your map display to a radial distance of ten miles or less. This makes sense, as the $100 \mathrm{~K}$ Roads layer is a very data-rich map layer. If you try to display the $100 \mathrm{~K}$ Roads map layer over a large area (for 
instance, 30-50 miles), the system would spend too much time trying to display all the many roads in the area. In some cases, the system can run out of memory while trying to display all the details, resulting in a system lockup. Check with your system manager for more details concerning which map layers need to be restricted to small areas.

7. When you have finished typing in the new restrictions, press GOLD-Z to exit the menu. This will cause the system to display the chosen map layers. The graphic screen will go blank for a moment, then the map will display with the new layers. These layers will now display each time you start IBS. 


\section{Exercise 3. Adjusting the Map Display}

To change and adjust the map display, perform the following procedures.

1. From the IBS Main Menu, select the Map Analysis command with the cross hairs and press the Space bar. The Map Analysis menu will display, as shown.

IBS MAIN MENU
ITAH


2. From the Map Analysis menu, select the Display Text command. Descriptive text will display on the base map, as shown. This command toggles between Display Text and Turn Off Text each time you select it. Now that you have selected the Display Text command, the Turn Off Text command displays in its place.

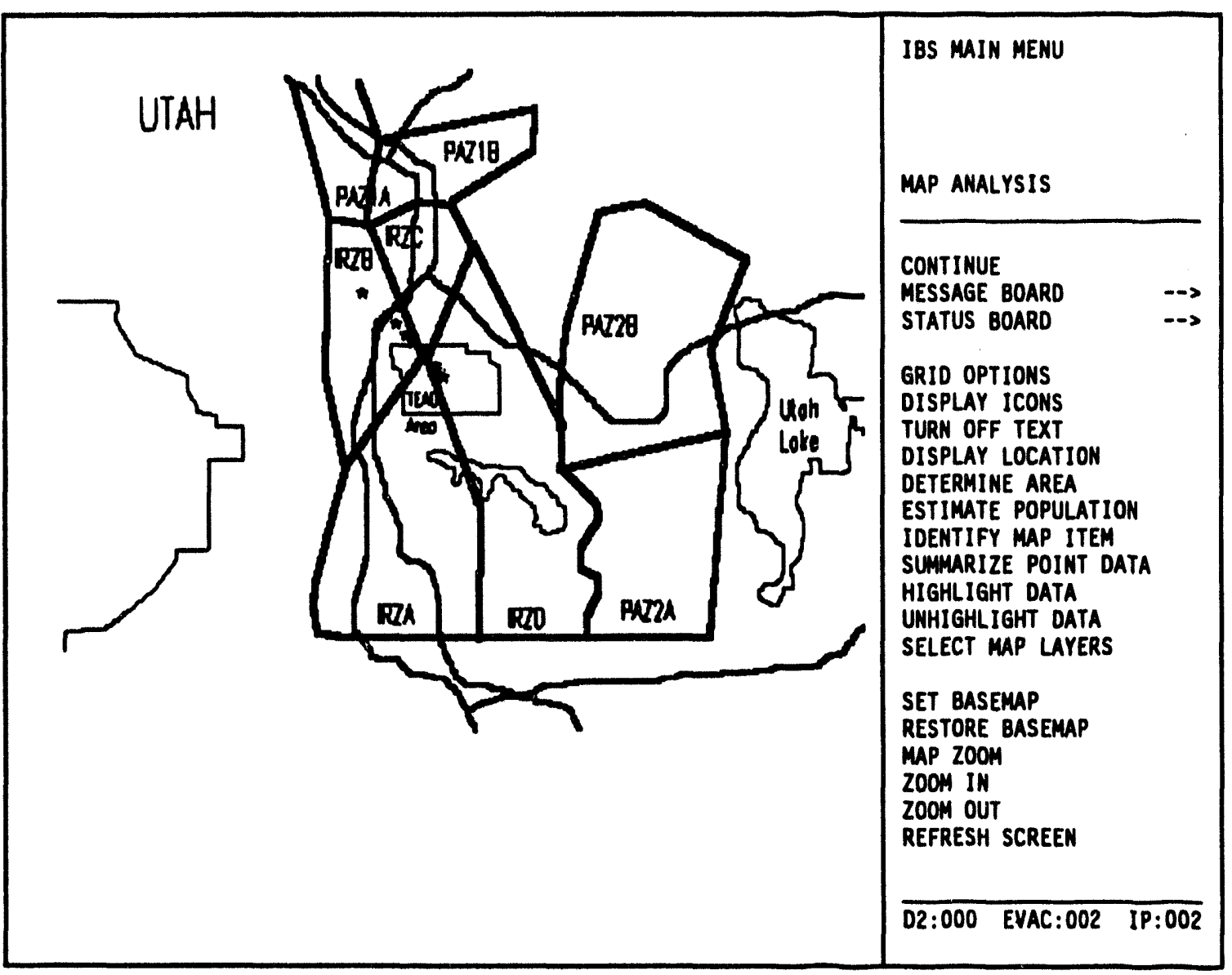

3. For a closer view of an area, select the Zoom In command from the Map Analysis menu.

The Zoom In command will highlight in green and blink, while the following text message will display in the upper left corner of the screen:

* * MSG: select center and one edge w/mouse

4. Move the cross hairs on your screen so that they cross over the center of the area where you want to zoom in. Press the Space Bar once.

5. Move the cross hairs out to a spot which will become the new corner or edge of the zoomed in display. Press the Space Bar. A red square will display momentarily to show the area you have marked, then the screen will blank out 
as the system zooms in on the map. The new area you indicated will display, as shown in the following example.

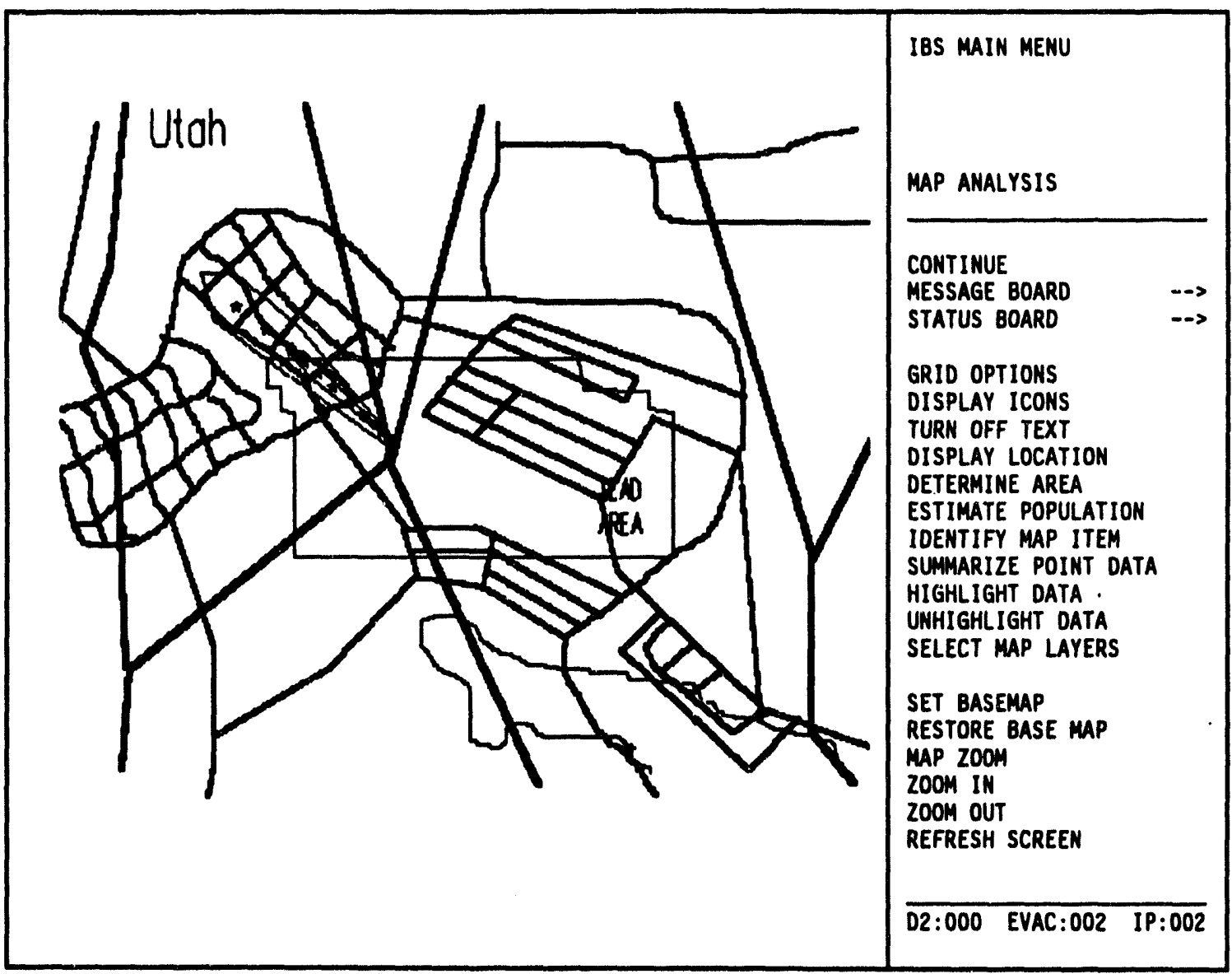

You can repeat this procedure to get as close a view as you wish. Use the Zoom Out command in a similar way to move your view back.

Note: If you have used the Select Map Layers option to display a map layer with data-rich information while you are zoomed in, you may get the message:

\section{Data Exceeds Memory}

when you try to zoom out or restore the base map. The system may not draw all the information on the larger area, or it may take too much time trying to draw the information. To avoid this problem, use the Default Map Layers option under the Setup command to restrict the areas on which data-rich map layers will display (as described in Exercise 2). 
6. To return to your original viewpoint on the map, select the Restore Basemap command from the Map Analysis menu.

7. From the top of the Map Analysis menu, select the IBS Main Menu command. The IBS Main Menu will display.

8. From the IBS Main Menu, select the Resource Management command. The system will display the various standard facility icons on the map, as shown.

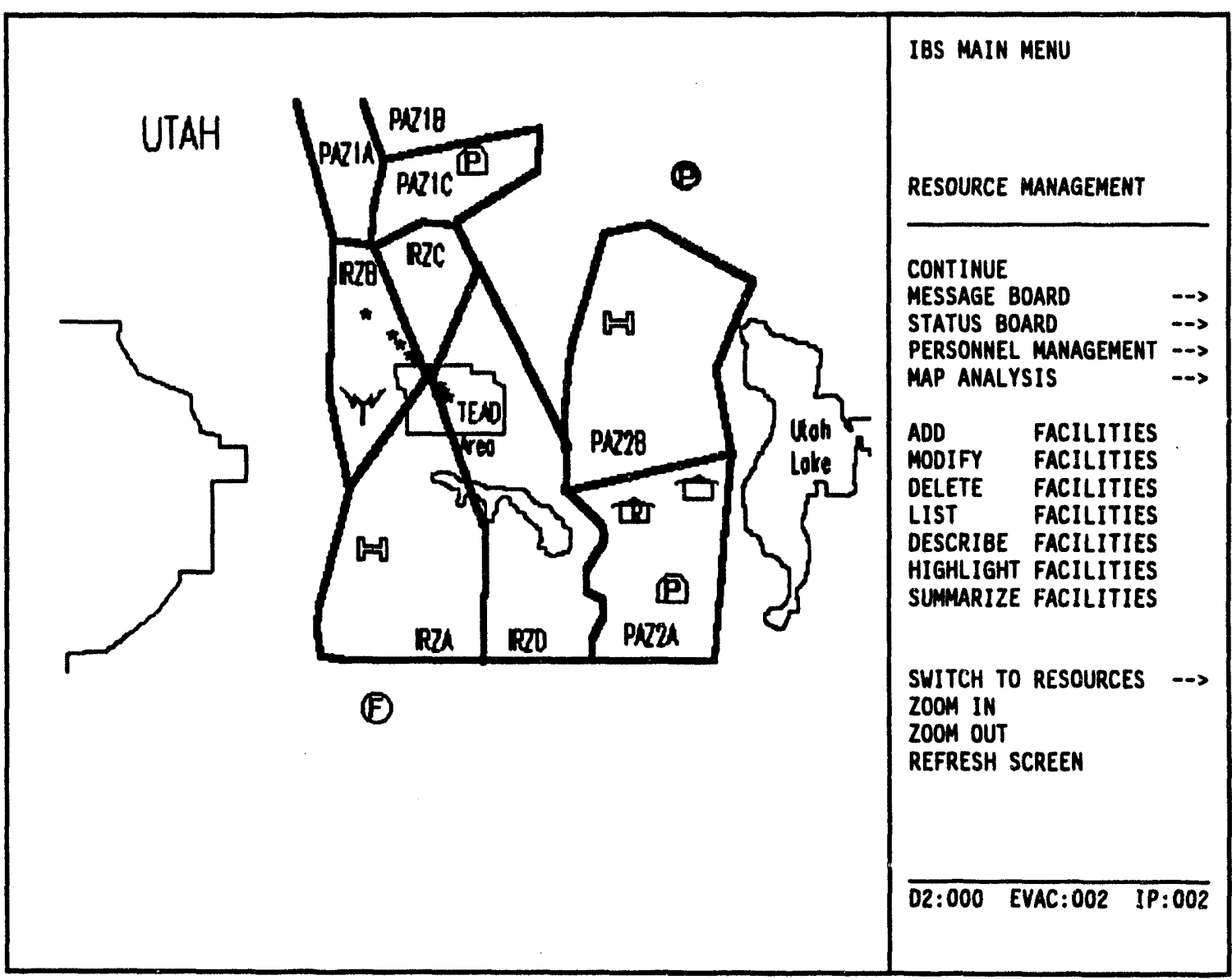

The Resource Management menu will display.

9. Select the List Facilities command from the Resource Management menu. The List Facilities command will highlight in green, then the system will overlay the map display with a text listing of the facilities represented by the icons. 
Note: If your system has not been set up for default screen display of reports, the Ouput Redirection Menu will display:

Output Redirection Menu

$0:$ ExIT
$1:$ Display on screen
$2:$ Print on default printer
$3:$ Mail to other user $(8)$
$4:$ Save to an AScII file
Menu Choice $(?=H e l p)=>$

At the Choice prompt, type 1 and press the Return key. The facilities listing will display.

An example of the facilities listing follows.

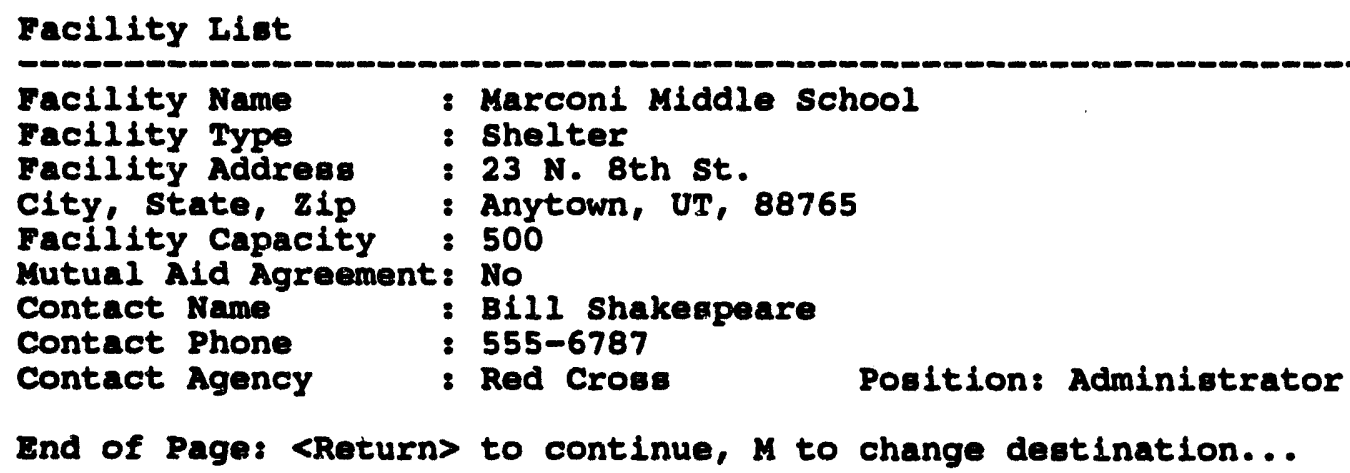

10. Press the Return key to page through the listings. When you have displayed all the facilities, the system returns to the map display and the Resource Management menu.

The listings can continue for several pages. To exit the listing without scrolling through every page, press Ctrl-Z.

11. Select the IBS Main Menu command to return to the top level of IBS. Notice that the facility icons remain on the map display. 


\section{Exercise 4. Using Emergency Activities}

1. From the IBS Main Menu, select the Emergency Activities command with the cross hairs and press the Space bar. The Emergency Activities menu displays, as shown.

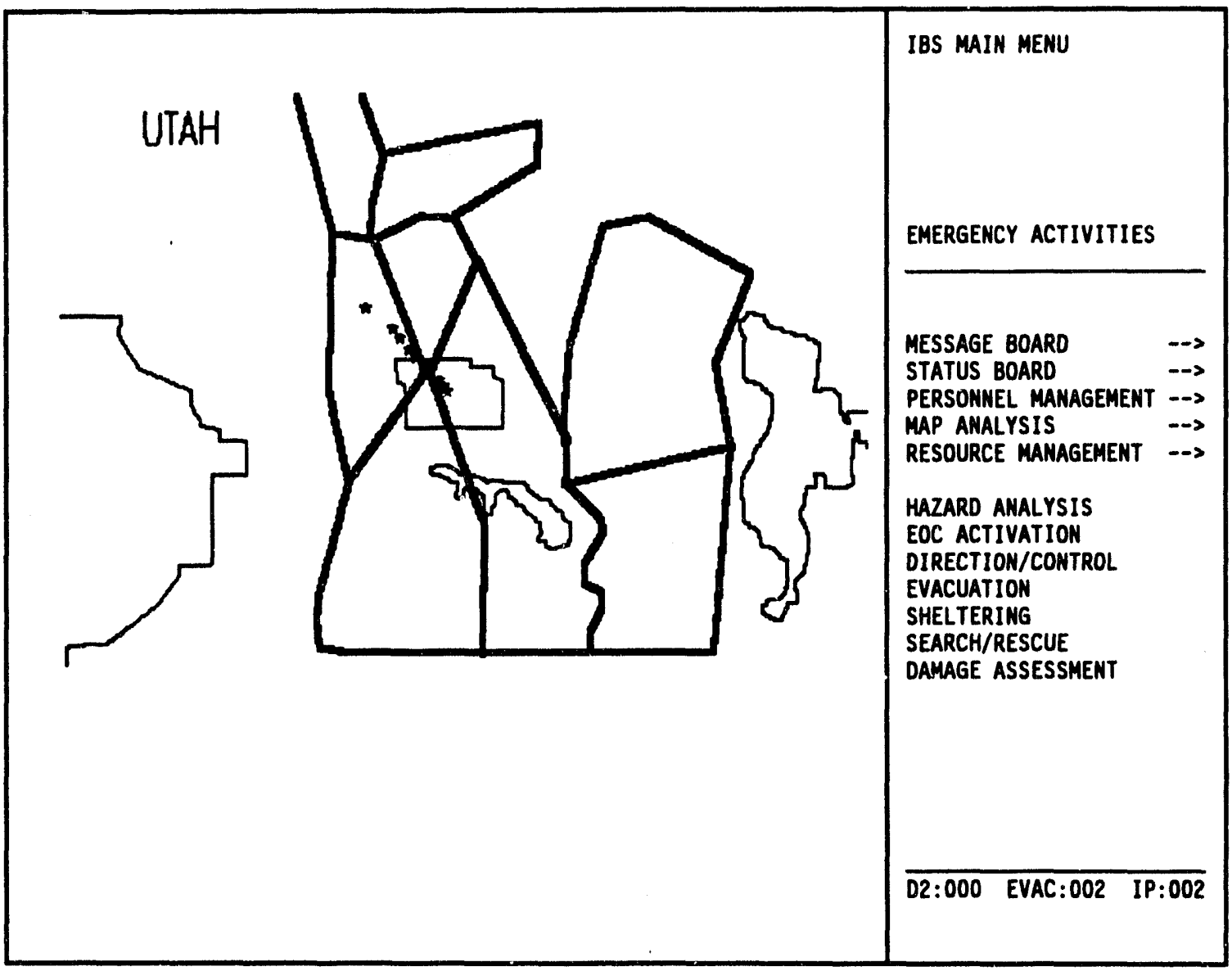


2. From the Emergency Activities menu, select the Direction/Control command. The Direction/Control menu displays, as shown.

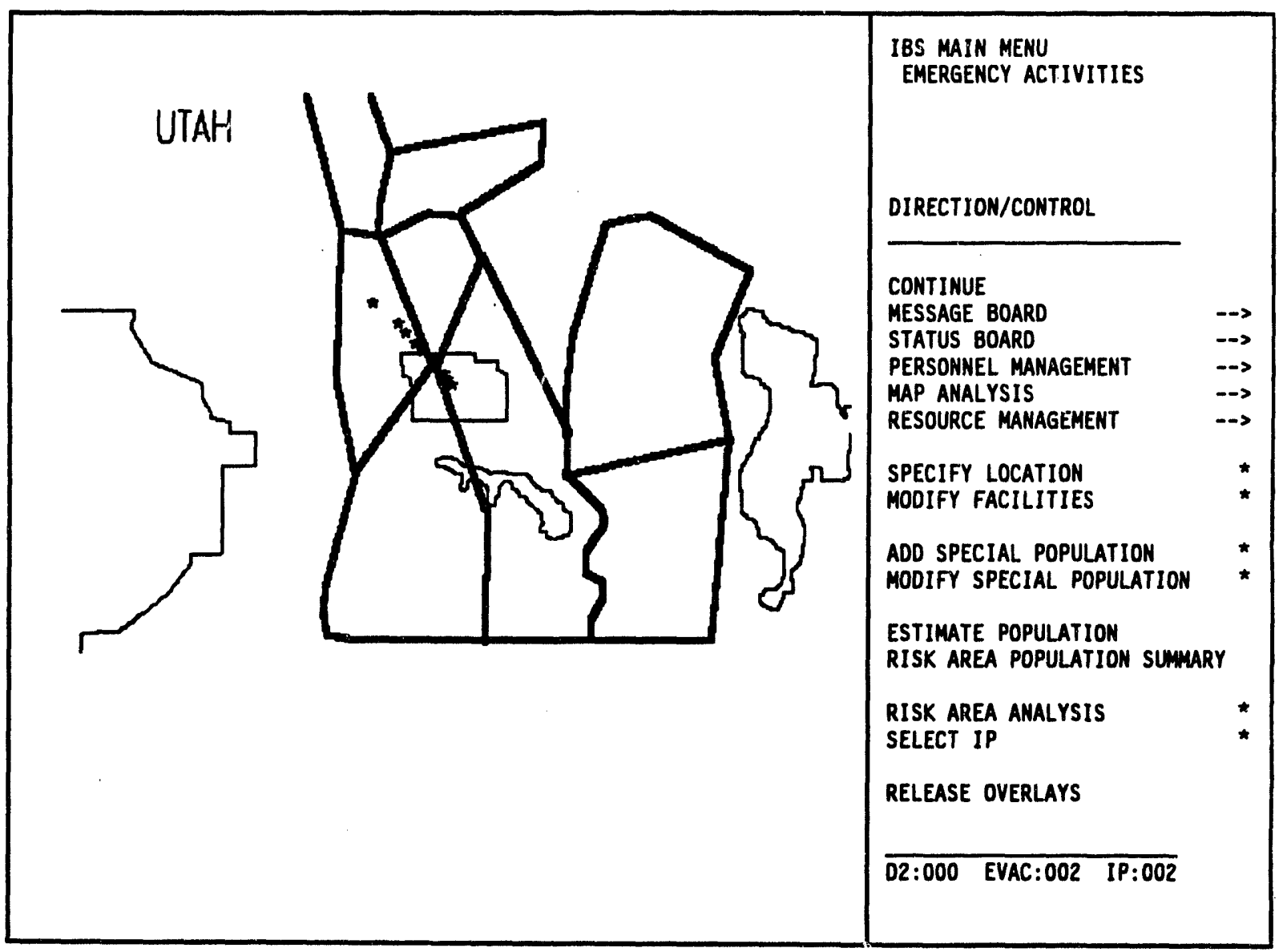


3. From the Direction/Control menu select the Risk Area Analysis command. The system draws in any existing risk polygon in bold white lines over the base map display, as shown. The Risk Area Analysis menu displays.

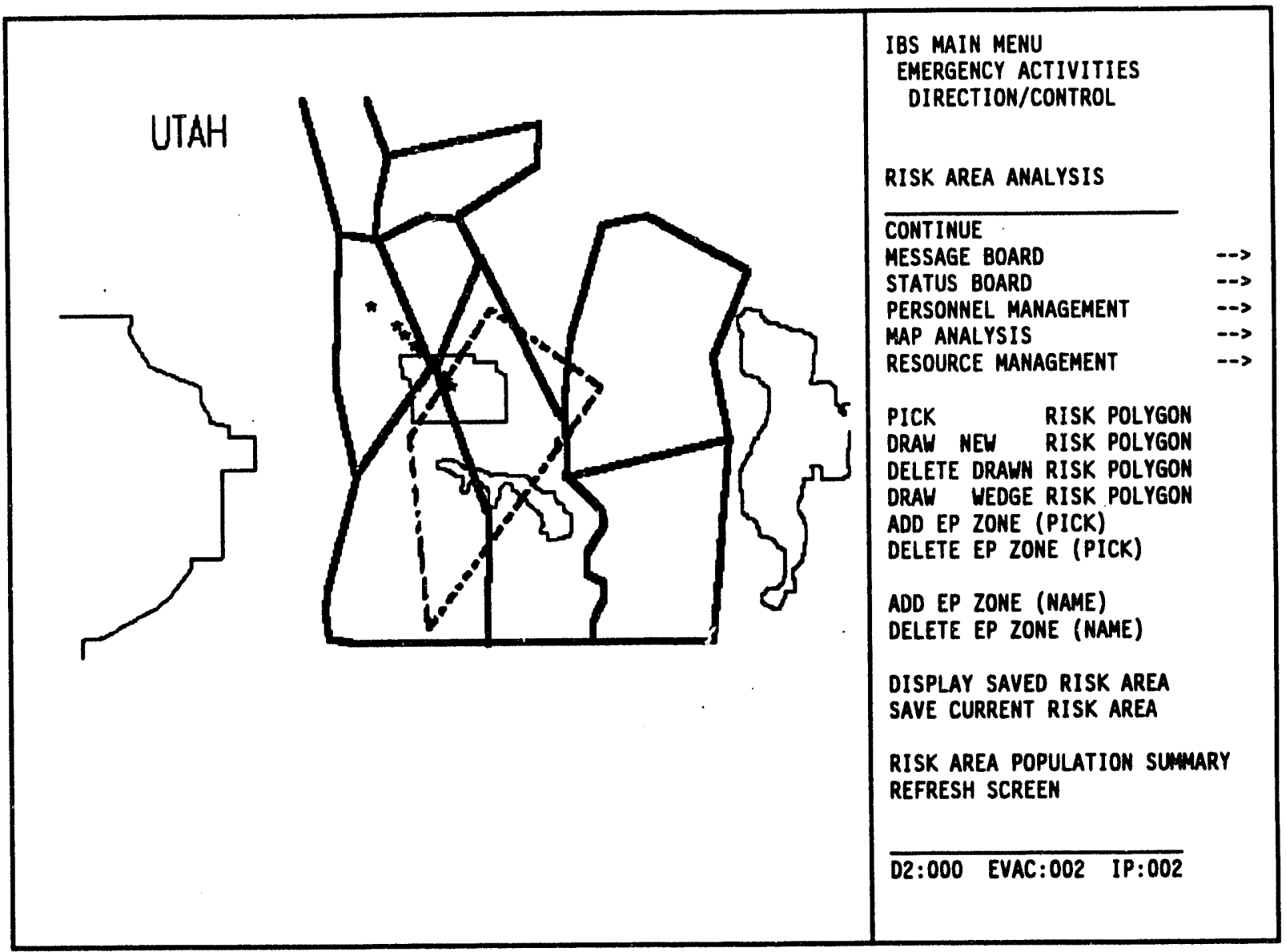

4. From the Risk Area Analysis menu, select the Draw New Risk Polygon command. The system displays the following message:

* * *SG: Draw a new Risk Polygon. CONTINUE when done

5. Use the cursor (cross hairs) to draw a risk polygon on the map display. Press the Space bar to indicate the point of each corner. The polygon lines are initially drawn in green. 
6. When you have drawn the polygon, select the Continue command to close the polygon. The new risk polygon is redrawn in bold white lines. The evacuation zones that intersect or are contained in the new risk area will be redrawn in bold lines. Those zones not touched by the risk polygon are redrawn in thin lines.

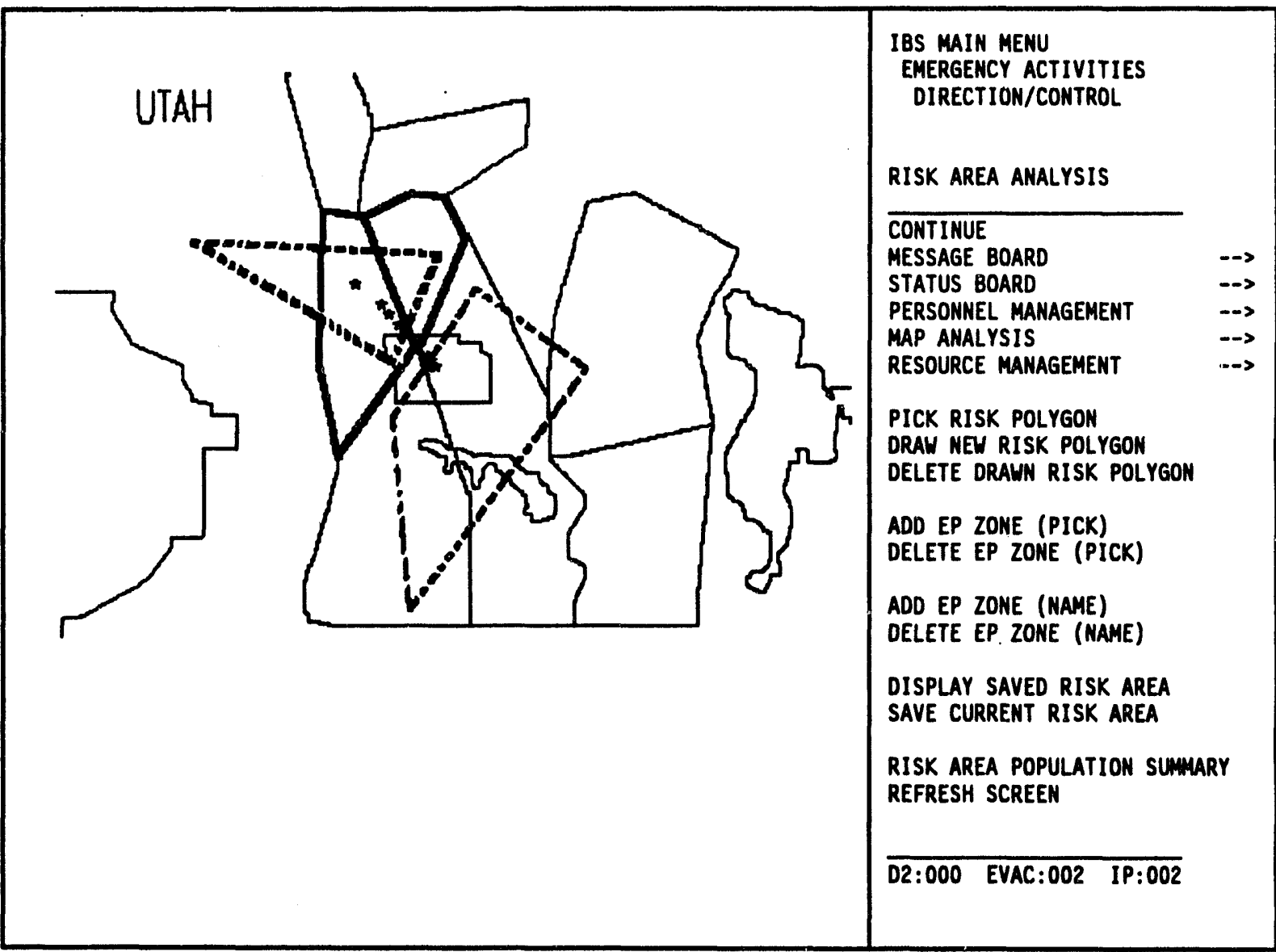

Delete the old risk polygon and leave the new risk polygon on your map display.

7. To delete the old risk polygon, select the Delete Drawn Risk Polygon command from the Risk Area Analysis menu. The system displays the following message:

* * MSG: Select Riek Polygon to delete. CoNTINUE when done.

8. Use the cursor to select any point on the polygon you want to delete. Move the cursor over the polygon and press the Space bar. The polygon you have selected will blink. If you select the wrong polygon, move the cursor and select a point on the correct polygon.

9. Delete the polygon by selecting the Continue command from the menu. The blinking polygon is deleted. 
The polygons outlined in bold orange are EPZs. These EPZs compose the risk area. Now you can add or delete EPZs to the risk area.

10. To add an EPZ to your risk area, select the Add EP Zone (Pick) commana from the Risk Area Analysis menu. The system displays the following message:

* * MSG: Select EPZ to add to Risk Area. CONTINUE when done

11. Use the cursor to select an orange EPZ polygon from those displayed on the map. The selected zone is highlighted in white and blinks.

12. Select the Continue command to add the zone to the Risk Area. The zone will highlight, flash once, then redisplay in bold orange. The population data from this zone is then included in the Risk Area.

13. From the Risk Area Analysis menu select the Risk Area Population Summary command. The Output Redirection Menu displays, as shown (unless you have used the Setup command to set a default). See Section 12 for more information.

\begin{tabular}{l} 
Output Redirection Menu \\
\hline $0:$ ExIT \\
$1:$ Display on screen \\
3 : Print on default printer \\
\hline Menu Choice $(?=H e l p)=m$
\end{tabular}

14. Type a 1 at the Choice prompt and press the Return key. The Risk Area Population Selection Menu displays, as shown.

Risk Area Population Selection Menu

\begin{tabular}{ll} 
0: ExIT & \\
1: Total Population & (Census) \\
2: Special population summary & (Special Population) \\
3: Special population by EPz & (Special Population) \\
\hline Menu Choice $(?=\mathrm{Help})=x$ &
\end{tabular}


15. Select the Total Population option by typing a 1 at the $==>$ prompt. Press the Return key.

The population summary displays, as shown.

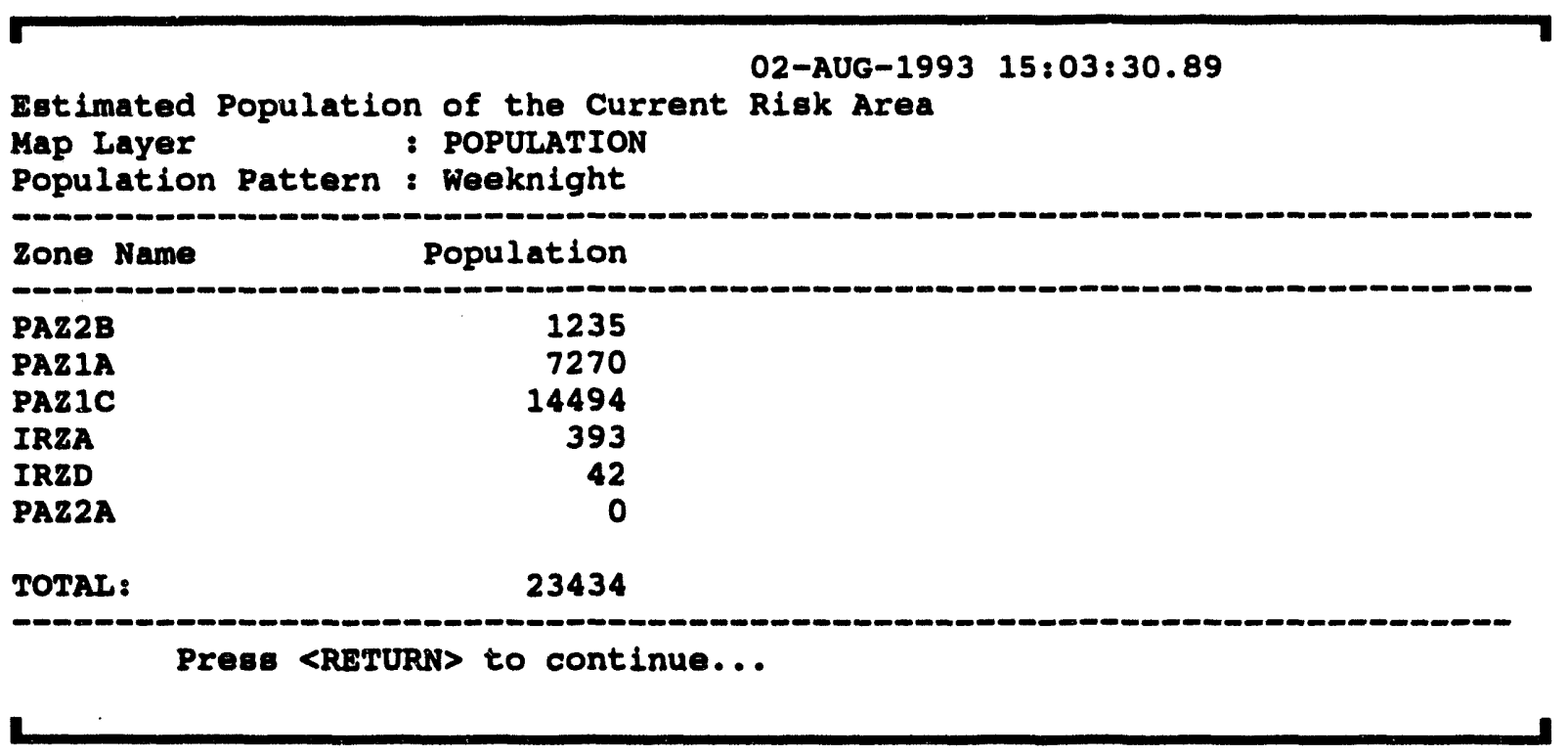

16. Press the Return key to return to the Risk Area Analysis menu.

17. From the top of the Risk Area Analysis menu select the Emergency Activities command. The system displays the following message.

Do you wish to save the RISK AREA [Y]? $\Rightarrow$

Press the Return key to save the new risk area. The Emergency Activities menu displays.

18. From the Emergency Activities menu select the Sheltering command. The Sheltering menu displays.

19. From the Sheltering menu select the Shelter or Center Info command.

Note: In some cases, you will have a better view of facility icons if you first use the zoom in function on an area of interest. If you are in an extreme zoom out view, the icons may be so crowded together that the map display is difficult to interpret. 
The Shelter or Center Info command will highlight in blinking green. If you do not have a default Selection method (see Section 12 for details on defaults), the system displays the Facility Selection method menu.

\begin{tabular}{l} 
Facility selection method menu \\
\hline $0:$ ExIT \\
$1:$ Type in Facility name \\
$2:$ Select racility name from a list \\
$3:$ Type in long/lat coordinates \\
$4:$ Use mouse to select Facility \\
Choice (?-Help) $=0$
\end{tabular}

20. At the Choice prompt, type a 4 and press the Return key. The system displays the following prompt.

Draw facilities onscreen? $[Y$ ] =m

Press the Return key. The system draws the facility icons and displays the following message:

* * MSG: Select a Facility w/mouse

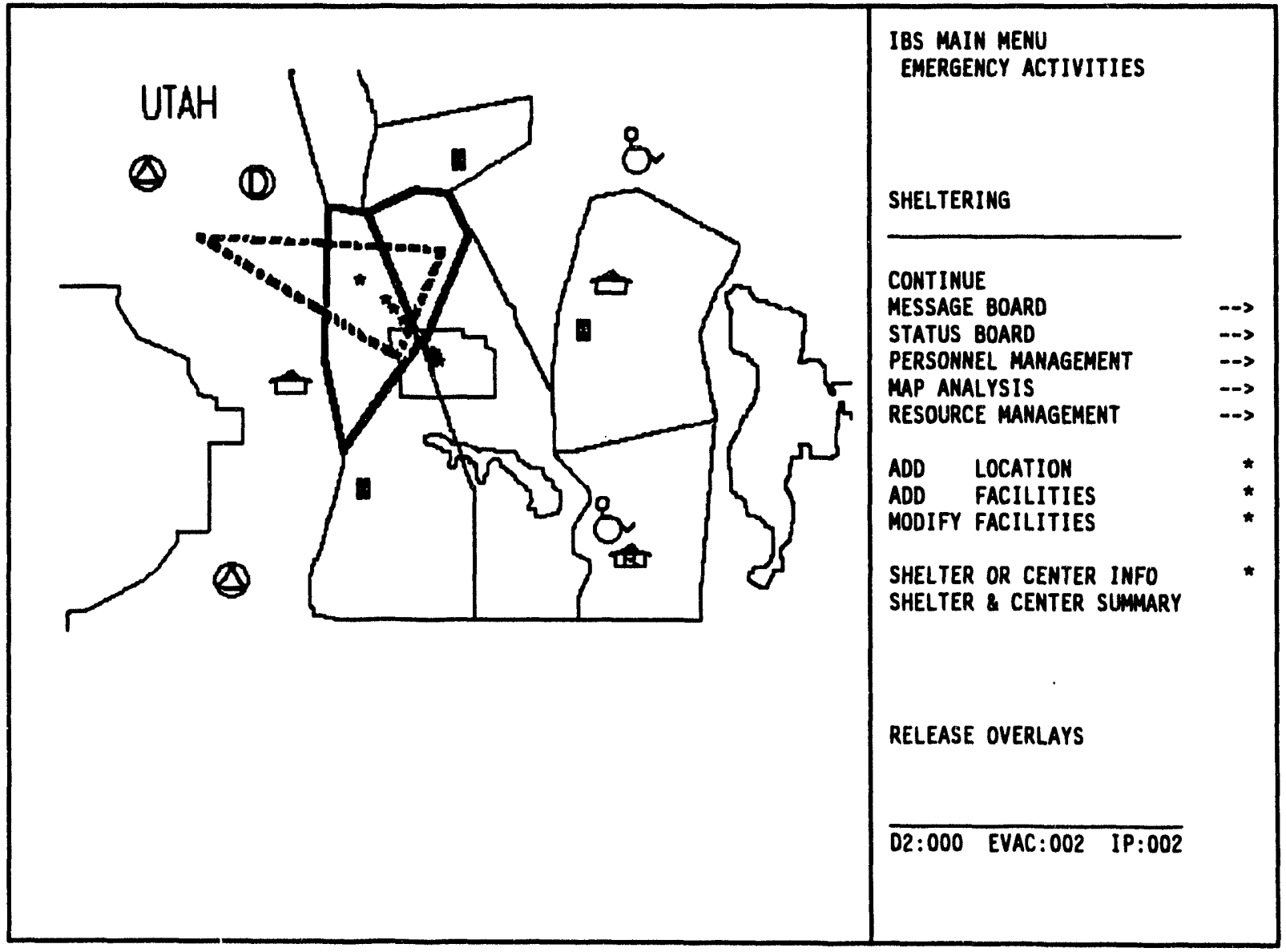


21. Use the cross hairs to select a shelter facility icon and press the Space bar. The system displays a full screen text Facility Form, as shown in the following example.

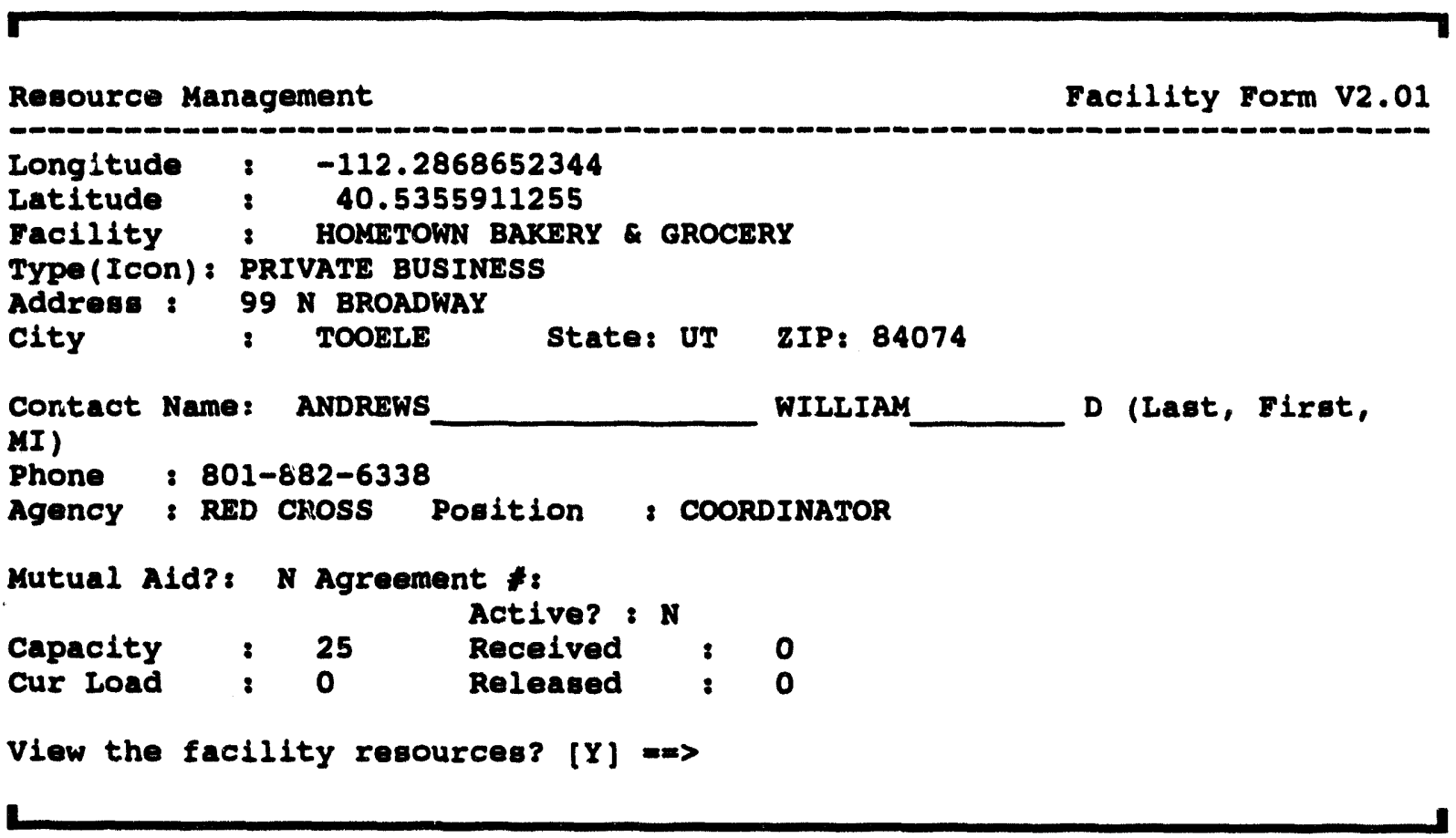

22. Press the Return key to answer yes to the View the facility resources? prompt. A Facility Resource report will display following the Facility Form, as shown. 


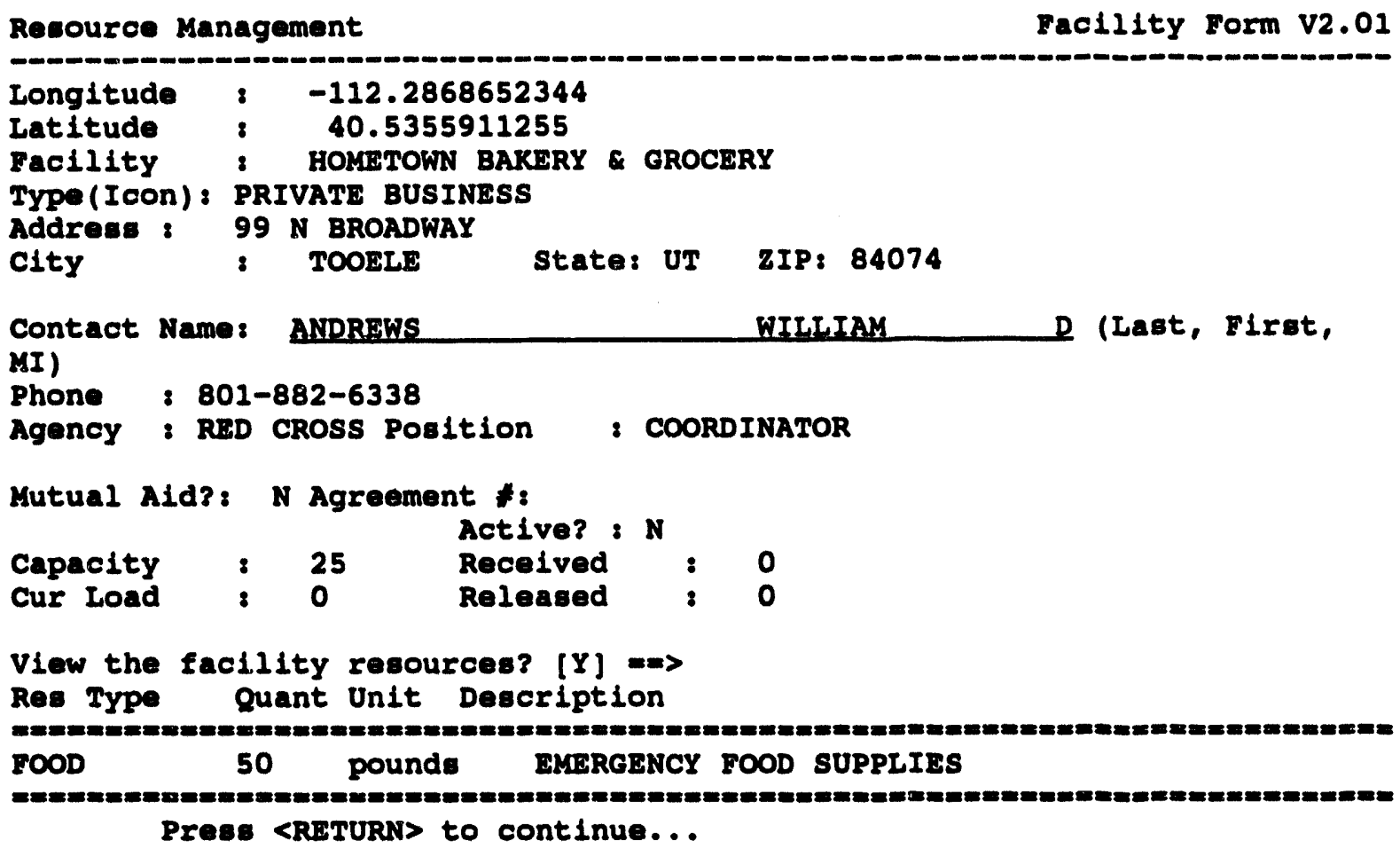

Press the Return key to return to the Facility Selection method menu. You can repeat the preceding procedures to view more facility information, or you can exit.

23. To exit, select 0 : EXIT and press the Return key. The Sheltering Menu displays.

24. From the top of the Sheltering menu select the IBS Main Menu command. The IBS Main Menu displays.

25. From the IBS Main Menu, select the Exit IBS command to return to the system prompt. 
Section 2

Message Board 


\section{Section 2 \\ Message Board}

\section{MESSAGE BOARD}

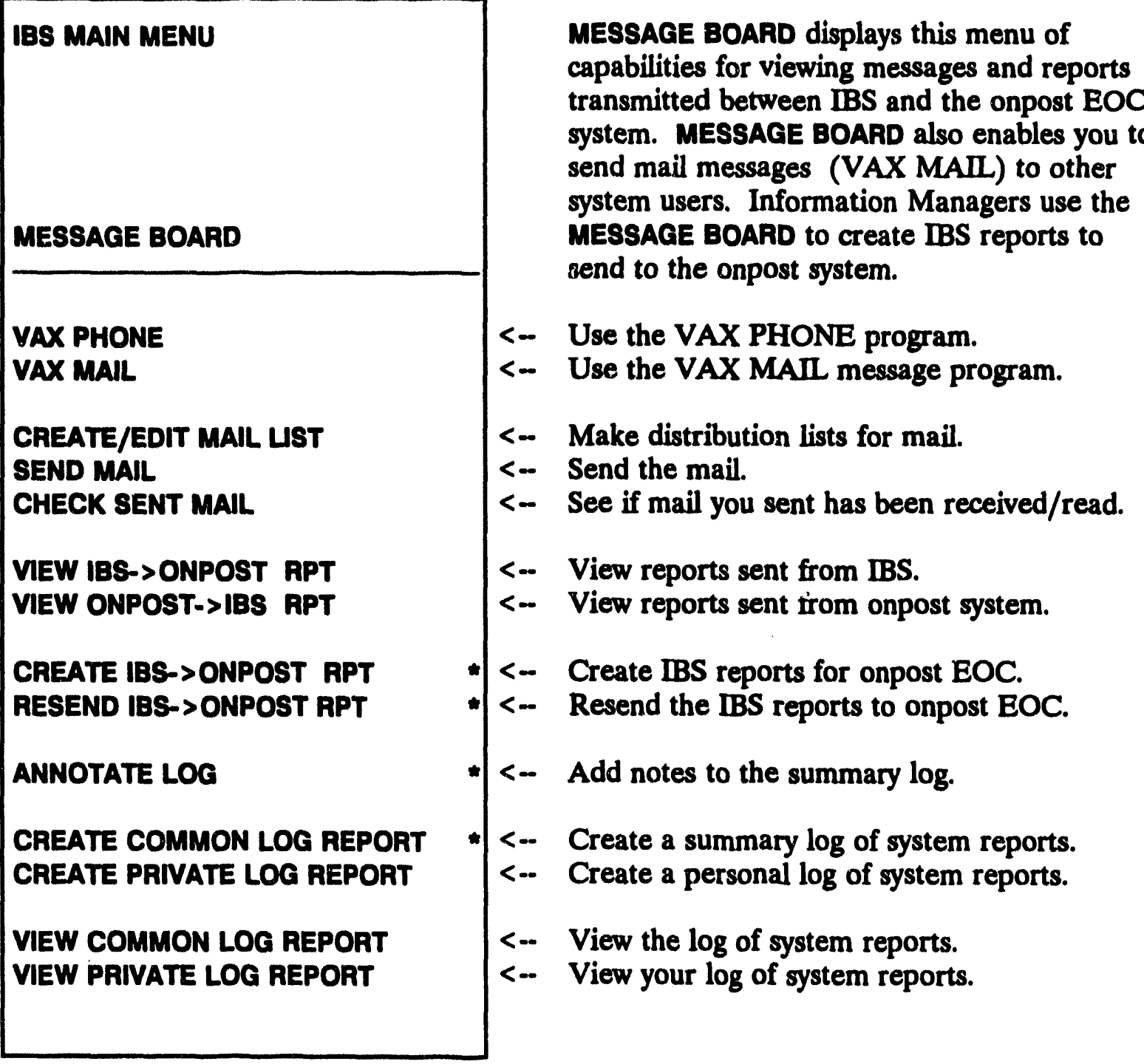

The MESSAGE BOARD option occurs on most IBS menus, so you can view messages at any time without returning to the IBS main menu. The MESSAGE BOARD capabilities in this section are described in alphabetical order. 


\section{Onpost Emergency Event Notification}

If an event occurs onpost, you will immediately see an Onpost Emergency Event Notification. (See Section 3, Status Board, ONPOST EVENT STATUS for a depiction of the information on this screen.) Event notifications and other reports from the onpost system can be reviewed by using VIEW ONPOST->IBS RPT.

To refresh the screen after a notification, do the following:

- For IBS forms, press Ctrl-Z

- For menus and lists, type an $\mathbf{R}$

- In graphic mode, press the Dialog key to remove/show text on the screen.

\section{Exchange of Map Graphic Information}

All graphic map overlays exchanged between IBS and the onpost system are passed as ASCII files using the "optional" Digital Line Graphics (DLG) data format (as defined in the US GeoData Users Guide 2). Conversions to and from IBS's normal Digital Mapping Structure (DMS) format is accomplished without special user interactions for normal IBS inputs and products.

\section{Mall Checker}

An automatic program called Mail Checker runs on the VAX without user intervention. Once every minute the program will check all user mail files. If you get new mail, or if your mail arrives late, the program will display a message across the bottom of the IBS graphic menu. For example, if you have new mail, the system will display the message:

NEW MAIL

\section{ANNOTATE LOG}

This option enables you to add some text to the IBS Common Log Report file. This text can be anything you want to enter and can be up to 1000 lines in length.

When you select this option, you will be placed in the VAX/VMS EDT editor. Consult the VAX VMS documentation for more information on using EDT editor.

When you use the Exit command and save the file, the contents of the file are added to the IBS Activity Log. 


\section{CHECK SENT MAIL}

This option enables you to check the list of unread messages you sent to a specific user. By doing this you can find out if a particular message has been received and read.

The following menu displays.

Mail Destination menu (Check Sent Mail)

$0:$ ExIT
$1:$ Select User Distribution 1ist
$2:$ Select System Distribution list
$3:$ Select Users by Mail Address
$4:$ Select Usars by Real name
$5:$ Select Users by Position
Menu Choice (?=Help) =m

If you select option 4, Select Users by Real name, the following menu will display.

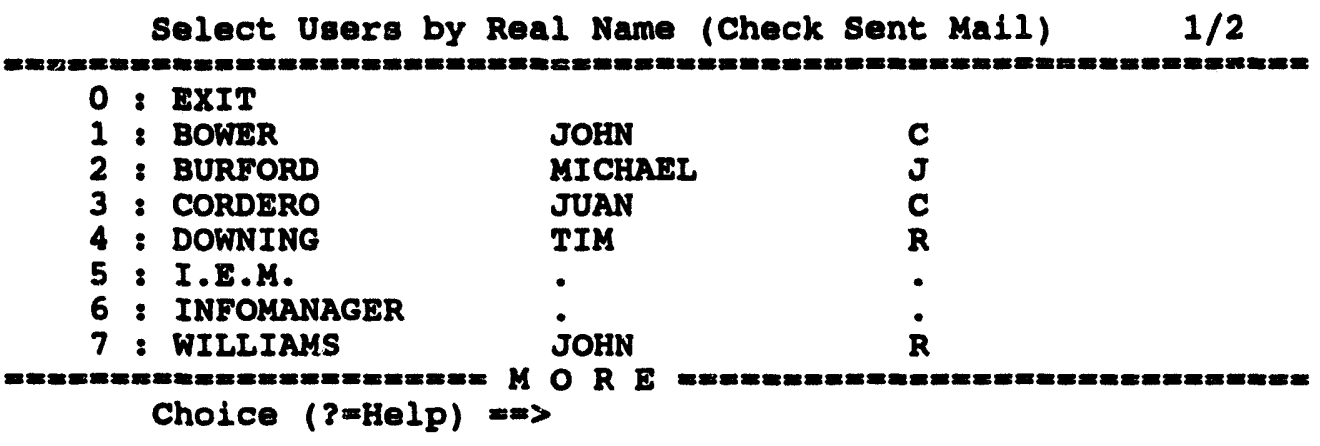

Select the user you want by typing the number corresponding with the name. Press the Return key. An arrow $=>$ will display by the selected name. Continue to select names from the list until you have selected all the users you want. To see if the selected users have read the mail sent by you, select the 0 : EXIT option and press the Return key. The system will display messages similar to the following for each user you selected. In this example the user had read all the mail.

Listing unread mail messages sent from COLLEEN WINTERS to TIM DOWNING...

All messages you sent have been read.

Press <RETURN> to continue, <CTRL-Z> to Abort Checking Mail...

Check more users? [N] $m=>$

If you want to check more users, type a $Y$ (yes) at the prompt and press the Return key. The Mail Destination menu will redisplay. 


\section{ID CREATE COMMON LOG REPORT and CREATE PRIVATE LOG REPORT}

During the use of the IBS software, many different operations are performed that log significant events into several Log Files. The following sources are searched to find the appropriate logged events to create the Common log report.

- VAX MAIl messages (a collection of important messages)

- the IBS event $\log$ (reports from IBS to the onpost system)

- the onpast event log (reports from the onpost system to IBS)

- the IBS activity log (resource management activities, Implementation Plan (IP) selection, updates to the people locate database, etc.)

These options enable you to create and view either a Common Log Report (if you have the appropriate privilege) or a Private Log Report of a selected group of these logged events. If you have the privileges to create a Common Log Report, or if you selected Create Private Log Report, the Select Message Category List will display.

If you do not have privileges to make a Common Log Report, the list will not display.

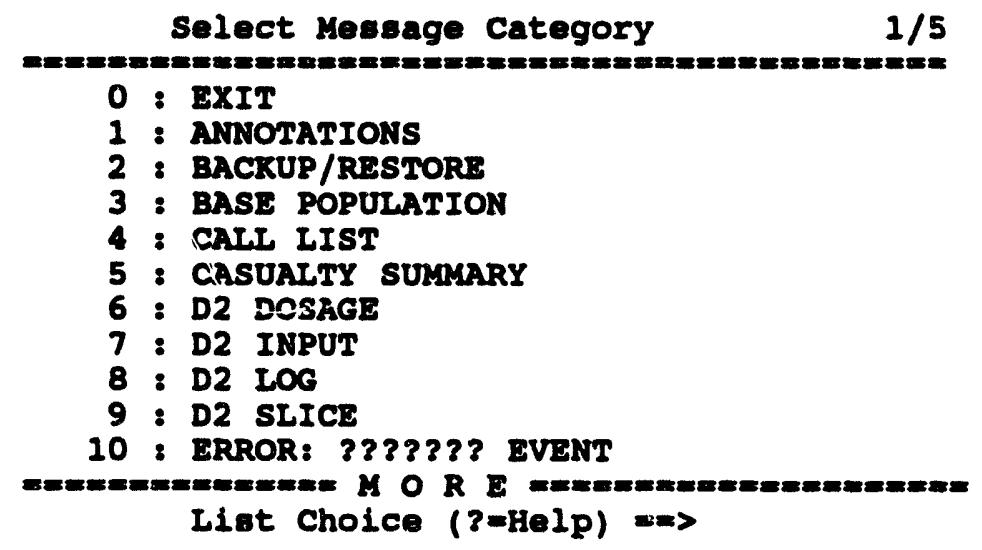

Select one or more categories and press the Return key. 
The system then displays the following Report Selection Method menu.

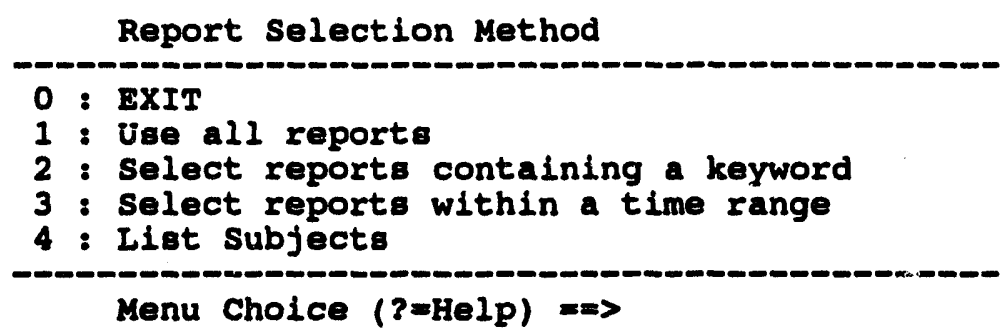

If you select items 2,3 , or 4 , the system will display additional prompts which will enable you to enter a keyword, time range, or subject.

The following table shows how you can either view all reports in the selected category or specify criteria for restricting the selection of messages.

Table 21. Criteria for Restricting Message/Report Selection

Your Response

1) All reports

2) Key word
Selection of Reports

All reports of the chosen type are selected, from the most recent to the earliest.

Entex key word >

Enter any string of characters (up to 40 characters). The string may include blanks and is sensitive to upper- and lower-case lettering. All messages containing exactly those characters are selected, from the most recent to the earliest.

Then select from the following displayed options:

View AIL that fit qualifications? $(N=$ Latest Only) $(Y / N)=m$ 
Your Response

3) Time range

4) List Subjects

Selection of Reports

Choose the time of creation or time of recording:

\begin{tabular}{l} 
Time Range Selection Method \\
0 : ExIT \\
1 : Based on date/time records entered \\
\hline Menu choice $(3=H e l p)==$
\end{tabular}

Then, specify the time range itself:

Enter begin date $(\mathrm{mm} / \mathrm{dd} / \mathrm{yy})>$
Enter begin time $(\mathrm{hh:mm})>$
Enter end date $(\mathrm{mm} / \mathrm{dd} / \mathrm{yy})>$
Enter end time (hh:mm) >

All messages within that time range are selected, from the most recent to the earliest.

Select from the following displayed options:

View ALI that fit qualifications?

(N=Latest Only) $(Y / N)=>$

The system then displays a list of specific logged subjects. Select the items you want to view from the list. For example, if you selected Resources as the message category, a list similar to the following would display.

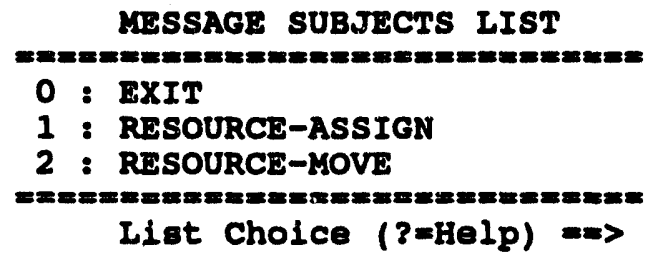

If you do not have a default setting for information, the Output Redirection Menu will display.

The log report will then be generated and sent to the destination you chose earlier. IBS takes a moment to assemble the information and then displays up to 500 lines of messages, one screen at a time. The messages start with the most recent messages (regardless of the source) and continue in re /erse chronological order.

General users can select VIEW COMMON LOG REPORT to obtain the latest complete log on their screen. It is displayed in read-only mode, but can be scrolled. 


\section{CREATE/EDIT MAIL LIST}

This option enables you to

- Create a new mail distribution list

- Change an existing list

After you select Create/Edit Mail List, the following menu displays.

\begin{tabular}{l} 
Distribution List Selection Menu (Create/Edit) \\
0 : EXIT \\
$1:$ Select SYSTEM mail distribution list \\
$2:$ Select PERSONAL mail distribution list \\
\hline Menu Choice $(?=$ Help) $\Rightarrow \Rightarrow$
\end{tabular}

Select the type of mail distribution list you want to work with: System, or Personal.

Option 1 : Select SYSTEM mail distribution list, will enable you to edit one of the System mail distribution lists. A copy of the System Mail list you select will be placed in your own directory and will reflect any changes you make. You can not change the master System mail distribution list.

Note: System mail lists are those found in the Infomanager's home directory. The Infomanager can modify them using the Select PERSONAL mail distribution list option.

Option 2 : Select PERSONAL mail distribution list, will enable you to edit an existing distribution list in your directory, or to create a new distribution list which will be placed in your directory.

After you select either of the two options, the following menu will display.

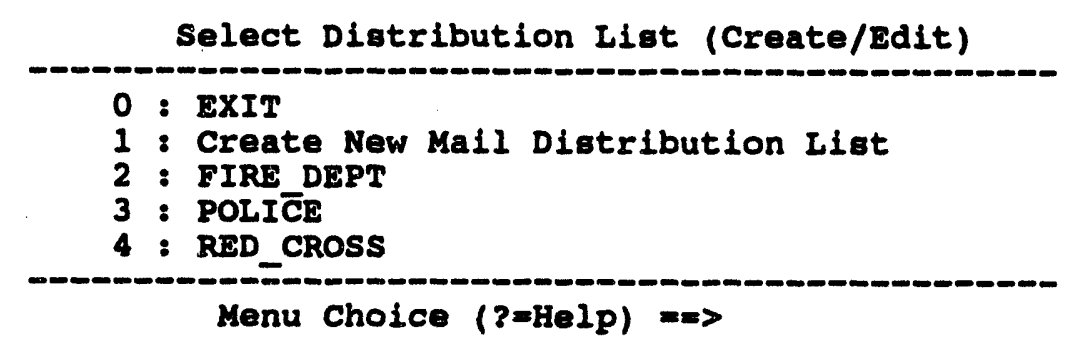

Note: Option 1 : Create New Mail Distribution List will not display if you selected the SYSTEM mail distribution list option from the preceding menu. 
You can select an existing distribution list to edit from the menu, or select option 1 : Create New Mail Distribution List to create a new list. Press the Return key. The following prompt will display.

Enter name for new mail distribution file $=m$

At the prompt, type the name of the distribution list you want to create and press the Return key.

The following menu will display once you have selected a distribution list to edit, or entered the name of a new distribution list.

Mail List Criteria (Create/Edit)
0 : EXIT
1 : Mail distribution by MAIL ADDREss
2 : Mail distribution by REAL NAME
3 : Mail distribution by POSITION
Menu Choice $(?=\mathrm{Help})=\mathrm{m}$

Options 1 and 2 enable you to select people from a menu. These menus will display people listed by:

- System username

- Real name

After you select any of the above options (1 or 2 ) a list similar to the following will display.

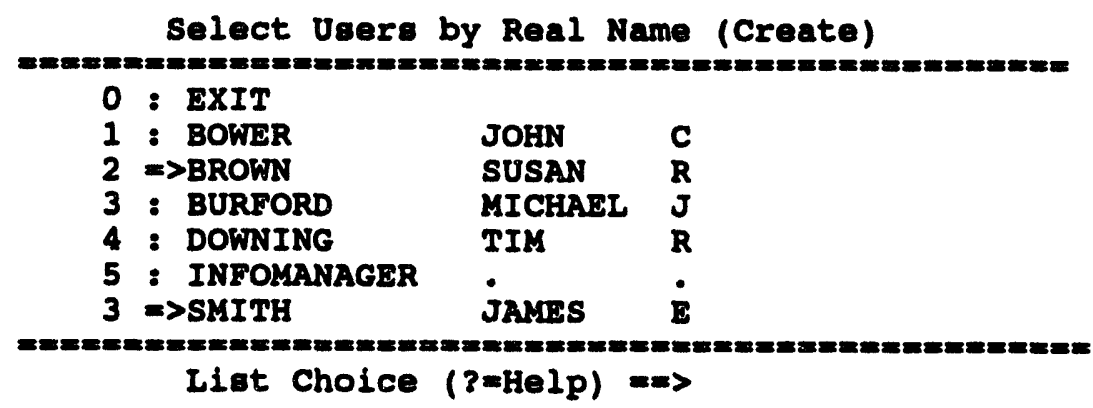

This list and the similar lists for username or title enable you to make several selections at a time. When a person is selected, an arrow $=>$ appears in place of the : symbol in the list. In the above example, both Susan Brown and James Smith have been selected. " 0 deselect an item from the list, select it again and the $=>$ symbol will be removed.

If you are creating a new distribution list, the above menu will display with no people preselected. If you are editing an existing list, the people on the list will 
display preselected on the menu. You can then select or deselect people to add or delete them from the list.

When you have selected all the people you want to add to your list, select option 0 : EXIT.

Option 3 : Mail distribution by POSITION will display the same menu shown in Personnel Management, List People by Position. From this menu you can select one or more positions. Any personnel in the personnel database with the selected position and an account on the system will display on a menu list similar to the example shown above. This list will be sorted by real name. You can then select the people you want to add to your distribution list.

Note: To set the positions for people in the master mail list, use the MLMGR utility. See the IBS Utilities Guide for complete information on this utility.

When using the VAX MAII message capability, you can address messages to distribution lists as well.as individual addressees. Contact your system manager for the names of distribution lists that have already been set up on your system.

\section{CREATE IBS-> ONPOST RPT*}

This option displays the menu shown here for creating reports (messages) transmitted from IBS to the onpost computer system.

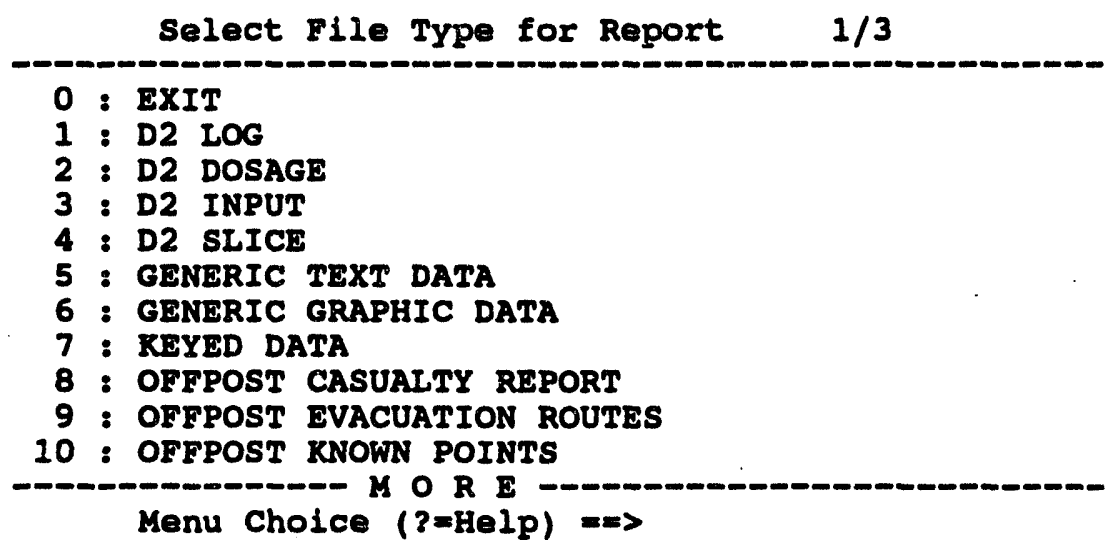

The sample menu shown lists the first 10 of the current reports you can generate. IBS will only display 10 lines in a menu, with the word MORE in the final line to tell you there are more options available. To see the extra menu items, type $D$ (down) or $U$ (up) at the $==>$ prompt and press the Return key.

Each menu item corresponds to one type of report. Information Managers can use the menu to select which types of reports are generated and sent to the onpost system. 
After one type of report is selected, IBS displays one or more screen forms for your information input and approval. After your approval, that report is generated, logged in the IBS event log, and copied to the onpost system.

The specific report formats are shown in Appendix E.

\section{Changing Report File Headers}

Option 21 : Change File Headers enables you to set the report headers that identify the created report.

After you select this option, the following messages will display, listing the current report headers.

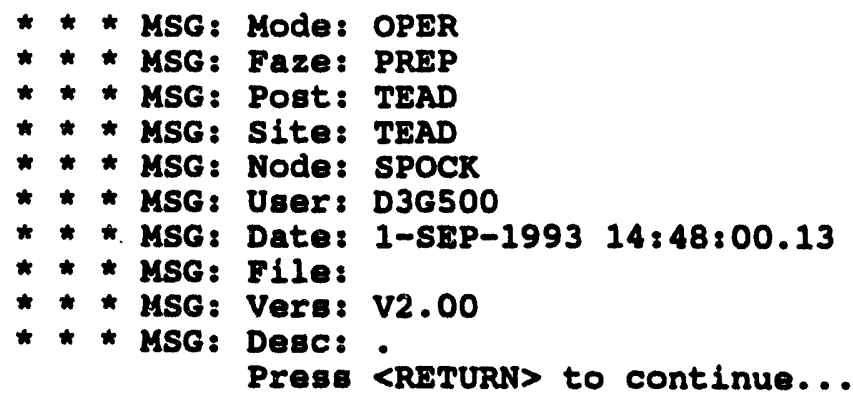

After you press the Return key, the following series of menus will display. Select the header elements you want from the lists of options.

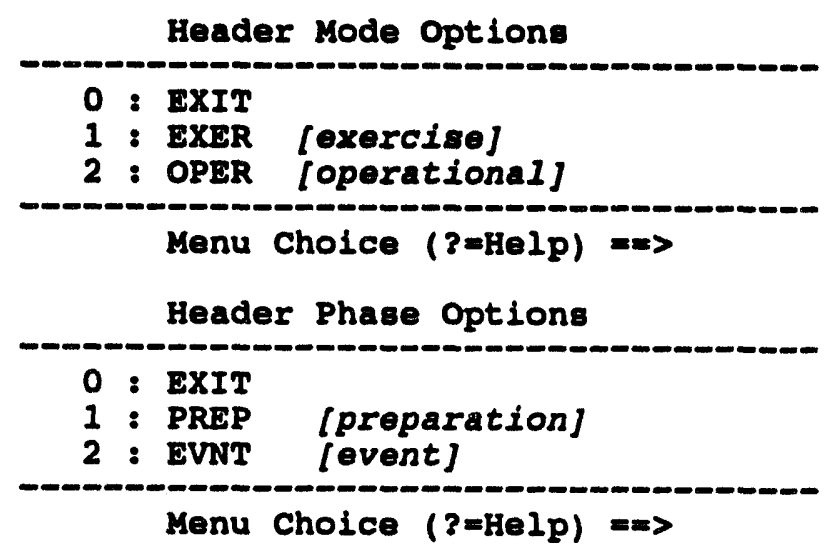




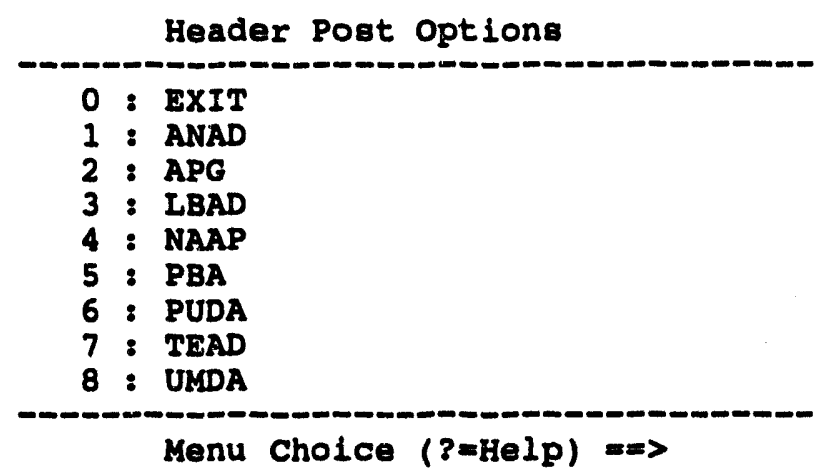

After you select a Post Option, the following prompt displays.

Enter description $==>$ type text description here

Enter any description you want (up to 70 characters). Press the Return key to complete the new report header. The system will then list the header elements on the screen. Press the Return key to return to the Select File Type for Report menu. All new reports generated will now have the new header you have selected.

The mode, phase, post, and description are combined to form the first record of all reports sent to the post.

\section{Exiting from the Data Input Forms}

Exiting from a form is handled similarly for all report formats:

- Exiting normally (with approval): If you press RETURN in the last field of the form (or GOLD $\mathrm{Z}$ in any field), the system automatically prompts you for the information needed to send the report to the onpost system:

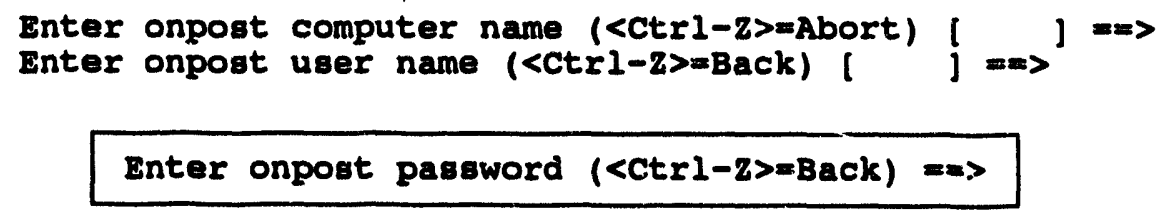

Using the information you have entered, IBS will resend the report to the onpost system. A sequence of messages will display.

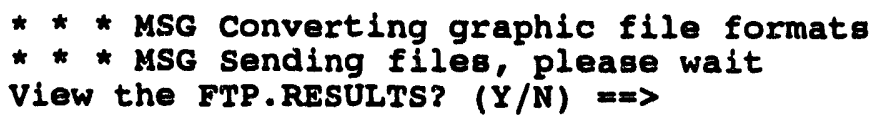

If you want to know if your report was successfully sent, type a $Y$ (Yes) at the View the FTP.RESULTS? prompt. The system will then display the related file transfer messages. These will list either a successful or unsuccessful file transfer attempt. If the attempt was 
unsuccessful, you can resend the report, or contact your system manager for assistance.

- Cancelling directly: If you press GOLD Y, the report is NOT sent, no prompt appears, and IBS returns to the MESSAGE BOARD menu.

\section{RESEND IBS-> ONPOST RPT*}

This option enables you to resend a report to the onpost system. The following menu will display:

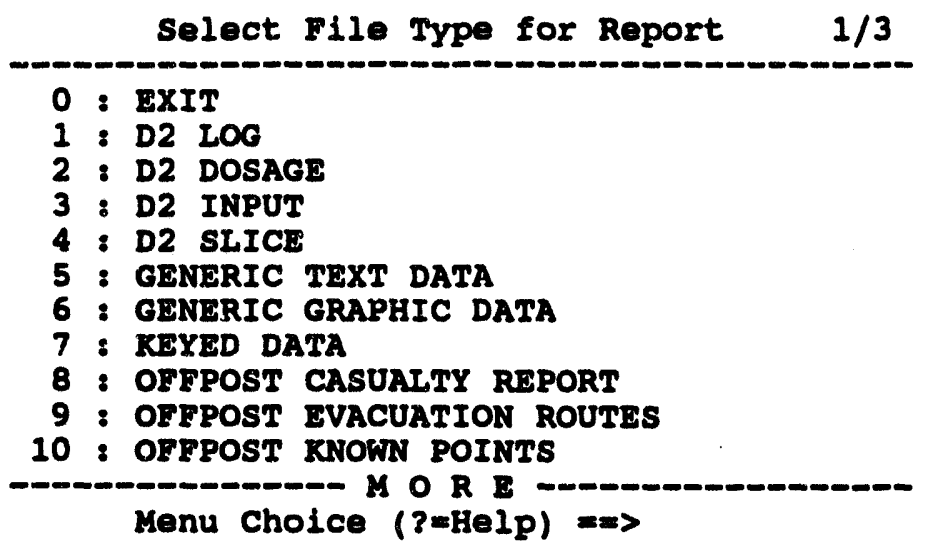

Select the type of report you want to resend. This report must have been created and sent earlier, if you want to send or create a new report, see CREATE IBS-> ONPOST RPT.

After you select a report type, a menu similar to the following will display. The menu will list all existing reports of this type. In this example, the user has selected option 10 : OFFPOST KNOWN POINTS.

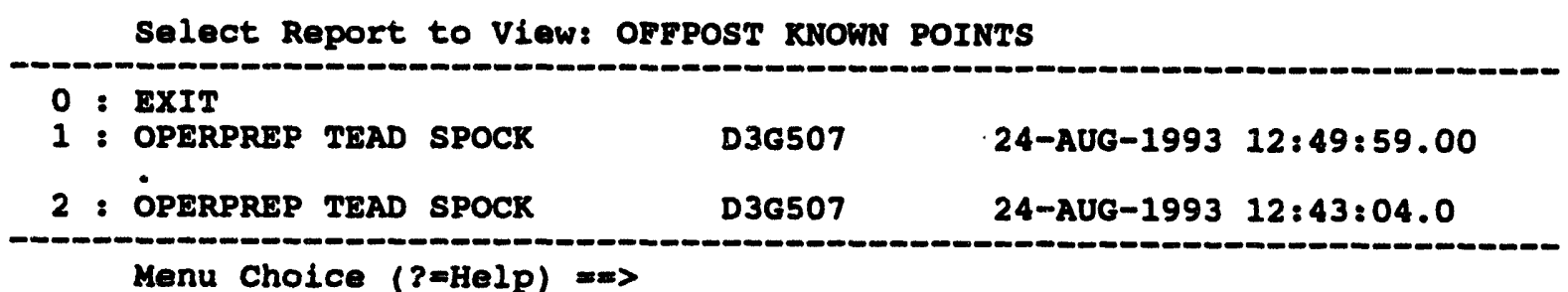

Menu Choice $(?=$ Help $)=m$

Select the report you want to resend from the list. 
Once you have selected a report, that report will display on screen as shown in the following example. You can make text changes at this point if you want.

$\begin{array}{llll}\text { Known Points Form } & 08 / 24 / 93 & 12: 49: 59 & \text { BV2.00 }\end{array}$

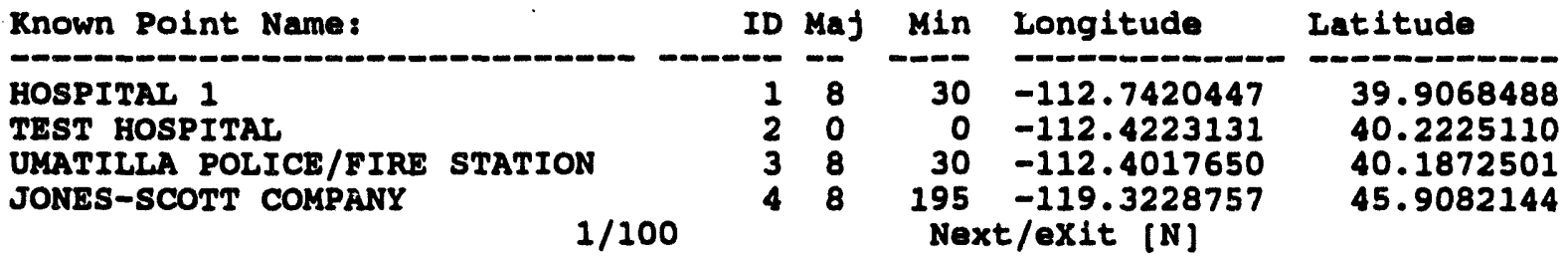

When you have finished, type an $\mathrm{X}$ in the Next/eXit field and press the Return key. The system will display the following series of prompts. Enter the requested information and press the Return key.

Enter onpost computer name (<Ctrl-z>aAbort) (

Enter onpost user name (<Ctrl-z=Back) [ ] $\Rightarrow$ ] $=$

Enter onpost password (<Ctrl-z>mBack) $\Rightarrow=>$

Using the information you have entered, IBS will resend the report to the onpost system. A sequence of messages similar to the following example may display.

* * MSG Converting graphic file formate

* * MSG Sending files, please wait

View the FTP.REsulas file? $(Y / N)=>$

If you want to know if your report was successfully sent, type a Y (Yes) at the View the FTP.RESULTS file? prompt. The system will then display the related file transfer messages. These will list either a successful or unsuccessful file transfer attempt. If the attempt was unsuccessful, you can resend the report, or contact your system manager for assistance. 


\section{SEND MAIL}

This option enables you to send a mail message to the mail distribution list created by CREATE/EDIT MAIL UST, or to a selection of users. The following menu will display:

\begin{tabular}{l} 
Mail Destination menu (Send Mail) \\
\hline $0:$ ExIT \\
1 : Select User Distribution list \\
2 : Select System Distribution list \\
3 : Select Usere by Mail Address \\
4 : Select Users by Real name \\
$5:$ Select Users by Position \\
\hline Menu Choice $(?=H e l p)$ =
\end{tabular}

Options 1 and 2 will display a menu of the available distribution lists similar to those shown under the CREATE/EDIT MAIL LST command in this section. Select a distribution list from the menu and press the Return key. Mail will be sent to all users appearing on the selected distribution list.

Options 3, 4, and 5 enable you to select a set of users to which you can send mail. The selection process is the same as that described under the CREATE/EDIT MAlL UST command. Mail will be sent to all users selected on the menu lists.

After you have selected the mail recipients, the following menu displays:

Mersage Selection Menu
$0:$ Exit
$1:$ Create New Message to send
$2:$ Enter Filename to send
Menu Choice $(?=$ Help) $=>$

1. Create New File to send - enables you to create a new file using the VAX EDT editor.

2. Enter Filename to send - enables you to send an already existing file, which can be edited before sending.

After you have created a new file or identified an edited and existing file, this form requests that you enter the following information:

MAIL SUBJECT FORM

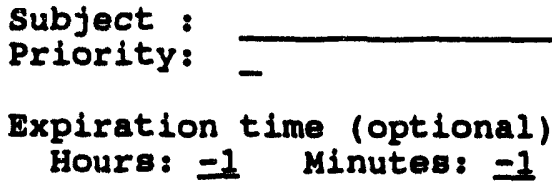


- Subject: Enter a subject or title for the message. (If you wish this message to be listed within one of the IBS message categories, enter the category name as part of the subject line.

- Priority: Enter one character to indicate message priority. (This can be any character: message priority levels have not yet been established.)

- Expiration time ( 0 to 16 hours; -1 cancels the feature): To set an alarm that tells the message recipient the content of a message is about to become obsolete, enter a number of hours and minutes as the expiration time. When that time expires the message ** IATE MAIL * * displays at the bottom of the menu area. After the recipient reads the mail, the message disappears.

- To show the expiration message immediately: enter zeros for both the hours and minutes.

- To cancel any expiration message: enter the default values $(-1)$ for both the hours and the minutes.

After you complete this form, the message is sent, and the screen returns to the MESSAGE BOARD menu.

\section{VAX MAIL}

When you select VAX MAlL, the system starts the electronic mail program, VAX MAII, which operates as explained in the documentation supplied by Digital Equipment Corporation. You will see the following MAIL prompt where you can enter MAII commands:

MAIL>

To exit from mail, enter the command QUIT or EXIT, returning the screen to the MESSAGE BOARD menu.

Erequently Used Commands. In getting started, you will probably use these commands most frequently:

- HELP

- HELP command

- SEND

- READ
Show MAIL commands and information on how to use MAIL.

Show information about a specific MAIL command.

Compose and send a message to one or more people.

Display the next available message (or page of the message). 
- READ/NEW Display the next new message (not previously read).

- DIRECTORY List your messages.

- DELETE Delete the current message.

- EXIT Exit from the MAII utility.

- QUIT Leave the MAIL utility and cancel any message deletions.

Qne-Time Setup Commands. Use the HELP command to find out more about the following commands, which you can use to set up some convenient MAIL features.

- SET PERSONNEL_NAME name Specify the "From:" name or title in your messages.

- SET COPY_SELF

Send yourself a copy of any message that you REPLY to, SEND, or FORWARD.

- SET CC_PROMPT

Set up MAIl to prompt for the names of people to be sent "carbon copies" of the message (in addition to the "To:" addressee).

You can address messages to distribution lists, as well as to individual addressees. You can create distribution lists or use lists that have already been set up on your system. See CREATE/EDIT MAIL LIST.

\section{Adding Messages to the Common Log Report}

To add selected mail messages (or parts of mail messages) to the IBS Common Log Report file perform the following procedures:

- To copy an entire message to the Log file, read the mail message with the mail command READ (message). If you are using the default IBS EDT Template file, you press Ctrl-W to save the current message. If you are not using the default IBS EDT Command file, you must enter Ctrl-Z (to get to the EDT Command line) and then type the command WRITE SYS\$LOGIN:ANNOTATE.TMP.

- To copy a selected section of a message to the Log file, read the mail message with the mail command READ (message). Select the section you want to copy to the Log by moving the cursor to the top of the section and pressing the period key (use the period key in the numeric keypad on terminals with keypads). Then move the cursor to the end of the section to select it (the text should be highlighted in the selected section). 
If you are using the default IBS EDT Command file, press Ctrl-X to save the selected section. If you are not using the default IBS EDT Template file, you must enter Ctrl-Z (to get to the EDT Command line) and then type the command WRITE SYS\$LOGIN:ANNOTATE.TMP SEL. Press Gold-period to stop the text selection process. This process can be repeated to select several sections within a single mail message.

When you exit VAX Mail, any selections you have made will be added to the IBS Common Log Report file.

\section{VAX PHONE}

When you select VAX PHONE, the system starts the VAX phone program, which operates as explained in the documentation supplied by Digital Equipment Corporation. When in Phone, the following screen displays.

8

VAX/VMs Phone Facility

$2-\operatorname{SEP}-1993$

SPOCK: : D3G510)

Erequently Used Commands. In getting started, you will probably use these commands most frequently:

- HELP

Type this at the \% prompt to show PHONE commands and information.

- HELP command Show information about a specific PHONE command.

- DIAL [node::] username Call another user, press any key to stop the call before they answer.

- ANSWER Answer a call placed by another user to you.

- EXIT Exit the VAX PHONE program and return to IBS.

Once you have established a connection with another user, what you type will be displayed on the screen of both the sender and the receiver. When you have finished your conversation, type \%hangup and press the Return key, or press Ctrl-Z to hang up your end of the conversation and return to the $\%$ prompt. 
To exit from phone, enter the command QUIT or EXIT, returning the screen to the MESSAGE BOARD menu.

\section{VIEW COMMON LOG REPORT and VIEW PRIVATE LOG REPORT}

These options enable you to view a log report (created using either Create Common Log Report or Create Private Log Report). If you have not set a default report destination, the Output Redirection Menu will first display as shown.

\begin{tabular}{l} 
Output Redirection Menu \\
\hline $0:$ ExIT \\
$1:$ Display on screen \\
$2:$ Print on default printer \\
3 : Mail to other user $(8)$ \\
$4:$ Save to an AscII file \\
\hline Menu Choice $(?=H e l p)=>$
\end{tabular}

If you select option 1 : Display on Screen, the complete log appears as scrollable, read-only information.

LOG REPORT CONTAINS:

AIL Reports

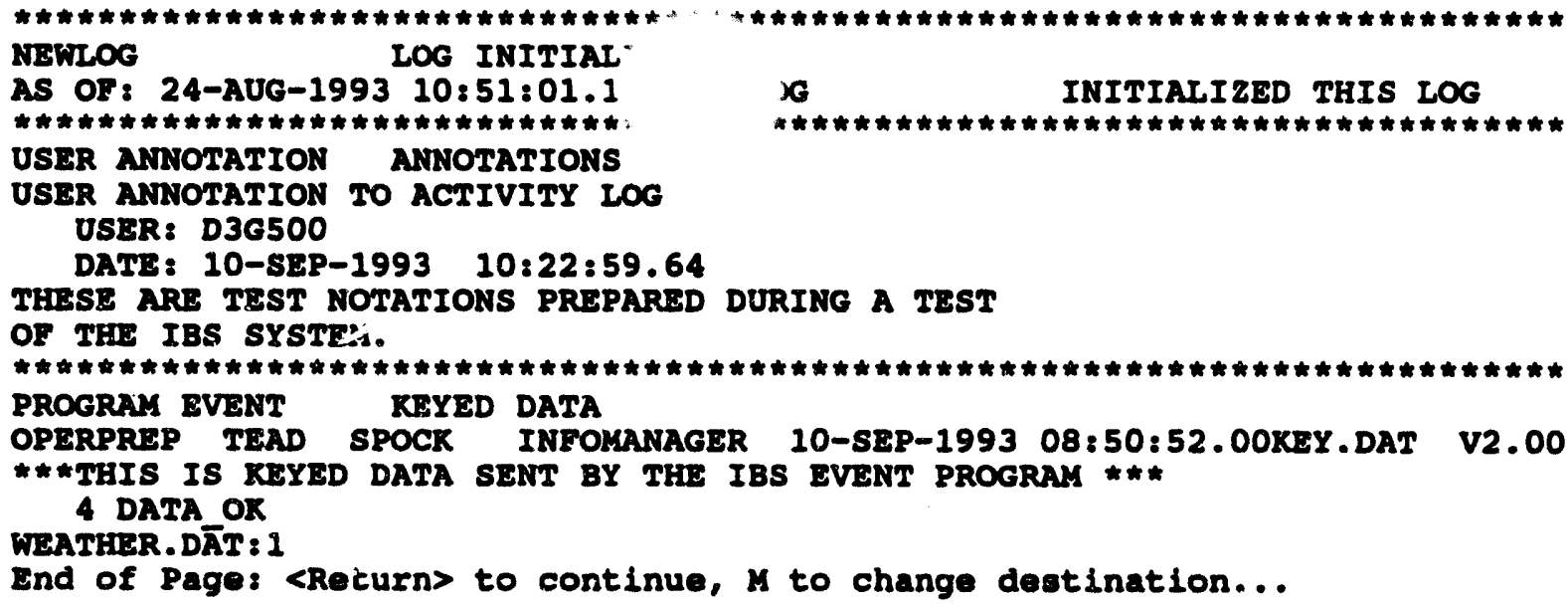

\section{$\square$ VIEW IBS-> ONPOST RPT}

VIEW IBS-> ONPOST RPT displays a menu for reviewing reports (messages) that have been transmitted from IBS to the onpost system. Each menu item corresponds to one type of report. The actual contents of each type of report are described in Appendix $E$. 


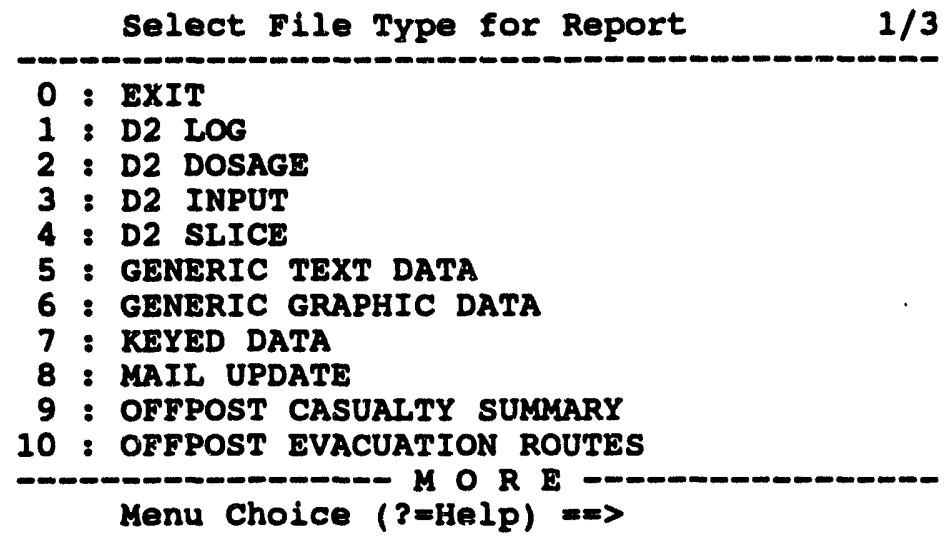

After selecting the type, You will be given a menu from which to select the report you want to view. The menu contains the header of the report that was sent. The header is in the following format:

line 1: ModePhase Site Node Username Date/Time Filename line 2: Description

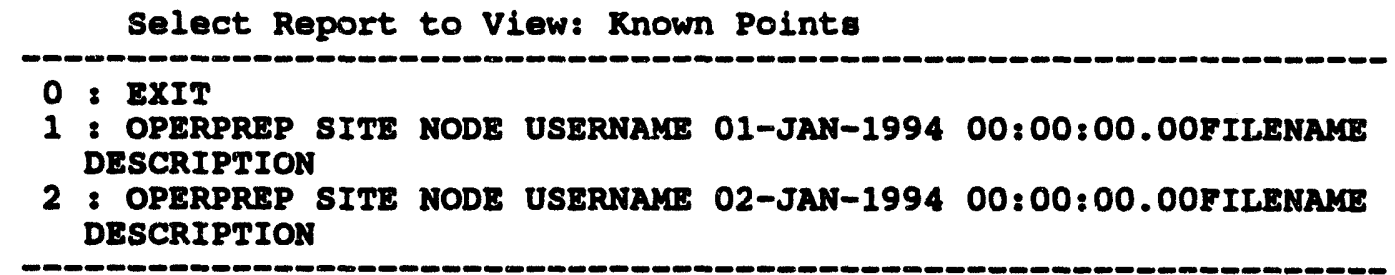

Menu Choice $(3-$ Help $)=2$

After selecting a report from the above menu, a form will display. Forms are different for each different file type. For example, if you selected Known Points, a report similar to the following will display.

$\begin{array}{llll}\text { Known Points Form } & 08 / 24 / 93 & 12: 49: 59 & \text { BV2.00 }\end{array}$

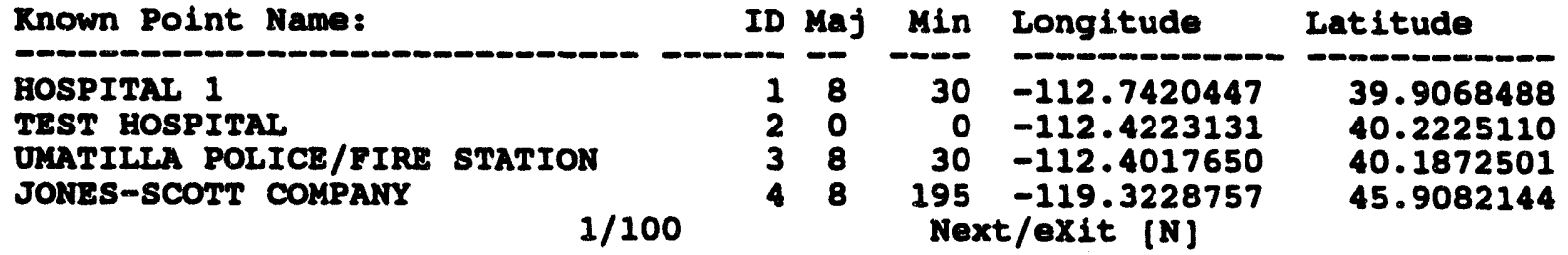

Although you can move the cursor around in this form, any changes made to the data in this form will not be saved. After exiting the form, you will be returned to the Select Report to View menu so you can select another report to view. 


\section{IIVIEW ONPOST->IBS RPT}

VIEW ONPOST->IBS RPT displays a two page menu for reviewing reports (messages) that have been transmitted from the onpost system to IBS. Each menu item corresponds to one type of report. The formats for reports from the onpost system are shown in Appendix $E$. To see the second page, type $D$ (Down) at the Menu Choice $==>$ prompt.

Select File Type for Report

$0: \operatorname{EXIT}$

$1:$ D2 LOG

2 : D2 DOSAGE

3 : D2 INPUT

4 : D2 SLICE

5 : WEATHER

6 : WORK PLAN

7 : ENVIRONKENT

8 : NOTIEICATION

9 : CASUALTY SUMMARY

10 : TOWER SELECTION

Menu Choice $(?=\mathrm{Help})=\mathrm{R}$
Select File Type for Report $2 / 2$

\begin{tabular}{l}
$11:$ BASE POPULATION \\
$12:$ CALL LIST \\
$13:$ KNOWN POINTS \\
$14:$ MCE DIRECTORY \\
$15:$ SIGNIFICANT EVENTS \\
$16:$ GENERIC TEXT DATA \\
$17:$ GENERIC GRAPHIC DATA \\
$18:$ KEYED DATA \\
\hline MeNu ChOICe $(3=H e l p)=$
\end{tabular}

After selecting the type, You will be given a menu from which to select the report you want to view. The menu contains the header of the report that was sent. The header is in the following format:

line 1: ModePhase Site Node Username Date/Time Filename line 2: Description

Select Report to View: Rnown Points

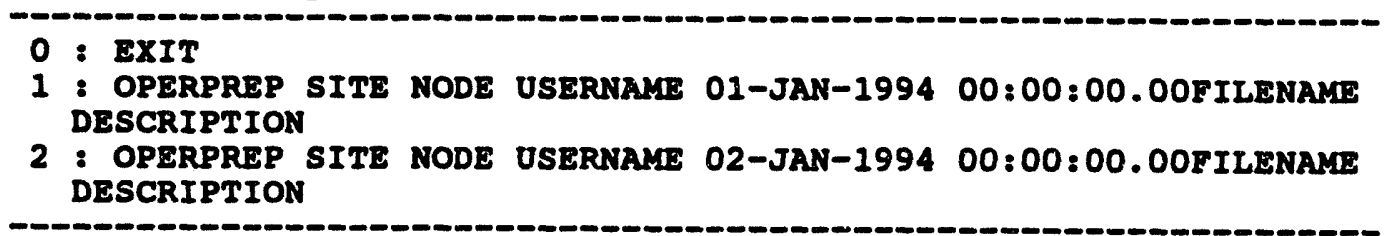

Menu Choice $(?=$ Help $) \Rightarrow$ 
After selecting a report from the above menu, a form will display. Forms are different for each different file type, for example, if you selected Known Points, a report similar to the following will display.
Known Points Form
$08 / 24 / 93$
$12: 49: 59$
BV2.00

KnOWn POInt Name:
HOSPITAL 1
TEST HOSPITAL
ULATILLA POLICE/FIRE STATION
JONES-SCOTT COMPANY

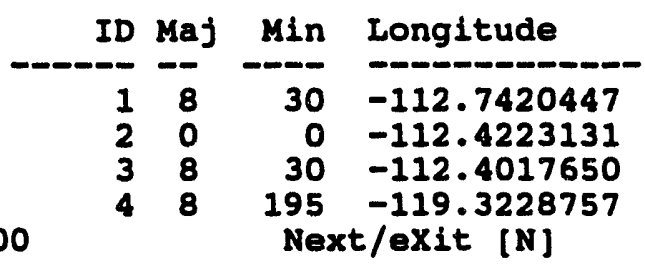

Latitude

39.9068488

40.2225110

40.1872501

45.9082144

Although you can move the cursor around in this form, any changes made to the data in iuis form will not be saved. After exiting the form, you will be returned to the Select Report to View menu so you can select another report to view. 


\section{parog enyus}

$\varepsilon$ uopoos 


\section{Section 3 \\ Status Board}

\section{STATUS BOARD}

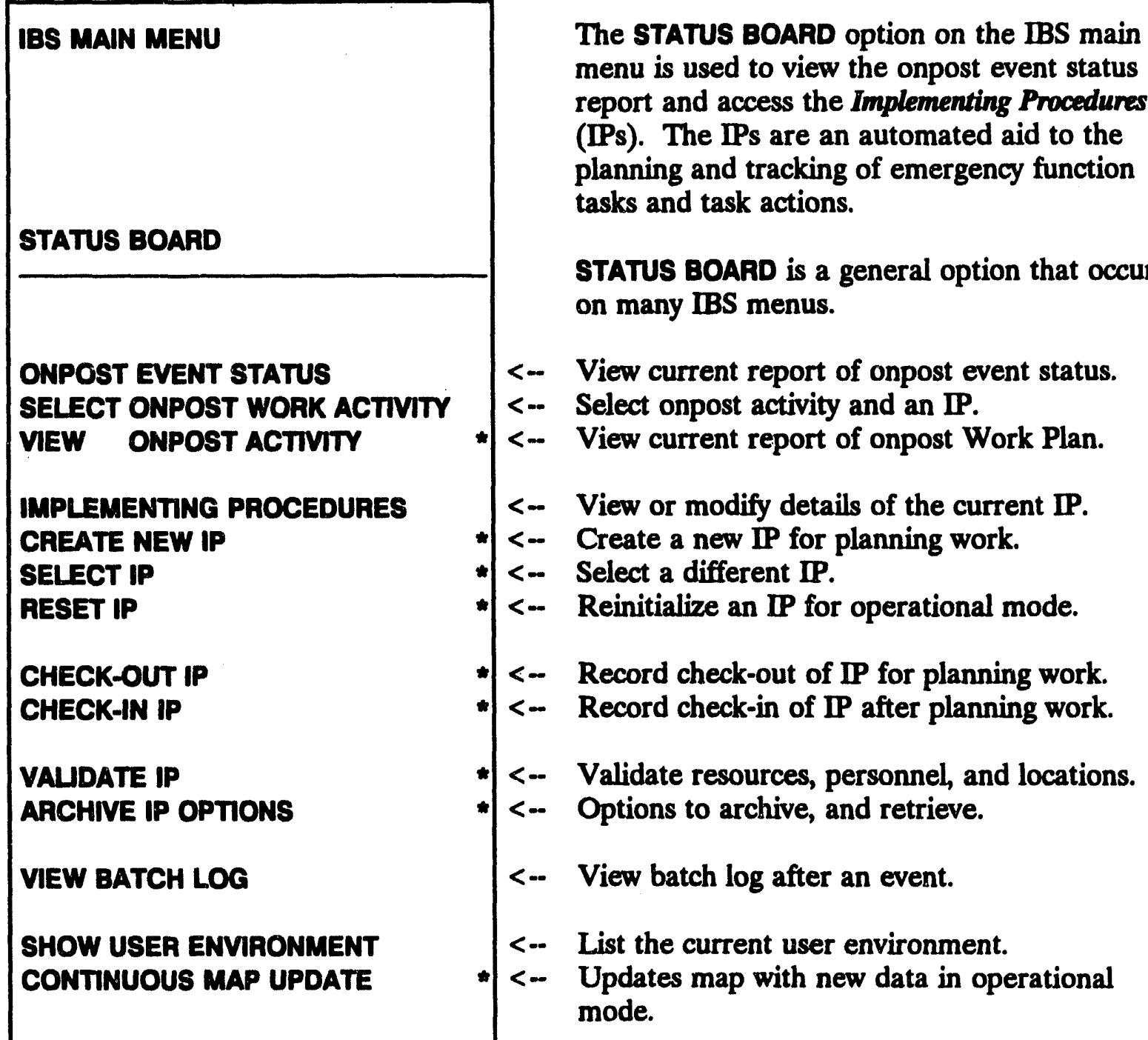


Many of the STATUS BOARD capabilities concern the IBS IPs. The following discussion of the IPs and IP operating conditions provides information needed for understanding the use of IPs.

Following this background information on IPs, the STATUS BOARD options in this section are explained in alphabetical order.

\section{Understanding Implementing Procedures}

In IBS, an Implementing Procedure is a set of preplanned emergency actions that are designed to cope with one or more chemical release situations or scenarios. IBS enables emergency managers and planners to create and assemble a set or library of IPs that can be applied in different event situations. The Implementing Procedures supply an automation-assisted means of defining and tracking specific emergency actions that are needed to accomplish the more general objectives of an Emergency Operations Plan (EOP).

Each IP includes time-ordered tasks, which are grouped by Emergency Function. Each task consists of a numbered set of actions and requires certain resources (materials and equipment at certain locations or facilities) to accomplish task goals. A descriptive IP note can be entered for each IP, and three descriptive notes can be entered for each task: one general task note, one action mote, and one resource note.

This structure is described in Table 3.1 and illustrated by Figure 3.1.

IP Development Conditions. In general, it is expected that IPs will be developed by planners under planning conditions; this means that a planner would create or modify an IP as a part of the planner's own planning site database. When the IP is ready for general use, the planner copies the IP into the reference database for the local site.

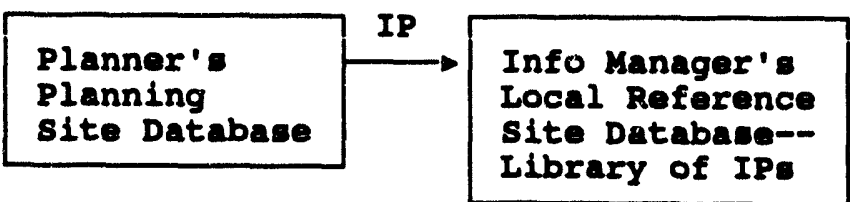

TABLE 3.1. Descriptions of IP Structures and Components

\section{IP Structure}

Implementing Procedure (+ Note)

Emergency Functions

Tasks

(+ Note)
Description

Up to 1000 IPs

1 IP Note per IP (up to 99 lines of text)

Up to 36 Emergency Functions

Up to 99 tasks per Emergency Function

1 Task Note per task (up to 99 lines) 
Actions

(+ Note)

Resources

$(+$ Note $)$
Up to 99 actions per task

1 Action Note per task (up to 99 lines)

Up to 99 resources per task

1 Resource Note per task (up to 99 lines)

Implementing Procedure \#n

1 IP Note

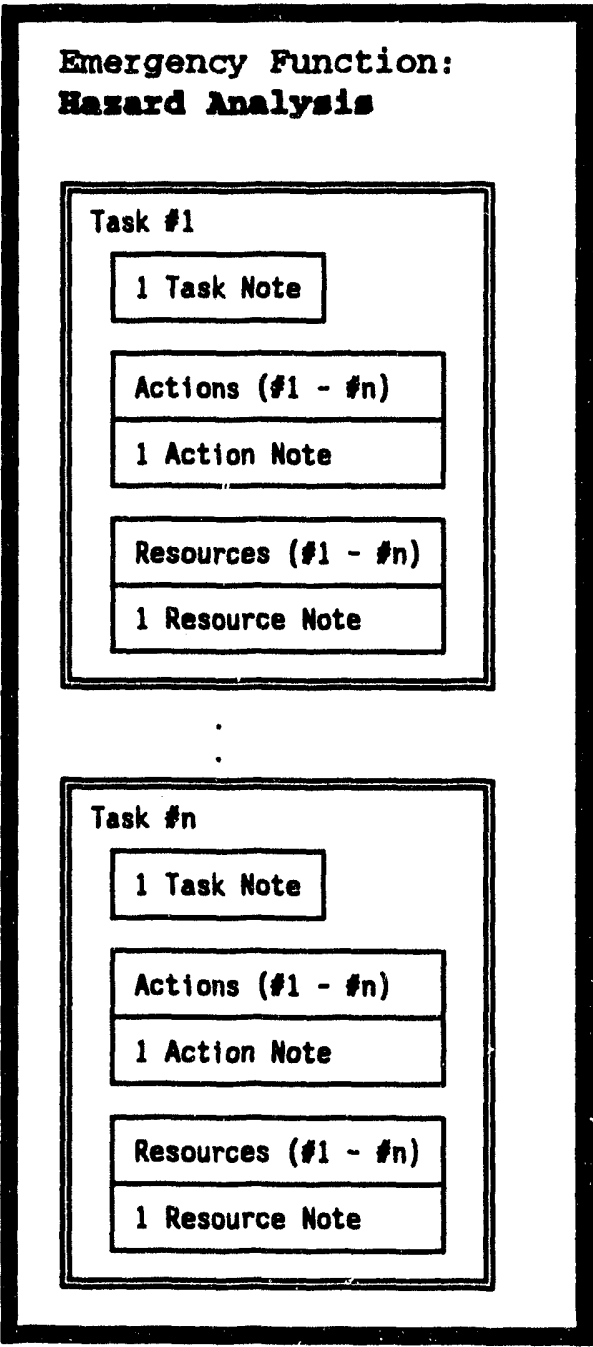

Bmergency Function: zoc Iativation

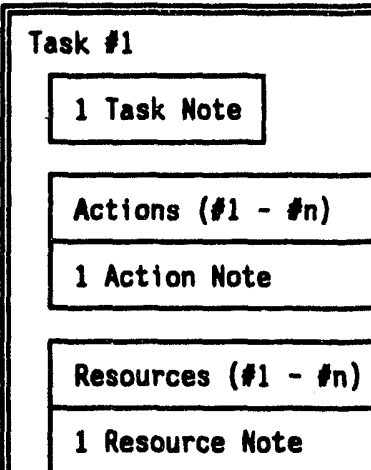

1 Resource Note
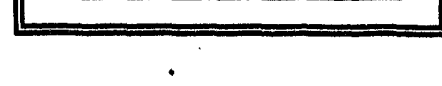

Task in

1 Task Mote

Actions $(n-(n)$

1 Action Note

Resources $(\$ 1-(n)$

1 Resource Note

Figure 3.1. Components of an Implementing Procedure 
The operation of STATUS BOARD IP options varies, depending on whether the IPs are being used under planning conditions or under other (operational/exercise) conditions. The conditions of operation are dependent on which site database is selected as the current site database. General users usually use the event site database under operational conditions. Planners may own and use other site data sets, changing between site databases by using SETUP-CHANGE SITE (for more information, see Section 12). Some IP screens have labels that identify the IP activity as PLANNING, OPERATIONAL, or EXERCISE.

If you select an IP in Operational mode and the selected IP case has been checked out by a planner, a message similar to the following will display.

* * MSG: The selected case has been checked out by a planner. They will be

* * MSG: unable to check in their case while it is aelected as the current

* * MSG: Operational case.

The planner who has checked out this case will not be able to check it back in as long as it is selected as the current Operational IP case.

Note that task times display in different ways depending on the mode you are in. The following diagram shows the differences in time display. Planning mode will display delta times: time before or after a hypothetical zero hour event time. Operational mode will display real times and dates, calculated from a projected event time, or from an actual event time if an event is declared. The default display setting in operational mode is for post-event task times to be visible only if an event has been declared. Use the PH (phase) option in the Use Tasks or Change Tasks forms to force post-event task times to display without an event being declared.

Planning Mode P

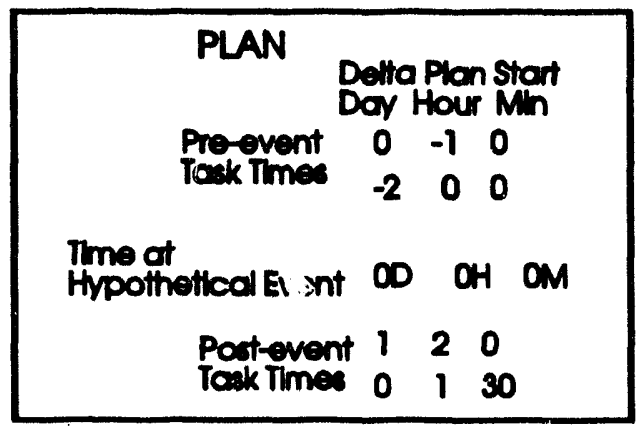

Operational Mode IP

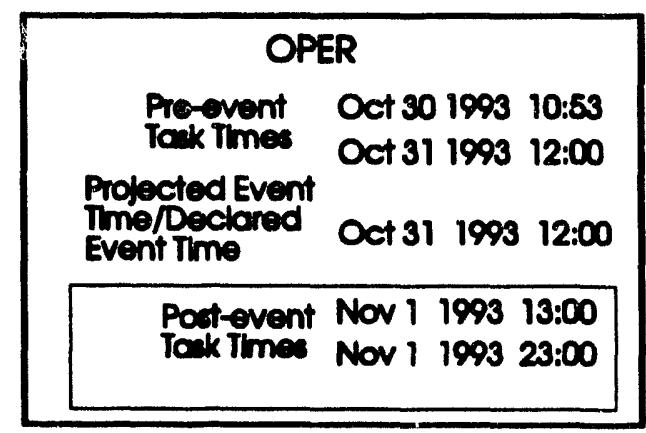

Pott-event tack thes become vilble whin you une the Pincese option. 


\section{ARCHIVE IP OPTIONS}

ARCHIVE IP OPTIONS enables users to make an archival copy of the current IP and to retrieve this copy at a later time.

When you select Archive IP, the system displays the following menu.

IMPLEMENTING PROCEDURES ARCHIVE OPTIONS
0: EXIT
1: Archive Current IP
2: Retrieve Archived IP to Current IP
Menu Choice $(?=\mathrm{Help})=>$

1. Archive Current IP: (Operational or planning mode) enables you to archive the current IP to a backup file. If you select Option 1, the following message displays.

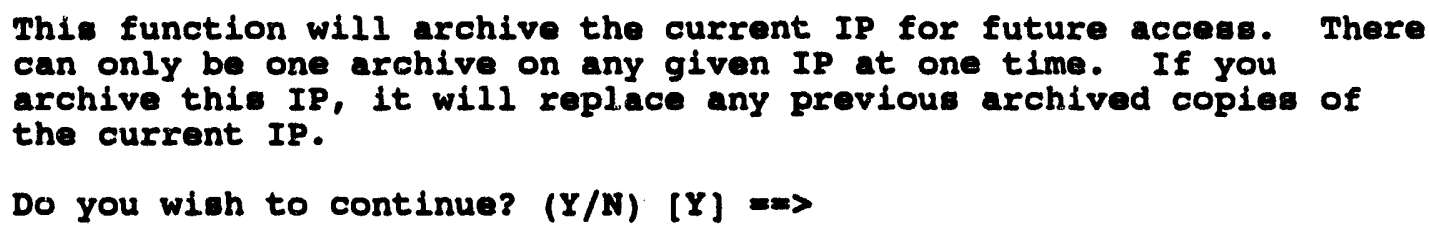

The system will display a message after successfully completing the archive.

2. Retrieve Archived IP to Current IP: (Operational or planning mode) enables you to retrieve an archived IP and use it in place of the current IP. If you select Option 2, the following message displays.

This function will retrieve the last archived copy of the current IP, and use it to replace the current IP. All changee to the current IP since the last archive will be deleted.

Do you wish to continue? $(Y / N)[Y]=>$

The system will display a message after successfully completing the archive. 


\section{ID CHECK - IN IP and CHECK - OUT IP}

The CHECK-IN IP and CHECK-OUT IP options are used by planners who may be updating or refining an IP in the local reference site database (or in another site database).

If you are a planner, CHECK-OUT IP allows you to "check out" an IP from the library of IPs incorporated in the local reference site database (or another site database).

Note: Before checking out an IP with CHECK-OUT IP, make sure your current site is set to an appropriate planning site database. It does not make sense to check out an IP for one site and use it with data from a physically different site.

When you select CHECK-OUT IP, the system displays menus similar to the following example. Select the characteristics you want from the menus to check out an IP.

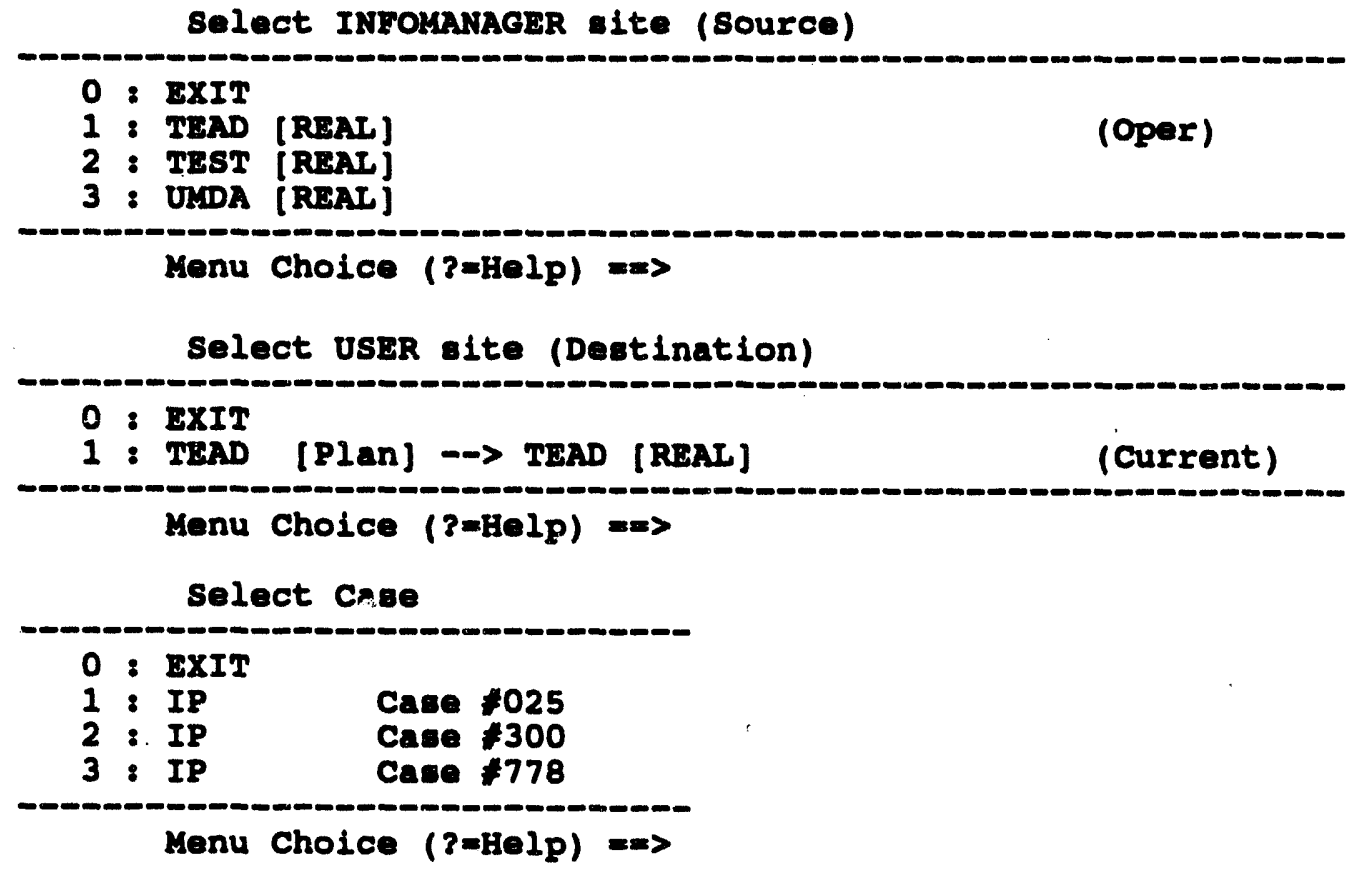

After you specify which IP to use, the system checks to see whether or not the specified IP is already checked out (that is, already assigned to another planner).

- If the IP is already checked out, the system cannot check it out to you until the IP has been checked back in.

- If the IP is available, the system copies the IP and associated records from the scenario table to your current planning site database. The 
system will display a series of messages and prompts similar to the

following example.

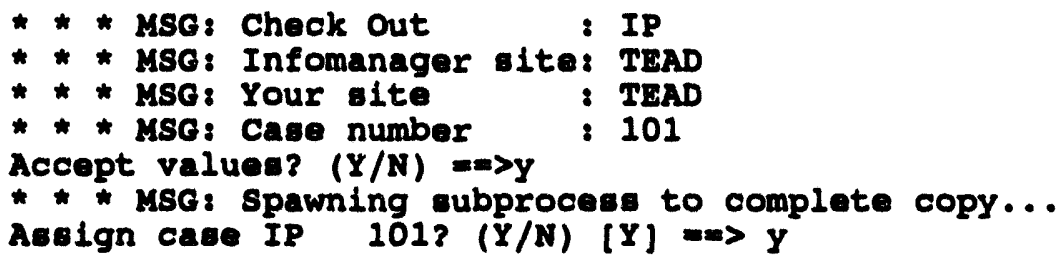

After you press Return, the system will display a series of messages similar to the following.

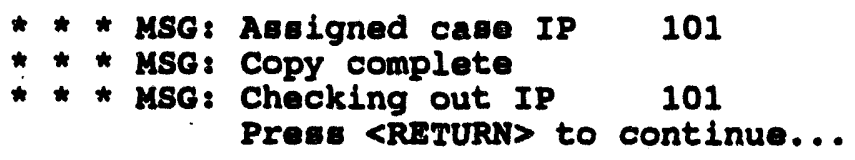

When you check out an IP, the system notes the IP is assigned to you. No one else can check out the same IP until you check it in again.

CHECK-IN IP copies the IP and scenario table records back into the local reference site database while leaving you a copy in your planning database.

When you select CHECK-IN IP, the system displays menus similar to the following example.

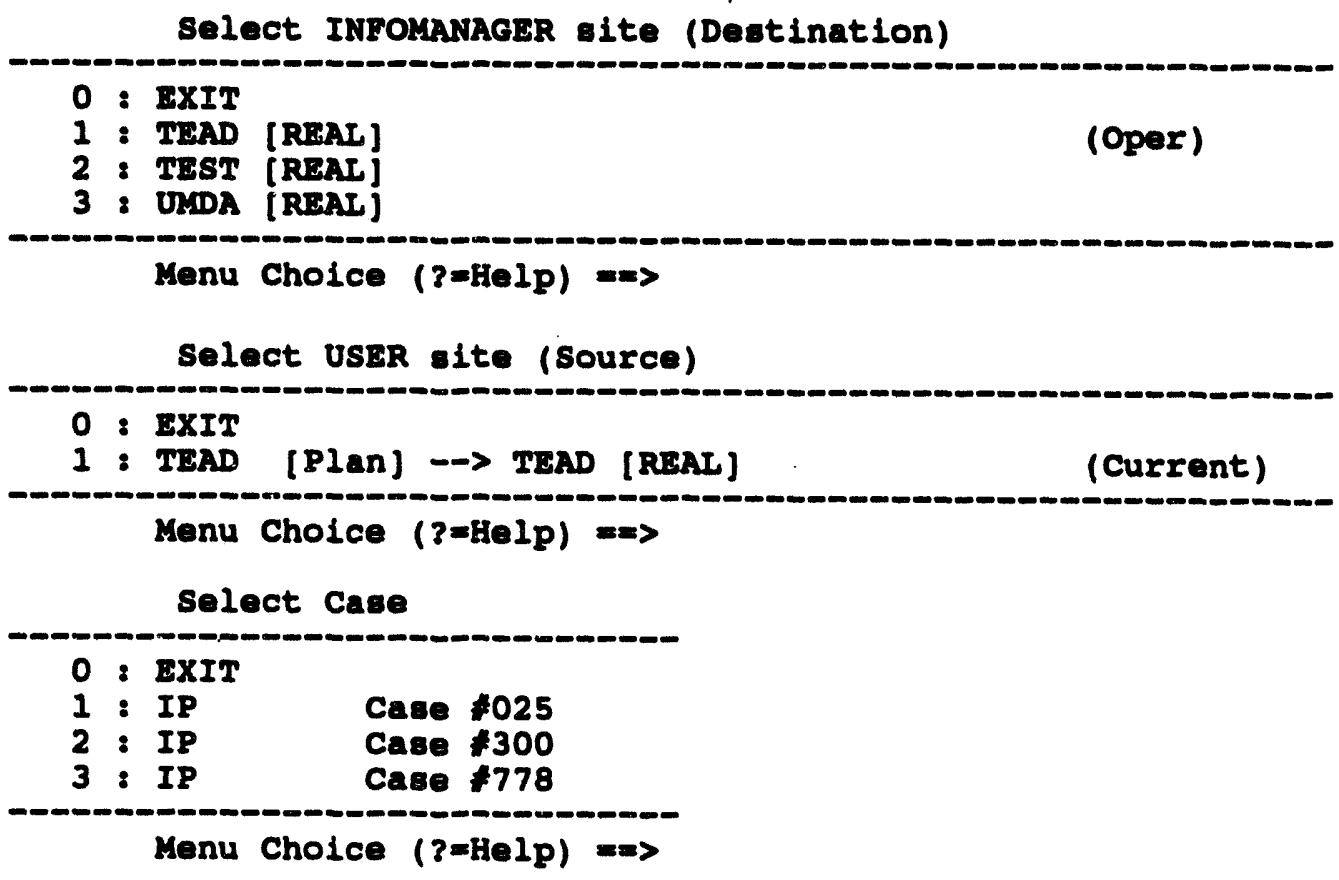

The system then returns you to the Status Board menu, leaving a copy of your modified IP in your planning database, as well as in the corresponding 
INFOMANAGER site database. The modified IP then becomes available for check-out by planners once again.

Until you change your planning IP, you will still be set to the IP you just checked in. If you want to make changes to this IP and then check it in with the same number, make the changes while the IP is assigned to you. If you want to make changes to your private copy, you can check it in again under a new IP number (see Renumbering an IP). In this way, you can base a new IP on an existing one.

\section{Renumbering an IP}

In some circumstances, you may want to check in an IP from your planning database, and you discover the IP number is checked out to someone else. (This may happen if you create the IP from scratch in your planning site or if you checkin an IP and continue to make changes to the copy in your planning site.) If, for whatever reason, the IP is checked out to someone else, you will get the following message on check-in:

IP case nnn is not checked out to you.

Would you like to renumber your case? [Y] $m$

If you answer $Y$, the software will prompt you to pick a new number. The given IP will then be renumbered and checked into the specified site under the new number. If you answer $\mathbf{N}$, nothing will happen and you will be returned to the STATUS BOARD menu. 


\section{CREATE NEW IP *}

The CAEATE NEW IP option allows planners to create a new "blank" IP or create a new IP based on an existing IP, which can then be filled in by using other IBS capabilities for editing IPs. The system displays the following menu.

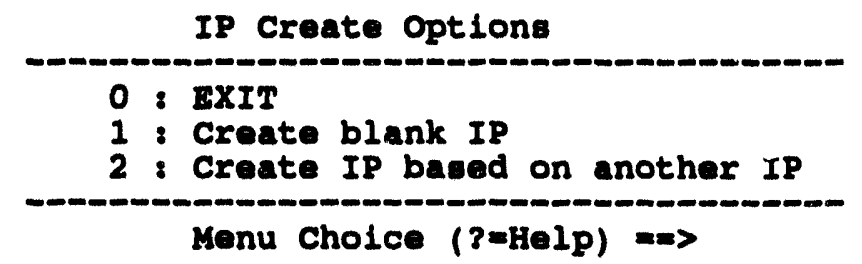

If you select option 1, the system will prompt you to enter a new IP number.

Please enter the IP number you wish to create $=\Rightarrow$

Type a new IP number and press the Return key. If that IP number is not already used in your planning site, the system creates a blank template for the new IP, informs you that the new IP is your current IP, and returns the screen to the STATUS BOARD menu.

If you select option 2, the system will prompt you to select an IP on which to base the new IP from a list.

\begin{tabular}{ll} 
IP & DESCRIPTION \\
\hline 1 & One line description of IP 1 \\
1 & One line description of IP 7 \\
11 & One line description of IP 11 \\
\hline Select desired base IP:
\end{tabular}

You can select an IP from the list or press GOLD Y to escape IP selection. If the list is too long to fit on one page, you can use the following commands to scroll the through list:

Key Result

D Scrolls Down to the next page of tasks
D\# Scrolls Down \# pages
U Scrolls Up to the previous page of tasks
U\# Scrolls Up \# pages
T Scrolls to the Top of the list (first page)
B Scrolls to the Bottom of the list (last page)

After you select a base IP, the system will request that you enter a new IP number.

Please enter the IP number you wish to create $=m$ 
Type in the number of the new IP. The system will create the new IP based on the existing IP you selected.

To add task details to the new IP use IMPLEMENTING PROCEDURE-C) Change Tasks.

\section{IMPLEMENTING PROCEDURES}

This option of the STATUS BOARD allows you to view details of the current IP. Information Managers may also modify the IP or switch between existing IPs.

When you choose IMPLEMENTING PROCEDURES, the following menu screen displays information about the current IP and enables you to start activities for using the procedure. (The screen shows 14 Emergency Function categories at a time. The categories shown are the default examples. Your local system may have up to 36 Emergency Function categories with different names chosen specifically for the system.) The following screen is labeled for operational use; for planning use, the screen and the menu options are somewhat different (as shown on the next page).

Note: If an event has been declared, the system will display the following message:

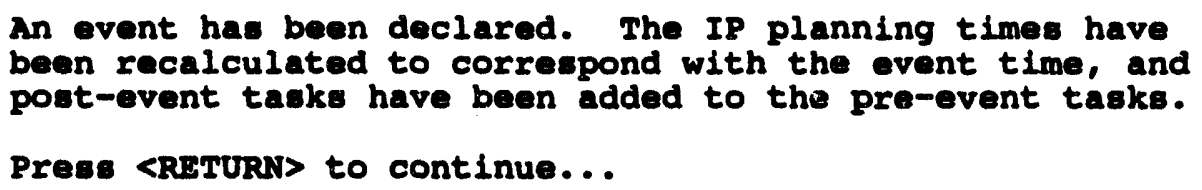

If an event has been declared over the system will display the following message.

An event has been declared over. You will now return to pre-event tasks. 
Implementing Procedures Menu (nonplanning modes)

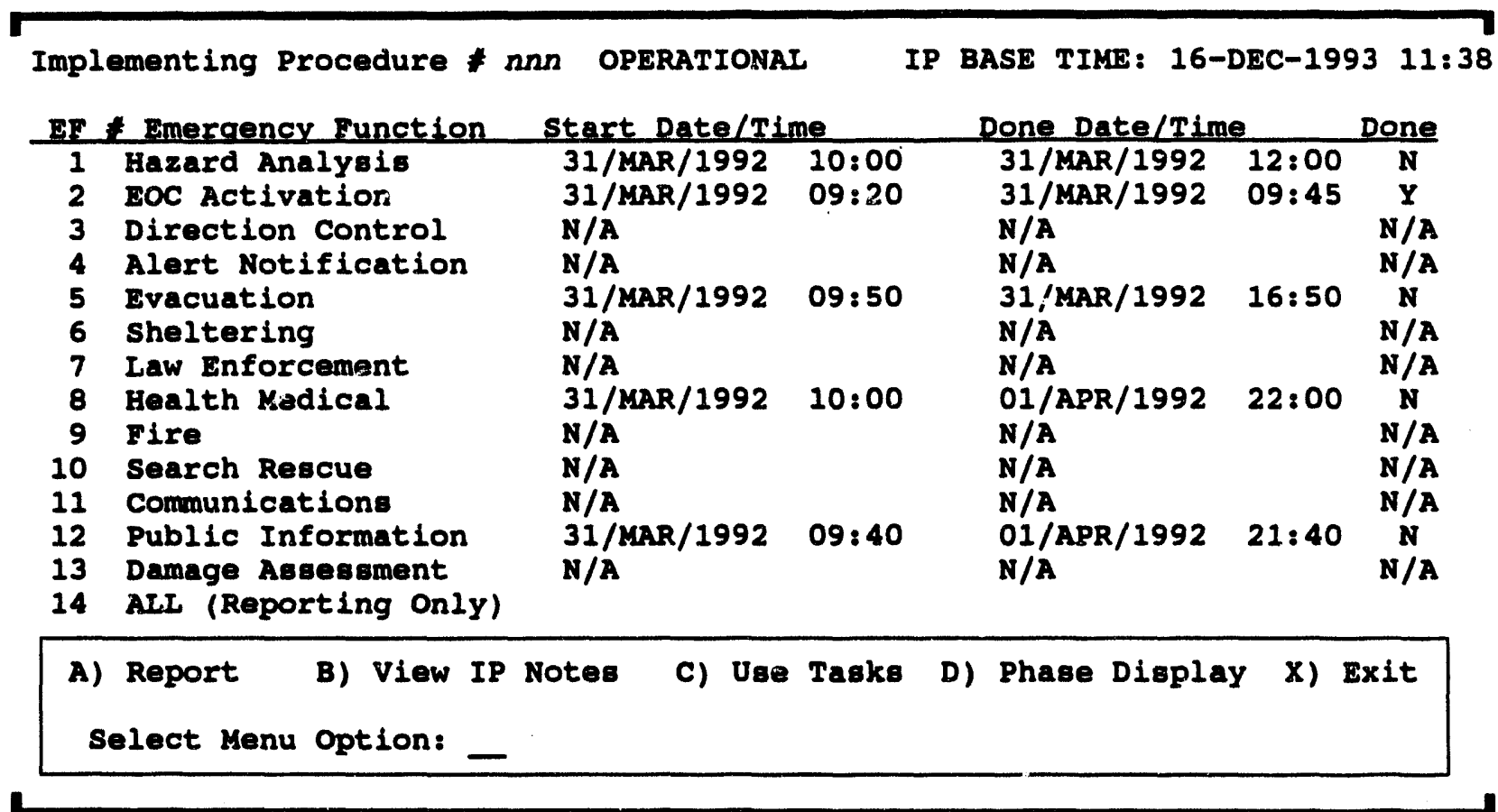

Operational/Exercise Mode Display Items - The upper part of the screen is filled in automatically with summary information for the given activities:

- The IP number is the number of the current IP.

- Usually, unless an event has been declared, you will see only pre-event tasks. You can use PH (phase) in the Use Tasks or Change Tasks forms to display both pre-event and post-event tasks. If an event is declared you will see both pre-event and post-event tasks.

- The Start/Done times and the Done flags are filled in, based on the progress of the tasks. If no tasks exist for a particular Emergency Function, these times are 'abeled as N/A (not applicable). 
Implementing Procedures Menu (planning mode)

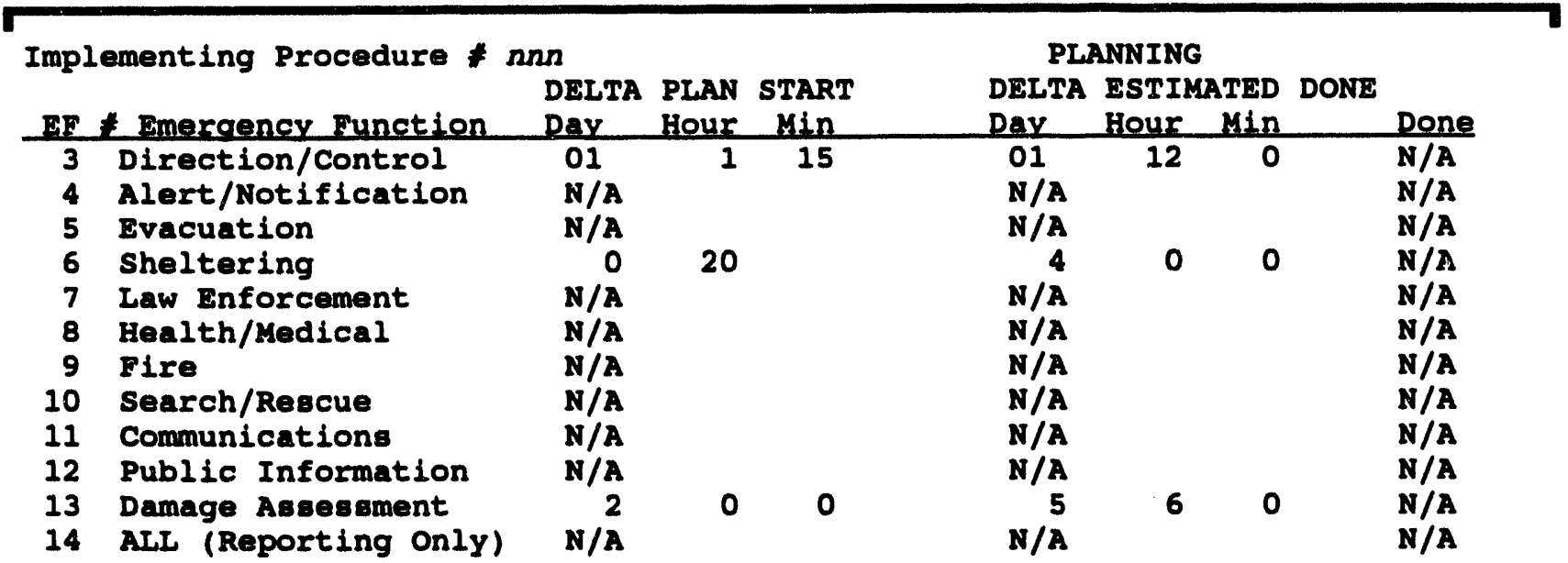
A) Report
B) View IP Notes
C) Use Tasks
D) Phase Display
X) Exit

Select Menu Option:

Planning Mode Display Items - The upper part of the screen is filled in automatically:

- The IP number is the number of the current IP.

- In planning mode, the Done flags are always listed as N/A (not applicable).

Selecting IP Options - To initiate an activity, select one menu option (A-C) or X to exit. If you choose A) Report, C) Change Tasks in planning mode or C) Use Tasks in operational mode, another prompt requests a specific Emergency

Function: Emergency Function *:

To choose an Emergency Function, enter the index number of the function. If the total number of Emergency Functions are more than 12, you can show the other functions by using the following key commands at the Emergency Function number prompt:

Key Result

D Scrolls Down to the next page of functions

U Scrolls Up the previous page of functions

T Scrolls to the Top of the list (first page)

B Scrolls to the Bottom of the list (last page)

Selecting ALL Functions applies only for Option A) Report. 
The IP options are summarized in the following table and described in detail in the following sections.

TABLE 3.1. Summary of IMPLEMENTING PROCEDURES Options

Option Description

A Report presents the IP report production options.

B View IP Notes (operational mode only) ${ }^{(a)}$ displays the notes (up to 99 lines) for the current IP. These are general descriptions and explanatory notes associated with the IP. Action, resource, and task notes associated with specific tasks can be accessed through Option C.

$B^{(b)} \quad$ Change IP Notes (planning mode only) displays the IP notes for editing by planners.

C Use Tasks/View Tasks (operational mode only) displays details of the tasks for the chosen Emergency Function. Users with basic privileges will see option $\mathrm{C}$ listed as View Tasks. This enables users to view tasks, actions, and resources in the IP. Users with appropriate privileges will see option $\mathrm{C}$ listed as Use Tasks. These users can enter task starting and completion times, mark tasks as done, insert and edit any part of the task, action, and resource information.

C Change Tasks/View Tasks (planning mode only) displays details of the tasks for the chosen Emergency Function. Planners can modify the IP by changing tasks, actions, resources, and the notes associated with each. Other users will only see the View Tasks version of this option.

D Phase Display Users with appropriate privileges will see this option, which enables them to choose which tasks to view: pre-event, post-event, or all tasks.

X EXIT exits this IP screen and returns to the STATUS BOARD menu.

\section{A) Report}

This option allows you to produce predefined or user-defined reports about an IP. Reports can be displayed, printed, written to a file, or mailed.

(a) The IP capabilities for Operational, Exercise, and Backup use are all the same. The IP capabilities and menu options for Planning use are different.

(b) Planner or Information Manager privileges required. 
When you select the A) Report option, the second prompt requests you identify an Emergency Function by entering an Emergency Function number on the IP menu.

After the Emergency Function(s) are identified, the system displays the following menu screen for choosing reports about the current IP.

REPORT IP

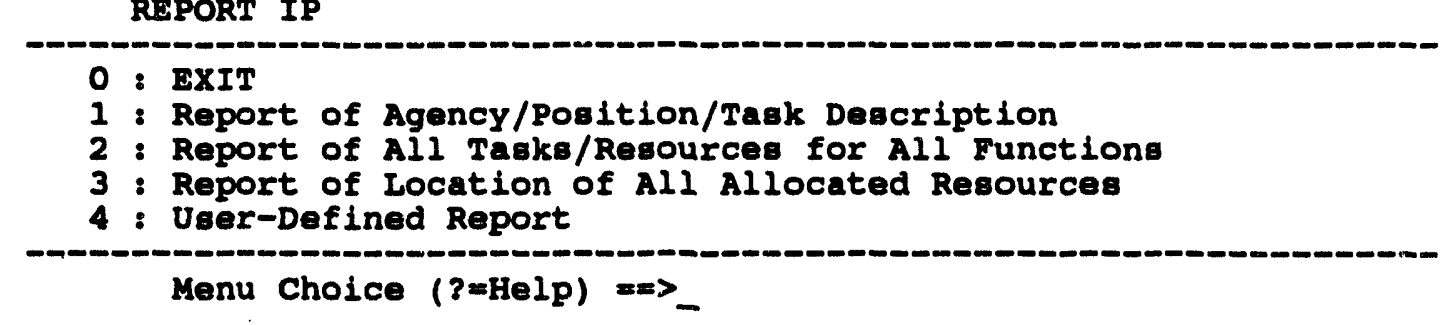

Options 1, 2, and 3 provide predefined reports that include the items specified in the report type title. Remember the resources in these reports are the planned or required resources, and NOT the actual resources. For tracking actual resources, see Section 6, Resource Management.

Option 4 displays the following screen for tailoring the contents of a report of IP information.

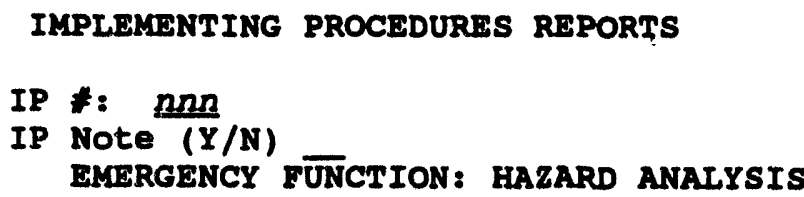

TASK NOTE

$(\mathbf{Y} / \mathrm{N})$

ACTIONS

ACTION NOTES

$(Y / N)$

$(Y / N)$

RESOURCE LISTS

$(Y / N)$

RESOURCE IIST NOTES $(Y / N)$

starus (Done, Not done, or All)

To tailor the report, specify your choices for each item in the screen fields. The IP information that you specify is then assembled for the report. The fields of the screen are explained here. 
- IP \#: The current IP \# is displayed. You may accept this value, specify a different IP \#, or enter a -1 (negative one) to produce a report for ALL IPs in the current database. (If an event has been declared, only the current IP is searched or displayed.)

- IP Note: To include the general IP notes, enter a $Y$ in the corresponding field.

- Emergency Function: The Emergency Function selected on the previous screen is displayed. You may accept this choice or enter a different Emergency Function. (Entering two question marks ?? in this field displays a list of all Emergency Functions.)

- Task \#. Enter a specific task number or a -1 to indicate ALL tasks in the specified Emergency Function. (Entering two question marks ?? in this field displays a list of all Task numbers.)

- Agency. Enter a specific 5-character agency code to request a report containing information on a specific agency. Leave this field blank to get a report containing information on all agencies. (Entering two question marks ?? in this field displays a list of all Agencies.)

- Position. Enter a specific 20-character position cude to request a report containing information on a specific agency position. Ieave this field blank to get a report containing information on all positions. (Entering two question marks ?? in this field displays a list of all Positions.)

- Note (Task, Action, Resource List): To include these notes in the IP report, enter a $Y$ in the corresponding NOTE field.

- Actions and Resource Lists: To include actions or resource lists, enter a $\mathbf{Y}$ in the corresponding field.

- Status: Enter D, N, or A for the following results.

D Done : Only tasks that ARE done are reported.

N Not done: Only tasks that are NOT done are reported.

A All : If Status is A (or is left blank), ALL tasks are reported (done or not) and a done/not done indicator is included in the report.

After you have completed the report form, the following menu will display.

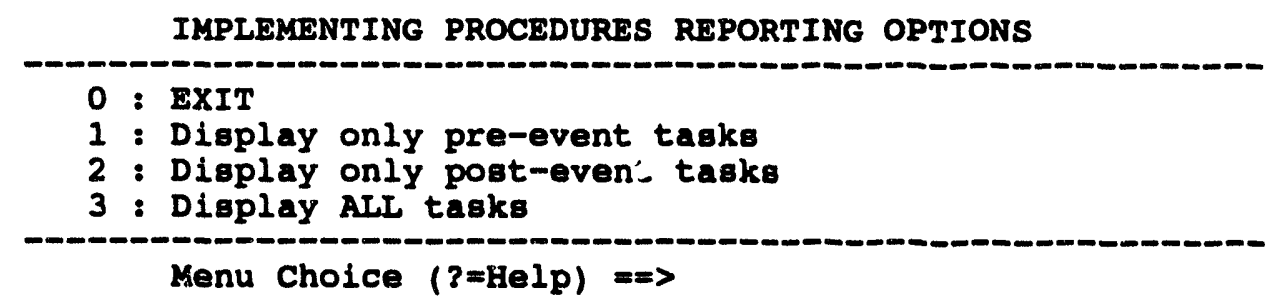




Output Redirection Menu
$0:$ ExIT
$1:$ Display on screen
2 : Print on default Printer
3 : Mail to other user (B)
$4:$ Save to an AscII file
Menu Choice $(?=$ Help) $=>$

\section{Sample IP Reports:}

option 2: Report of All Tasks/Resources for All Functions

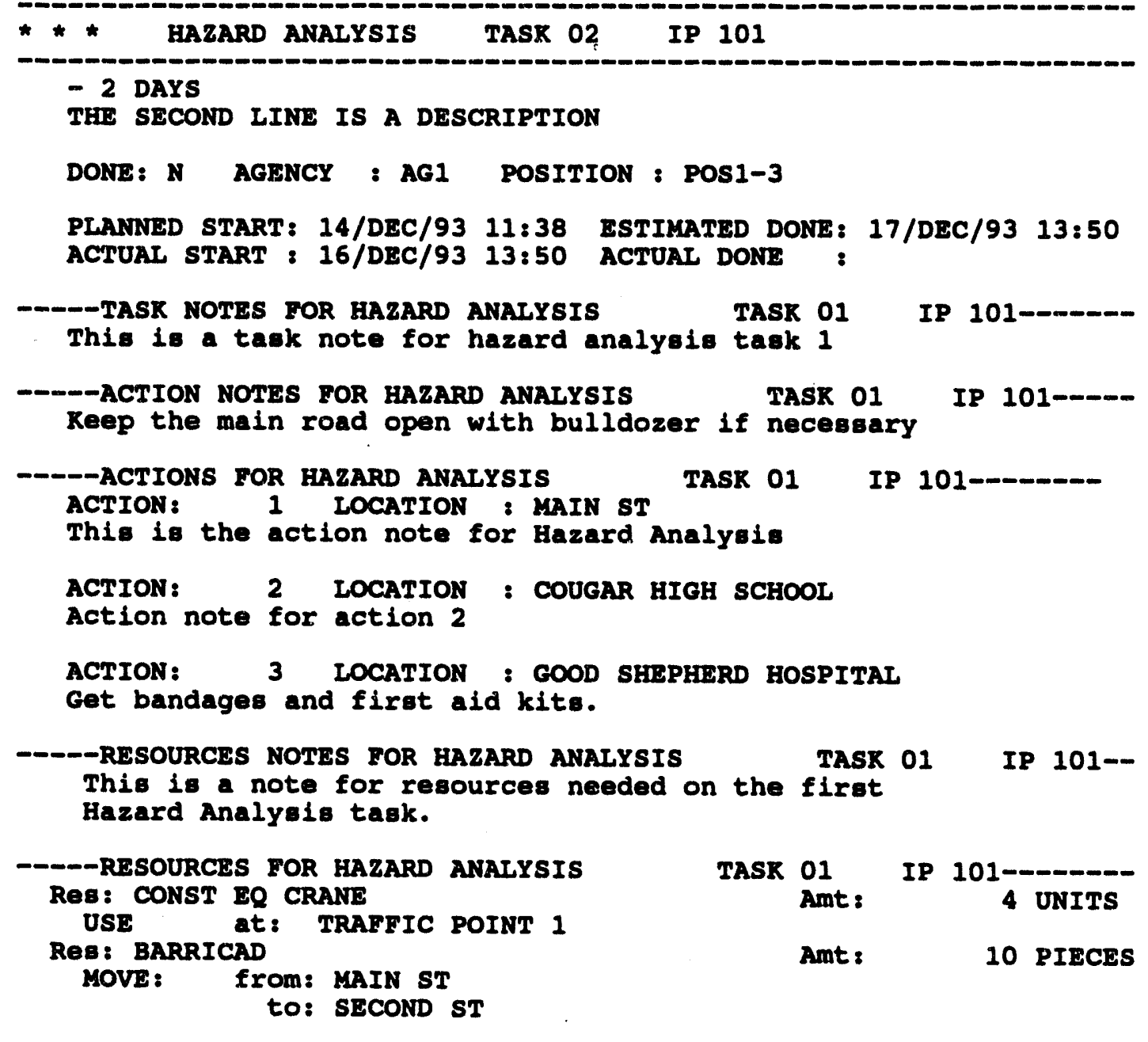




\section{B) View IP Notes and Change IP Notes}

The View IP Notes (in operational mode) and Change IP Notes (in planning mode) options on the Implementing Procedure menu display the IP-level note lines for the current IP. ${ }^{(a)}$ The operational IP note screen displays.

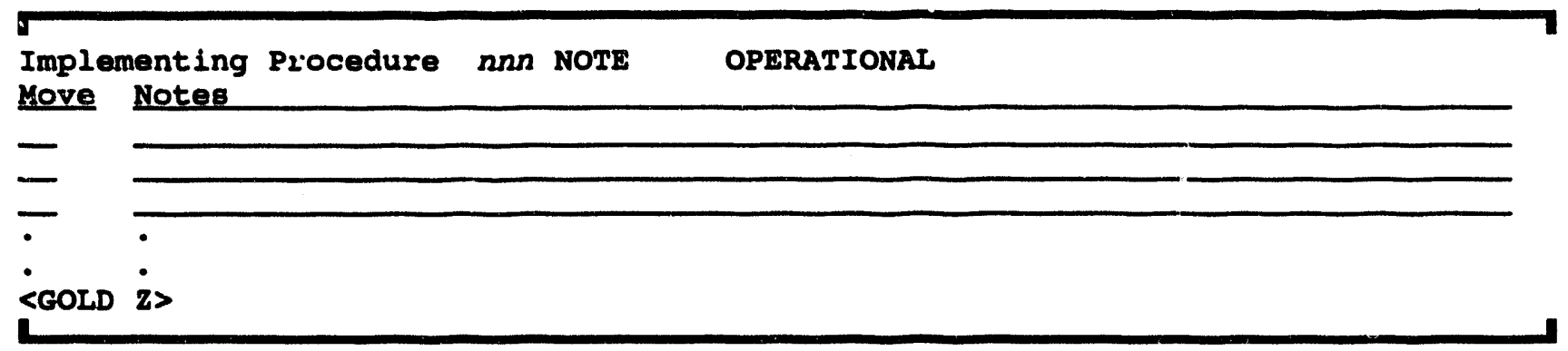

Enter each line of the note independently by pressing RETURN at the end of each line. Each line is preceded by an initial Move field.

To scroll through the note lines: use the arrow keys OR enter one of the following key commands in a Move field:

Key Result

D crolls Down to the next page of tasks

D\# scrolls Down \# pages

U Scrolls Up to the previous page of tasks

U\# Scrolls Up \# pages

T Scrolls to the Top of the list (first page)

B Scrolls to the Bottom of the list (last page)

If you have privileges to add or modify notes, you can enter up to 99 lines of notes in planning.

- To edit an existing line, type over the existing text.

- To delete a line, enter a blank at the beginning of the line.

- To add a line, move the cursor to the first blank line and type new information.

- GOLD $\mathrm{Z}$ exits and saves any changes.

- GOLD Y exits and leaves the note in its original form.

(a) To view notes for a task, action, or resource list, you must first select D) Use Tastes (operational) or Change Tasts from the IP menu and then choose to view notes, as described in following sections. You may also view notes using the A) Report option. 


\section{C) Use Tasks}

Use Tasks (in operational mode) on the Implementing Procedure menu displays a task list screen for the selected Emergency Function, similar to the following example screen. All users can retrieve information about tasks, actions, resources, and the notes for each in the boxed working area of the screen.

If you have appropriate privileges, you can also indicate tasks as started or done, mark tasks as crucial or not, insert new tasks, or edit any task information (task, action, resource, or notes associated with each).

Use Tasks Screen (operational mode)

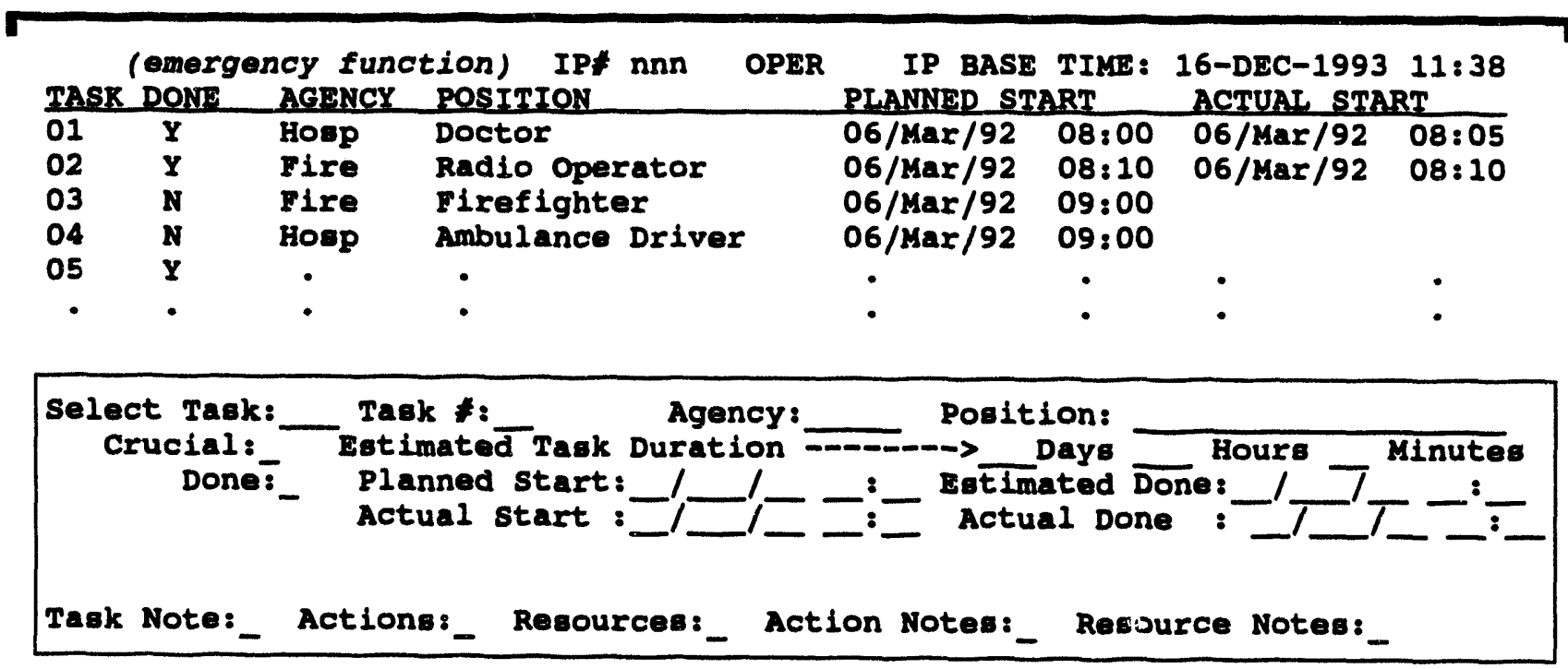

To select tasks for viewing and use: Enter a task number (or one of the following key commands) in the Select Task field.

Key Result

?? Displays HELP information on screen functions

C Cancels and clears information from the boxed working area

O Displays a list of overdue tasks (nonplanning modes only)

H Switches between alternative Headings and task information

I Switches to INSERT mode for adding tasks

D Scrolls Down to the next page of tasks

D\# Scrolls Down * pages

U Scrolls Up to the previous page of tasks

U\# Scrolls Up \# pages

$T$ Scrolls to the Top of the list (first page)

B Scrolls to the Bottom of the list (last page)

$<$ Control-E> Refreshes the screen display for all forms

P Lists personnel responsible for the current task.

PH Enables you to switch between pre-event and post-event tasks. 
Note: If you use PH before an event to see post-event tasks, the system will display a message similar to the following.

$$
\begin{aligned}
& \text { NOTE: YOU ARE IOORING AT POST-EVENT TASKS BEFORE AN } \\
& \text { BVENT HAS BEEN DECLARED. }
\end{aligned}
$$

After you enter a task number in the Select Task field, the system retrieves the IP information on that task and clears the Select Task field for another key command. The Task \# field displays the selected task number: this task number is for display only and cannot be changed directly. The other fields on the Use Tasks screen are modifiable only by those who have privileges to do so. When you enter a number in the Select Task field, the system saves the current task information before retrieving information on the next task.

- Date and Time Fields. Type the complete date and time, or enter $\mathbf{T}$ or $\mathbf{D}$ in a field to get the current system date and time. The hours are entered on a 24 -hour clock $(1 \mathrm{pm}=13: 00)$.

The following fields are ones modified during normal operational use.

- Done: Enter $\mathbf{Y}$ (yes), $\mathbf{N}$ (no), or I (ignore). If you enter I to ignore the task, it does not appear on the list of overdue tasks when the estimated completion time is past.

- Actual Start: Enter the actual start date and time.

- Actual Done: Enter the actual completion date and time.

- Crucial: Enter Y (no) or N (no),

- Actions and Resources: To immediately display a list of actions or resources for the selected task, enter $\mathbf{Y}$ in either of these fields.

- Task Notes, Action Notes, and Resource Notes: To immediately display a list of any of the three kinds of notes, enter a $Y$ in the corresponding fields. A screen of notes will display. In the following example, the Resource Notes for Hazard Analysis have been selected. 


\begin{tabular}{l} 
RESOURCES FOR HAZARD ANALYSIS \\
INDEX TYPE \\
\hline $001 \quad$ DOOSCRIPTION
\end{tabular}

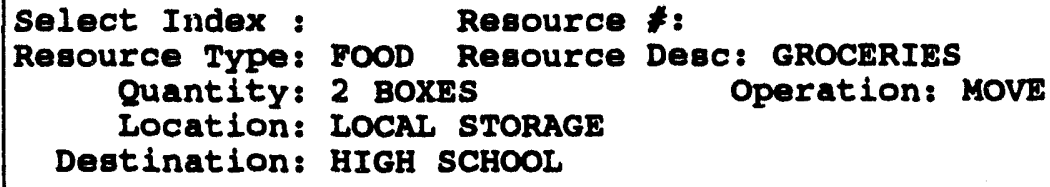

The Operation field enables the IP to automatically adjust the amounts of resources at selected facilities as tasks are completed.

Note: Be aware that marking a task as Done will modify the location of resources in the database. This is a powerful feature that must be used carefully. Make frequent backups of your site database, especially before exercises or training. This will enable you to restore the correct database following an exercise.

You can enter the following operations which will be performed on the resource at the selected facility:

Produce: Add the quantity of resources to the Location

Move: Move the quantity of resources from one location to another.

Use: Use a quantity of resources for the duration of the task, returning them to the location when the task is completed.

Consume: Remove the quantity of resources from the location.

The Destination field must be filled when you Move resources. Enter a facility location, or type ?? to see a list of locations.

As the IP is used in Operational mode, resources will be moved/produced/used or consumed according to the resource information associated with each task. When an IP is reset you will have the option to reset the resource levels to the levels set before the IP was used.

As tasks are marked as either started or done, the corresponding resource operations will be performed. For example: a task Uses 3 radios at the police station. When the task is marked as Started, the 3 radios would be removed from the quantity at the police station. Then, when the task is marked as Done, the 3 radios would be added back to the quantity at the police station. 


\section{Caution}

Changing task resources for tasks that have been Started or Completed will cause unpredictable results when the IP is reset.

The remaining fields are normally entered only during planning: Agency, Position, Planned Start, Estimated Done, and Estimated Duration.

If you enter a new agency or position code, the system will enable you to create it.

- If you enter a new position code, the system will prompt you to confirm the creation of the new position. If you answer yes to the prompt, the system will add the new position.

- If you enter a new agency code, the system will prompt you to confirm the creation of the new agency. If you answer yes to the prompt, the system will prompt you to enter the new agency name. Type the agency name and press the Return key. The system will create the new agency. (See Section 4, Personnel Management for more information on agencies and positions.)

Those with appropriate privileges are able to edit any task information and even insert new tasks: they are able to do everything that a planner can do during planning use, except remove a task from the task list. For specific instructions on editing, planning, and inserting new tasks, see Editing Task Information under C) Change Tasks.

Note: Changing the planning information and inserting new tasks during operational use have a potential for serious confusion, uniess the people responsible for executing the modified or new tasks are immediately aware of the changes.

To exit the Use Tasks screen: press GOLD $Z$ to exit and SAVE modifications of the current task OR press GOLD Y to exit and CANCEL modifications (of the current task only). You will return to the Implementing Procedure menu.

\section{Usting Overdue Tasks}

To see a list of overdue tasks: enter $O$ in the Select Task field (O for Overdue). The list part of the screen displays only tasks that are overdue to start or to finish. To switch back to the normal task list, press RETURN. 
Use Tasks Screen - Overdue Tasks (operational mode)

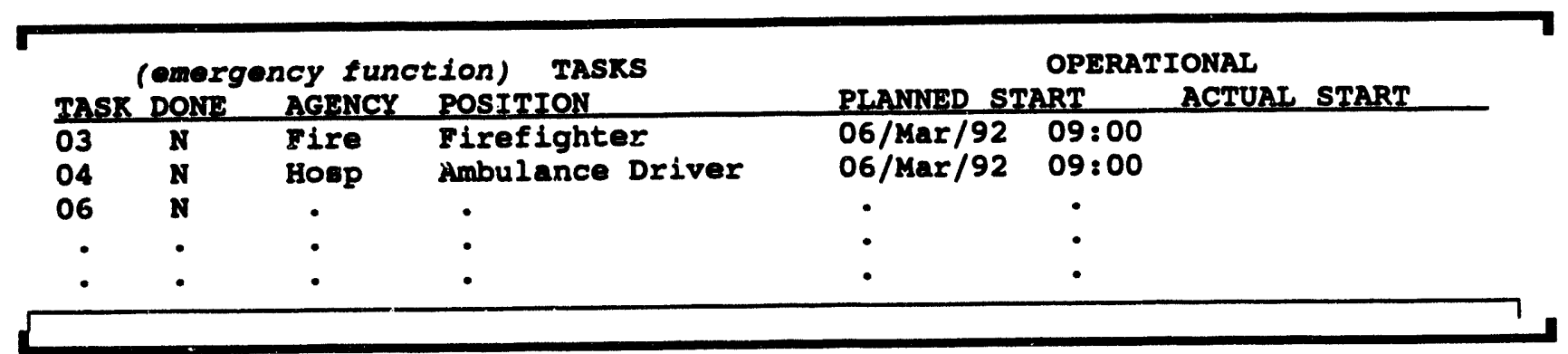

The listed Use Task capabilities are also available through the Change Tasks capability ani are described in detail in the following text.

- I.isting tasks by description (alternative heading)

- Viewing (and changing) task actions

- Viewing (and changing) task resources

- Viewing (and changing) task/action/resource notes. 


\section{Lsting Tasks by Description}

To switch to a task list with alternative headings: enter $\mathbf{H}$ in the Select Task field $(H$ for Heading). This switches the column headings from Agency, Position, and task times to the task Description, as in the following example. Enter $\mathbf{H}$ again to switch back.

Tasks Screen with Alternative Heading (any mode)

\begin{tabular}{|c|c|c|}
\hline TASK & $\begin{array}{l}\text { (emerg } \\
\text { DoNrs }\end{array}$ & $\begin{array}{l}\text { ncy function) } \\
\text { DFscRIPTION }\end{array}$ \\
\hline $\begin{array}{l}1 \\
2 \\
3 \\
4 \\
5 \\
.\end{array}$ & $\begin{array}{l}\mathbf{N} \\
\mathbf{N} \\
\mathbf{N} \\
\mathbf{N} \\
-\end{array}$ & $\begin{array}{l}\text { Report to st. Elizabeth's Medical Center } \\
\text { Dispatch trafic control point personnel } \\
\text { Seal intake fan vents to fire station } \\
\text { Report to decontamination point } \\
\text { - }\end{array}$ \\
\hline
\end{tabular}

\section{Vlowing (and Changing) Task Actions}

If you enter a $\mathbf{Y}$ in the Actions field of the Use Tasks screen or the Change Tasks screen, the actions for the selected task are immediately displayed in another screen that can be scrolled to view additional actions for this task.

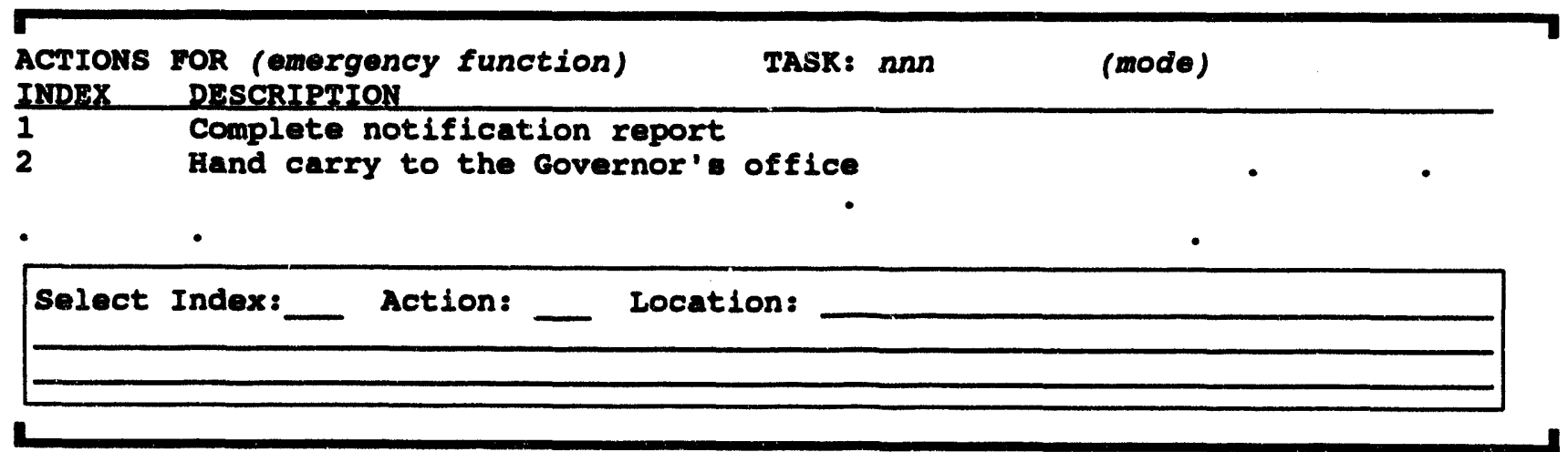

Enter an $\mathbf{H}$ in the Select Index to display the alternate heading as shown in the following example. 


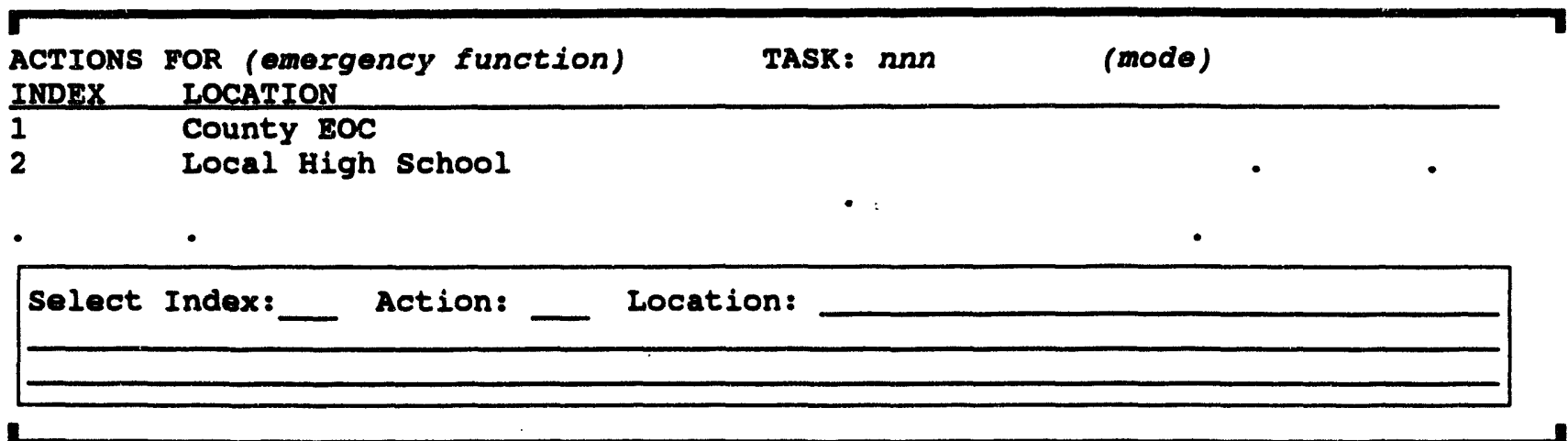

To process actions: In the Select Index field, enter an action number OR one of the following key commands:

Key Result

? Displays HELP info on key commands for scrolling resources:

Up, Down, Top, Bottom (U, U\#, D, D\#, T, B)

$H$ Switches between alternative Headings

I\# Inserts an action at position \# on the action list

R\# Removes action \# from the action list

When you enter an action number, the system puts that number in the Action field and displays the action information in the boxed area. If you have privileges to do so, you can modify the action information:

- Location: Enter a facility location or enter two question marks ?? to see a list of the available locations. To select an item from the list, type a $>$ followed by the index number of the item in the help list.

- Description: Enter two lines of description.

To insert an action into the task action list: Enter I\# in the Select Index field, where \# is the index position where you want to insert the new action. Enter data in the appropriate fields. The new information is shown in the action list as you press RETURN after entering each value.

To remove an action from the task action list: Enter $\mathbf{R}$ \# in the Select Index field, where \# is the index of the action that you want to delete.

\section{Vlewing (and Changing) Task Resources}

If you enter a $Y$ in the Resources field of the Use Tasks screen or the Change Tasks screen, the resources for the selected task are immediately displayed on another screen that can be scrolled to view additional resources for this task. 


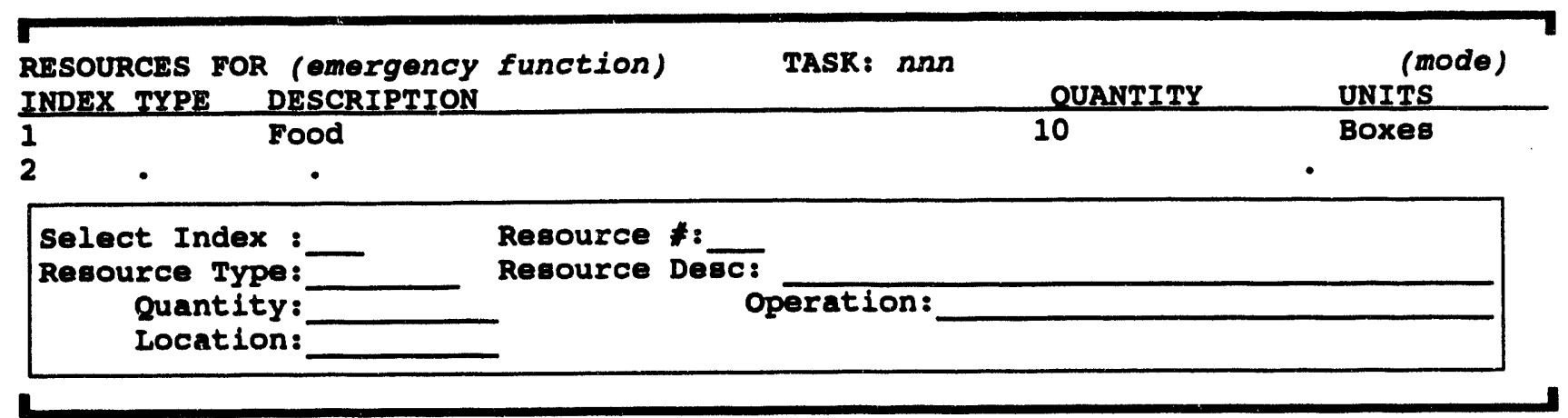

Enter an $\mathbf{H}$ in the Select Index to display the alternate heading as shown in the following example.

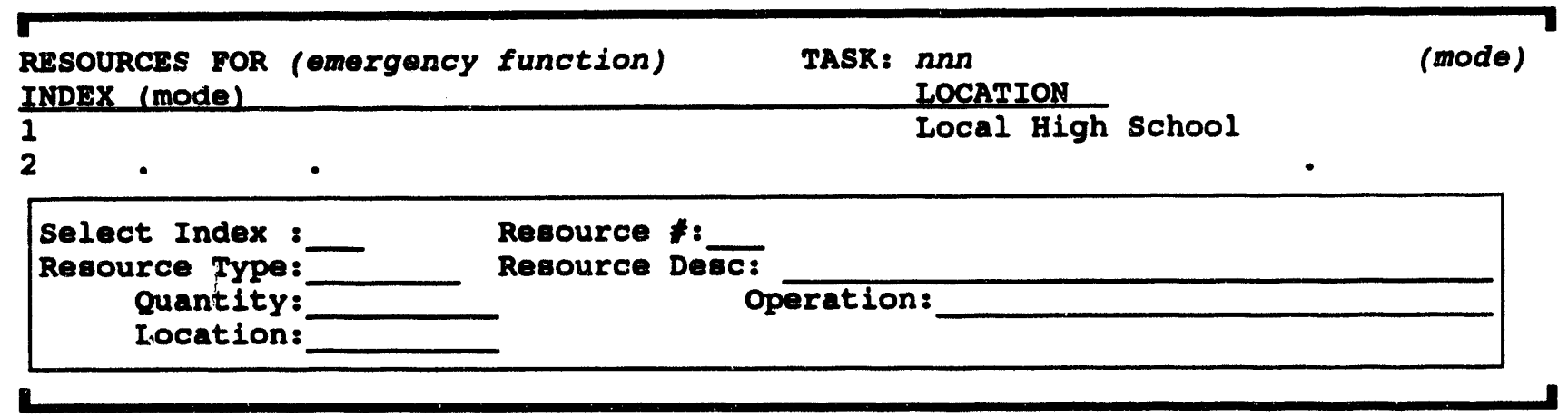

To process resources: In the Select Index field, enter a resource number OR one of the following key commands:

Key Result

? Displays HELP info on key commands for scrolling resources:

Up, Down, Top, Bottom (U, U\#, D, D\#, T, B)

$\mathrm{H}$ Switches between alternative Headings

I\# Inserts a resource at position \# on the resource list

R\# Removes resource \# from the resource list

When you enter a resource number, the system puts that number in the Resource \# field and displays the resource information in the boxed area.

If you have privileges to do so, you can modify the resource information:

- Resource Type: Enter the general resource type or enter two question marks ?? to see a list of resource types. To select an item from the list, type a > followed by the index number of the item in the help list.

- Resource Description: A resource description will fill in automatically once you select a Resource Type. You can enter two question marks ?? to see a list of other resources of this type. To select an item from the list, type a > followed by the index number of the item in the help list. 
- Quantity: Enter a nonzero quantity.

- Location: Enter a facility location (or enter ??) to see a list of locations.

To insert a resource into the resource list: Enter I\# in the Select Index field, where \# is the index position where you want to insert the new resource. Enter data in the appropriate fields. The new information is shown in the resource list as you press RETURN after entering each value.

\section{Vlewing (and Changing) Task/Action/Resource Notes}

If you enter a $Y$ in one of the Notes fields of the Use Tasks screen or the Change Tasks screen, the task note, action note, or resource note for the selected task is immediately displayed on another screen that can be scrolled to view additional lines of the note. The heading for the Task Note follows:

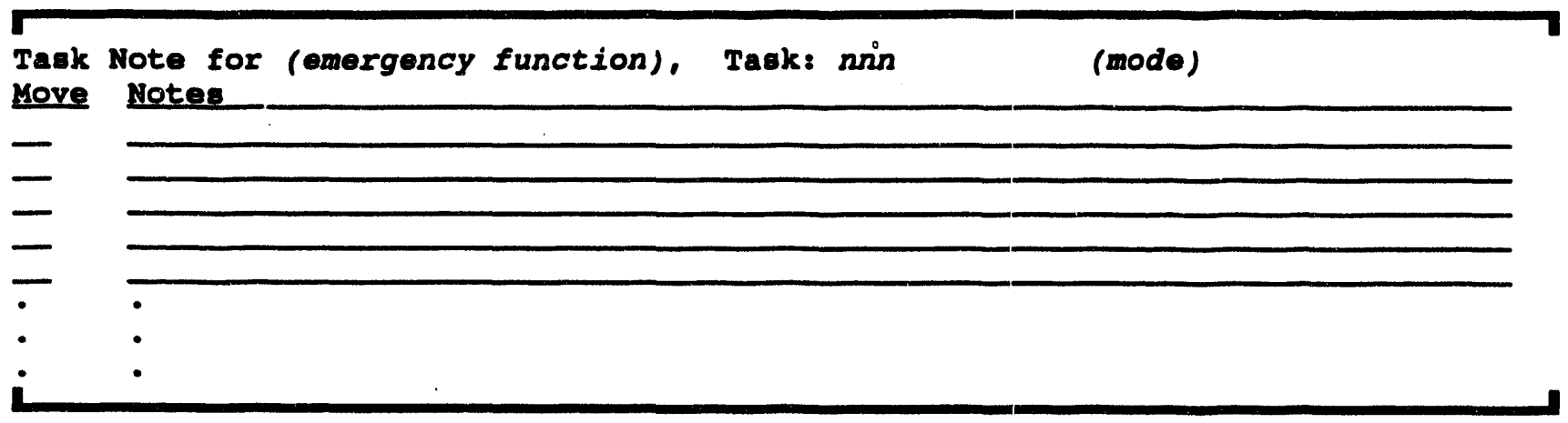

Enter each line of the note independently by pressing RETURN at the end of each line. Each line is preceded by an initial Move field.

To scroll through the note lines: use the arrow keys OR enter one of the following key commands in a Move field:

Key Result

? Displays HELP info on key commands for scrolling resources:

Up, Down, Top, Bottom (U, U\#, D, D\#, T, B)

$D$ Scrolls Down to the next page of tasks

D\# Scrolls Down \# pages

U Scrolls Up to the previous page of tasks

U\# Scrolls Up \# pages

$T$ Scrolls to the Top of the list (first page)

B Scrolls to the Bottom of the list (last page)

If you have privileges to add or modify notes, you can enter up to 99 lines of notes.

- To edit an existing line, type over the existing text. 
- To delete a line, enter a blank at the beginning of the line.

- To add a line, move the cursor to the first blank line and type new information.

- GOLD Z exits and saves any changes.

- GOLD Y exits and leaves the note in its original form.

\section{C) Change Tasks *}

Change Tasks (in planning mode) on the Implementing Procedure menu displays a task list screen for the selected Emergency Function, similar to the following example Change Tasks screen. Planners or other authorized users can modify tasks, actions, resources, and associated notes in the boxed working area of the screen. General users do not use this screen.

The Change Tasks screen is nearly identical to the Use Tasks screen except that it lacks a few nonplanning fields (Done, Actual Start, Actual Done) and lists the delta start time before and after the Event time instead of the actual start time in the task list.

\section{Change Tasks Screen (planning mode)}

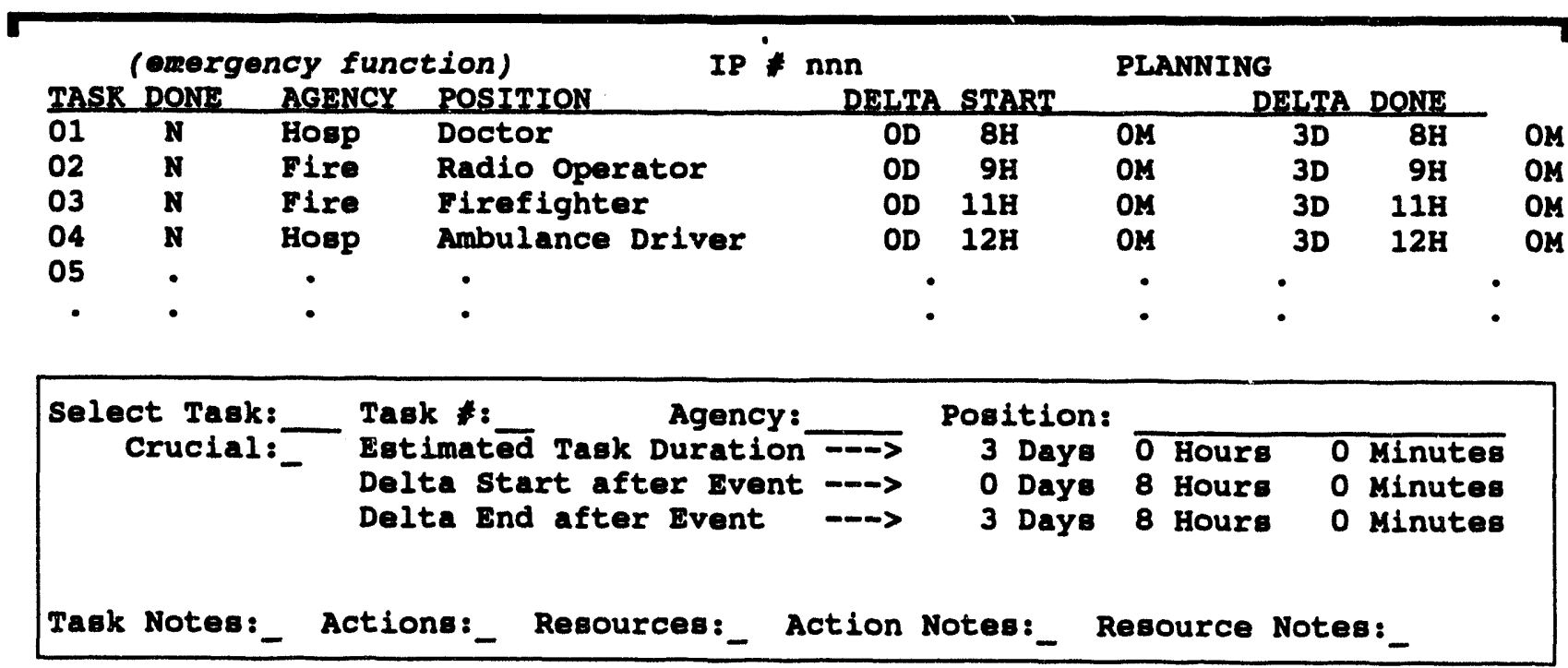

Te select tasks for viewing and use: Enter a task number (or one of the following key commands) in the Select Task field.

Key Result

?? Displays HELP information on screen functions 
\# Select a task number to edit

C Cancels and clears information from the boxed working area

H Switches between alternative Headings and task information

I Switches to INSERT mode for adding tasks

R\# Removes task number \# from the task list

D Scrolls Down to the next page of tasks

D\# Scrolls Down \# pages

U Scrolls Up the previous page of tasks

U\# Scrolls Up \# pages

T Scrolls to the Top of the list (first page)

B Scrolls to the Bottom of the list (last page)

P Show personnel responsible for a task. A + indicates the person is scheduled to be on duty.

PH Enables you to switch between pre-event and post-event tasks.

L Toggle between Task Link mode and the main task screen in planning mode.

\section{Changing Phases}

In planning mode (or operational mode if you have the privelege to change the IP) you can switch between the pre-event and post-event tasks on the Change Tasks screen by typing PH (PHase) in the Select Task field. The following prompt will display below the Select Task box:

\begin{tabular}{|c|c|c|c|c|c|}
\hline $\begin{array}{r}\text { Select Task: } \\
\text { Cruclal:- }\end{array}$ & $\begin{array}{l}\text { Task : Agency: } \\
\text { Batimated Task Duration } \\
\text { Delta start after Event } \\
\text { Delta End after Event }\end{array}$ & $\underset{m-\infty}{\longrightarrow-\infty}$ & $\begin{array}{l}\text { Pogition: } \\
3 \text { Days } \\
0 \text { Days } \\
3 \text { Days }\end{array}$ & $\begin{array}{l}0 \text { Hours } \\
8 \text { Hours } \\
8 \text { Hours }\end{array}$ & $\begin{array}{l}0 \text { Minutes } \\
0 \text { Minutes } \\
0 \text { Minutes }\end{array}$ \\
\hline Task Notes: & Resources: _ & Action & Notes:_ & lesource & Notes: _ \\
\hline
\end{tabular}

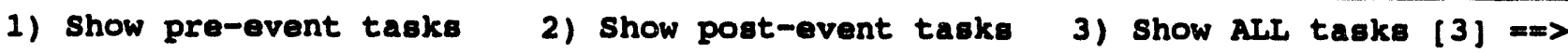

The current display phase is in brackets to the left of the $==>$ prompt. As shown in the previous example, the default is phase 3) Show ALL tasks. If you select 1) Show pre-event tasks, the system will display only tasks which have a negative delta estimated start time. If you select 2) Show post-event tasks, the system will display all tasks which have a positive planned start time.

\section{Task Information Fields}

The fields of the task area of the Change Tasks screen are explained in the following paragraphs.

- Agency and Position: Enter the agency code (up to five characters) and the position of the contact person for the task. To see a numbered list of possible agencies (or positions), enter two question marks ?? in the Agency (or Position) field. To select an item from the list, type a > followed by the index number of the item in the help list. 
- Crucial: A prompt similar to the following will display.

$$
\text { Are you sure the task is crucial? [Y] }
$$

Enter Y (Yes) or N (No).

If you enter values for any two of the following three time periods, the system calculates the third value.

- Estimated Task Duration: Enter the number of days, hours, and minutes needed to complete the task.

- Delta Start after Event: During the planning phase, the delta start time is determined by subtracting the task duration from the delta end time.

- Delta End after Event: The time by which you want the task completed.

- Task Description: Enter two lines of task description in the available space. The first 66 characters of the first line of text will display in the task description lists.

After a task has been added, you can use the following fields for adding task actions, task resources, and notes.

- Actions and Resources: To display a screen for adding actions or resources for the selected task, enter $\mathbf{Y}$ in either of these fields.

- Task Notes, Action Notes, and Resource Notes: To display a screen for entering any of the three kinds of notes, enter a $\mathbf{Y}$ in the corresponding fields.

\section{Editing Task Information}

The following capabilities are available to planners from the Change Tasks screen (in planning mode): inserting, removing, and changing a task on the task list. Users with appropriate privileges may also insert.and change (but not remove) tasks from task list on the Use Tasks screen (in operational mode).

\section{To insert a new task:}

1. Enter I in the Select Task field.

This puts you in insert mode for adding tasks. The screen displays the following message 
You are in INSERT mode

2. Fill in the screen information.

Required

- Agency and Position

- Two of Planned Start, Estimated Done, and Estimated

Duration: After two of these values are entered, the third value is calculated.

\section{Recommended}

- Crucial: Indicate whether the task is crucial ( $\mathbf{Y}$ or $\mathbf{N})$.

- Task Description: Enter two lines of task description.

The first 66 characters of the first line of text will display in the task description lists.

Once you enter the second line of description the task will be inserted automatically and insert mode will turn off.

After the new task has been inserted, you can add the other task information:

- task actions

- task resources

- task notes, action notes, and resource notes

To remove a task from the task list: Enter $\mathbf{R} \#$ in the Select Task field, where \# is the number of the task. The chosen task is then deleted from the task list. Task removal is available only during planning; under nonplanning conditions, unwanted tasks can be ignored by entering an I in the Use Task screen's Done field.

To change a task:

1. Enter the task number in the Select Task field.

When you press RETURN, the form box on the screen fills with that task's information.

2. Change the task information.

3. Do one of the following: 
Action

Press GOLD Z.

Enter another task number for editing.

Press GOLD Y.
Result

Saves the modified task information and exits the Change Task screen. Updates the task listing, if necessary.

Saves the modified task information before filling in the box with the next task's information. Updates the task listing, if necessary.

Cancels any changes you have made (for the current task only) and exits the Change Task screen.

To exit the Change Tasks screen: press GOLD $Z$ to exit and SAVE modifications of the current task OR press GOLD Y to exit and CANCEL modifications (of the current task only). The screen returns to the Implementing Procedure menu.

\section{Lnking Tasks}

IBS provides some basic task link functions similar to that provided by project management software. The task link functions enable you to assign relationships between tasks. If you have two tasks which are dependent upon each other, you can link the tasks. This will enable you to adjust the starting time on only one of the tasks and any successor task times will be recalculated automatically. For example, if you have the two following tasks:

1. Open road for evacuation

2. Direct traffic to newly opened road

The road must be opened before you can direct traffic to it. You can link the tasks so that the traffic direction will begin whenever the road opening is complete. In this example, the task open road is a predecessor to the task direct traffic. The task direct traffic is a successor to the task open road. The tasks must have a finish to start relationship because the predecessor must finish before the successor can begin.

To link tasks, type an $L$ (Link) in the Select Task field of the Change Tasks form. The Task Link form will display as shown.

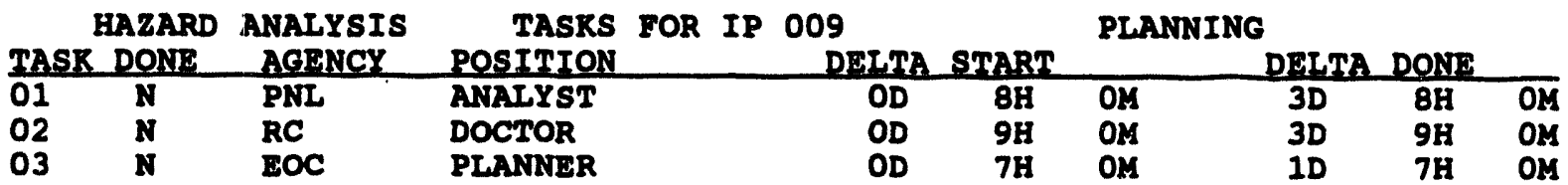

\begin{tabular}{|c|c|c|c|c|c|c|}
\hline $\begin{array}{l}\text { Select } \\
\text { Pred }\end{array}$ & 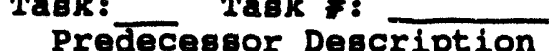 & & & & Cor & straint \\
\hline & Transfer medicine & $\begin{array}{l}\text { irs } \\
\text { rs }\end{array}$ & $\begin{array}{l}0 \text { Days } \\
\text { Days } \\
\text { Days } \\
\text { Days } \\
\text { Days }\end{array}$ & 1 & $\begin{array}{l}\text { Houra } \\
\text { Houra } \\
\text { Houra } \\
\text { Houra } \\
\text { Houra }\end{array}$ & $\begin{array}{r}0 \text { Minutes } \\
\text { Minutes } \\
\text { Minutes } \\
\text { Minutes } \\
\text { Minutes }\end{array}$ \\
\hline
\end{tabular}


Use the following fields to enter the following information.

Select Task The Select Task field on the Task Link form works the same way as the Select Task field on the Change Tasks form. You can scroll the tasks listed at the top of the form, toggle the header, and select a current task to work with.

Task \# If you select a task, the Task \# field will be filled in with the current number and a portion of the task description will be filled in to the right of the number.

Constraint This can be either ASAP (As Soon As Possible) or FIX (fixed time). If a task is to start ASAP it will be adjusted to start as soon as all of its predecessor conditions are met. If a task is fixed (FIX) in time, it will not be adjusted when its predecessors change. A fixed task will generate error messages if its predecessors change in such a way that they cannot complete in time to start the fixed task. Any predecessor task information which the current task may have will be filled in on the lines below.

Pred \# When you type a task number in this field, the Predecessor Description field will be filled in with a short description of the task. Each task can have up to 20 predecessors, but only five will fit on the screen at any one time. Use the previously described IP scroll commands to see all of the predecessors.

Predecessor Description This field is read only. You can change it by changing the task description on the Change Task form.

Type This field contains the task relationship and will initially be filled with the default type FS (Finish-Start).

IBS supports 3 types of task relationships:

FS - When the predecessor Finishes, the successor Starts

SS - Both successor and predecessor Start at the same time

FF - Both successor and predecessor Finish at the same time.

Lead/Lag Time This field will initially be set to 0 . Use this field to link tasks with some leeway time. For example, you may want 3 hours to pass after closing a road before removing the traffic control officer. Use a positive number to set a lag time, use a negative number to set a lead time. The successor task will be adjusted according to the combination of task constraint, task relationship, and lead/lag time with the predecessor.

Note: Task link functions work only in planning mode. 


\section{D) Phase Display}

In planning mode (or operational mode if you have the privelege to change the IP) you can switch between the pre-event and post-event tasks by typing $D$ (Phase Display) in the Select Menu Option field. The following prompt will display below the Implementing Procedure screen:

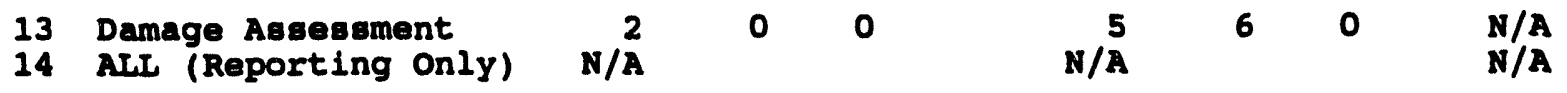

A) Report B) View IP Notes C) Use Tasks D) Phase Diaplay X) Exit
select Menu Option:

1) Show pre-event tasks 2) show post-event tasks 3) Show ALL tasks [3] =s

The current display phase is in brackets to the left of the $==>$ prompt. As shown in the previous example, the default is phase 3) Show ALL tasks. If you select 1) Show pre-event tasks, the system will display only tasks which have a negative delta estimated start time. If you select 2) Show post-event tasks, the system will display all tasks which have a positive planned start time. 


\section{ONPOST EVENT STATUS}

This option displays the Onpost Status Board screen, which is shown in the following example.

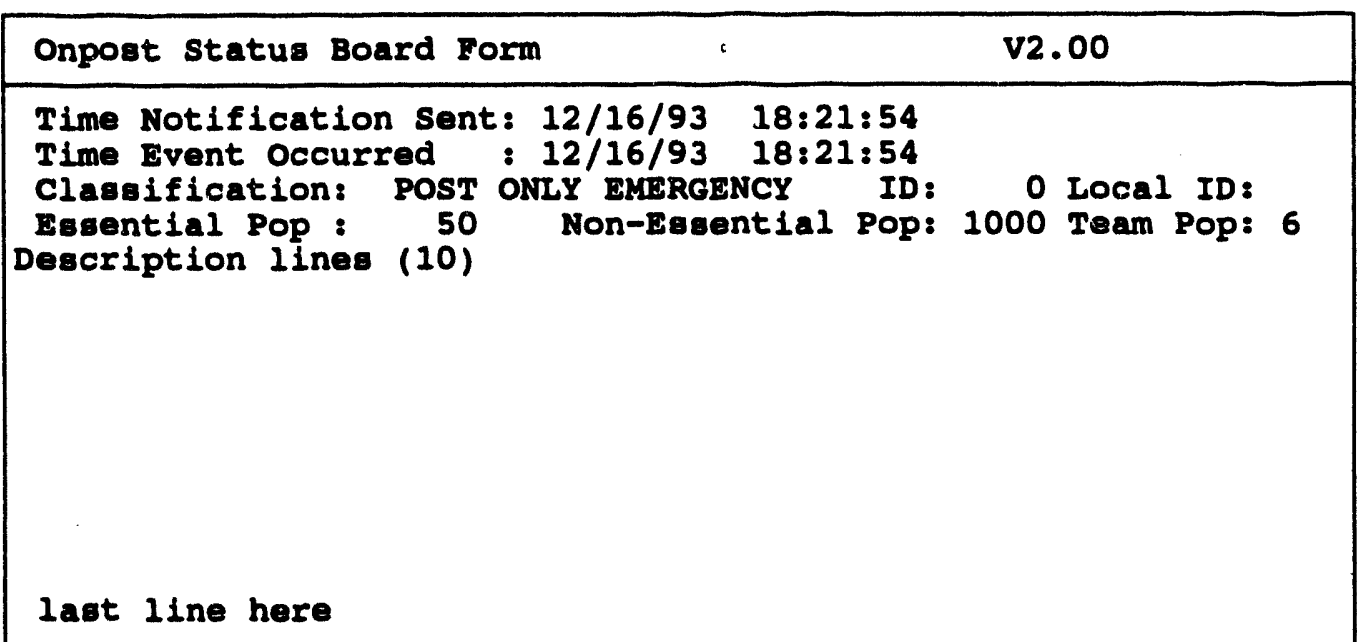

The entire screen is for display only: you cannot alter any of the information here.

- EVENT CLASSIFICATION on the form is one of four types of emergencies:

- $\quad$ Non-Surety Emergency

- $\quad$ Limited Area Emergency

- $\quad$ Post Only Emergency

- Community Emergency.

If an event has not been declared, the system will display the following message.

* * MSG: An event has not been declared

Press <RETURN> to continue...

\section{ID RESET IP *}

The RESET IP option enables the user to

- It also allows the user to reset the base time of the IP

- Clear all done flags, actual start times, and actual completion times.

- Reset the Resources back to the levels they were at before the IP was used.

This option is available only in Operational mode. The following message prompt wil! display: 


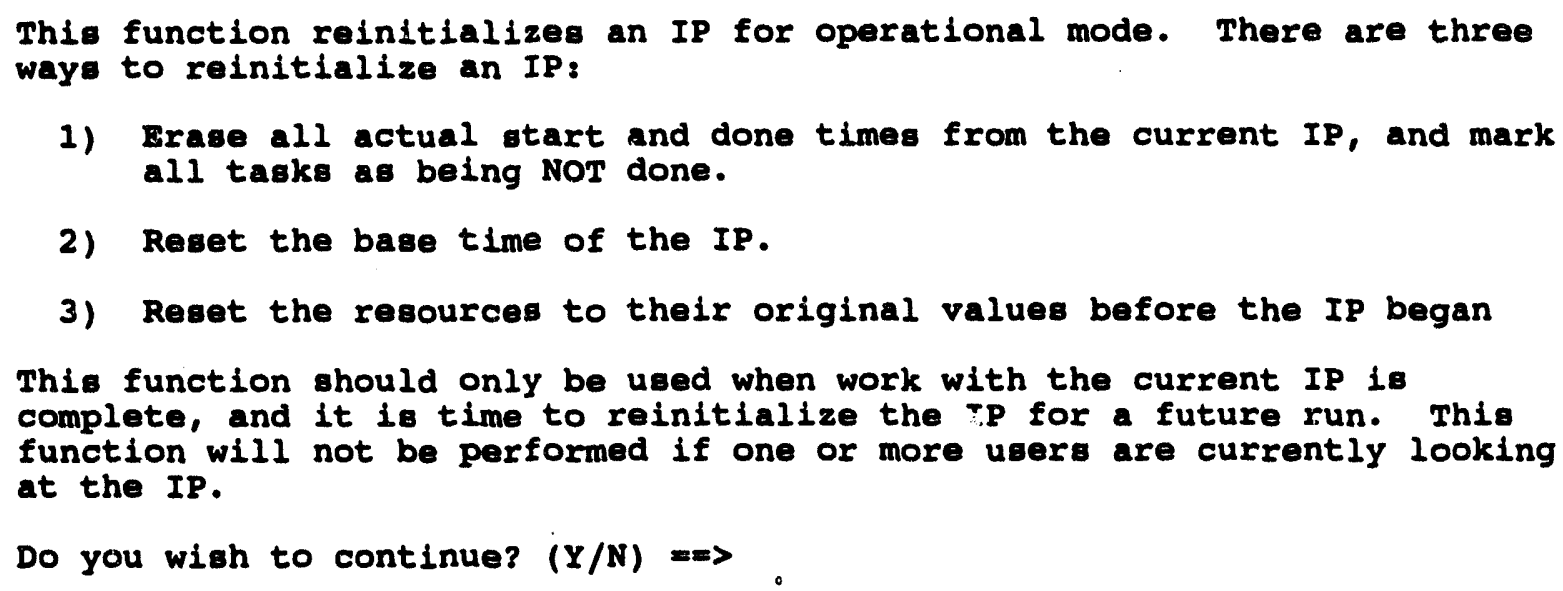

1) Irase all actual start and done times from the current IP, and mark all tasks as being NOT done.

2) Reset the base time of the IP.

3) Reset the resources to their original values before the Ip began

This function should only be used when work with the current IP is complete, and it is time to reinitialize the TP for a future run. This function will not be performed if one or more users are currently looking at the IP.

Do you wish to continue? $(Y / N)=\infty$.

If you type a $Y$ (Yes), the following prompt will display:

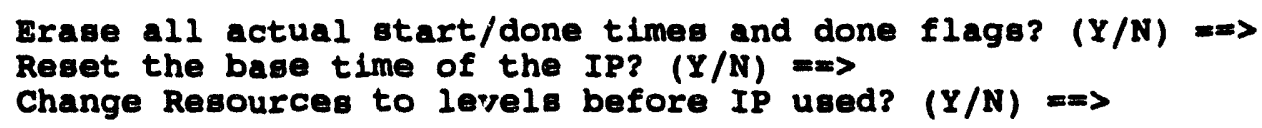

If you type a $Y$ (Yes) at the Reset the base time of the IP prompt, the system will display another prompt to enable you to enter the new the time.

Type an $N($ No) to leave the resources unchanged at their current levels. Type a $Y$ (Yes) to reset the resources to the levels before the IP was used - resources will be Moved-back, un-Consumed, and un-Produced, depending upon which tasks have been performed.

If the IP reset is successful, the following message will display.

Current IP has been reset.

Prese <RETURN> to continue... 


\section{Caution}

Resources should never be reset while other users are doing resource management tasks.

After an IP has been reset without changing the levels of resources, you can not later reset the IP and change the levels of resources. Once an IP is reset, all information about which resources were changed is lost.

If users have changed the resource data manually, the results of resetting the resources will be unpredictable.

You may want to make a backup of the Resource Management and IP data before an IP is used, and also make a backup before an IP is Reset.

\section{SELECT IP *}

Only a user with the correct privileges can select the system IP in operational mode.

Noto: All planners have the privilege to select an IP in planning mode under their personal planning site.

\section{Selecting a New IP in Operational Mode}

In operational mode, you are given the option of selecting an IP directly by IP number or by searching the scenario table based on the current work plan. In planning mode, you can only select an IP by number.

Tc select an IP in operational mode, perform the following procedures:

1. Choose IP selection method and select IP.

A. Choose IP by NUMBER: from a list of IPs, select one IP.

B. Chouse IP by SEARCH FOR IP CRITERIA

1) Identify appropriate D2 çases by using a D2 Track Qualification screen to search for and identify the D2 cases you want.

2) From a list of the D2 cases identified, select one case.

3) From a list of IPs that use the selected D2 case, select one IP. 
2. Now that the new IP number has been selected, choose whether to retain completed tasks from the previous IP.

3. Set IP base time.

This procedure is detailed in the following sections.

When you select Select IP in operational mode, the Choose IP menu displays.

CHOOSE IP MENU

\begin{tabular}{l}
$0:$ EXIT \\
$1:$ Choove IP by NUMBER \\
$2:$ Choove IP by SEARCH FOR IP CRITERIA \\
\hline Menu Choice $(?=\mathrm{Help})=\mathrm{C}$
\end{tabular}

\section{Choose IP by NUMBER}

If you select Choose IP by NUMBER, a list of all possible IPs displays:

\begin{tabular}{|rl|}
\hline IP & DESCRIPTION \\
\hline 1 & One line description of IP 1 \\
7 & One line description of IP 7 \\
11 & One line description of IP 11 \\
$:$ & - \\
\hline
\end{tabular}

Select desired IP:

You can select an IP from the list or press GOLD Y to escape IP selection. If the list is too long to fit on one page, you can use the following commands to scroll through the list:

Key Result

D Scrolls Down to the next page of tasks

D\# Scrolls Down \# pages

U Scrolls Up to the previous page of tasks

U\# Scrolls Up \# pages

T Scrolls to the Top of the list (first page)

B Scrolls to the Bottom of the list (last page)

\section{Choose Whether to Retain Completed Tasks from the Previous IP}

After you select an IP, the following message displays.

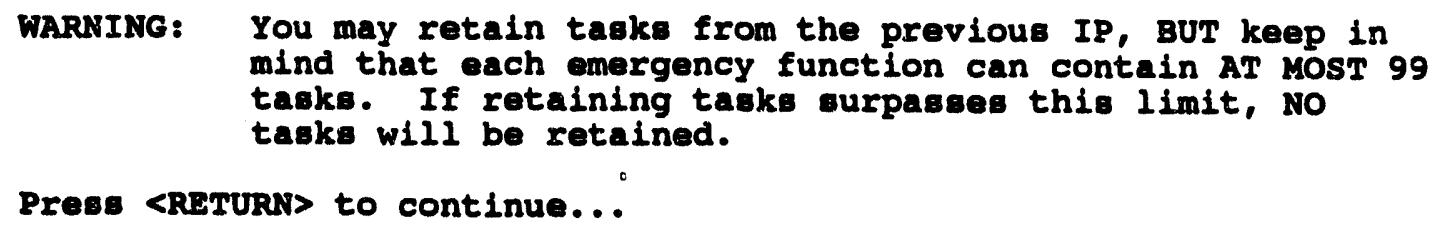


After you press the Return key, if you have already been checking off tasks in the previous IP you can retain the completed tasks as part of the current data. The system gives you a number of options by displaying the following menu:

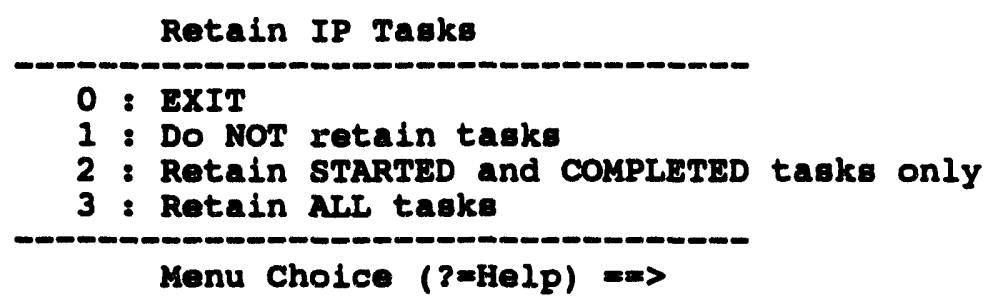

Select an option based on your current situation:

0. EXIT. Exit the current menu.

1. Do NOT retain tasks. In this case the IP will be changed to the new IP without retaining any tasks from the previous IP.

Note: If you retain tasks, the newly selected IP will have all the tasks from the previous IP. These tasks will remain in the new IP until removed in planning mode or overwritten by an archived IP.

2: $\quad$ Retain STARTED and COMPLETED tasks only. The started and completed tasks are merged with the tasks of the newly selected IP for each Emergency Management category. Example: When an event occurs, you can select this option, so that the tasks in progress and completed IP tasks remain as a part of the overall preparation for and response to the event. Be sure that the new IP has sufficient space for the number of tasks being retained. The current limit is 99 tasks. If there is not enough space for all the tasks, no tasks will be retained.

Note: If tasks are not retained, resetting the IP later will have unpredictable results on the Resource data. If this happens, use the Reset IP option to restore the Resource Management data to its original state.

3: Retain ALL tasks. All tasks, completed or incomplete, are merged with the tasks of the newly selected IP for each Emergency Management category.

\section{Set IP Base TIme}

Finally, you will need to set a base time for your IP. In planning mode, planners create an IP based on delta times from an event. When this IP is selected for use in operational mode, it is up to the person selecting the IP to input an appropriate base event time. This time can be when people are supposed to begin work on the plan; it can be when an event occurs; it can be the current time. It is left to the user to decide what is appropriate. Pre-event and post-event times will be based on this time and the delta task times specified in planning mode. 
When the new base time is specified, all tasks in the IP will be changed relative to this new base time.

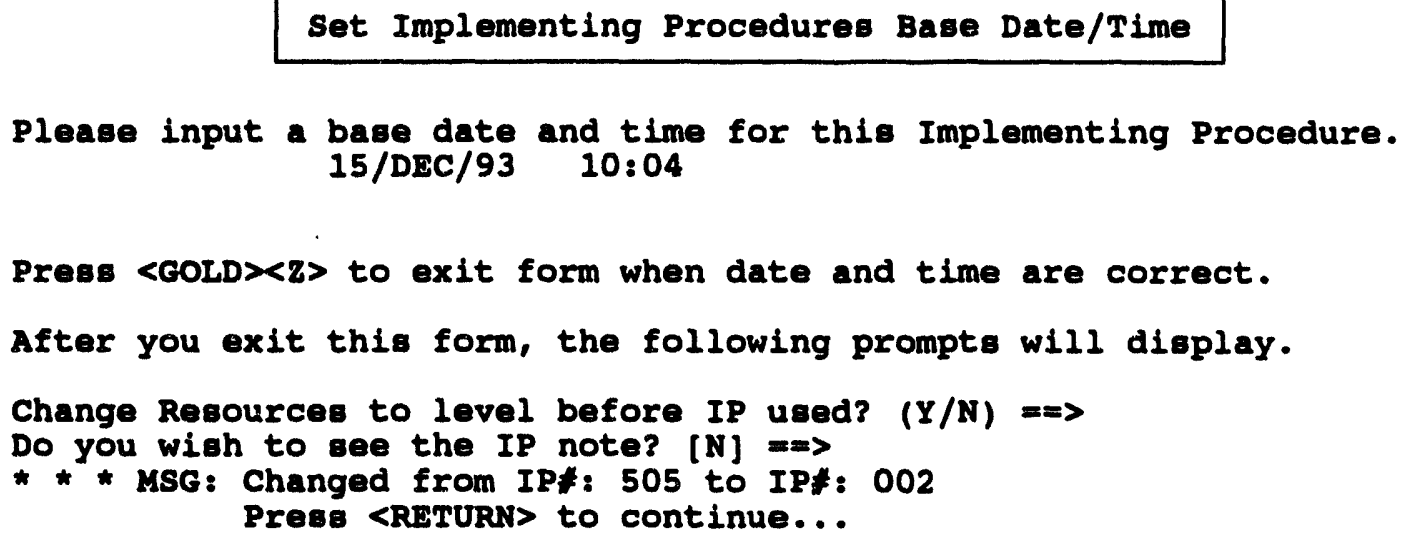

Note: This method can only be used if pre-planning has linked D2 cases with IP scenarios. See Section 11, Emengency Activities, HAZARD ANALYSIS, EXECUTE D2 for more information on scenario tables.

\section{Choose IP by SEARCH FOR IP CRITERIA}

The following method for selecting a new IP is based on using information from the current onpost Work Plan. This IP selection method is also accessible through CHANGE ONPOST WORK PLAN. It is expected that you will use this method most frequently to select the IP. An alternative method for selecting the IP based on Emergency Planning Zones (EPZs) is described under EMERGENCY FUNCTIONSDIRECTION/CONTROL.

If no actual event has occurred, you will be using the pre-event IP tasks based on the Work Plan for the day. (It is expected that information about the day's Work Plan will be obtained from onpost sources such as the work plan report.) If an event occurs, the system defaults to the related post-event IP tasks, which is based on the Work Plan.

\section{Identify Appropriate D2 Cases}

You will see the following D2 Track Qualification screen for describing the current chemical and weather situation for a D2 model track. This screen contains fields that serve as search criteria for identifying D2 cases that match or approximate the release situation described in the fields. Information from the Work Plan screen (when the information is available) automatically appears in the corresponding fields of the D2 Track Qualification screen. (See the Work Plan screen)

You can modify the fields, which are used as search keys into the D2 cases included in the scenario table:

- The default tolerances for wind direction, wind speed, and agent quantity are displayed. You can change these values for this particular search. 
- You can remove one or more criteria from the search by leaving blank the text fields (agent, munition, release type, stability class) or by entering a negative one $(-1)$ in the numeric fields. If all fields are removed from the search, you must then select one case from a list of all D2 cases in the scenario table.

- If any criteria are used, the IBS compares these case input criteria with D2 cases in the scenario table. (If no perfect matches can be found, the IBS displays a message to indicate how many criteria were actually matched.) You must then select from a list of D2 cases that match the greatest number of criteria (see the next screen).

- If no cases match the specified criteria, you will see this message:

SORRY: THERE WERE NO EXACT MATCHES.

O CRITERIAL MATCHED.

PRESS <RETURN> TO CONTINUE...

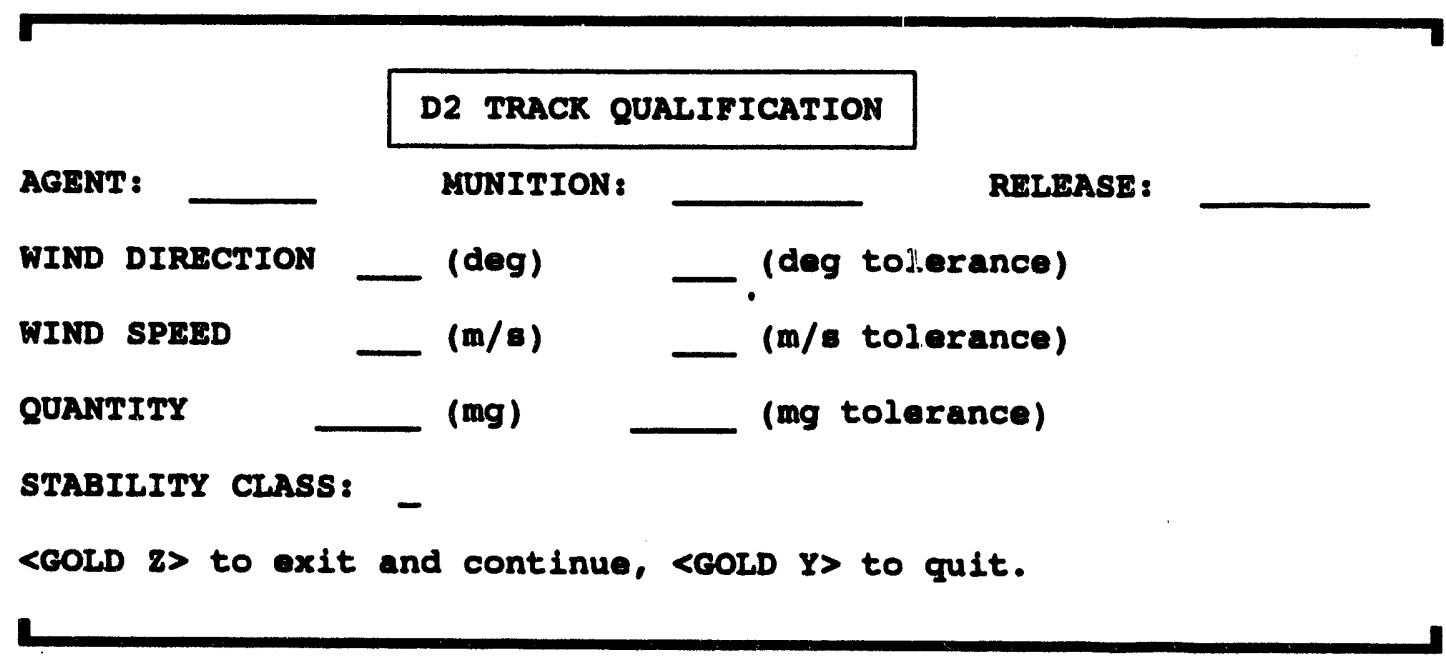

\section{Select from a List of Identfified D2 Cases}

If the search identifies a set of possible D2 cases, a screen similar to the following one lists the cases (in numerical order by $D 2$ case number).

If the cases are too many to fit on one screen, you can scroll through the remaining case descriptions by entering a key command at the Select Case $\#:$ prompt $(U, U \#, D$, D\#, T, B). (Or enter $\mathbf{H}$ to switch the heading display to show the D2 case description instead of the D2 case qualifications shown here.)

To select a case, enter the case number at the Select desired IBS D2 Case: prompt. The next step is to actually choose an IP that contains the selected D2 case. 


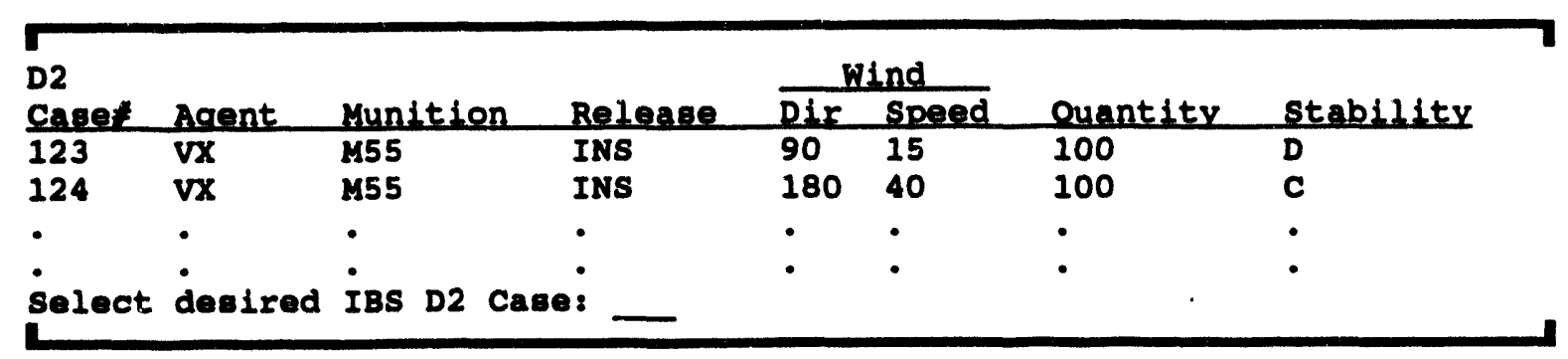

\section{Select the IP You Want}

After you select a D2 case, a screen similar to the following one lists the IPs that contain that case. If more than one IP is associated with the selected D2 case, use the evacuation case, population and description to decide which IP to select.

If the IPs are too many to fit on one screen, you can scroll through the remaining IP descriptions by entering a key command at the Select desired IP: prompt (U, U\#, D, D\#, $\mathbf{T}, \mathbf{B})$. (Or enter $\mathbf{H}$ to switch the heading display to show a longer D2 case description line instead of the case numbers and population patterns shown here.)

To select an IP, enter the IP number.

\begin{tabular}{lllll} 
IP & EVAC & D2 & Population & Degcription \\
\hline 008 & 222 & 123 & Seasonal & Firet day of Hunting season \\
009 & 400 & 123 & Weeknight & Nighttime \\
010 & 401 & 123 & Neekday & Regular Day \\
- & & &
\end{tabular}

After selecting a new IP, the only remaining step is to choose whether to retain completed tasks from the previous IP. If you reselect the current IP you will be returned to the Status Board menu without any changes being made.

\section{Choose Whether to Retain Completed Tasks from the Previous IP}

This option is the same as described in Select IP by NUMBER.

\section{Set IP Base Time}

This option is the same as described in Select IP by NUMBER.

This concludes the process of selecting an IP in operational mode, which is initiated by choosing the Select IP from the Status Board menu. 


\section{Selecting an IP in Planning Mode}

Following is a discussion of selecting an IP in planning mode.

If you select Select IP in plan mode, a list of all the possible IPs in your planning database is displayed.

\begin{tabular}{|cc|}
\hline IP & DESCRIPTION \\
\hline 1 & One line description of IP 1 \\
7 & One line description of IP 7 \\
8 & One line description of IP 8 \\
$:$ & $\vdots$ \\
\hline
\end{tabular}

Select desired IP:

You can select a number from the list or press GOLD-Y to escape IP selection. In planning mode you do not have the option of selecting an IP by searching the scenario table. It is also not possible to retain tasks from the previous IP. Planning mode uses delta times from the start of a hypothetical event, so you need not specify a base date and time as you would in operational mode.

\section{ID SELECT ONPOST ACTIVITY * and VIEW ONPOST ACTIVITY}

Note: To enable general users to view onpost activity, you must first use SELECT ONPOST ACTIVIV to make the information available to everyone else.

Using SELECT ONPOST ACTIVITY, those with Information Manager privileges can view and modify the current work plan description, declare an event, and select an IP based on the current Work Plan.

Eoth SELECT ONPOST ACTIVITY and VIEW ONPOST ACTIVITY display information from the current Work Plan as shown in the following procedures.

\section{Viewing a.. Onpost Activity}

To view the current Work Plan, select VIEW ONPOST ACTIVITY. This option enables general users to view the current Work Plan description. 


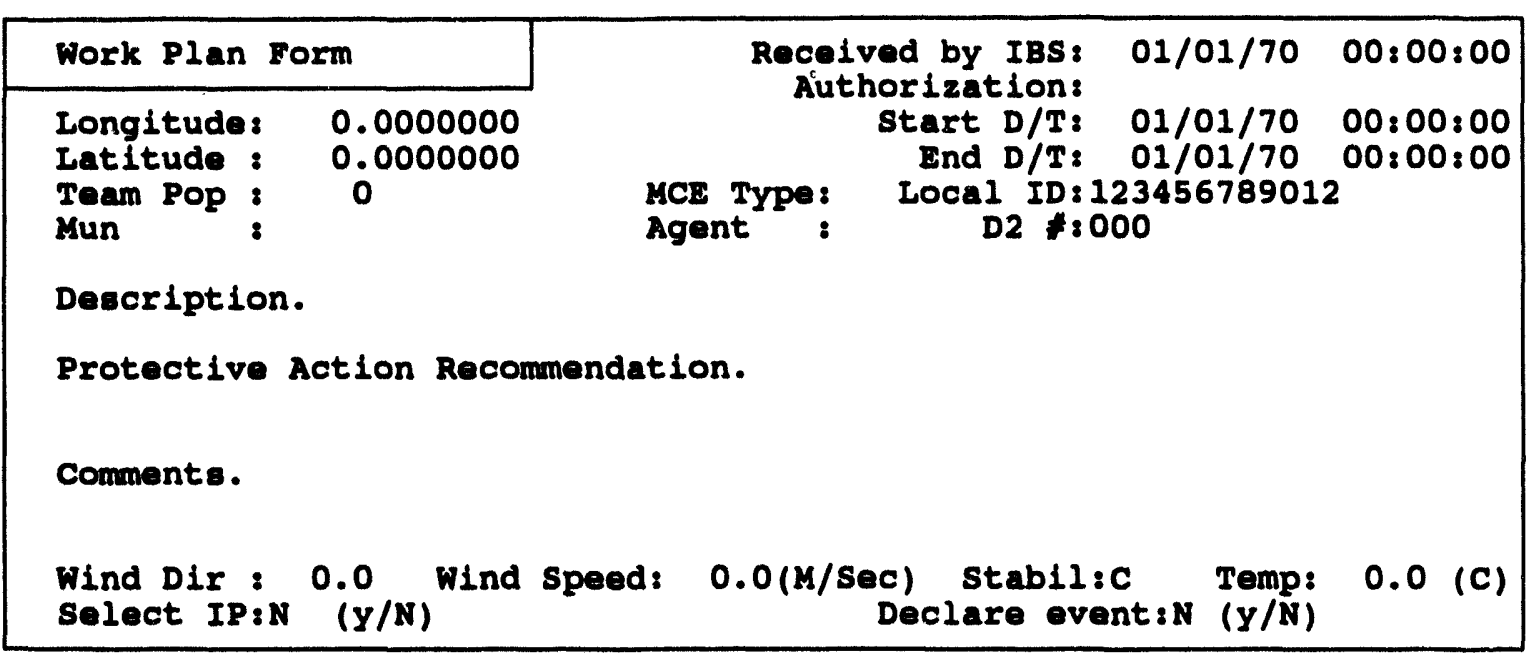

To exit the Work Plan, press GOLD Y.

\section{Selecting an Onpost Activity}

Use SELECT ONPOST ACTIVITY to display and edit the onpost work plan. Once you have done this the work plan is available for other IBS users to view using the VIEW ONPOST ACTIVITY option.

Note: You must have the appropriate privileges to use this function.

If you have the privilege to use this function, the following prompt will display:

Use onpost work plan? $(Y / N)[Y]=m$

If you type an $N$ (No) to this prompt, no updates will be made to the work plan, and the system will display the following prompt:

Use latest met data? $(Y / N)[Y]=\equiv$

After you select the desired met data the main Work Plan form will display for manual editing.

If you type $Y$ (Yes) or press the Return key, the following menu will display before the WORK PLAN:

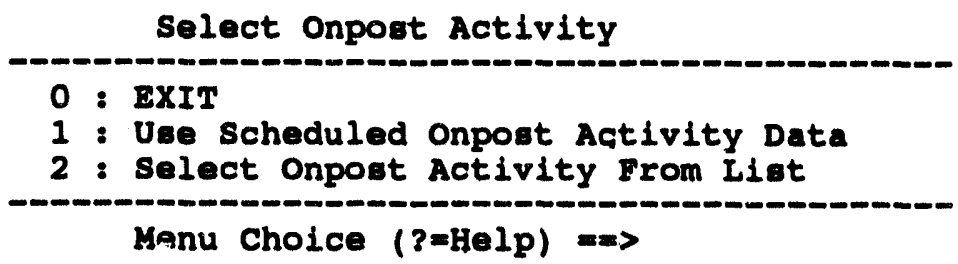


1 : Use Scheduled Onpost Activity Data - if you select option 1, the work plan will be filled in with the work plan information sent by the post for the current time period. This information includes:

- The chemical agent being handled

- The type of munition

- A location

- A one-line description

If no new data from the post exists, the system will display error messages similar to the following.

* * ERR: 29 Opening flle OFFSFROMDIR: MORRPLAN. DAT

Preve <RETURN> to continue...

2 : Select Onpost Activity From List - if you select option 2, you can select an onpost work plan activity from a list of onpost work plan data.

Regardless of which option you select, the following prompt will display.

Uee latest met data? $(Y / N)[Y]=$

Type an $N$ (No) to leave the current met information in the work plan display. Type a $Y$ (Yes) to update the work plan with the most recent met data. If no met data exists, the system will display an error message.

Once the onpost data has been used to update the Work Plan, the Work Plan form will display for any manual updating you want to perform.

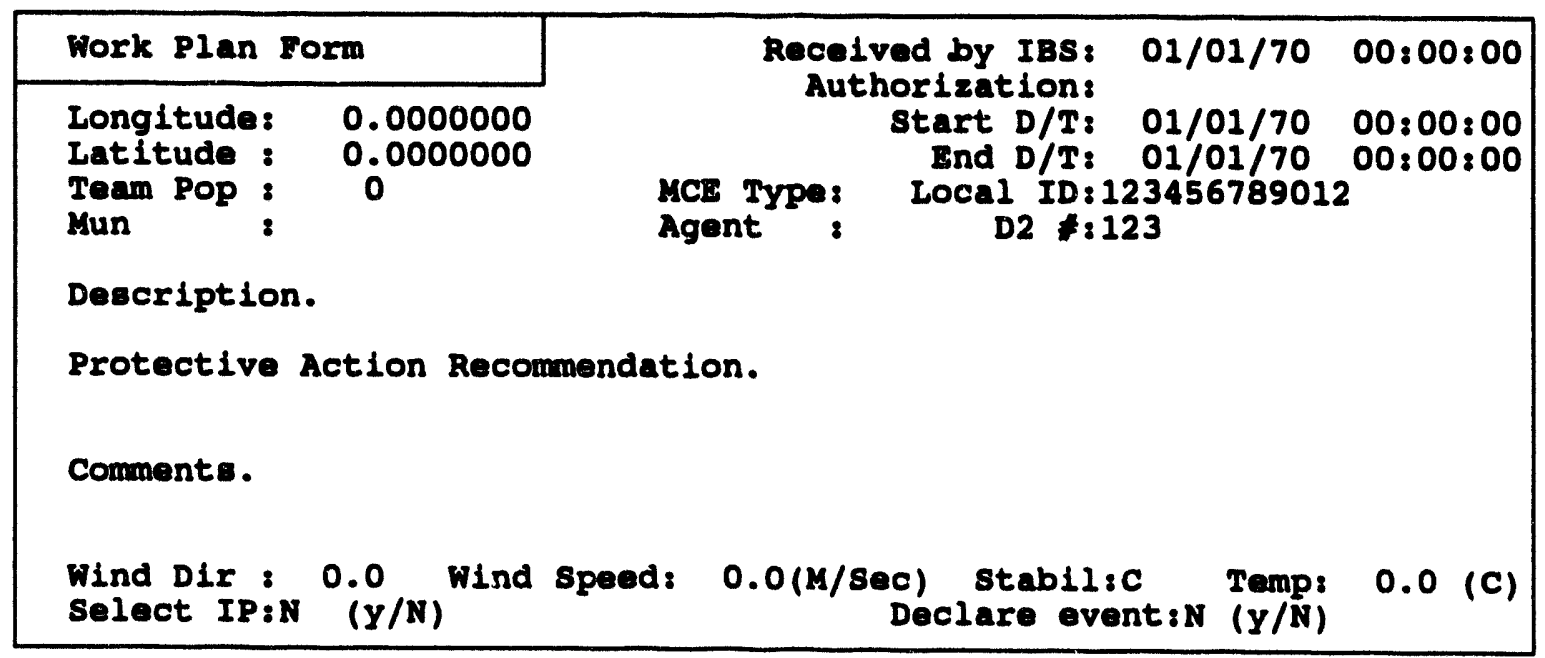

Only those with Information Manager privileges can modify the following information on the Work Plan form. 
- Work Plan: Information from the onpost work plan report or the most recent version of the work plan (edited by the Information Manager) is displayed automatically in the upper part of the form.

- Meteorological Data: In the lower part of the form, you can enter metcorological data from whatever data sources are available.

- Select IP: If you wish to use the Work Plan data as the basis for selecting an IP, enter $\mathbf{Y}$. A response of $\mathbf{N}$ simply saves the form data for the current Work Plan.

If you choose to select a new IP, you can do so by selecting an IP number or by searching for scenarios that closely match the current situation, based on the current Work Plan. This method is described in detail under STATUS BOARD-SELECT IP.

An alternative method for selecting the IP based on Emergency Planning Zones (EPZs) is described in Section 11, Emergency Activities, DIAECTION/CONTROL.

- Declare event?: A Y answer declares an event and notifies IBS users by displaying a message at the bottom of their terminal screens.

After altering the Work Plan form, press GOLD Y to save and exit the form.

The system then displays the following sequence of menus and messages. Enter your choice of options for the work plan headers.

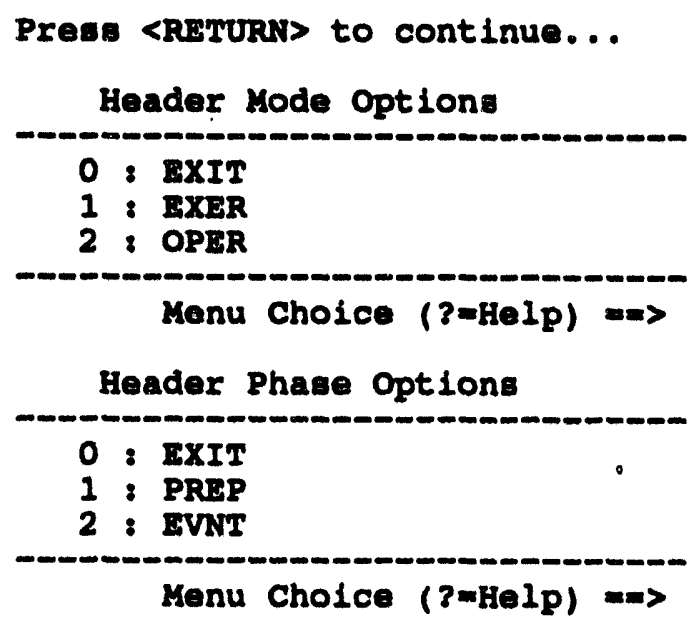




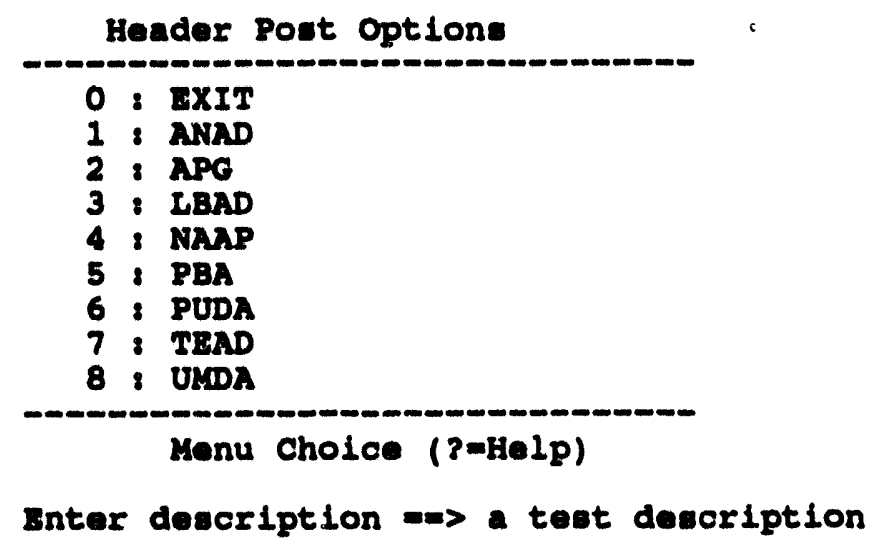

After you enter the text description and press the Return key, the system will display the headers you have chosen for the new work plan.

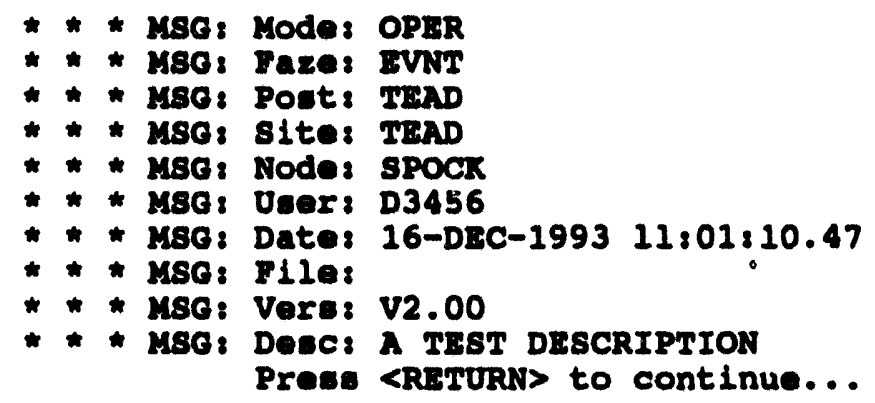

The system then displays the Notification Form, taken from the onpost work plan. Modify this form as needed.

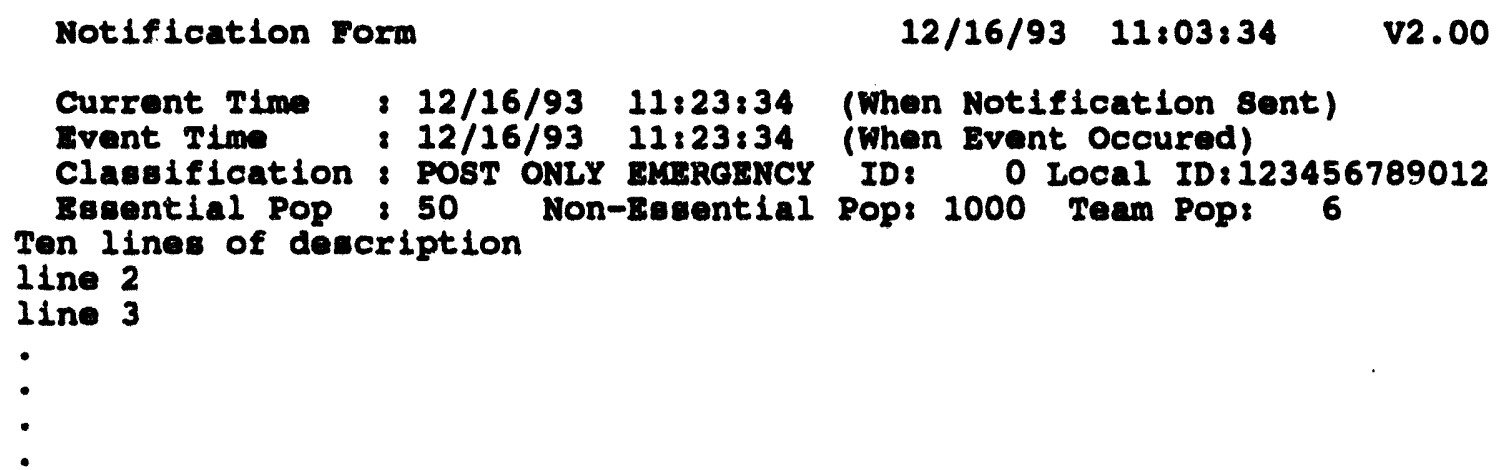

Exit the form by pressing GOLD Y. The system displays the following message: select IP? $(Y / N)[N]=\infty$

A notification will display on screen when an event has been declared.

If an event is already under way, a different inquiry displays on the form: Declare event over?. In that case, a $Y$ answer declares the event over and notifies IBS users 
the event is finished. When an event is declared over, the system will display a sequence of messages similar to the following.

The event has been declared over. Following is a list of things you may wish to consider:

1) It 1s STRONGLY suggested that you archive the operational site by using BACKUP/RESTORE SITE DATA from the setup menu.

2) If you wish to restore your IP to its pre-event status, you should retrieve the previously archived copy. On the other hand, if you wiah to incorporate changes made to the IP during the event, you should archive your current IP. You may also wish to reset your current IP.

3) You should verify that your IP, D2 dispersion case, and evacuation case reflect current conditions.

4) You should verify that the onpost work plan reflects current conditions.

5) You may wish to delete the people location database and make all shelters inactive by typing DELPTDB at the command line prompt.

6) You may wish to restart the IBS loge by typing NEWLOG at the command line prompt.

Press <RETURW> to continue ...

select IP? $(Y / N)$ [N] $m=>$

Press the Return key to send the new work plan to the onpost system.

\section{SHOW USER ENVIRONMENT}

The SHOW USER ENVIRONMENT option is used by planners who want to view their current operating environment. This option displays a report similar to the following examples.

\section{Planning Mode}

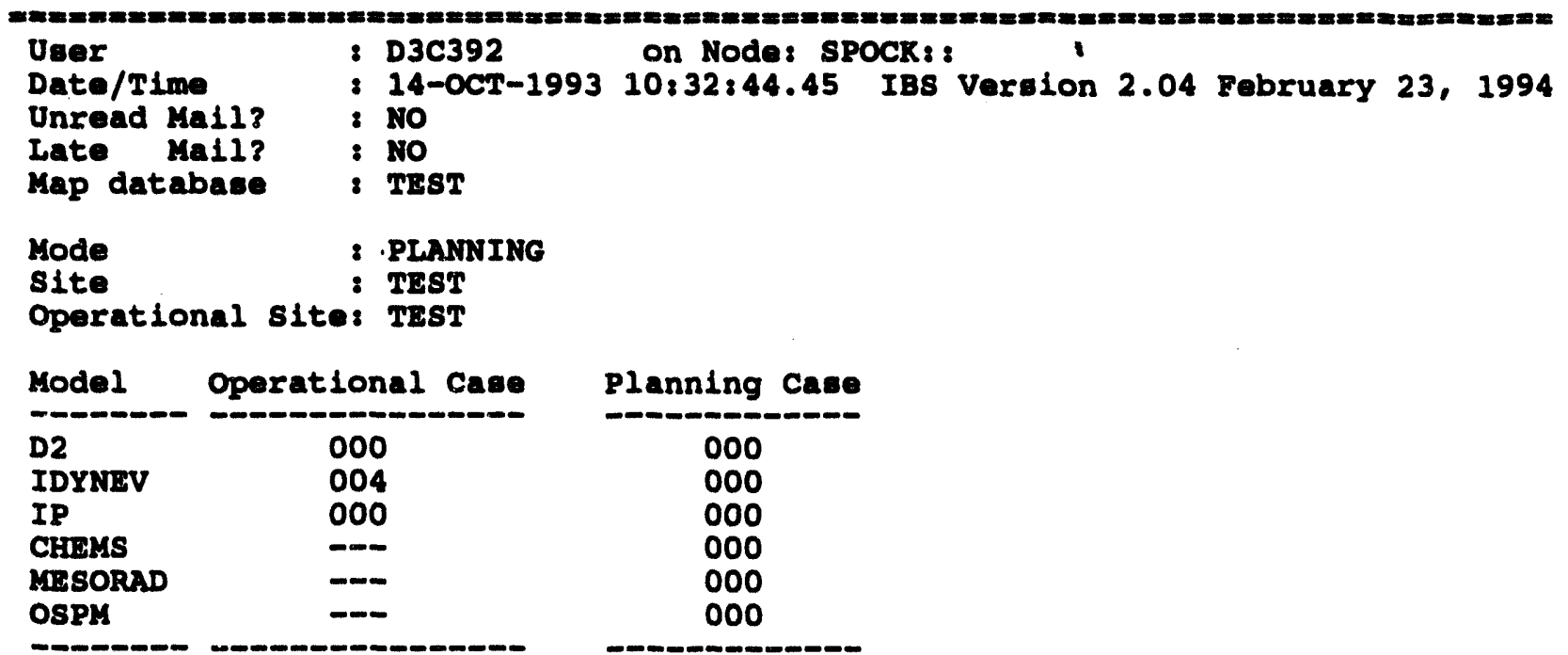

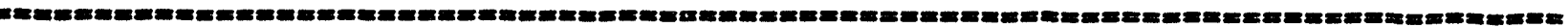

End of Report: <Return>=Continue, <Ctrl-2>=Exit, M=Redirect... 


\section{Operational Mode - Event Not Declared}

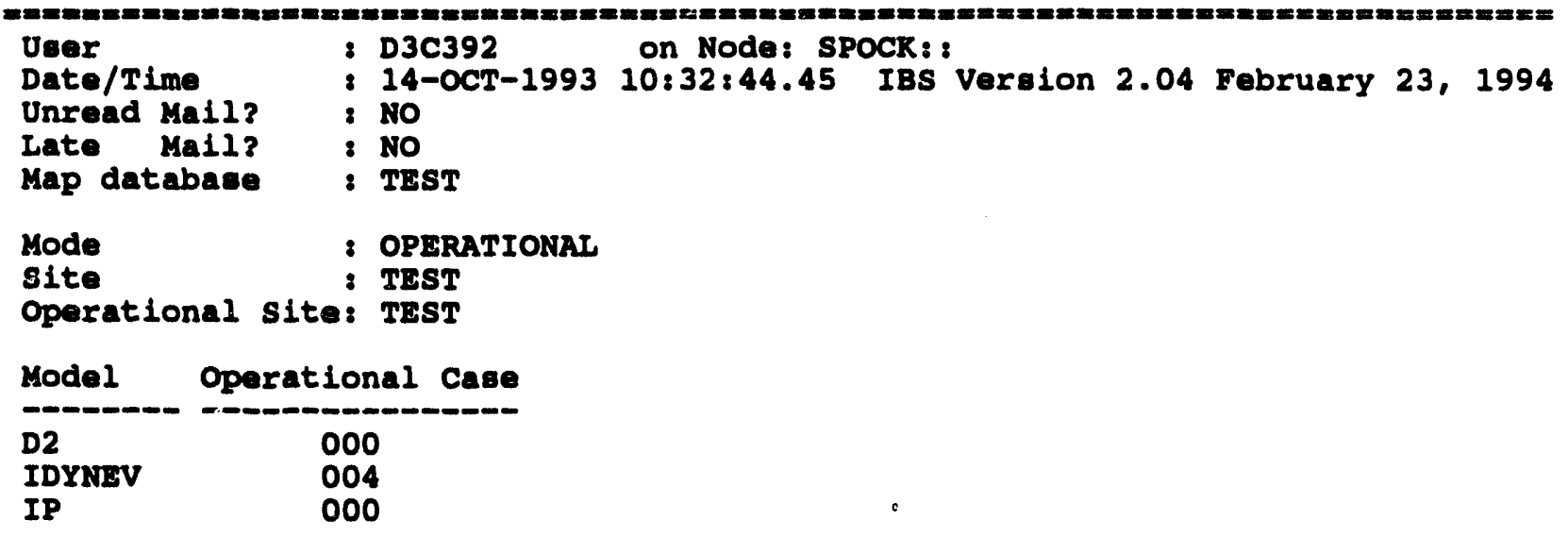

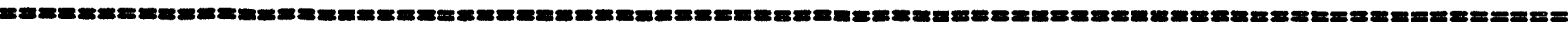
End of Report: <Return>mContinue, <Ctrl-z>=Exit, $M=$ Redirect...

Operational Mode - Event Declared

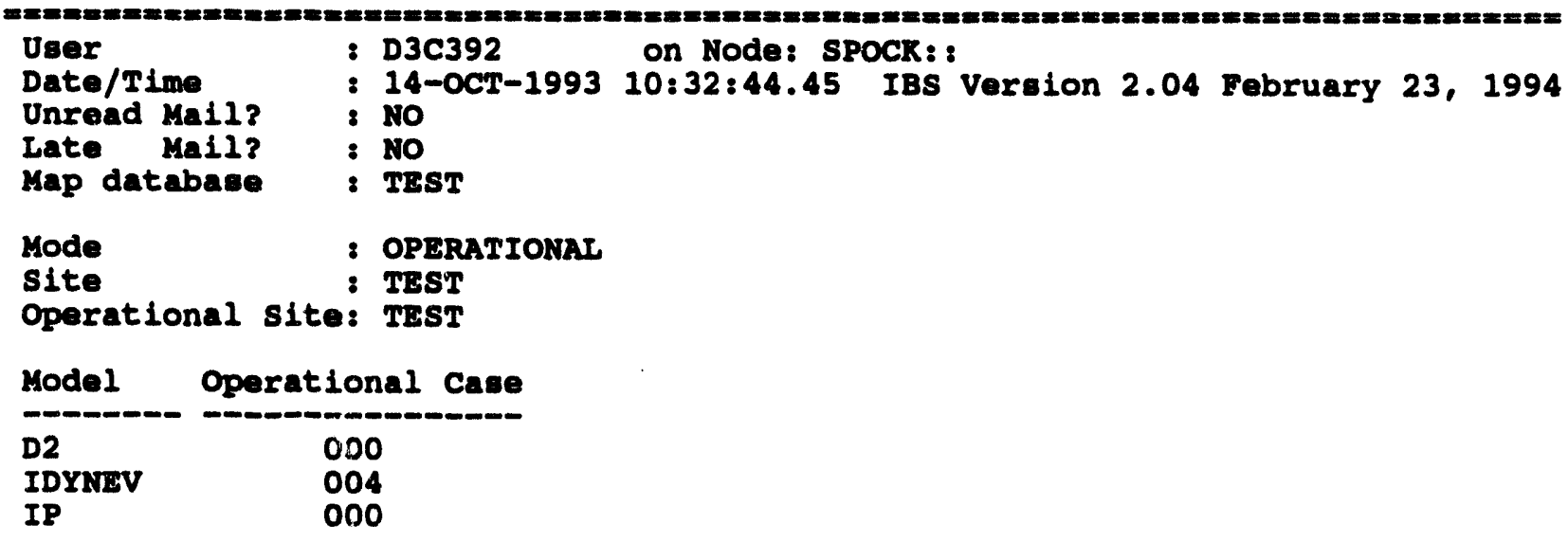

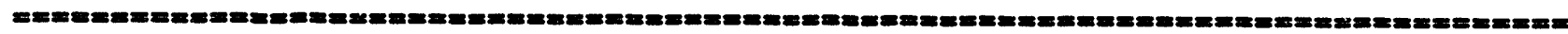
End of Report: <Return>mContinue, <Ctrl-z>=Exit, M=Redirect...

This option is useful for planners who want to check whether they are in planning or operational mode, and which cases they are using. 


\section{VALIDATE IP}

This option enables the system to determine if there are sufficient Resources and Personnel to perform the current IP. It can also display locations at which the plume may have arrived before the tasks are scheduled to complete.

Note: This function can be time consuming: if the IP is detailed and complex, it could take several minutes to perform a validation.

This option displays the following prompt:

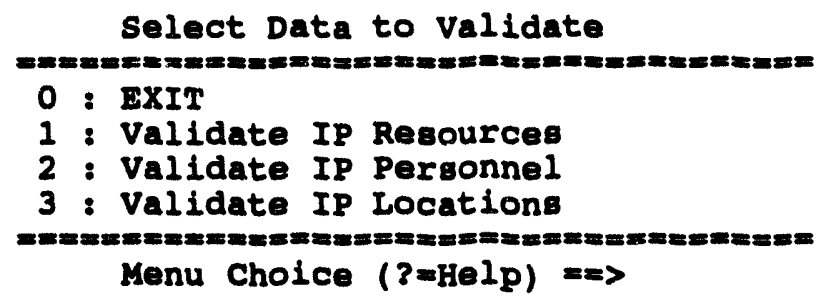

Select the types of data you want to validate. You can make more than one selection, a marker $=>$ will display beside your selections. After you have selected the options, type a $O$ (Exit) and press the Return key.

Validating resources creates a report that lists all tasks that require more resources at a location than are (or would be) available if the IP was executed exactly as designed.

Validating personnel creates a report that lists all positions for which demands for personnel are greater than the number of personnel. This can be calculated either on all personnel, or just those personnel who are on duty.

Validating locations creates a report that lists locations where the plume from the current D2 case may have arrived before the tasks requiring that location are scheduled to complete.

If you selected to validate Personnel, the following additional prompt will display.

On Duty personnel only? $(Y / N)=\infty$

Type a $Y$ (Yes) to validate the IP against all available personnel who would (according to the schedule information in the personnel records) be working at the time each task starts, given that the Event occurs at a time you specify. It will not take into account that more personnel may be called in to work, or that others will work overtime.

Type an $N$ (No) to validate the IP against all personnel, ignoring whether or not they are actually on duty. You may wish to use some combination of the reports to determine if enough personnel are available - such as only using the On Duty personnel report for the first hour after an IP is started. 
If you entered $I^{\prime}$ is to the prompt, the following form will display. Set the base Event time to use. Enter the date and time in the fields provided (use a 24 hour clock for the time). This date and time is important, if the event occurs at 1:00 on a Sunday morning, you are (probably) less likely to have sufficient personnel to perform all the required tasks.

\section{Enter a Date/Time}

Please input a base date and timo 23/SEP/93 11:30

Preme $<G O L D<r 2>$ to exit form when date and time are correct.

If you seiected to validate Locations, you will receive the additional prompt:

Check only Point: within Riak Area? (Y/N/<Ctrl-z>=Abort) $=\Rightarrow$

This enables you to select whether or not to check all points around the source of the plume, or only points that fall in the currently selected risk area.

The IP will then be stepped through, performing resource adjustments, personnel requirements, and location crecks as required. A report will be printed indicating problems, the contents will depend on what types you selected. The following report is an example of all types:

Validate IP 012

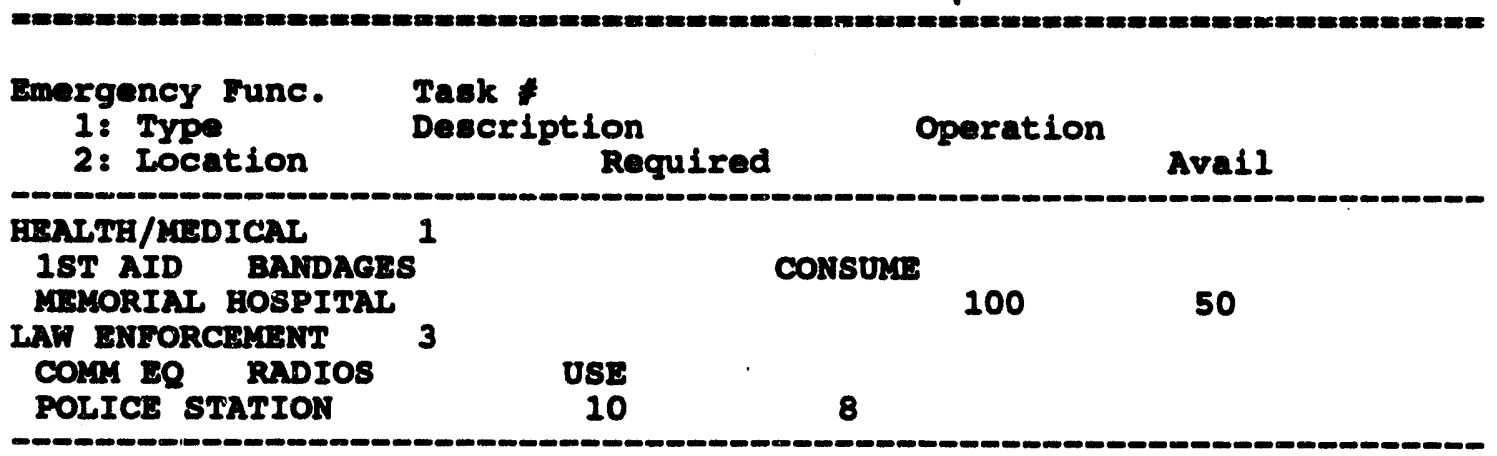

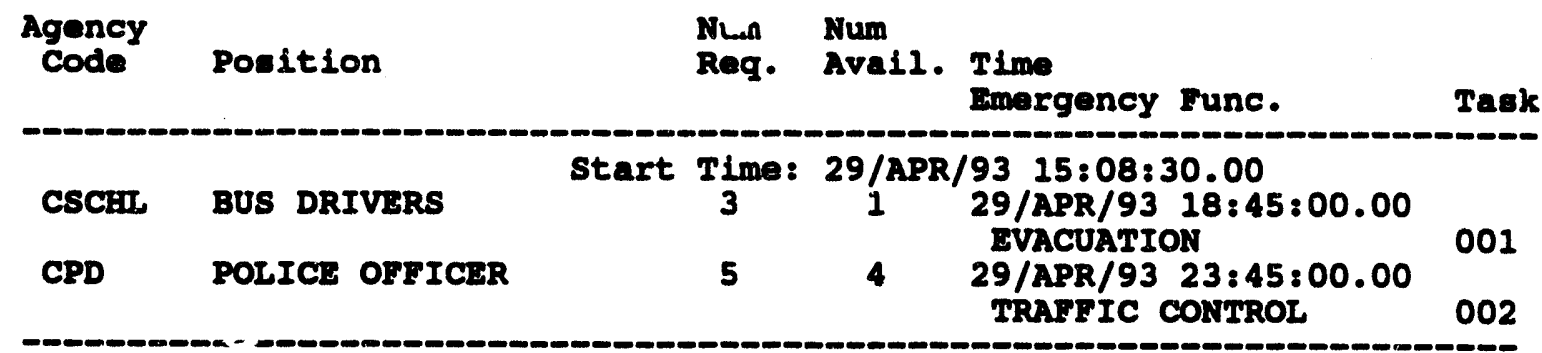


Emergency Func. Task * Res/Act *\# Possibly Unsafe Location

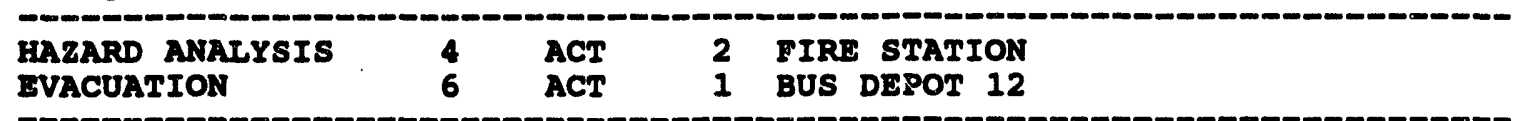

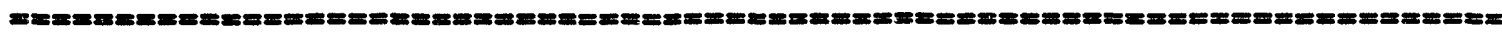
Find of Report: <Return> to continue, $M$ to change destination...

The sample report shows that there are insufficient bandages and radios for this IP, insufficient Bus Drivers and Police Officers to perform tasks at the shown times, and that the plume may reach the fire station and bus depot 12 before all tasks are completed there.

If the report did not use only On Duty personnel, the report would not indicate a time. Using all possible personnel, the report would list requirements that are more than available personnel.

\section{VIEW BATCH LOG}

The VIEW BATCH LOG option is used by planners who want to view the batch log file generated by the Event program. This can be useful after an event for planning purposes. The batch log will be similar to the following sample (an actual batch log can be considerably larger).

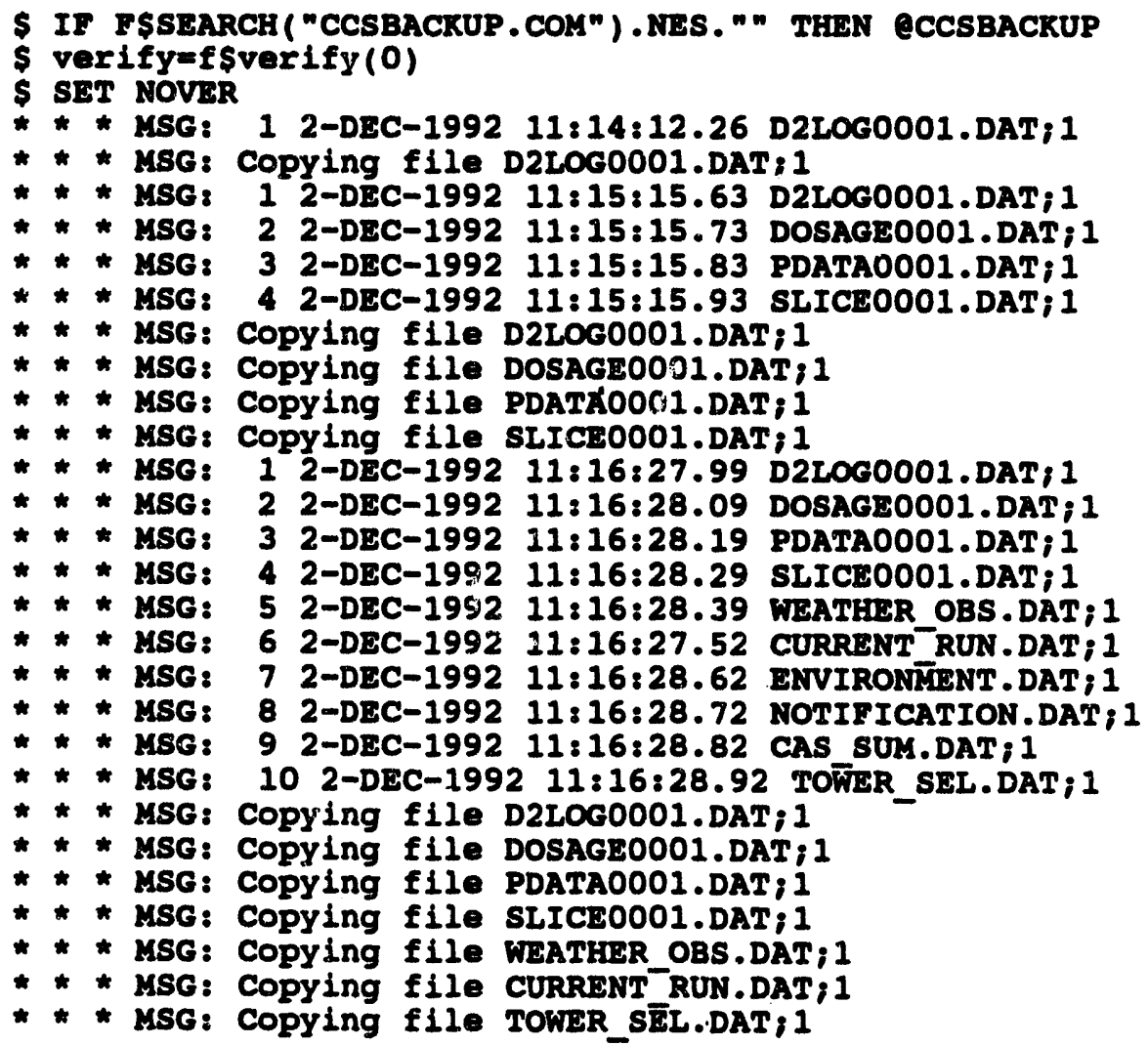


Accounting information: Buffered I/O count:

Direct $I / O$ count:

Page faulte:

Charged CPU times

3955

$0 \quad 00: 08: 22.37$

Peak working set size: 2454

Peak page file size: 48183

<Return> to continue...

Mounted volumes:

Elapeed time: 0 07:32:44.70

\section{VIEW ONPOST WORK PLAN}

(See CHANGE ONPOST WOAK PLAN) 
○

Howobeuew jounosiod - uopoes 


\section{Section 4 \\ Personnel Management}

\section{PERSONNEL MANAGEMENT}

\begin{tabular}{|c|c|c|c|}
\hline \multicolumn{2}{|c|}{$\begin{array}{l}\text { IBS MAIN MENU } \\
\text { PERSONNEL MANAGEMENT }\end{array}$} & & \multirow[t]{2}{*}{$\begin{array}{l}\text { PERSONNEL MANAGEMENT presents this } \\
\text { menu of capabilities for managing the CSEPP } \\
\text { personnel database. The personnel database } \\
\text { includes the names, addresses, agencies, } \\
\text { positions (such as a job title or assignment), } \\
\text { and telephone contact numbers of people who } \\
\text { are involved with emergency management } \\
\text { activities. }\end{array}$} \\
\hline $\begin{array}{l}\text { MESSAG } \\
\text { STATUS }\end{array}$ & $\begin{array}{l}\text { DARD } \\
\text { RD }\end{array}$ & & \\
\hline $\begin{array}{l}\text { ADD } \\
\text { MODIFY } \\
\text { DELETE } \\
\text { UST }\end{array}$ & $\begin{array}{l}\text { AGENCIES } \\
\text { AGENCIES } \\
\text { AGENCIES } \\
\text { AGENCIES }\end{array}$ & $\begin{array}{l}<- \\
<- \\
<-- \\
<-\end{array}$ & $\begin{array}{l}\text { Add to list of agencies in the database. } \\
\text { Modify list of agencies in the database. } \\
\text { Delete list of agencies in the database. } \\
\text { List the agencies in the database. }\end{array}$ \\
\hline $\begin{array}{l}\text { ADD } \\
\text { MODIFY } \\
\text { DELETE } \\
\text { LST }\end{array}$ & $\begin{array}{l}\text { POSITIONS } \\
\text { POSITIONS } \\
\text { POSITIONS } \\
\text { POSITIONS }\end{array}$ & $\begin{array}{l}<-- \\
<-- \\
<-- \\
<-\end{array}$ & $\begin{array}{l}\text { Add to list of positions at agencies. } \\
\text { Modify list of positions at agencies. } \\
\text { Delete list of positions at agencies. } \\
\text { List positions (assignments) at agencies. }\end{array}$ \\
\hline $\begin{array}{l}\text { ADD } \\
\text { MODIFY } \\
\text { DELETE } \\
\text { LST } \\
\text { UST } \\
\text { UST }\end{array}$ & $\begin{array}{l}\text { PEOPLE } \\
\text { PEOPLE } \\
\text { PEOPLE } \\
\text { PEOPLE BY NAME } \\
\text { PEOPLE BY AGENCY } \\
\text { PEOPLE BY POSITION }\end{array}$ & $\begin{array}{l}<- \\
<- \\
<-- \\
<-- \\
<-- \\
<--\end{array}$ & $\begin{array}{l}\text { Fill in new information form for one person. } \\
\text { Modify information form for one person. } \\
\text { Delete information form for one person. } \\
\text { List info for personnel selected by name. } \\
\text { List personnel at a specific agency. } \\
\text { List personnel by position (assignment). }\end{array}$ \\
\hline
\end{tabular}


The PERSONNEL MANAGEMENT menu options are explained on the following pages in alphabetical order within three general categories:
- Agency Tasks
- People Tasks
- Pasition Tasks

\section{Agency Tasks}

Different agencies or organizations employ personnel involved in emergencyrelated activities. The IBS agency lookup table is a list of agency acronyms and the associated agency names. The listing looks similar to the following example.

$\begin{array}{ll}\text { Code } & \text { Agency Name } \\ \text { NES } & \text { NATIONAL FOREST SERVICE } \\ \text { PEL } & \text { PACIFIC NORTHWEST LABORATORY } \\ \text { OEM } & \text { FEDERAL EMERGENCY MANAGEMENT AGENCY } \\ \text { OREGON EMERGENCY MANAGEMENT } & \end{array}$

The agency lookup table is used throughout Personnel Management and Resource Management, and also in the Implementing Procedures.

The complete list of options available in Personnel Management for using the agency lookup table are:
- ADD AGENCIES
- MODIFY AGENCIES
- DELETE AGENCIES
- LIST AGENCIES

Any IBS user can look at the table by using the LST AGENCIES option, but only a user with the appropriate privileges can change the contents of the table, either through ADD AGENCIES, MODIFY AGENCIES, or DELETE AGENCIES. 


\section{ADD AGENCIES *}

This option enables a user with the appropriate privileges to add information to the agency lookup table.

The system prompts:

Enter new Agency code $==>$

1. Enter the acronym for the agency (or press Gold $Z$ to quit).

You are restricted to only five characters, so you may need to truncate the acronym. If that acronym is already in the lookup table, you must try again.

The system prompts:

Enter new Agency name $=2$

2. Enter the full name of the agency.

You are restricted to 64 characters, so once again, you may need to truncate your input. If that name is already in the lookup table, you must try again.

After the new agency code and name information are saved, the system returns to Step 1 and prompts you again. Use GOLD-Z to exit the prompt when you are finished.

\section{IDDELTE AGENCIES *}

This option enables a user with the appropriate privileges to delete information from the agency lookup table. The system displays the Agency Selection method menu as described in Modify Agencies. Use the menu in the same way as in MODIFY AGENCIES to choose the agencies you want to delete.

The system will then prompt:

Delete agency: (agency code) $(Y / N)[N]=m$

Enter $Y$ (Yes) to delete the agency.

\section{$\square$ MODIFY AGENCIES *}

This option enables a user with the appropriate privileges to modify information already in the agency lookup table. This consists of 1) specifying which agency (by code or by name) and 2) entering a new agency code and name. 


\section{Specify Which Agency to Modify}

If your default selection method is none, the system will display the following menu:

Agency selection method menu
0: ExIT
1: Type in Agency code
2: Select Agency code from a list
3: Type in Agency name
4: Select Agency name from a $118 t$
Menu Cholce $(?=\mathrm{Help})=\infty$

Note: If you have a prior default selection method set up, you will see one of the following four prompts instead of the Selection method menu.

Use one of these four methods to select an agency to modify:

1. Type in Agency code: Prompts you to enter the agency code (up to five characters).

\section{Enter Agency code $=2$}

Enter the acronym for the agency you wish to modify, or Gold $Z$ to exit. If it is not $i$ the table, you must try again.

2. Select Agency code from a list: Prompts you to choose one agency from a numbered list of agencies (ordered by agency code).

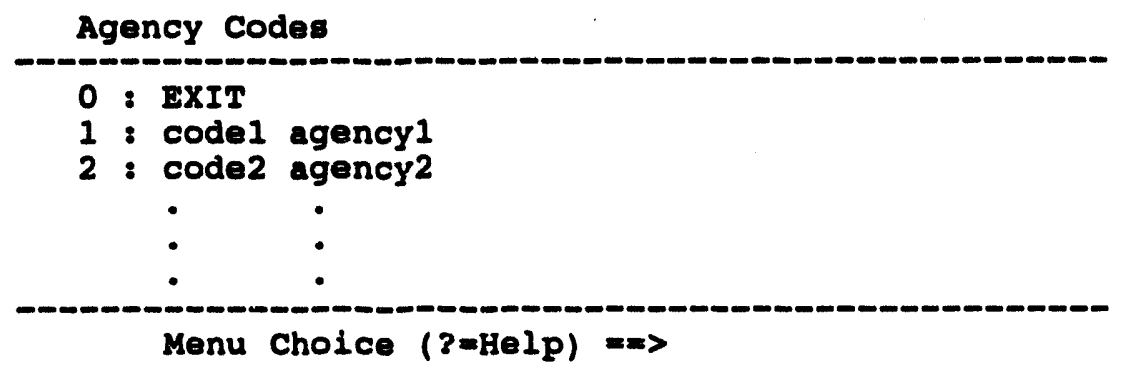

3. Type in Agency name: Prompts you to enter the agency name.

Enter Agency name $=>$

Enter the name of the agency you wish to modify, or Gold $\mathbf{Z}$ to exit. If the name you enter is not in the table, you must try again, or enter a $Q$ (Quit) to display the Agency Selection method menu. 
4. Select Agency name from a list: Prompts you to choose one agency from a numbered list of agencies (ordered by agency name).

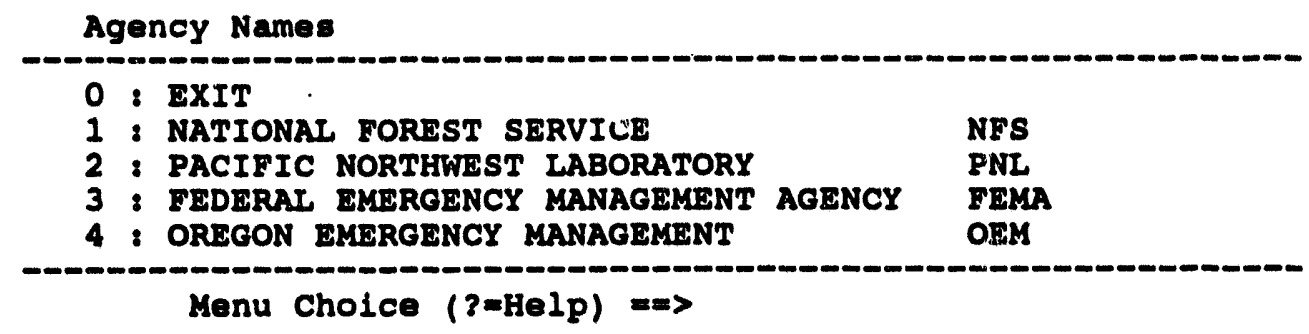

After selecting an agency, you then enter into the actual modification phase.

\section{Modify the Agency (Name and Code)}

The system prompts:

Modify the Agency name? $[Y]=\infty$

You must now decide whether you want to modify the agency code or the agency name - you cannot do both at once.

To change the agency name: Enter $Y$. The system prompts:

Enter new Agency name [Code] $=\equiv$

Enter the full name of the agency. You are restricted to 64 characters, so once again, you may need to truncate your input. If that name is already in the lookup table, you must try again.

To change the agency code: Enter $\mathbf{N}$. The system prompts:

Enter new Agency code $[$ Code] $=>$

Enter the acronym for the agency. You are restricted to only five characters, so you may need to truncate the acro:ym. If that acronym is already in the lookup table, you must try again.

After the modified agency code or name information are saved, the system returns to Step 1 and prompts you again. To exit, select 0 : EXIT from the menu. 


\section{LIST AGENCIES}

This option enables you to list and view the contents of the agency lookup table, one screen at a time.

\section{People Tasks}

The personnel database includes the names, addresses, agencies, positions (such as a job title or assignment), and telephone contact numbers of people who are involved with emergency management activities.

The complete set of Personnel Management options for creating and reviewing this information for using the position lookup table are:

- ADD PEOPLE

- MODIFY PEOPLE

- DELETE PEOPLE

- LIST PEOPLE BY NAME

- LIST PEOPLE BY AGENCY

- LIST PEOPLE BY POSITION

Any IBS user can look at this information by using the UST PEOPLE BY... options, but only a user with appropriate privileges can change the contents of this information, either through ADD PEOPLE, MODIFY PEOPLE, or DELETE PEOPLE. 


\section{$\square$ ADD PEOPLE *}

ADD PEOPLE displays the following form for entering information about CSEPP personnel:

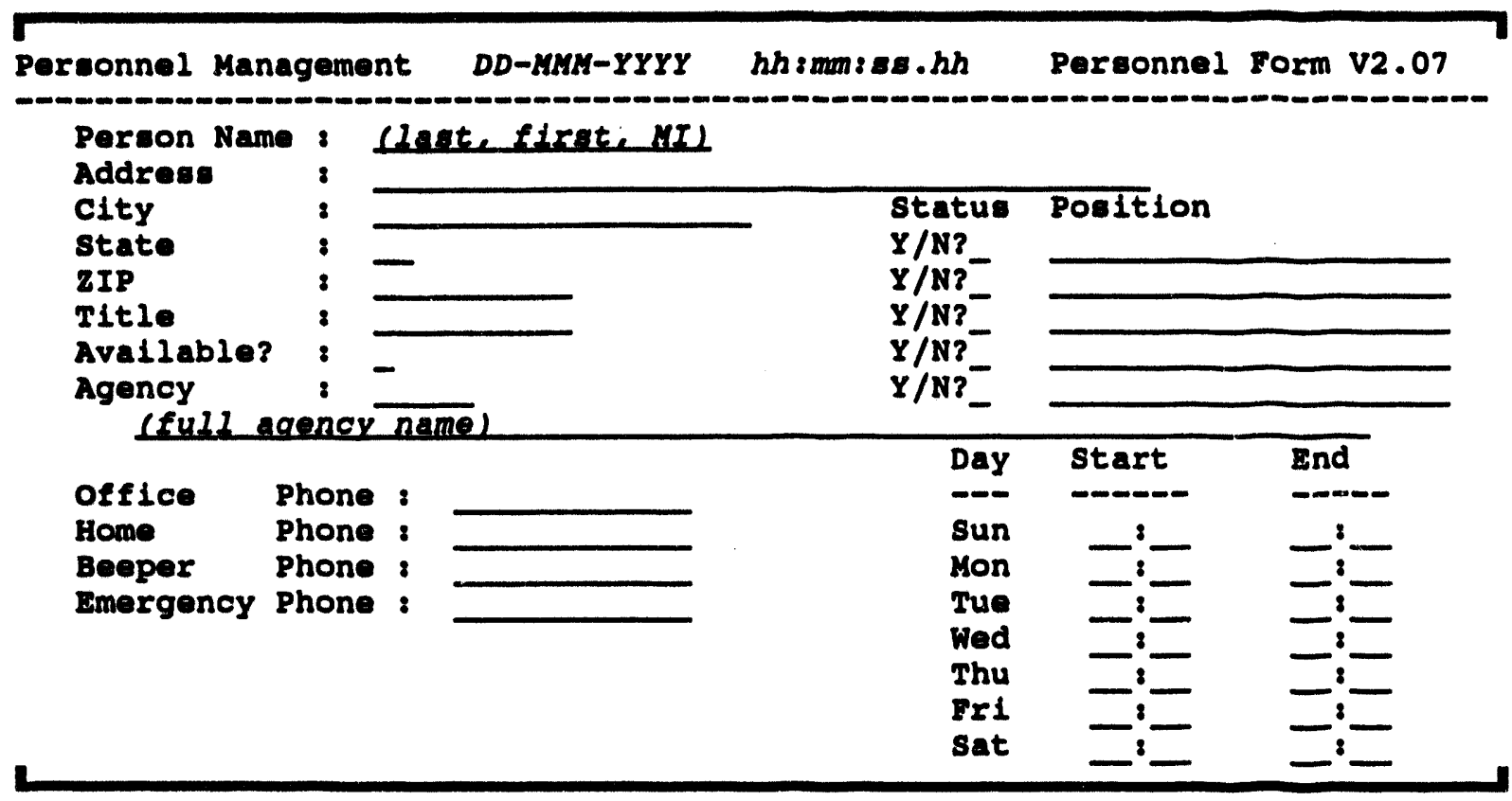

The date and time are the system date and time. You can add information in any of the other fields.

- Avallable? ( $\mathrm{Y}$ or $\mathrm{N}$ ): Is the person available $(\mathrm{Y}$ ) or unavailable for some reason, such as travel. (N). The person must be available to have active status in any of the positions for which the person is qualified.

- Status and Position: $A$ list of up to five position titles can be entered to indicate emergency positions for which the person is qualified. Status indicates whether the person is currently active in the corresponding position ( $\mathrm{Y}$ or $\mathrm{N}$ ).

- Ofince Phone: If the person is the designated contact person for a particular facility, it is expected that the "Office Phone" is the contact phone number included in the facility database. (For more information on the facility database, see RESOURCE MANAGEMENT-ADD FACILITIES.)

- Schedule: The schedule is an area located in the lower right corner of the screen. The schedule is used for indicating the person's scheduled work times for each day of the week. Enter times for a 
24-hour clock; for example, 13:00 is 1 p.m. You can enter the hours for night shift workers as well. For example, if a worker works from 10 p.m. on Monday to 6:00 a.m. Tuesday, enter the times as follows: Monday Begin 22:00 End 06:00. Even though this appears to give a negative amount of hours, the system will take the night shift hours from Monday through Tuesday into account.

Use GOLD-Z to save the information, GOLD-Y to exit without saving. Use GOLD-Y in a blank form to exit the Add People option when you have finished adding.

\section{ID DELETE PEOPLE *}

This option enables a user to delete information about a specific person in the personnel database. The system displays the Personnel Selection method menu as described in MODIFY PEOPLE. Use the menu in the same way to choose the people you want to delete.

After you select a person, the system will prompt:

Delete person: (last name) $(Y / N)$ [N] $=>$

Type a $Y$ (Yes) to delete the record of the person from the database. 


\section{LIST PEOPLE BY NAME...AGENCY...POSITION}

These three options allow you to produce three different lists of personnel. You can list personnel by

$-\quad$ Name
$-\quad$ Agency
$-\quad$ Position

You must specify the information necessary to generate the personnel list by selecting an option from the following menu.

\begin{tabular}{l} 
Personnel selection method menu \\
0 : ExIT \\
1 : Type in Person name \\
\hline : Select Person from a list \\
Menu Cholce (3=Help) $m$
\end{tabular}

If you select Option 1: Type in Person name. The system then displays the following prompts. You can enter a whole or partial name, for example, BE for BELL.

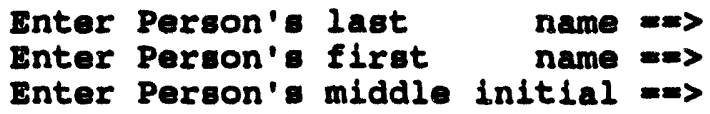

After you have entered the name of the person you want listed, the system displays the Personnel Selection method menu again. Continue selecting people until you are finished.

If you select Option 2: Select Person from a list, a menu similar to the following displays.

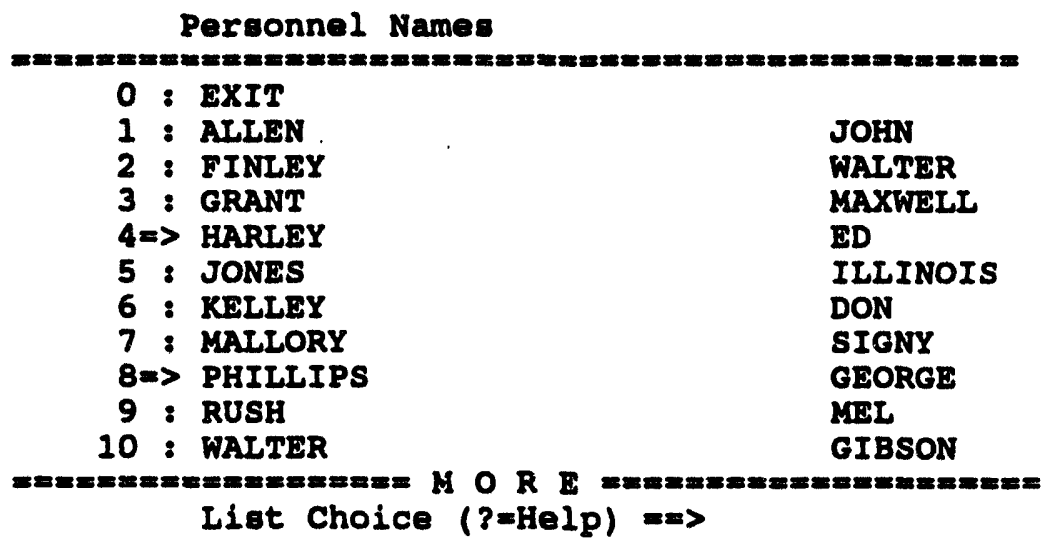

You can select multiple people from this menu. Enter the number of the person you want to select at the $==>$ prompt, or indicate a range of numbers. For example, select numbers 2 through 8 by typing: $2+8$. The system will indicate the 
selection by displaying $\mathrm{a}=>$ symbol by the selected names. To finish your selection, select the 0: EXIT option. The Personnel Selection method menu will display.

Select the 0: EXIT option and the system displays the report listing the people you requested. The report looks similar to the following example.

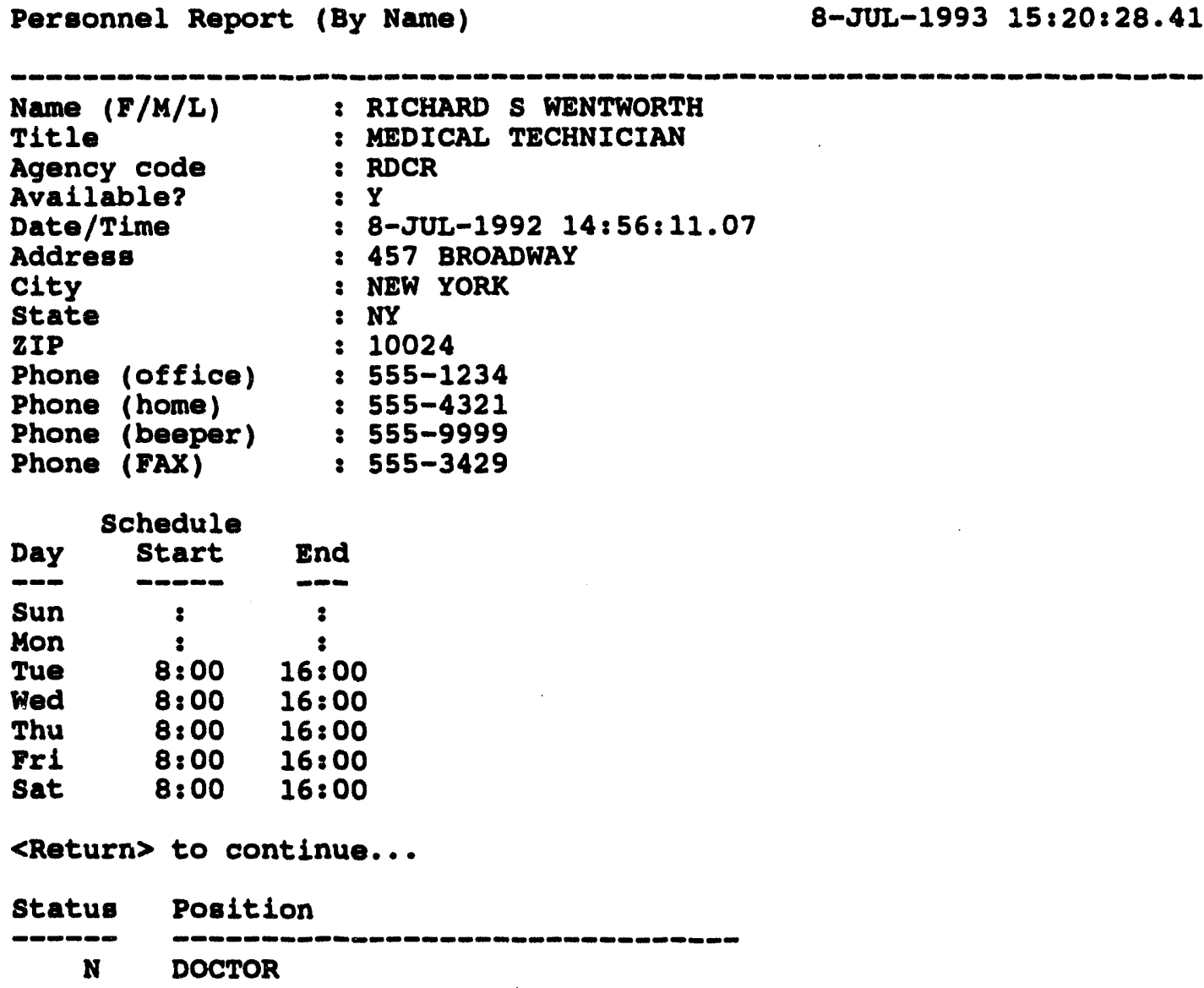




\section{MODIFY PEOPLE *}

This option enables an Information Manager to modify information about a specific person in the personnel database. Modifying personnel information consists of 1) specifying the person name and 2) entering new information about the person.

\section{Specify Which Person to Modify}

The system prompts:

\begin{tabular}{l} 
Personnel selection method menu \\
0 : ExIT \\
2 : Type in Person name \\
\hline Menu Choice $(3=\mathrm{Help})=\mathrm{C}$
\end{tabular}

Use one of these two methods to specify the person for whom to modify information:

A. Type in Person name: Prompts you to enter the three parts of the person's name. For example:

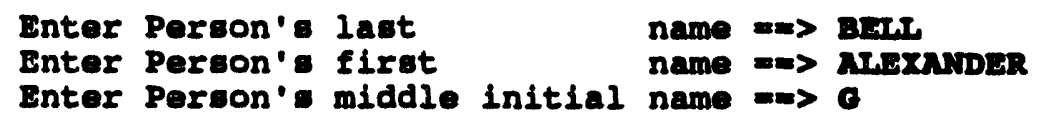

You can enter a whole or partial name, for example, BE for BELL. If you enter a partial name, the system will display the first matching name. If the name is found in the personnel database, proceed to Step 2.

B. Select Person from a list: Prompts you to choose one name from a numbered list of personnel names. For example:

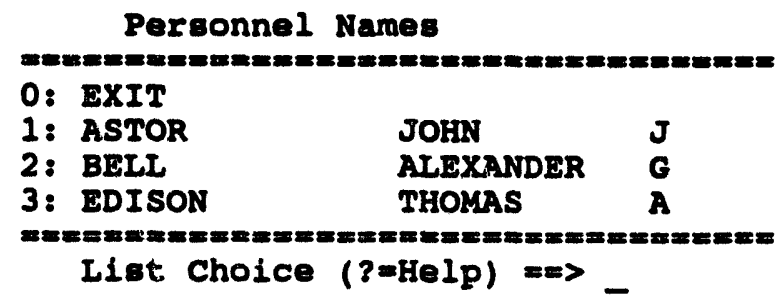

Enter the number that corresponds to the desired name, or select 0 to exit. Proceed to modify information in Step 2. 


\section{Enter New Information about the Person}

The personnel data form is then presented for updating or modification. You can modify any fields except the system date and time. For example:

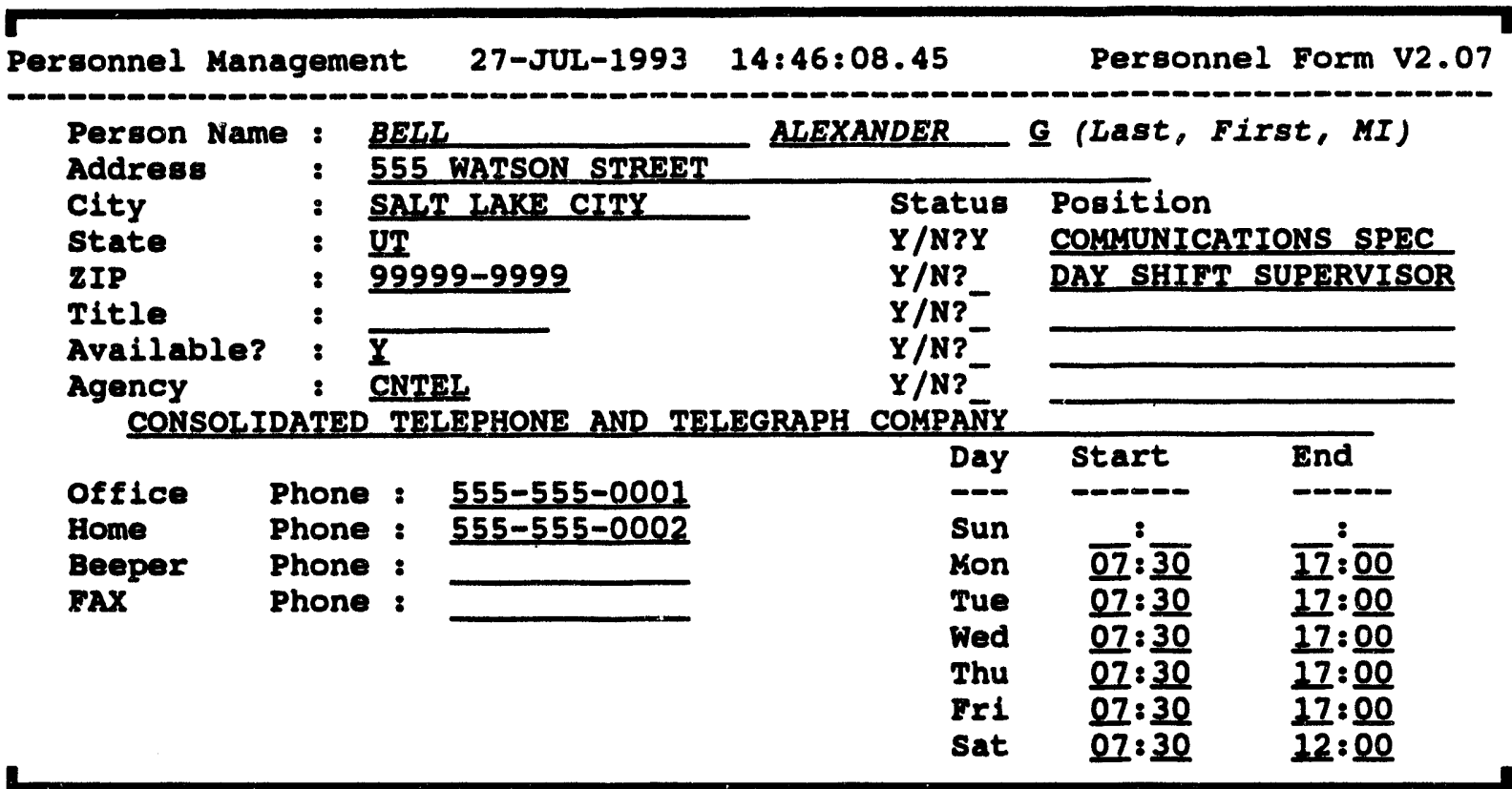

Exit the form and save the changes by pressing GOLD-Z. Exit the form and do not save the changes by pressing GOLD-Y.

\section{Position Tasks}

Within different agencies or organizations, personnel can hold one or more pasitions (job titles, assignments, etc.). The IBS's position lookup table is a list of agency acronyms and positions associated with that agency. For example,

$\begin{array}{ll}\text { Agency } & \text { Position } \\ \text { PNL } & \text { PROJECT MANAGER } \\ \text { PNL } & \text { GIS PROGRAMMER } \\ \text { OEM } & \text { COMMUNICATIONS OFFICER }\end{array}$

The position lookup table is used throughout Personnel Management and Resource Management, and also in the Implementing Procedures.

While any IBS user can look at the table by using the LST POSITIONS option, only a user with appropriate privileges can change the contents of the table, either through ADD POSITIONS, DELETE POSITIONS, or MODIFY POSITIONS. 
The complete list of options available in Personnel Management for using the position lookup table are:

$\begin{array}{lll}- & \text { ADD } & \text { POSITIONS } \\ - & \text { MODIFY } & \text { POSITIONS } \\ \bullet & \text { DELETE } & \text { POSITIONS } \\ - & \text { LIST } & \text { POSITIONS }\end{array}$

\section{ADD POSITIONS *}

This option enables an Information Manager to add information to the position lookup table. This consists of

1. Specifying which agency is associated with the position.

2. Entering a new position name.

\section{Specify Which Agency}

If your default selection method is none, the system will display the following menu:

Agency selection method menu
0: ExIT
1: Type In Agency code
2: Select Agency code from a list
3: Type in Agency name
4: Select Agency name from a list
Menu Cholce (?=Help) $=>$

Note: If you have a prior default selection method set up, you will see one of the following four prompts instead of the Selection method menu.

Use one of these four methods to select an agency to which you will add a position:

1. Type in Agency code: Prompts you to enter the agency code (up to five characters).

Enter Agency code $==>$

Enter the acronym for the agency, or Gold $Z$ to exit. If it is not in the table, you must try again.

2. Select Agency code from a list: Prompts you to choose one agency from a numbered list of agencies (ordered by agency code). 


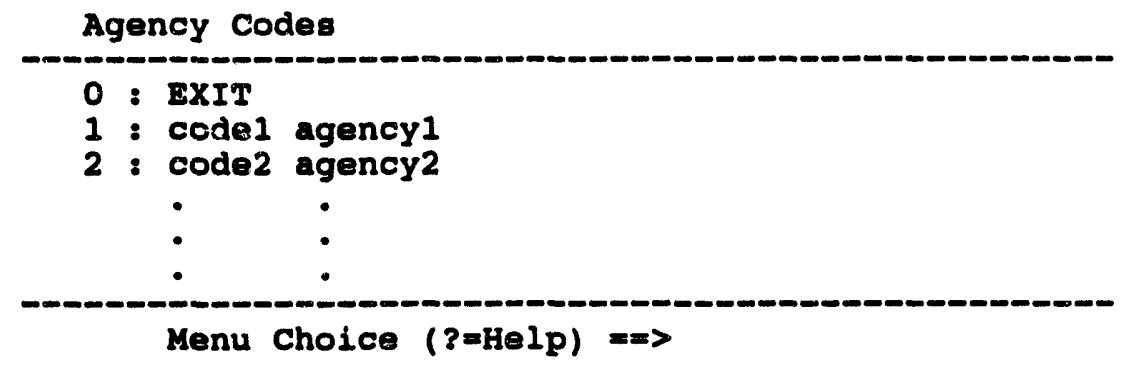

3. Type in Agency name: Prompts you to enter the agency name.

Enter Agency name $=>$

Enter the name of the agency to which you will add a position, or Gold $Z$ to exit. If the name you enter is not in the table, you must try again, or enter a $Q$ (Quit) to display the Agency Selection method menu.

4. Select Agency name from a list: Prompts you to choose one agency from a numbered list of agencies (ordered by agency name).

Agency Names

0 : EXIT

1 : NATIONAL FOREST SERVICE NES

2 : PACIFIC NORTHWEST IABORATORY PNL

3 : EEDERAL EMERGENCY MANAGEMENT AGENCY PEMA

4 : OREGON BLERGENCY MANAGEMENT OEM

Menu Choice $(?=$ Help $)=x$

After selecting an agency, you can then add a position. 


\section{Enter a New Position Name}

The system prompts:

Enter new Position for (agency code) $m$

Enter the name of the position you want associated with the agency.

You are restricted to only 20 characters, so you may need to truncate your input.

After the new position information is saved, the system returns to Step 1 and prompts you again. When you are finished, select the $0:$ EXIT option and press the Return key.

\section{IDELETE POSITIONS *}

This option enables a user with appropriate privileges to delete a position associated with an agency.

The system displays the Agency/Position Selection Method menu.

\begin{tabular}{c} 
Agency/Position Selection Method Menu \\
\hline 0 : ExIT \\
$1:$ Type in Agency/Position \\
\hline $2:$ Select Agency/Position from a list \\
Menu Choice $(?=H e l p)==$
\end{tabular}

Note: If your default selection method is menu or list, you will not see the above menu, instead the system will skip directly to one of the following two options.

If you select option 1 : Type in Agency/Position, the system will prompt you to enter the agency code.

Enter Agency Code $=>$

Then the system will prompt you to enter the position.

Enter Position $=\approx$ 
If you select option $2:$ Select Agency/Position from a list, the system displays the Agency/Position menu.

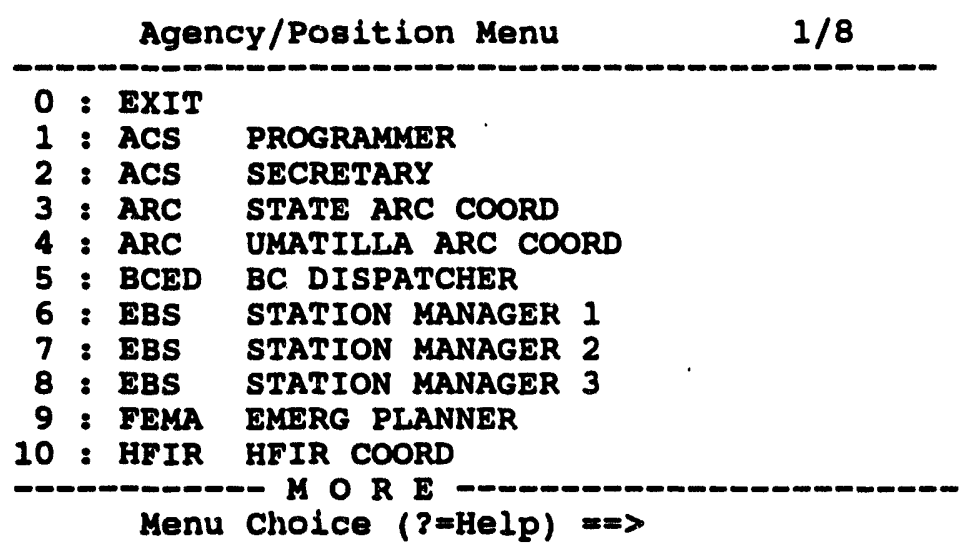

Select the agency position you want to delete from the menu and press the Return key.

After you select an agency position, the system will display the following prompt.

Delete position: $\operatorname{XXX}(Y / N)[N]==>$

Type a $Y$ (Yes) at the prompt to delete the agency position, or press the Return key to cancel the deletion. The system will return you to the previous menu or prompt.

\section{MODIFY POSITIONS *}

This option enables a user with appropriate privileges to modify information already in the position lookup table. This consists of 1) selecting which position to modify and 2) entering a new name for the position.

\section{Specify Which Position to Modify}

The system prompts:

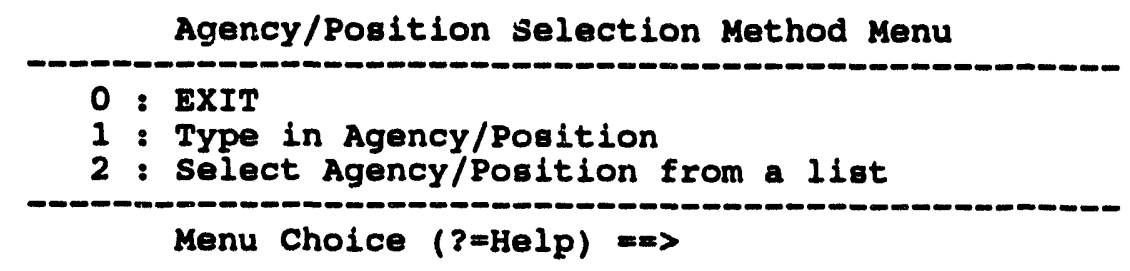

Note: If your default selection method is menu or list, you will not see the above menu, instead the system will skip directly to one of the following two options. 
Use one of these two methods to select a position to modify.

1. Type in Agency/Position: Prompts you to enter the agency acronym and then the position at that agency.

Enter Agency Code $=m$

Enter Position $==>$

Enter the agency acronym and the position you wish to modify. If either are not in the position lookup table, you must try again.

2. Select Agency/Position from a list: Prompts you to select a position from a numbered list of positions at different agencies.

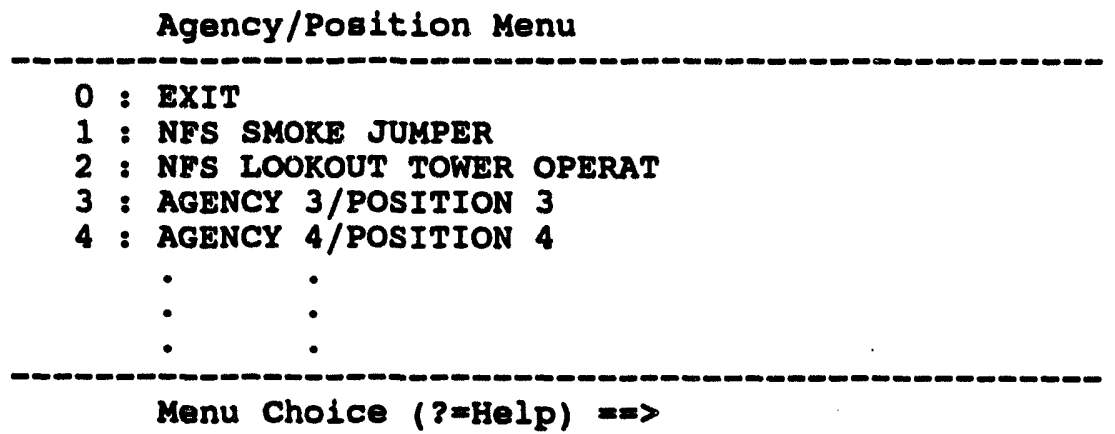

Enter the number of the position you wish to modify.

\section{Enter a New Name for the Position}

The system then prompts:

Enter new Position $=\Rightarrow$

Enter the new name for the position. If it is already in the table, you must try again.

To quit any of these prompts, press GOLD-Z or CTRL-Z.

After the modified position information is saved, the system returns to the Agency/Position Selection method menu. To quit, select option 0: EXIT.

\section{LIST POSITIONS}

This option enables you to list and view the contents of the position lonkup table, one screen at a time. 


$$
=
$$




\section{Section 5 Map Analysis}

MAP ANALYSIS

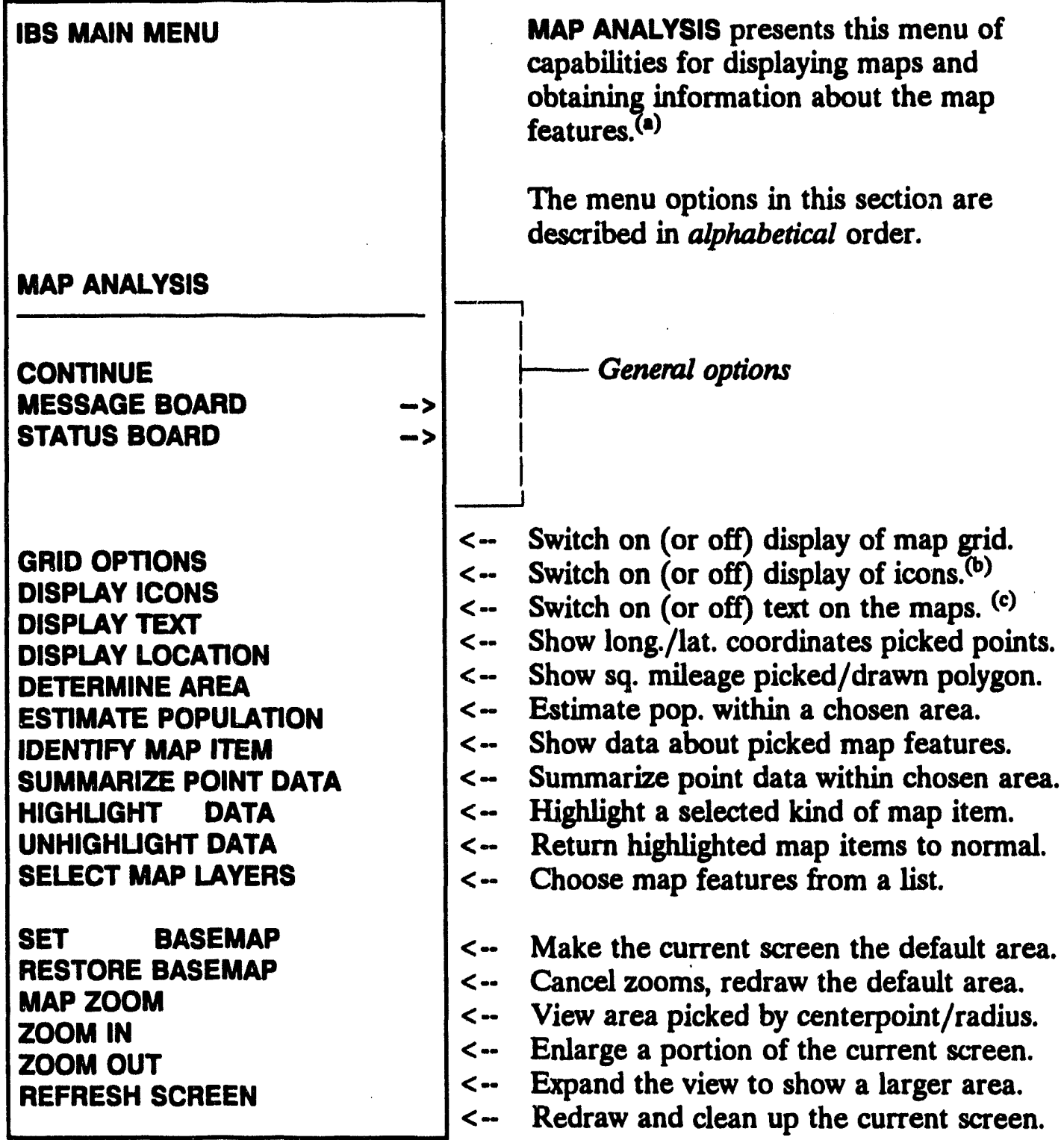

(a) An independent utility program, GEDIT, provides map editing capabilities. GEDIT is documented in the IBS Utilities Guide.

(b) When chosen, DISPLAY ICONS switches to TURN OFF ICONS at the same position.

(c) When chosen, DISPLAY TEXT switches to TURN.OFF TEXT at the same position. 


\section{DETERMINE AREA}

DETERMINE AREA displays the area (in both actes and square miles) of a polygonal region. The region's perimeter is also displayed (in both feet and miles).

When you select DETERMINE AREA, the program prompts you to define the region in one of three ways:

\begin{tabular}{l} 
Select Area of Interest Menu \\
\hline $0:$ ExIT \\
$2:$ Current screen \\
$3:$ Delect existing polygon polygon \\
\hline Menu Choice $(?=$ Help $)=$
\end{tabular}

Your choices are these:

1. Current screen: Determines the area of the current screen.

2. Select existing polygon: Enables you to pick an existing polygon to define the desired region.

3. Draw polygon: Enables you to pick points that define a polygon around the desired region.

These methods for defining a region are fully described in Section 1.

Note: Remember to select the Continue option after you have defined an area.

After the polygon is defined, the requested data are displayed:

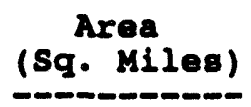

167.657

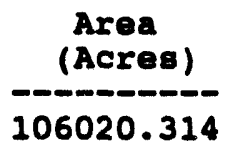

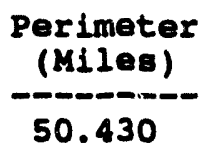

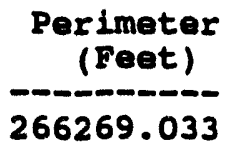

End of Report: <Return> to continue, $M$ to change destination...

The units of measure in the display can be different, depending upon the default settings for units of measure-english or metric. You can change these settings under SETUP-JOB ENVIRONMENT-MISCELANEOUS SETTINGS.

4. Press $M$ if you want to send the data to another output destination. For example, you can send the on screen information to a printer. Pressing $\mathbf{M}$ displays the Output Redirection Menu for your use. 


\section{DISPLAY ICONS (TURN OFF ICONS)}

DISPLAY ICONS is a switch that turns on the display of any icons included in the current map display data. (When you pick DISPLAY ICONS, the menu item switches to TURN OFF ICONS.)

TUAN OFF ICONS is the reverse operation that cancels the display of any icons included in the current map display data. (When you pick TURN OFF ICONS, the menu item switches back to DISPLAY ICONS.) Select REFRESH SCREEN to finish removing the icons.

\section{DISPLAY LOCATION}

DISPLAY LOCATION displays the following information about a point (or sequence of points) that you pick:

- Longitude, latitude

- Delta miles, or the miles from the last point you picked

- Total miles accumulated along the chain of points you pick

- Miles to the center of the screen

When you select DISPLAY LOCATION, the program prompts:

* * MSG Uge crosghair to pick a known point.

After you pick a point, the information is displayed in a table. For example:

\begin{tabular}{lcccc} 
Longitude & Latitude & Delta Miles & Total Miles & Miles to Center \\
\hline-112.079 & -40.445 & 0 & 0 & 13.9530 \\
-112.2602 & 40.233 & 4.4324 & 10.0719 & 6.0672
\end{tabular}

The units of measure in the display can be different, depending upon the default settings for units of measure-english or metric. You can change these settings under SETUP-JOB ENVIRONMENT-MISCELLANEOUS SETTINGS.

As you continue to pick points, the information about previous points remains on the screen. Choosing CONTINUE or picking another menu item ends the function and removes the information from the screen.

\section{IDISPLAY TEXT (TURN OFF TEXT)}

DISPLAY TEXT immediately displays the text labels associated with items on the current map screen. When you select DISPLAY TEXT, the menu item switches to TURN OFF TEXT. 
TURN OFF TEXT enables you to cancel the display of text labels on the screen. To remove the text, select REFRESH SCREEN after selecting TURN OFF TEXT.

\section{IIESTIMATE POPULATION}

ESTIMATE POPULATION provides an estimate of the population within a defined area. There are two sources of data for population reports within ESTIMATE POPULATION:

- Census data

- People Locate data

Census data (if present in the site database) comes from static census database map layers chosen using SELECT MAP LAYERS in MAP ANALYSIS, or CHANGE Default LAYens in SETUP. People Locate data is generated by the People Location (LOCATE) program (see Appendix C). The source of population data accessed within ESTIMATE POPULATION depends on the type of population report selected. When you select Estimate Population, the system displays the following menu.

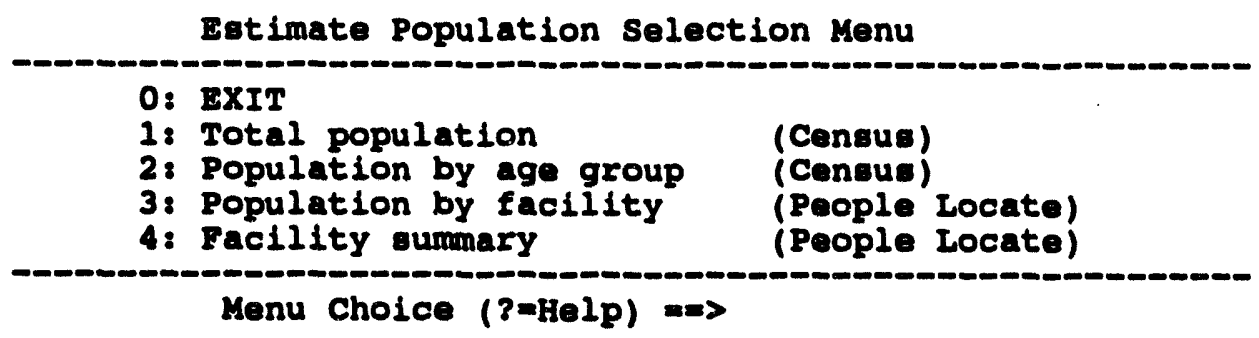

Select the type of report data you wish to see from these choices. The choices marked with Census will use census data for calculation. The choices marked with People Locate will use the Locate database for calculation.

Note: If the data required for population estimation is not present, the system will display a message similar to the following:

* * MSG: No population topography selected Press <ReTURN> to continue...

Your choices are: 
1. Total population (Census): Produces a report of the total population for the selected area. Census population data is used to generate this report.

Estimated Population Based on Census Data

DD-MMDS-YYYY HH : MY : SS

Map Layer
Population Pattern :
Total Population $:$ Xeeknight

Press <Return> to continue ...

If no population map layer is selected, the program will display the following message:

* * MSG: No population topography selected Press <Return> to continue...

If this happens, use SELECT MAP LAYERS in MAP ANALYSIS, or CHANGE DEFAULT LAYERS in SETUP to select a population map layer.

2. Population by age group (Census): Produces a report of the population in the selected area summarized into age categories. Census demographic data is used to generate this report.

Estimated Population Based on Census Data

DD-MQQS-YYYY HH: MM:SS

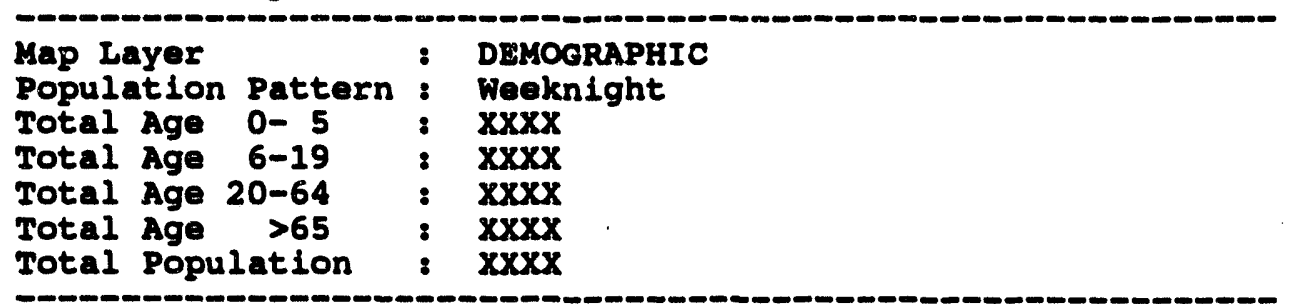

<Return> to continue ...

If no demographic map layer is selected, the program will display the following message:

* * MSG: No demographic topography selected Press <Return> to continue...

If this happens, use SELECT MAP LAYERS in MAP ANALYSIS, or CHANGE DEFAULT LAYERS in SETUP to select a demographic map layer.

3. Population by facility (People Locate): Produces a report of the number of people received, released, and remaining at emergency-related facilities. These facilities are of the following type: 1) shelters, 2) reception centers, 3) decontamination centers, 4) hospitals, and 5) morgues. People Location data is used to generate this report. 


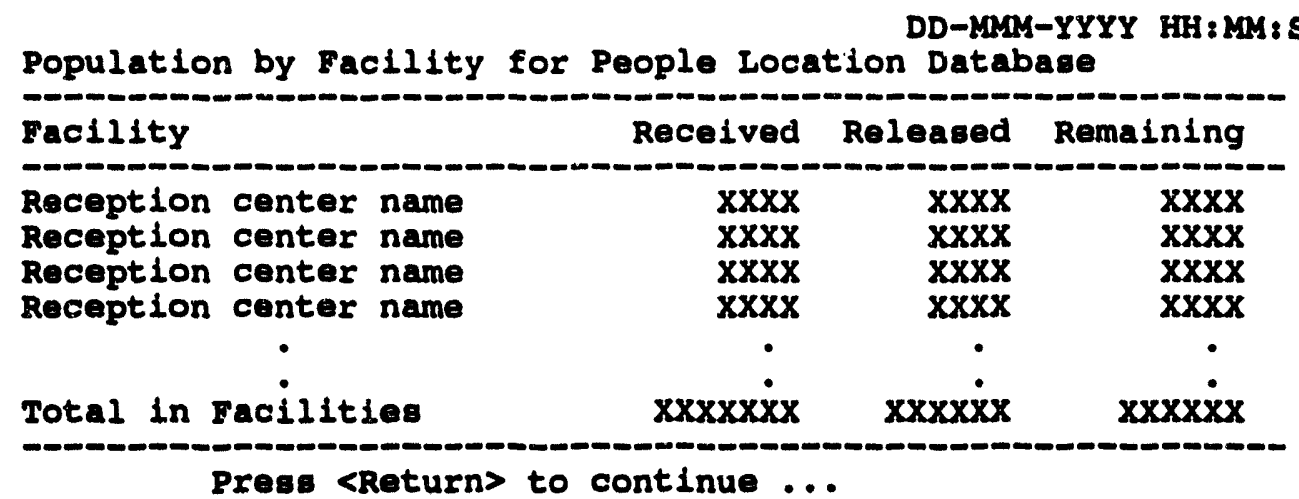

4. Facility summary (People Locate): Produces a facility summary report for number of facilities, total number of people remaining, and percent load (people remaining/capacity) for emergency-related facilities. People Location data is used to generate this report.

Fac1lity Summary for People Location Database

\begin{tabular}{|c|c|c|c|c|c|c|}
\hline Facility & (1ve) & $\begin{array}{l}\text { umber } \\
\text { (Total) }\end{array}$ & $\begin{array}{r}\text { Pop } \\
\text { (Activa) }\end{array}$ & $\begin{array}{l}\text { lation } \\
\text { (Total) }\end{array}$ & $\begin{array}{r}\text { Load } \\
\text { (Active) }\end{array}$ & $\begin{array}{c}\text { Cap (\$) } \\
\text { (Total) }\end{array}$ \\
\hline $\begin{array}{l}\text { Shelter } \\
\text { Reception centers } \\
\text { Decontamination center: } \\
\text { Hoepital } \\
\text { Morgue } \\
\text { Other }\end{array}$ & $\begin{array}{l}\mathbf{X X X} \\
\mathbf{X X X} \\
\mathbf{X X X} \\
\mathbf{X X X} \\
\mathbf{X X X}\end{array}$ & $\begin{array}{l}\mathbf{X X X} \\
\mathbf{X X X} \\
\mathbf{X X X} \\
\mathbf{X X X} \\
\mathbf{X X X} \\
\mathbf{X X X}\end{array}$ & $\begin{array}{l}\mathbf{X X X} \\
\mathbf{X X X} \\
\mathbf{X X X} \\
\mathbf{X X X} \\
\mathbf{X X X} \\
\mathbf{X X X}\end{array}$ & $\begin{array}{l}\mathbf{X X X} \\
\mathbf{X X X} \\
\mathbf{X X X} \\
\mathbf{X X X} \\
\mathbf{X X X} \\
\mathbf{X X X}\end{array}$ & $\begin{array}{l}\mathbf{X X X} \\
\mathbf{X X X} \\
\mathbf{X X X} \\
\mathbf{X X X} \\
\mathbf{X X X} \\
\mathbf{X X X}\end{array}$ & $\begin{array}{l}\mathbf{X X X} \\
\mathbf{X X X} \\
\mathbf{X X X} \\
\mathbf{X X X} \\
\mathbf{X X X} \\
\mathbf{X X X}\end{array}$ \\
\hline TOTAL: & $\mathrm{XXXX}$ & $\operatorname{xxxx}$ & $\operatorname{xxxx}$ & $\mathbf{x x x}$ & $\operatorname{Xxxxx}$ & $x \times x \times$ \\
\hline
\end{tabular}

The report lists:

A. The number of total and active facilities.

B. The number of people remaining at active facilities, and combined inactive and active facilities.

C. The percent load (people remaining/facility capacity) for active, and combined inactive and active facilities.

After you make a choice from the Estimate Population Selection Menu, the system displays the following menu.

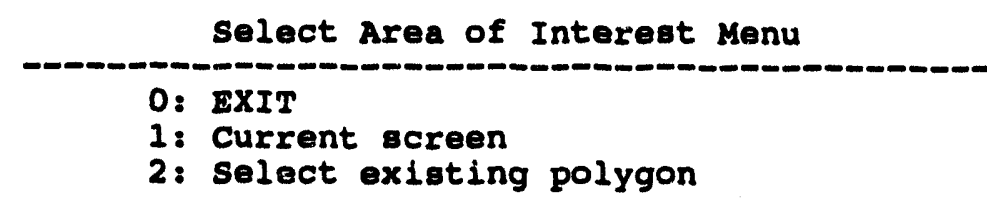




\section{3: Draw polygon}

Manu Choice $(z=$ Help) $=\Rightarrow$

Use one of these three methods to specify which items on the graphic display screen are used to calculate population.

1. Current screen: Will calculate population for the entire display area.

2. Select existing polygon: Prompts you to select a polygon from the screen with the cross hairs.

Note: If you select a polygon which is partly offscreen, the following message will display:

* * MSg: Polygon selected is partially off the current screen.

* * MSG: The population shown may not be accurate.

Any population information you receive after viewing this message should be verified by using the zoom out option so the polygon is completely onscreen, then estimating the population of the polygon again.

3. Draw polygon: Prompts you to draw an area on the screen with the cross hairs.

After you have selected an area, the system will display or output your choice. The Output Redirection Menu may display, if you have not defined a default output choice as described in Section 12, Setup. 


\section{GRID OPTIONS}

This option enables you to superimpose a grid over the current map display. You can select the color of the grid, the line type, and type of units displayed.

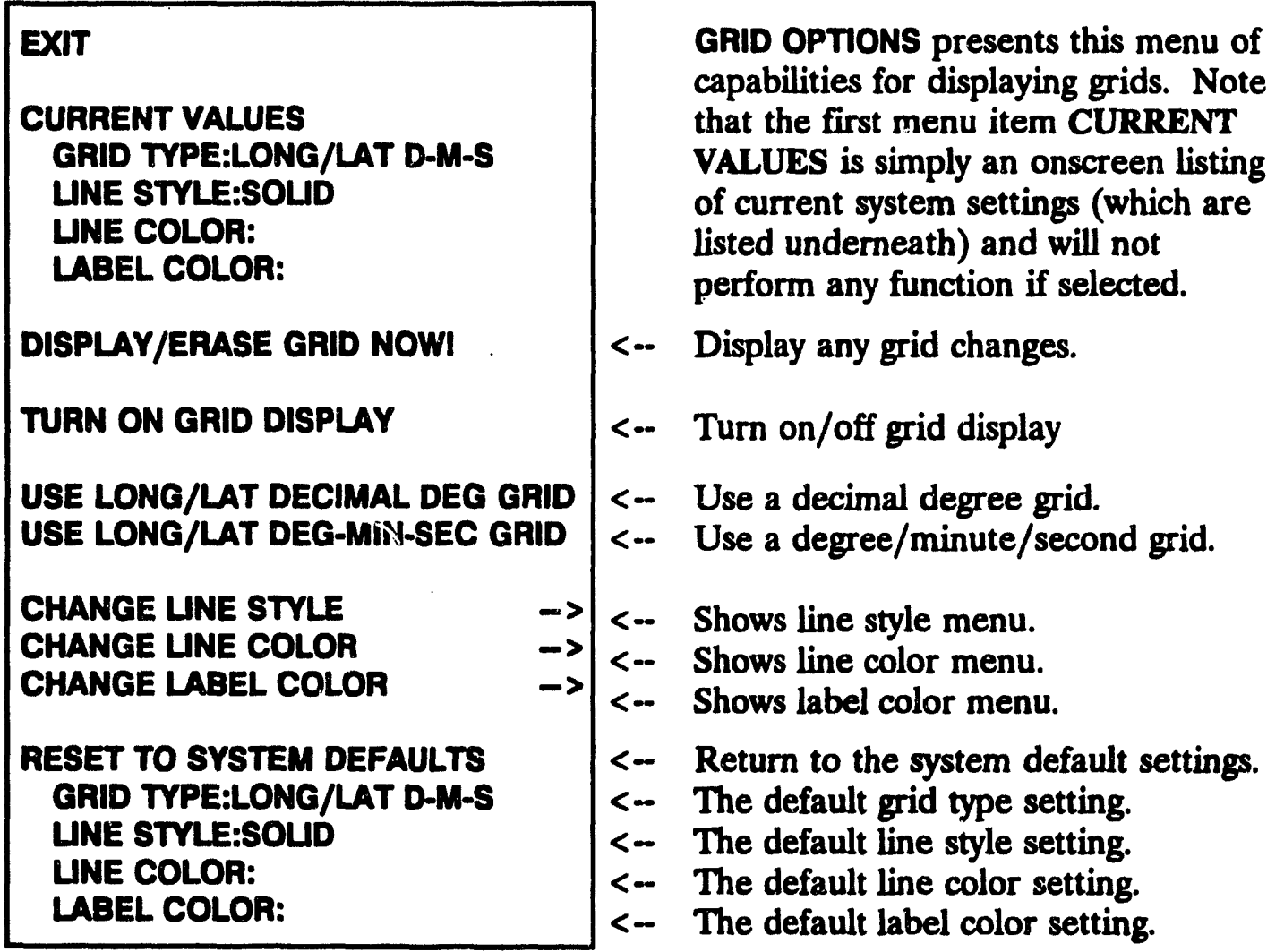

Select from the above menu the grid characteristics you want to change.

- Longitude and Latitude Decimal Degree grid

- Longitude and Latitude Degree/Minute/Second grid

- Line Style

- Line Color

- Label Color

After you make changes, you can select DISPLAY/ERASE GRID NOW! to display the changes on the screen immediately. If you do not select this option, your changes to the grid will display after you exit this menu.

Selecting RESET TO SYSTEM DEFAULTS will reset all the values to the default values used before you made any changes.

Note: If you accidently pick an unreadable combination of colors, you can use Non-Graphic IBS to return to the default colors or pick some other readable combination. See Appendix B, Non-Graphic IBS for further instructions. 


\section{HIGHLIGHT DATA}

HIGHLGHT DATA enables you to highlight specific types of graphic items (lines, points, icons, etc.) within the map display area. The graphic items must be visible within the display area. ZOOM IN or ZOOM OUT first, as required, before selecting Highlight Data. (See also-UNHIGHLIGHT DATA.)

After you select HIGHLGHT DATA, the system prompts with the following menu:

\begin{tabular}{c} 
Highlight Data Menu \\
\hline 0 : ExIT \\
$1:$ Enter attribute description \\
\hline Menu Choice $=>$ List attributes for current screen
\end{tabular}

Use one of these two methods to specify which items on the graphics display screen are to be highlighted:

1. Enter attribute description: Prompts you to enter an attribute description:

Enter data description $=>$

Enter any text that describes the feature you are interested in (from 1 to 60 characters). You can enter the entire attribute description (example, NATIONAL FOREST OR GRASSLAND), or only part of the attribute description (FOREST). All attributes that contain the text you entered will be displayed in a menu.

2. List attributes for current screen: Presents a menu of attributes for all data items within the current screen display area. 
After using either of the above methods, a menu of the attributes on the screen is presented. An example of such a menu follows:

Attribute Description Menu

\begin{tabular}{l} 
Attribute Description Menu \\
\hline $0:$ EXIT \\
$1:$ BARRICAD \\
$2:$ BLOCK GROUP \\
$3:$ CARS \\
$4:$ COMM EQ \\
$5:$ CONST EQ \\
$6:$ DAY FOR TAIL OF PLUME \\
$7:$ DECONTAMINATION CENTER \\
\hline
\end{tabular}

Select an attribute from the menu of attributes. All data with this attribute description are then highlighted. Lines are redrawn as wide lines and the location of points or icons are shown as highlighted white asterisks.

To highlight additional types of data, select HIGHLGHT DATA again. Highlighted areas remain onscreen until you cancel the highlighting or exit IBS. To cancel highlighting, use the UNHIGHLIGHT DATA option. 


\section{IIIDENTIFY MAP ITEM}

IDENTIFY MAP ITEM displays attribute information about a graphic item (or sequence of items) that you pick on the map screen. When you select IDENTIFY MAP ITEM, the following prompt appears:

* * MSG: Pick a map item using mouse or crosshair.

After you pick an item on the map, attributes for that item are listed as shown in the following example.

\begin{tabular}{lll} 
* Parm & Description \\
\hline 1) & 2000 & DISTANCE IN METERS \\
2) & 243 & 243 TIME IN TENTHS OF MINUTES OF TIP OF PLUME
\end{tabular}

As you continue to pick graphic items, the information about previous items is superseded. Picking Continue or another menu item ends the capability and removes the information from the screen.

\section{IIIAP ZOOM}

The zoom capabilities change or affect the size of the region shown in the map display area of the graphics screen. MAP ZOOM enables you to specify the center point and radius of an area displayed on the screen. (See also ZOOM IN, ZOOM OUT, SET BASEMAP, RESTORE BASEMAP.)

MAP ZOOM prompts you to define the center in one of three ways:

Selection of Map Center Menu

$0:$ ExIT
$1:$ Point to center with crosshair
$2:$ Enter longitude and latitude values
$3:$ Use current screen center
$4:$ Select Known Point as center
Menu Choice $(3=H e l p)=\infty$

Your choices are:

1. Point to center with crosshair: Enables you to point to the location that you wish to be screen center. The system prompts:

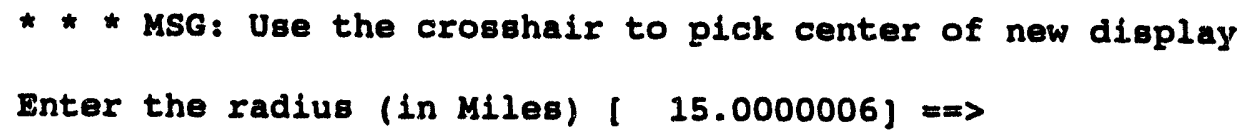

You can accept the default radius displayed in the square brackets, or enter a new radius at the $==>$ prompt. Press the Return key. 
2. Enter longitude and latitude values: Enables you to enter specific longitude and latitude values. The system prompts:

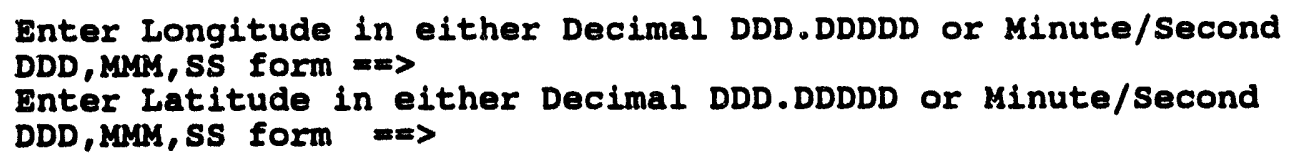

3. Use current screen center: Enables you to use the current center point of the screen. The system displays the following prompt.

Enter the radius (in Miles) i 15.0000006] $\Rightarrow$

You can accept the default radius displayed in the square brackets, or enter a new radius at the $==>$ prompt. Press the Return key.

4. Select Known Point as center: Enables you to enter a known point name and use that as the center point of the zoom. The system displays the following menu:

Known Point Selection method menu

\begin{tabular}{l} 
Known Point Selection method menu \\
0 : ExIT \\
1 : Type in Known Point name \\
2 : Select Rnown Point name from a list \\
3 : Type in long/lat coordinates \\
\hline Menu Choice $(3=\mathrm{Help})=\mathrm{P}$
\end{tabular}

Select a method for selecting a known point. See Section 6, Resource Management for more information about working with known points.

In all of these cases, after you select a zoom center point, you are then prompted for the desired radius:

Enter the radius (in miles) | 15.0000000 ) $\Rightarrow=>$

You can accept the default radius displayed in the square brackets, or enter a new radius at the $==>$ prompt. Press the Return key.

When you have entered all required information, the map screen is redrawn with the center and radius as you have specified.

Note: If you use a known point as the center of your map zoom, the known point may not be displayed on the screen. 


\section{ID REFRESH SCREEN}

REFRESH SCREEN redraws the current map display screen. This may be needed after text or graphic items have been erased, redrawn, or overdrawn: these operations sometimes create "holes" in the displayed data.

\section{RESTORE BASEMAP}

RESTORE BASEMAP enables you to refresh the display and restore the original extents of the map to the area displayed before any zoom operations. However, if you have used SET BASEMAP, then RESTORE BASEMAP resets the display size to the area that was displayed when SET BASEMAP was last picked.

\section{SELECT MAP LAYERS}

\section{IBS MAIN MENU \\ MAP ANALYSIS \\ SELECT MAP LAYERS}

FORWARD

BACKWARD

MAP LAYER 1

MAP LAYER 2

.

:

MAP LAYER $n$
SELECT MAP LAYERS produces this submenu, which lists the different groups of map features (layers) available for display in the map database. The currently displayed map layers are already selected (listed in a different color than your default color) when you first see this menu.

You can select additional map layers for temporary display or cancel some of those already selected. When you exit this menu, the selected map layers are drawn on the map screen and remain for the rest of your work session unless you change them again here.

Note: As soon as you exit Map Analysis and redraw the screen, default map layers defined in SETUP will supersede any map layers you alter in MAP ANALYSIS. 
Not all map layers than can be shown on a single menu. Use the FORWARD and BACKWARD options to display other pages of the map layer list:

- FORWARD shows the next page of map layers. When you reach the end of the list, the next FORWARD returns you to the first page.

- BACKWARD shows the previous page of map layers. When you reach the first page of the list, the next BACKWARD sends you to the last page.

\section{ID SET BASEMAP}

This enables you to reset the base map-the default display area for this session-to be the area currently displayed on the screen. If you later use RESTORE BASEMAP, the display is redrawn to show this default display area. 


\section{SUMMARIZE POINT DATA}

SUMMARIZE POINT DATA produces a summary of information about the point data within a defined area.

The program prompts you to define the area in one of three ways:

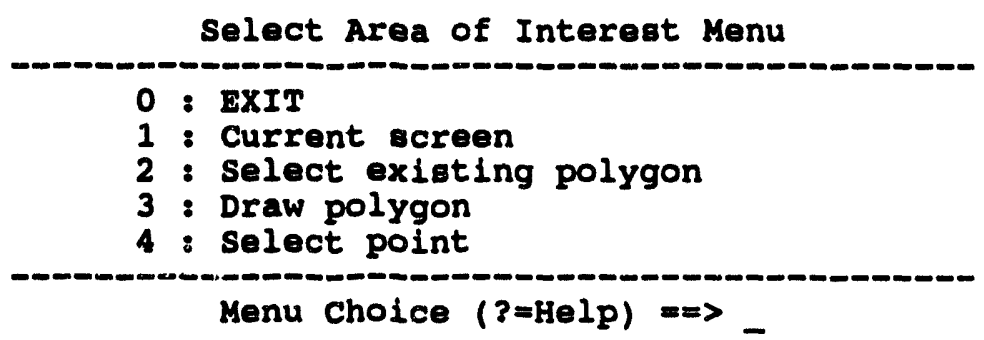

Your choices are these:

1. Current area: Produces summary information for all point data within the current screen map area.

2. Select existing polygon: Enables you to choose an existing polygon to define the desired area.

3. Draw polygon: Enables you to pick points to define a polygon around the desired area.

4. Select point: Prompts you to select a point with the cross hairs or mouse. You can use the HIGHLGHT DATA command to make the point easier to see before selecting it with the SUMMARIZE POINT DATA command. If you select this option, the following message displays.

* * MSG: Pick a data point using mouse or crosshair

After you have selected an area, the following menu displays.

\begin{tabular}{l} 
List Attribute Description Menu \\
0: EXIT \\
1: Iist attributes for selected area \\
2: Enter attribute description \\
\hline Choice $(?=$ Help) $\Rightarrow$
\end{tabular}


Use one of these two methods to specify which attributes from the selected area are to be displayed.

1. List attributes for selected area: Presents a list of attributes for all data items within the previously selected area.

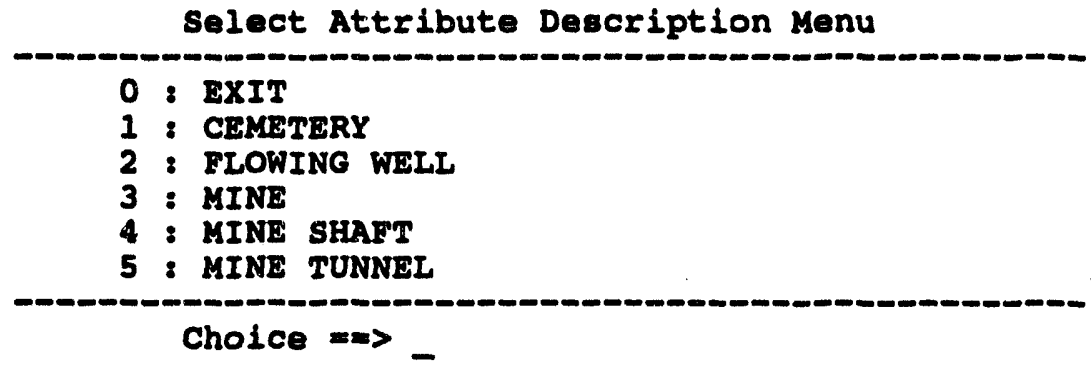

Each description is associated with one or more point(s) on the screen. Enter the index number that corresponds to the data that you want summarized.

2. Enter attribute description: The system prompts you to enter an attribute description:

Enter data description $=>$ -

Enter any text (from 1 to 60 characters). You can enter the entire attribute description (example, NATIONAL FOREST OR GRASSLAND), or only part of the attribute description (FOREST). All attribute descriptions that match the entered text and are within the selected area of interest are listed.

After you have selected an attribute, the IBS summarizes information for all point data within the selected area which have that attribute. For example:

\begin{tabular}{l} 
Point Data Summary for Selected Area \\
Description: DAY FOR TAIL OF PLUME \\
\hline of Points \\
Attribute Parameter Statiatics
\end{tabular}

L

Press <RETURN> to continue... 
The point data summary includes:

- The number of points with the selected attribute

- The SUM, MINIMUM, MAXIMUM, and AVERAGE of the attribute parameter values associated with those points.

\section{TURN OFF ICONS (DISPLAY ICONS)}

TURN OFF ICONS is a switch that cancels the display of any icons included in the current map display data. Select REFRESH SCREEN to finish removiay the icons. When you pick TURN OFF ICONS, the menu item switches to DISPLAY ICONS.

DISPLAY ICONS is the reverse operation that turns on the display of any icons included in the current map display data. When you pick DISPLAY ICONS, the menu item switches back to TURN OFF ICONS.

\section{ID TURN OFF TEXT (DISPLAY TEXT)}

TURN OFF TEXT enables you to cancel the display of text on the screen. Select REFRESH SCREEN after selecting TURN OFF TEXT to complete the removal of text from the screen.

When you select TURN OFF TEXT, the menu item switches to DISPLAY TEXT. DISPLAY TEXT immediately redraws the text on the map screen. 


\section{UNHIGHLIGHT DATA}

UNHIGHLIGHT DATA can be used to cancel the effect of HIGHLIGHT DATA, which highlights all instances of a particular type of map item. UNHIGHLIGHT DATA returns one type of highlighted map item to normal.

After you select UNHIGHUGHT DATA, the system prompts you with the following menu:

UnHighlight Data Menu
$0:$ ExIT
$1:$ Enter attribute description
$2:$ Iist all highlighted attributes
$3:$ UnHighlight all Highlighted Items
Choice $(3=\mathrm{Help})=\mathrm{P}$

Use one of these three methods to specify which items on the graphics display screen are to be unhighlighted:

1. Enter attribute description: Prompts you to enter a data attribute description:

Enter data description $=>$

Enter any text (from 1 to 60 characters). You can enter the entire attribute description (example, NATIONAL FOREST OR GRASSLAND), or only part of the attribute description (FOREST). All highlighted attribute descriptions that match the entered text are listed.

2. List all highlighted attributes: Presents a list of attributes which are currently highlighted.

3. Unhighlight all highlighted items: Selecting this menu item unhighlights all of the data which is currently highlighted.

After selecting a method, a listing of the highlighted attributes (which match the input description, if the user entered an attribute description) is presented. An example of such a listing follows: 


Highlighted Attribute Description Menu
$0:$ EXIT
$1:$ EMERGENCY PLANNING ZONE BOUNDARY
$2:$ INDIAN RESERVATION
$3:$ NATIONAI FOREST OR GRASSLAND
$4:$ NATIONAI SCENIC WATERWAY OR WILDERNESS AREA
$5:$ SHELTER

Choice $(z=$ Help $)=\equiv$

Select an attribute from the list of attributes. All data with this attribute description are then unhighlighted and returned to normal.

To unhighlight additional types of data, select UNHIGHLGHT DATA again.

Restoring map items to their original appearance with UNHIGHLIGHT DATA may produce graphic fragments where the map items are redrawn. If this happens, pick REFRESH SCREEN to clean up the screen.

\section{ZOOM IN}

ZOOM IN enables you to enlarge a square portion of the current display screen. (See also MAP ZOOM.)

The program prompts:

* * MSG: select center and one edge w/mouse

1. Position the graphics cursor (cross hairs) on the center of the area you want to zoom in and press the Return key.

2. Position the graphics cursor on the edge of the zoom region and press the Return key.

A square zoom in box is drawn by the system, indicating the zoom in area. The screen is refreshed, and the zoom in area is expanded to fit the entire map graphics area. 


\section{WZOM OUT}

ZOOM OUT enables you to view a larger area of interest on the screen. (See also MAP ZOOM.)

The program prompts:

* * MSG: select center and one edge w/mouse

1. Position the graphics cursor (cross hairs) on the center of the area you want to zoom out and press the Return key.

2. Position the graphics cursor on the edge of the zoom out region and press the Return key.

A square zoom out box is drawn by the system, indicating the zoom out area. The screen is refreshed, and the previous map display area is compressed and redrawn within the zoom out box area. The zoom out box area is centered in the new map display screen. 


$$
9 \text { uopoes }
$$




\section{Section 6 \\ Resource Management}

\section{RESOURCE MANAGEMENT}

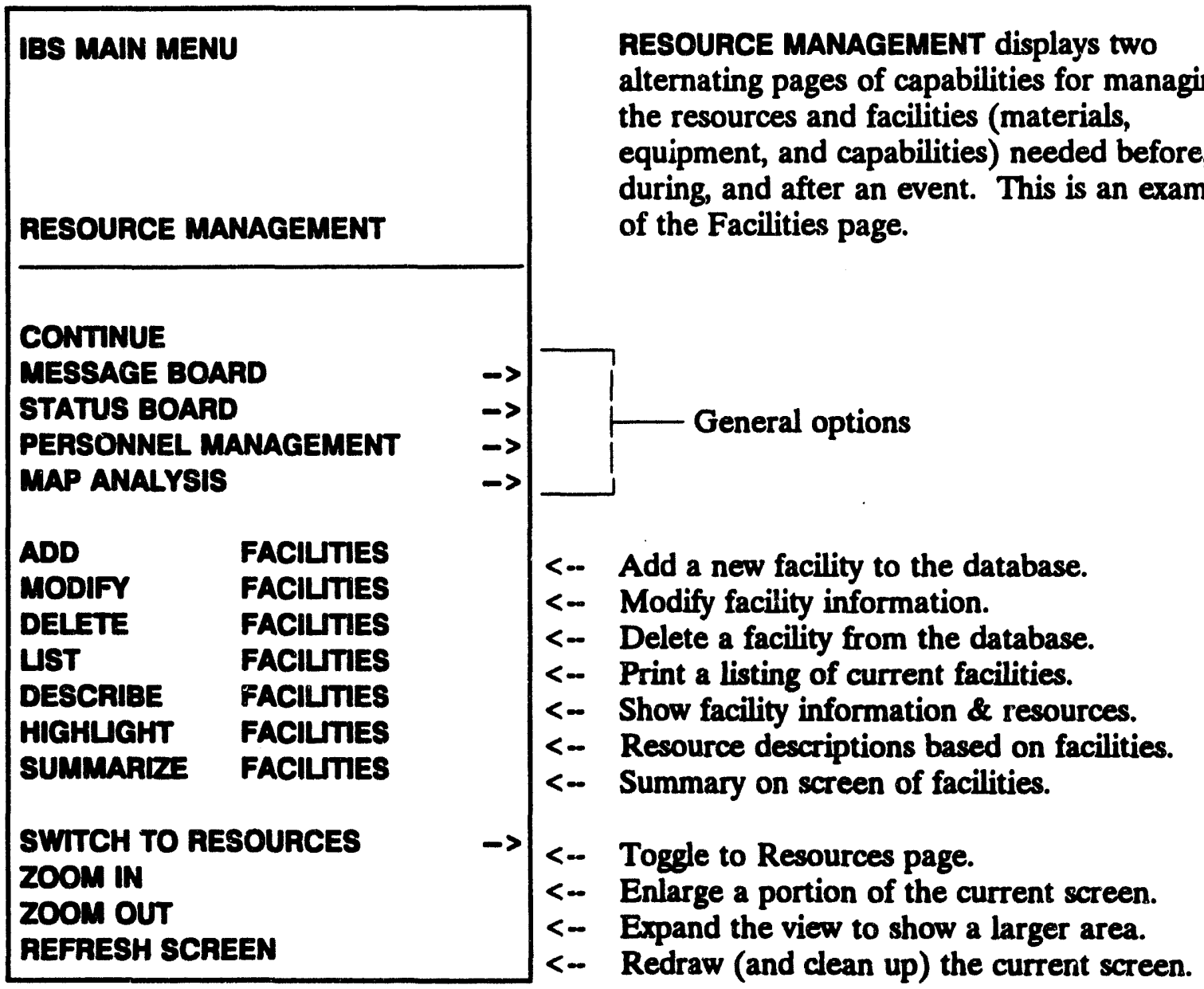

The locations of resources and facilities are depicted by graphic icons. Each of these resource and facility icons represents a major resource type. Each facility can include any number of unique resources. Thus, a facility icon often depicts the location of one or more individual resources within one resource type. 


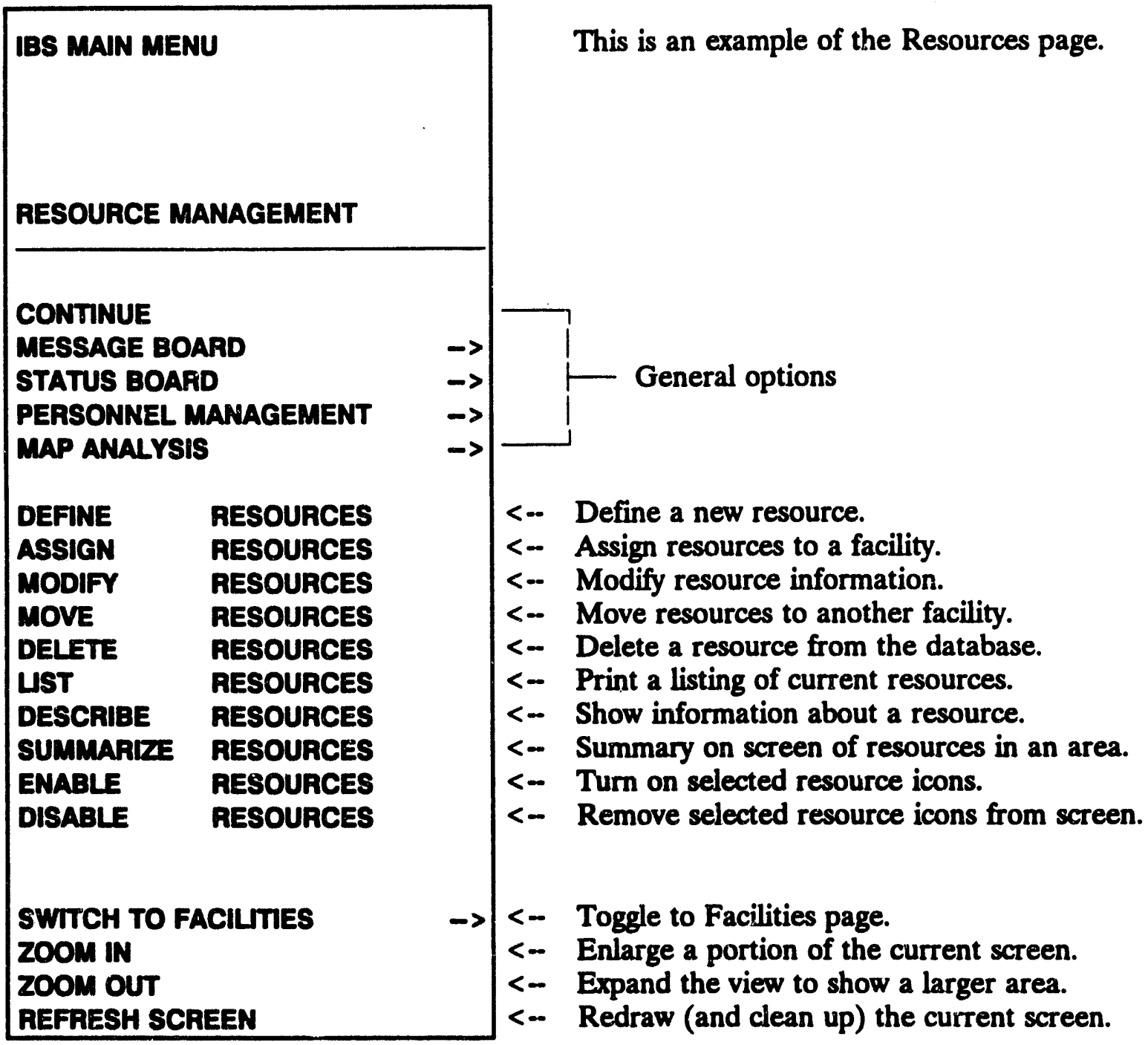

Facility icons that graphically depict the locations of facilities are automatically displayed when you start RESOURCE MANAGEMENT. Each facility can have up to 60 resource types associated with it. All IBS users can view facility information and list the resources located at the facilities. Information Managers can also define resources, define facility locations, assign quantities of resources at facilities, update this information in the resource database, and check (validate) the available resources against the resources required by the current Implementing Procedure.

The RESOURCE MANAGEMENT menu options are described in alphabetical order within two general categories:

- Facility Tasks 


\section{- Resource Tasks \\ REFRESH SCREEN and ZOOM IN/OUT are explained as options of MAP ANALYSIS in Section 5. \\ Facility Tasks}

The tasks of adding a new facility, updating facility information, and viewing information about a facility share some procedures in common. The following figure illustrates these common elements:

ADD FACIUTIES *

MODIFY FACIUTIES *

DELETE FACILTIES

DESCRIBE FACILTIES

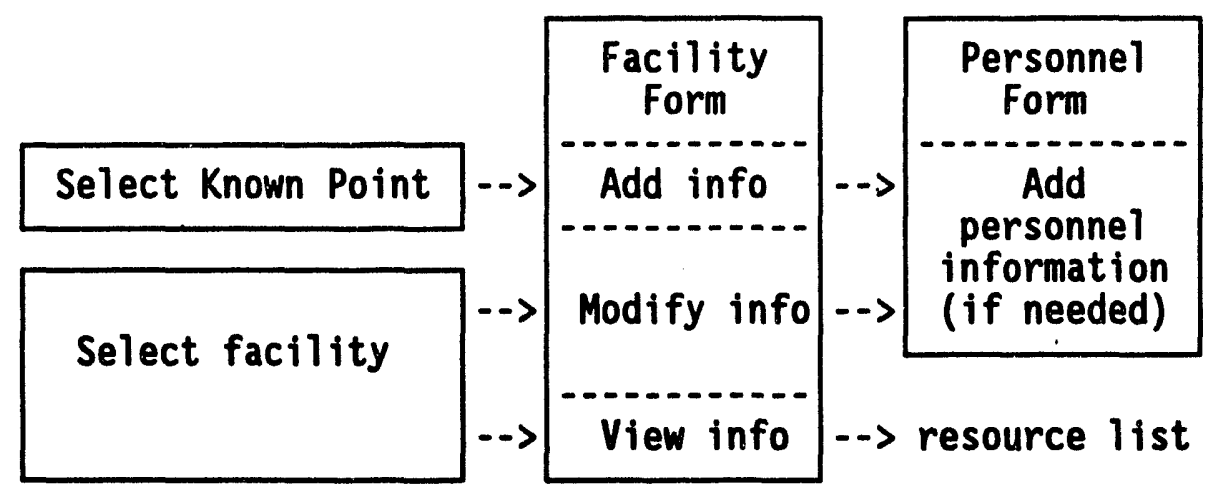

HIGHUGHT/

SUMMARIZE

FACIUTIES

Select area of interest

\section{$-->$} $\rightarrow$ facility icons displayed

- Three options (ADD FACIUTIES, MODIFY FACILTIES, and DESCRIBE FACILTIES) present facility information in the same facility form. (See ADD FACILTIES for a complete description of this information form.)

- MODIFY FACILITES and DESCRIBE FACILTIES allow you to first select which facility to modify or describe. Selecting a Facility is explained as an independent facility task.

- ADD FACIUTIES and MODIFY FACIUTIES can involve the use of a personnel form for entering the information about the facility contact person into the personnel database.

- HIGHUGHT FACIUTIES is used to highlight (flash) the icons of facilities that contain resources of a selected type. Selecting a Resource Type is explained as an independent resource task. 


\section{ADD FACILITIES*}

This option enables an Information Manager to add a new facility. Adding a facility consists of 1 ) specifying a facility location, 2) entering a facility description, and 3 ) entering personnel information about the facility contact person (if necessary).

\section{Specify a Facility (Known Point) Location}

The system displays the following menu

Known Point Selection Method menu

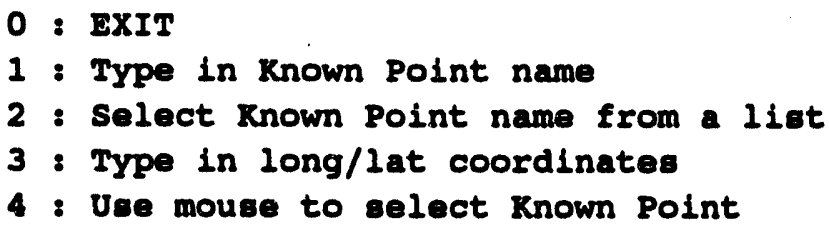

Menu Choice $(?=$ Help $)=>$

Use the Known Point Selection Method menu to choose the method you want to use to select a known point. For example, if you select Option 4 : Use mouse to select Known Point, the following message will display.

* * MSG: Select known Point location w/mouse

If you select a point near an existing facility, the system will display a message similar to the following example.

<facility name>

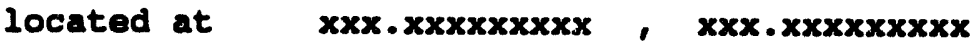

Use new point $x \times x \cdot \operatorname{xx} \times x \times x \times x \times, \quad x \times x \cdot \operatorname{xx} \times x \times x \times x \times x$

anyway? [N] $m>$

If you select a point with no preexisting facility, the system displays a message similar to the following example.

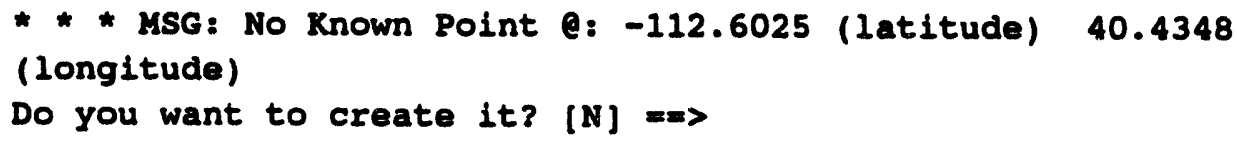

If you enter a $\mathrm{Y}$ for yes at the prompt, the system displays the following prompt.

Enter new known Point name $=m$ 
You can enter the name (up to $\mathbf{4 0}$ characters) of a point location. After you enter the new known point name, the system displays the Resource Management Facility Form as shown in 2. Enter a Facility Description.

\section{Enter a Facility Description}

After specifying the facility location, enter facility information in the following facility form (also used for DESCRIBE FACILITIES and MODIFY FACILITIES).

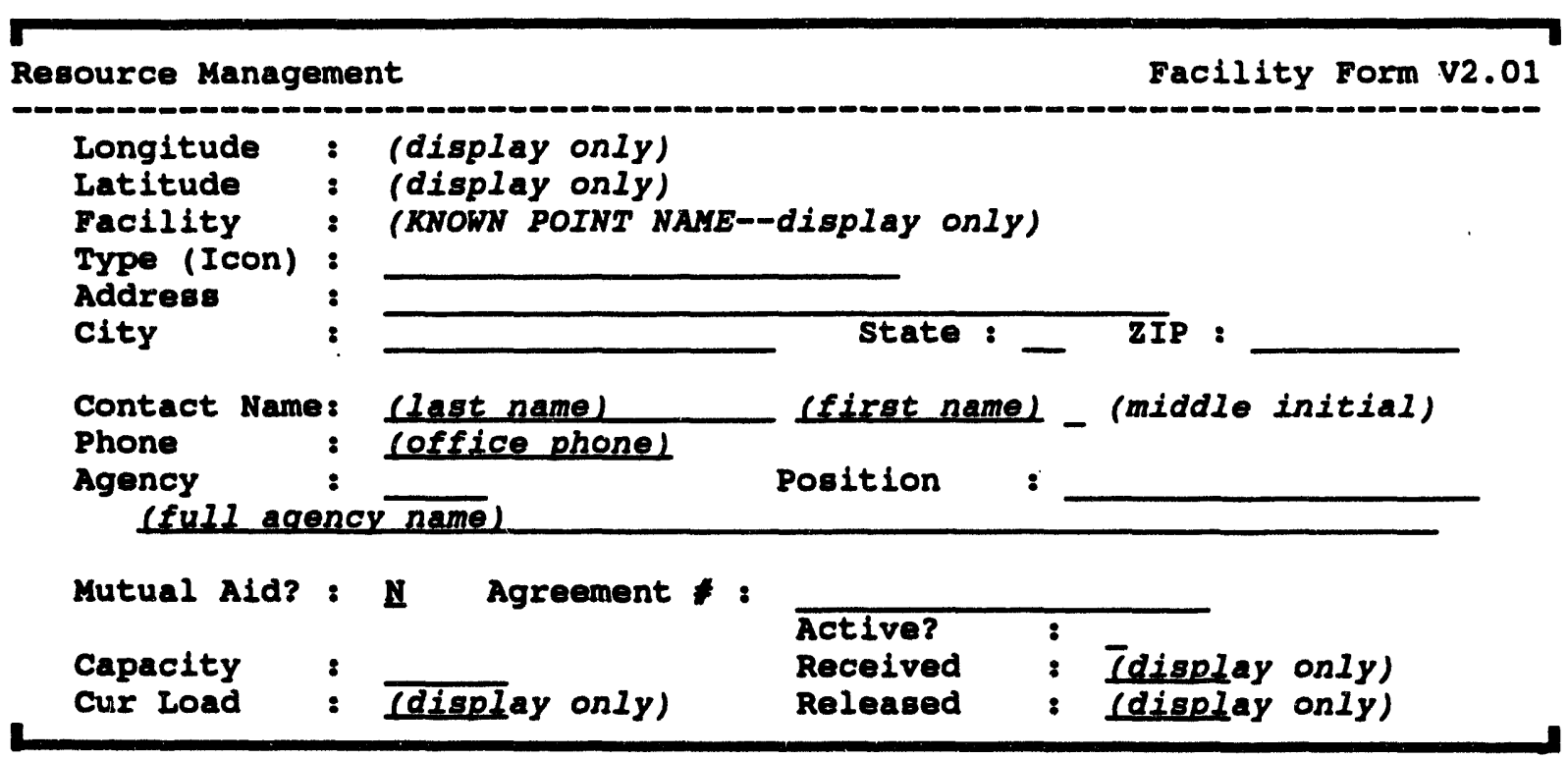

The location coordinates, facility name, current load, received and released information are for display only. Enter the following information on this form:

- Type (Icon): the name of the icon associated with this facility.

This field has some special features to help you:

Enter this: ??
To get this result: a numbered list of all possible icon names:

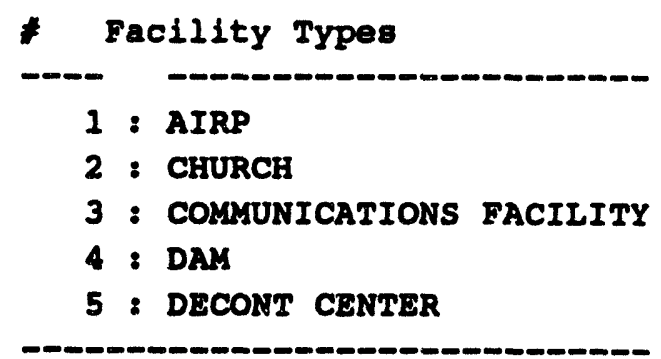

More... 
Press RETURN to display more icon names, or CTRL-Z to exit this list.

$3 x x$ a numbered list of all icon names starting with $x x x$

$?^{*} x x$ a numbered list of all icon names containing $x 0 x$

>icon number icon name automatically entered in the Type field

- Address/City/State/ZIP: the complete mailing address of the facility, including ZIP code

- Contact Name: the name of the contact person for this facility. If the contact person is already in the current personnel database, the rest of the contact fields are prefilled. If the contact person is NOT in the current CSEPP personnel database, the system informs you that you need to supply additional personnel information for the CSEPP personnel database:

* * MSG: Name not in personnel database

- Phone: the contact person's office phone number

- Agency: the agency code (an acronym, up to five characters) and the full agency name with which the contact person is affiliated

- Position: the contact person's job position

- Mutual Aid?: $\mathrm{Y}$ or N--Is there a mutual aid agreement in force?

- Agreement \#: the mutual aid agreement number (if agreement exists)

- Capacity: the number of people this facility can hold (if the facility is a shelter or care facility)

When you finish and exit this form, you will return to the Known Points Selection method menu, where you can continue to add facilities.

\section{Enter Personnol Information about the Facility Contact Person}

If the contact person is not in the personnel database, the following message will display after you finish entering information in the Facilities Form.

* * MSG: Need to add a personnel record

Press <RrTURN> to continue... 
To modify the personnel file, press RETURN to continue and then complete the personnel information on the following screen form. The Person Name and Office Phone are taken from the facility form. When you exit this personnel form, you will return to the Known Points Selection method menu, where you can continue to add facilities.

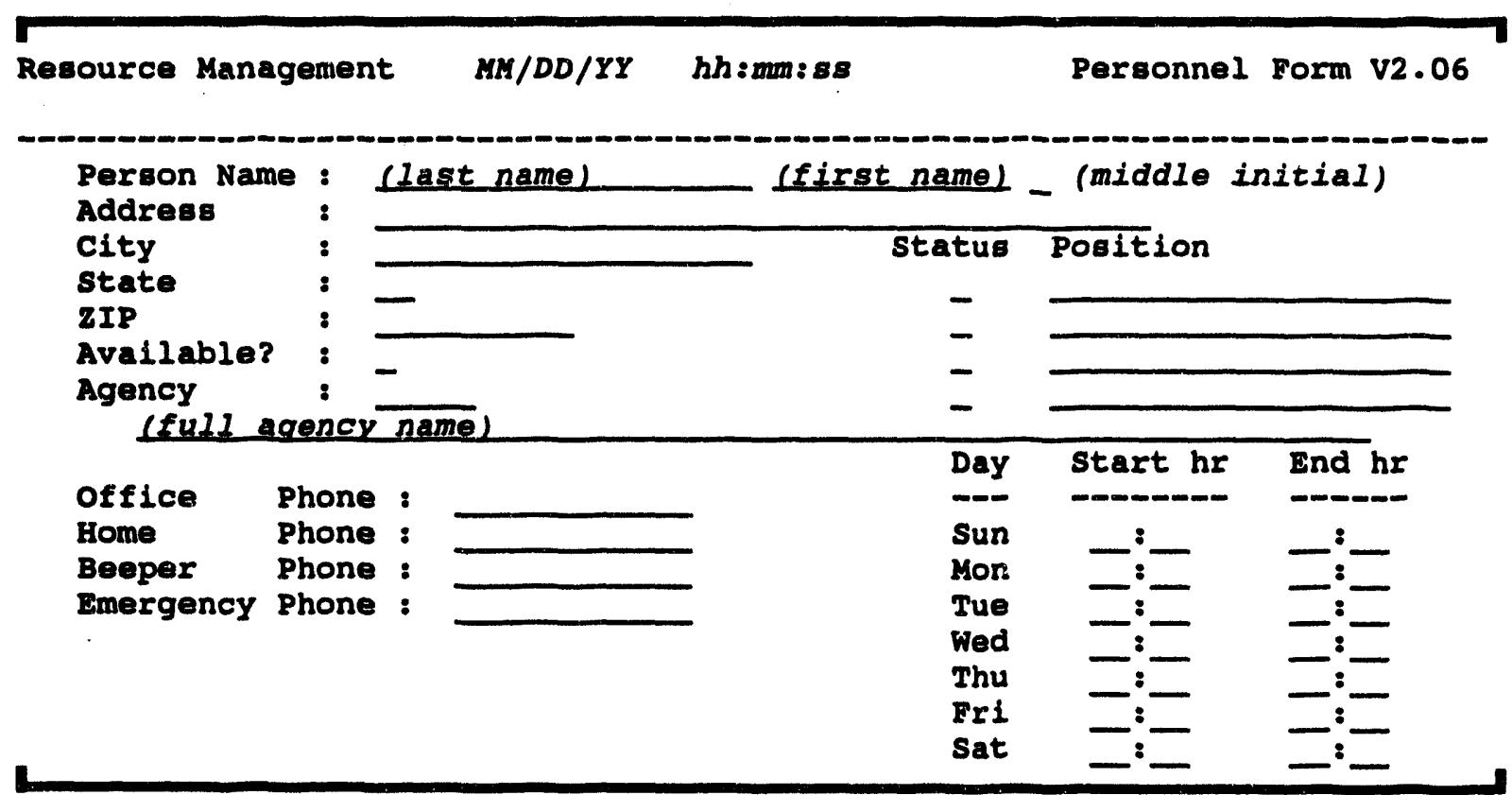




\section{IDDELETE FACILITIES*}

This option enables an Information Manager to delete a selected facility. The system displays the Facility Selection Method menu. You can use this menu to select facilities to delete.

Facility selection method menu

$0:$ ExIT
$1:$ Type in Facility name
$2:$ Select Facility name from a list
$3:$ Type in long/lat coordinates
$4:$ Use mouse to select racility
Menu Choice $(?=H e l p) ~$

When you have selected a facility, the system displays the Facility Form associated with that icon for you to check.

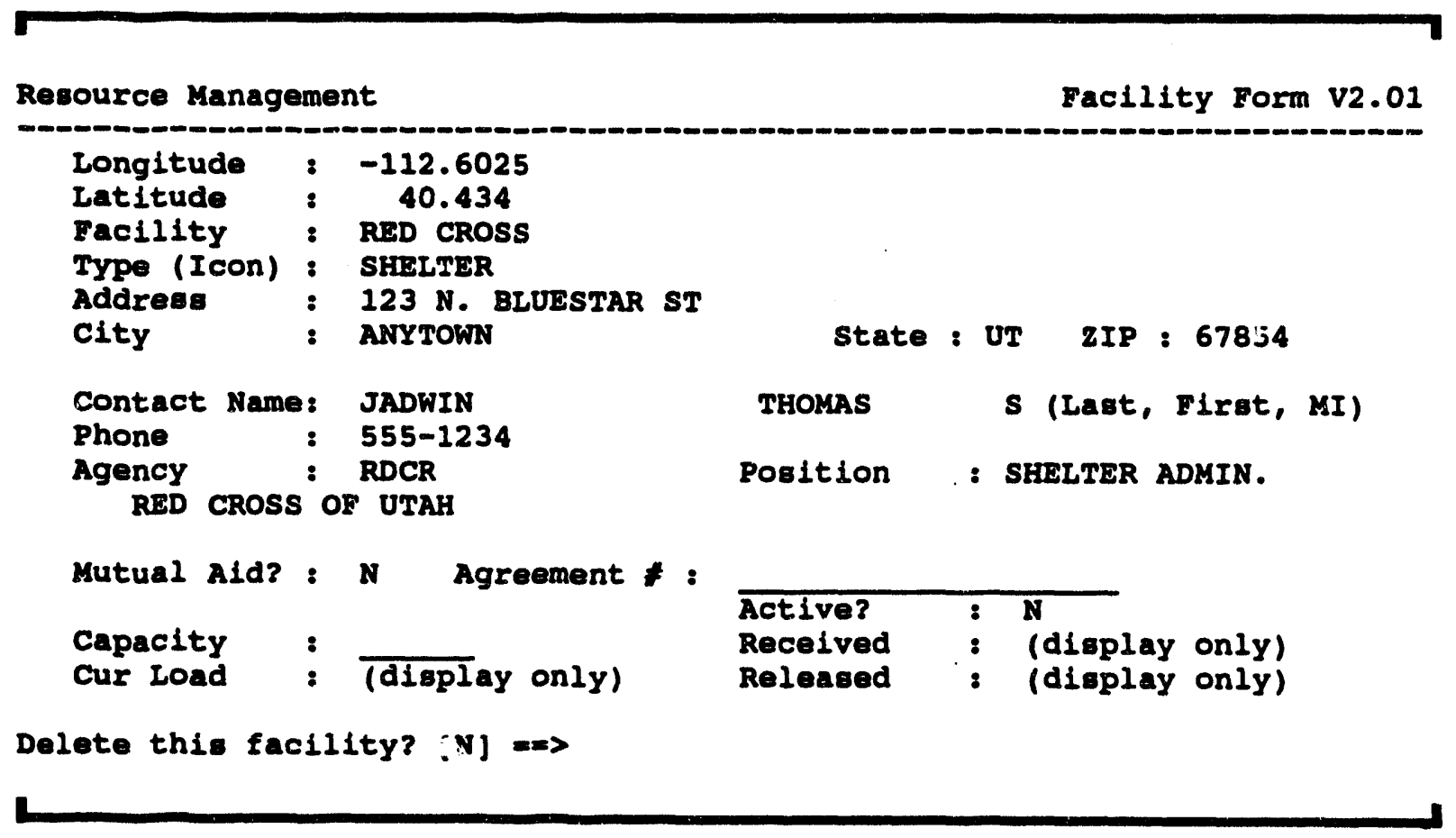

If you are certain this is the facility you want to delete, type a $Y$ at the Delete this facility? prompt and press the Return key. The system then returns the screen to the Facility Selection Method menu. Using this method, you can delete as many facilities as you want.

Exit the Modify Facilities function by selecting 0: EXIT from the menu. 


\section{DESCRIBE FACILITIES}

This option displays the description of a selected facility and gives you the option of listing the resources of the facility. The system displays the Facility Selection Method menu.

Facility Selection method menu

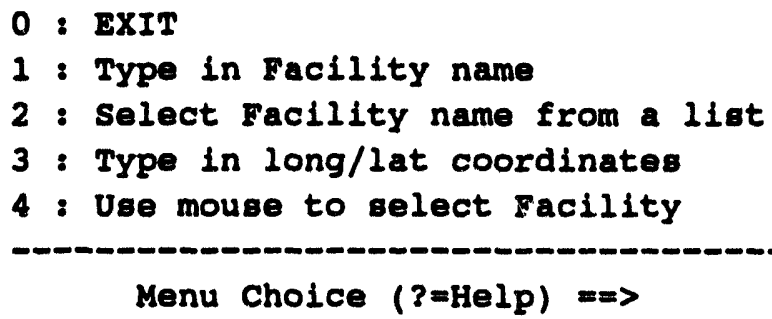

Use one of these four methods to select a facility, as described under the heading Selecting a Facility.

After you have selected a facility, the Facility Form displays, as shown in the following example. All fields are for display only.

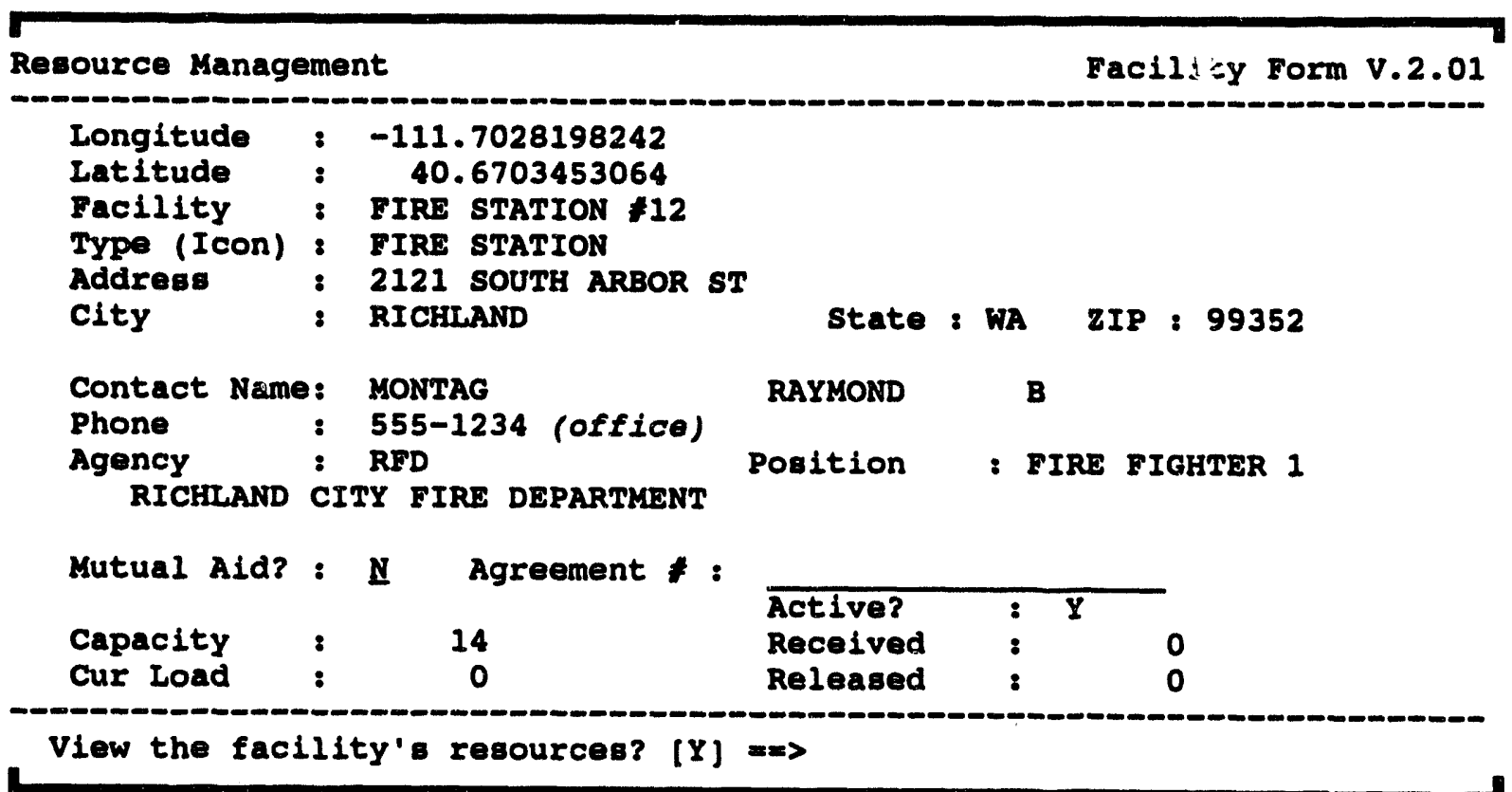


To view the resources at that facility, type $Y$ or press the Return key. The resources are then listed in alphabetical order by resource type:

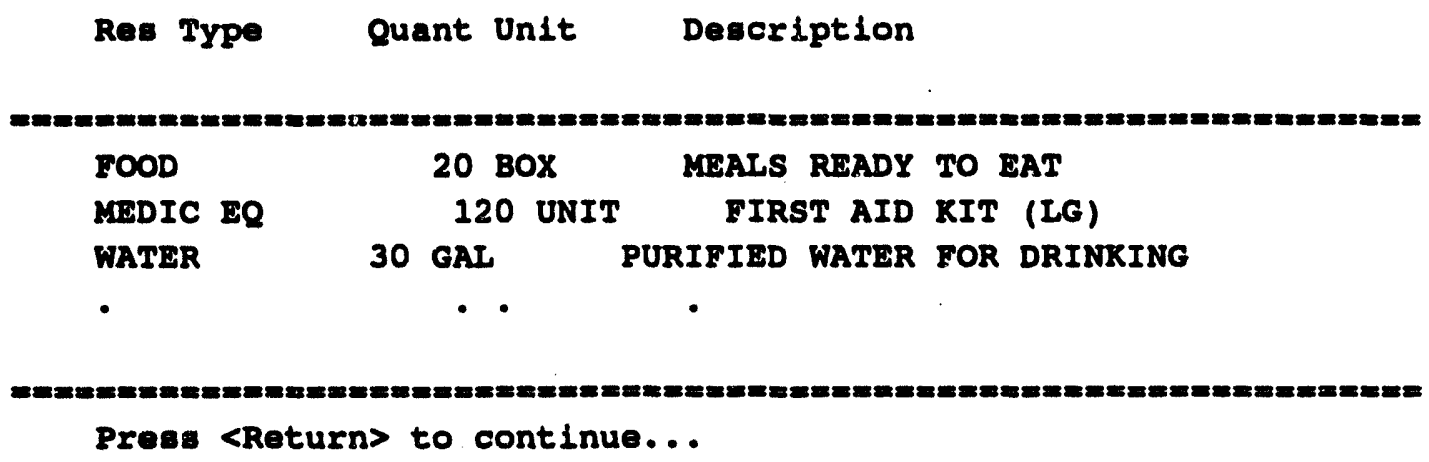




\section{HIGHLIGHT FACILITIES}

This option enables you to highlight facility icons that show the locations of certain resources within a specified area of interest. This involves 1) specifying an area of interest and 2) selecting the resource(s) to be noted at facilities within that area. The facilities that have the selected resources in that area then flash until you choose another menu option.

\section{Specify an Area of Interest}

The system prompts:

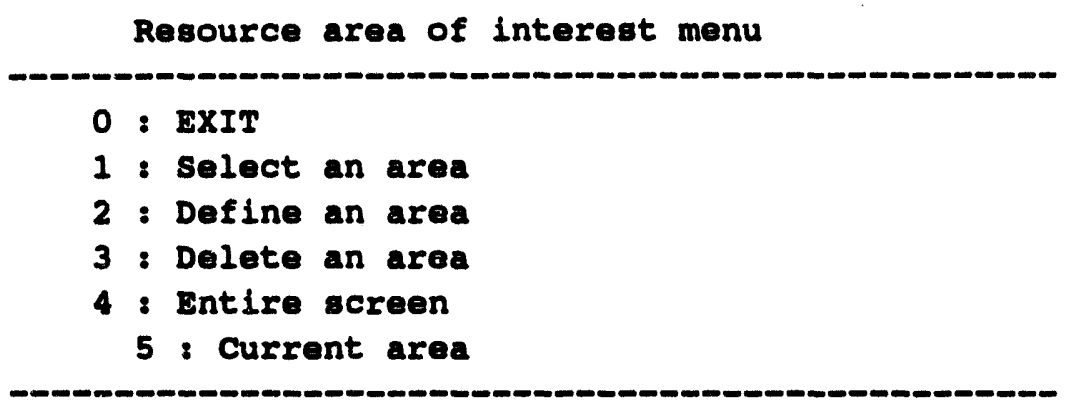

Menu Choice $(?=\mathrm{Help})=\mathrm{s}$

Use one of these methods to identify the area of interest:

1. Select an area: Prompts you to select an existing area by picking a polygon. For example, you could pick the outer polygon of the D2 model track output.

2. Define an area: Prompts you to define an area by drawing a polygon around the desired area.

When you pick CONTINUE to finish the last side of the polygon, the polygon lines are redrawn in white. The polygon remains on the screen until you use the Delete an Area option to erase it, or you exit Resource Management.

3. Delete an area: Prompts you to pick a polygon to be deleted from the area of interest. The polygon must be one that you have drawn by using the Define an Area option.

When you pick CONTINUE to confirm the deletion, the polygon is erased (redrawn in the background color). You may nieed to use REFRESH SCREEN.

4. Entire screen: Uses the entire current map area as the area of interest.

5. Current area: Uses the current polygon you picked using option 1: Select an area. This option only displays after you have selected a polygon by using option 1: Select an area. 
After you have specified the area, the subsequent selection of facilities by resource then applies only to facilities in that area.

\section{Select Which Resources to Locate}

The system displays the Resource Description Selection method menu.

\section{Resource Descr Selection method menu}

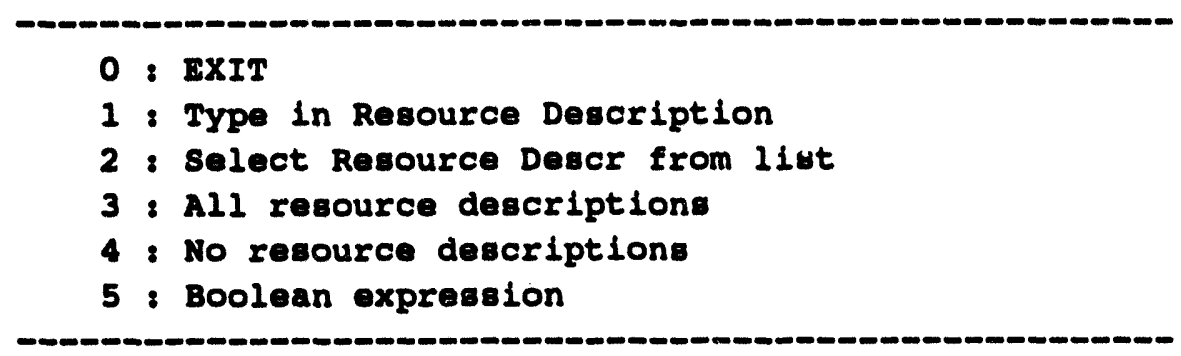

Menu Cholce $(8=$ Help) $\Rightarrow$

Use one of the following five methods to identify individual resources.

1. Type in Resource Description: Type in the name of a resource.

2. Select Resource Description from list: Displays the Resources Descriptions list.

3. All resource descriptions: Select any facilities with resources.

4. No resource descriptions: Unselect all selected (blinking) facilities.

5. Boolean expression: Presents a numbered list of resources (as in number 2) and prompts you for an expression that defines a set of resources:

Enter expression $==1,3$

If you enter Then facility icons flash for...

1 all facilities with resource 1

$1,7,5 \quad$ all facilities with resources 1 or 7 or 5

The system will then highlight any resources matching the selected description. The Resource Descr Selection method menu continues to display. Continue to select resources.

6. When you have finished selecting resources, select 0: EXIT to return to the Resource area of interest menu.

7. Select 0: EXIT to return to the Resource Management menu. 


\section{MODIFY FACILITIES*}

This option enables an Information Manager to modify facility information. Updating a facility consists of 1) deciding whether to update the facility itself (address, contact name), or 2) the known point of the facility (name and location).

The system will display the Facility Modification menu.

$\begin{aligned} & \text { Facility Modification menu } \\ 0 & : \text { ExIT } \\ 1 & : \text { Modify Facility } \\ 2 & : \text { Modify Known Point }\end{aligned}$

Menu Cholce $(? m$ Help) $=>$

Updating the facility consists of: 1) selecting a facility and 2) modifying the facility description.

Updating a known point consists of: 1) selecting a known point and 2) modifying either the location or the name.

\section{Select a Facility}

The Facility Selection method menu displays. For details on using this menu, see the heading Selecting a Facility.

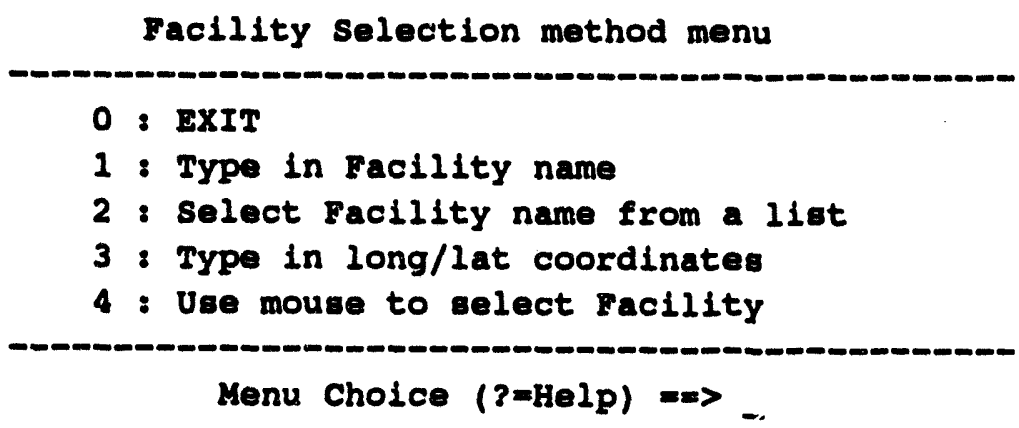

\section{Modify the Facility Description}

The facility form description of the selected facility is then presented for updating (for details on using or updating the form, see ADD FACILITIES, Entering a Facility Lescription). 


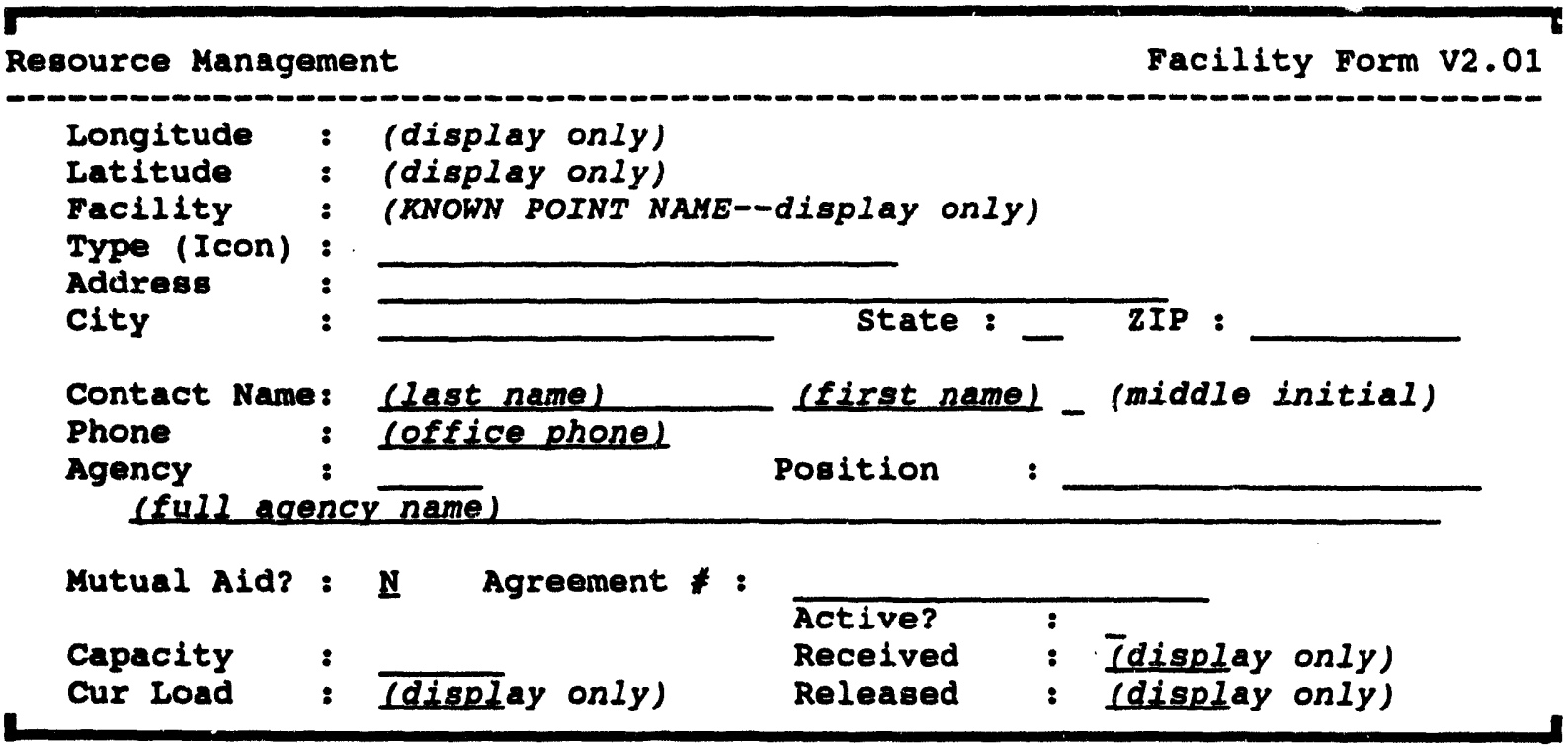

When you exit the facility form, the screen returns to the Facility Selection method menu, where you can choose another facility for modification.

Exit the Modify Facilities function by selecting 0: EXIT from the menu.

\section{Select a Known Point}

The Known Point menu displays. This menu works the same as the Facility Selection method menu described above. The only difference is that there can be known points with no associated facility that can be selected with this menu.

known Point selection method menu

0 : ExIT
1 : Type in known Point name
2 : Select known point name from a list
3 : Type in long/lat coordinates
: Use mouse to select known Point
Menu Choice $(?$ Help) mas

\section{Modify the Known Point Location or Name}

The Known Point name will display in a prompt similar to the following example.

Known POint: HIGH SCHOOL

Modify the known Point location? [Y] $=m$ 
Press the Return key (Yes) to modify the location. You will be prompted to select a new location for the Known Point with the mouse (or joydisk). After you select the new location, the facility will be moved.

If you enter $\mathrm{N}(\mathrm{No})$ at the prompt you can then modify the Known Point name. The following warning prompt will display.

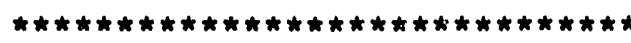

W A R N I N G !

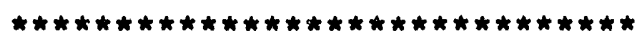

This allows you to change a known point name.

Any IP which uses this location WILL BE INVALIDATED!

Are you really sure you want to change the known point name?

$(Y / N)=>$

You can corrupt a lot of data if you change a Known Point name. Be sure of the consequences before you commit to the change.

If you choose to continue, the following prompts will display.

Known point: HIGH SCHOOL

Enter new known Point name: $=>$

Type in the new name at the prompt and press the Return key to change the name.

known Point: HIGH SCHOOL

Enter new known Point name: m=> GRADE SCHOOL 


\section{Selecting a Facility}

The following RESOURCE MANAGEMENT menu options require you to select a particular facility:

- MODIFY FACILITIES

- DELETE FACILITIES

- DESCRIBE FACILITIES

- ASSIGN RESOURCES

- DELETE RESOURCES

- DESCRIBE RESOURCES

- MOVE RESOURCES

In each case, the general sequence for selecting a facility is the same. The system displays the following menu:

Facility selection method menu

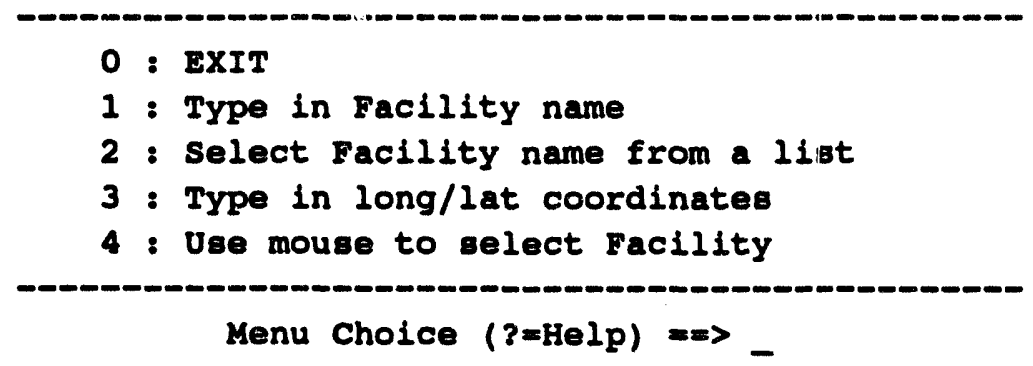

Select one of these four methods to identify the facility:

1. Type in Facility name: Prompts you to enter the name of an existing facility. For example:

Enter Facility name $\Rightarrow$ PIRE STATIOS $* 3$

2. Select Facility name from a list: Prompts you to choose one from a numbered list of facility names. For example:

Facility Nameg

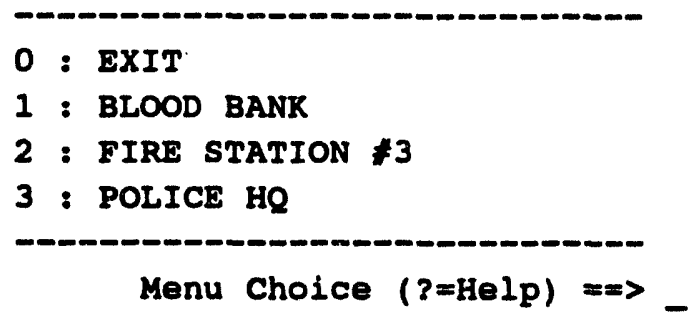

Enter the facility's number, or exit. 
3. Type in long/lat coordinates: Prompts you for the longitude and then the latitude coordinates of the facility location.

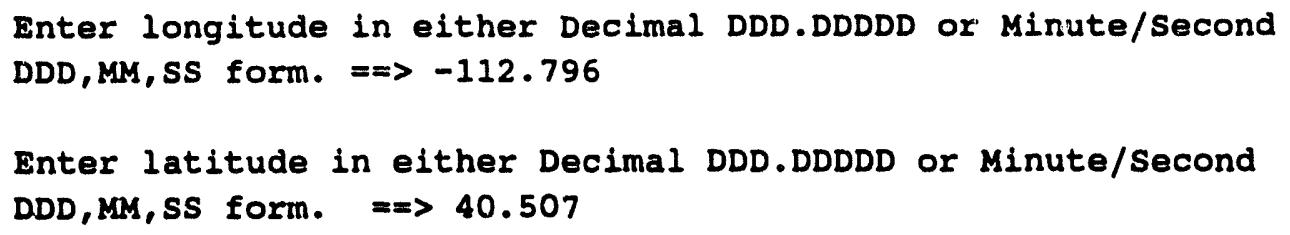

4. Use mouse to select Facility: Enables you to pick a facility icon on the screen by using the cross hairs.

The selected facility is then used in completing the current operation. 


\section{Resource Tasks}

The following figure illustrates that many of the resource tasks share common procedural elements:

DEFINE RESOURCES

ASSIGN RESOURCES

MODIFY RESOURCES

DELETE RESOURCES

MOVE RESOURCES

DESCRIBE RESOURCES

ENABLE RESOURCES

HIGHUGHT

FACILTIES

SUMMARIZE RESOURCES

\section{Resource Form}

Select facility $\rightarrow$ Resource Form

Select resource $\rightarrow->$ Resource Form

(at a facility)

Select resource $\rightarrow->$ Resource Form (at a facility) \& Amt to move facility
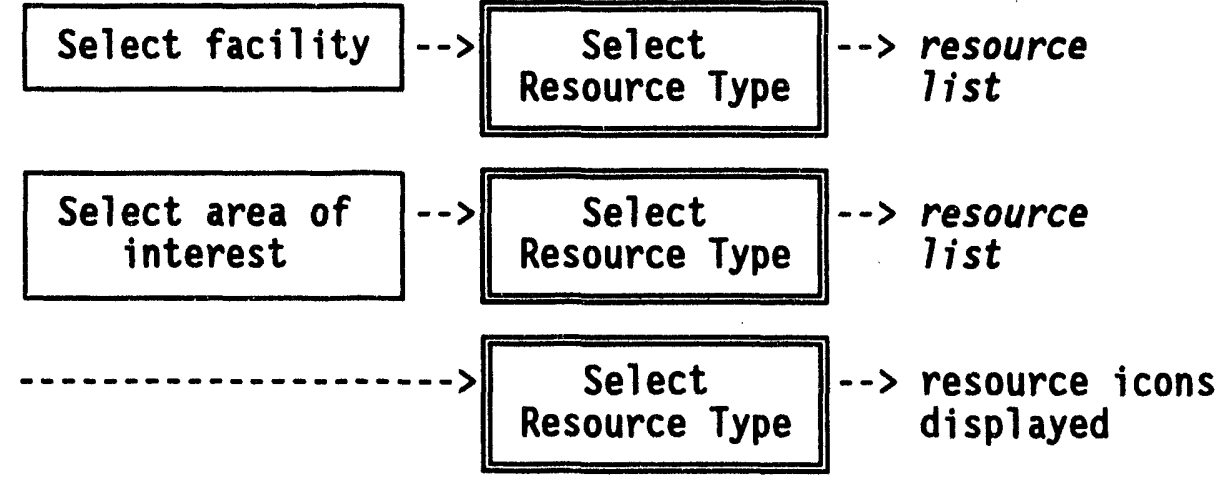

Select area of interest
Select Resource Type $\rightarrow$ facility icons displayed 
- The Information Manager tasks-DEFINE RESOURCES, ASSIGN RESOURCES, MODIFY RESOURCES, DELETE RESOURCES, and MOVE RESOURCES--present facility information in the same resource form. (See Resource Form Use for a summary description of how to use this information form.)

- Selecting a Resource is explained independently as a resource task.

- Selecting a Resource Type is explained independently as a resource task.)

- Selecting a Facillty is explained independently as a facility task.

- Note that HIGHUGHT FACIUTIES is a facility task that relates to locating resources. 


\section{ASSIGN RESOURCES*}

This option enables an Information Manager to assign a quantity of a resource to a specific facility. (The resource type and description must have been already defined with DEFINE RESOURCES.) Assigning resources consists of 1) selecting the facility where the resource is to be assigned and 2) entering the resource information.

\section{Select a Facility}

The Facility Selection method menu will display.

Facility selection method menu
0 : ExIT
1 : Type in Facility name
2 : Select Facility name from a list
3 : Type in long/lat coordinates
4 : Use mouse to select Facility
Menu Choice $(?=H e l p)=m$

Use one of these four methods to select a facility, as described under the heading Selecting a Facility.

After you have selected a facility, the Resource Form displays, as shown in the following example.

\section{Enter the Resource Information}

After selecting the facility, enter resource information in the Resource Management Resource Form.

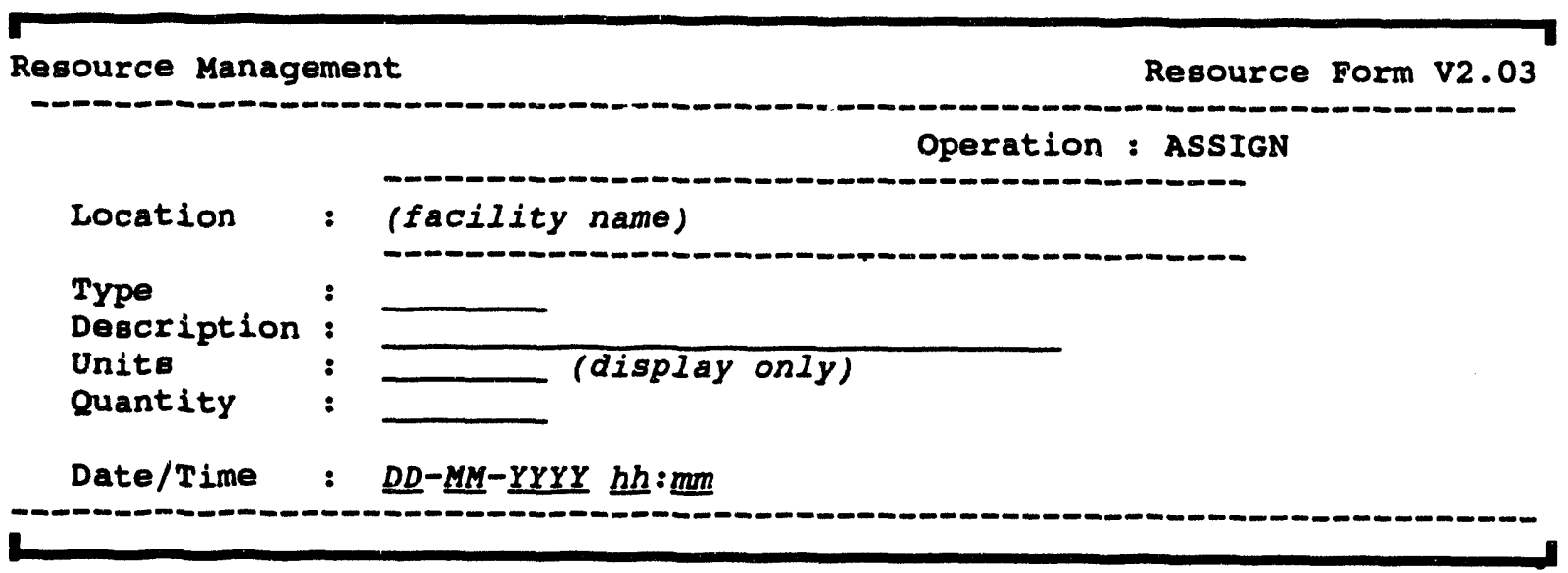


The Operation, Location, and Units fields are automatically filled and cannot be modified.

Enter the following information on this form. (For details on special entry features, see Resource Form Use under the heading Resource Tasks.)

- Type: the general type of resource (or ?? to see a list of resource types)

This must be a defined resource type or the system ignores your input.

- Description: the name of a specific resource of the selected Type (or ?? to see a list of resource descriptions)

If you enter a resource description that is NOT defined for the entered resource type, the system ignores your input.

- Quantity: a number of units greater than zero.

- Date/Time: the date and time at which the resource was assigned.

When you approve the information and exit the form with GOLD-Z, the screen returns to the Facility Selection method menu, where you can choose another facility for assigning resources. 


\section{IDEFINE RESOURCES*}

This option enables an Information Manager to define individual resources within general resource types. The defined resources can then be assigned in various quantities to facilities. A resource is defined by its

- Type

- Description

- Units of measure

These fields are in the following resource form. (For details, see Resource Form Use under the heading Resource Tasks.)

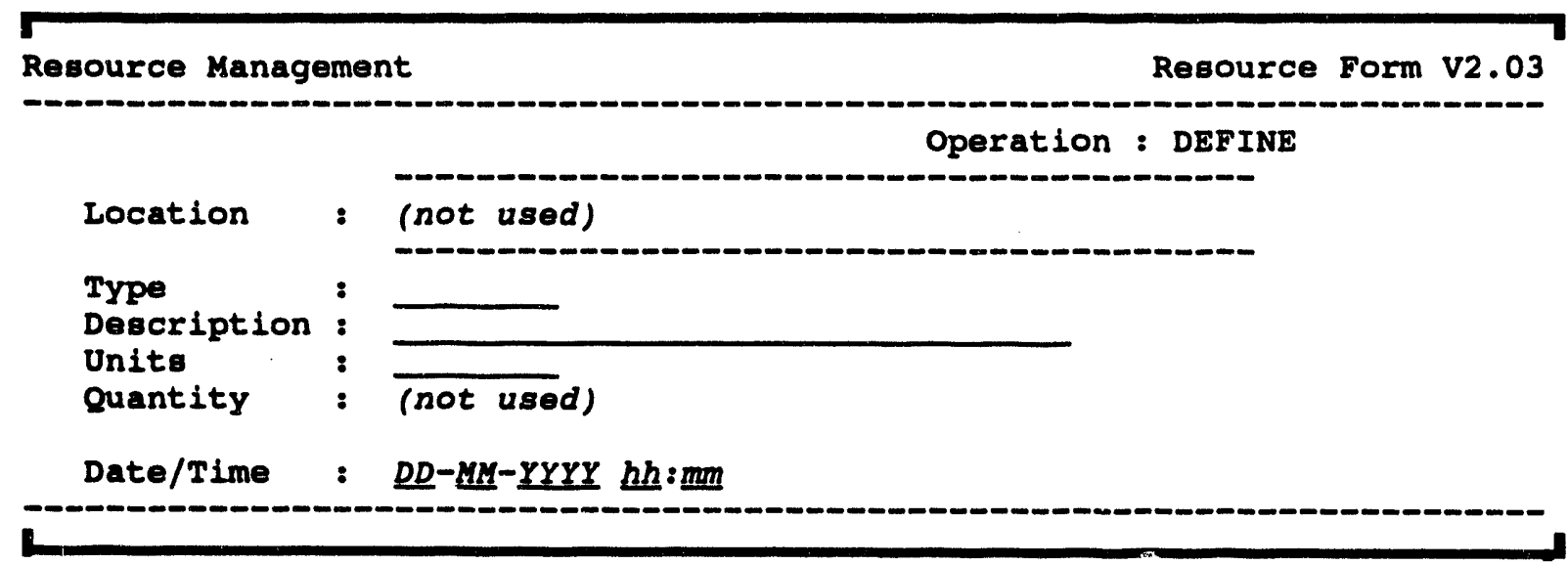

The Operation field is automatically filled in. The Location and Quantity fields do not apply to resource definition.

Enter the following information on this form:

- Type: the general type of resource (up to eight characters) or ?? to see a list of resource types. This type of help list is similar to the following example.

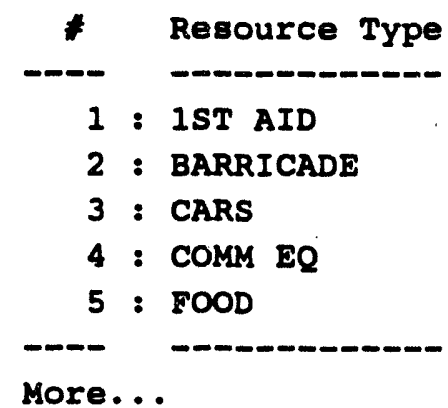


- Description: a unique description (up to 32 characters).

If you enter resource description that is already defined, the system informs you and enables you to enter a different description.

- Units: any units of resource quantity (up to eight characters).

- Date/Time: the date and time when the resource was defined.

When you approve the information and exit the form by pressing the RETURN key or GOLD-Z, another blank resource form is presented so you can continue to define resources. To quit when you are finished, press GOLD-Y. 


\section{ID DELETE RESOURCES*}

This option enables an Information Manager to delete individual resources from the resource database. The Resource Selection method menu displays as shown.

Resource selection method menu

0 : ExIT
1 : Type in Resource Location \& Name
3 : Tylect Resource from a list
4 : Use mouse to select Resource
Menu Choice $(?=H e l p)==$

Use one of these four methods to select a resource type, as described under the heading Selecting a Resource.

After you select a resource using one of the above methods, it is deleted from the database and the screen is returned to the Resource Selection method menu. You can continue to delete resources, or you can select option 0 to exit.

If you have deleted resources, the following message appears when you exit the delete function.

\footnotetext{
* * MSG: Run VALIDATE IP since you have deleted resources
}

Press <RETURN> to continue... 


\section{ID DESCRIBE RESOURCES}

DESCRIBE RESOURCES enables you to view a list of resources of a specific type at a specific facility. Describing a resource consists of 1) selecting a facility and 2) selecting a resource type. The Resource Selection method menu displays as shown.

Resource selection method menu

0 : EXIT
1 : Type in Resource Location \& Name
2 : Select Resource from a list
3 : Type in long/lat coordinates
4 : Use mouse to select Resource
Menu Choice $(?=H e l p)==>$

Use one of these four methods to select a resource type, as described under the heading Selecting a Resource.

After you select a resource using one of the above methods, the system displays a list of the resources of that type located at that facility:

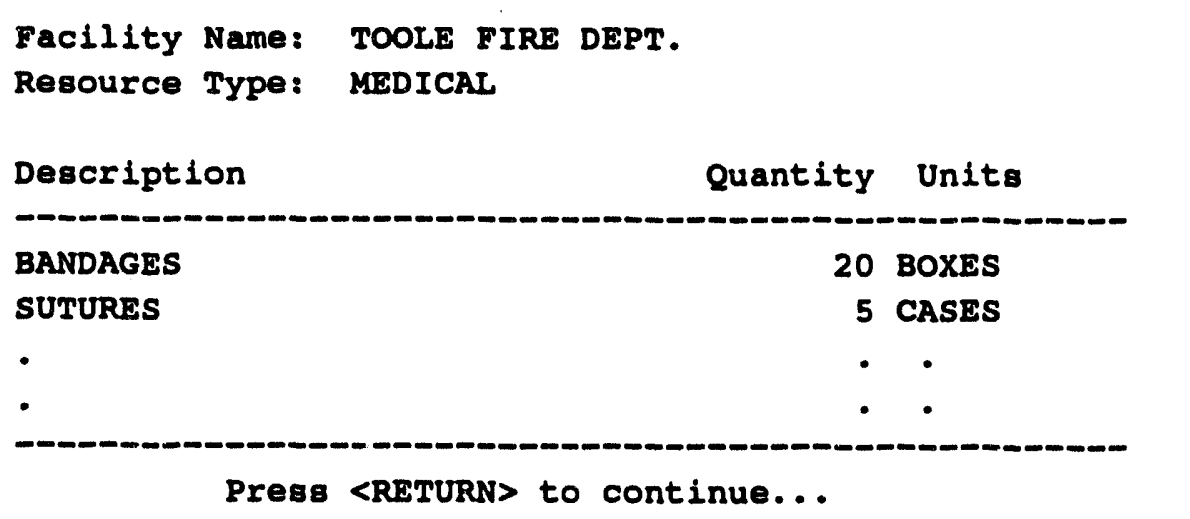

Press the Return key to exit the list and return to the Resource Selection method menu. Select $0:$ EXIT to exit the menu. 


\section{IIISABLE RESOURCES}

This option enables you to erase resource icons that show the locations of selected resources (icons that have been drawn on the screen by using the ENABLE

RESOURCES option). When you select Disable Resources, the system displays the Resource Type Selection method menu.

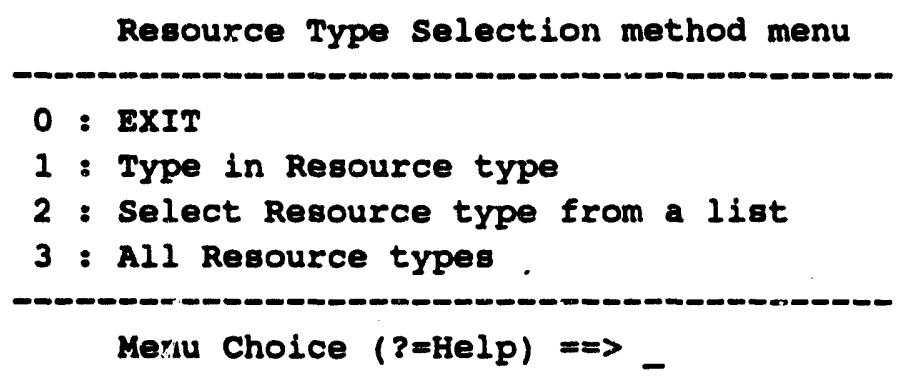

Use one of the three options to select resource type(s).

The selected icons are then erased. Erasing is done by drawing the icons in black (the background color), which can obscure other map features. If this occurs, use REFRESH SCREEN to cleail up the display. 


\section{ENABLE RESOURCES}

This option enables you to display resource icons that show the locations of selected resources. When you select Enable Resources, the system displays the Resource Type Selection method menu.

Resource Type selection method menu

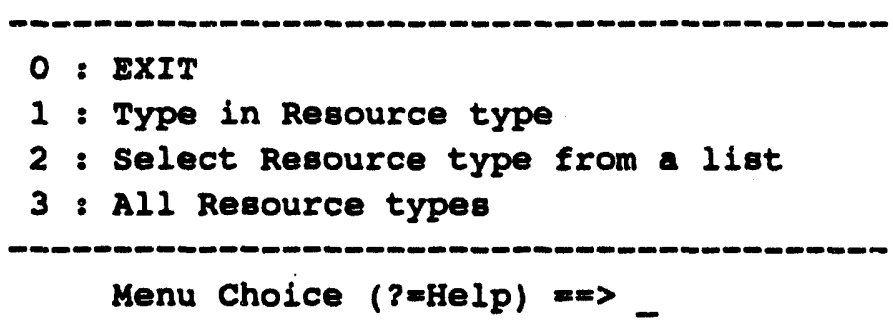

Use one of the three options to select resource type(s).

The selected icons are then displayed at the locations of that resource. Each icon represents a major resource type, which can include any number of unique resources. 


\section{ILIST RESOURCES}

This option enables you to list all

- Resources

- Resource types

- Quantities

- Units

- Facility where the resources are located

When you select this command, the system displays a report similar to the following example.

\begin{tabular}{llrl}
\hline LIGHTS & PROPANE IANTERNS & 1 UNIT & USED CAR DEALERSHIP \\
CARS & TAXIS & 5 UNIT & USED CAR DEALERSHIP \\
TRUCKS & CEMENT MIXERS & 1 UNIT & USED CAR DEALERSHIP \\
MEDIC EQ STRETCHERS & 34 UNIT & USED CAR DEALERSHIP \\
EMERG EQ BLANKETS & 5 UNIT & FIRE STATION \\
LIGHTS & PROPANE IANTERNS & 5 UNIT & FIRE STATION \\
IST AID SUTURES & 6 BOXES & FIRE STATION
\end{tabular}

Press <RETURN> to continue...

Page through the list by pressing the Return key. When all resources have been listed, the system returns you to the Resource Management menu. 


\section{MODIFY RESOURCES*}

This option enables an Information Manager to modify the:

- Quantity of a resource that is already assigned to a facility

- Description or Units of any resource

Modifying the quantity consists of 1) selecting a resource at a particular facility and 2) modifying the quantity information for one resource assigned to that facility. This change will be updated in the resource database.

Modifying the Description or Units consists of 1) selecting a resource at a particular facility and 2) modifying the Description or Units of the resource. All facilities that contain this resource will be updated in the resource database.

Note: You must have enabled resources (turned on their icons) before using this option. Use the Enable Resources option to do this.

\section{Select a Resource for Modifying}

After you select the Modify Resources option, the system prompts:

Resource Modification Menu

0 : EXIT
1 : Modify amount of resources at a facility
2 : Modify resource Description or Units
Menu Choice $(?=\mathrm{He} l p)=>$

Select the parameter or parameters you want to modify and press the Return key. The system will display the following menu:

Resource Selection method menu

0 : ExIT
1 : Type in Resource Location \& Name
2 : Select Resource from a list
3 : Type in long/lat coordinates
4 : Use mouse to select Resource
Menu Choice $(?=\mathrm{Help})$ mes

Use one of these four methods to identify a resource as described under the heading Selecting a Resource. 
When you select a resource to modify the Description or Units, the system will display the following warning prompt.

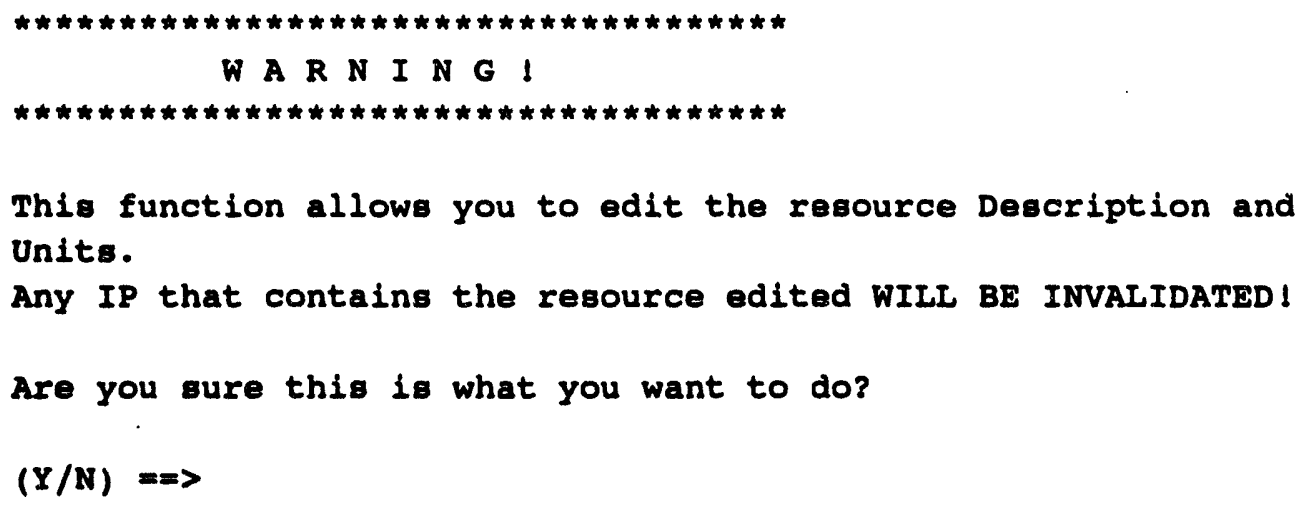

Be sure you understand the consequences of changing the data before you answer yes $(\mathbf{Y})$ to the prompt.

\section{Modifying the Resource Information}

After identifying a resource, you can modify the Description and Units information in the resource form. (For details, see Resource Form Use under the heading Resource Tasks.) With the exception of Description, Units, and date/time, all items in the Resource Form are Read Only.

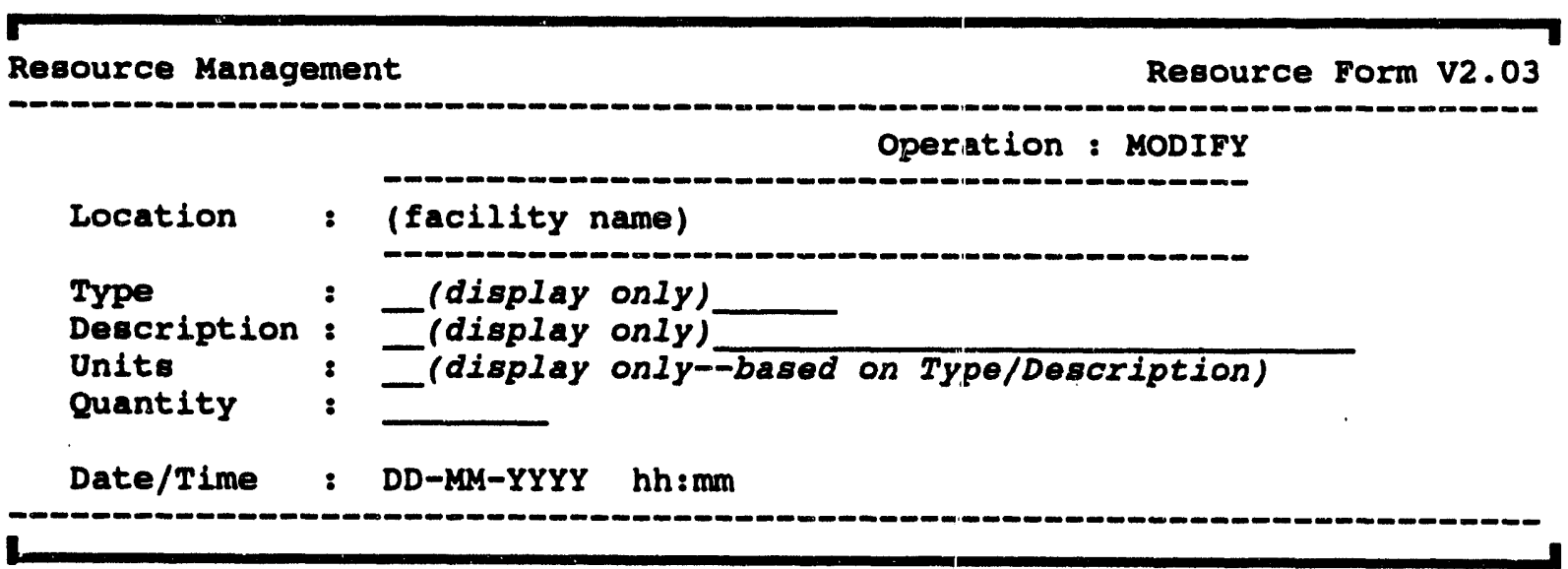

All form fields are filled in automatically, based on the resource and facility that you selected. You can modify only the Quantity and Date/Time fields to update the resource at that facility:

- Type (display only): the general type of resource

- Description (display only): the description of an individual resource 
- Units (display only): the units of measure that apply to the resource named by the Description field. Units cannot be changed in this field.

- Quantity: the current quantity of the resource named by Description. The quantity cannot be less than zero.

If you change the quantity of an existing resource, the system prompts

* * MSG: Run VAIIDATE IP, resources have been moved

When you exit the resource form, the screen returns to the Resource Selection method menu, where you can continue to select other resources for modification.

To exit, select the 0: EXIT option. 


\section{MOVE RESOURCES*}

MOVE RESOURCES enables you to move currently assigned resources between facilities. Moving a resource consists of 1) selecting a resource that is associated with a particular facility, 2) specifying the quantity to be moved and 3) selecting a destination facility for the moved resource.

\section{Select a Resource to Move}

The system displays the Resource Selection method menu.

Resource Selection method menu
0: EXIT
1 : Type in Resource Location \& Name
2 : Select Resource from a list
3 : Type in long/lat coordinates
4 : Use mouse to select Resource
Menu Choice $(?=H e l p)$ =

Use one of these four mathods to identify a resource, as described under the heading Selecting a Resource.

\section{Specify an Amount of Resource to Move}

After selecting the resource to be moved, the resource form appears on the screen:

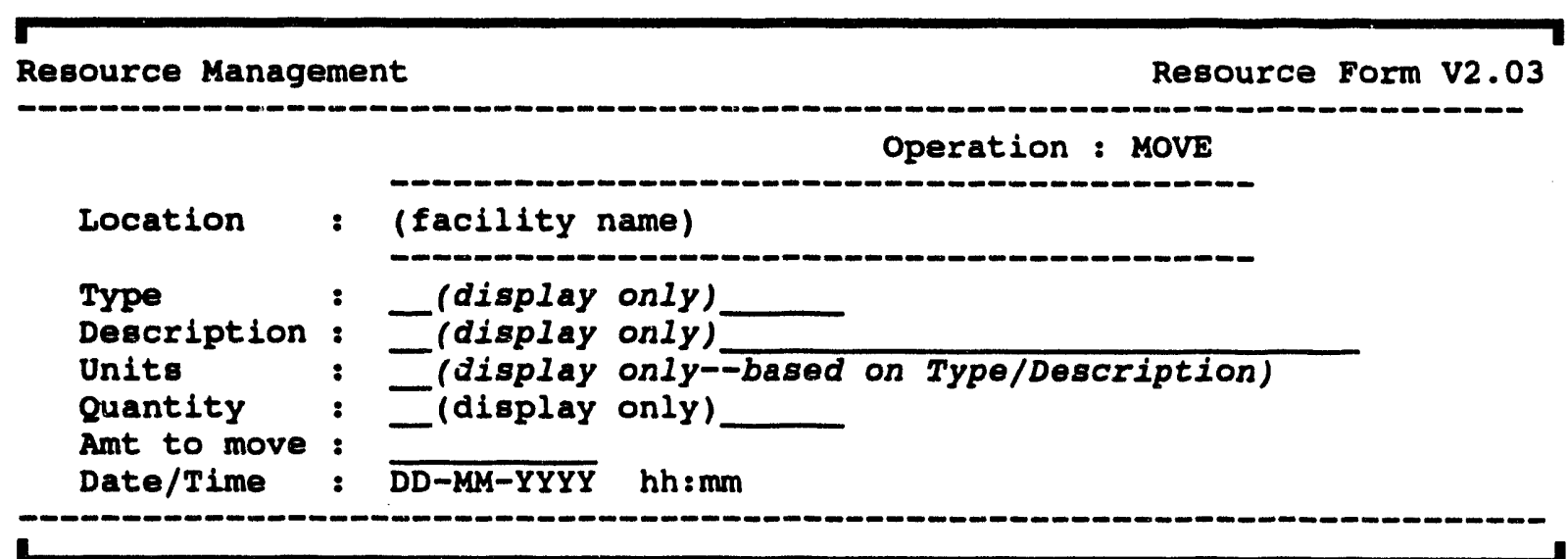

The Operation, Location, Type, Description, Units, and Quantity fields are automatically filled in and cannot be changed.

- Amt to Move: The amount moved must be less than the current quantity. 
- Date/Time: Change the date and time, if necessary, to reflect the date of the change.

\section{Select a Destination Facility}

The system displays the Facility Selection method menu.

Facility selection method menu

$0:$ ExIT
$1:$ Type in Facility name
$2:$ Select Facility name from a list
$3:$ Type in long/lat coordinates
$4:$ Use mouse to select Facility
Menu Choice $(?=$ Help $)==$

Use one of these four methods to identify a resource as described under the heading Selecting a Facility.

After you have selected a destination facility, the system makes the desired changes in the resource database and returns to the Select a Resource prompt, where you can continue with another move.

If you try to move more resources than the facility has in stock, the system displays the following message:

* * ERR: Cannot move more than is held

If you need to adjust quantities, use the Define Resources or Modify Resources options.

When you exit the resource form, the screen returns to the Resource Selection method menu, where you can continue to select other resources for modification.

To exit, select the 0: EXIT option. 


\section{Resource Form Use}

Many RESOURCE MANAGEMENT options present the following form for specifying resource information.

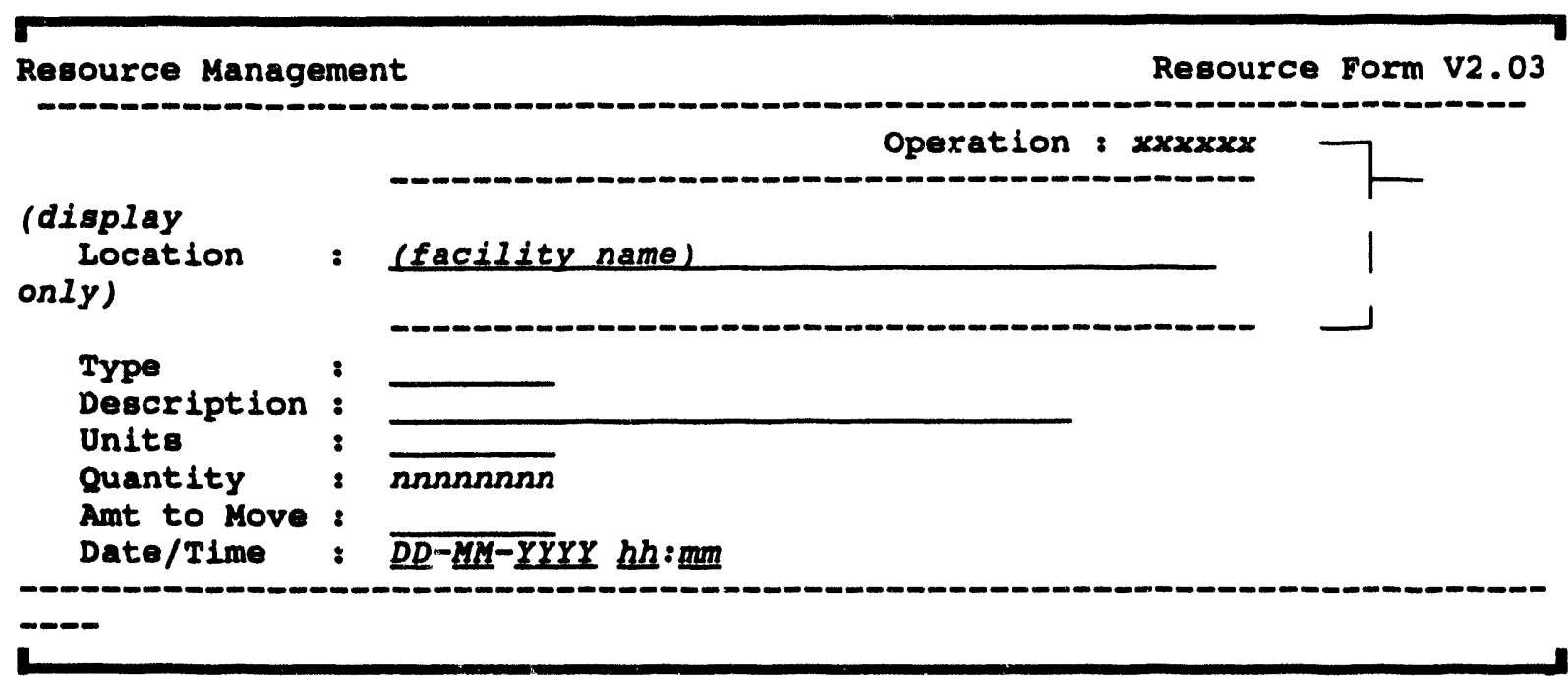

The form fields are described here.

- Operation (display only): DEFINE, ASSIGN, MODIFY, or MOVE

- Location (display only): the name of the facility where the resource is located. (During the DEFINE operation, this field is blank.)

- Type: the general type of resource (up to eight characters). This field includes special help features (see the following page).

- Description: a unique description (up to 32 characters). This field includes special help features (see the following page).

- Units: the units of resource quantity (up to eight characters). Units are entered only during the Define Resources operation. At other times, the units are an automatic display, based on the Type and Description values.

Units are coordinated with the resource description. The units of some resources can be simply "units". For example:

$\begin{array}{ll}\text { Resource Description } & \text { Units } \\ \text { Rice (50-lb) } & \text { Sacks } \\ \text { Blankets } & \text { Units } \\ \text { Gas Masks } & \text { Units } \\ \text { Sutures } & \text { Boxes }\end{array}$


- Quantity: the number of units of the resource at the designated facility. (For the DEFINE and MOVE operations, the quantity is for display only.)

- Amt to move: amount of resource to move between facilities. This appears only during the Move Resources operation.

- Date/Time: the date and time the resource was actually defined, assigned, modified, or moved. 
Help Features for Type and Description

These fields have identical special features to help you:

Field Enter this: To get this result:

Type ?? a numbered list of all resource types. For example:

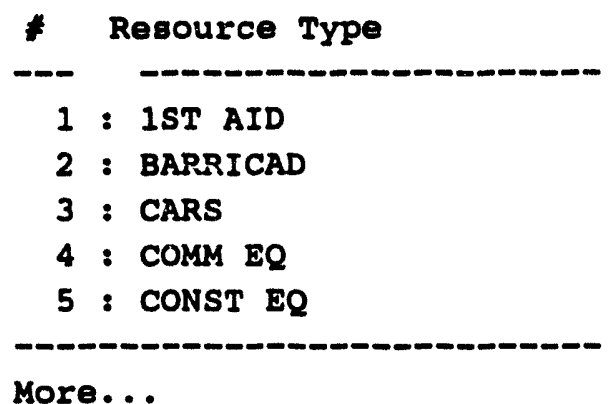

Press RETURN to display more resource names, or CTRL-Z to exit this list.

?xxx a list of all resource types starting with $x x x$

$? * x \times x \quad$ a list of all resource types containing $x x x$

>index \# resource type from the numbered list automatically

(from list) entered in the "Type" field

Descrip. ??

a numbered list of all resource descriptions. For example:

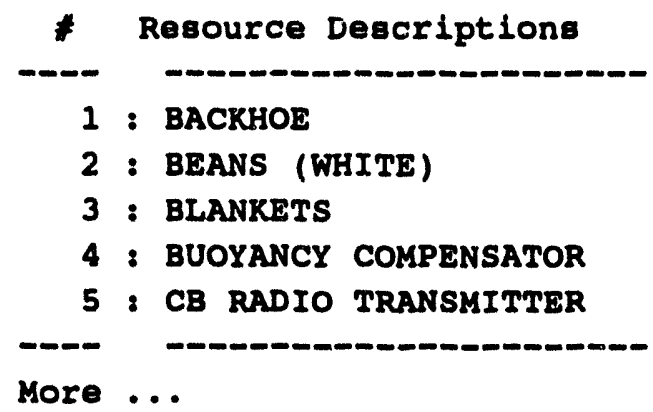

Press RETURN to display more resource descriptions, or CTRL-Z to exit this list.

?xox a list of all descriptions starting with $x x x$

>index \# $\quad$ resource description from the numbered list

(from list) automatically entered in the "Description" field 


\section{Selecting a Resource}

The following RESOURCE MANAGEMENT menu options require you to select a specific resource within a general resource type:

\section{MOVE RESOURCES MODIFY RESOURCES DELETE RESOURCES}

In each case, the general sequence for selecting a resource type is similar. The system prompts:

Resource Selection method menu

$0: \operatorname{EXIT}$

1 : Type in Resource Location \& Description

2 : Select Resource from a list

3 : Type in long/lat coordinates

4 : Use mouse to select Resource

Menu Choice $(?=$ Help $) \Rightarrow$

Use one of these four methods to identify a resource at a facility:

1. Type in Resource location and name: Prompts you to enter the name of an existing facility and a resource description.

Enter Resource location $\quad \Rightarrow$

Enter Resource description =\#>

2. Select Resource from a list: Prompts you to choose one from a numbered list of resources at various facilities. For example:

Resources

\begin{tabular}{|c|c|c|}
\hline 0 & : EXIT & \\
\hline 1 & : POLICE HEADQUARTERS & SQUAD CARS \\
\hline 2 & : SHELTER 1 & BLANKETS \\
\hline 3 & : ERANKLIN SCHOOL & FIRST AID RITS \\
\hline 4 & : FIRE STATION & HOOK AND LADDER \\
\hline
\end{tabular}

Enter the number that corresponds to the desired facility and resource, or press CTRL-Z to exit.

3. Type in long/lat coordinates: Prompts you for the longitude and then the latitude coordinates of the resource loration. 
4. Use mouse to select Resource: Enables you to pick a resource icon on the screen by using a mouse (or other pointing device).

Note: You must first have enabled (turned on the icons) the resources before you can select them with the mouse. Use the Enable Resources option to do this.

The selected resource description is then used in completing the current operation.

\section{Selecting a Resource Type}

The following RESOURCE MANAGEMENT menu options require you to select a general resource type:

\section{DESCRIBE RESOURCES ENABLE RESOURCES SUMMARIZE RESOURCES}

In each case, the general sequence for selecting a resource type is similar. The system prompts:

\begin{tabular}{l} 
Resource Type Selection method menu \\
\hline $0:$ ExIT \\
$1:$ Type in Resource type \\
$2:$ Select Resource type from a list \\
$3:$ All Resource types \\
Menu Cholce (?=help) =x
\end{tabular}

Use one of these three methods to select the resource type:

1. Type in Resource type: Prompts you to enter the name of an existing resource. For example:

Enter Resource type $=\Rightarrow$ FOOD

2. Select Resource type from a list: Prompts you to choose one from a numbered list of resource types. For example:

Resource Typer

$0:$ EXIT
$1:$ IST AID
$2:$ BARRICAD
$3:$ CARS
$4:$ FOOD
Menu ChOICe $(?=\mathrm{Help})=\mathrm{D}$


Enter the number corresponding to a resource type, or exit.

3. All resource types: Will select all resource types in a defined area of interest.

The selected resource type is then used in completing the current operation. 


\section{SUMMARIZE RESOURCES}

SUMMARIZE RESOURCES enables you to view a list of all resources of one resource type within a specified area. Producing this summary of resources consists of 1) selecting an area of interest and 2) selecting a resource type.

\section{Select an Area of Interest}

The system prompts:

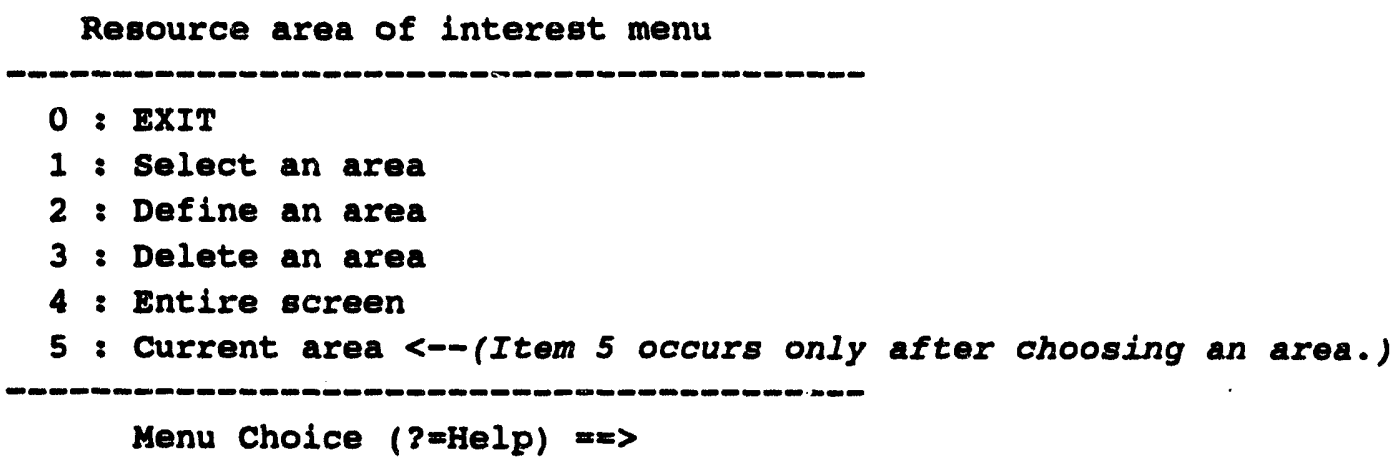

Use one of these five methods to identify the area of interest:

1. Select an area: Prompts you to select an existing area by picking a polygon. For example, you could pick the outer polygon of the D2 model track output.

2. Define an area: Prompts you to define an area by drawing a polygon around the desired area.

When you pick CONTINUE to finish the last side of the polygon, the polygon lines are redrawn in white. The polygon remains on the screen until you use the "Delete an area" option to erase it, or exit the Summarize Resources option.

3. Delete an area: Prompts you to pick a polygon to be deleted. The polygon must be one that you have drawn by using the "Define an area" option.

When you pick CONTINUE to confirm the deletion, the polygon is erased (redrawn in the background color). You may need to use REFRESH SCREEN.

4. Entire screen: Uses the entire current map area as the area of interest.

5. Current area: "Re-uses" the last-specified area. This option appears on the menu only after you have selected an area of interest once.

After you have specified the area, the subsequent selection of resource type applies only to resources within that area. 


\section{Select a Resource Type to be Summarized}

The system prompts with the Resources Types, list as shown in the following example.

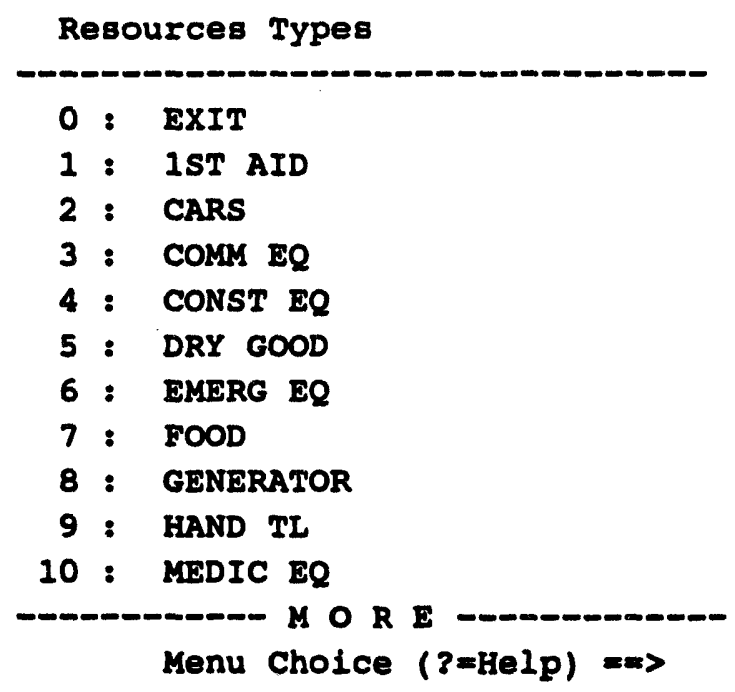

You can select a resource type directly from the list or press the Return key to display the Resource Type Selection method menu.

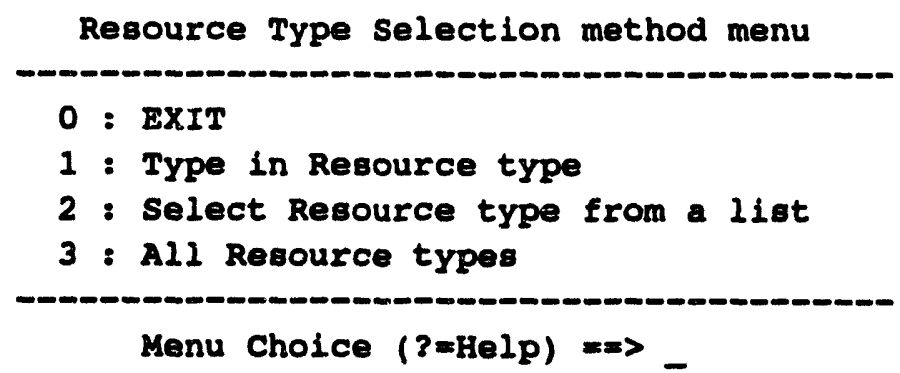

Use one of the three options to select resource type(s). For detailed instructions on using this menu, see the heading Selecting a Resource Type. 
All resources for that resource type within the specified area are then listed in a summary table. For example:

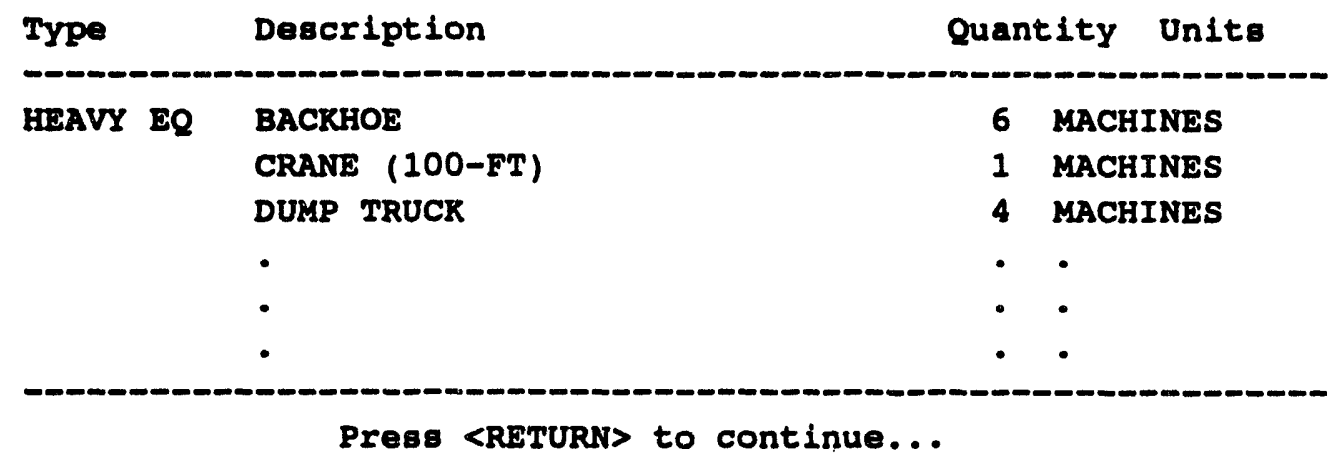


Section 7

Show/Refresh Latest

Onpost Track 


\section{Section 7 \\ Show, Remove, and Refresh Latest Onpost Track}

\section{SHOW (REMOVE) LATEST ONPOST TRACK}

SHOW LATEST ONPOST TRACK displays the latest D2 track from the onpost system, overlaying it on the current D2 track for the IBS event database. This allows two tracks to be displayed simultaneously. To make it clear that you are viewing both tracks, the menu item then changes to REMOVE LATEST ONPOST TRACK.

When REMOVE LATEST ONPOST TRACK is selected, the screen is refreshed, removing the onpost track from the display. The current D2 case track continues its display.

Whenever new information is received from the onpost system, the IBS displays a single-line message at the bottom of your iscreen. If the information received from the onpost system is adequate for the generation of a new D2 model case, the system creates the new case, assigns it a model number, and puts the output file in the appropriate directory. Use REFRESH ILATEST ONPOST TRACK to display the latest information. You can use the MESSAGE BOARD at any time to view other textual information for the latest onpost system case.

\section{REFRESH LATEST ONPOST TRACK}

When you receive a notification message concerning new D2 output from the onpost system, you may ignore it or choose REFRESH LATEST ONPOST TRACK to display the new information in addition to the track from the current D2 case. 
Section 8

Analyze D2 Track 


\section{Section 8 Analyze D2 Track}

\section{ANALYZE TRACK}

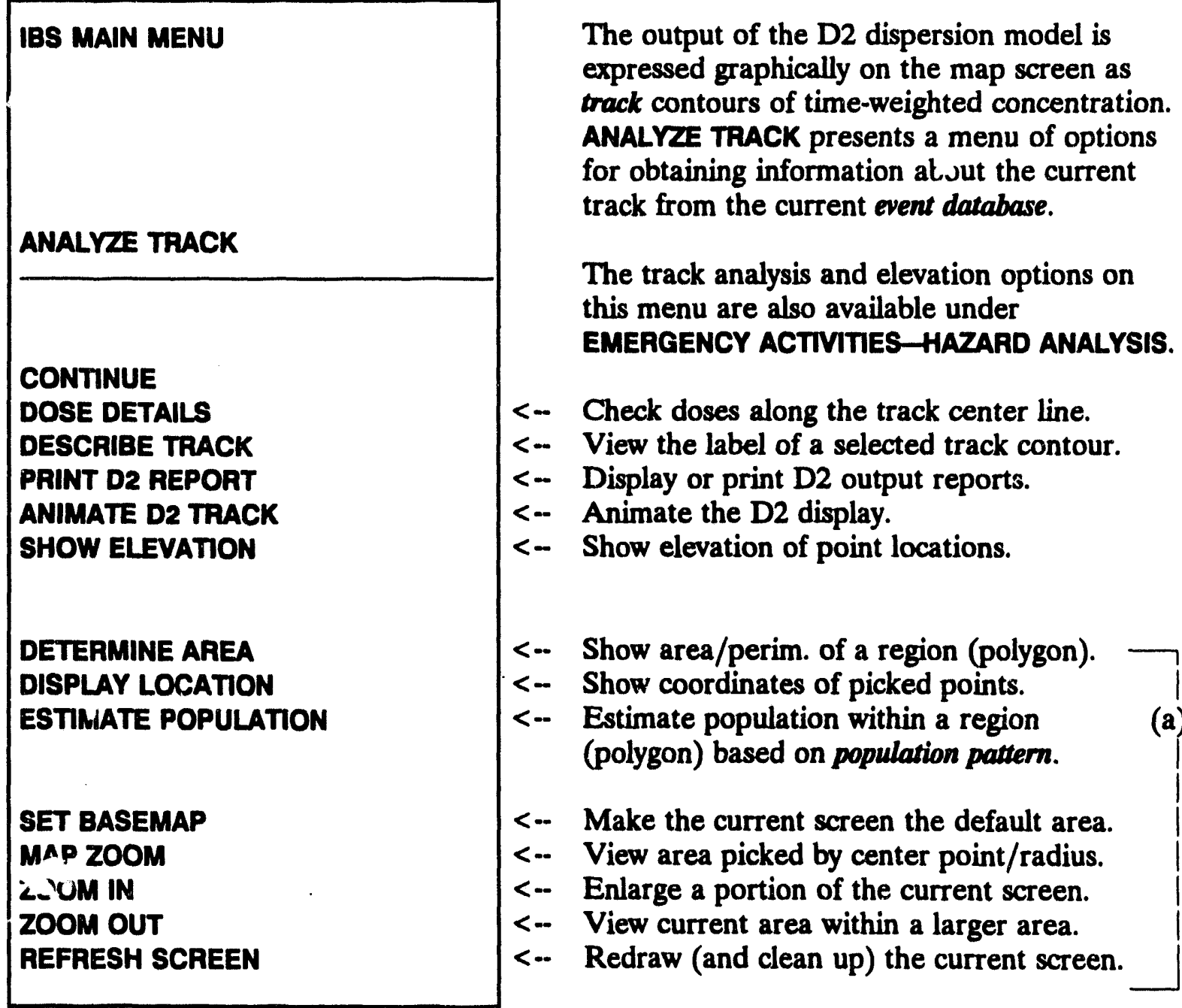

The track analysis and elevation options in this section are described in alphabetical order.

(a) These options are explained as menu items on the MAP ANALYSIS menu and are NOT duplicated in this section. 
D2 Track: The time-weighted concentration track on the map screen consists of contour lines. Each contour represents a constant level of dose or concentration (depending on the original inputs io the D2 model). A series of asterisks (*) along the track center line (if they appear) indicate slice points along the track where the DOSE DETAILS option can be used to display dose or concentration information about those locations. Some chemical agents do NOT result in the generation and appearance of these points. 


\section{ID ANIMATE D2 TRACK}

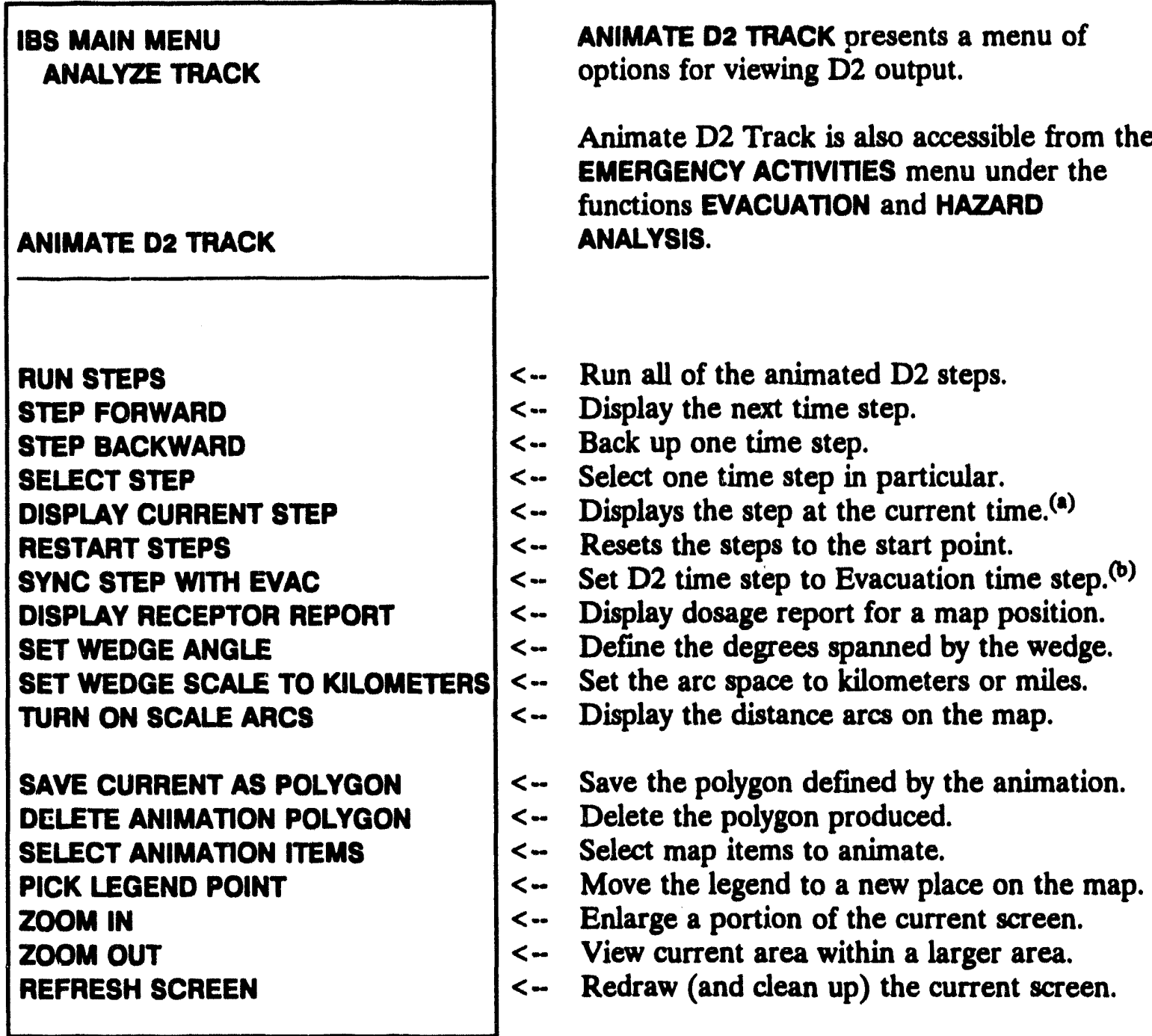

\section{Animating the D2 Track}

To animate the D2 output, perform the following procedures.

1. Select Select Animation Items from the menu and select one or more items to animate.

2. Select Set Wedge Angle. This will display a wedge over which you will view the animation

(a) Available in operational mode only when an event has been declared.

(b) Available from the Evacuation submenus only. You can also use this option to set up concurrent animation. 
3. Select the Run Steps command, or one of the other Step commands.

The D2 animation will then display in a series of steps. The following illustration is an example of a D2 animation step.

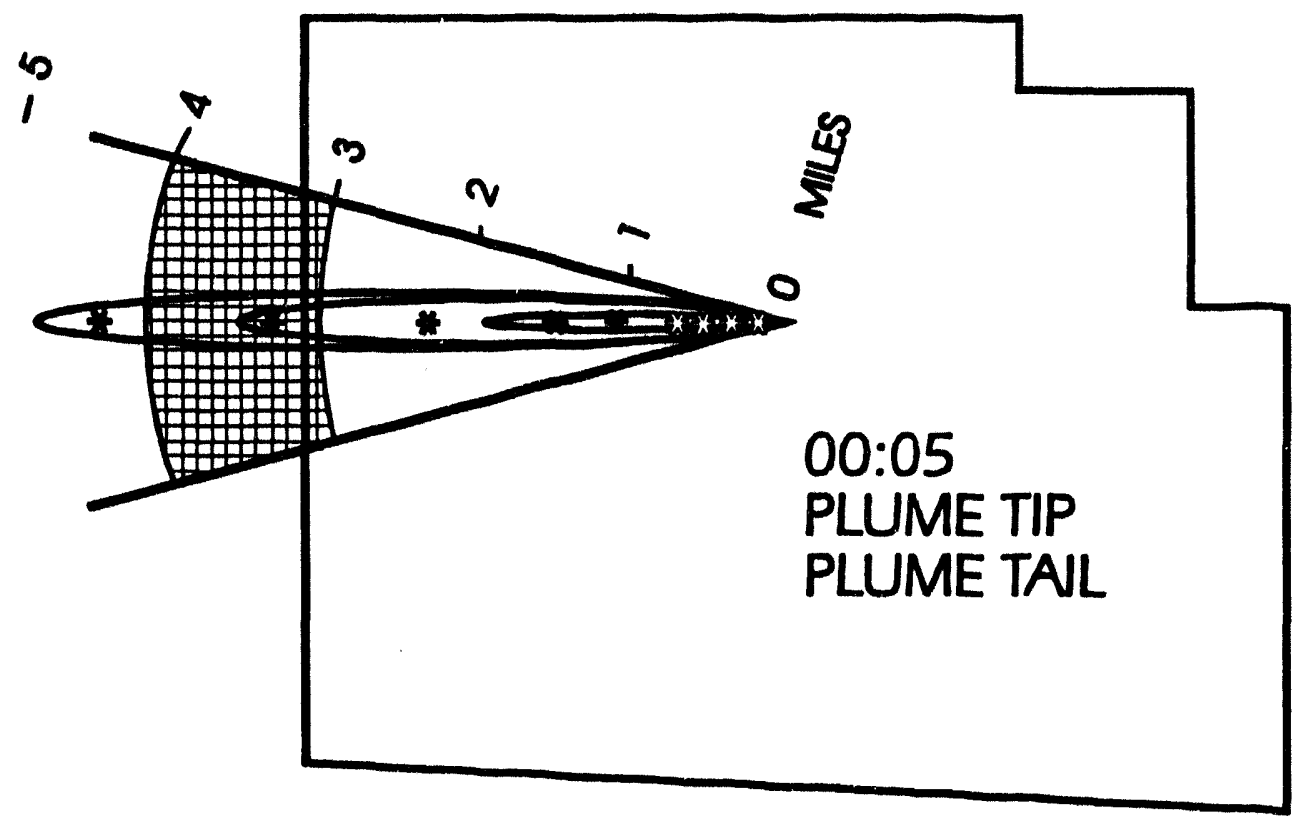

The options for using the animation function are:

Run Steps - Sequentially step through each 1 minute frame of the D2 track display.

Step Forward - Display the next frame of the D2 track.

Step Backward - Display the previous frame of the D2 track.

Display Current Step - Display the D2 track frame which corresponds to the current time since the release and continue to update the display by advancing frames each minute (Operational mode only).

Select Steps - Display a specified frame of the D2 track.

Restart Steps - Display the first frame of the D2 track.

Sync Step with Evac - (Only available from the EMERGENCY

ACTIVITIES-EVACUATION menu.) Set $\mathrm{d} 2$ animation time step to the number of minutes from the release that matches the time shown for the current evacuation time step. 
You will be prompted to set up concurrent animation of D2 and Evacuation model output. If you select this option, using the D2 animation step functions will also cause the evacuation network animation to change where appropriate.

Display Receptor Report - Any point can be a discrete receptor. This option prompts you with the following text menu.

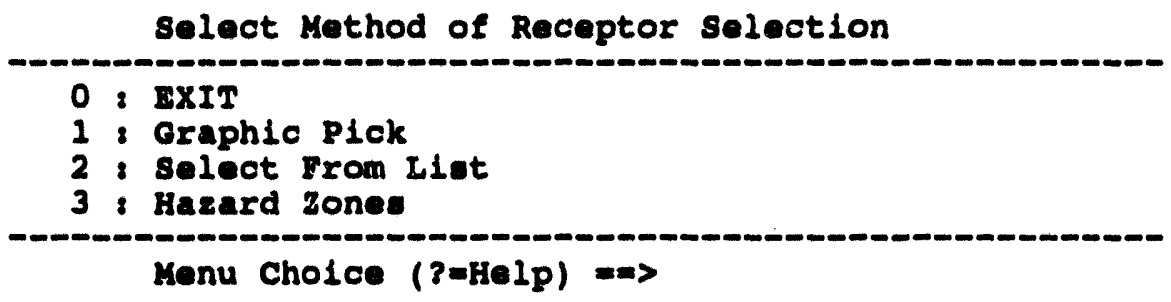

Provide the identified means of selecting locations for which to perform PARDOS calculations and obtain PARDOS reported values.

Option 1 : Graphic Pick may display a prompt similar to the following example.

Draw faclities onecreen? [Y] $\Rightarrow$

Press the Return key if you want the facilities icons to display. The system will then display the following prompt.

\section{* Hser select Known Polnt location w/moure}

If you select a point at or near an existing known point, a prompt similar to the following will display.

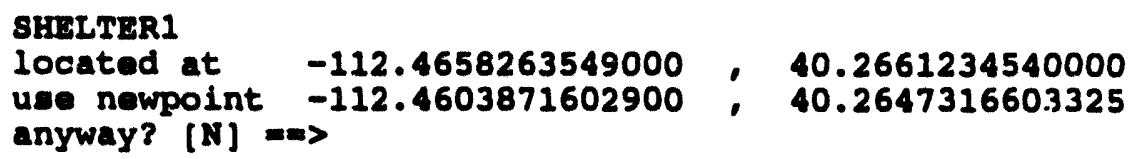

Press return or type $\mathbf{N}$ to use the current known point value. The system will display a message similar to the following.

* * MSG Performing calculations. Please wait.

The system will then display a report on the distance to the point selected.

If you type a $Y$ the system will prompt you to create a new known point value.

Enter new known Polnt name $=>$

Enter any name up to 40 characters in length.

If you select a point that is not near an existing known point, the system will prompt you to create a new known point. 
* * MSG: No known Point 0: -112.6537814730

Do you want to create it? [N] $==>$

If you press Return or type $\mathrm{N}$ (No), the following message will display.

* MSG: Performing calculations. Please wait.

The system will then display a report on the unnamed location.

If you type a $Y$ (Yes) at the prompt, the system will prompt you to create a new Known Point.

Enter new known Point name $a=>$

Enter any name up to $\mathbf{4 0}$ characters in length.

Option 2 : Select From List will display a menu list similar to the following example.

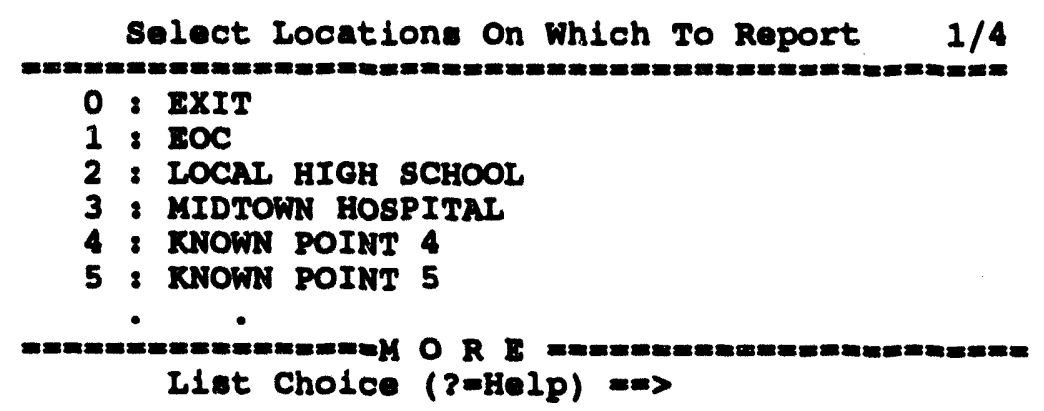

Note: If you select a receptor that is more than 50 kilometers from the source, the system will display the following message.

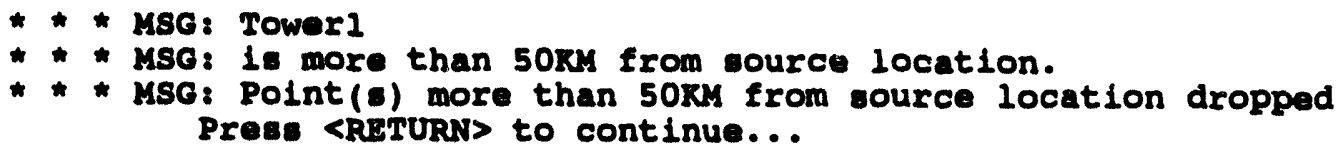

Press Return and the system will continue with the calculations for the rest of the receptors you selected.

If you select Option 3: Hazard Zones, the following prompt will display.

Check only Polnt: within Rigk areas? $(Y / N)=\infty$

Type a Y (Yes) to display a report on all Known Point locations within the current risk area. The system gives no consideration to the direction from the source to the known point, only the distance and the fact that the point is in the current risk area.

Type an $\mathbf{N}(\mathrm{No})$ to display a report on all known points in the current database. 
Note: A large number of known points can cause the following message to display.

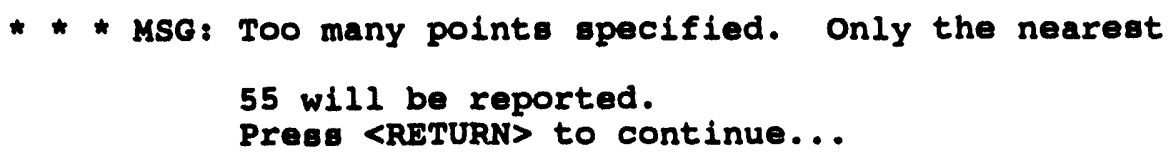

After you select one or more points, select 0 : EXIT and the system will print a report similar to the following example.

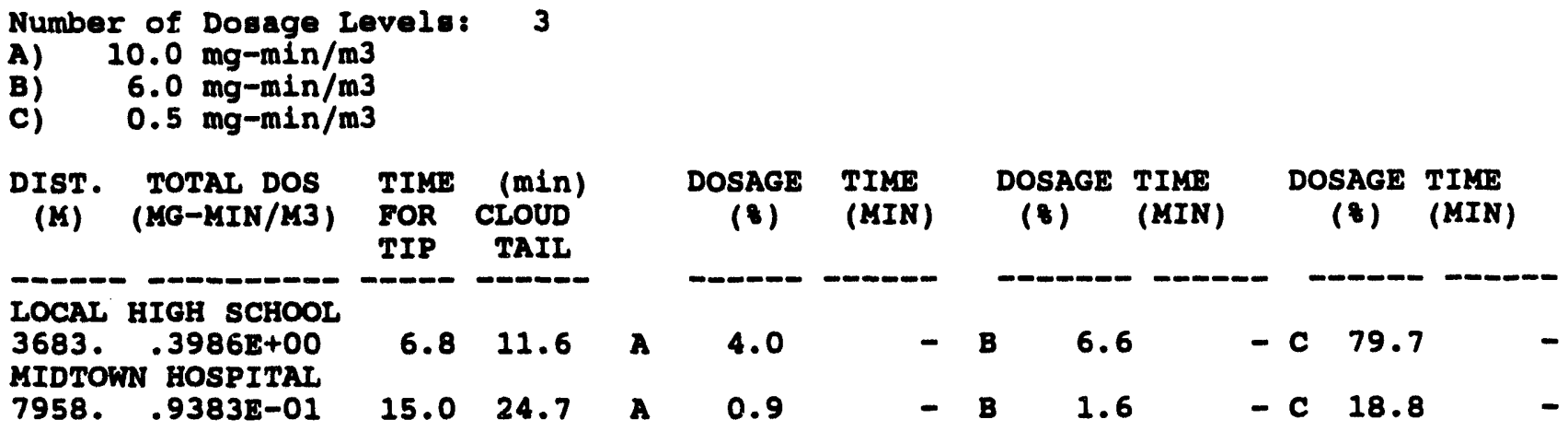

End of file.

End of Report: <RETURN>=Continue, <Ctrl-z>mExit, M=Redirect...

Set Wedge Angle - Prompts you to specify the width of an angle about the track centerline. Select an angle from the following menu.

\begin{aligned} Select Full Angle of Wedge, Currently $=40.0$ Degrees \\ \hline $0:$ EXIT \\ $1: 20$ DEGREES \\ $2: 30$ DEGREES \\ $3: 40$ DEGREES \\ $4: 45$ DEGREES \\ $5: 90$ DEGREES \\ $6: 120$ DEGREES \\ $7: 180$ DEGREES \\ $8: 360$ DEGREES \\ $9:$ OTHER \\ $10:$ NO WEDGE \\ \hdashline Menu Choice $(8=H e l p)=m\end{aligned}$

This angle is used in creating the D2 animation. Note that if no angle is specified, no animation items will be displayed.

Set Wedge Scale to Kilometers/Miles - will redraw the current wedge scale using the specified units. 
Turn On Scale Arcs - will display regularly spaced arcs in the wedge denoting distance from source. Either 1 mile or one kilometer spacing will be used depending on whether wedge scale is provided in miles or kilometers.

Save Current As Polygon - will save a polygon, defined by the current wedge arc, current time step, and the distance(s) associated with one or two items selected from a menu. The items are the same as those in the SELECT ANIMATION ITEMS menu. If two items are selected, the polygon saved will look something like a segment of a tire. If only one item is selected the release origin is used as one point of a pie shaped polygon. In either case the polygon is saved in the current D2 map layer and is displayed on your screen. Remember, you must have selected a wedge and time before an animation frame can be created and then saved. The polygon you save can also be used in Risk Area Analysis (under DIRECTION/CONTROL in EMERGENCY ACTIVITIES) to define the current risk area.

Delete Animation Polygon - will remove the polygon created with SAVE CURRENT AS POLYGON from the D2 map overlay.

Select Animation Items - Displays a list of the various items reported by D2/PARDOS. You must select at least one item from the list to animate the D2 track.

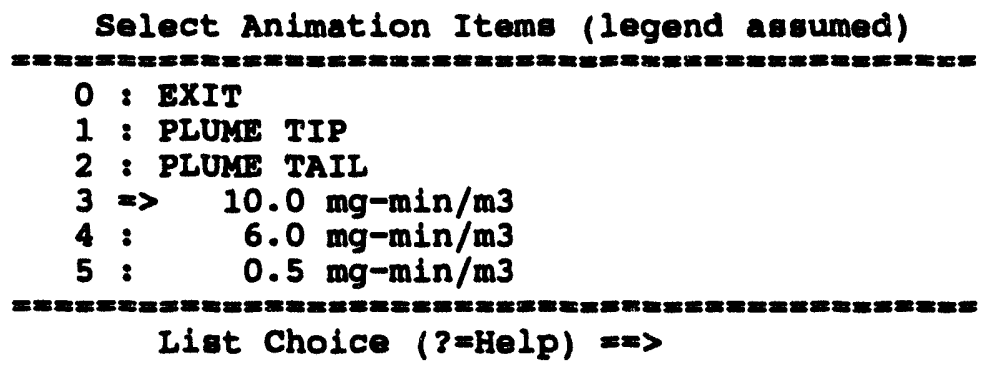

Any combination of items can be selected. If both TIP and TAIL are selected, the region between the tip and tail will be shaded.

Pick Legend Point - Enables you to move the location of the animation legend. By default the legend will appear with its upper left corner in the middle of the map display. Use the mouse or crosshairs to select a new point. When you pick a different location, the current legend will be erased and repositioned with its upper left corner at the location you picked. 


\section{ID DESCRIBE TRACK}

DESCRIBE TRACK enables you to pick one or more of the three contours displayed in the current D2 track. When you select Describe Track, the system will display the following message at the top of the screen.

* * *SG: Select TRACK boundary with crosghairs

As you pick a track contour, a text description of the contour is displayed.

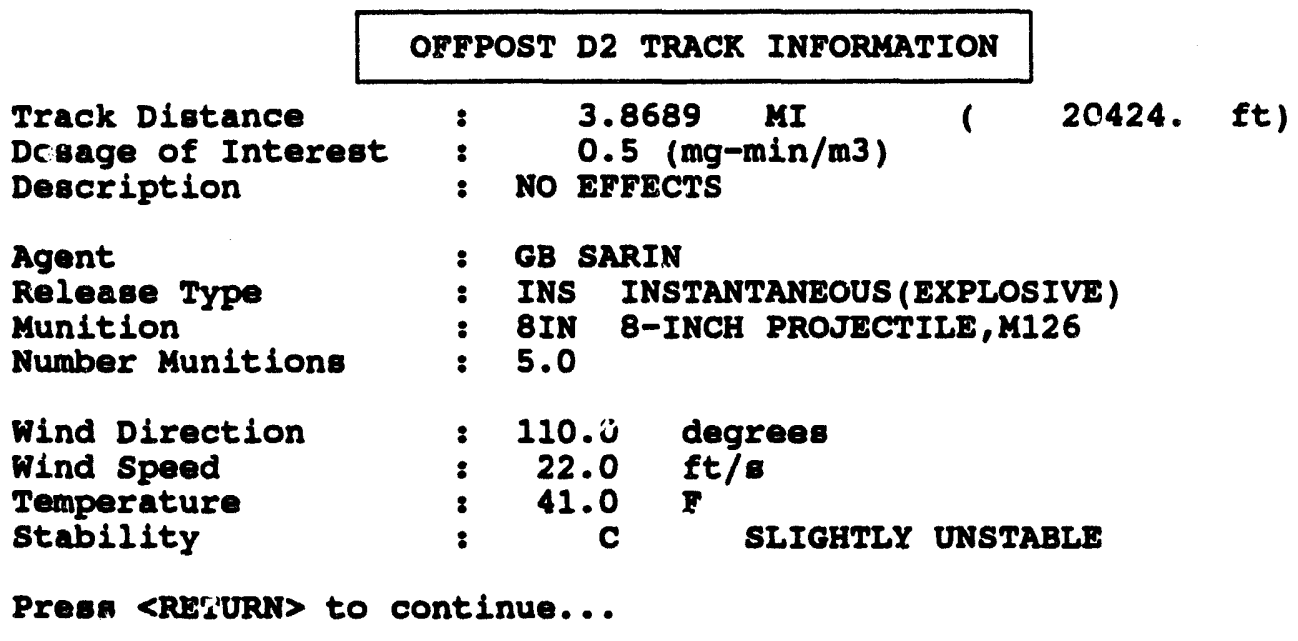

Be sure to place the cross hairs inside the track when you make your selection. The selected contour highlights in white and also blinks. You can pick more than one contour. When you have finished selecting contours, select Continue to stop.

Note: Not all D2 variables are listed on this screen. For a complete listing of all D2 input variables, you need to check the D2 input forms found under the following options: EMERGENCY ACTIVITIESHAZARD ANALYSIS. Under HAZARD ANALYSIS, select the option EXECUTE D2 and then select the option 2 : Modify D2 Case Input.

\section{IIDOSE DETAILS}

Asterisks $\left(^{*}\right)$ are used to mark locations of changing dose along the D2 track center line. DOSE DE AILS enables you to select an asterisk on the track center line to display dose information for that location. When you select Dose Details, the system displays the following message at the top of the screen.

select dose site (*) with crosshairs 
Pick an asterisk location. The information includes details such as those in the following example:

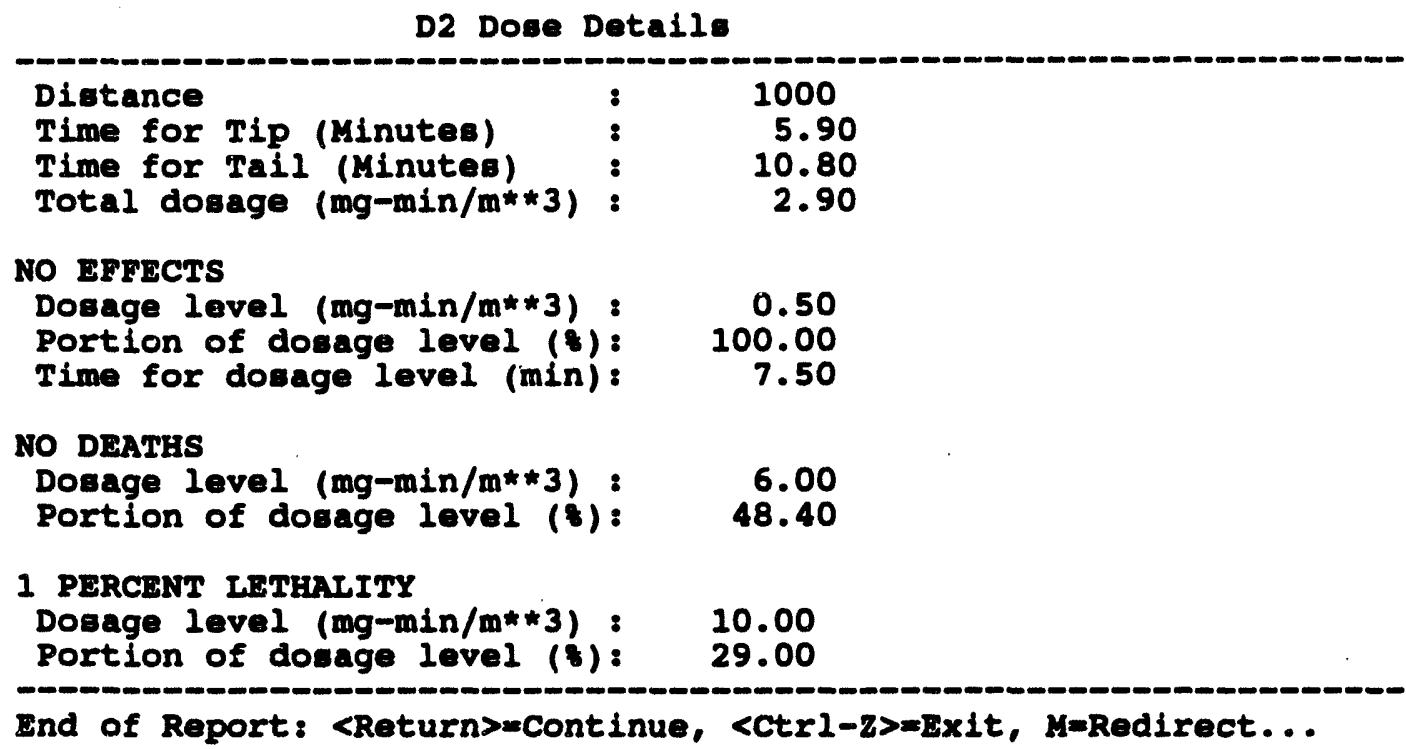

When you have finished selecting asterisks, select CONTINUE to stop the selection process.

The information provided can vary somewhat, depending on the input parameters selected for the D2 cases. For example, dosage information is not available when the D2 input requests concentrations.

\section{PRINT D2 REPORT}

This option enables you to display or print the output reports produced by the IBS implementation of D2.

The system first prompts you to identify the desired report:

\begin{aligned} Select report type \\ \hline $0:$ EXIT \\ $1:$ D2log \\ $2:$ Dosage \\ $3:$ Slice \\ \hdashline Menu Choice $(3=\mathrm{Help})=>\end{aligned}$

To select the type of report, enter the number associated with the desired report. To exit without selecting a report, type 0 and press the Return key. 
When you select one of these reports, you choose whether to display or print the report. Refer to the discussion of the MESSAGE BOARD capability for illustrations of the report outputs.

\section{SHOW ELEVATION}

SHOW ELEVATION displays the elevation (meters above sea level) associated with the point location you pick with the graphic cursor. You can pick more than one point location. The information from the previous picks remains visible on the screen until you choose another menu option. 
-8eว za e6ue4ว 6 uoppos 


\section{Section 9 \\ Change D2 Track Case}

\section{CHANGE D2 TRACK CASE*}

CHANGE D2 TRACK CASE is used to select an existing D2 case as the "current" D2 case for the IBS event database. This erases the currently displayed track from the map screen and replaces it with the track for the "new" current D2 case. If you select a case without output, the system will display the following message.

* * MSG: Output for case nnn does not exist

Go ahead and select case $n n n$ ? $(Y / N)[Y]=\infty$

When an Information Manager switches between D2 cases, other system users see a message that instructs them to pick REFRESH SCREEN to see the current D2 track case.

If you are in Operational mode and the selected case has been checked out by a planner, a message similar to the following will display.

* * MSG: Case 019 has been checked out

Go ahead and eelect case $019 ?(Y / N)[Y] \Rightarrow$

The planner who has checked out this case will not be able to check it back in as long as it is selected as the current Operational D2 case.

CHANGE D2 TRACK CASE gives you the options of entering a case number directly or specifying a set of case description criteria:

\begin{tabular}{l} 
Choose D2 Case Menu \\
\hline 0 : EXIT \\
1 : Choose D2 case by CASE NUMBER \\
2 : Choose D2 Case by SEARCH FOR D2 CRITERIA \\
3 : Choose D2 Case by CASE IIST
\end{tabular}

Menu Choice $(?=\mathrm{Help})=\approx$ 


\section{Choosing a D2 Case by Case Number}

Select option 1 : Choose D2 case by CASE NUMBER to see a listing of D2 cases similar to the following example. Select the D2 case number you want from the listing.

\begin{tabular}{|c|c|c|c|c|c|c|c|}
\hline D2 & AGENT & MUNITION & RELEASE & $\begin{array}{l}\text { NGE CASE } \\
\text { WIND DIR }\end{array}$ & WIND SPEED & QUANTITY & STAB \\
\hline $\begin{array}{r}0 \\
1 \\
2 \\
6 \\
7 \\
10 \\
20\end{array}$ & $\begin{array}{l}\text { GA } \\
\text { GA } \\
\text { GB } \\
\text { GB } \\
\text { VX } \\
\text { GB } \\
\text { GB }\end{array}$ & $\begin{array}{l}8 I N \\
8 I N \\
\text { M23 } \\
\text { M55 } \\
\text { NON } \\
\text { M23 } \\
\text { M23 }\end{array}$ & $\begin{array}{l}\text { INS } \\
\text { INS } \\
\text { INS } \\
\text { IGL } \\
\text { FIR } \\
\text { INS } \\
\text { INS }\end{array}$ & $\begin{array}{r}180.0 \\
90.0 \\
150.0 \\
199.0 \\
199.0 \\
180.03 \\
90.05\end{array}$ & $\begin{array}{l}3.21 \\
8.10 \\
5.01 \\
1.00 \\
3.00 \\
1.05 \\
2.31\end{array}$ & $\begin{array}{l}0.658000 \mathrm{E}+07 \\
0.658000 \mathrm{E}+07 \\
0.149680 \mathrm{E}+08 \\
0.658000 \mathrm{E}+07 \\
0.658000 \mathrm{E}+07 \\
0.149860 \mathrm{E}+08 \\
0.100700 \mathrm{E}+9\end{array}$ & $\begin{array}{l}\text { A } \\
\text { B } \\
\text { B } \\
\mathbf{E} \\
\mathbf{S} \\
\text { A } \\
\text { B }\end{array}$ \\
\hline
\end{tabular}

Select de: ired IBS D2 case (Current= 7): nnn.

To move around in the form, you can type in the following options at the Select desired IBS D2 case prompt.

$\mathbf{H}=$ Display alternate headers. This option will enable you to toggle between the above form and a one-line description of each case.

$\mathrm{D}=$ Move down the list to see more cases.

$\mathrm{U}=$ Move up the list.

$T=$ Go to the top of the list.

$B=$ Go to the bottom of the list.

$?=$ Help.

D\# = Move down number (\#) of pages.

$\mathrm{U \#}=\quad$ Move up number $(\#)$ of pages.

\section{Choosing a D2 Case by Searching for D2 Criteria}

Select option 2 : Choose D2 case by SEARCH FOR D2 CRITERIA to display the following screen for specifying a set of case description criteria. IBS then generates a selection list of D2 cases that match (or approximately match) the criteria.

On this screen you can modify the fields, which serve as "search keys" into the database of $\mathrm{D} 2$ cases: 
- The default tolerances for wind direction, wind speed, and agent quantity are displayed. You can change these values for this particular search.

- You can remove one or more criteria from the search by leaving blanks in the text fields (agent, munition, release type, stability class) or by entering a negative one $(-1)$ in the numeric fields.

If you enter a non-existent case number in the IBS D2 Case Number field, the following message displays.

Case not found. please specify another case or input search criteria by hand.

D2 Track QUALIFICATION

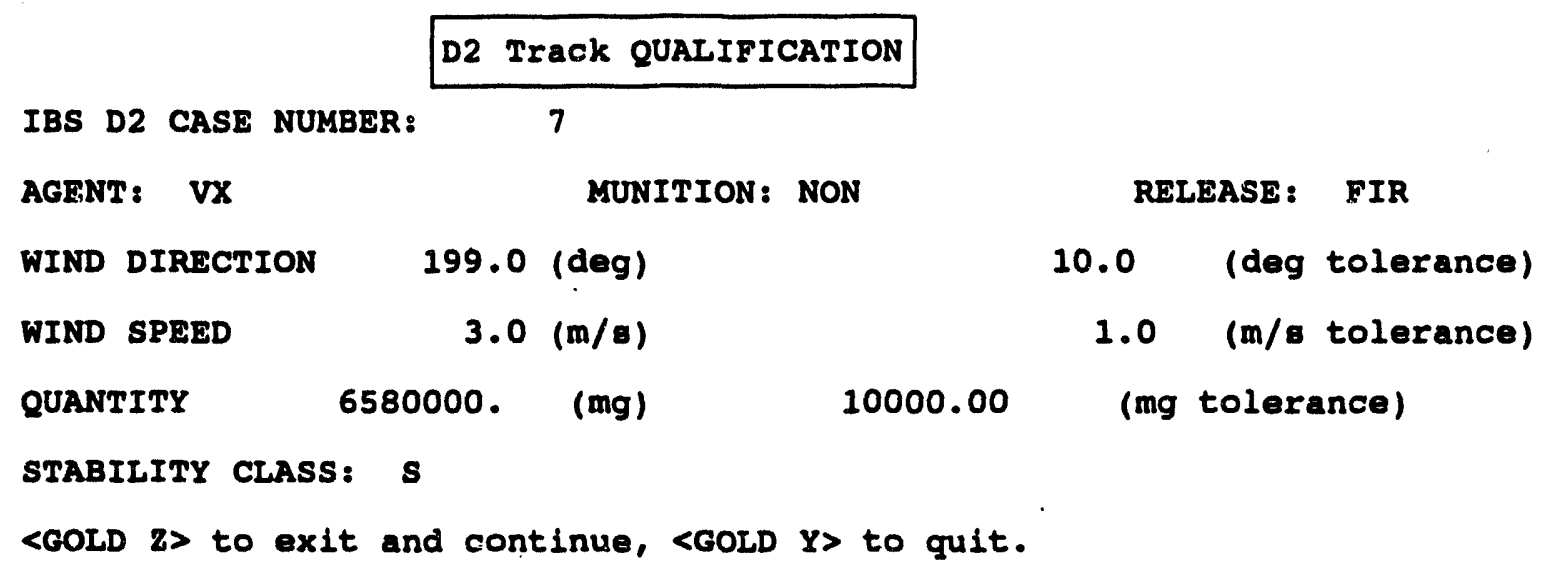

- If all fields are removed from the search by entering 0 or -1 in each field, you must instead select one case from a list of all D2 cases (see the next screen).

- If any criteria are used, the IBS compares these case input criteria with the database of D2 cases. (If no identical matches can be found, the IBS displays a message to indicate how many criteria were actually matched.) You must then select from a list of $D 2$ cases that match the greatest number of criteria (see the next screen).

- Press the Return key in the Stability Class field to complete the form and start the search.

- If all fields are removed from the search, the system displays a list of all D2 cases. Select one case from the list. 
The selection list of D2 cases looks like the following example:

\begin{tabular}{|c|c|c|c|c|c|c|c|}
\hline D2 & AGENT & MUNITION & RELEASE & $\begin{array}{l}\text { NGE CASE } \\
\text { WIND DIR }\end{array}$ & WIND SPEED & QUANTITY & STAB \\
\hline $\begin{array}{r}0 \\
1 \\
2 \\
6 \\
7 \\
10 \\
20\end{array}$ & $\begin{array}{l}\mathbf{G A} \\
\mathbf{G A} \\
\mathbf{G B} \\
\mathbf{G B} \\
\mathbf{V X} \\
\mathbf{G B} \\
\mathbf{G B}\end{array}$ & $\begin{array}{l}8 I N \\
8 I N \\
\text { M23 } \\
\text { M55 } \\
\text { NON } \\
\text { M23 } \\
\text { M23 }\end{array}$ & $\begin{array}{l}\text { INS } \\
\text { INS } \\
\text { INS } \\
\text { IGL } \\
\text { IIR } \\
\text { INS } \\
\text { INS }\end{array}$ & $\begin{array}{r}180.0 \\
90.0 \\
150.0 \\
199.0 \\
199.0 \\
180.03 \\
90.05\end{array}$ & $\begin{array}{l}3.21 \\
8.10 \\
5.01 \\
1.00 \\
3.00 \\
1.05 \\
2.31\end{array}$ & $\begin{array}{l}0.658000 \mathrm{E}+07 \\
0.65800 \mathrm{E}+07 \\
0.149680 \mathrm{E}+08 \\
0.65800 \mathrm{E}+07 \\
0.65800 \mathrm{E}+07 \\
0.149860 \mathrm{E}+08 \\
0.100700 \mathrm{E}+9\end{array}$ & $\begin{array}{l}\mathbf{A} \\
\mathbf{B} \\
\mathrm{B} \\
\mathbf{E} \\
\mathbf{S} \\
\mathbf{A} \\
\mathrm{B}\end{array}$ \\
\hline
\end{tabular}

Select desired IBS D2 case (Current= 7): nnn.

If the cases are too numerous to fit on one screen, you can scroll through the remaining case descriptions by entering a key command at the Select desired IBS case: prompt (U, U\#, D, D\#, T, B). (Enter $\mathbf{H}$ to switch the heading display to show the D2 case description instead of the D2 case qualifications shown here.)

To select a case, enter the case number at the Select desired IBS case: prompt. The IBS program then removes the previous track contours and displays the D2 results for the selected D2 case.

\section{Choosing a D2 Case by Case List}

Select option 3 : Choose D2 Case by CASE LIST to display a list similar to the following example.

D2 Case Selection Menu (Current= 31 )

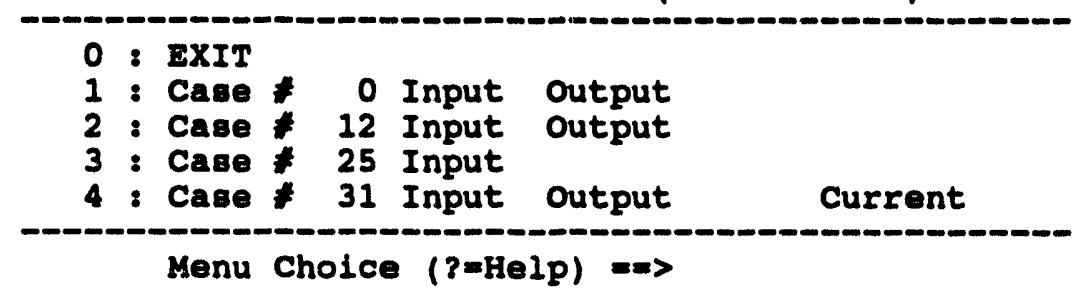

Notice that each case listed has input and output markers associated with it. Also the current case is labeled in the list and in the title line.

Note: All D2 cases listed should have input. If a D2 case is listed without input, there is a file maintenance problem.

This option differs from the other methods of D2 selection in that the other methods concentrate on D2 input variables, whereas this form of selection concentrates on whether input/output files exist. 
Section 10

Show D2

Deecription 


\section{Section 10 Report Current D2 Description}

\section{TEPORT CURRENT D2 DESCRIPTION}

This option displays a description of the current D2 case. This description consists of the two lines entered on the D2 Standard Input form shown for the HAZARD ANALYSIS emergency activity. For more information, see Section 11, Emergency Activities.

When you select Report Current D2 Description, a message similar to the following example displays.

Current D2 Description:

Th1s is a sample D2 template

Press <RETURN> to continue...

Press the Return key to return to the IBS Main menu. 
-

-

0

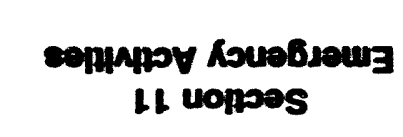




\section{Section 11 Emergency Activities}

\section{- EMERGENCY ACTIVITIES}

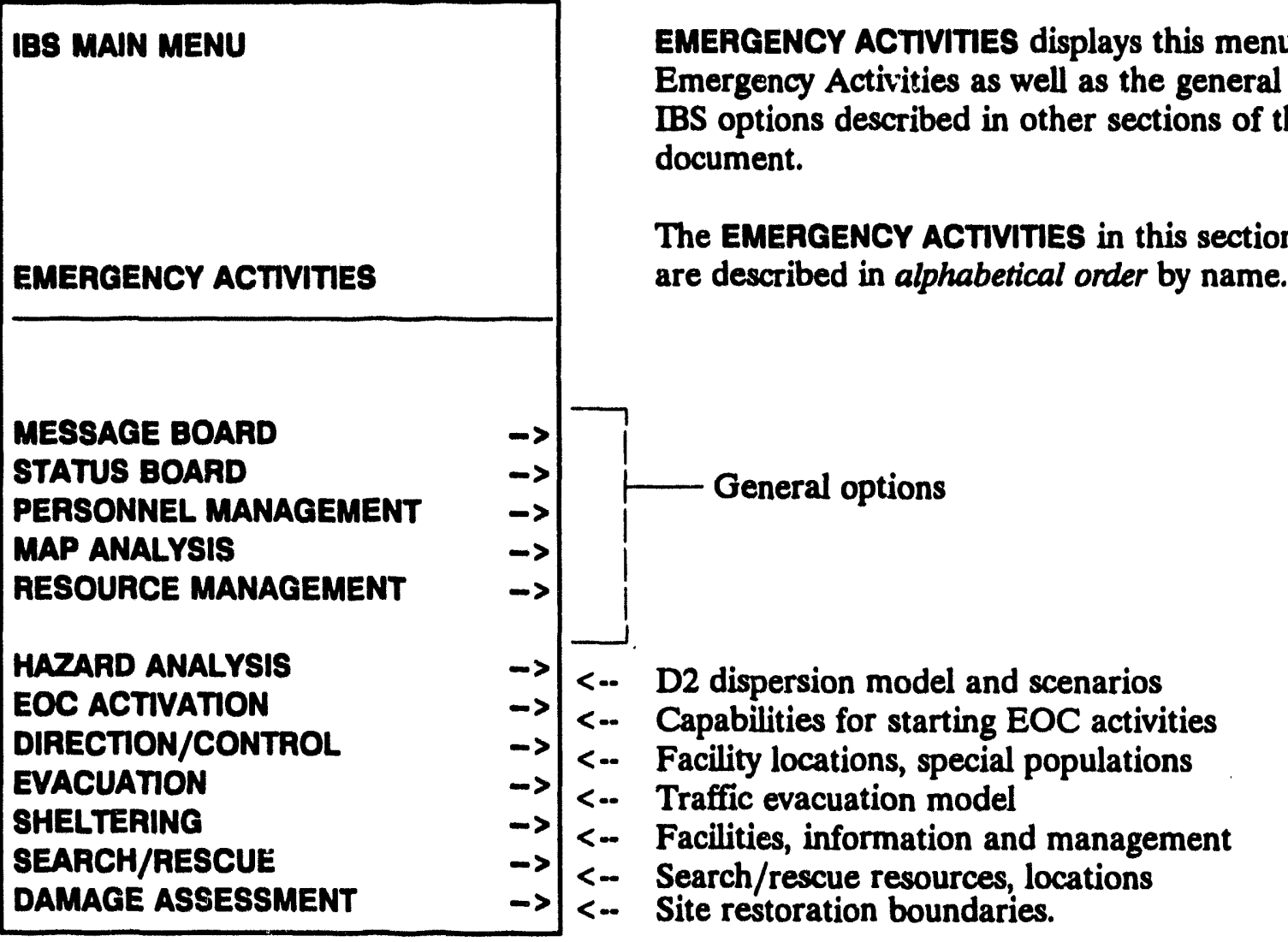

When you select any one of the seven Emergency Activities, the IBS presents a submenu of capabilities for that function. These Emergency Activities submenus usually include an overlay option that is similar from one function to another:

- Release OVerlays (Retain OVerlays). The map layers associated with an Emergency Activity are automatically overlaid on the screen map when you first use that function. These overlays continue to be displayed (both in and out of Emergency Activity operations) until you cancel their display. 
To cancel their display, pick RELEASE OVERLAYS (the menu item then switches to RETAIN OVERLAYS). To redisplay them, pick RETAIN

OVERLAYS (the menu item switches back to RELEASE OVERLAYS). To choose the overlay map layers for each Emergency Activity, use SETUP-MAP LAYERS BY FUNCTION. 


\section{IDAMAGE ASSESSMENT}

\section{IBS MAIN MENU \\ EMERGENCY ACTIVITIES}

DAMAGE ASSESSMENT

CONTINUE

MESSAGE BOARD

STATUS BOARD

PERSONNEL MANAGEMENT

MAP ANALYSIS

RESOURCE MANAGEMENT
This Emergency Activity currently includes boundary drawing options to be used in developing and evaluating strategies for restoring a contaminated area.
DRAW NATIONAL DEFENSE AREA * DELETE NATIONAL DEFENSE AREA * DRAW CONTAMINATION AREA DELETE CONTAMINATION AREA

RELEASE OVERLAYS
<-- Draw boundary of Nat. Def. Area.

<-- Pick/delete a Nat. Def. Area Loundary.

<-- Draw boundary of a contamination area.

<-- Pick/delete a contam. area boundary.

<-- Cancel display of DAMAGE ASSESSMENT map layers.

The DAMAGE ASSESSMENT menu options are described in alphabetical order. 


\section{UI DELETE CONTAMINATION AREA*}

This option enables you to pick and delete a boundary that identifies a contamination area (see DRAW CONTAMINATION AREA) by selecting it on the screen:

1. After picking DELETE CONTAMINATION AREA, the system displays the following message.

* * * MSG: Select Contaminated Area to delete. CONTINUE when done

Use the mouse (or joydisk) to pick any point on the boundary that you want to delete.

The selected boundary blinks to indicate your selection.

2. Pick CONTINUE to confirm the deletion.

The selected boundary is then removed from the screen.

\section{H. DELETE NATIONAL DEFENSE AREA*}

This option enables you to pick and delete a boundary that identifies a National Defense Area (see DRAW NATIONAL DEFENSE AREA) by selecting it on the screen.

After picking DELETE NATIONAL DEFENSE AREA, the system displays the following message.

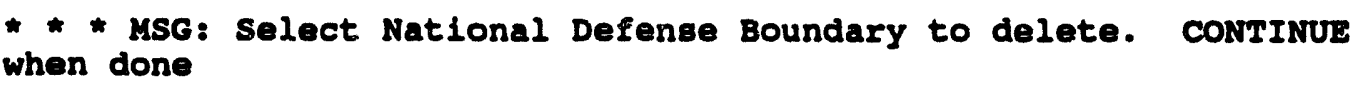

Use the same procedures described under DELETE CONTAMINATION AREA to complete the deletion.

\section{DRAW CONTAMINATION AREA*}

This option enables you to plot points that define the boundaries of a contamination area. Selecting this menu item causes it to highlight and flash in green. The system displays the following message.

* * MSG: Draw a Contaminated Area. ConrINUE when done

Move the cursor to the first point of the area you want to draw. Select this point and then move the cursor to the next point. Select this point and a green line is drawn between the two points. Continue this selection process until you are ready to select the last segment to close the area. Select the CONTINUE option from 
the menu. The area automatically is redisplayed with the last segment completed and the Contamination area boundary drawn in white.

\section{DRAW NATIONAL DEFENSE AREA*}

This option enables you to plot points that define the boundaries of a National Defense Area. Selecting this menu item causes it to highlight and flash in green. The system displays the following message.

* * MSG: Draw a National Defense Boundary. CONTINUE when done

Move the cursor to the first point of the area you want to draw. Select this point and then move the cursor to the next point. Select this point and a green line is drawn between the two points. Continue this selection process until you are ready to select the last segment to close the area. Select the CONTINUE option from the menu. The area automatically is redisplayed with the last segment completed and the National Defense Area boundary drawn in white. 


\section{IDIRECTION/CONTROL}

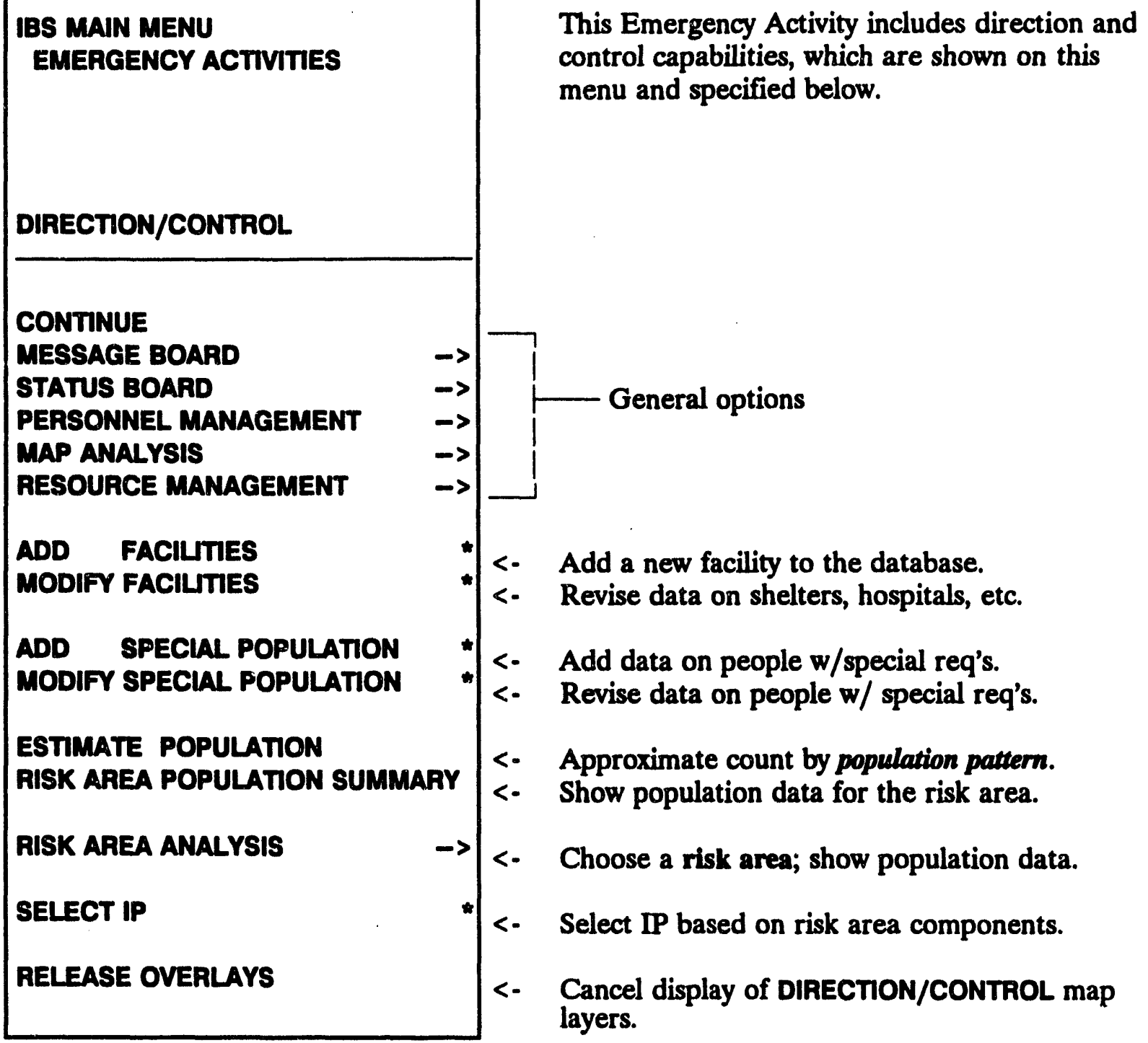

This Emergency Activity includes direction and control capabilities, which are shown on this menu and specified below.

<- Add a new facility to the database.

<- Revise data on shelters, hospitals, etc.

<- Add data on people w/special req's.

$<-\quad$ Revise data on people w/ special req's.

<- Approximate count by population pattern.

<- Show population data for the risk area.

<- Choose a risk area; show population data.

<- Select IP based on risk area components.

<- Cancel display of DIRECTION/CONTROL map layers.

The following options are the same as those described in Section 6, Resource Management in this guide. See Section 6 for complete information on using these options.

ADD FACILITIES

MODIFY FACILITIES 


\section{ADD SPECIAL POPULATION}

This option is used to enter data about populations with special requirements (such as transportation dependence). Special population data must be added to an existing facility, or a new facility must be created prior to adding the special population data.

After selecting ADD SPECIAL POPULATION, the system prompts with the following menu:

Add Special Population Menu

\begin{tabular}{l} 
Add Special Population Menu \\
\hline 0 : ExIT \\
1 : Add epecial population to existing facility \\
2 : Create new facility and add special population \\
\hline Menu Choice $(?=H e l p)==$
\end{tabular}

Use one of these two methods to specify adding a special population:

Option 1 : Add special population to existing facility: The system will display the following prompt.

Draw facilities onscreen? $[Y]=m$

After you press return, the system will draw the facility icons on the screen and display the following prompt.

* * MSG: Select a Facility w/ mouse. CONTINUE for menu.

Once you have selected a facility, the Special Population Form displays as shown in the following example.

If you select Continue, the system displays the Facility Selection method menu, as described in Section 6, Resource Management, MODIFY FACILITIES. This menu will enable you to select facilities by name, from a list, or by location.

Option 2 : Create new facillty and add special population: Prompts you for information to create a new facility. When you select this option, the system displays the Known Point Selection method menu, as described in Section 6, Resource Management.

You can now create a new Known Point, or add facilities to an existing Known Point. The procedures you use to add the facility are similar to those described in Section 6, Resource Management, under ADD FACILITIES. 
After a facility has been selected, or created, the following special population form displays:

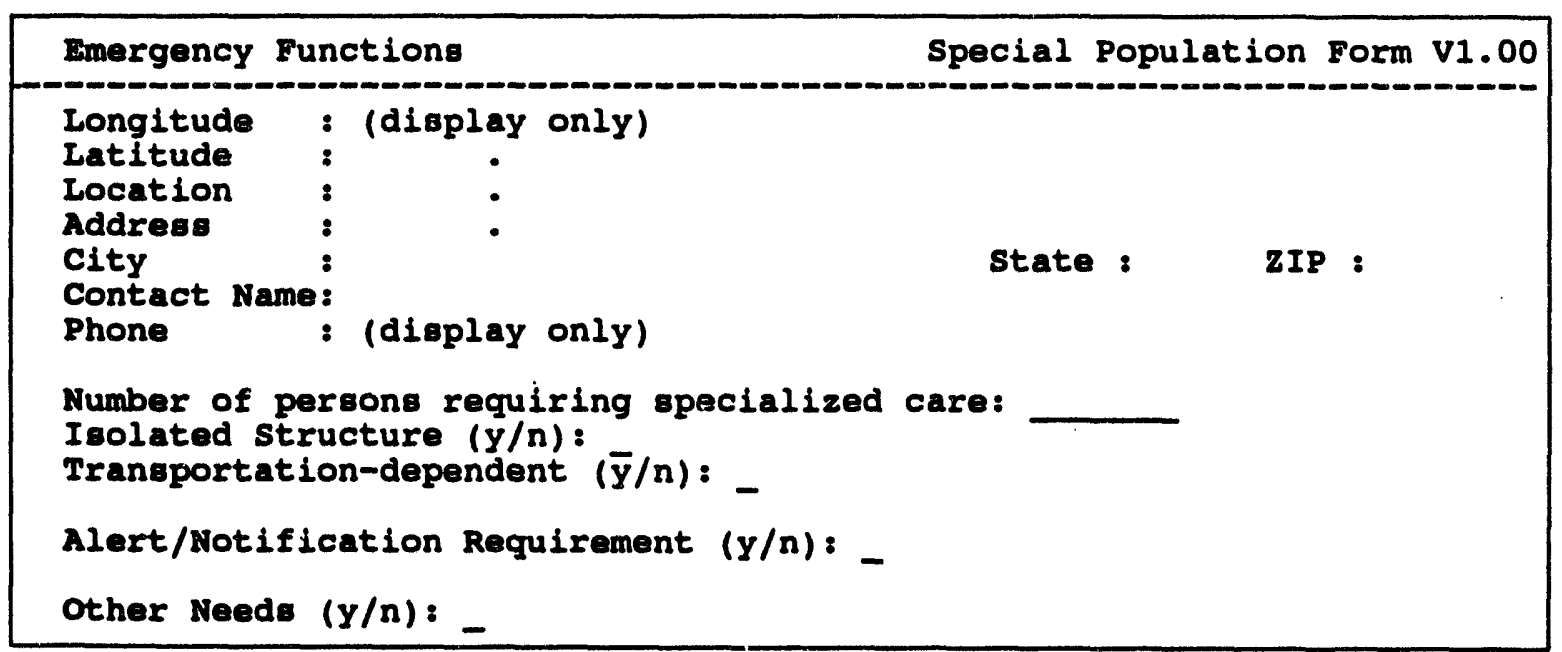

The upper part of the special population form is for displaying facility information only. The lower part of the form is used to enter special population data. Enter the following information on this form:

Number of persons requiring specialized care: Enter the number of persons at the facility requiring specialized care (special population).

Isolated Structure $(y / n): Y$ or $\mathbf{N}$ - Is the special population located at an isolated structure?

Transportation-dependent $(y / n): Y$ or $\mathrm{N}$ - Is the special population transportation dependent? Use the following line for adding comments.

Alert/Notification Requirement $(y / n): ~ Y$ or $\mathrm{N}$-- Is an alert/notification required for the special population? Use the following line for adding comments.

Other Needs $(\mathbf{y} / \mathbf{n}): \mathrm{Y}$ or $\mathbf{N}-$ Are there other additional needs? Use the following line for adding cominents. 


\section{MODIFY FACILITIES*}

This option enables an Information Manager to modify facility infornuation by 1) selecting a facility and 2) modifying the facility data.

After selecting MODIFY FACIUTIES, the system displays the Facility Modification menu.

\begin{tabular}{l} 
Facility Modification menu \\
$0:$ EXIT \\
$1:$ Modify Facility \\
$2:$ Modify Rnown Point \\
\hline Menu Choice $(?=H e l p)=m$
\end{tabular}

See Section 6, Resounce Management, MODIFY FACIUTIES for a complete description of how to select a facility.

\section{Modify the Facillty Description}

The facility form description of the selected facility is then presented for updating (for details, see the heading Entering a Facility Description in Section 6, Resource Management, under the ADD FACILTY option). When you exit the facility form, you return to the Facility Selection method menu above, where you can choose another facility for updating.

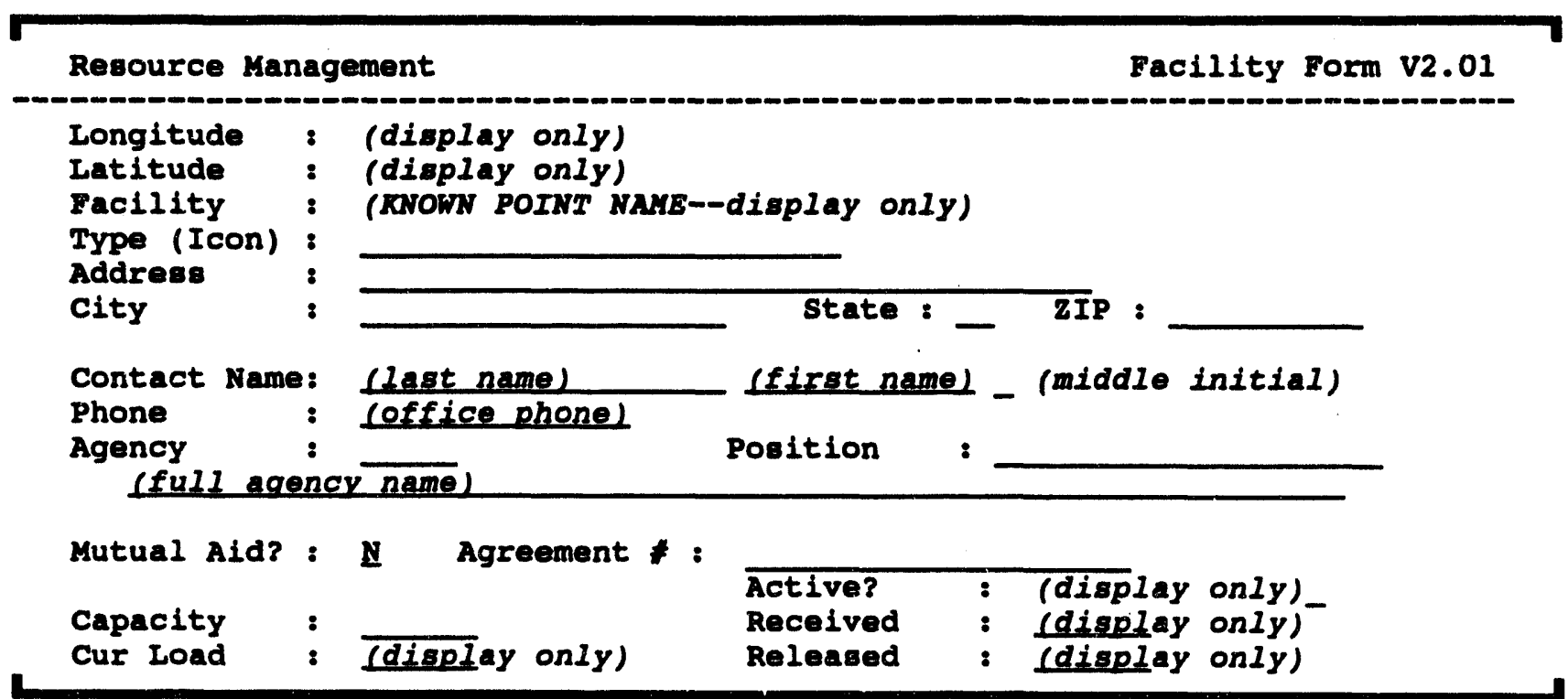

If you cannot find the facility in graphic selection mode that you want to modify, or if you want to quit modifying facilities, select CONTINUE from the menu. The system returns you to the Facility Selection method menu. 


\section{MODIFY SPECIAL POPULATION*}

This option is used to modify special population data that has been previously entered.

After selecting MODIFY SPECIAL POPULATION, the system prompts with the following menu:

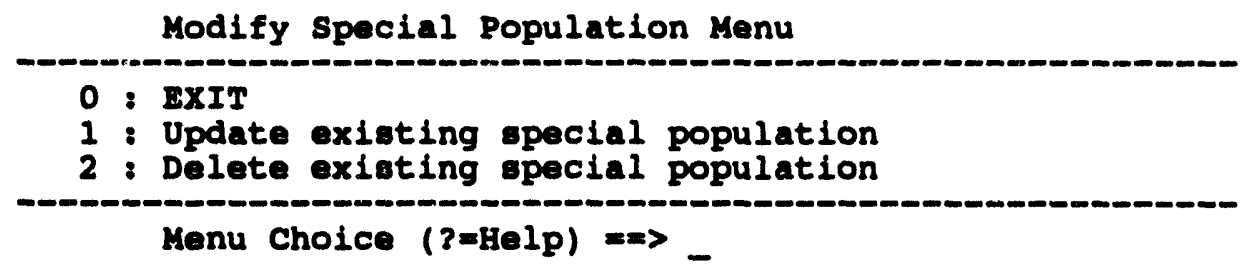

Use one of these two methods to specify adding a special population:

1. Update existing special population: The system displays the Facility Selection method menu, as described in Section 6, Resource Management.

After you select the facility, the special population form (see ADD SPECIAL POPULATION) will display. This menu enables you to modify the special population data at the facility.

2. Delete existing special population: Prompts you to select an existing facility by displaying the Facility Selection method menu.

After the facility has been selected, a prompt appears verifying that you want to delete the special population data at this facility:

Delete special population: facility name $(Y / N)$ [N] $=$ -

Enter ' $\mathrm{Y}$ ' or <ENTER > to delete the special population data at the facility. 


\section{IIU ESTIMATE POPULATION}

ESTIMATE POPULATION provides an estimate of the population within a defined area. The two sources of data for population reports within ESTIMATE POPULATION aTe:

- Census data

- People Locate data

To use this option, see the complete procedures in Section 5, Map Analysis, under Estimate Population.

\section{RELEASE OVERLAYS}

This option enables you to switch on or switch off the display of the map layers associated with DIRECTION/CONTROL. (To choose these map layers, see Section 12, Setup, under MAP LAYERS BY ACTIVITY.) 


\section{RISK AREA ANALYSIS}

An Information Manager can establish the risk area, which is made up of one or more Emergency Planning Zones (EPZs). (EPZs are areas defined during emergency planning. Generally, the risk area includes any EPZs where the D2 model predicts the chemical track.) The Information Manager can establish a risk area by defining a risk polygon: any EPZ that overlaps a part of this risk polygon is considered to be part of the initial risk area. If a risk area is chosen or modified, the Information Manager must inform the general users. The general users can then display the boundaries of the risk area, as well as determine the populations of the EPZs within the risk area.

\section{IBS MAIN MENU \\ EMERGENCY ACTIVITIES DIRECTION/CONTROL}

RISK AREA ANALYSIS

Continue

MESSAGE BOARD

STATUS BOARD

PERSONNEL MANAGEMENT

MAP ANALYSIS

RESOURCE MANAGEMENT

PICK RISK POLYGON

DRAW NEW RISK POLYGON

DELETE DRAWN RISK POLYGON

DRAW WEDGE RISK POLYGON

ADD EP ZONE (PICK)

DELETE EP ZONE (PICK)

ADD EP ZONE (NAME)

DELETE EP ZONE (NAME)

DISPLAY SAVED RISK AREA

SAVE CURRENT RISK AREA

RISK AREA POPULATION SUMMARY

REFRESH SCREEN
When you select RISK AREA ANALYSIS, the IBS displays this submenu (left) along with the event site, the surrounding EPZs, the current D2 track, and the RISK POLYGONS map layer. When you exit, the system prompts you to save any changes.
<-- Pick an existing polygon (e.g., track)

<-- Pick points to draw a new polygon.

$<-$ Delete the new risk polygon.

$<-\quad$ Draw a wedge risk polygon.

- Include or exclude EPZs in the final risk area.

-- Highlight the currently saved risk area

$<-$ Save the current risk area.

<-- Show populations by EPZ in the risk area.

$<-$ Redraw (and clean up) the screen. 
These RISK AREA ANALYSIS options are explained in the following paragraphs.

PICK RISK POLYGON enables you to pick an existing polygon as the risk polygon that is used to specify which Emergency Planning Zones compose the risk area. (For example, a convenient choice might be to pick the polygon that represents the outer contour of the D2 track.) When you pick the desired polygon (and finish by picking CONTINUE), the boundaries of the risk area (all EPZs that intersect the chosen polygon) are drawn with bold lines.

DRAW NEW RISK POLYGON enables you to plot points that define a new risk polygon. As you use the cursor to plot points on the screen, line segments are drawn between the points. When you draw the final line segment between the first and last points (by picking CONTINUE), the boundaries of the risk area (all EPZs that intersect the drawn polygon) are then drawn with bold lines. Risk polygons that are defined in this way are then stored as a map layer named Risk Polygons.

DELETE DRAWN RISK POLYGON enables you to pick a risk polygon for removal from the Risk Polygons map layer. Select the polygon you want to remove then select CONTINUE.

DRAW WEDGE RISK POLYGON provides a menu of wedge angles you may choose from and then draws a risk polygon based on the current D2 case track and the wedge angle chosen.

The ADD and DELETE options enable you to include or exclude specific EPZs within the risk area:

- ADD EP ZONE (PICK) enables you to use the cursor to pick the boundary of an EPZ to be included. When you pick the desired EPZ boundary (finishing by picking CONTINUE), the boundary is then redrawn with bold lines like the rest of the risk area.

- DELETE EP ZONE (PICK) enables you to use the cursor to pick the boundary of an EPZ to be excluded. When you pick the desired EPZ boundary (finishing by picking CONTINUE), the boundary lines are then restored to lines of normal width.

- ADD EP ZONE (NAME) lists he EPZs not included in the current risk area and prompts you to select the EPZ to be included. The boundary of the identified EPZ is then redrawn with bold lines like the rest of the risk area.

- DELETE EP ZONE (NAME) lists the EPZs in the current risk area (by name) and then prompts you to select the EPZ to be excluded. The boundary lines of the identified EPZ are then restored to lines of normal width. 
DISPLAY SAVED RISK AREA displays the most up-to-date risk area by drawing the EPZ boundaries with bold lines. General users of the IBS must use this option to update the current risk area when the Information Manager changes the risk area boundaries. Usually this option is used after receiving a message from the Information Manager.

SAVE CURAENT RISK AREA saves the currently defined risk area to the system database.

REFRESH SCREEN redraws the current screen and cleans up any graphic debris left from selecting a risk polygon or from manipulating the EPZs that are included in the risk area.

RISK AREA POPULATION SUMMARY provides an estimate of the population within the current risk area. The two sources of data for risk area population reports are:

- Census data

- Special Population data

Census data (if present in the site database) comes from static census database map layers chosen using SELECT MAP LAYERS in MAP ANALYSIS, or CHANGE DEFAULT LAYERS in SETUP. Special population data is generated by the functions ADD SPECIAL POPULATION and MODIFY SPECIAL POPULATION within DIRECTION/CONTROL and contains data for people with special requirements (such as transportation dependence)

After selecting RISK AREA POPULATION SUMMARY, the system displays the Output Redirection menu if you have not specified a default output. The system then prompts with the following menu:

\begin{tabular}{l} 
Risk Area Population Selection Menu \\
\hline $0:$ ExIT \\
$1:$ Total population \\
$2:$ Special population summary \\
(Spensus) \\
(Special Population) \\
\hline Menu Choice me>
\end{tabular}

Your choices are these: 
1. Total population (Census): Produces a report of the total population within the current risk area. Census population data is used to generate this report.

\begin{tabular}{l} 
DD-MMM-YYYY HH:MM:SS \\
Eetimated Population of the Current Rigk Area \\
Map Layer \\
Population Pattern: Weeknight \\
\hline zone Name
\end{tabular}

End of Report: <Return>=Continue, <Ctrl-z>=Exit, M=Redirect ...

If no population map layer has been selected, the program displays the following message:

* * MSG: No population topography eelected

If this happens, use SELECT MAP LAYERS in MAP ANALYSIS, or CHANGE DEFAULT LAYERS in SETUP to select a population map layer.

2. Special population summary (Special Population): Produces a report of the total special population in the current area of interest. Special population data is used to generate this report.

Special Population Summary statue

DD-MMM-YYYY HH: MQS:SS

\section{All Special Populations in Risk Area}

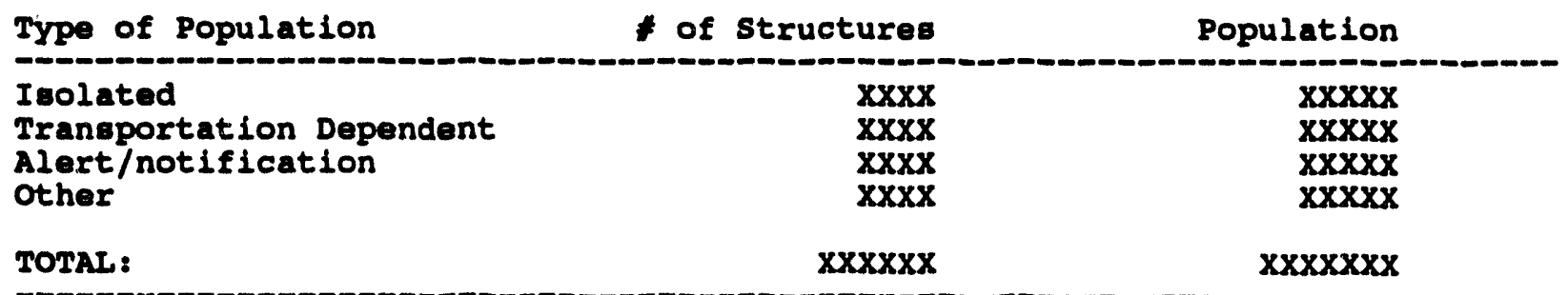

End of Report: <Return>acontinue, <Ctrl-z>-Exit, M=Redirect...

Note: Some special population facilities can be counted more than once in the \# of Structures or Population columns. A special population facility can qualify for more than one category of facility. For example, the same facility can have transportation dependent people and be isolated. This can cause the Totals to not match. 
3. Special population by EPZ (Special Population): Produces a report of the special population for each emergency planning zone within the current risk area. Special Population data is used to generate this report.

special Population Summary status

DD-MMM-YYYY HH: MM: SS

All special Populations in EPzXX

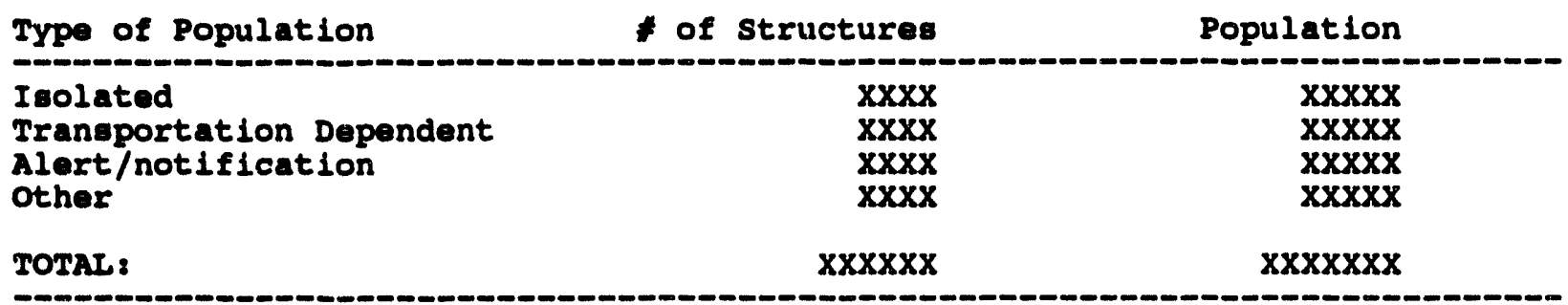

End of Report: <Return>=Continue, <Ctrl-2>=Exit, M=Redirect ...

Note: Some special population facilities can be counted more than once in the \# of Structures or Population columns. A special population facility can qualify for more than one category of facility. For example, the same facility can have transportation dependent people and be isolated. This can cause the Totals to not match.

\section{SAVE CURRENT RISK AREA}

This option enables you to save the current risk area to the system database. The risk area then displays whenever you start the IBS and select the RISK AREA ANALYSIS option.

When you select this option, the system prompts you to define a risk area, if one has not been defined earlier.

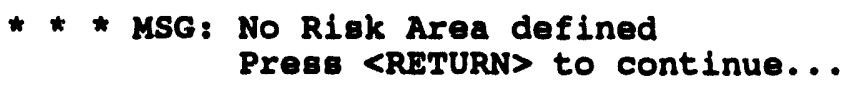

If a risk area has been drawn on screen, the system displays the following message.

Do you wish to gave the RISR AREA? [Y] $=\Rightarrow$

Press the Return key to complete the option and save the risk area. If you decide you do not want to save the risk area, type $\mathrm{N}$ at the prompt and press the Return key. 


\section{SELECT IP*}

The Select IP option enables you to change your current IP. This option is only used by information managers, planners, and others with appropriate authorization. For more information on IPs and their use, see Section 3, Status Board, under the heading Implementing Procedures.

The system displays a listing of the Emergency Planning Zones.

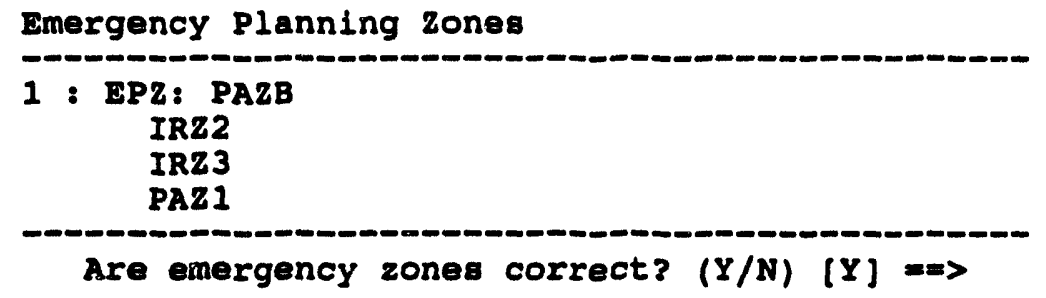

If you answer yes ( $Y$ ) at the prompt, the system displays a listing of all IPs in the database (Planning or Operational, depending on which mode you are in).

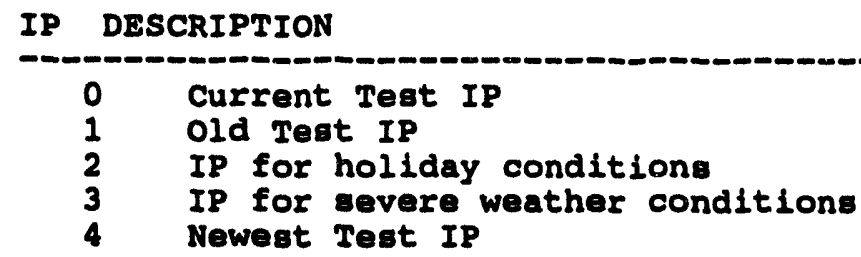

Select desired IP :

Type the number of the IP you want to use at the Select desired IP prompt and press the Return key. The system displays a message similar to the following example.

Your old IP number was 000

Your new IP number is 001

Press <ReTURN> to continue...

You will now be using the new IP.

If you answer no (N) at the prompt, the system directs you to select new Emergency Planning Zones using RISK AREA ANALYSIS. 


\section{IEOC ACTIVATION}

\section{IBS MAIN MENU \\ EMERGENCY ACTIVITIES}

EOC ACTIVATION

MESSAGE BOARD

STATUS BOARD

PEASONNEL MANAGEMENT

MAP ANALYSIS

RESOURCE MANAGEMENT

UST FIRST TASKS

generate CALL UST
EOC ACTIVATION presents a menu of capabilities for initiating EOC activities in case of an event. These include listing the initial tasks for all Emergency Functions in an IP.
The EOC ACTIVATION options in this section are described in alphabetical order.

<-- Cancel display of DIRECTION/CONTROL map layers. 


\section{GENERATE CALL LIST*}

This option generates a phone call list for emergency management personnel. This list can be sent to the default printer or displayed on the screen. When you select GENERATE CALL LST, the system prompts you to select one of three types of lists.

Generate Call List
0 : EXIT
1 : Make call list of ALL IP tasks
3 : Make call list of IP tasks for a specified duration
Menu Choice $(?=H e I p)=0$

Option 1 : Make call list of ALL IP tasks. The following menu displays.

Generate Call List
0 : ExIT
$1:$ Iist only those on duty
$2:$ List those on duty and alternates
Menu Choice $(3=H e l p)=x$

Your choices are:

1. List only those personnel on duty.

2. List those personnel on duty and their alternates, if any.

After you select the personnel to list the system will display the following menu.

Generate Call List
0 : EXIT
1 : List only those assigned to pre-event tasks
3 : List only those assigned to post-event tasks
Lenu Choice $(3=H e l p)=0$

This menu enables you to select people assigned to pre-event or post-event tasks. After you select the type of assignments you want to list on the report, the system will display the following prompt.

Include task description in call list [N]? 
Option 2 : Make call list of IP tasks for a specified duration. The following prompt displays.

IBs will now generate a call list of personnel responsible for the current IP tasks. Only personnel required for those tasks to be started in the time period you specify will be listed.

Please apecify the number of hours after an event=s

After you specify the number of hours after an event and press the Return key, the systern displays the following menu.

Generate Call List

0: ExIT
1: List only those on duty
2: List those on duty and alternates
Menu Choice $(\mathrm{p}=\mathrm{Help}) \mathrm{m}$ )

Your choices are:

1. List only those personnel on duty.

2. List those personnel on duty and their alternates, if any.

After you select the personnel to list the system will display the following prompt.

Generate Call List

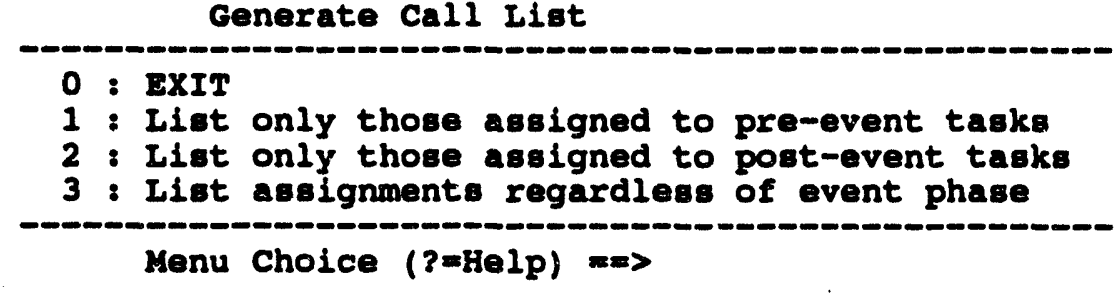

This menu enables you to select people assigned to pre-event or post-event tasks. After you select the type of assignments you want to list on the report, the system will display the following prompt.

Include task description in call list [N] ?

Option 3 : Make call list of ALL positions in database. The following menu displays.

Generate Call List

$0: \operatorname{EXIT}$

1: List only those on duty

2: Iist those on duty and alternates

Menu Choice $(?=\mathrm{Help})=>$ 
Your choices are:

1. List only those personnel on duty.

2. List those personnel on duty and their alternates, if any.

If you have not specified a default output (which you can define under SETUP, JOB ENVIRONMENT, MISCELLANEOUS SETTINGS), the following menu displays.

Output Redirection Menu

0 : ExIT
$1:$ Dieplay on screen
$2:$ Print on default printer
$3:$ Save to an AscII file

Menu Choice $(?=\mathrm{Help}) \Rightarrow$

After you finish selecting one of the three call list options, the system displays or prints a report similar to the following.

+ = person on duty

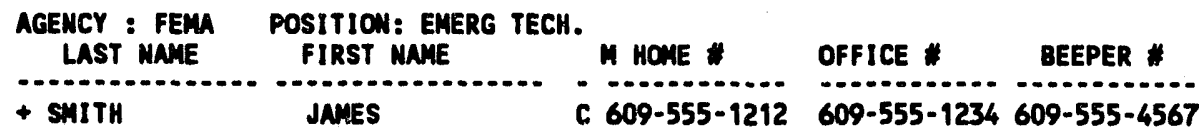

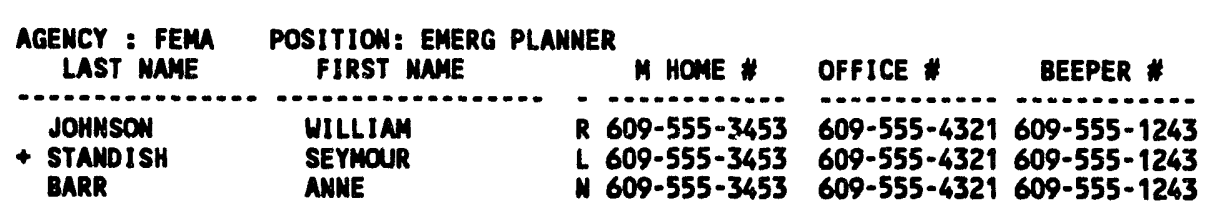

\section{LIST FIRST TASKS}

This option displays a list of the initial tasks that must be completed for all Emergency Functions. The list is shown in chronological order by the start time of the task.

The system prompts:

Ilsting tasks by planned starting time--

Liet tasks for how many hours? $m=>$ 
After entering a time period, you then specify the type of report:

REPORT IP
$0:$ ExIT
$1:$ Report of Agency/Position/Task Description
$2:$ Report of All Tasks/Resources for All Functions
$3:$ Report of Location of All Allocated Resources
$4:$ User-Defined Report
Menu Choice $(?=H e l p) ~$

After selecting a report type, you can then select from the following menu.

\begin{tabular}{l} 
Generate Call List \\
\hline 0 : EXIT \\
1 : List only those assigned to pre-event tasks \\
2 : List only those assigned to post-event tasks \\
3 : List assignments regardless of event phase \\
Menu Choice $(?=H e l p)=>$
\end{tabular}

Tasks that must be started within the specified time period are listed. Those tasks that have the earliest start times are listed first.

After you have selected a report, the system displays a report similar to the following example.

\begin{tabular}{l} 
IMPLEMENTATION PROCEDURES REPORT \\
$* * *$ \\
\hline LAN ENEORCEMENT TASK 01
\end{tabular}

DONE: N AGENCY : NYPD POSITION : POLICE DETECTIVE PLANNED START: 01/JAN/92 01:00 ESTIMATED DONE: 03/JAN/92 01:00 ACTUAL START:

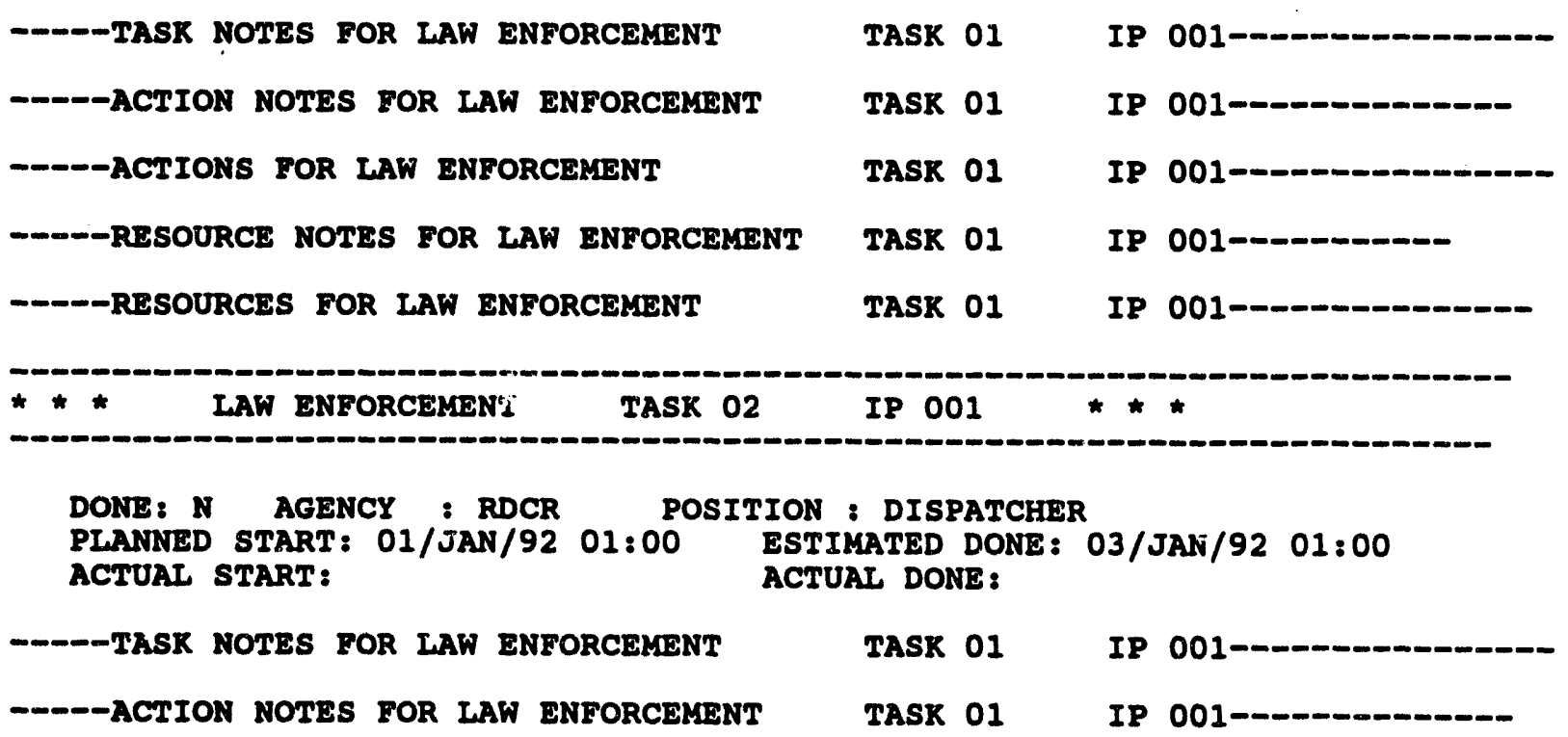


- --ACTIONS FOR LAW ENFORCEMENT

- - - RESOURCE NOTES FOR IAW ENFORCEMENT

- - - RESOURCES FOR LAW ENEORCEMENT

END OF IMPLEMENTING PROCEDURES

<Return> to continue...

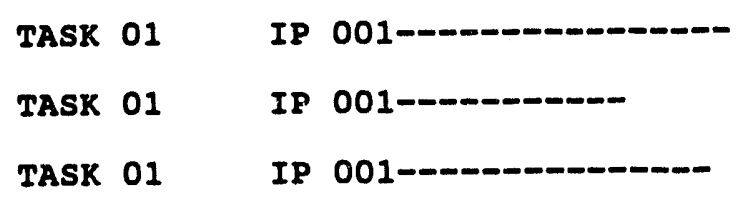

TASK 01

Figure 11.1 shows the general list format.

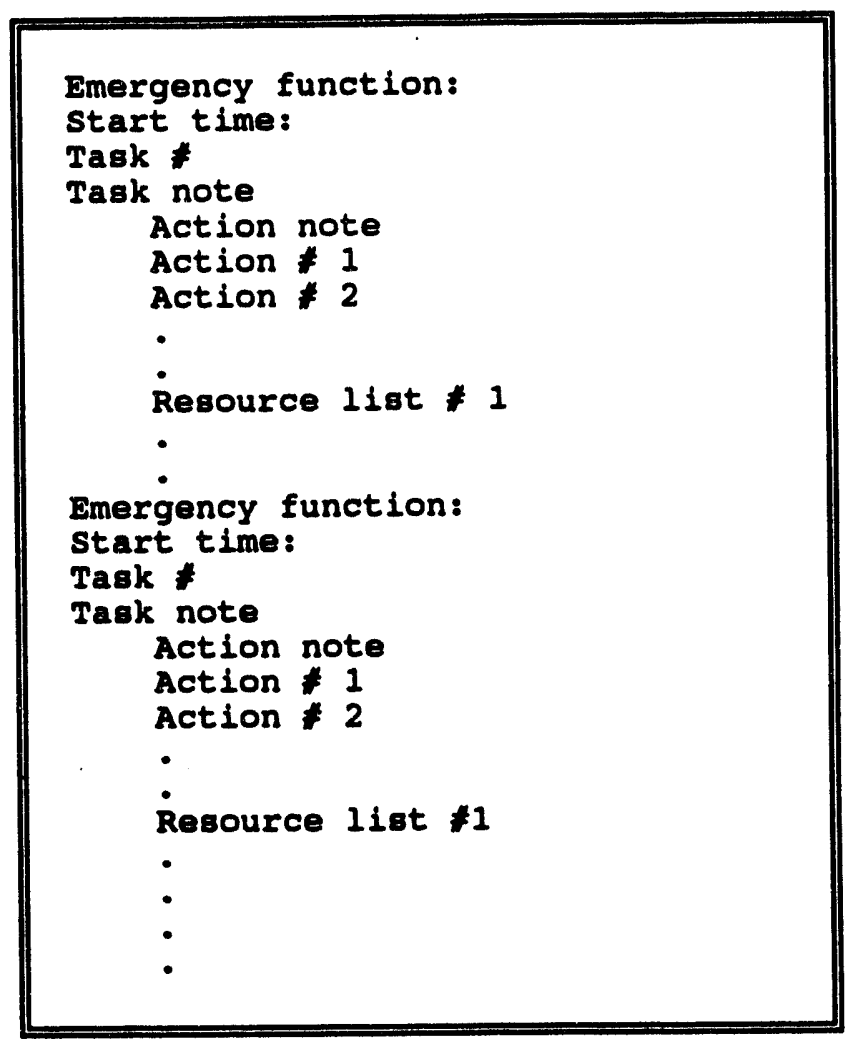

Figure 11.1. List Format for First Tasks of All Emergency Functions 


\section{EVACUATION}

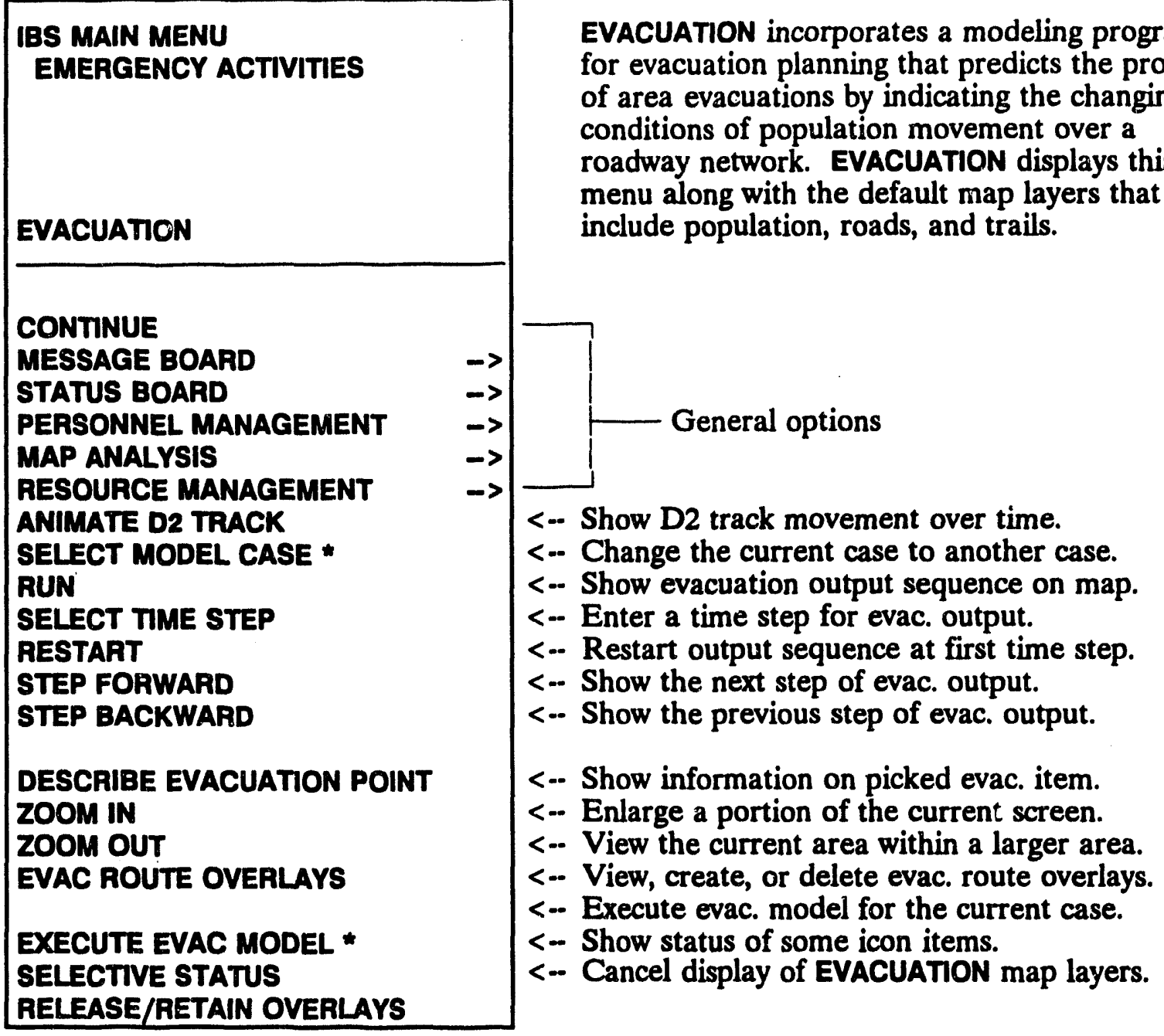

The evacuation model produces several measures of evacuation effectiveness, including travel times, vehicle counts, queues and delays, and person throughput over the links (street segments) and nodes (intersections) of the roadway network. Many of the model results are shown graphically: the network is overlaid on the site map, and you can visualize the results by stepping through the time sequence of the evacuation. Red bars on the network links indicate the extent of traffic lineups near intersections. When you pick EVACUATION, the evacuation network overlay (or link-node diagram) is automatically displayed for the current evacuation case. 
Note: In some cases, a message similar to the following can display when you initially select Evacuation from the Emergency Activities menu. The current case does not include record type 6 . One will now be created.
Enter the current site origin longitude $(-112.34010315)=\Rightarrow$

Press the Return key to accept the default longitude, or enter a new longitude. Another prompt will display.

Enter the current site origin latitude ( 40.29669952$)==$

Press the Return key to accept the default latitude, or enter a new latitude. A final prompt will display.

Enter the current site radius in miles $(37.40000153)=>$

Press the Return key to accept the default radius, or enter a new radius.

This message and sequence of prompts indicates that the current evacuation case is incomplete. If you are a planner, select Execute Evac Model from the Emergency Activities menu. Select A: Change Input Data from the Evacuation Model menu to complete the evacuation case.

If you are not a planner, you must notify the person responsible for the evacuation cases that the current case is incomplete. If the case is left incomplete, the message will display whenever you select a command or option requiring evacuation case input data.

ZOOM IN and ZOOM OUT operate as described in Section 5, Map Analysis. The EVACUATION options are described in alphabetical order.

\section{ANIMATE D2 TRACK}

This option presents a menu of options for viewing D2 output and is identical to the option of the same name on the ANALYZE TRACK menu. For a complete discussion of ANIMATE D2 TRACK, see Section 8, Analyze Track. ANIMATE D2 TRACK is also accessible from the EMERGENCY ACTIVITIES menu under the function HAZARD ANALYSIS. 


\section{EVAC ROUTE OVERLAYS}

This option displays a menu of three evacuation route functions similar to the following example. This menu enables you to perform the following activities:

List Select from a menu of existing evacuation route overlays and display your selection graphically.

Create Select a roadway segment to be identified as a named evacuation route overlay.

Delete Remove an overlay from a list of named evacuation route overlays.

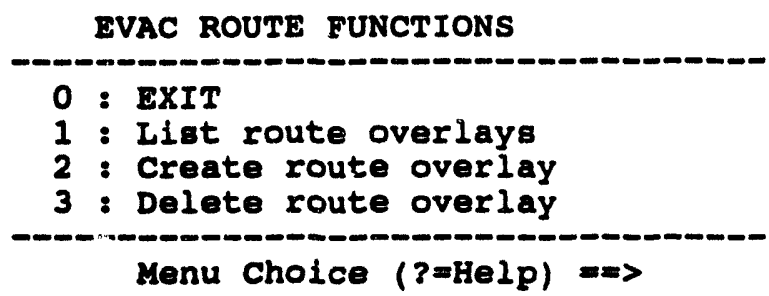

Option 1 : List route overlays: this option lists the evacuation route overlays in a list similar to the following example.

RnOwn Routes
$0:$ EXIT
$1:$ SOUTH
$2:$ NORTH
$3:$ COMBINED
Menu Choice $(3=\mathrm{Help})=>$

After you select an evacuation route, the system will display the route in blinking highlight on the graphic screen. The system will display the prompt:

Press <RETURN> to continue...

Press the Return key to redisplay the Known Routes menu. As you select other choices from the menu, each route will be added to the display. To end the selection of evacuation routes, select 0 : EXIT. The routes you have selected will be redrawn on screen.

Option 2 : Create route overlay: this option enables you to create a graphic overlay showing an evacuation route. This evacuation route overlay can be made available to the onpost system as a map graphics file. The primary purpose of this option is to pass evacuation-related information to the onpost system. The system prompts:

Enter route name (single word - no special characters) $=$ 
Enter any name (up to 40 characters).

If you enter a route name that already exists, the system informs you and prompts again. After obtaining an appropriate name, the system prompts:

Trace the evacuation route by picking roadway segments.

After picking the last segment, select CONTINUE.

Pick a sequence of roadway segments, as instructed.

Each picked roadway segment blinks continuously to indicate selection. To unselect any segment, pick on it again and it will stop blinking. When you pick CONTINUE, the segments are stored using the name you specified earlier and you are returned to the Evacuation menu.

Option 3 : Delete route overlay: this option enables you to delete one of the evacuation route overlays by selecting from a list:

Known Routes

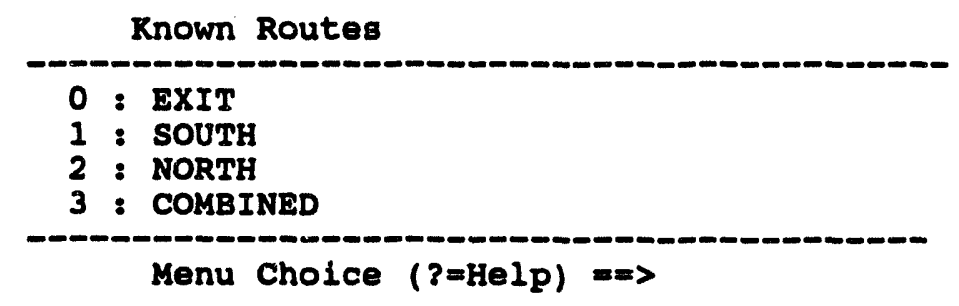

The system draws the route with blinking roadway segments and prompts:

Is this the route you want to delete? $(Y / N)$ [N] $==>$

- $\mathbf{Y}$ deletes the evacuation route overlay (graphics file) and returns you to the EVACUATION menu.

- $\quad \mathbf{N}$ returns you to the EVACUATION menu without deleting the route overlay. 


\section{DESCRIBE EVACUATION POINT}

This option enables you to graphically pick a part of the evacuation network overlay (the link-node diagram) and display model information for that part. If you have displayed a time step (see RUN, STEP FORWARD, STEP BACKWARD, and SELECT TIME STEP) the system displays a menu similar to the following.

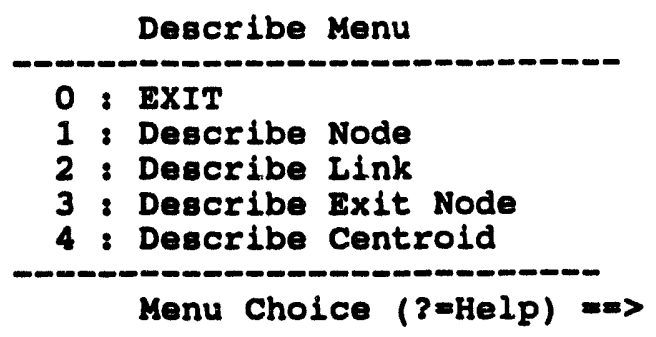

If you do not have a time step displayed, the menu will display as follows.

\begin{tabular}{l} 
Degcribe Menu \\
$0:$ ExIT \\
$1:$ Describe Exit Node \\
\hdashline Mescribe Centroid \\
\hline Menu Choice $(?=$ Help $=m$
\end{tabular}

These selections provide the following information.

- links (roadway segments)--Link information includes, for example, Level of Service (LOS) codes that indicate traffic conditions from free-flow (code A) to unmoving (code F), number of vehicles discharged through the link, and people statistics for the current time step.

If you select a link, the system will display information similar to the following example.

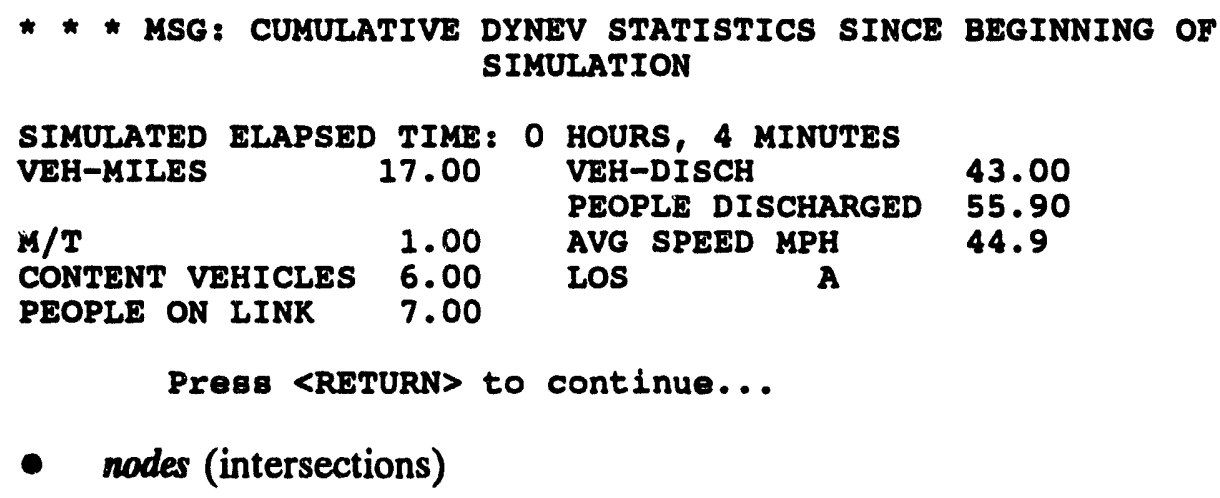

If you select a node, the system will display information similar to the following example. 


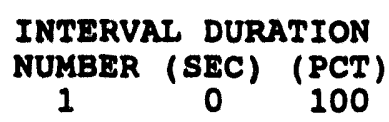

NODE 99 IS UNDER SIGN CONTROL

-

$(97,99)(100,99)(101,99)$

Prese <RETURN> to continue...

- exit nodes (intersection of a link and the evacuation boundary)

- centroids (traffic loading and exit points internal to the network).

\section{EXECUTE EVAC MODEL*}

EXECUTE EVAC MODEL displays the following short menu, which enables Information Managers or planners to prepare evacuation data or run the evacuation model.

Note: This option is available only in Planning mode. To change from Operational to Planning mode, use the SETUP option under the IBS Main Menu. For complete instructions on changing modes, see Section 12, Setup.

3

EVACUATION MODEL

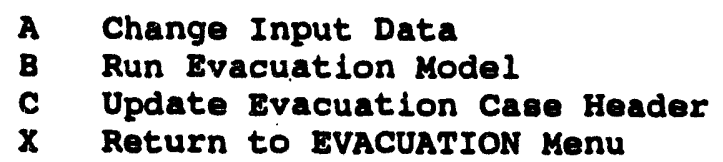

Enter option selection:

Option A Change Input Data enables you to modify the input data for the evacuation model. The IBS Models Guide describes background and procedures for modifying evacuation model input.

Option B Run Evacuation Model first displays a check list for the current evacuation case. For example: 


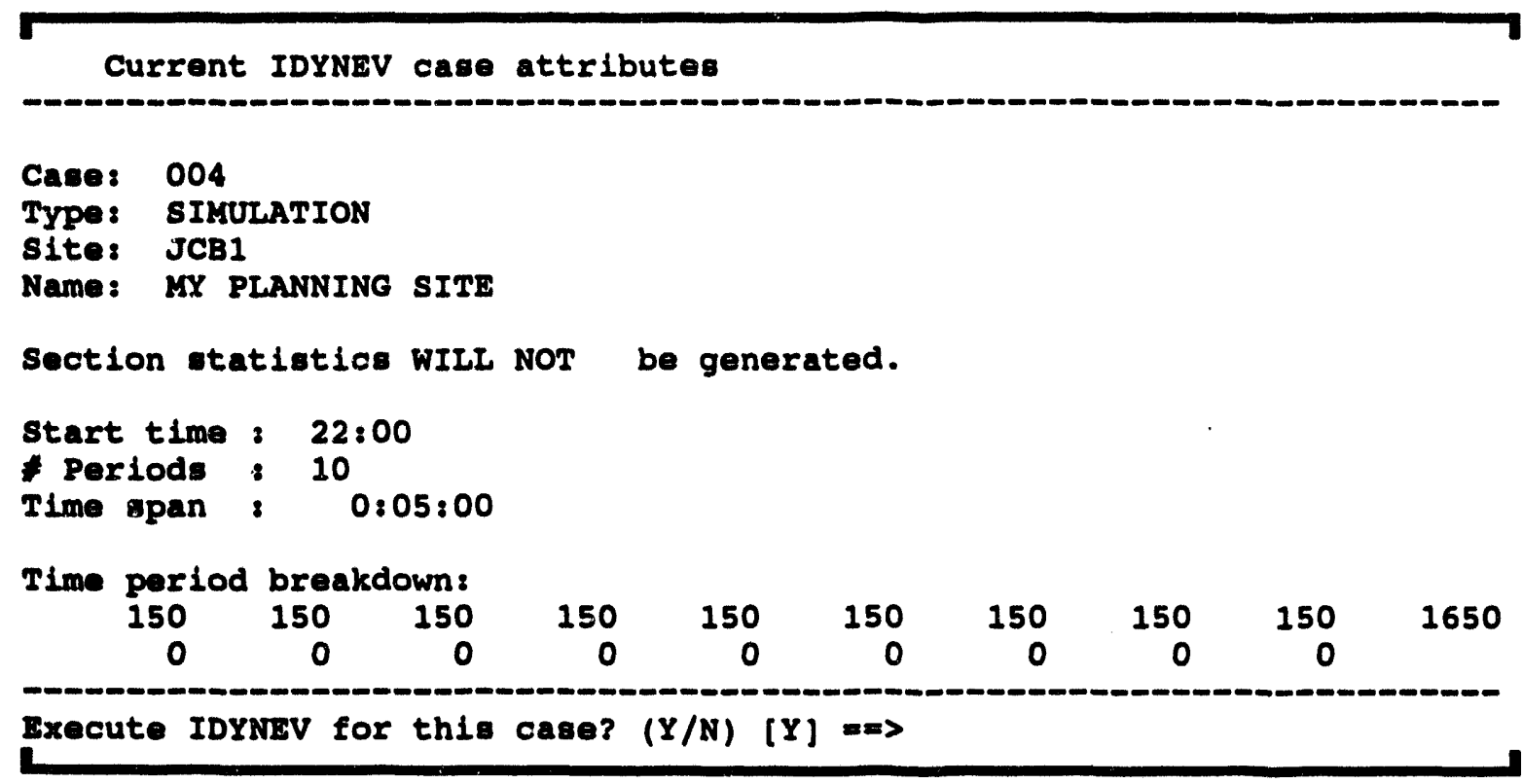

The check list is for your information only: you cannot change any of the information shown. Read the check list to be sure that the case is set up to run as you wish.

Press the Return key to run the model. While the model is running, you CANNOT interact with the modeling program or with any other IBS capability.

The following prompt will display.

Do you want to wait for completion of model $(Y / N)$ (N) $=\Rightarrow$

The system will generate and display a series of messages as it runs the model. If you choose to wait, the model run will complete, after which the system will display the following prompt.

* * MSG: Do you wish to execute a related simulation case? (Y/N) [N] $=\approx>$

Type a $Y$ (Yes) only if the current case is a traffic assignment case and you want to merge the results into a related simulation case.

After the evacuation model has finished executing, IBS displays a brief summary report and then draws the roadway network on the site map. The system prompts you to enter two items that serve as additional case descriptors:

Enter percent of population evacuated $m=>$

This refers to the population inputs to the model as a portion of the population expected in the evacuation area. That is, what part of the estimated population data set was supplied to the model as the total 
number of people to be evacuated? (This should be 100 percent unless you: 1) decided that some people within the evacuation boundary did NOT have to be evacuated and 2) adjusted the model inputs accordingly.)

The system will display a menu similar to the following.

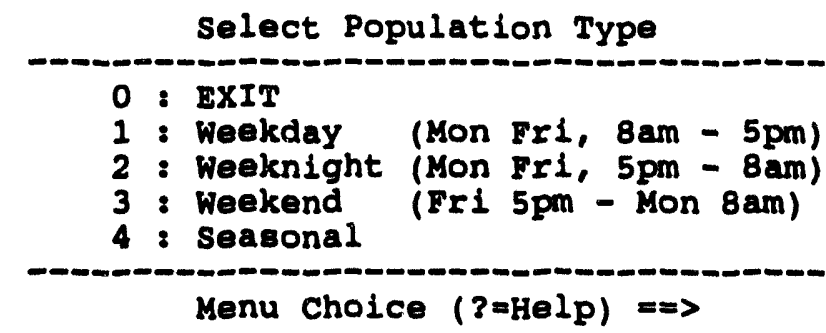

Use this menu to specify the population pattern that was used as the base population evacuated by the simulation.

Each population pattern defines a data set that estimates the number and distribution of people for that time period.

As the evacuation case modeler, you must supply these two case descriptors here because they are considerations that are outside the actual inputs to the model. They can later serve as a basis for categorizing evacuation cases (for example, see SELECT MODEL CASE in this section).

If the model needs further information, you can be presented with one or all of the following prompts.

Enter total minutes load time. $\Rightarrow$

Enter persons per car. $\Rightarrow$

Enter number of evacuation zones. $=>$

The following prompt will display once for each evacuation zone specified.

Enter evacuation zone name for zone nnn. $=>$

Stopping the Model. No clean way is provided to halt the evacuation model while it is running. Pressing CTRL-Y is a standard system interrupt command that halts model execution, but it does not guarantee where you will regain control. The model can be restarted only from the beginning of its execution.

Evacuation Model Report. If the model is executed for a traffic simulation, and if one or more time steps of the simulation are completed, the IBS produces a summary report of the evacuation following model completion. This report file contains various statistics extracted from the last simulation time period reported by the evacuation model: vehicle miles, vehicle minutes, vehicle trips, average speed, percentage of vehicles that stopped, average 
number of vehicles per queue, average delay per vehicle, etc. The summary report file is named as follows:

\section{[username.SITES.site.OUTPUT.DYNEV]CnnnSUM.RPT}

where usemame is your system username, site is a four-character site code, and $n n n$ is the evacuation case number. The summary file is also displayed on your screen as shown in the following example.

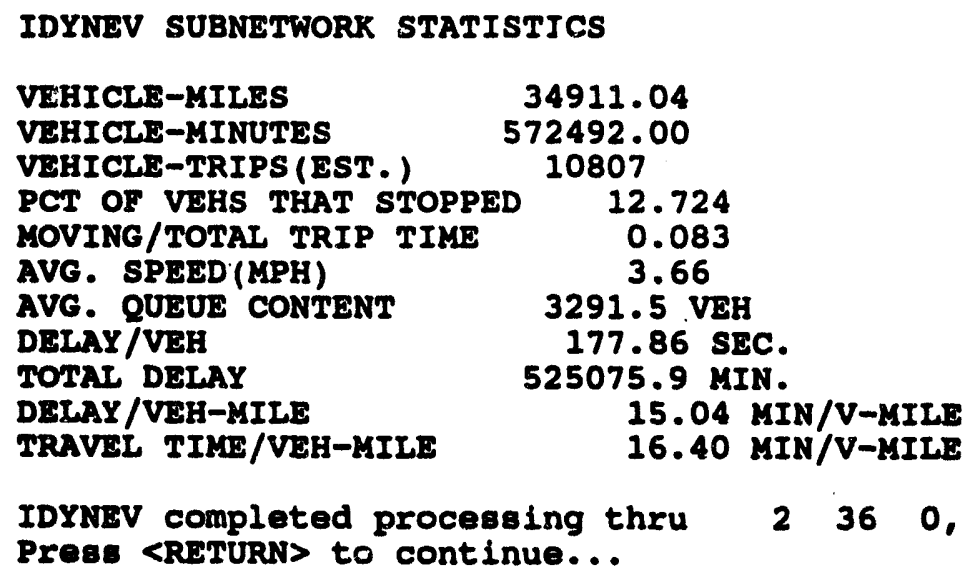

Option C Update Evacuation Case Header enables you to change or update the case he the current evacuation case. The system displays th $\quad \mathrm{g}$ prompt and menu.

Enter percent of population evacuated. $\Rightarrow$

\begin{tabular}{l} 
Select Population Type \\
\hline 0 : ExIT \\
1 : Weekday (Mon Fri, 8am - 5pm) \\
2 : Weeknight (Mon Fri, 5pm - 8am) \\
3 : Weekend (Fri 5pm - Mon 8am) \\
4 : Seasonal
\end{tabular}

Menu Choice $(?=\mathrm{Help})==$

\section{UI] RELEASE/RETAIN OVERLAYS}

The appearance of this option on the menu switches back and forth between RELEASE OVERLAYS and RETAIN OVERLAYS. When you use the EVACUATION Emergency Activity for the first time, the default map layers associated with evacuation are automatically overlaid on the map screen and RELEASE OVERLAYS appears on the EVACUATION menu. 
Pick this option

RELEASE OVERLAYS

RETAIN OVERLAYS

\section{To see this effect on your map screen}

Removes all the map layers associated with this emergency activity

Re-displays the map layers-The map layer overlays continue to be display until you select RELEASE OVERLAYS.

To choose which map layers are the ones associated with the emergency activity, see Section 12, Setup - MAP LAYERS BY ACTIVITY.)

\section{RESTART}

RESTART resets the model output display at the first time step.

\section{RUN}

This option displays the evacuation model output, showing changes in the traffic network as the output steps from the first time step to the last.

Red bars on the network links (street segments) indicate the extent of traffic lineups near nodes (intersections).

\section{u SELECT MODEL CASE*}

SELECT MODEL CASE enables you to change the current evacuation model case. You are asked to supply selection criteria for searching through the existing set of evacuation cases. All cases matching the specified criteria are then displayed in a list from which you can select one.

If you are in Operational mode and the selected evacuation model case has been checked out by a planner, a message similar to the following will display.

\footnotetext{
* * USG: The selected case has been checked out by a planner. They will be

* * MSG: unable to check in their case while it is selected as the current

* * MSG: Operational case.
}

The planner who has checked out this case will not be able to check it back in as long as it is selected as the current Operational evacuation case. 
SELECT MODEL CASE gives you the options of entering a case number directly or specifying a set of case description criteria:

Change eVACUATION CASE MENU

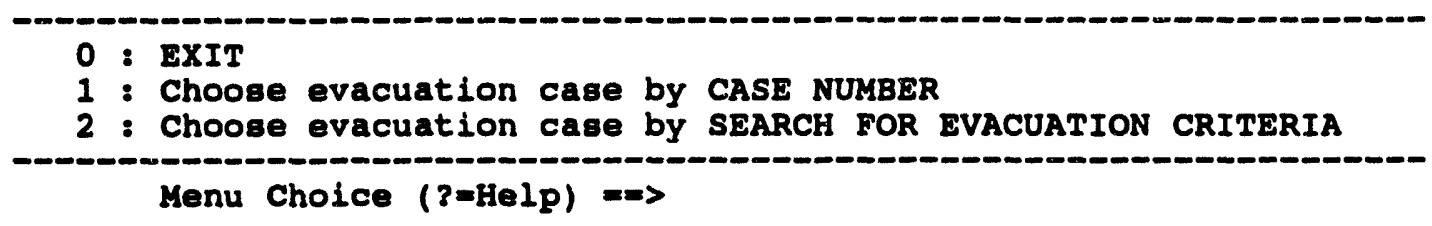

These options are explained here.

Option 1. Choosing an Evacuation Case by Case Number. Choose this option if you know the number of the evacuation case that you want to use. The system displays the following prompt.

Would you like to create a new evacuation case? [N] $\Rightarrow$

Press the Return key to accept the default. The system displays a listing of evacuation cases.

\begin{tabular}{|c|c|c|c|c|}
\hline $\begin{array}{l}\text { EVAC } \\
\text { CASE }\end{array}$ & POPULATION & $\begin{array}{l}\text { PERSON/ } \\
\text { VEHICLE }\end{array}$ & $\begin{array}{l}\text { PERCENT } \\
\text { EVAC }\end{array}$ & $\begin{array}{l}\text { LOADING } \\
\text { PERIOD CLASS }\end{array}$ \\
\hline 0 & $\begin{array}{l}\text { WEEKDAY } \\
\text { ez011 }\end{array}$ & 1.4 & 100.0 & 60.00 \\
\hline$\frac{1}{2}$ & - & $-\infty$ & - & $--\infty-\infty$ \\
\hline 3 & $-\infty-\infty-\cdots-$ & $-\infty$ & $-\infty$ & $-\infty-\infty$ \\
\hline 4 & - - & - & $-\infty-\infty$ & $-\infty-\infty$ \\
\hline 5 & - & $--\infty$ & $-\infty$ & $-\infty-\infty$ \\
\hline 11 & $-\infty-\infty$ & $-\infty$ & $-\infty-\infty$ & $-\infty-\infty$ \\
\hline 12 & $-\infty-\infty-\infty-\infty$ & $-\infty$ & - - & - - - \\
\hline 13 & $-\infty-\infty$ & $-\infty-\infty$ & $--\infty$ & $-\infty-\infty$ \\
\hline 14 & $-\infty-\infty-\infty-\infty$ & $-\infty$ & $-\infty-\infty$ & $-\infty-\infty$ \\
\hline 21 & $-\infty-\infty$ & $-\infty$ & - - & $-\infty-\infty$ \\
\hline 22 & $-\infty-\infty$ & $-\infty$ & $-\infty-\infty$ & $--\infty-\infty$ \\
\hline $\begin{array}{l}23 \\
24\end{array}$ & -4 & $-\infty$ & $-\infty-\infty$ & $-\infty-\infty$ \\
\hline
\end{tabular}

Select Evacuation Case * :

To scroll through the cases on the list, use the U, D, T, B keys as described in Section 1, Introduction and Overview. Select an evacuation case by typing the Evac Case number at the prompt. 
Option 2. Selecting an Evacuation Case by Search for Evac Criteria. Choose this option if you want to search the evacuation criteria to select an evacuation case. This second option displays the following screen where you can specify criteria for selecting the evacuation case. The IBS then generates a selection list of evacuation cases that match (or approximately match) the criteria. For example:

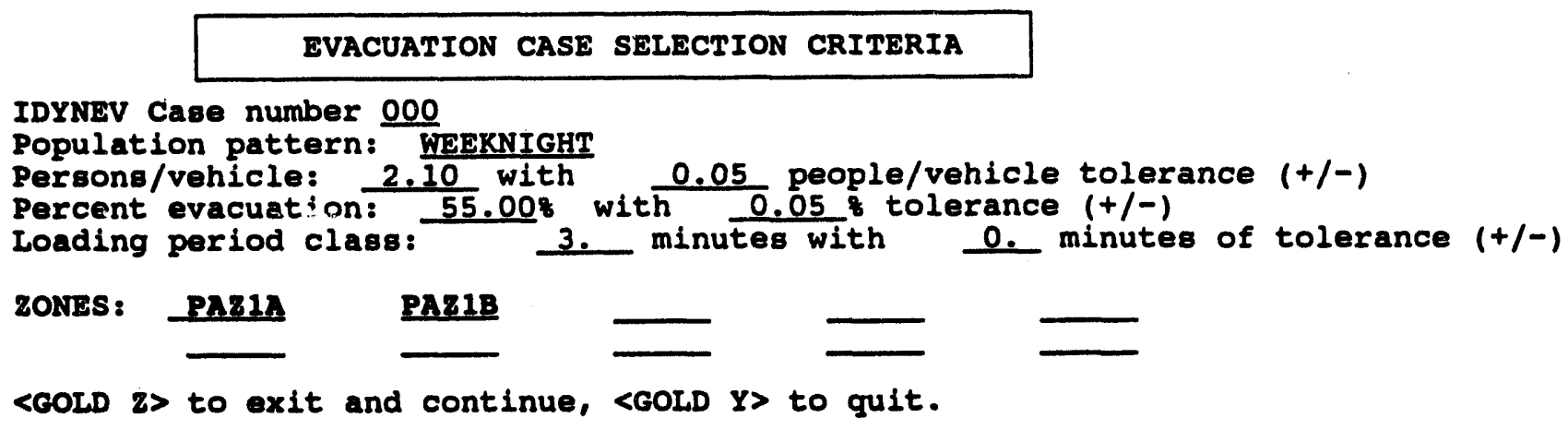

The entry fields serve as search keys into the database of evacuation cases:

- The default tolerances are displayed. You can also change these values for this particular search.

- You can remove one or more criteria from the search by entering blanks in the text fields or a negative one $(-1)$ in the numeric fields. If all fields are removed from the search, you must instead select one case from a list of all evacuation cases.

- If any criteria are used, the IBS compares these case input criteria with the database of evacuation cases. (If no identical matches are found, the IBS displays a message to indicate how many criteria were actually matched.) You must then select from a list of evacuation cases that match the greatest number of criteria (see the next screen). 
After the search, the resulting set of evacuation cases are listed by Evacuation case number, as shown in the following screen example.

\begin{tabular}{|c|c|c|c|c|}
\hline $\begin{array}{l}\text { EVAC } \\
\text { CASE }\end{array}$ & POPULATION & $\begin{array}{l}\text { PERSON/ } \\
\text { VEHICLE }\end{array}$ & $\begin{array}{l}\text { PERCENT } \\
\text { EVAC }\end{array}$ & $\begin{array}{l}\text { LOADING } \\
\text { PERIOD CLASS }\end{array}$ \\
\hline 44 & $\begin{array}{l}\text { WEEKEND } \\
\text { PAZ1A }\end{array}$ & ${ }_{\text {PAZ1B }}^{2.1}$ PAZ1C & 55.0 & 3.10 \\
\hline
\end{tabular}

Select Evacuation Case * :- 


\section{SELECT TIME STEP}

This option enables you to set the display of model results to a specific time step. After you select this option, the following message will briefly display.

* * MSG: Opening and Reading evac model files

After the message, a prompt similar to the following will display.

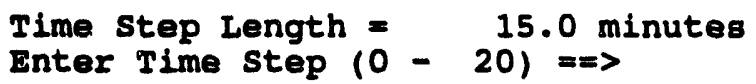

Enter a time step number and press the Return key. The time displays in white on the menu.

\section{STEP FORWARD}

This displays the traffic network results for the next sequential time step in the model output. The step forward is calculated from your currently displayed time step.

\section{STEP BACKWARD}

This displays the traffic network results for the previous sequential time step in the model output. The step backward is calculated from your currently displayed time step. 
II HAZARD ANALYSIS

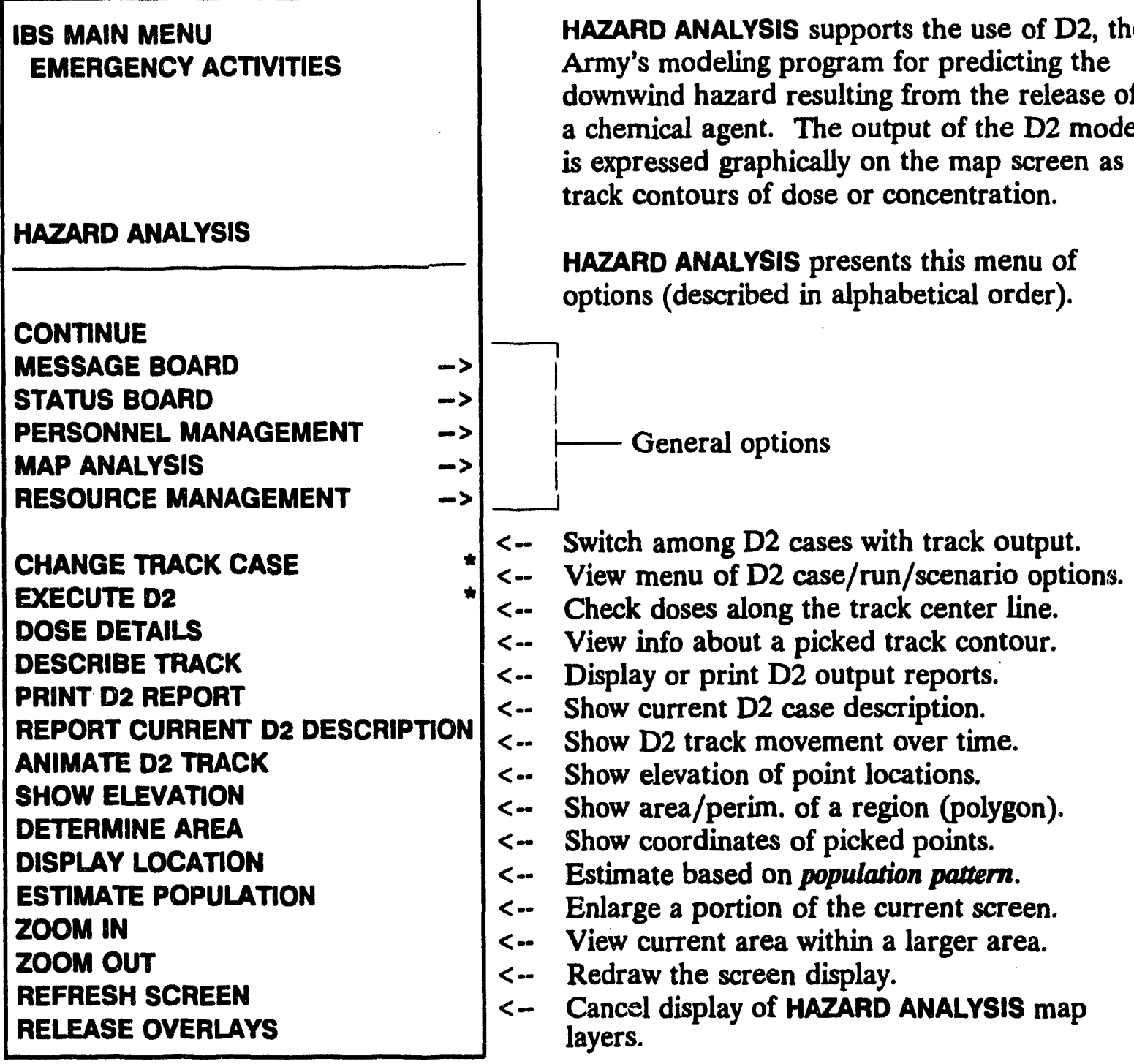

When you begin HAZARD ANALYSIS, the map screen automatically displays the default map layers associated with this function. These map layers should include POPULATION and D2 TRACK for the current D2 case.

D2 Track. The D2 output track on the map screen consists of contour lines. Each contour represents a level of dose or concentration (depending on the original inputs to the D2 mod ?). A series of asterisks (*) appearing along the track center line indicate slice points along the track where the DOSE DETAILS option can be used to display dose or concentration information about those locations. Some releases do NOT result in the generation and appearance of these points. 


\section{ANIMATE D2 TRACK}

This option presents a menu of options for viewing D2 output and is identical to the option of the same name on the ANALVZE TRACK menu. For a complete discussion of ANIMATE D2 TRACK, see Section 8, Analyze Track. ANIMATE D2 TRACK is also accessible from the En 'ERGENCY ACTIVITIES menu under the function EVACUATION.

\section{CHANGE TRACK CASE*}

This option for identifying the current D2 case is identical to the option of the same name on the IBS main menu (see Section 9, Change D2 Track Case). CHANGE TRACK CASE is available only to the Information Manager and Planners (for their planning site databases).

\section{DESCRIBE TRACK}

DESCRIBE TRACK enables you to pick one or more of the contours displayed in the current D2 track. When you select this option, the Describe Track command highlights in blinking green and the following message displays.

* * MSG: select TRACR boundary with crosshairs

As you pick a contour, a text description of the contour is displayed at the top of your screen. For example:

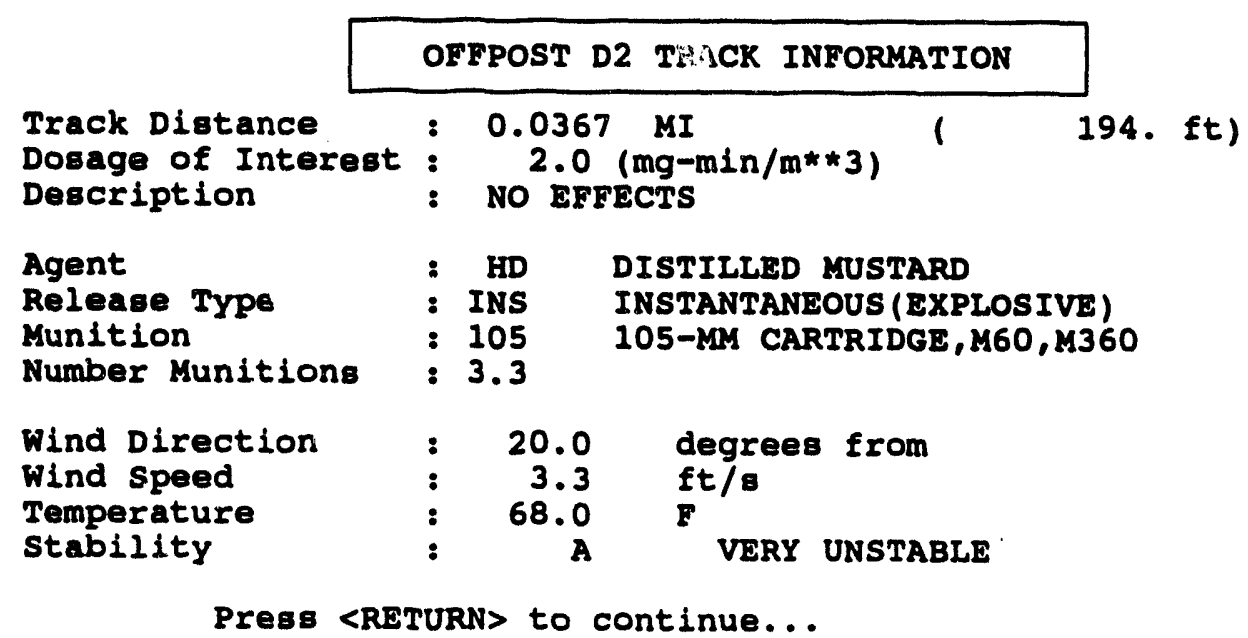

You can pick more than one contour. The information from the previous picks remains visible on the screen until you choose another menu option. To stop, select the CONTINUE command from the menu. 


\section{RELEASE/RETAIN OVERLAYS}

The appearance of this option on the menu switches back and forth between RELEASE OVERLAYS and RETAIN OVERLAYS. When you use the HAZARD ANALYSIS Emergency Activity for the first time, the default map layers associated with hazard analysis are automatically overlaid on the map screen and RELEASE OVERLAYS appears on the HAZARD ANALYSIS menu.

Pick this option

RELEASE OVERLAYS

RETAIN OVERLAYS

\section{To see this effect on your map screen}

Removes all the map layers associated with this emergency function

Re-displays the map layers-The map layer overlays continue to be displayed until you select RELEASE OVERLAYS.

To choose which map layers are the ones associated with the emergency function, use SETUP-MAP LAYERS BY ACTIVITY.)

\section{DOSE DETAILS}

Asterisks (*) are used to mark intervals of predetermined length along the D2 track center line. DOSE DETAILS enables you to pick one asterisk on the track center line to see a report of dosage information for that location. When you select this option, the Dose Details command highlights in blinking green and the following message displays.

* * MSG: Select dose site (*) with crosshairs

After you select a dose site, the Output Redirection Menu will display if you have not specified a default output format. You can pick more than one asterisk location to see further reports. For each pick you will see information details similar to those shown in the following example report. The report provided can vary somewhat, depending on the input parameters selected for the D2 cases.

Note: It is possible that some chemical releases will not result in the generation of dose details. 
Example Report:

D2 Dose Details

\begin{tabular}{|c|c|}
\hline $\begin{array}{l}\text { Digtance } \\
\text { Time for Tip (Minutes) } \\
\text { Time for Tail (Minutes) } \\
\text { Total dose (mg-min/m**3) }\end{array}$ & $\begin{array}{r}2000 \\
12.10 \\
21.30 \\
: \quad 4.10\end{array}$ \\
\hline $\begin{array}{l}\text { NO EFFECTS } \\
\text { Dosage level (mg-min.m**3) } \\
\text { Portion of dosage level (8) } \\
\text { Time for dosage level (min) }\end{array}$ & $\begin{array}{r}0.50 \\
100.00 \\
14.90\end{array}$ \\
\hline $\begin{array}{l}\text { NO DEATHS } \\
\text { Dosage level (mg-min.m**3) } \\
\text { Portion of dosage level (8) }\end{array}$ & $\begin{array}{r}6.00 \\
69.20\end{array}$ \\
\hline $\begin{array}{l}\text { 18 LETHALITY } \\
\text { Dosage level (mg-min.m**3) } \\
\text { Portion of dosage level (*) }\end{array}$ & $\begin{array}{l}10.00 \\
41.50\end{array}$ \\
\hline
\end{tabular}

End of Report: <Return>=Continue, <Ctrl-z)=Exit, $M=$ Redirect...

To stop, select the Continue command from the menu. 


\section{EXECUTE D2*}

This option displays the Execute D2 Menu Options menu. The menu includes options for creating a new case (based on an existing case), modifying the input, running the model, and maintaining the model cases (input and output data). Also included is a key capability for creating scenarias: scenarios are unique combinations of situational data that link the D2 case output with an evacuation model case, meteorological conditions, and population pattern for a specific Implementing Procedure.

\section{Caution}

The D2 model inputs are easy to change; however, the knowledge of what those changes will be is left up to you. ${ }^{(0)}$ For other than testing purposes, you probably should IYOT change D2 model input unless you have a clear understanding of the model. The many input parameters are interrelated in nonstraightforward ways. Also, please interpret the D2 model results cautiously. The D2 model itself is unchanged from previous implementations: data that caused aborted runs in the D2PC model will do so in the IBS as well.

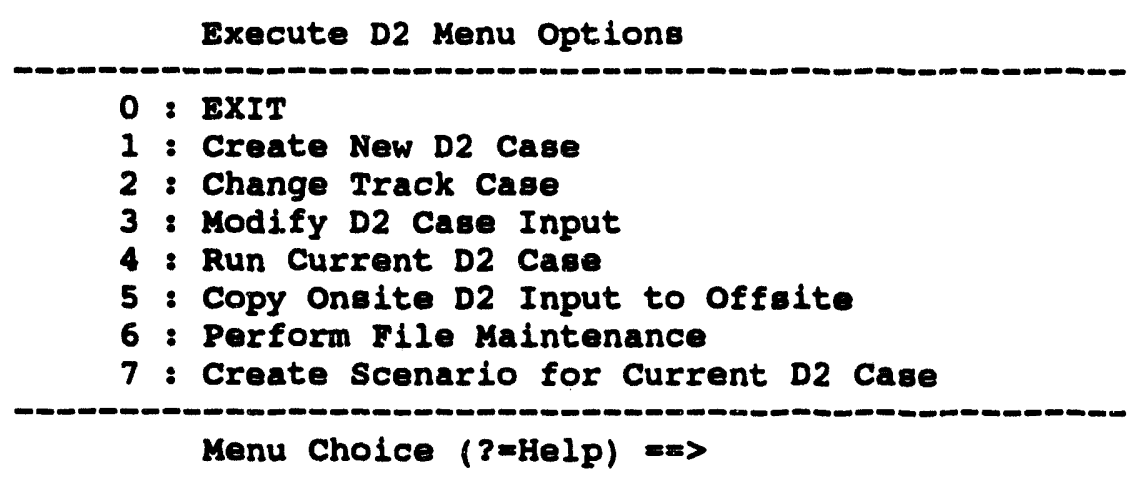

Note: For Option 3 : Modify D2 Case Input a case marked as a Maximum Credible Event (MCE) cannot be edited. This setting can be changed by using the INFOMANAGER ROOT MAINTENANCE command under the SETUP main menu option.

The options of the D2 RUN Capabilities menu are described in the following paragraphs.

(a) See Whitacre, C.G., J.H. Griner III, M.M. Myirski, and D.W. Sloop. 1987. Personal Computer Program for Chemical Hazard Prediction (D2PC). CRDECTR-87021, L.S. Army Munitions Chemical Command, Aberdeen Proving Ground, Maryland. 
Option 1 : Create New D2 Case enables you to create a new case based on an existing case. The existing case is then referred to as the base case. You select the case to be used as a base case by either: 1) entering a D2 case number directly, 2) searching the agent, munition, and meteorological data for the cases, or 3) selecting the D2 case from a list of cases-as explained for CHANGE D2 TRACK CASE on the IBS main menu. After selecting a case the following form is displayed.

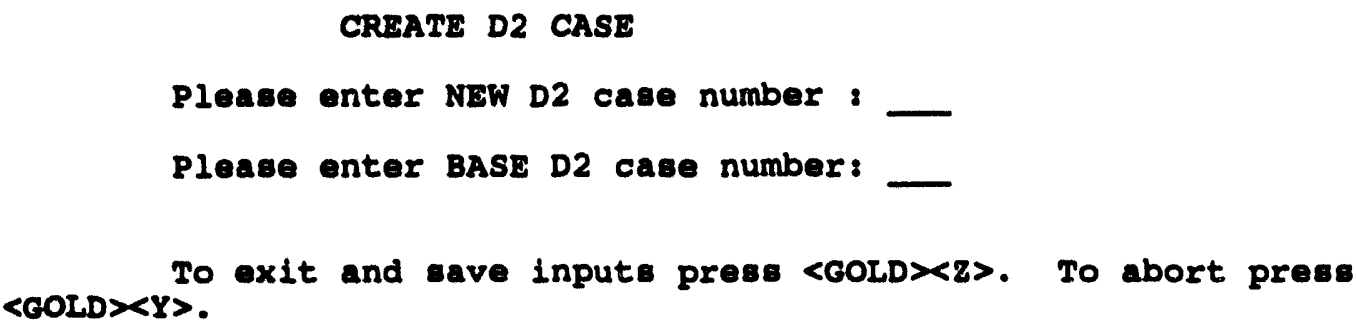

Option 2 : Change Track Case is the same as the main menu option CHANGE D2 TRACK CASE described in Section 9.

Option 3 : Modify D2 Case Input displays an input screen similar to the following example for entering D2 input data:

D2 STANDARD INPUT FOR CASE $\$ 200$

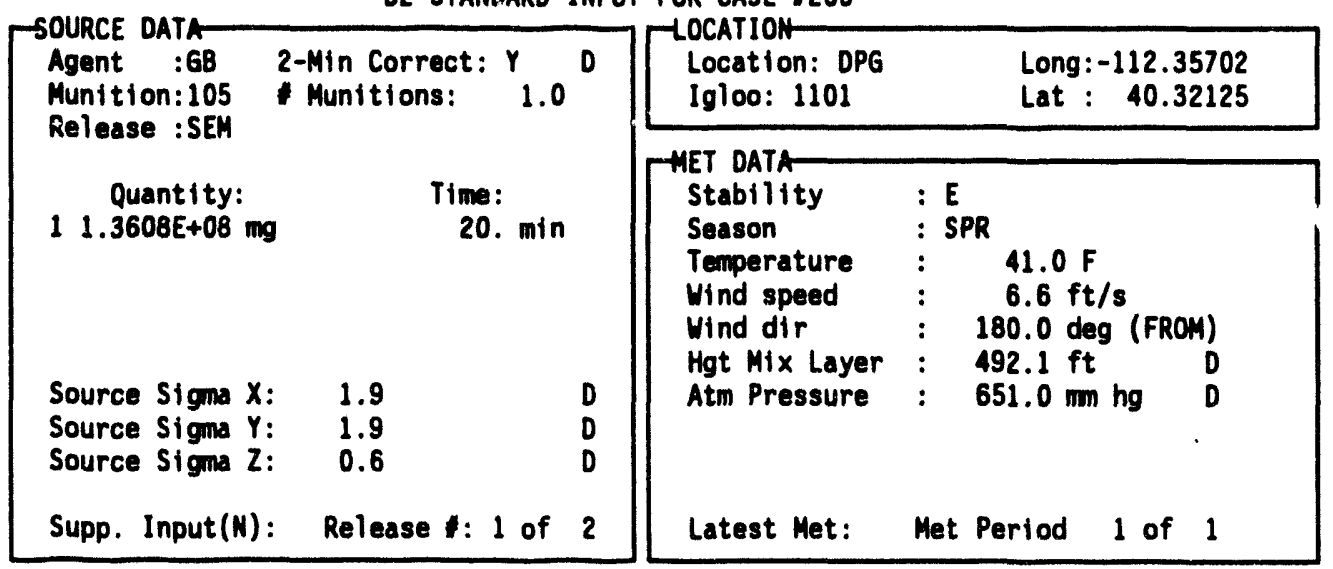

Enter a text 02 description here: 02 case 1200 . Agent $6 B$,

Release type Semi-continuous. Temperature $41.0 \mathrm{~F}$. Wind speed $6.6 \mathrm{ft} / \mathrm{s}$

To view more information about the possible inputs on this screen, press ? (or the HELP key) at each fieid. To exit the form and save, press GOLD-Z, to exit without saving, press GOLD-Y.

Note: As shown in the previous example, you can enter a two line text description at the bottom of the D2 input form. Use this area to enter the agent, munitions, release type, and other useful information. The two line description is what the system will display when you select REPORT CURRENT D2 DESCRIPTION from the main menu, so be as descriptive and specific as possible when you enter the text. 
In Modify D2 Case Input there are a number of different input screens.

- There is a main input screen with commonly changed parameters,

- An additional input screen for less commonly changed parameters,

- Six screens which display depending on user input for the first two screens. In general, the other input screens will display when a stability or release type change causes D2 to prompt for more information.

Supplemental screens display for the following:

EVP and EVS releases

STK and STJ releases

FIR and FLS releases

U stability

S stability

Finally, if you type a W (woods) in the Stability field, the system will display the following menu.

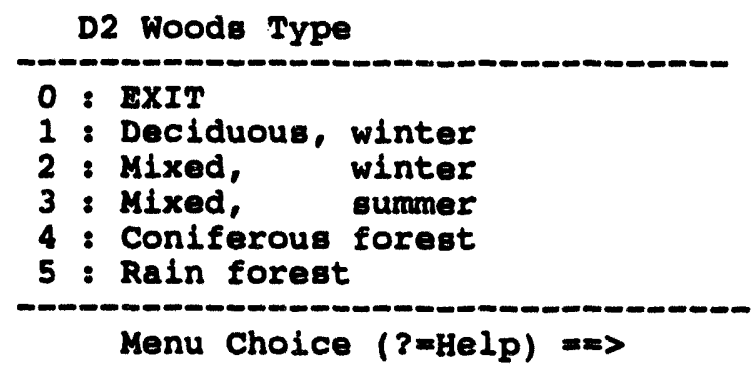

Select the type of woods from this menu and press the Return key.

\section{Holds on Variables}

The D2 model has internal defaults for some of its variables. Each of these variables has a source flag which causes D2 to use its default values or to use the user defined values. Most of these variables display on the main D2 input form, and the source flag can be found to the right of the variable itself. A $\mathbf{U}$ specifies the user defined value should be used (hold the variable), and a D specifies the default D2 value should be used (release the variable). The variables which can be held in this manner on the D2 Standard Input form are:

\section{Sigma $x$}

Sigma $y$

Sigma $z$

Two-minute correction

Atmospheric pressure

Height of the mixing layer

Quantity. 


\section{Changing Met Conditions}

In the D2 model it is possible to change some weather conditions during the course of the run. For example, if the wind speed is $1 \mathrm{~m} / \mathrm{s}$ for the first 5 minutes and then picks up to $10 \mathrm{~m} / \mathrm{s}$ for the remainder of the dispersion run, you could model this using the Met Period: function. This function breaks up the D2 run into segments based on weather conditions. The only met data which can be changed in this way are stability class, wind speed, and the height of the mixing layer.

The Met Period: displays the index of the met change records the user is currently editing. (For example Met Period: 1 of 2.)

To create a new met peri d, simply enter the index you wish to create. For example, if you currently have two met change periods and wish to create a third, type the number three over the number two in the Met Period: 1 of 2 field. The system will display the following prompt.

Do you wish to create a new met change interval? $[Y$ ] $=>$

If you answer Yes to the prompt, you will be set to the third met change period. For all met change periods greater than one, only stability, wind speed, height of mixing layer, and the time to the next met change will be accessible.

Once met change records have been added, you can easily move between met change periods by typing the appropriate index in the Met Period field.

To remove a met change interval from the list, type $R \sharp$ in the Met Period field where \# is the number of the met change interval you want to remove.

\section{Summing Dosage Distribution}

The D2 model also enables you to sum the dosages between separate runs of the same agent at the same location. For example, if a palletized M55 rocket were to explode and cause neighboring rockets to leak and evaporate, you could model this case by summing instantaneous and evaporative releases.

The Release \# field at the bottom of the form displays the index of the current release being edited and the number of releases, for example Release \#: 2 of 2 . By default there is one release. If you want to add more, just type the next release number in the Release \# field. (Release numbers must be consecutive.) When you enter a new release number, the values for your current release will be saved, and the form will be redisplayed for you to enter the next release.

To remove a release from the list, type $R \#$ in the Release \#: field where \# is the number of the release you wish to remove. You will be prompted:

Are you sure you wish to delete summation release number $x x x$ [N] $=\Rightarrow$ 


\section{Quantity Information}

In D2 there are two types of quantities that you can input. For all releases except instantaneous and evaporative, you input quantity in up to six source time increments. For evaporative and explosive releases, you only input one quantity. The quantity fields displayed will vary, depending on which release mode is specified. If you are using the source time increments, you will also be prompted for the number of increments.

\section{Two-Minute Correction}

The 2-Min Correct: field is only applicable for GB and VX releases, and will only display on the main input form when one of these agents are specified.

Note: Two minute correction has to do with the body's ability to detoxify itself for low dosage levels in the first two minutes of exposure. If twominute correction is turned on, this is taken into account when modeling.

\section{Converting Units}

The user may select default units for several fields on the main D2 input form. Subsequent D2 forms will follow these unit defaults. Notice that if you change units on the main D2 input form, the actual data field will be converted automatically.

\section{Time After Functioning}

For explosive releases of HD or HT (mustard), you will be prompted for a time after functioning in minutes.

\section{Latest Met}

To load the latest met conditions into the D2 input file, the user should type a $Y$ into the Latest Met field. This will update the form with the latest met data found at the current time. 


\section{Supp Input}

If you want to access some of the more obscure D2 variables, you can do so by typing a $Y$ in the Supp Input (Supplemental Input) field. A Y or N (Yes or No) displayed beside the Supp Input field indicates whether or not supplemental data currently exists. The D2 Supplementary Inputs form displays similar to the following example.

D2 SUPPLEMENTARY INPUT FOR CASE $\$ 200$

\begin{tabular}{|c|c|c|c|c|c|}
\hline 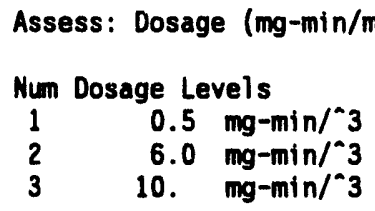 & $\begin{array}{l}\text { 3) } \\
\text { Dosage } \\
0.5 \\
\text { D6 } \\
\text { D10 }\end{array}$ & $\begin{array}{l}\text { From: } 02 \\
\text { Level Deser } \\
\text { NO EFFECTS } \\
\text { NO DEATHS } \\
\text { 1\% LETHALITY }\end{array}$ & $\begin{array}{l}\text { Default Levels } \\
\text { riptions } \\
Y\end{array}$ & Num & Levels: 3 \\
\hline $\begin{array}{l}\text { Vapor Depletion } \\
\text { Slope of Frost Wind } \\
\text { Breathing Rate } \\
\text { Skin Factor. } \\
\text { Reflection Coefficient }\end{array}$ & $\begin{array}{r}\text { OFF } \\
0 \\
\quad 25 \\
0 \\
0 \\
\quad 1\end{array}$ & $\begin{array}{l}N \\
H \\
N \\
N \\
N\end{array}$ & $\begin{array}{l}\text { Roughness Length } \\
\text { Settling Velocity } \\
\text { Sampling Height } \\
\text { Height of Source }\end{array}$ & $\begin{array}{l}: \\
: \\
: \\
:\end{array}$ & $\begin{array}{l}0 . \\
0 . \\
0 . \\
0 .\end{array}$ \\
\hline
\end{tabular}

In D2 you can assess either dosage or concentration. The top half of this form enables you to specify what to assess, how many levels to assess, and what levels should be assessed.

When assessing dosage, you can use the three default dosage levels, $1 \%$ lethality, no deaths, and no effects, or you can specify your own levels.

The bottom half of this form enables you to access some miscellaneous variables which are not used very often. To the right of each variable listed at the bottom of this form is a source flag. If you do not wish to specify any value for a given variable, type an $\boldsymbol{N}$ (for Not defined) in the source flag field of that variable. If you do want to input a value for one of these variables, type a $U$ (for User defined) in the source flag field for that variable. Unless you have a good understanding of these inputs into the model, it is recommended that all the source flags at the bottom of this form be set to $\mathrm{N}$.

Option 4 : Run the Current D2 Case executes the D2 model for the current case inputs. Based on the case results, IBS creates output files that are identified with the current IBS D2 case number. IBS also creates one graphic output file that contains polygons depicting the D2 track contours. Note that the amount and type of information contained in this graphic output file depends on the D2 input. If possible, the model produces information on dose slice points along the track. Those points appear as asterisks along the track center line. Some releases do NOT result in the generation and appearance of these points. In that case, this message is displayed after D2 execution: 
* * * MSG: SLICE FILE NOT CREATED. DOSAGE ATTRIBUTES WILL NOT BE GENERATED.

Option 5 : Copy Onsite D2 Input to Offsite enables you to create a new offsite D2 case based on an onsite D2 case. It copies the input of the case only. You must rerun the case after you copy it. The new offsite case becomes the current D2 case.

When you select this option, the following menu will display.

Copy Onpost D2 to Offpost D2 Menu
0 : ExIT
1 : Copy current onpost D2 to offpost case
Menu Choice $(?=H e l p)=m$

If you select Option 2: Select onpost case to copy to offpost case, the following menu will display.

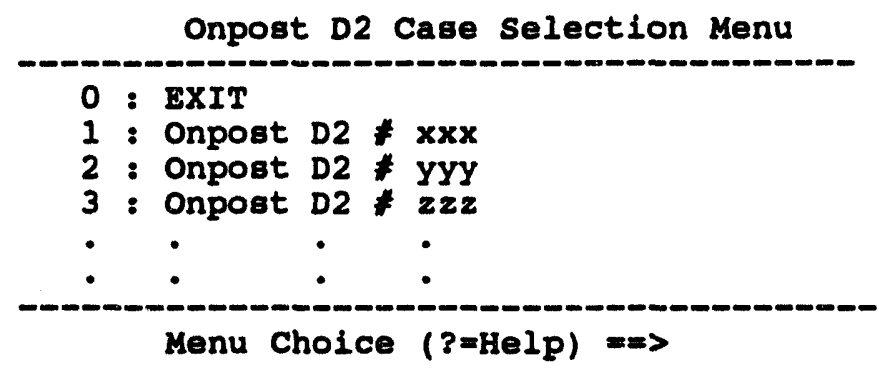

Select the onpost case on which you want to base the offpost case.

If you selected option 1, or after you select a case from option 2, the system will display the following menu.

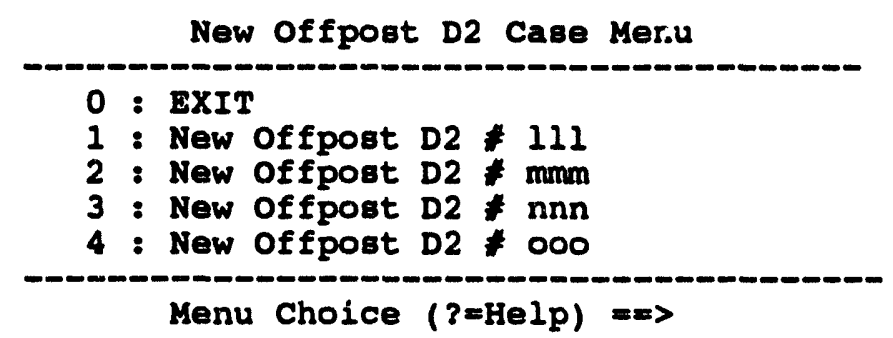

Select a new offpost case number which will be based on the onpost case. Once you have selected a new case number, the system will display the following prompt:

Do you wish to make this your current planning(operational) D2 Case? (Y/N) m=>

If you type a $Y$ (yes) at the prompt the system will switch you to the newly created offpost D2 case. The system will then display a prompt similar to the following example. 
You are now set to case nnn.

Press <RETURN> to continue...

If you type a $N$ (no) at the prompt the new case will be created, but your current case will still remain in effect. The system will display a message similar to the following example.

Offpost D2 case *nnn has been created based on an onpost case. Your current D2 case remains mmm.

Press <RETURN> to continue...

Option 6 : Perform File Maintenance displays the following menu. The menu options enable you to list the directories of evacuation cases for the current site. You also can delete selected input and output files from the system (if you own the files). Exercise care here, especially in deleting input files, because recreating files can be time consuming.

\section{$\boldsymbol{\sigma}$}

PERFORM FILE MAINTENANCE

Selection

Designator selection

A Display Directory of Cases

B Delete Case Output for a Specified Case

C Delete Input and Output for a specified Case

$x$ Exit to Previous Menu

Enter selection designator:

Option 7 : Create Scenario for Current D2 Case enables you to create scenarios to be included in the scenario table for the current D2 case: this scenario applies to the current Implementing Procedure (IP). The following illustration is a compressed example of the scenario table. 


\section{Scenario Table}

\begin{tabular}{|c|c|c|c|c|c|c|c|c|c|c|c|c|c|c|}
\hline p & meraiprion & mant & 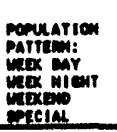 & neent & mensrion & $\frac{\text { eazeast }}{\text { mat }}$ & 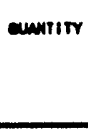 & 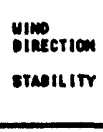 & 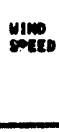 & case " & & & & evacuminum \\
\hline & & & & & & & & & & & $\frac{18}{2}$ & $a_{2}^{m a n}$ & $\frac{p a n}{z}$ & Evaoumreo \\
\hline & & & & & & & & & & & & & & 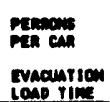 \\
\hline
\end{tabular}

Each record in the scenario table represents a unique combination of

- D2 case

- Evacuation case (IDYNEV)

- Meteorological conditions

- Population pattern

A single IP can apply to several different scenarios, but each scenario maps to only one IP.

The case number of the current D2 case is assigned to the new scenario(s). If you want to create scenarios that are based on a different D2 case, use the CHANGE D2 TRACK CASE option before creating a new scenario.

This Create Scenario option is used extensively in the planning phase. In operational mode the menu will only enable you to print the current scenario table. In planning mode you can Add, Modify, Delete, or Print records in the scenario table by using the following text menu:

SCENARIO TABLE

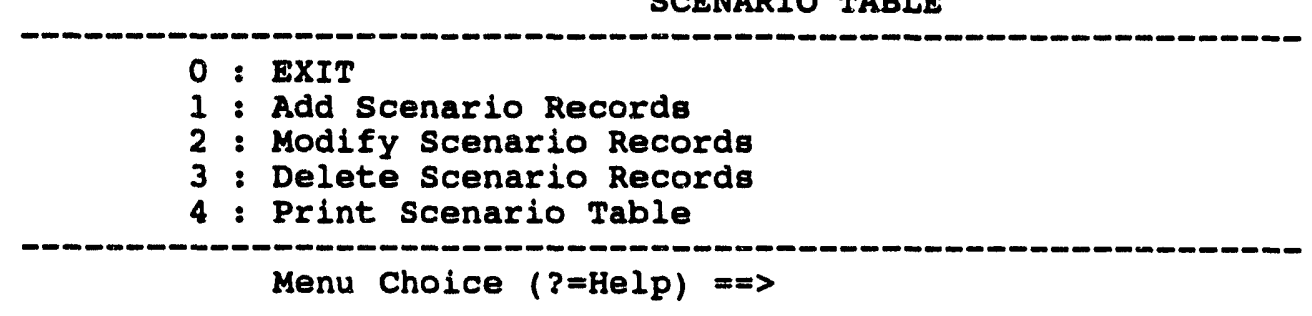


The options of the scenario table menu are explained in the following paragraphs.

Option 1. Add Scenario Records - The IBS prompts for the number of the IP for which you wish to add a scenario:

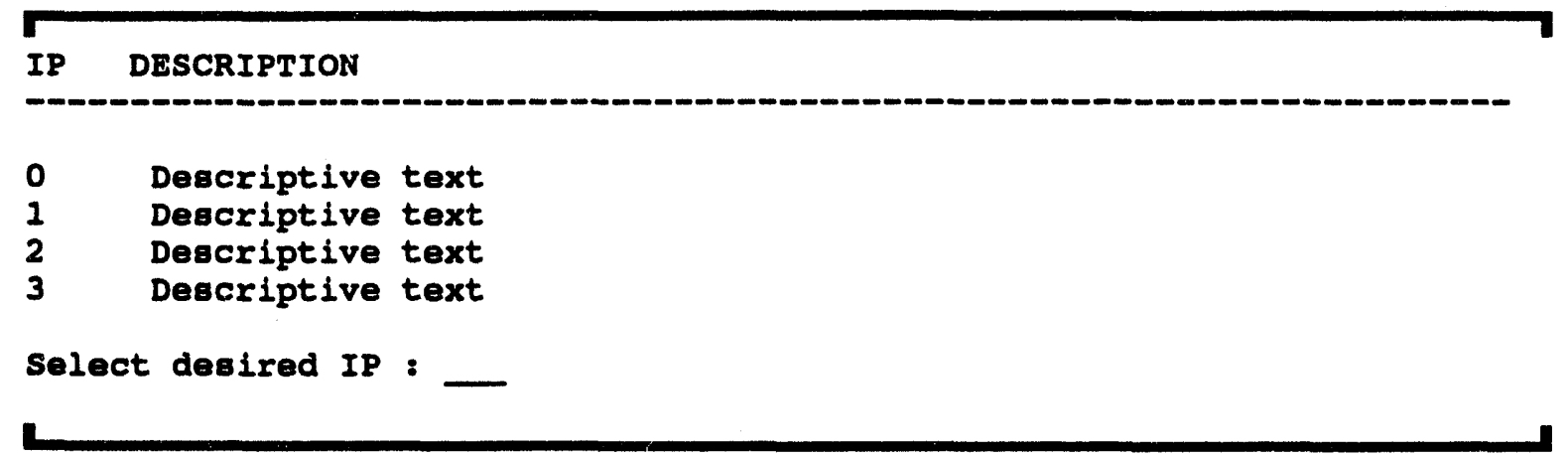

You must already know the number of the IP for which you wish to add a scenario record.

After entering the IP number, add the scenario table records during several stages in which you must define or select the following:

risk area: one or more Emergency Planning Zones that intersect either the current D2 case track or a polygon that you draw

population pattern : the number and distribution of people at a specific time of week and day

evacuation model case : the number of the evacuation model case associated with the current D2 case

The current D2 case is automatically entered in the scenario record for the IP. (The records also include data used in creating the D2 case: munition, agent, quantity, wind direction, wind speed, release type, and stability class. This allows searching of the scenario table to find matching cases during selection of an IP at a later date.)

A. Defining a risk area: The risk area consists of a number of Emergency Planning Zones (EPZs) that are affected by the event. To help you define the risk area, the system directly displays the RISK AREA ANALYSIS menu from the DIRECTION/CONTROL Emergency Activity. After defining the risk area and 
picking CONTINUE SCENARIO CREATION, you have an opportunity to save the risk area before continuing.

B. Associating population pattern with the IP: You are then asked to select the population pattern for the IP:

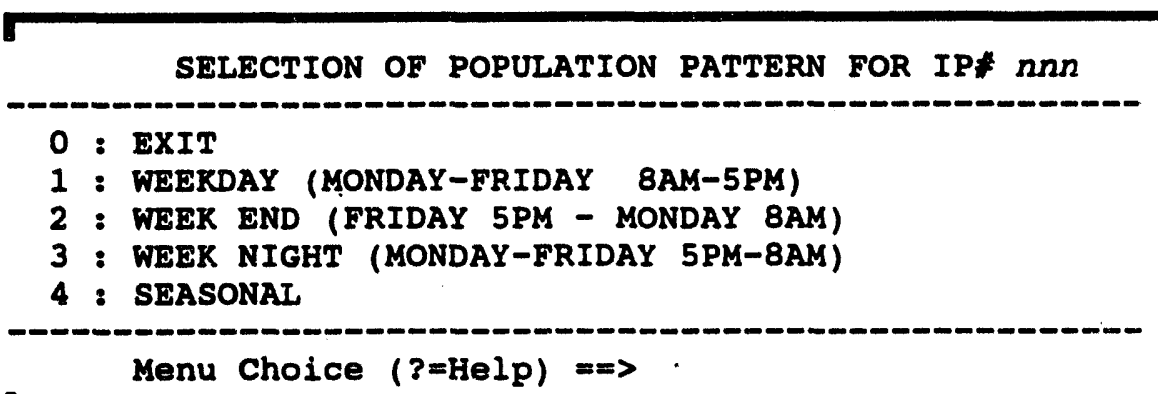

C. Associating an evacuation case with the D2 case (for the IP): After selecting the D2 case and population, you must select an evacuation case. IBS first displays a screen on which you can specify criteria for selecting the evacuation case. The entry fields on this screen serve as search keys int , the database of evacuation cases. For example:

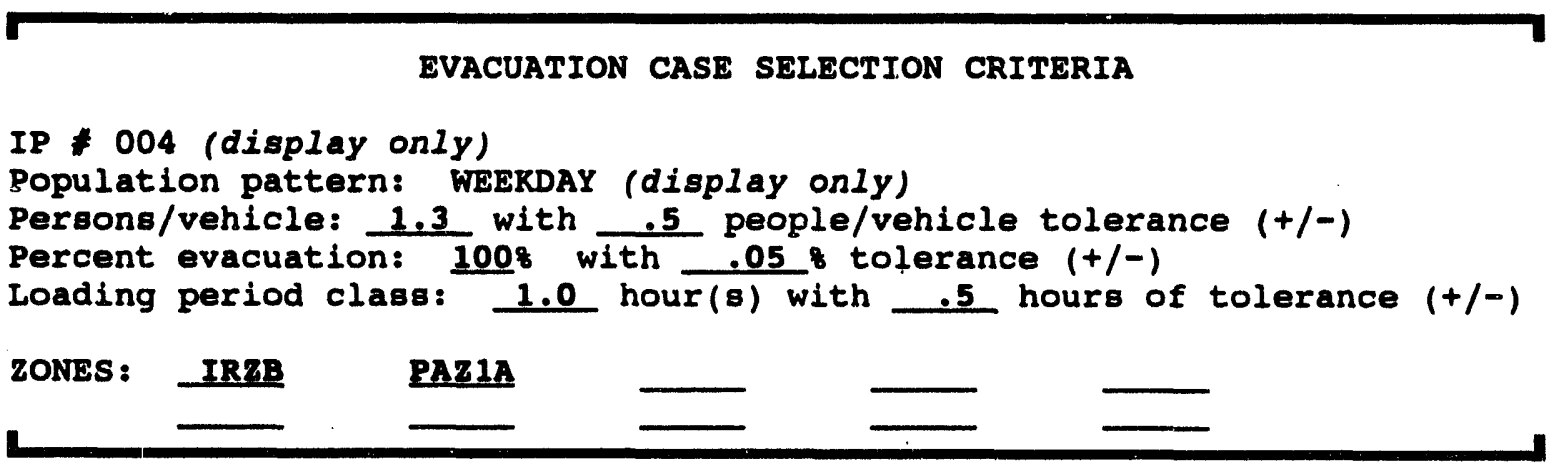

- The default tolerances are displayed. You can also change these values for this particular search.

- You can remove one or more criteria from the search by leaving blanks in the text fields or by entering a negative one $(-1)$ in the numeric field(s).

- If all fields are removed from the search, then no search is made. You must then select one case from a list of all evacuation cases (see the next screen). 
- If entries are made in one or more fields, the IBS compares these case input criteria with the database of evacuation cases. (If no identical matches can be found, the IBS displays a message to indicate how many criteria actually matched.) You must then select from a list of evacuation cases that match the greatest number of criteria (see the next screen).

After the search, the IBS lists the resulting set of cases in numeric order by IBS case number:

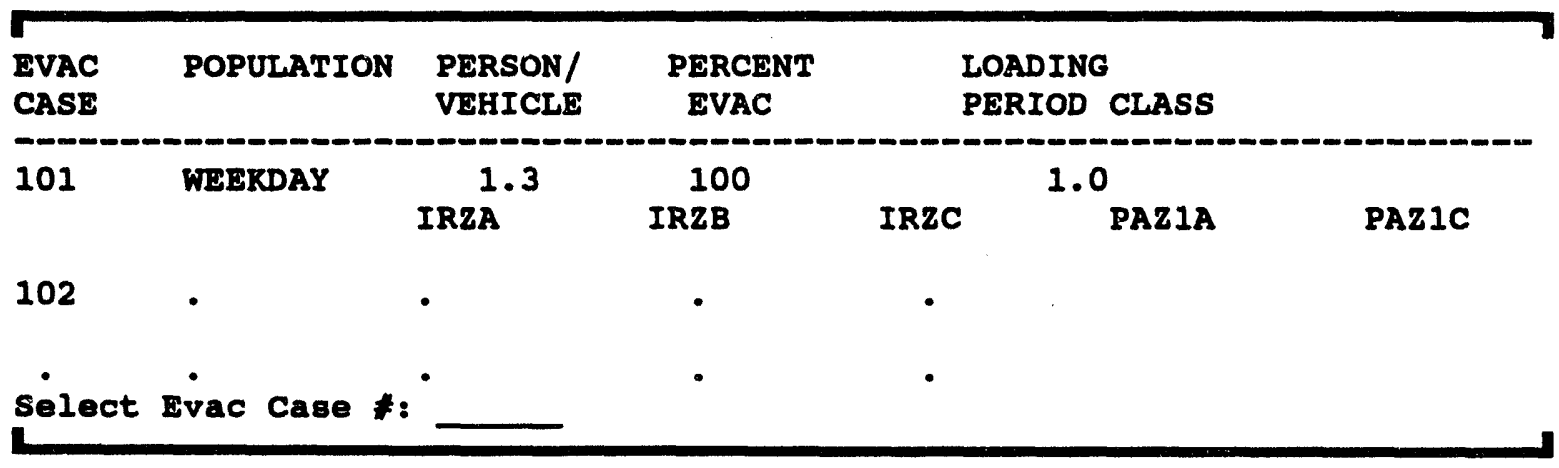

To scroll through the cases on the list, enter a command key in the field after Select Evac Case \# (U, U\#, D, D\#, T, B). To select an evacuation case, enter the case number in the same field. Note that a single evacuation case can be mapped to several different IPs (because the particular combination of the D2 case, meteorological data, and/or population pattern is different for each IP).

After finishing the scenario, the system displays the following message.

Enter a one line description for this scenario record:

After you enter the description, the system displays the record you have created and prompts you to verify its addition. Press the Return key to add the scenario record. The system returns you to the Scenario Table menu.

Option 2. Modify Scenario Records - You can search the scenario table using IP \#, D2 case \#, and Evac case \#. The matching records are then displayed, and you can select one record to modify. You can modify the IP \#, D2 case \#, Evac case \#, population pattern, and the scenario record description. This action 
creates a new scenario record. An example of the Scenario Record Form follows.

Scenario Record Form

(scenario record description)

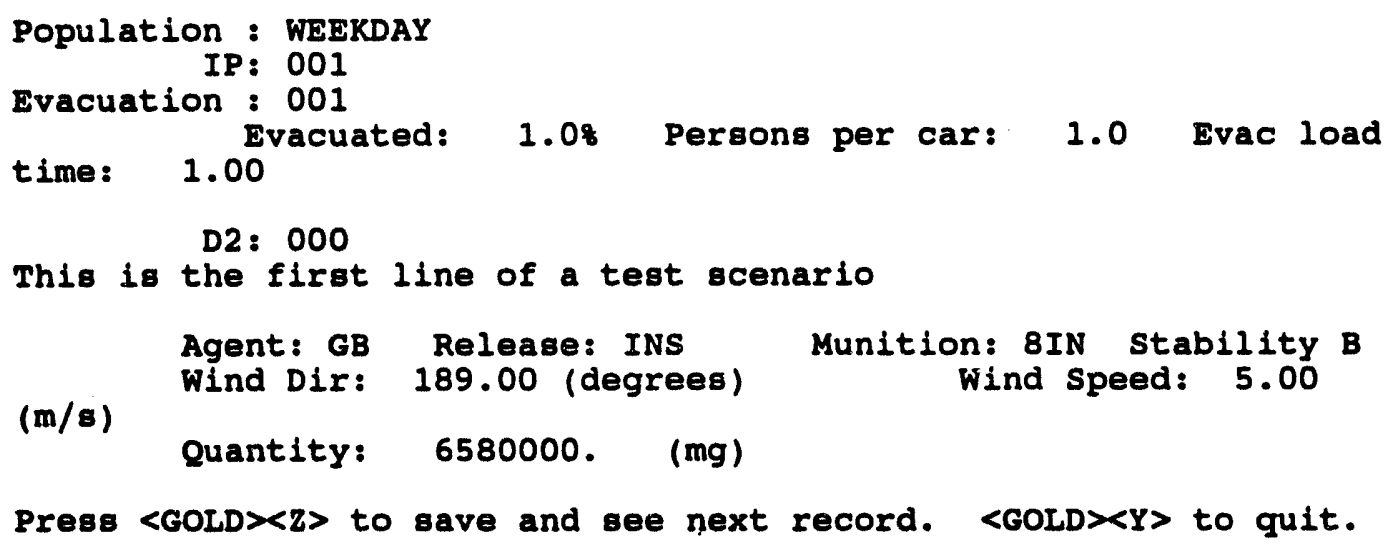

After you exit the form, the system displays the following prompt:

Modify more records? $[Y]=>$

If you press the Return key, or type a $\mathrm{Y}$, the system enabled you to modify more records. If you type $\mathrm{N}$, the system returns you to the Scenario Table menu.

Option 3. Delete Scenario Records - Is similar in function to Modify Scenario Records. You can search the scenario table using IP \#, D2 case \#, and Evac case \#. You can delete a scenario record by specifying the record number. After you confirm the deletion of the selected record, that record is removed from the scenario table.

Option 4. Print Scenario Records - If you have not specified a default output, the Output Redirection menu displays. After you select the type of output you want, the IBS prints a list of all scenario table records, one page at a time. 


\section{PRINT D2 REPORT}

This option allows you to display or print the output reports produced by the IBS implementation of D2.

The system prompts you to identify the desired report:

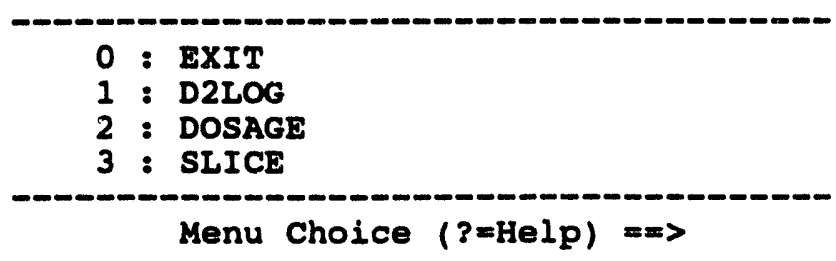

To select the type of report, enter the number of the type of report you want. To exit without selecting a report, press Ctrl-Z.

You can have these reports displayed on the screen, or sent to a printer. See Section 12, Setup for a complete description of setting up your system for default printing.

\section{REPORT CURRENT D2 DESCRIPTION}

This option displays a description of the current D2 case at the top of the screen. This description consists of the two lines entered on the D2 Standard Input form illustrated in EXECUTE D2.

\section{SHOW ELEVATION}

SHOW ELEVATION displays the elevation (meters above sea level) associated with one or more point locations that you pick with the graphic cursor. The information from previous picks remains visible on the screen until you quit by selecting another menu option. To use this option, you must have the Elevation map layer selected under either the Setup or Map Analysis options. 


\section{SEARCH/RESCUE}

\section{IBS MAIN MENU \\ EMERGENCY ACTIVITIES}

SEARCH/RESCUE

CONTINUE

MESSAGE BOARD

STATUS BOARD

PERSONNEL MANAGEMENT

MAP ANALYSIS

RESOURCE MANAGEMENT

DRAW SEARCH AREAS

DELETE SEARCH AREA
The SEARCH/RESCUE activity supports search and rescue planning and operations. The default map layers for this Emergency Activity include roads and trails as well as search and rescue resources. See Section 12 for more information on activating default map layers.

<-- Stop the command and return to the menu.

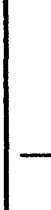

General options

<-- Draw a search area boundary.

<-- Delete a search area boundary.

RELEASE OVERLAYS

<-- Cancel display of SEARCH/RESCUE map layers.

\section{DRAW SEARCH AREAS}

This option enables you to draw boundary lines that define a search area.

1. After picking DRAW SEARCH AREAS, the system displays the following message.

* * * MSG: Draw a Search \& Rescue Area. CONTINUE when done

Use the mouse (or joydisk) to pick three or more points that define the sides of the search area. 
A boundary line segment is drawn between each new point and the previous point.

2. Pick CONTINUE to complete the search area.

The final boundary line segment is then drawn between the first and last points picked. The entire search area redisplays in white.

\section{DELETE SEARCH AREA}

This option enables you to delete an existing search area boundary by selecting it on the screen:

1. After picking DELETE SEARCH AREA, the system displays the following message.

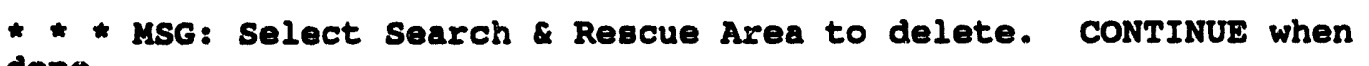

Use the mouse (or joydisk) to pick any point on the boundary that you want to delete.

The selected boundary blinks to indicate your selection.

2. Pick CONTINUE to confirm the deletion.

The selected boundary is then removed from the screen.

\section{U RELEASE/RETAIN OVERLAYS}

This appearance of this option on the menu switches back and forth between RELEASE OVERLAYS and RETAIN OVERLAYS. When you use the SEARCH/RESCUE Emergency Activity for the first time, the default map layers associated with search/rescue are automatically overlaid on the map screen and RELEASE OVERLAYS appears on the SEARCH/RESCUE menu.

Pick this option

RELEASE OVERLAYS

RETAIN OVERLAYS
To see this effect on your map screen

Removes all the map layers associated with this emergency activity

Redisplays the map layers-The map layer overlays continue to be displayed until you select RELEASE OVERLAYS.

To choose which map layers are the associated with the emergency activity, see Section 12, Setup under the heading MAP LAYERS BY ACTIVITY. 
ID SHELTERING

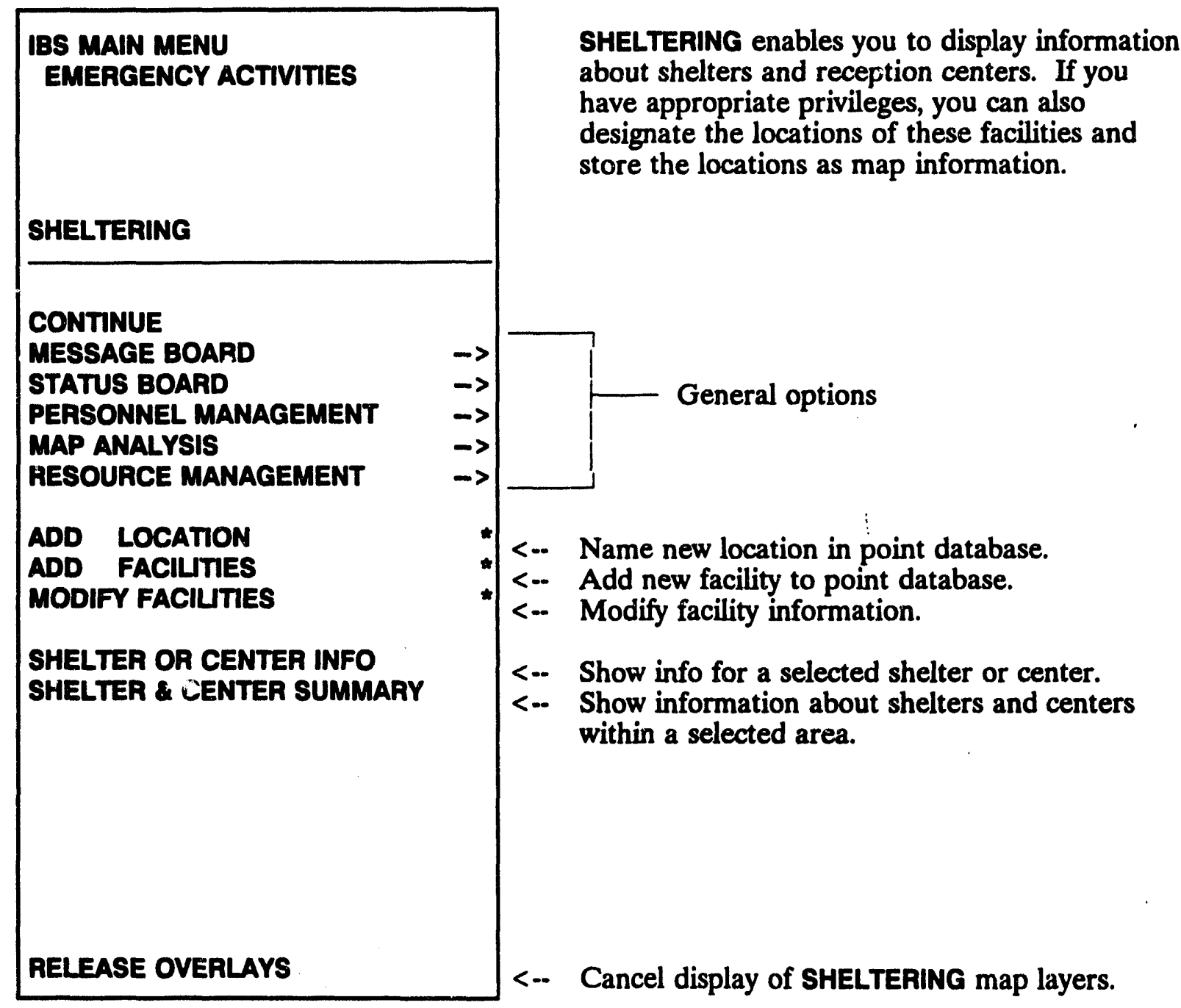




\section{ADD FACILITIES*}

This option allows an Information Manager to add a new facility. Adding a facility consists of: 1) specifying a facility location, 2) entering a facility description, and 3) entering personnel information about the facility contact person, if necessary. Details for this task are described in Section 6, Resource Management, under ADD FACIUTIES.

\section{ADD LOCATION*}

ADD LOCATION adds a new location to the database of Known Points. The following prompt appears first:

Enter new known Point name $==>$

1. Enter any name (up to 40 characters) and press the Return key or press CTRL-Z to exit.

This location name serves as the facility name for any facility that is added at that location.

If you enter a name that is already used for a location, the system prompts you to enter another name. After you enter a valid new location name, the following prompt appears:

* * MSG: Select new Known Point location w/ mouse

2. Pick a location on the map screen.

If you pick a location that is already specified as a Known Point location, the system prompts you to select another point.

After you pick a valid location, that location is placed in the database of Known Points. The system then returns to Step 1 where you can continue to add point locations until you quit by pressing CTRL $\mathbf{Z}$.

\section{MODIFY FACILITIES*}

This option enables an Information Manager to modify facility information. Updating a facility consists of: 1) selecting a facility and 2) modifying the facility description. Details for this task are described in Section 6, Resource Management, under MODIFY FACILITIES. 


\section{RELEASE/RETAIN OVERLAYS}

The appearance of this option on the menu switches back and forth between RELEASE OVERLAYS and RETAIN OVERLAYS. When you use the SHELTERING Emergency Activity for the first time, the default map layers associated with search/rescue are automatically overlaid on the map screen and RELEASE OVERLAYS appears on the SHELTERING menu.

Pick this option

RELEASE OVERLAYS

RETAIN OVERLAYS
To see this effect on your map screen

Removes all the map layers associated with this emergency activity

Redisplays the map layers-The map layer overlays continues to display until you select RELEASE OVERLAYS.

To choose which map layers are the associated with the emergency activity, see Section 12, Setup, under MAP LAYERS BY ACTIVITY.)

\section{SHELTER \& CENTER SUMMARY}

SHELTER \& CENTER SUMMARY enables you to view a table of information about the shelters and reception centers within a specified area.

\begin{tabular}{l} 
Resource area of interest menu \\
\hline $0:$ ExIT \\
$1:$ Select an area \\
$3:$ Define an area \\
$4:$ Delete an area \\
Menu Choice $(?=$ Help $)==$
\end{tabular}

For example, if you select Option 1, the system displays the following message.

* * * MSG: Select an area. conTINUE when done 
Select an area with the mouse or cross hairs. The area you have picked highlights in white and blinks. Select the Continue command when you have finished. The system then displays a shelter and center summary report similar to the following example.

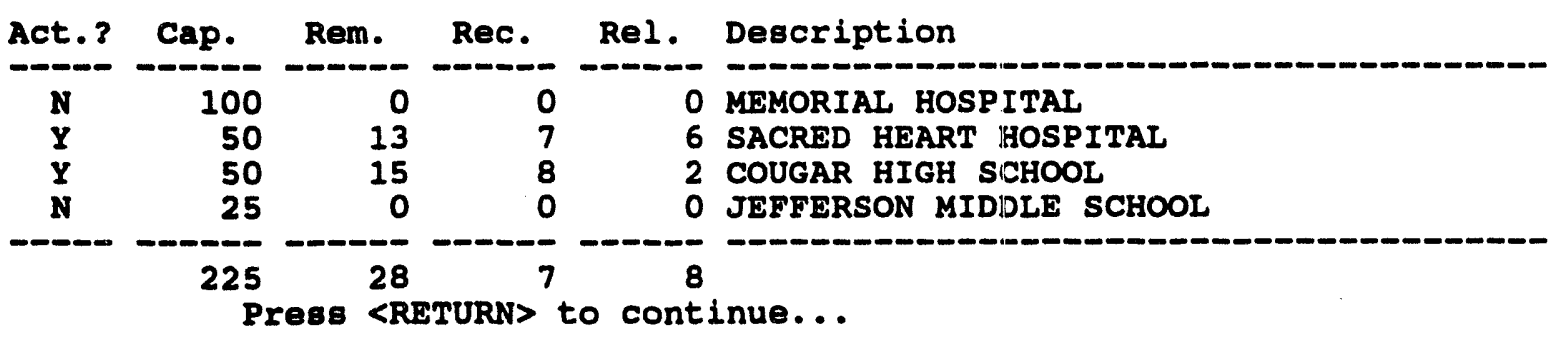

Press the Return key to return to the Resource area of interest menu. You can continue to select and view summary reports, or exit by selecting Option 0 .

\section{SHELTER OR CENTER INFO}

This option displays the description of a selected shelter or reception center and gives you the option of listing the resources of the facility. Details for this task are described in Section 6, Resource Management, under DESCRIBE FACILTIES. 
동 $\frac{8}{9}$ 


\section{Section 12 Setup}

\section{SETUP}

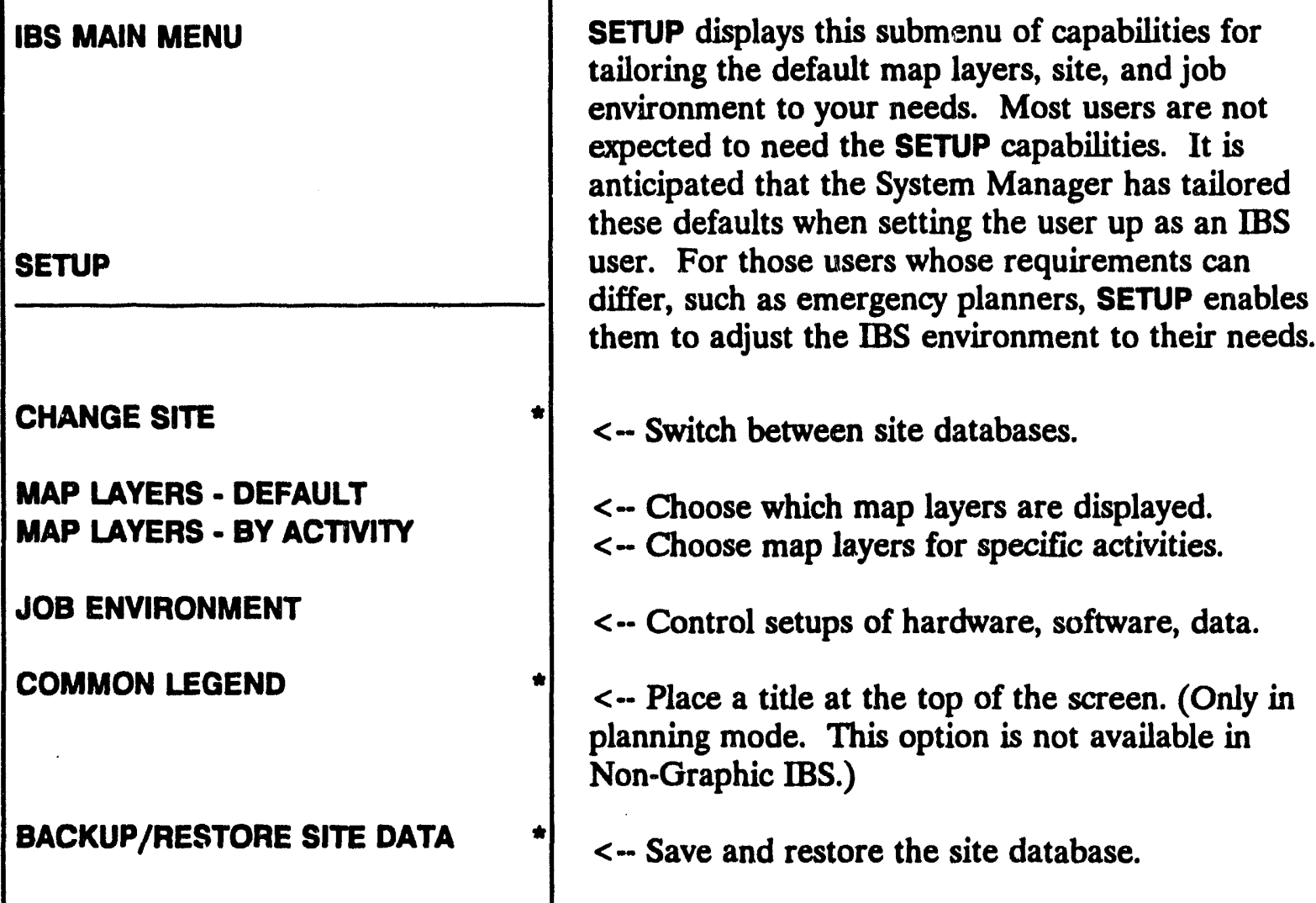

The SETUP menu options and capabilities are specified in alphabetical order in the following sections. 


\section{BACKUP/RESTORE SITE DATA *}

This option enables you to save and restore different types of site data, such as Resource Management data, or Model Case data.

When you select BACKUP/RESTORE SITE DATA, the following menu displays.

\begin{tabular}{l} 
Select Backup/Restore operation \\
\hline $0:$ EXIT \\
1 : Backup Selected Data \\
2 : Restore Selected Data \\
4: List all Backup Sets \\
\hline Melete Backup Set
\end{tabular}

Select the menu option corresponding to your choice. The options are:

\section{1 : Backup Selected Data}

This option enables you to create a backup set containing selected types of IBS data. The following list will display.

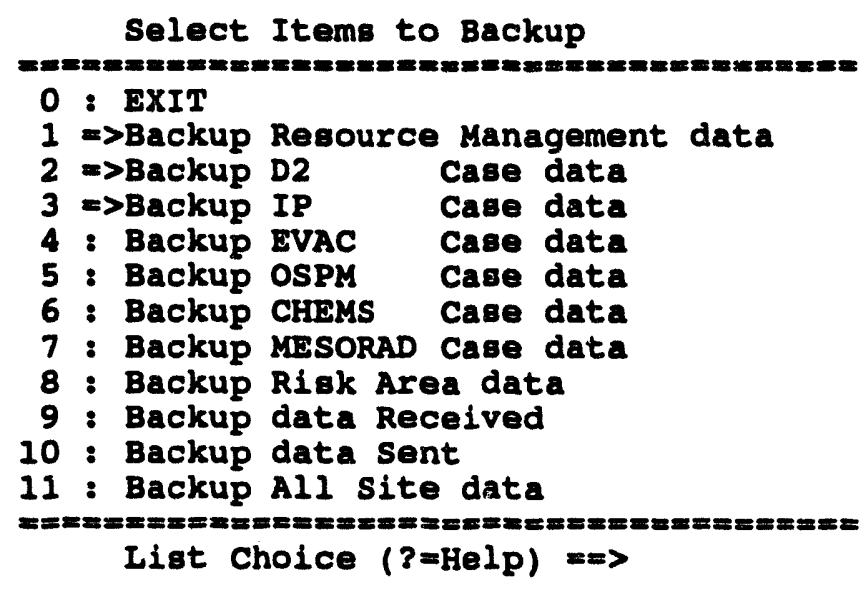

Select all the data types you want to include in this backup. An arrow = > will display in front of any selected items (in the above example, items 1,2 , and 3 have been selected.) When you have selected all the items you want, select 0 to Exit. The following prompt will display:

View output of Backup? $(Y / N)=\Rightarrow$

Entering $Y$ (Yes) will list files as they are backed up.

Note: To get out of the backup at the View output prompt, press Ctrl-Z to return to the Select Backup/Restore operation menu. 
The backup will then begin. It may take over 10 minutes for the backup to complete, depending on how much data you selected to include in the backup, so be patient.

After the backup is complete, you will be prompted to enter a brief description of this backup.

Please enter a brief (one line) description of this backup. $\Rightarrow 4 / 22 / 93$, MJB. Backup made before Exercise.

\section{2 : Restore Selected Data:}

This option enables you to restore backed up data. This data will become the current data for a site.

Note: You must have write access to all directories when restoring data, and read access to all directories when backing up data.

The following menu will display. Select how to choose the Backup set.

\begin{tabular}{c} 
Backup Selection Method \\
\hdashline 0 : ExIT \\
1 : Select Backup by Description \\
\hline 2 Select Backup by Date \& User \\
\hline Menu Choice $(?=$ Help) $=m$
\end{tabular}

Depending on the method you select, menus similar to one of the following will display:

Select Backup by Description

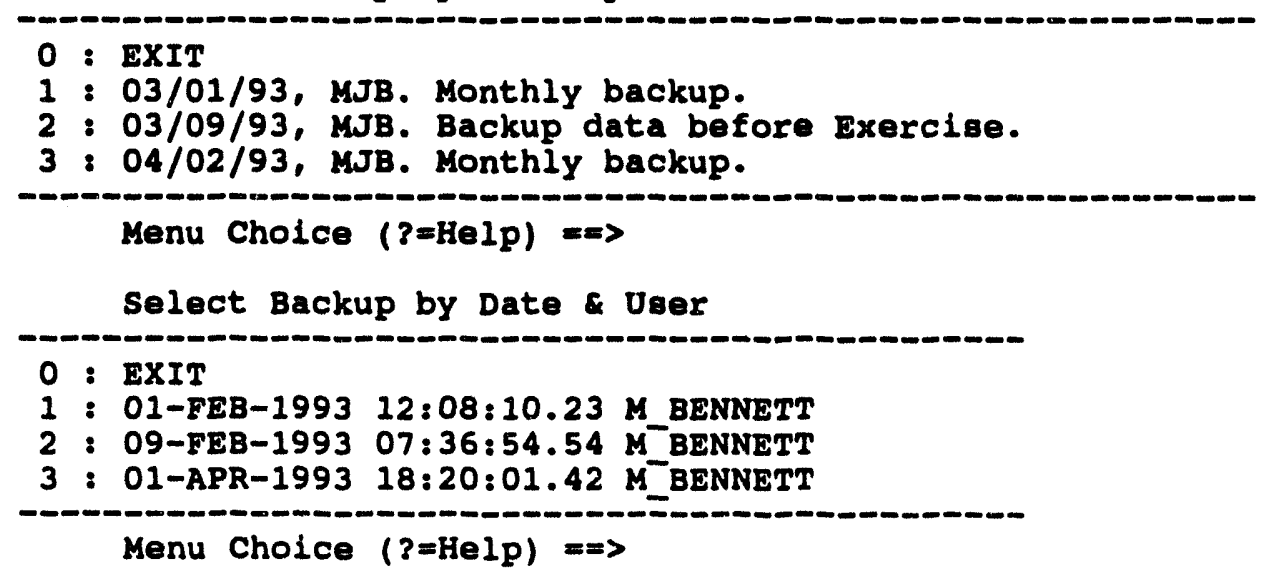


After selecting a backup set from the menu, a menu containing all the data types stored in the selected backup set will display.

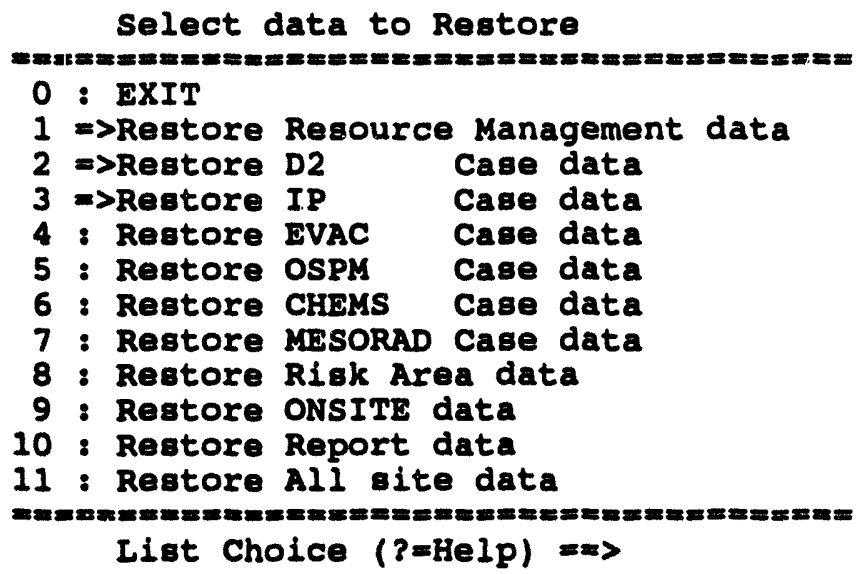

All data types are shown in the above menu, but only those types that are stored in the selected backup set will actually be shown. Select the data types you want to restore. An arrow $=>$ will display next to every selected item (in the above example, items 1,2 , and 3 are selected).

If some of the data you have selected to restore is Shared, such as the Resource Management data, the following prompt will display:

* * MSG: You will be restoring Shared data. If others are currently

* * MSG: using the system, this can easily corrupt data!

Really restore shared data? $(Y / N)=>$

\section{Caution}

You should NEVER restore shared data while other users are using the system. It can corrupt the data base.

If you are not restoring all site data, the following prompt will display:

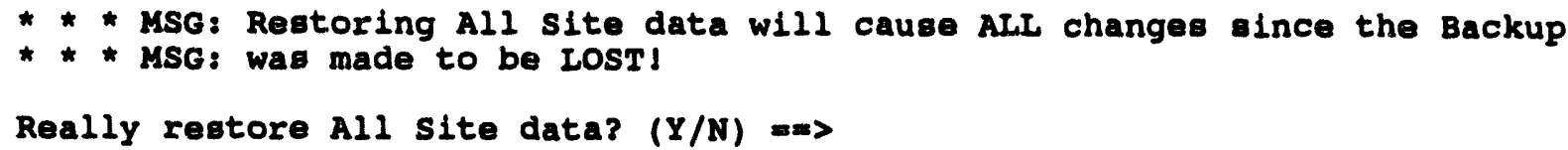

If you type a $Y($ Yes) at either of the prompts, the following message will display. View output of Restore? $(Y / N)=>$

Typing $Y$ (Yes) will list files as they are restored from backup. 
The restore will then begin. It may take over 10 minutes for the restore to complete, depending on how much data you selected to include in the restore, so be patient.

\section{3 : List all Backup Sets:}

This option prints information about all the backup sets that have been made for the current site. The report will contain the following information:

- When the backup was made

- Who made it

- A brief description by the person who made the backup

- The data types included in the backup.

The report will be sent to your default report destination. If you have not specified a default output destination, the Output Redirection Menu will display and you can select a destination for the report.

The report will be similar to the following example:

BACKUP SET IIST

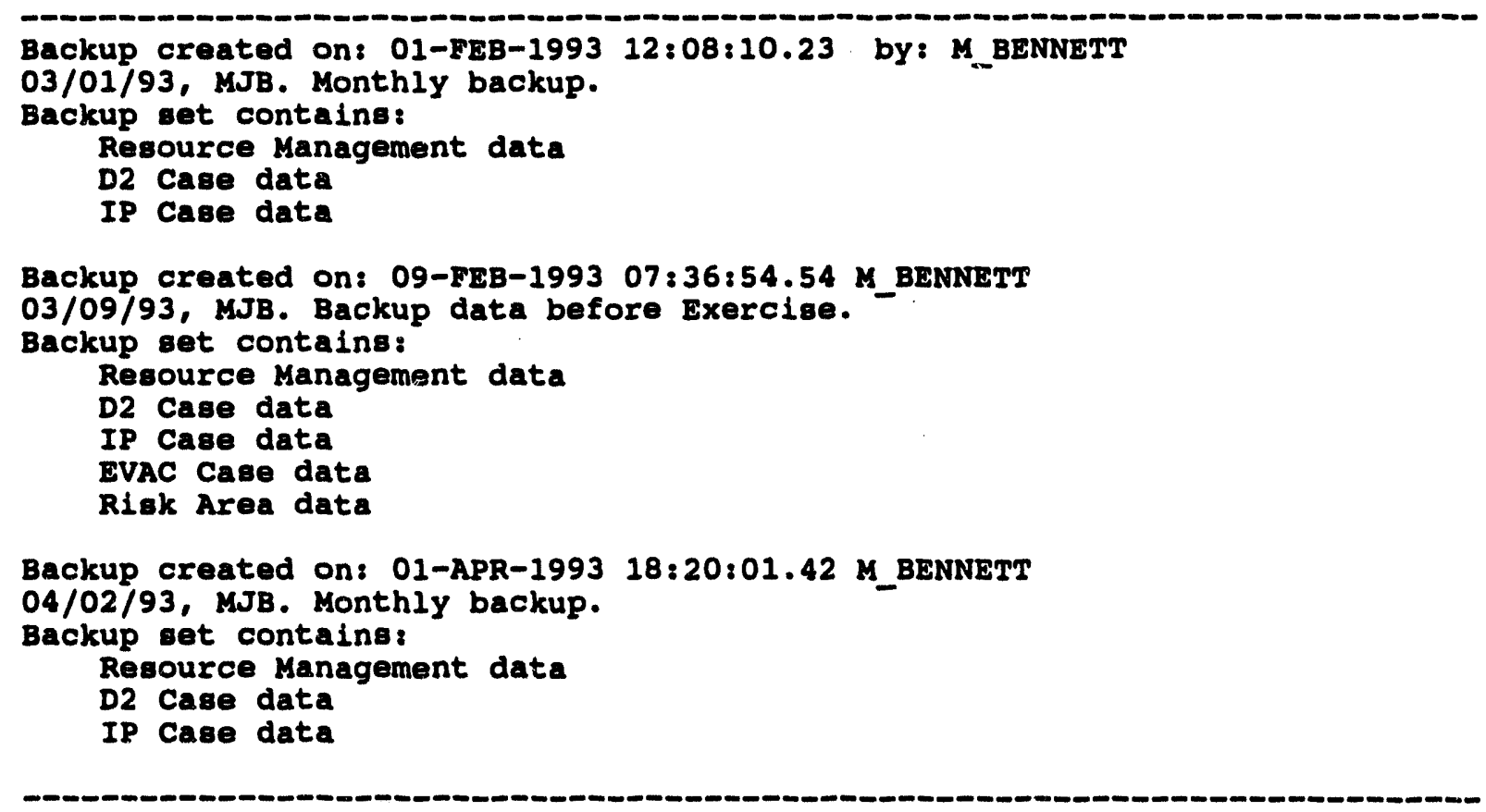

\section{4 : Delete Backup set:}

Backed up data can use lots of disk space, especially if many backup sets are made. This option allows you to delete selected backup sets. This option displays a menu to select how to choose the Backup set to delete. 


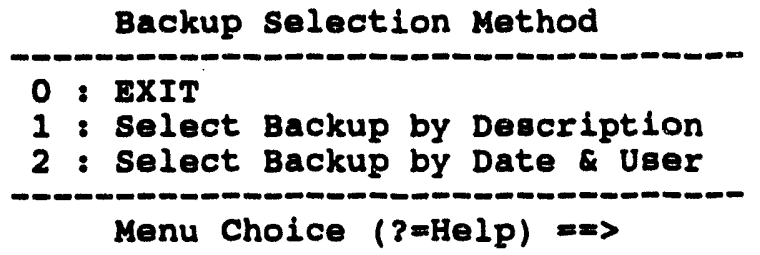

Depending on the method you select, menus similar to one of the following will display:

select Backup by Description

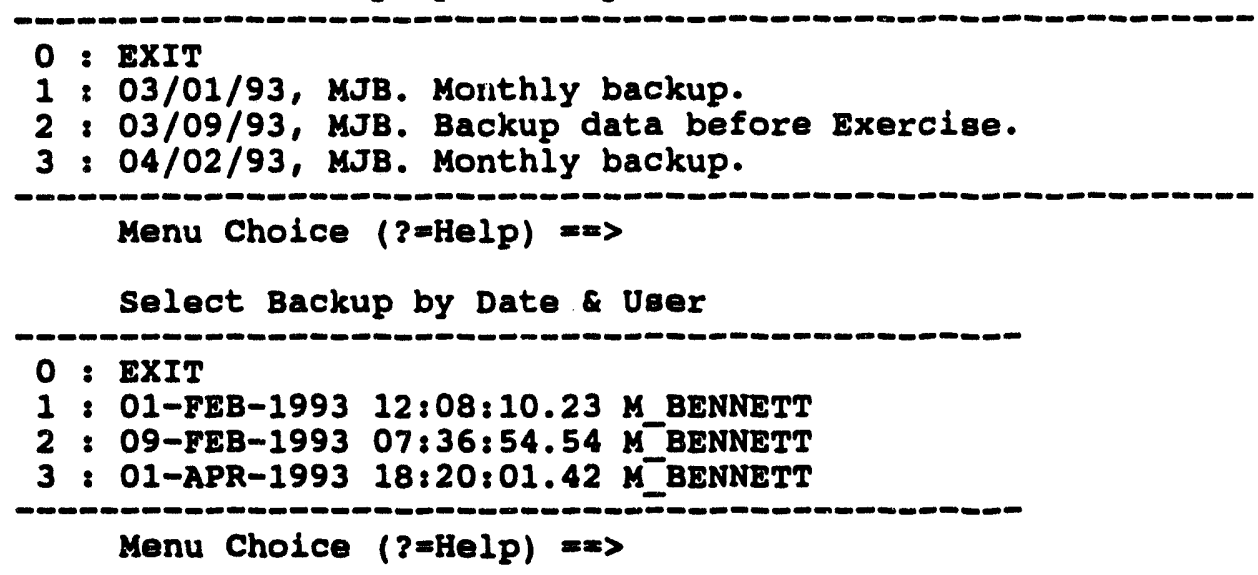

After selecting a backup set, the contents and information about that backup set will be displayed and you will be asked to verify that this is the backup set you wish to delete. The following is an example of a backup contents listing.

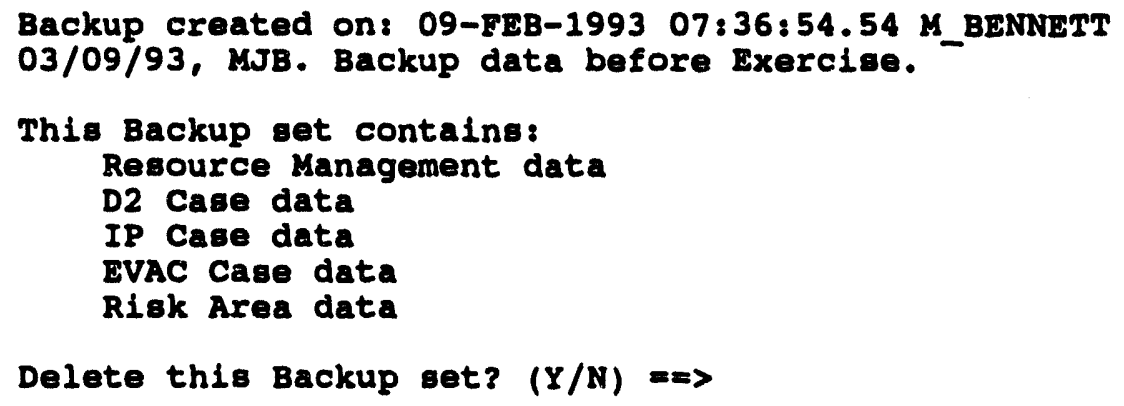

Type a $Y$ (Yes) to delete the Backup. Unless the data has also been backed up to tape, the data will be lost. 


\section{CHANGE SITE*}

CHANGE SITE enables planners, and others who have appropriate privileges, to switch their current site database between the

- Operational site database(s)

- Their own planning site database(s)

General users do NOT have this option: they use only the current operational site database.

After you select this option, if you have the privilege to change the operational site database, you will either proceed to Step A, or go directly to Step C.

\section{Step A:}

You have the privilege to change the operational site. The system displays the following prompt:

Do you want to change the operational site? $(Y / N)[N]=\Rightarrow$

The current operational site is what all users who are not in planning mode are currently using. Changing it for yourself also changes it for them.

If you do not want to change the current operational site database, then type an $N(\mathrm{No})$ at the prompt and go to Step C.

\section{Step B:}

You said you wanted to change the operational site database. The system displays the following message and prompt:

* * MSG: If other users are using the system, changing the operational

* * MSG: site May cause them to lose changes they have made.

Do you really want to change the operational site? $(Y / N)=x$

If you really do want to change the operational site, type a $Y(Y e s)$ at the prompt.

Note: Use caution before changing the operational site database. You should normally only change the operational site when no other people are using the IBS program. A privileged user can change the operational site while others are using the program even though this can cause them to lose some recent changes.

\section{Step C:}

A menu similar to the following will display. If you have the appropriate privileges and you want to change the operational site, then the menu will contain only operational 
sites, the first item in the menu being the current operational site. Otherwise, the menu will contain the current operational site and all your own planning sites. The first item in the menu will be your current site, whether it is a planning site or the current operational site.

\begin{tabular}{l} 
Select new site \\
\hline $0:$ EXIT \\
$1:$ TOOE [Plan] $\rightarrow$ TOOE [Real]
\end{tabular}

To select no new site, select either 0 : (EXIT) or 1 : (your current site). Otherwise, select the new site you want to use. This menu indicates which site is your current site, and which site is the operational site. A site which is both the current and the operational site will be marked (Curr/Oper). Planning sites also reference operational sites, which is what the $\rightarrow$ means. In the above example, the TOOE planning site references the TOOE operational site. The other designations are:

Plan Planning database

Real Real database

Exer Exercise database

Changing planning sites will not affect other users of the system.

If you selected a new operational site, the system then stops and resets to the new site database. Users in operational mode are changed to the new site database. Users in planning mode remain in planning mode looking at their own data.

If you selected a new site, the system will display a message similar to the following as it stops and resets to the new site database.

Changing Current site to: TOOE [Real]

Changing sites. Please wait... 


\section{COMMON LEGEND*}

This option enables you to display a title legend or other information at the top of the display screen. You can choose from two predefined legends or define your own. The legend appears in tall white lettering and can obscure some map information. The legend appears in Operational mode on all terminal screens tied into the system, so its use is restricted to the Information Manager.

Note: This option is available only in Operational mode. To change from Planning to Operational mode, use the CHANGE SITE option described in this section.

The system displays the following menu:

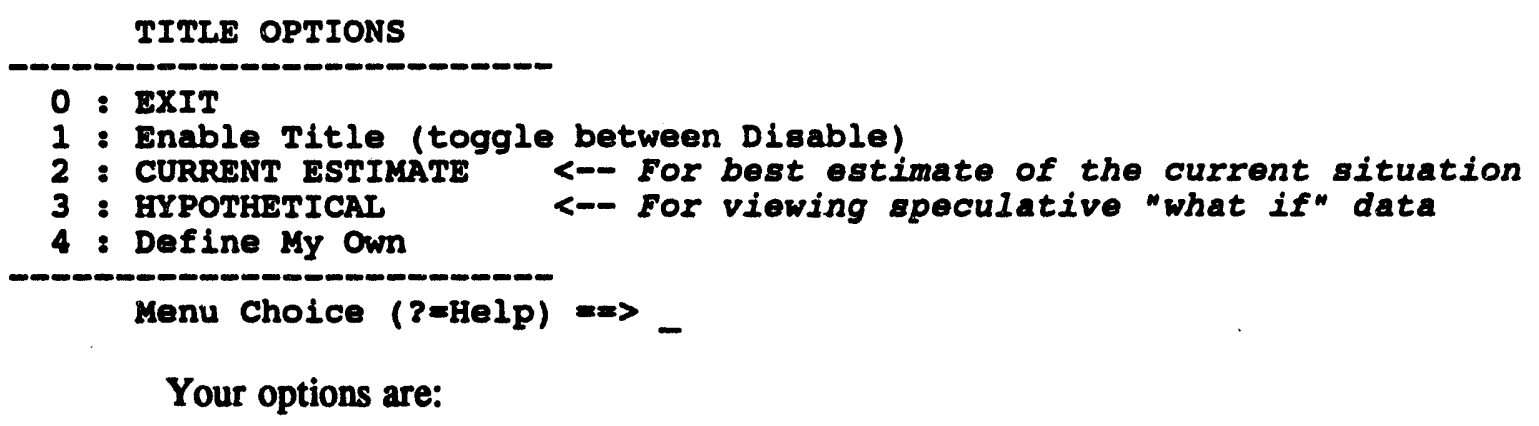

1. DISABLE TITLE: Removes any currently displayed title text from the screen. This can leave breaks in the map information where the title occurred; REFRESH SCREEN restores the missing information.

2. CURRENT ESTIMATE: Displays the title, "CURRENT ESTIMATE." Tisis is intended as a standard way of identifying the display as the most up-to- date information and modeling estimates about the current situation.

3. HYPOTHETICAL: Displays the title, "HYPOTHETICAL." This is intended as a quick way of indicating the display contains speculative modeling results or other information that does necessarily reflect the current situation.

4. Define My Own: Enables you to enter a title of your own choosing.

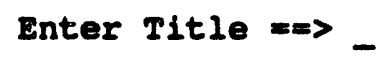




\section{JOB ENVIRONMENT}

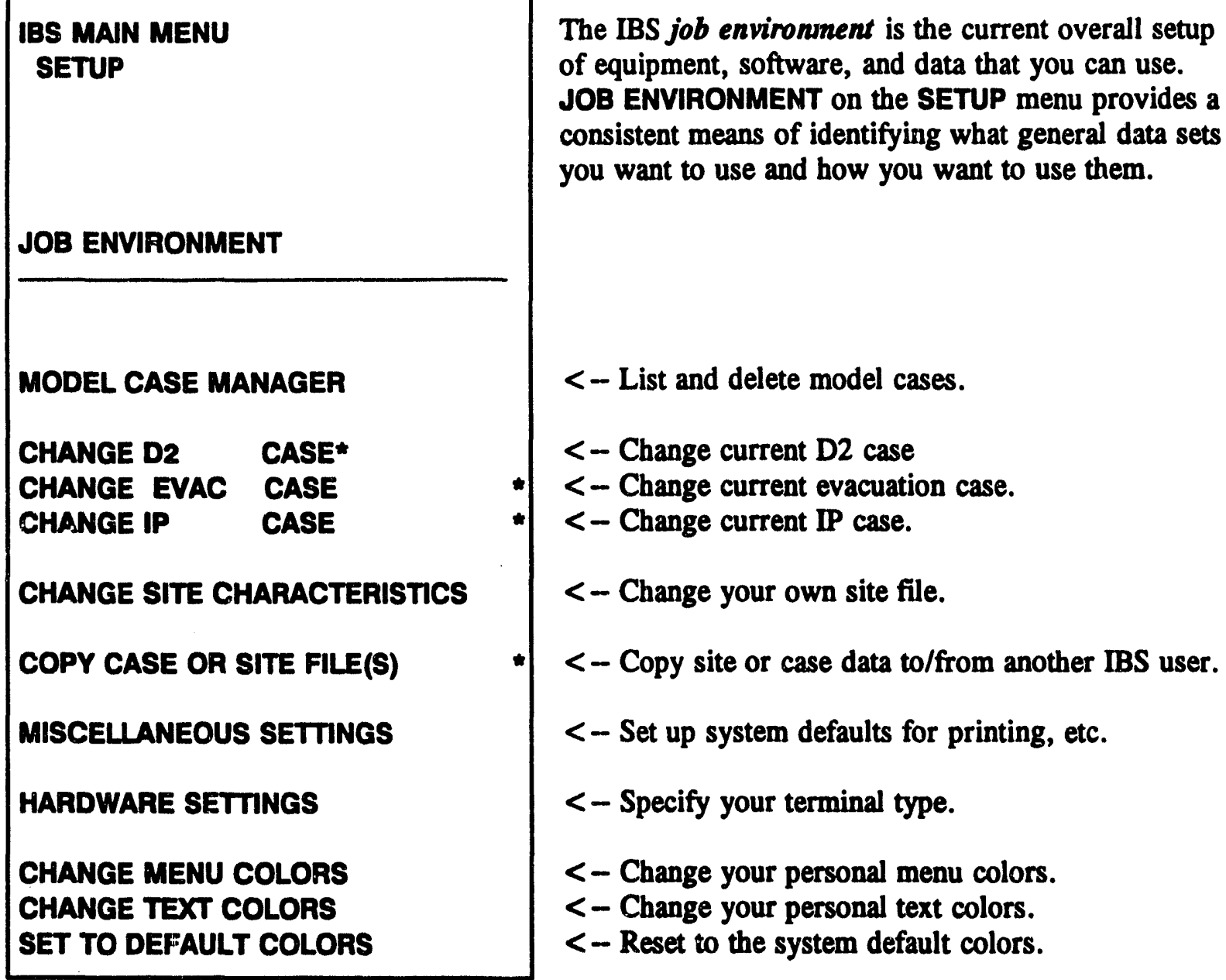

The following functions are the same as functions defined elsewhere in this manual:

- Change D2 Case - same as Change D2 Track Case, see Section 9.

- Change Evac Case - same as Select Model Case under the Evacuation function under the Emergency Activities menu, see Section 11.

- Change IP Case - Same as Select IP under the Status Board menu, see Section 3.

The job environment affects both mapping (graphic) interactions and modeling functions. For example, the job environment defines the type of graphics terminal you use.

For most users of the IBS, most parts of the job environment are fixed. Only those with special privileges (an Information Manager) are able to modify the files that define the job environment. In general, it is the responsibility of the system or data manager to supply general users with the appropriate job environment. 


\section{CHANGE MENU COLORS}

This option enables you to select different default colors for the graphic menu display.

\author{
IBS MAIN MENU \\ SETUP \\ JOB ENVIRONMENT
}

change colors

COLOR NUMBER 1
COLOR NUMBER 2
COLOR NUMBER 3

.

-

COLOR NUMBER 15
To select the default color for the graphic menus, select one of the color options from the menu display. The menu option is the color that will be used for all graphic menus. After you select an option, and exit the Setup function, the item you selected, for example, map displays, will change to the color you selected.

\section{Note:}

Since selected menu items flash in green, you should not change your default graphic menu color to green, since this will make selected items hard to see. 


\section{CHANGE SITE CHARACTERISTICS}

This option enables you to change the contents of your personal site file. It is normally used to change the default site center and radius that IBS uses for a site. A menu similar to the following will display.

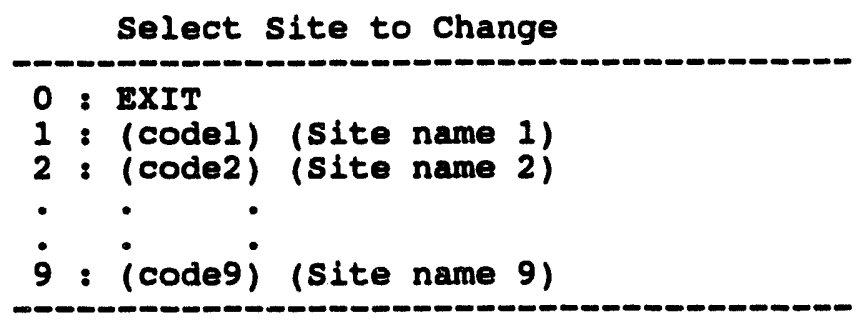

Menu Choice $(?=\mathrm{Help})==>$

Select the site you want to modify. If you are using the Infomanager account, and the site selected is the current operational site, the following prompt will display to verify that you want to modify the current Operational site.

* * MSG: Modifying the current Operational site could cause problems for

* * MSG: other users currently uBing IBS.

Really modify the Operational site? $(Y / N)==>$

You will not usually want to modify the current Operational site. If you either enter a $Y$, or selected a site other than the current Operational site, the following form will display.

\begin{tabular}{|c|c|c|}
\hline & EDIT SITE FORY & $\mathrm{v} 2.00$ \\
\hline $\begin{array}{l}\text { Site Code } \\
\text { Disk Name } \\
\text { Site Name } \\
\text { Site Type } \\
\text { Assoc Site } \\
\text { Longitude } \\
\text { Latitude } \\
\text { Radius }\end{array}$ & $\begin{array}{l}\text { (code for site) } \angle=\text { READ ONLY } \\
: \text { (disk where the site is located) } \\
: \text { (Site name) } \\
: \text { (Planning, Exercise, or Real site } \\
: \text { (associated site code) } \\
: \text { (longitude of site center) } \\
: \text { (latitude of site center) } \\
: \text { (radius of site to display) }\end{array}$ & $\begin{array}{l}<==\text { READ ONLY } \\
\text { e) }\end{array}$ \\
\hline
\end{tabular}

To exit and save inputs press <GOLD $<Z>$. To abort press <GOLD> $<Y>$.

Change the information as required (Note that the Site Code and Disk Name fields are read only-you cannot modify them). Press GOLD $\mathrm{Z}$ to exit and save your changes when you are done, or press GOLD $Y$ to exit without changing anything. The information you changed will be verified for correctness, then saved. 
If you receive a message informing you of some error with your input, your changes will not be saved.

If the site changed was your current site, the following message will be displayed if you changed the associated site:

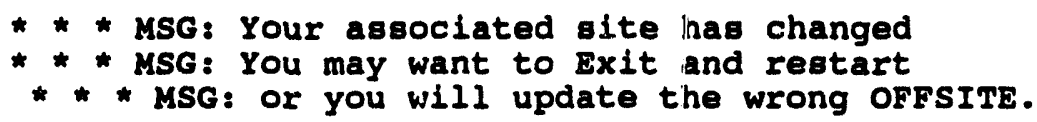

You need to exit IBS and restart for your changes to take effect.

Note: Before changes are made, a backup copy of the site file will be created. The file is named SITE.DAT_BCK and can be found in your login directory.

\section{CHANGE TEXT COLORS}

This option enables you to select the default colors for text prompts, menus, and forms. This enables you to select the most readable option for your specific hardware/software combination. IBS is delivered with text default colors of white text on a blue background. A menu similar to the following will display.

\begin{tabular}{l} 
Select Item to Change \\
$0:$ ExIT \\
$1:$ Text Color \\
$2:$ Background Color \\
\hdashline Menu Choice $(?=$ Help) $=>$
\end{tabular}

Option 1: Text Color, allows you to change the color of the text letters that will be displayed. Option 2 : Background Color, allows you to change the color of the background of the text display. From either of the above choices, a menu similar to the following will display.

\begin{tabular}{l} 
Select (Text/Background) Color \\
\hline $0:$ ExIT \\
$1:$ Black \\
$2:$ White \\
$3:$ Yellow \\
$4:$ Green \\
$5:$ Blue \\
$6:$ Cyan \\
$7:$ Magenta \\
$8:$ Red \\
\hline Menu Choice $($ (3=Help) als
\end{tabular}


After selecting an option, the menu will redisplay with the colors changed according to your selection. Select 0 : EXIT when the colors are set the way you want. The menu shown above is not exactly what will be viewed, the color of the opposite item will not be shown on the menu, to prevent you from accidentally picking a totally unreadable combination (such as white letters on a white background.)

Some terminals use Yellow (or another color) to indicate bold text. You should not use this color as the background color for the text display-it will be unreadable.

Note: TGRAF users: Depending on your hardware and Tektronix emulation software, the color names shown above may not match the actual colors that will be displayed. Do not be concerned; just select the most readable combination.

\section{COPY CASE OR SITE FILES *}

This option enables you to

- Copy site or case data from another person's directories to your own

- Copy similar information from your directories to another person

These operations require special IBS privileges, VMS privileges, and password use, especially when data are copied between different systems (nodes). At some point in the copying process, you are prompted to enter a user name and password.

When you select the COPY CASE OR SITE FILE option, the following Copy Case Site Options menu displays.

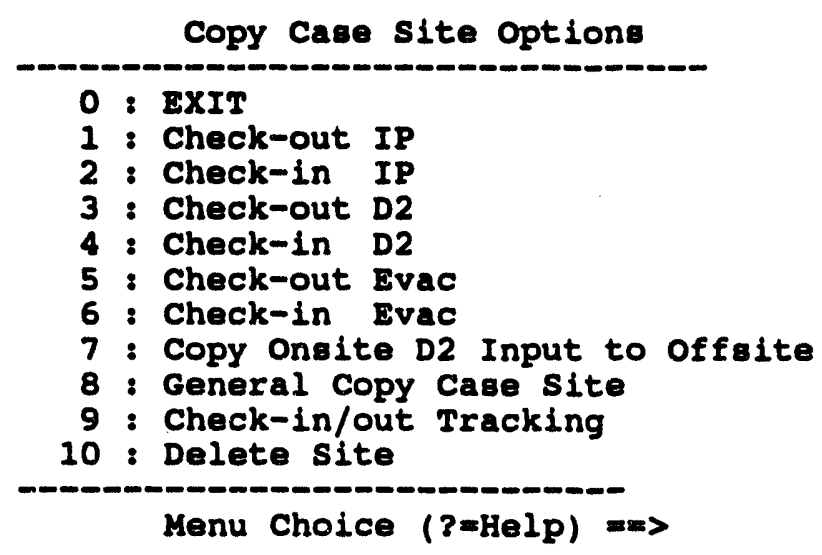

The following examples show the typical prompts for various menu selections.

Options 1 through 6 contain the Check-out and Check-in functions. For example, when you select Option 1 : Check-out IP, the following series of menus will display. 
Note: Before checking out an IP with Check-out IP, make sure that your current site is set to an appropriate planning site database. It would not make sense to check out an IP for one site and use it with data from a physically different site.

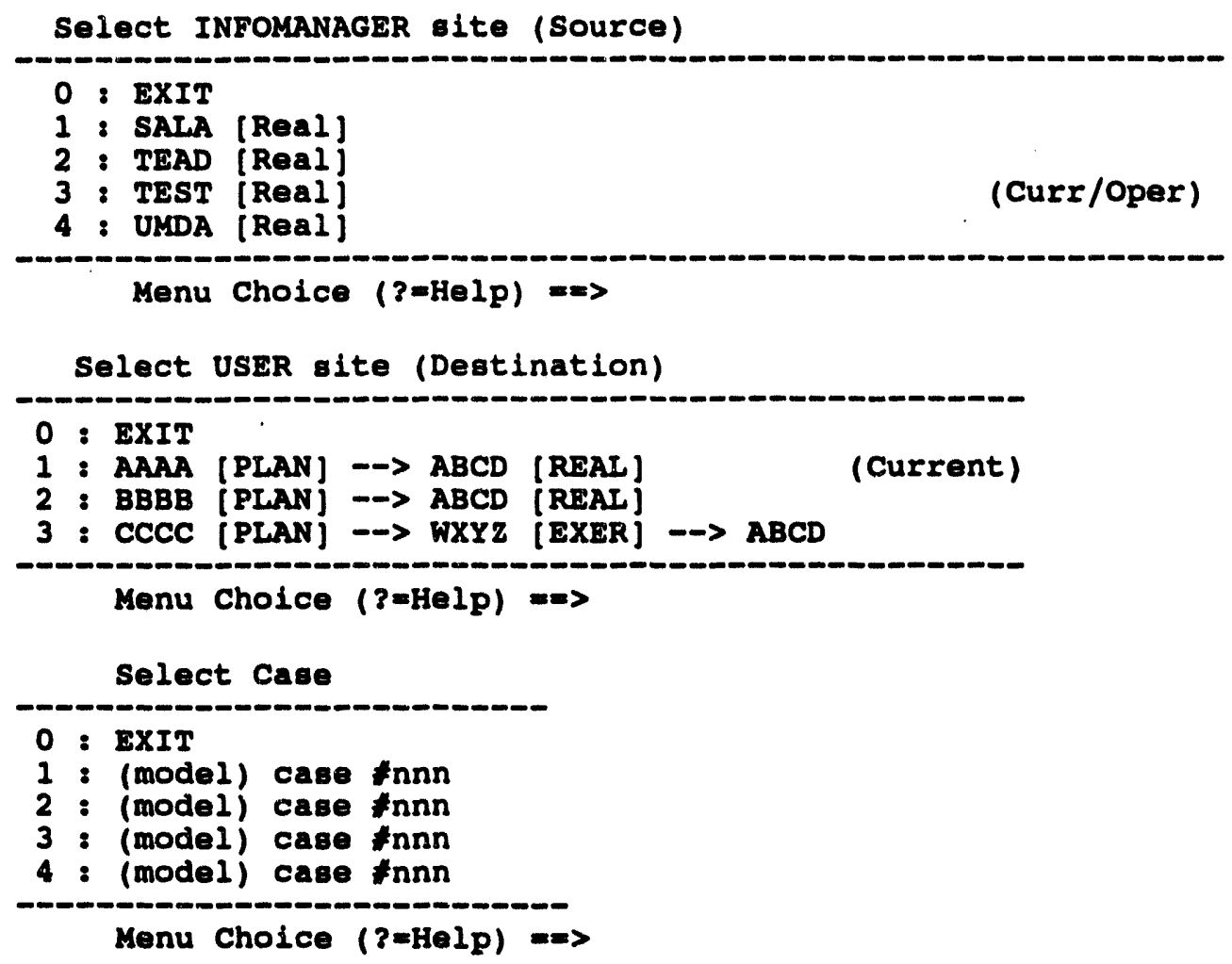

The following messages and prompt will display to allow you to verify that the operation you defined is correct.

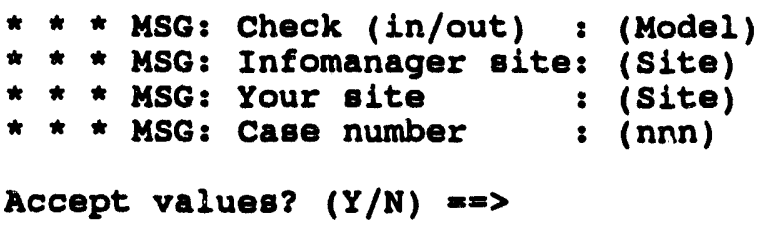

After you specify which IP to use, the system checks to see whether the specified IP is already checked out (that is, already assigned to another planner).

- If the IP is already checked out, the system cannot check it out to you until the IP has been checked back in.

- If the IP is available, the system copies the IP and associated records from the scenario table to your current planning site database.

When you check out an IP, the system notes the IP is assigned to you. No one else can check out the same IP until you check it in again. 
For more detailed information on CHECK-OUT IP and CHECK-IN IP, see Section 3, Status Board.

When you select Option 7: Copy Onsite D2 Input to Offsite, the following menu will display.

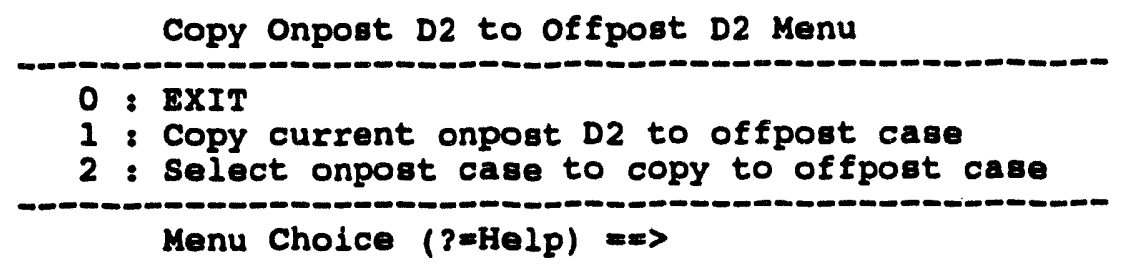

This function enables you to create a new offsite D2 case based on an onsite D2 case. It copies the input of the case only. You must rerun the case after you copy it. The new offsite case becomes the current D2 case.

If you select Option 2: Select onpost case to copy to offpost case, the following menu will display.

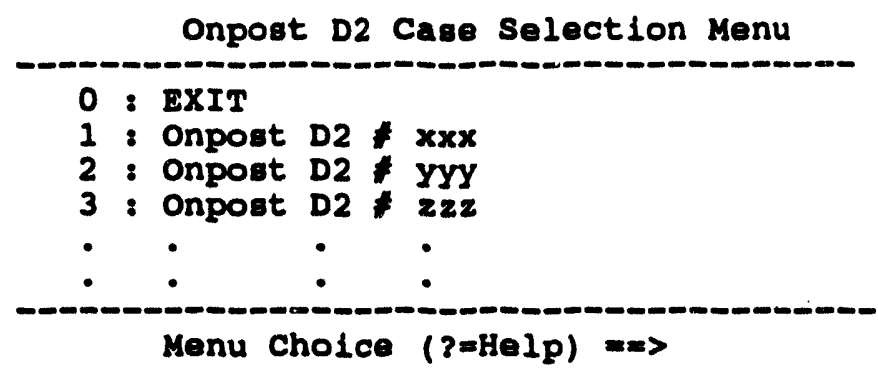

Select the onpost case on which you want to base the offpost case.

If you selected option 1, or after you select a case from option 2, the system will display the following menu, which contains only those case numbers which are not already in use.

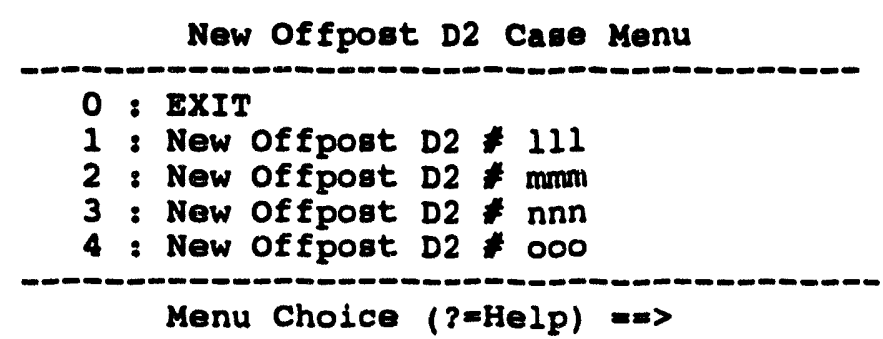

Select a new offpost case number which will be based on the onpost case. Once you have selected a new case number, the system will switch you to the newly created offpost D2 case. 
When you select Option 8: General Copy Case Site, the following two page form displays.

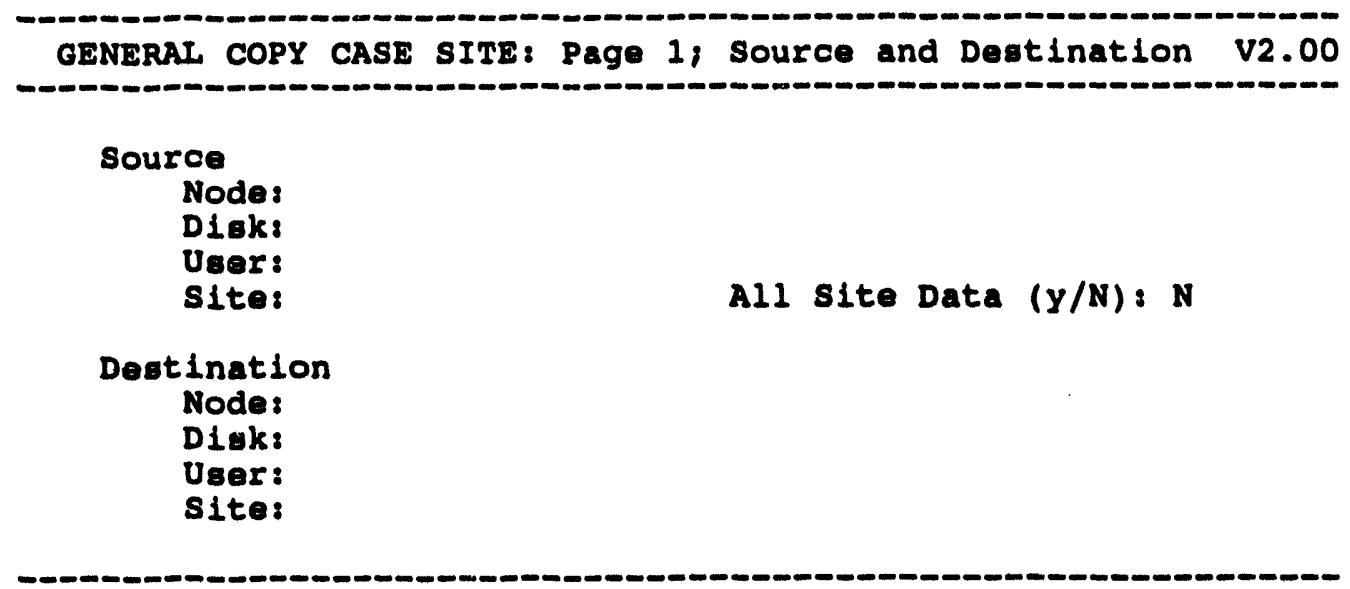

After filling in the first page of the form, press Return. Page two of the form will display.

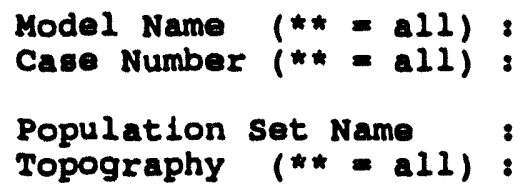

The same screens are used for copying data to or from another IBS user. These two processes are explained in the following sections. In general, you must know what kinds of data you want to copy (which fields to use on the screen). The IBS provides specific help with the names of models and data sets:

To see a menu listing of possible entries for a field of the screen: enter ?? in the field. A noenu appears so that you can select the model or data set name.

\section{Copying Site or Case Data FROM Another IBS User}

For example, if you were working with a planner to create evacuation scenarios for a specific site, you can copy case data from that person's directories directly into your own directories. 
The fields of the COPY CASE OR SITE FILES screen are explained here. A bullet $(\bullet)$ appears next to each input item. Remember: for some fields you can enter ?? to see a menu list of possible inputs.

- Source Node: Enter the name of the node (system) from which you wish to copy data. Type ?? for help.

- Source Disk: Enter the name of the disk used by the person whose files you want to copy. Type ?? for help.

- Source User: Enter the "user name" of the person whose files you want to copy. Type ?? for help.

- Source Site: Enter the 4-character site name of the site from which you wish to copy data. Type ?? for help.

- All Site Data?: Enter $\mathbf{Y}$ to copy a complete site. If necessary, site directories are created on the destination disk. All model data, mapping data, and other support files are then copied from the source disk to the destination disk. The site file in your login directory is also updated.

- Model Name or **: Enter a specific model name (such as D2 or IDYNEV)-or ** (two asterisks) to signify all models for the chosen site. Type ?? for help.

- OSPM TAC Files? ( $\mathbf{Y}$ or $\mathbf{N}$ ): Enter $\mathbf{Y}$ to copy TAC (cell data) files associated with the OSPM model. These files must comply with IBS naming conventions for OSPM TAC data files. Type ?? for help.

- Case Number or **: Enter a case number-or ** (two asterisks) to signify all cases for the chosen model. Type ?? for help.

- Population Set Name: Enter the name of the population set to be copied with the chosen site. Type ?? for help.

- Topography or **: Enter a two-character topographic code to identify one topography-or ** (two asterisks) to signify all topographies (map layers) from the chosen site. Type ?? for help.

- Model elevation files? $(\mathbf{Y}$ or $\mathbf{N}$ ): Enter $\mathbf{Y}$ to copy TAC (cell data) elevation files associated with the models. These files must comply with IBS naming conventions for model elevation data files. Type ?? for help.

- Destination Disk: Enter the name of the destination disk device to which IBS is to copy the desired files. Type ?? for help.

- Destination Site: Enter the 4-character site name of the site to which you want to copy data. Type ?? for help. 
- Destination User: Enter the user name of the person who will receive the data. Type ?? for help.

- Destination Node: Enter the name of the node to which you want to copy data). Type ?? for help.

Regardless of what you copy, the settings for such things as the current case, site, and population set remain unchanged in your job environment. You must explicitly set these items to the new data using SETUP-JOB ENVIRONMENT, if that is what you wish to do.

\section{Copying Slte or Case Files TO Another IBS User}

In this situation, you use the same input screen to specify that site or case files be directed to another IBS user.

\section{Tracking Case Check-In and Check-out}

Option 9 : Check-in/out Tracking enables you to determine who checked out a selected case, which of their sites they checked it into, and the date and time the case was checked out.

Note: Cases checked out with versions of IBS prior to 2.00 will not be able to be tracked until the case is checked back in.

After you select this option, the following menu will display:

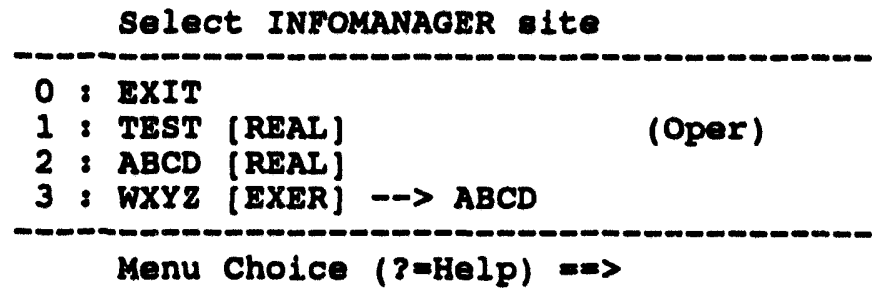

To check which cases have been checked out, select one of the Infomanager sites. The system will display the following menu.

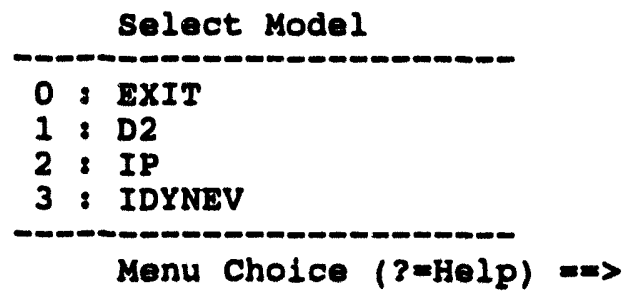


After you select an Infomanager site, the system will display a menu of cases from the selected site and model that have been checked out by users. Select a model and case from the menu.

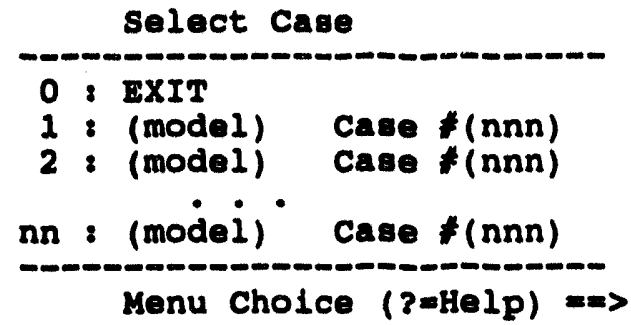

After you have selected a model and case, a report similar to the following example will display if the case was successfully found in the Tracking file.

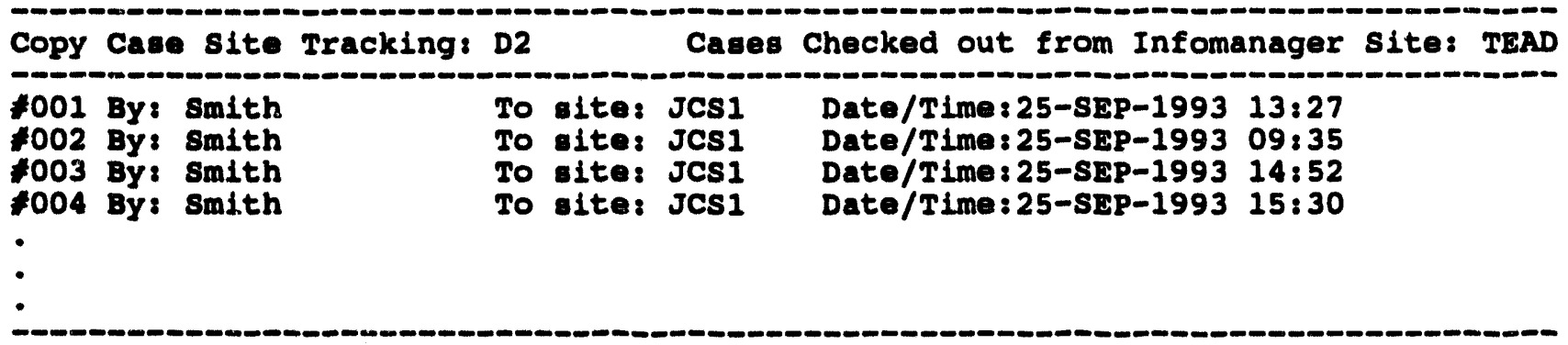

End of Report: <Return> to continue, 4 to change destination...

If the case was not found, a message similar to the following will display.

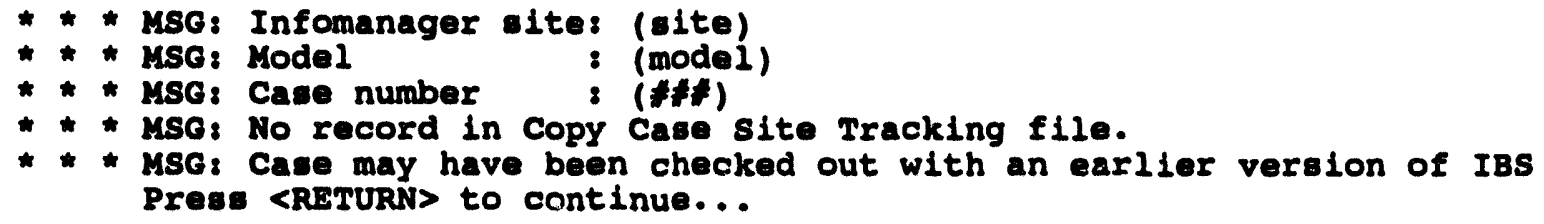

\section{Deleting a SHe Database}

Option 10 : Delete Site enables you to delete a site database by using the DELSITE utility.

The DELSITE utility deletes an entire IBS site database from the system, removing all the directories, subdirectories, and files associated with the site database. Anyone with the appropriate IBS privilege can delete a site database by using DELSITE. DELSITE is also accessible as a stand-alone utility as well as under the Delete Site option.

\section{Caution}

DELSITE permanently removes a ste database. Once deleted, a site database cannot be recovered unless it is avallable on system backups. 
This discussion covers the following topics:

- Why delete a site database?

- What You Need to Know Before Using DELSTTE

- Deleting a Site Database with DELSITE

- Results of Using DELSITE.

Why delete a site database?

If for some reason a site database becomes obsolete and is no longer needed, it can be removed by any user with the appropriate IBS privilege. The disk space used by the site database then becomes available for system use.

\section{What You Need to Know Before Using DELSITE}

Before using DELSITE, you must know the following information, which DELSITE will request as input:

disk This is the name of the disk device on which the user account currently resides.

Example: DISK1

user This is the name of the user account under which the site database is located. All IBS site databases are located as subdirectories under a user account directory.

site This refers to the four-character site code that serves as the subdirectory name of the site database to be deleted.

Examples: ABCD or TEST

Before using the DELSITE utility, make sure that this information is correct. If this information is wrong, DELSITE could remove the wrong site database. You could expect the owners of a wrongfully wiped database to be unhappy.

Note: To update system files that support site information, you should use the FIXMSTRDIR utility whenever you delete a site from the system. See FIXMSTRDIR.

\section{Deleting a Site Database with DELSITE}

The following is an example of how to delete a site database. 
The program will display a warning message, then prompts you for the information outlined in the previous section. The series of prompts will look like the following (simulated answers are in bold):

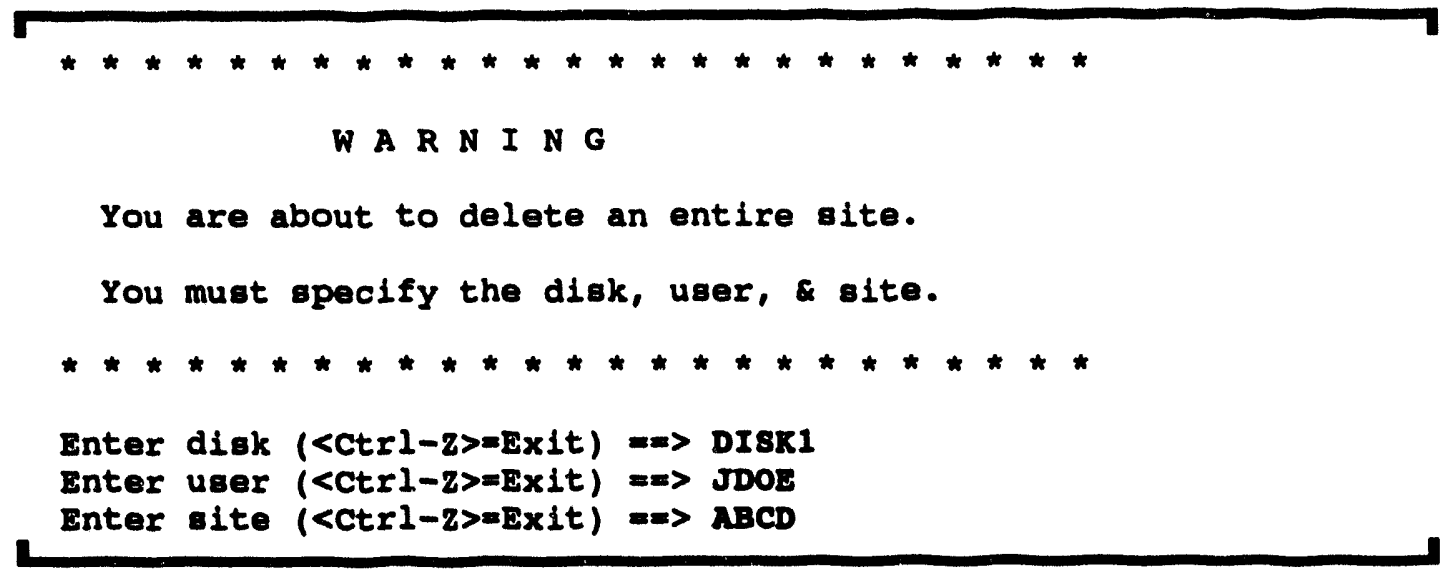

To cancel the deletion process at any of these prompts and exit, press CTRL-Z.

To delete a specific database, enter the appropriate disk, user, and site names as requested. Once you have supplied this information, the utility deletes the site database, displaying a sequence of messages similar to the following:

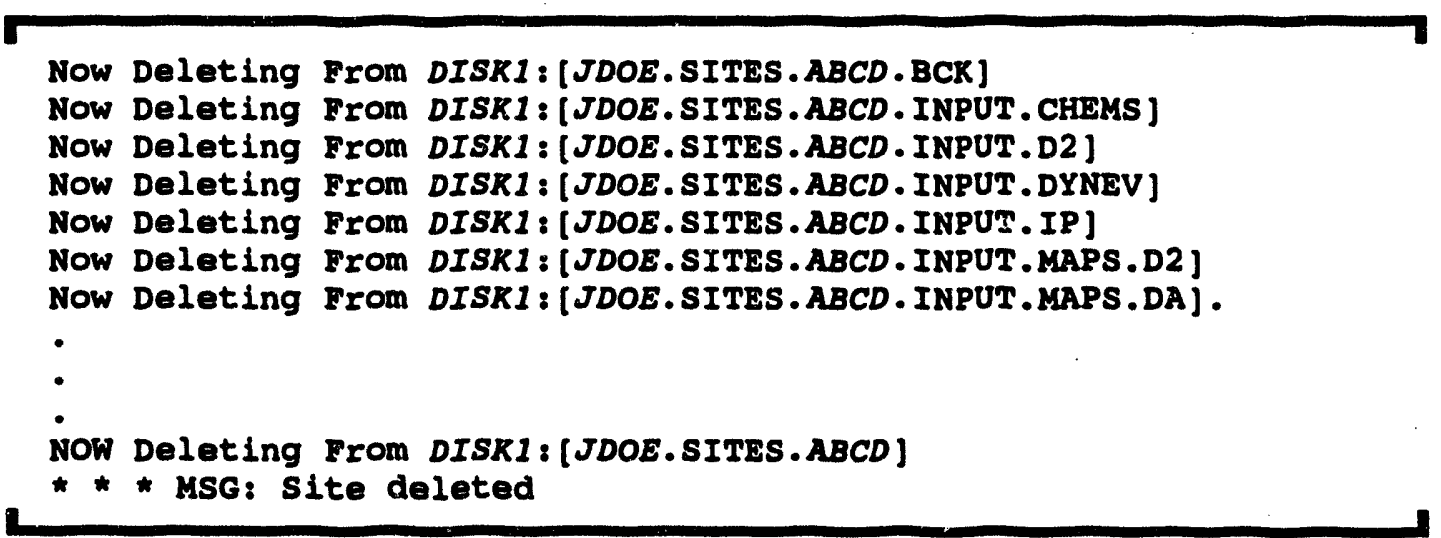

\section{Results of Using DELSITE}

DELSITE removes all the directories and files associated with a site database. Once removed, the files cannot be restored through any IBS utilities. If a mistake is made, the only possible way you could recover the data would be to retrieve it from system backups made earlier. 


\section{IIIHARDWARE SETTINGS}

The purpose of modifying hardware settings is to tell the system what kind of hardware devices you are using. When you select this option, the IBS displays the following input screen for modifying hardware parameters. The current hardware selections are indicated by the letters that appear in the input fields.

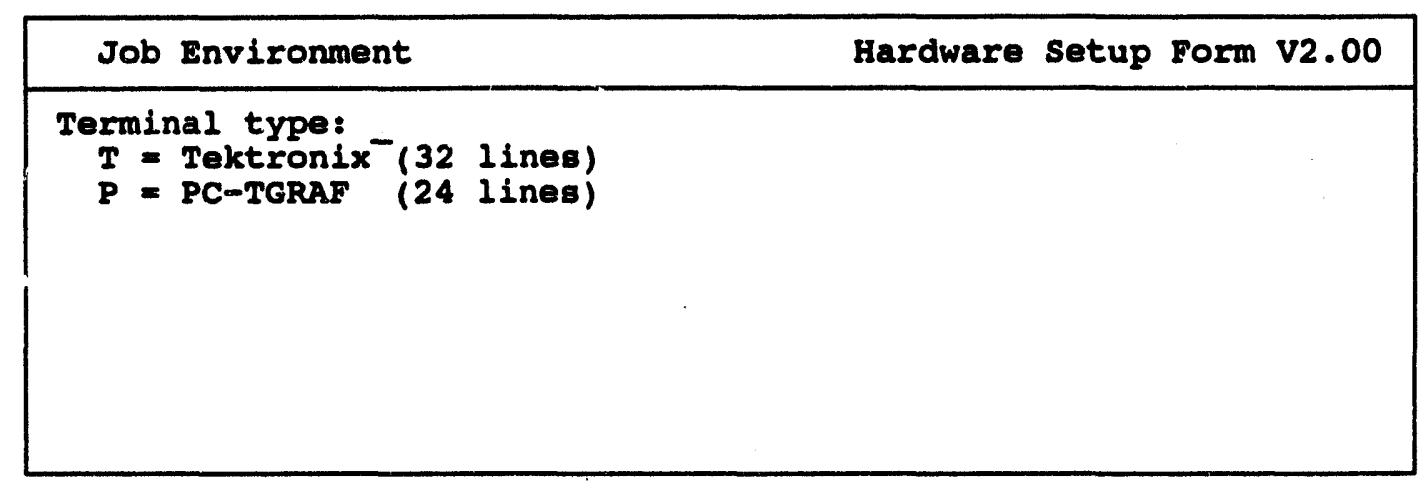

If you modify a hardware choice and accept the modification (when you exit the form), the system tells you that the previous value of the device's logical name has been superseded by your new choices.

Terminal (display device) type: Enter:

T - to use the Tektronix terminal monitor (or other terminal emulating a Tektronix monitor). Tektronix terminals have 32 lines on the screen.

P - to use the Tektronix emulation provided by TGRAF software on personal computer. These terminals have 24 lines on the screen.

\section{HIISCELLANEOUS SETTINGS}

This option enables you to specify the default

- Selection mode

- Report destinatiors

- Default units of measure (English or Metric)

When you specify a default selection mode, the system offers you that mode of selecting an item. This occurs whenever you have to select an item as part of another IBS option. The options for selecting (picking) are:

\section{List}


2. Mouse

3. Name

4. None

When you specify a default report destination, the system sends any generated report to your preferred destination. The destination can be:

0. None

1. Screen

2. Printer

3. Mail

4. File

When you specify a default units of measure, certain reports will use those units. The units can be:

1. English

2. Metric

If you select no defaults, the system displays the general selection and report destination menus whenever you select an option that requires these actions.

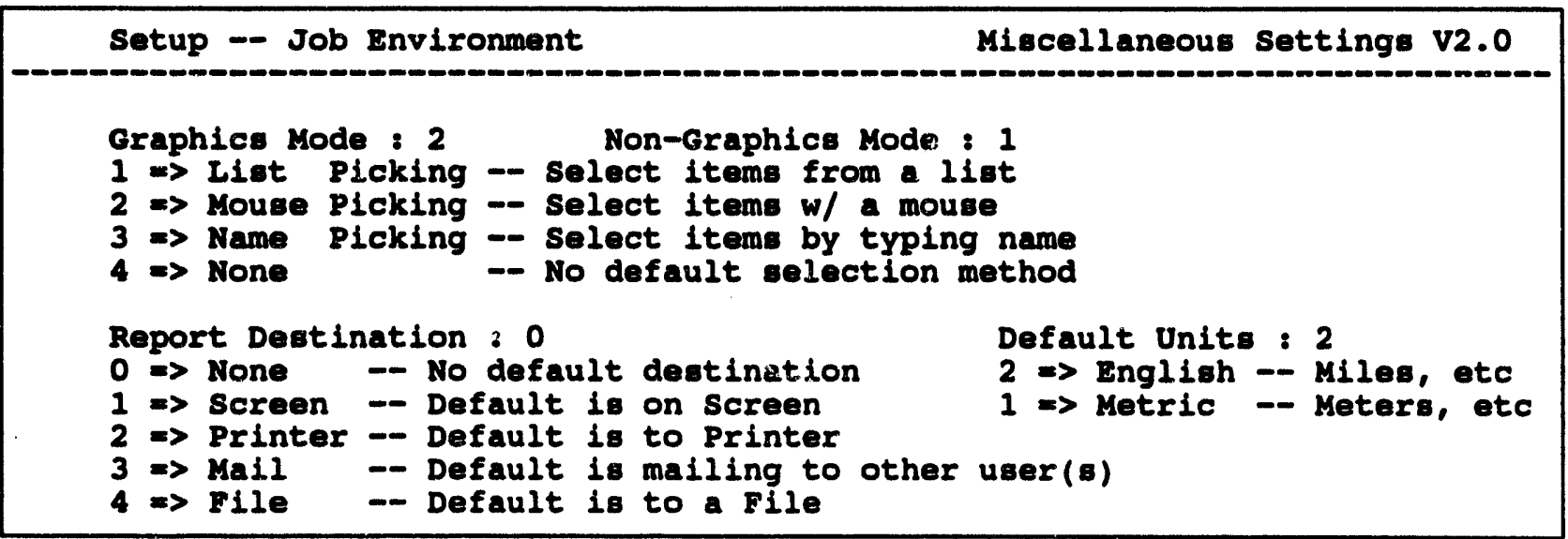




\section{MODEL CASE MANAGER}

This option enables you to:

- List model cases

- Delete model cases

- Change the model case index which contains the current state of each Model Case in a site.

A menu similar to the following will display.

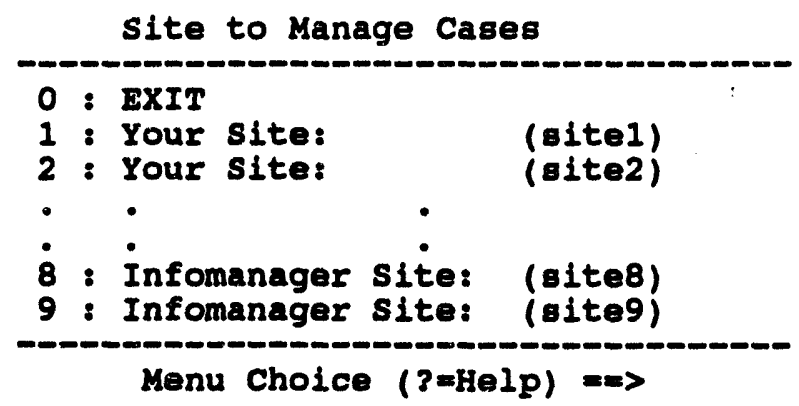

The menu will list all your sites, as well as all the Infomanager sites (if you have the appropriate privileges). Select the site you want to modify. If the site selected is the current operational site, the following prompt will display to verify that you want to modify the current operational site. * * MSG: Modifying the current Operational aite could cause problems for
* * MSG: other users currently using IBS.

Really modify the Operational site data? $(Y / N)=$ ?

You would not normally want to modify the current operational site. If you enter $Y$ at the prompt, or selected a site other than the current operational site, a menu similar to the following will display.

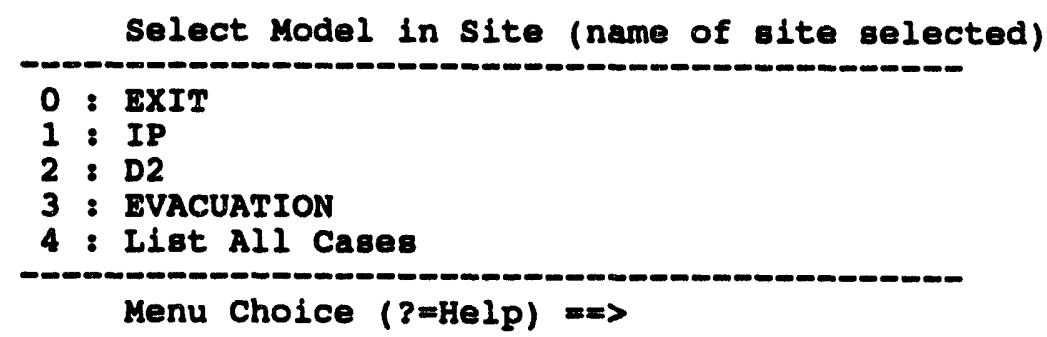

Select the model for which you want to change case information. If you do not have the correct privilege to change one of the models, it will not appear on the menu. Select List All Cases to receive paged lists of all the model cases for all the models (all models will be viewed in the list, whether or not you have privileges to change them). 
After selecting a model to change, the following prompt will display.

Enter model case number to change (IIST=Ligt all) $\Rightarrow$

Enter the number of the model case that you would like to change, or type list to display a paged list of all the model cases for the model selected. After entering a model case number, a menu similar to the following will display.

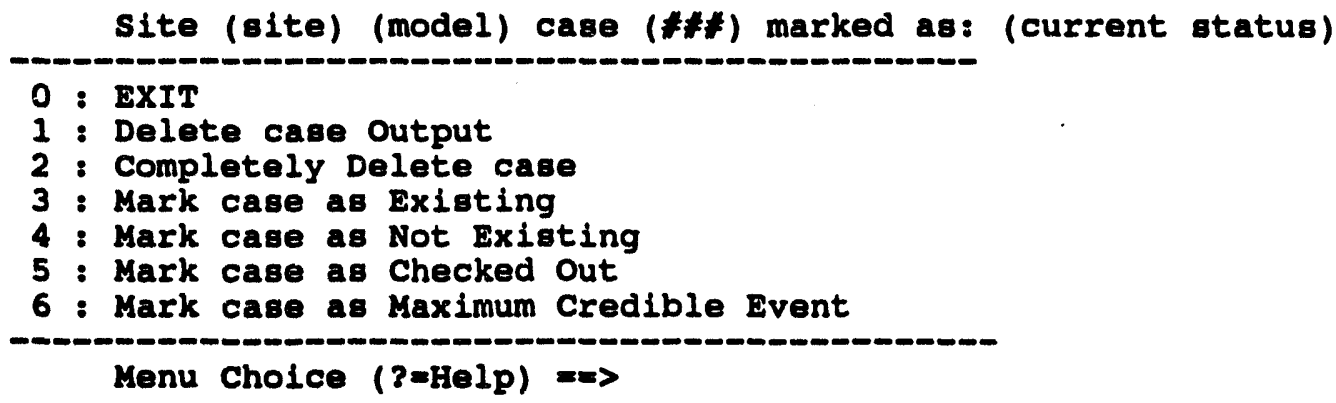

All possible menu options are shown in the example, but would not all display for a single case. Select the option you want from the menu. The options are:

Delete case Output: For D2 and Evacuation cases, this removes any data created by the case having been executed. To view the case output information, it would need to be re-executed. The following prompt will display to verify that you want to continue:

Delete Output for case $(* ; *) ?(Y / N)=>$

Completely Delete case: Allows all data for the selected case to be removed. The following prompt will display to verify that you want to continue:

Delete case (F*)? Data will be lostl $(Y / N)=$

Unless you have a backup copy, or have archived the site, all information about the selected case will be lost.

Mark case as Existing/Not Existing/Checked Out/Maximum Credible/Event: Allows you to change the status in the Model Case Index file for the selected model case to the status specified in the menu. The following prompt will display:

* * MSG: Change Case Index file can easily corrupt data.

Are you sure you want to do this? $(Y / N)=m$

Note: Be careful using this option, because you can easily corrupt the Model Case Index file. 


\section{IIISET TO DEFAULT COLORS}

This option enables you to reset your graphic display and text colors to the standard system default colors (orange menu, white on blue text). 


\section{MAP LAYERS - BY ACTIVITY}

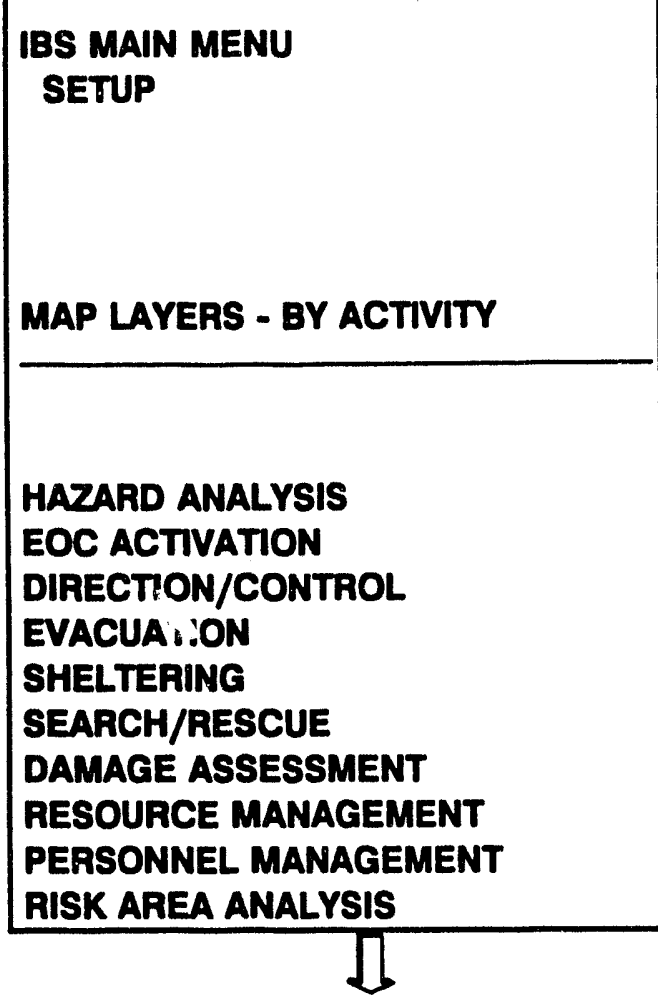

\section{IBS MAIN MENU \\ SETUP \\ MAP LAYERS - BY ACTIVITY (emergency activity) \\ (emergency activity)}

FORWARD

BACKWARD

ADMINISTRATIVE BOUNDARY

ELEVATION CONTOUR

ELEVATION

MAP LAYER 4

MAP LAYER 5

-

-

MAP LAYER N
MAP LAYERS - BY ACTIVITY enables you to choose which map layers you wish to display for each Emergency Activity. You can select one Emergency Activity at a time from the menu list.

After selecting an Emergency Activity, a submenu of map layers for that function displays, similar to the one at lower left.
The initial default map layers (see MAP LAYERS DEFAULT) and any map layers already defined as default layers for the chosen Emergency Activity are already selected (shown in highlight on the list). You can select additional map layer(s) to be included in the set of default map layers for this Emergency Activity. The new map layers also are highlighted. To deselect a map layer, pick on a highlighted map layer, so it returns to its original color.

When you exit from the menu, the form for restricting the display of map layers based on display size is shown. As described for MAP LAYERS - DEFAULT, this form enables you to make the display of map layer data dependent on the size of the displayed area. For each Emergency Activity map layer listed on the form, you can specify a range of display sizes within which that map layer is shown. The following screen example shows map layers that were selected for the HAZARD ANALYSIS Emergency Activity. 


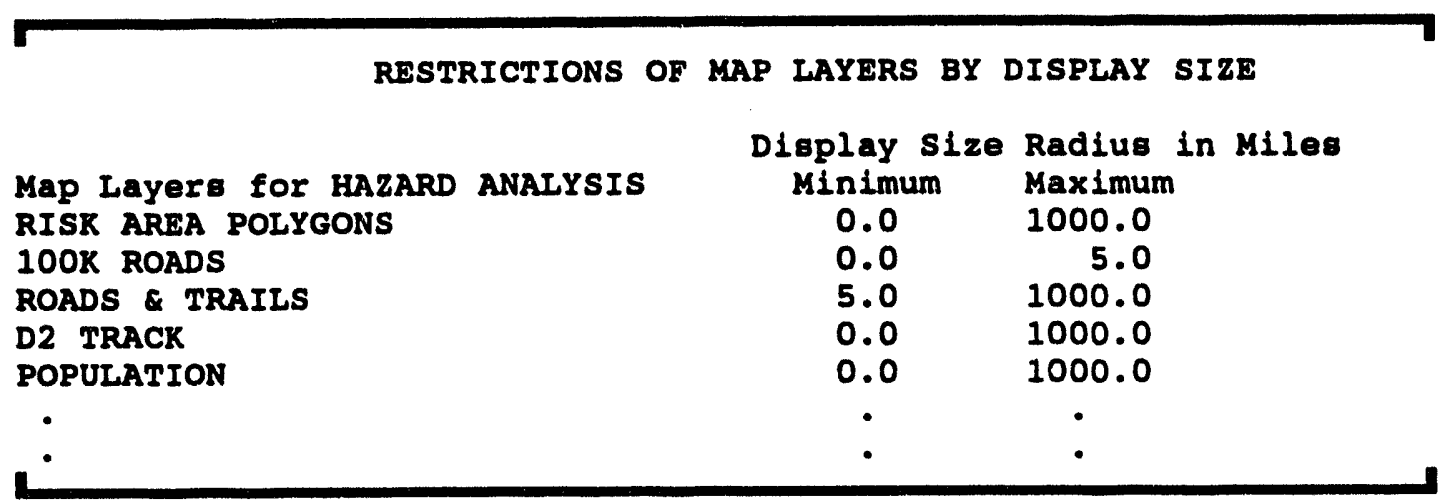

After you exit this form, the new set of default map layers will be displayed within that emergency activity. To display the new map layers, return to the IBS Main menu and select the desired emergency activity. The new map layers display when the graphic display is refreshed. 
I MAP LAYERS - DEFAULT

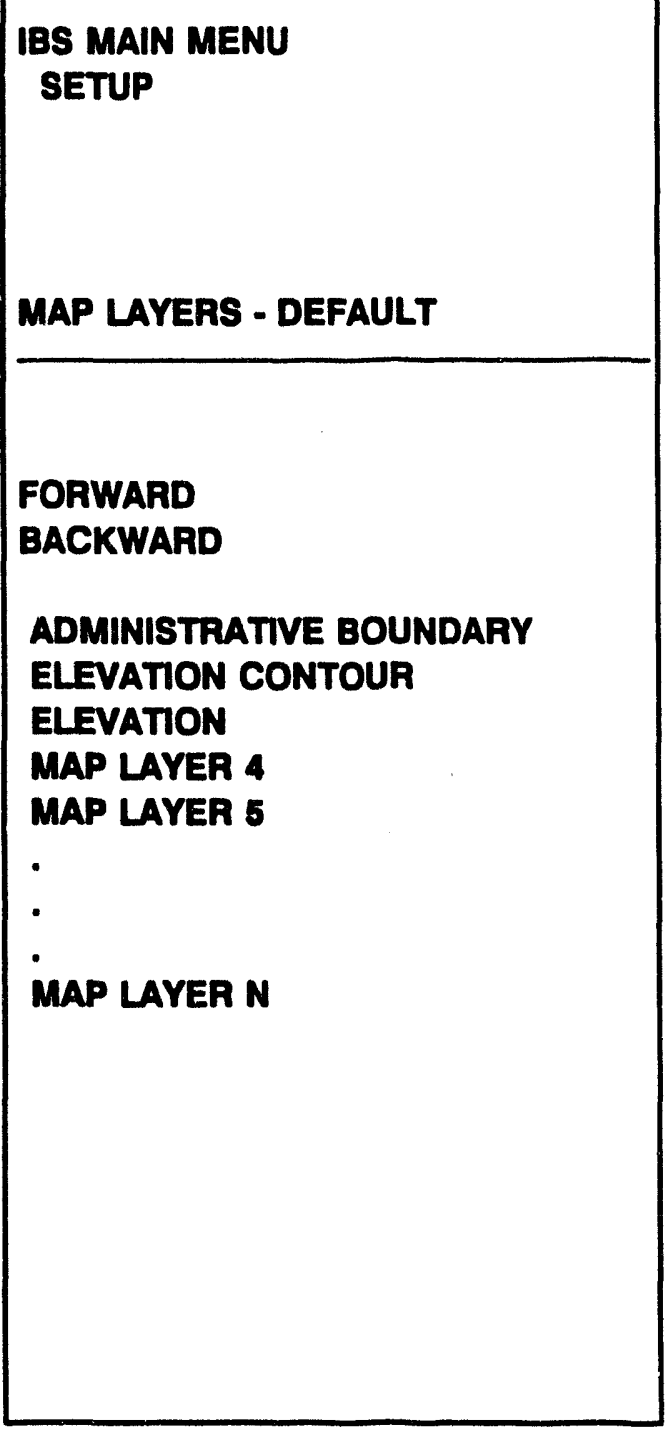

This option displays a menu that lists the different layers available in the current map database. Any highlighted menu items are the currently selected default map layers - the map layers that are automatically displayed when you start using the IBS. You can select additional map layers or remove some of those already selected. The selected map layers then appear on the map screen throughout this session - unless you remove map layers later.

The map layers are too numerous to show on a single screen. The menu shown here is the first of several "pages" of map layers. The actual list of map layers is dependent upon your current map database and may be different for other map databases.

Use the FORWARD and BACKWARD options to display other pages of the map layer menu:

- FORWARD shows the next page of map layers. If you reach the end of the list, the next FORWARD returns you to the first page.

- BACKWARD shows the previous page of map layers. If you reach the first page of the list, the next BACKWARD sends you to the last page.

\section{Restricting Map Layers Based on Display Size}


When you exit the menu, you see a form for restricting the display of map layers based on display size (0 to 9,999 miles or kilometers). For example:

RESTRICTIONS OF MAP LAYERS BY DISPLAY SIZE

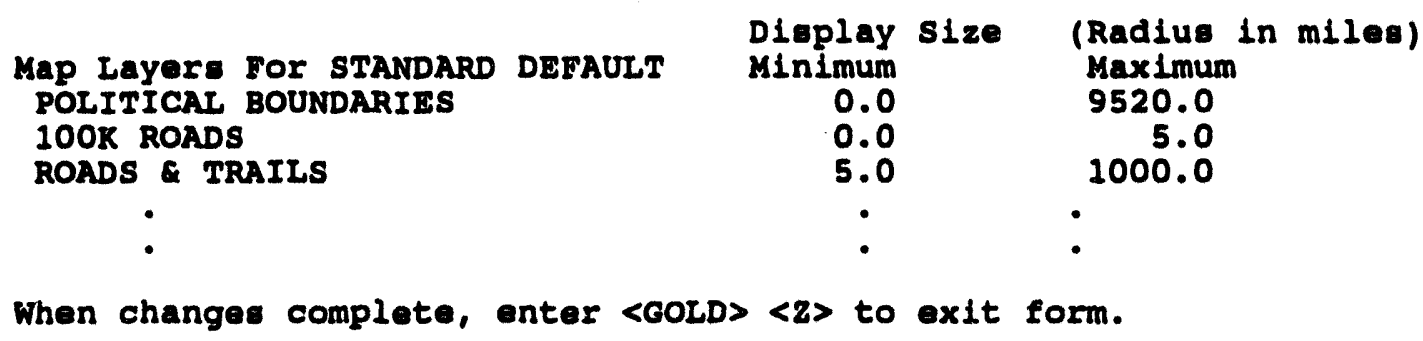

This form enables you to make the display of map layer data dependent on the size of the displayed area. For each map layer listed, you can specify a range of display sizes (radius in miles or kilometers) within which that map layer will be shown.

You can use this capability to customize the use of data sets that have different resolutions. For example, you might specify that 1:2 million-scale road data be shown for displays from 5 to 1000 miles across while 1:100,000-scale data is used for displays 0 to 5 miles across. This enables you to avoid the display of high-resolution data that might be appropriate for smaller areas but which are too detailed and time consuming to display for large areas.

Note: Some data rich map layers such as $100 \mathrm{~K}$ Roads will cause the system to hang if you try to display the map layer over a large map area. Restrict such layers in the same way as shown in the previous screen example. Recommended settings for $100 \mathrm{~K}$ Roads can be a minimum of 0.0 miles and a maximum of $\mathbf{5 . 0}$ miles. If you zoom out your map display to anything larger than a 5-mile radius, the 100K Roads layer does not display. This keeps your system up and running.

If you see blank map layer descriptions that have minimum and maximum display sizes listed, this is because your Job Environment file contains one or mors map layers that are not in the current map database. This should not interfere with the operation of the IBS program, but should be acdressed by your database administrator.

After you exit this form, the new set of map layer defaults are immediately displayed. 


\section{Appendix A IBS Graphic Menus}

This appendix shows the appearance and structure of the graphic-screen menus used by IBS. Most of the options listed on the IBS Main Menu result in the display of further submenus. These submenus are presented in the order in which they appear on the IBS Main Menu.

This appendix contains a series of menu diagrams which you can remove from the book and use for hanchy reference. The IBS Menu Structure is located at the back of this appendix. The menu structure reads from left to right; the first menu on the left is always the IBS Main Menu.

As you select options that result in further submenus, each level or layer of menu selection is listed in the upper area of the menu. The hierarchy of selections is indicated by indentation. You may go directly to any of the previous menus by selecting an item in the hierarchy of selections. For detailed information on selecting from a graphic menu, see Section 1, Introduction and Overview. 


\section{Example of a Submenu with Layered Menu Selections}

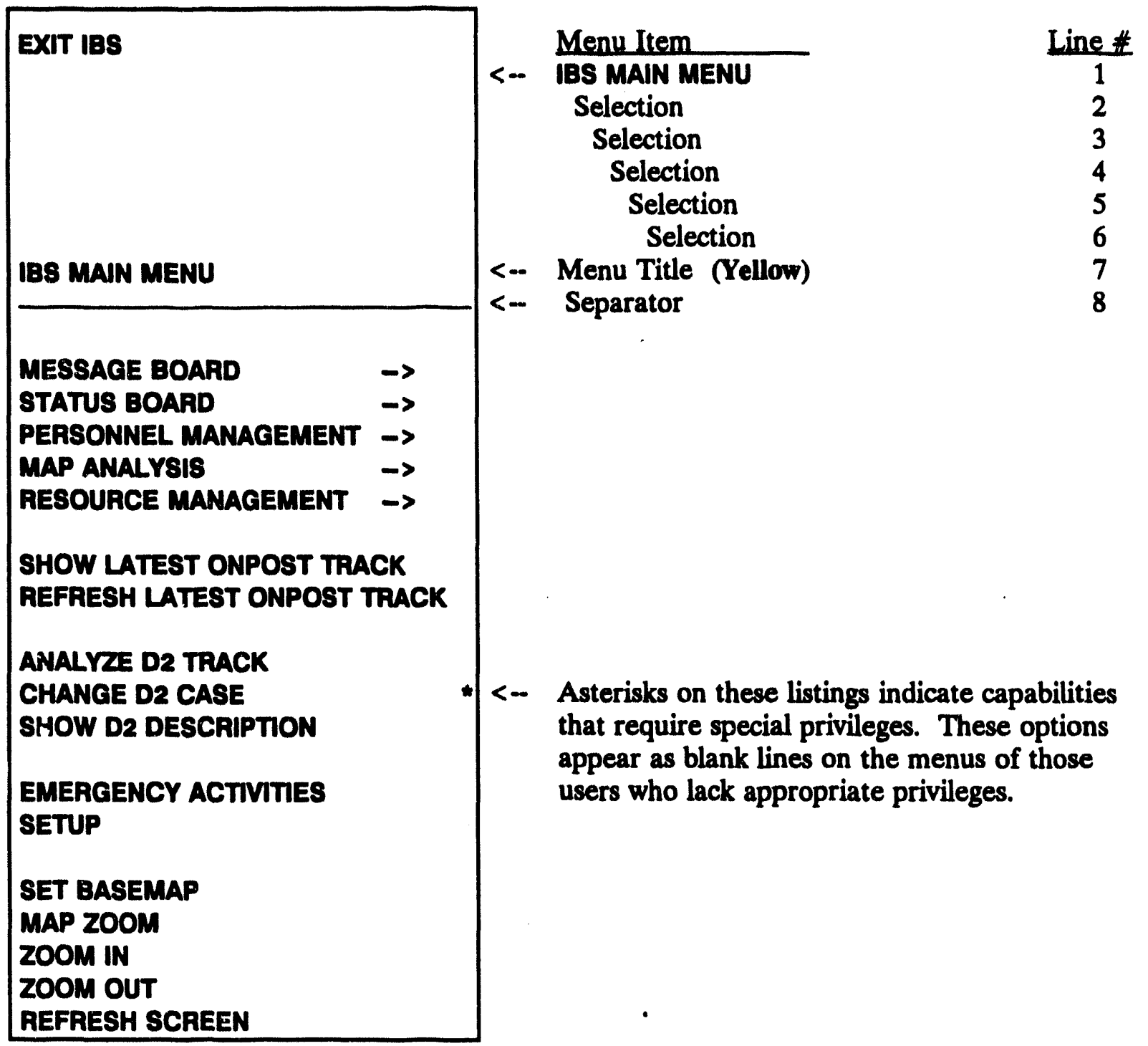




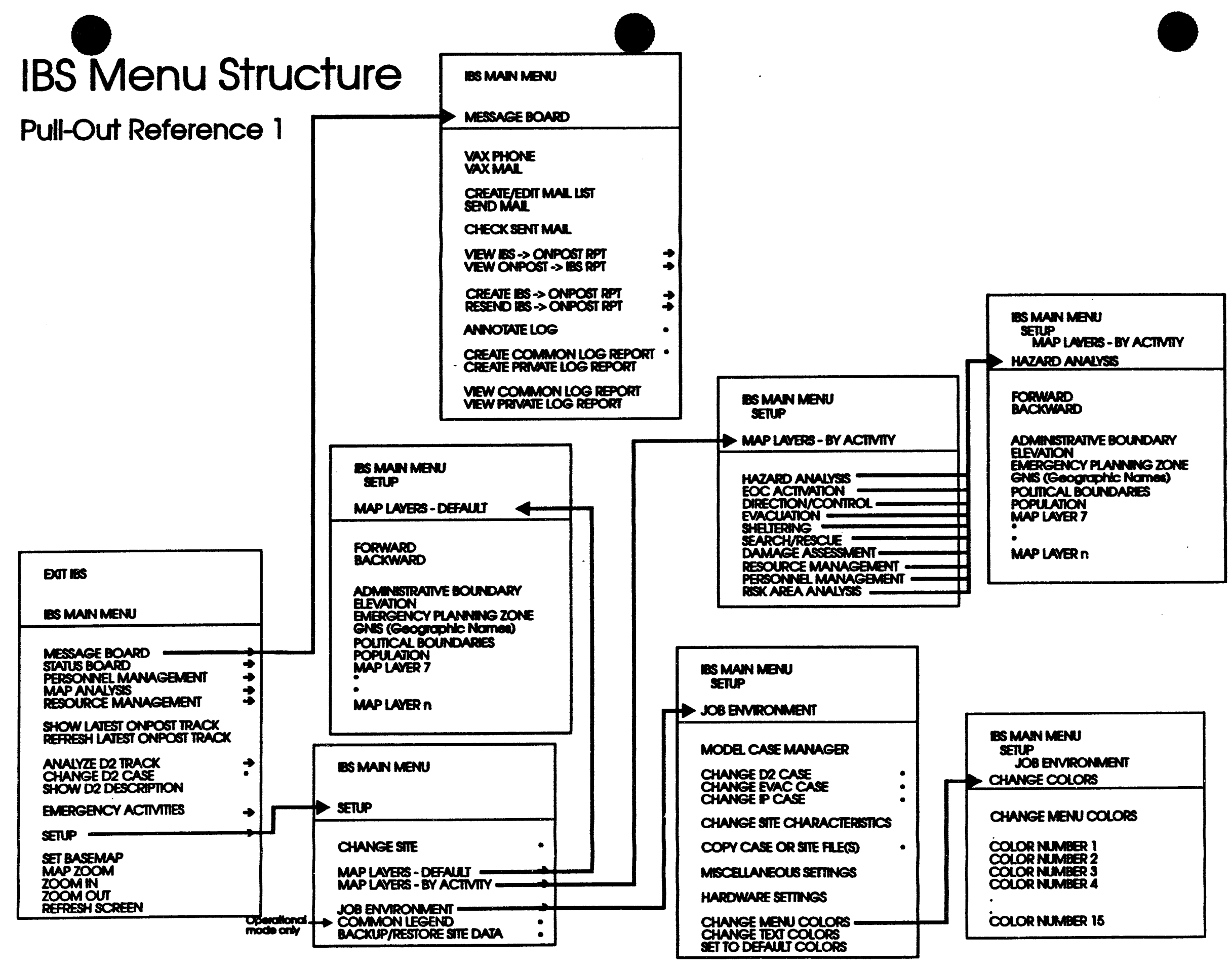




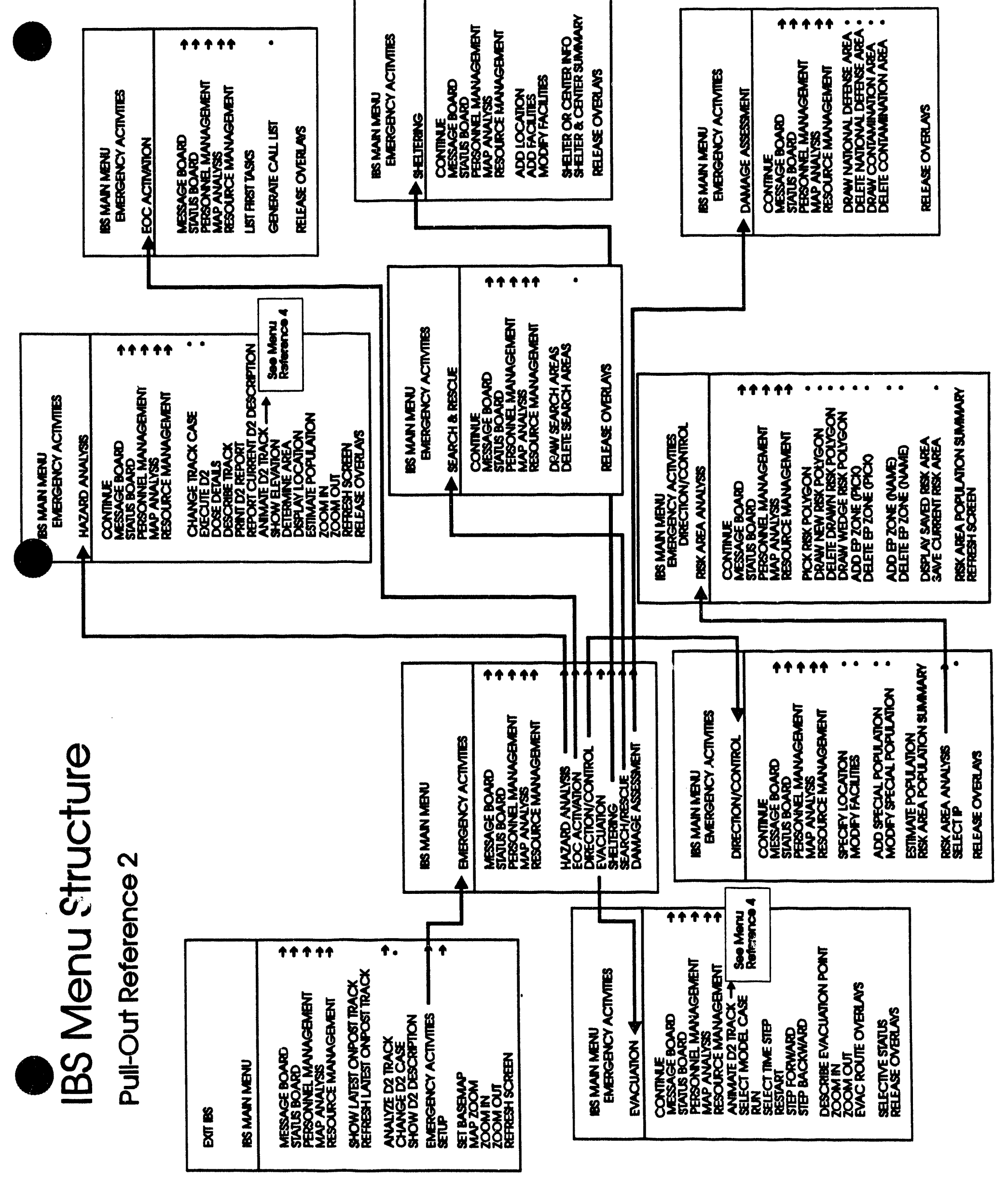




\section{IBS Menu Structure}

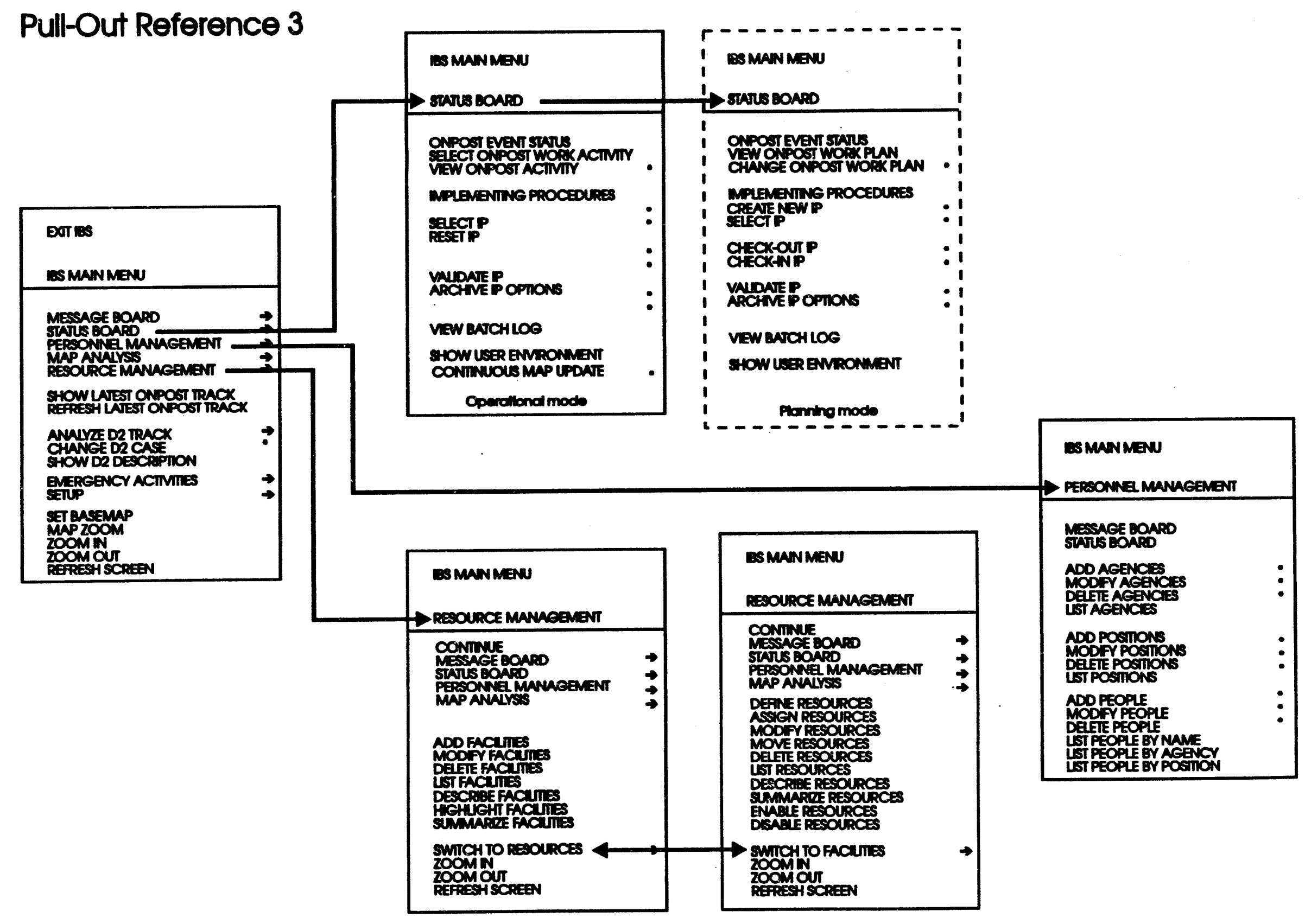




\section{IBS Menu Structure}

\section{Pull-Out Reference 4}

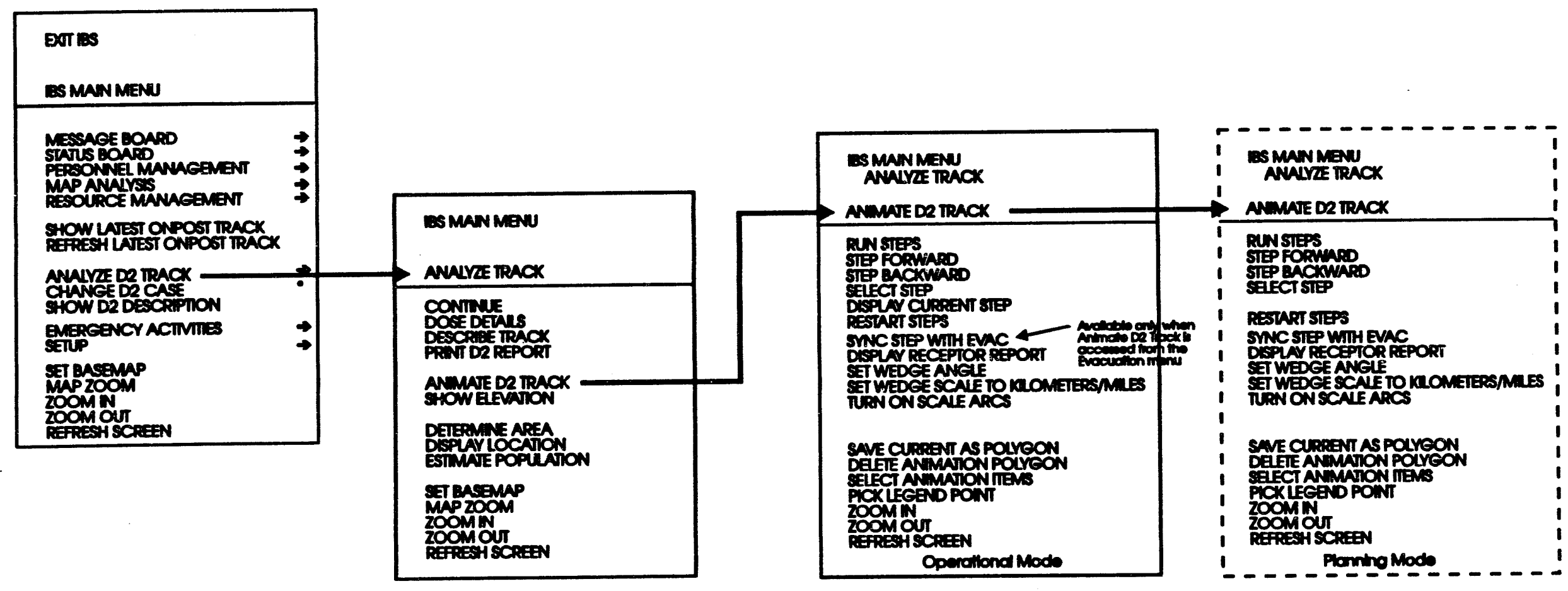




\section{IBS Menu Structure}

\section{Pull-Out Reference 5}

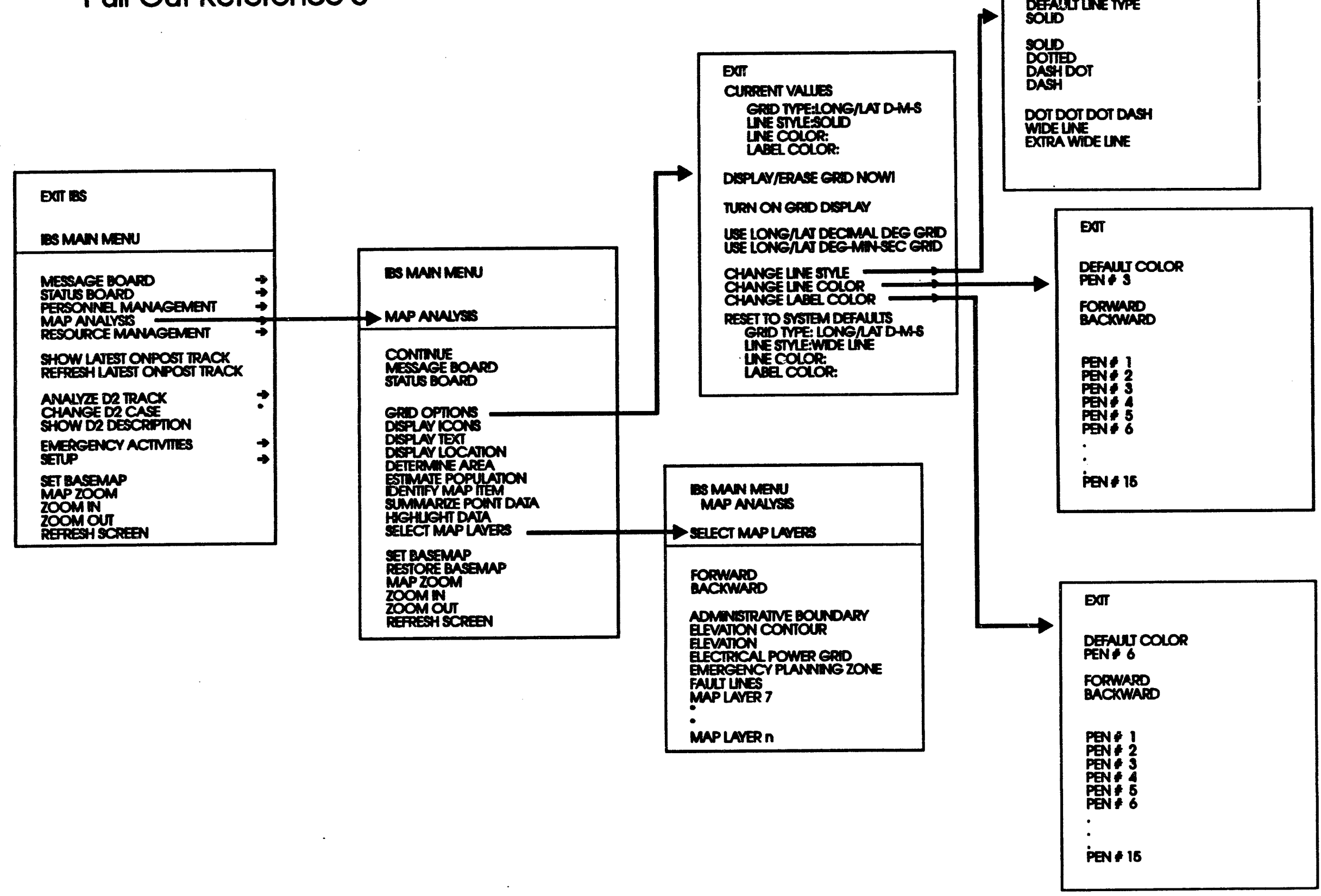


Appendlx B

Non-Graphlc IBS 


\section{Appendix B Non-Graphic IBS}

Although IBS is designed to be used with a terminal for displaying map graphics, you can also use the non-graphic capabilities of IBS from a non-graphic terminal by using a separate utility program called IBS_NOGR.

\section{To Start NON-GRAPHIC IBS (IBS_NOGR)}

Enter IBS_NOGR at the system prompt and press the Return key.

The system will display the following menu of IBS capabilities:

Non-Graphic IBS Main Menu
0: ExIT
1: Message Board
2: Status Board
3: Personnel Management
4: Resource Management
5: Current D2 Description
6: Emergency Activities
7: Setup
Menu Choice $(3=$ Help) $=0$

With minor changes to accommodate making selections with nurnbers instead of the graphics cursor (cross hairs), these options are implemented as they are described in the body of this document. Both versions of IBS act on the same database. Any changes made using one version of IBS are reflected in the other.

\section{Using IBS Shell to Run Non-Graphic IBS}

This program can also be accessed through the IBS Shell program.

Note: Running Non-Graphic IBS through the IBS Shell will cause your system to run slower.

Enter IBSSH at the system prompt and press the Return key.

This starts the IBS Shell. The IBS Shell: Main Menu will display.

IBS Shell: Main Menu
$0:$ EXIT
$1:$ Setup
$2:$ IBS Programs




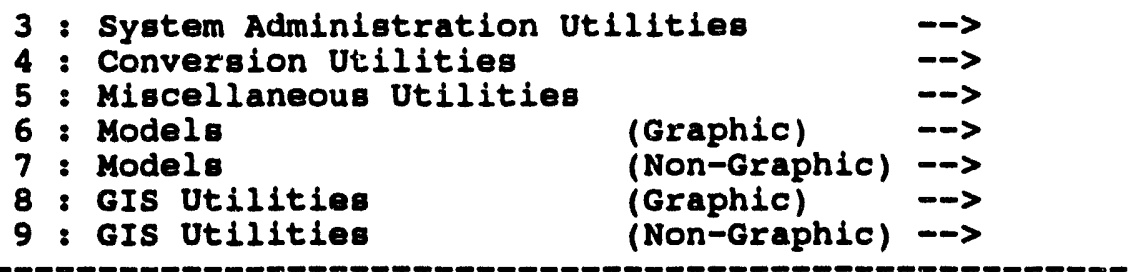

Menu Choice $(?=\mathrm{Help})=>$

Select the IBS Programs option and press the Return key. The IBS Shell: IBS Programs menu will display.

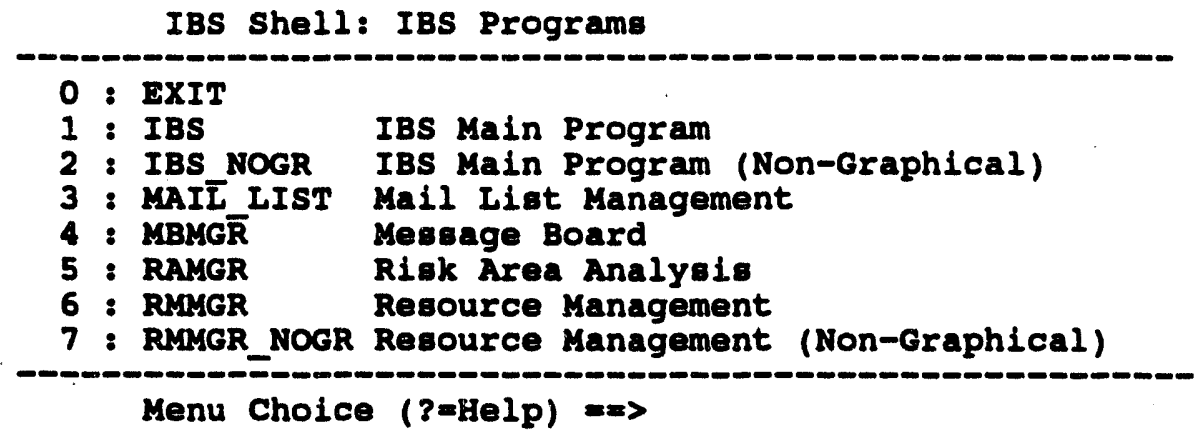

Select the IBS NOGR option and press the Return key. The Non-Graphic IBS Main Menu will display.

Non-Graphic IBS Maln Menu

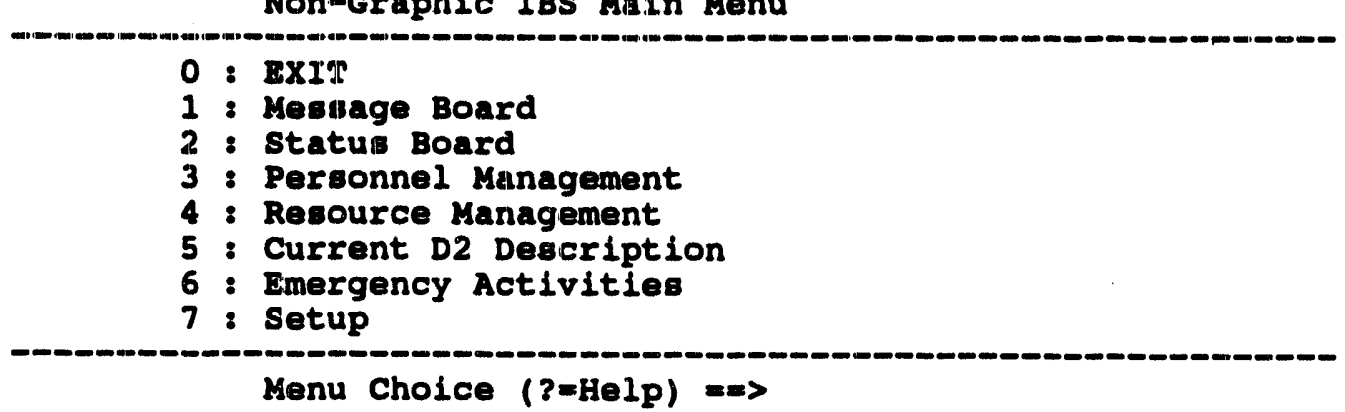


Appendix C

People Location 


\section{Appendix C People Location}

The people location program (LOCATE) enables personnel at various emergencyrelated facilities to record the names and whereabouts of people who enter or leave the facilities (shelters, reception centers, hospitals, etc.). If you are a Locator (an authorized operator of the LOCATE program), you can search the facility records in the IBS database to find information about specific persons or to determine the currently recorded loading status of facilities. The aggregate data are available in the main IBS program through the SUMMARY and SELECTION options on the emergency Function menus.

The people location program is designed to be used with an alphanumeric (textonly) workstation; it does NOT require a graphics workstation. This program is accessed through the IBS Shell program.

\section{To Start the LOCATE Program}

Enter LOCATE at the system prompt.

The system presents the following title screen and a list of the facilities in the IBS database:

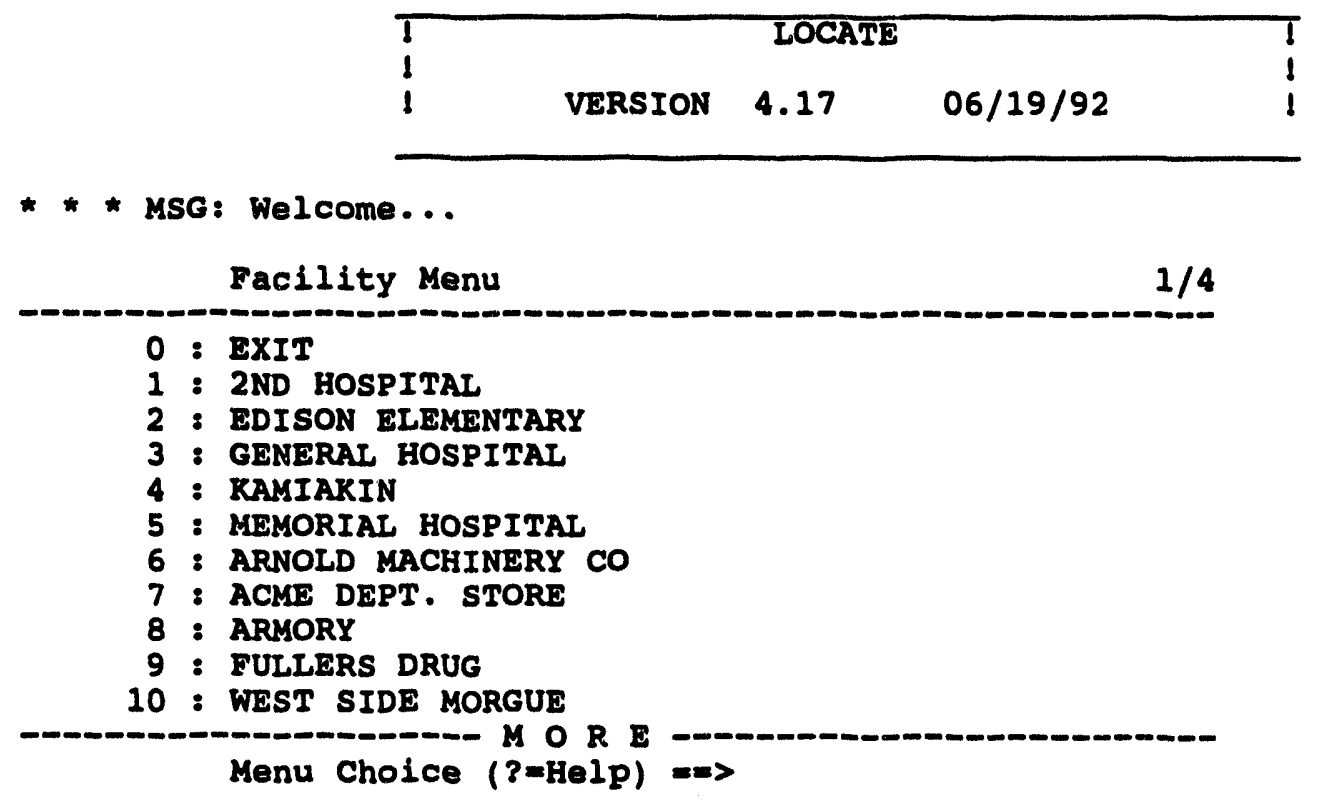

The facilities list is displayed one page at a time. 
The facility that you select is the initial facility for which person information is entered or updated.

\section{PEOPLE LOCATION Menu}

After you select a facility for making inquiries, the following general PEOPLE LOCATION menu displays.

\section{PEOPLE LOCATION}

Pacility Name: (facility name)

Facility status:

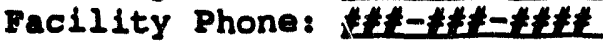

A. Enter Persons

B. Update Persons

C. Search for Missing Persons

D. Enter Default Values for the Enter Persons Form

B. Display Loading Data for Each Facility

F. Select a Different Facility (for Enter/Update)

G. Deactivate the Current Facility

x. Exit, with Optional Facility Deactivation

select Option:

The facility named at the top of the form is the facility entered or updated for each person chosen when you use the Enter Persons or Update Persons options. You can change this default by using Option $F$ above. The options of the menu are explained on the following pages in the order in which they appear on this menu.

The facility status displays for each facility you select. The status can be:

- Active

- Inactive 


\section{Option A. Enter Persons}

This first option enables you to record personal data on the following blank form, which is based on the Red Cross shelter registration form.

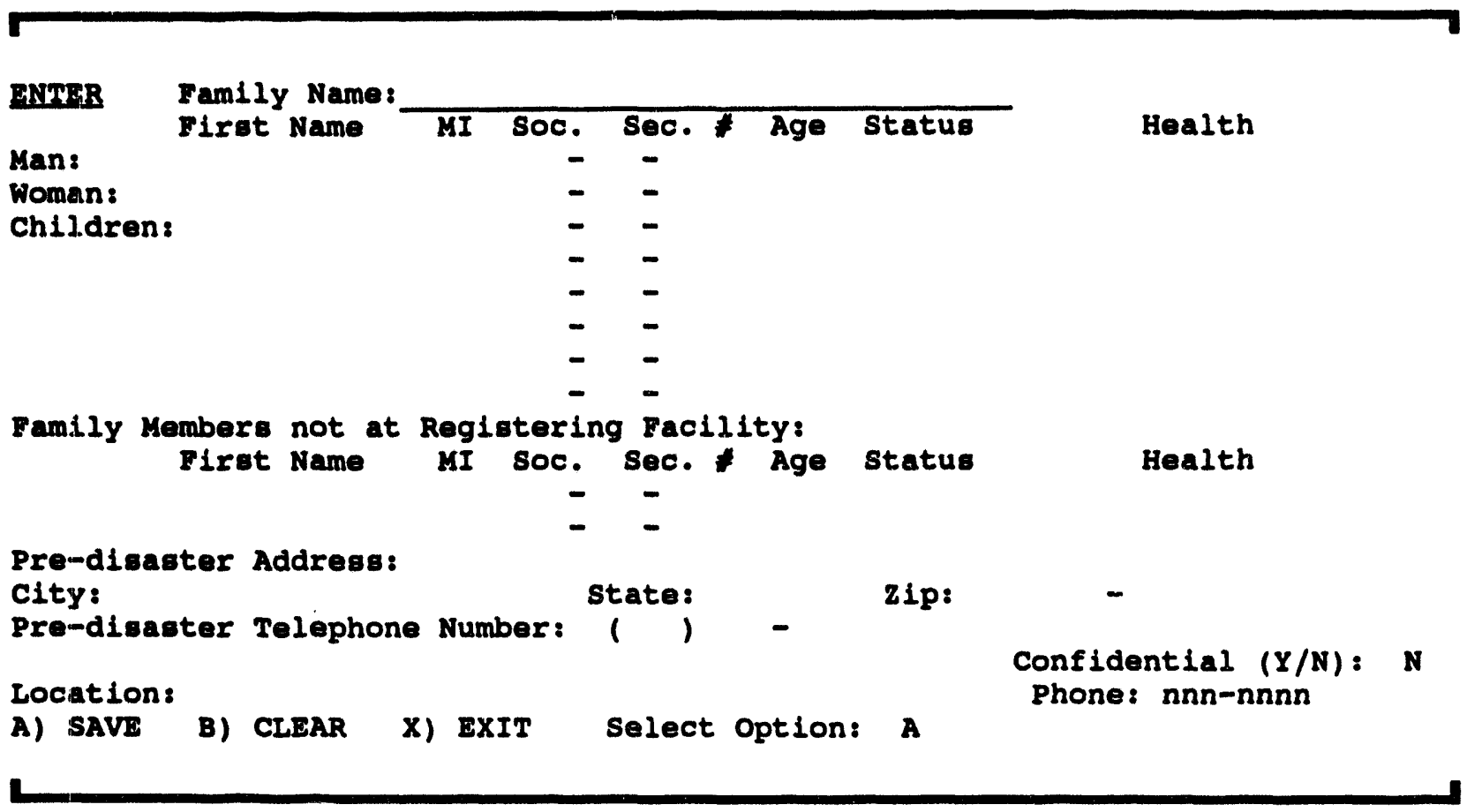

Unknown Names: If the name of a person at the facility is unknown, enter XXXXX as the name. The counts of persons at various facilities include these unnamed persons.

Default Values: If default values are already set for the city, address, and the telephone area code by using option D on the PEOPLE LOCATION menu, they appear on this form. All entries apply to the current facility.

To select one of the form's operative functions, enter the associated letter:

A SAVE - After modifying the data in an existing form or entering data in a blank form, you can select SAVE to add the data to the database. After selecting SAVE, a blank form appears for a new entry.

B CLEAR discards data entered on the current form and provides another blank form.

X EXIT returns you to the previous PEOPLE LOCATION menu. 


\section{Option B. Update Persons}

This option enables you to modify personal data using the same registration form with different operative functions. When you choose Update Persons, you see the following form, which is also blank until you specify which record you wish to update. All updates apply to the current facility.

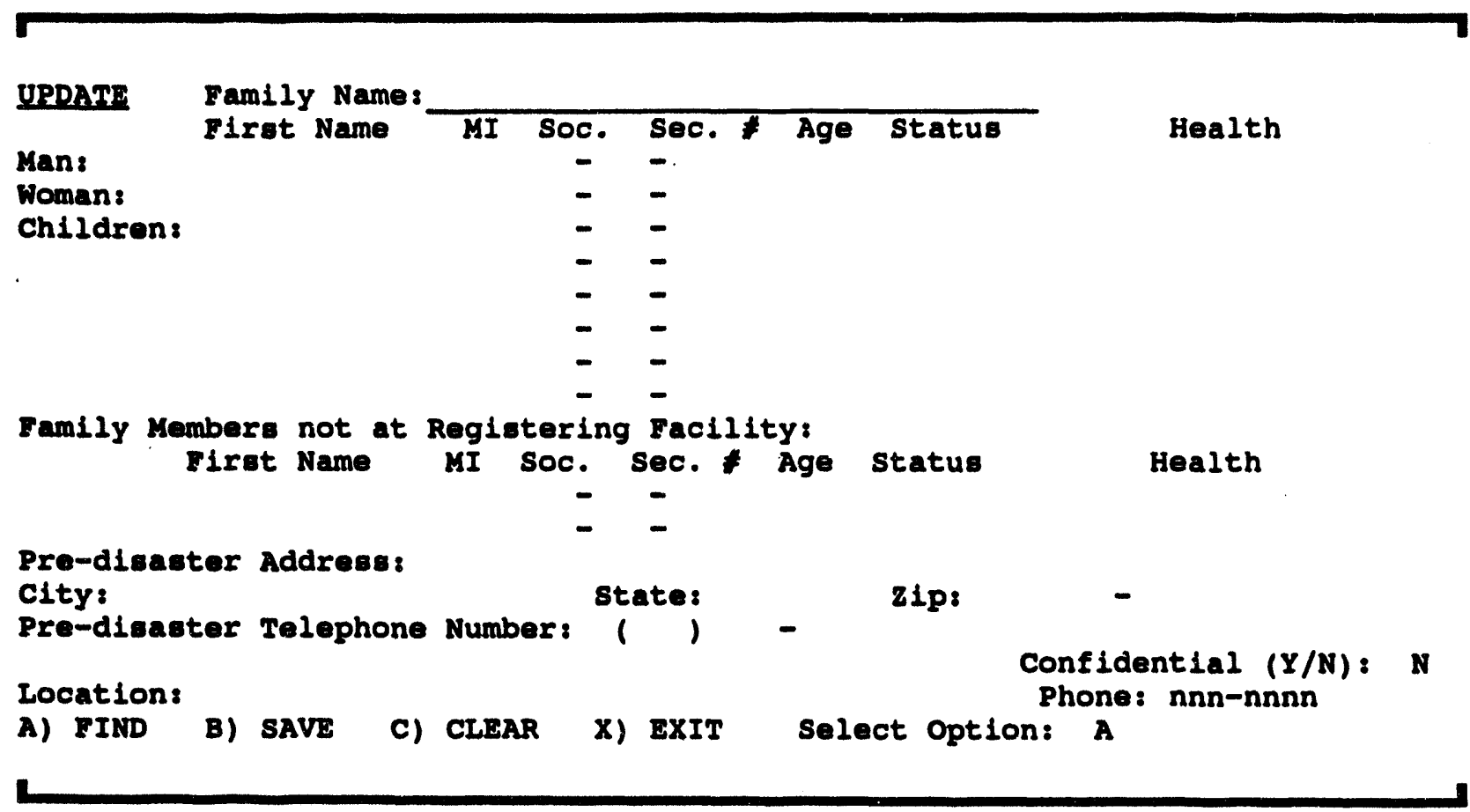


A EIND enables you to enter any known data in the name and address fields. The system then searches the database for matching records. Information from the selected record is then displayed in the form. If you have appropriate privileges, you can modify any field. Press GOLD-Z to see the next matching record, if any.

Searching with Inexact Names or Addresses. Note that partial names such as BRO* are valid search keys that match all names containing the specified string. The asterisk $\left({ }^{*}\right)$ serves as a wild card character that matches any string of characters.

To enter any changes in the database, you must use the SAVE option.

B SAVE - After modifying the data in an existing form or entering data in a blank form, you can select SAVE to add the data to the database. After selecting SAVE, a blank form appears for a new operation.

C CLEAR discards data entered on the current form and provides another blank form.

X EXIT returns you to the PEOPLE LOCATION menu.

\section{Option C. Search for Missing Persons}

This option enables you to search the people location database to find information about a person. When you choose Search for Missing Persons, you see the following form for identifying the source of the query. This information is required before you can search for the person.

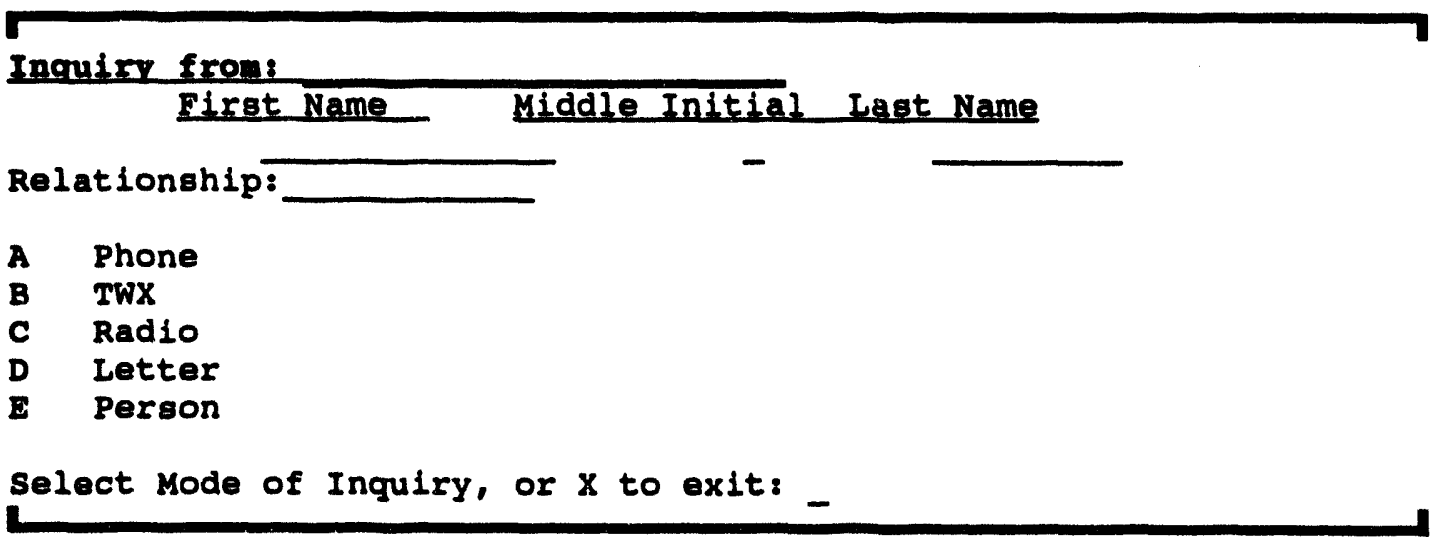

After identifying who made the query and how the query was made, you see another registration-type form similar to the form for Update Persons data. You can enter any or all information on this form. An example of this form follows. 
The system searches the database for matching records. Information from the selected record is then displayed in a form similar to that used for data entry.

Note: If the record has been marked confidential, no information is displayed. Press GOLD-Z to view the next matching record, if any.

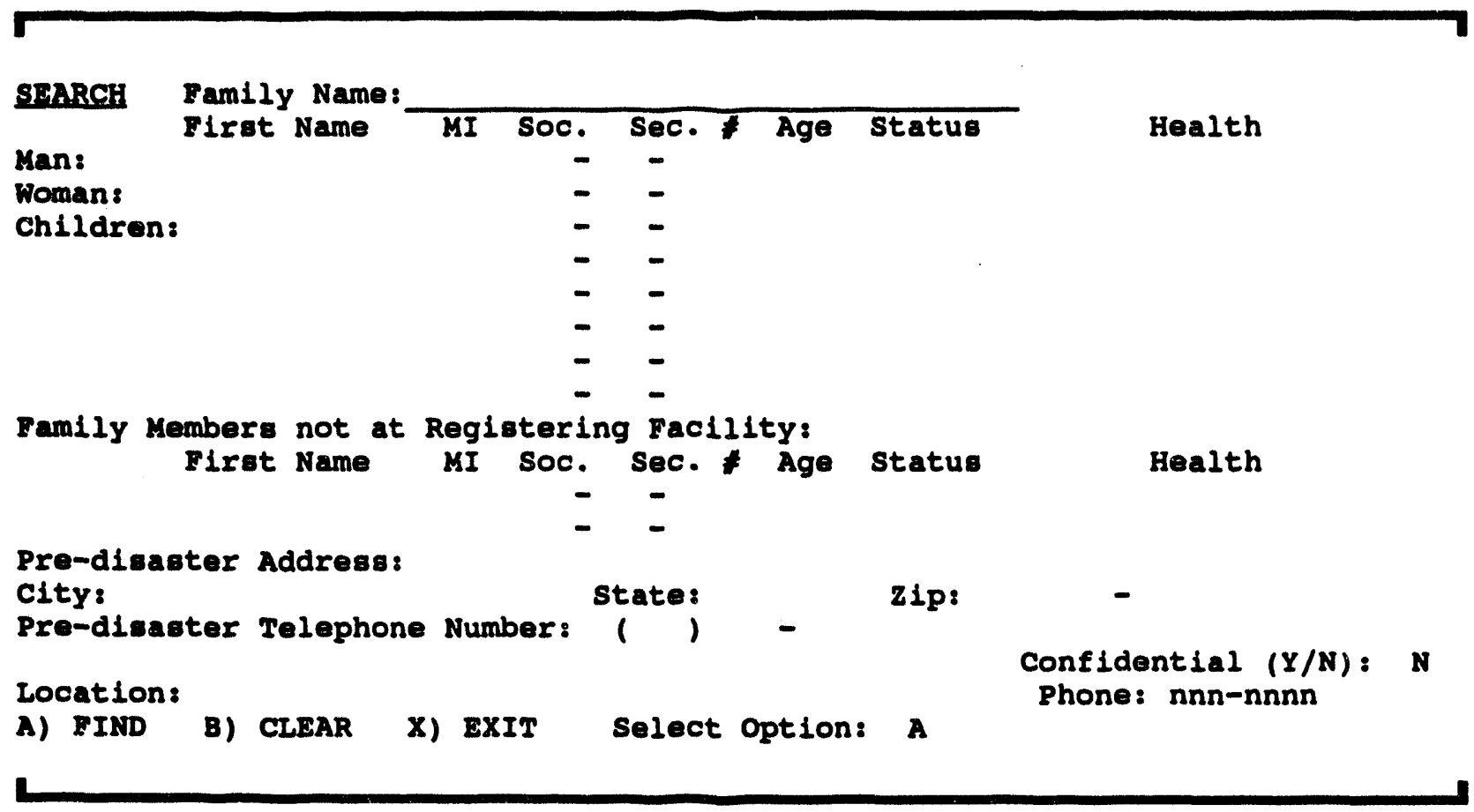

\section{Option D. Enter Default Values for the Enter Persons Form}

This option enables you to enter default values that automatically appear in the Enter Persons form when a blank form appears. Because the city address and telephone area code are likely to remain the same for entries made at any one facility, this feature saves time and makes these entries consistently accurate. (Or consistently inaccurate-check this information carefully when you enter it.)

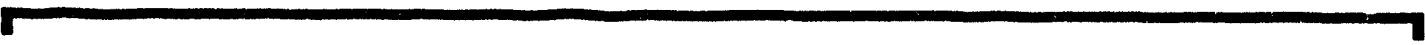

Default Information for the Dnter Persons Forr:

City: Pre-disaster Telephone area code: 1

State: _zip: $-$ 1

Use GOLD-Z to exit the form without filling in information. 


\section{Option E. Display Loading Data for Each Facility}

This option presents a scrolled tabular report of the capacities, status, and currently recorded loadings of emergency-related facilities in the IBS database. The report is similar to the following example:

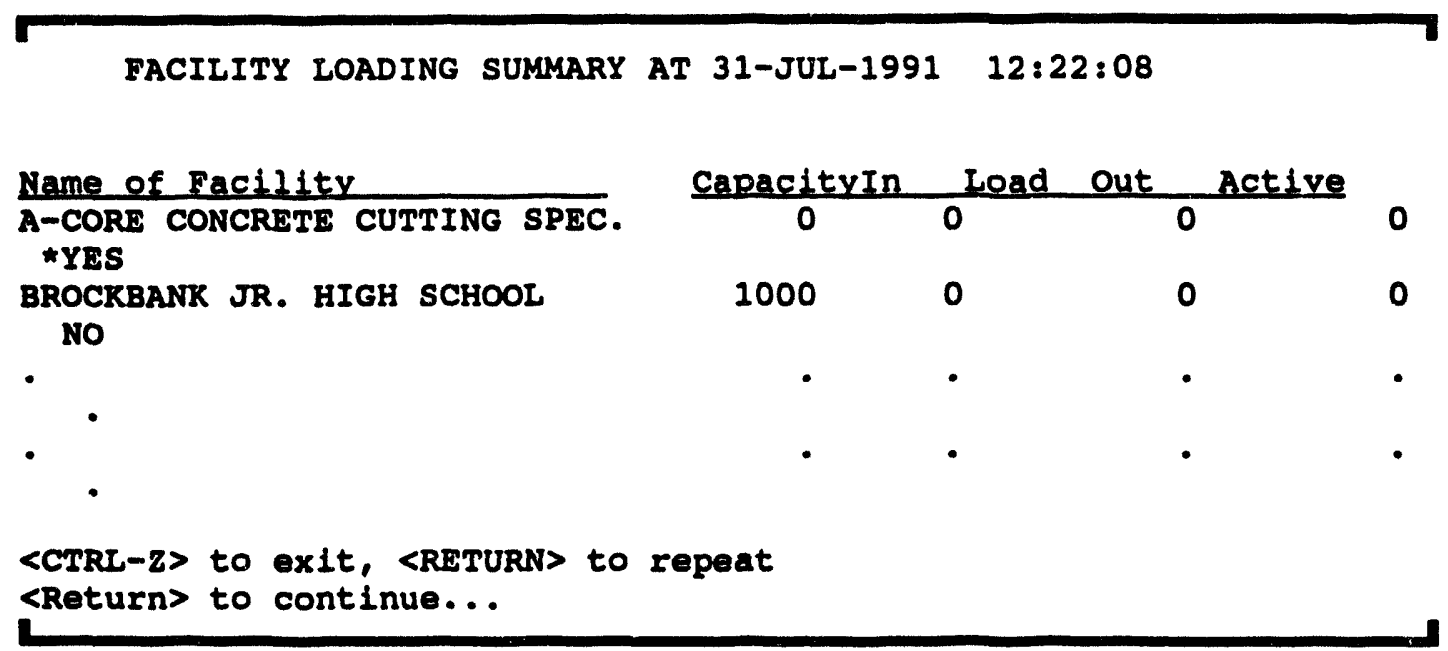

\section{Option F. Select a Different Facility (for Enter/Update)}

This option enables you to switch to a different default facility for entering or updating person records. You choose from the same scrolled list of facilities that displays when you first start the LOCATE program.

\section{Option G. Deactivate the Current Facility}

This option enables you to deactivate a facility.

The program displays the following prompt:

* * MSG: Facility has been deactivated: (facility name)

Press <Return> to continue ...

The same scrolled list of facilities that occurs when you first start the LOCATE program is displayed. After you choose another facility, the program displays the message

* * MSG: Activating Facility: (facility name)

and returns to the initial PEOPLE LOCATION menu. 


\section{Option X. Exit, with Optional Facility Deactivation}

This option enables you to exit the LOCATE program.

The program displays the following information and prompt:

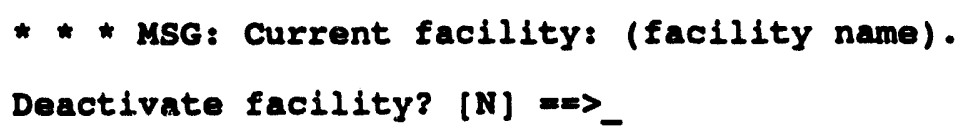

When you answer $Y$ (yes), the program displays the message

* *SG: Facility was deactivated: (facility name)

* * MSG: Good bye

and exits to the IBS Shell: Main Menu.

When you answer $N$ (no) the program displays the following message:

* * MSG: Good Bye

and exits to the IBS Shell: Main Menu.

\section{Using IBS Shell to Run People Location}

Enter IBSSH at the system prompt and press the Return key.

This starts the IBS Shell. The IBS Shell: Main Menu will display.

IBS She11: Main Menu

\begin{tabular}{|c|c|c|c|c|}
\hline $\begin{array}{l}0 \\
1 \\
2 \\
3 \\
4 \\
5 \\
6 \\
7 \\
8 \\
9\end{array}$ & $:$ & $\begin{array}{l}\text { XxIT } \\
\text { Setup } \\
\text { IBS Programs } \\
\text { system Administration Ut } \\
\text { Conversion Utilities } \\
\text { Miscellaneous Utilities } \\
\text { Models } \\
\text { Modele } \\
\text { GIs Utilities } \\
\text { GIs Utilities }\end{array}$ & $\begin{array}{l}\text { Ilities } \\
\text { (Graphic) } \\
\text { (Non-Graphic) } \\
\text { (Graphic) } \\
\text { (Non-Graphic) }\end{array}$ & $\begin{array}{l}--> \\
--> \\
--> \\
--> \\
-\rightarrow \\
-\rightarrow\end{array}$ \\
\hline
\end{tabular}


Select the Miscellaneous Utilities option and press the Return key. The IBS Shell: Miscellaneous Utilities menu will display.

IBS Shell: Miscellaneous Utilities

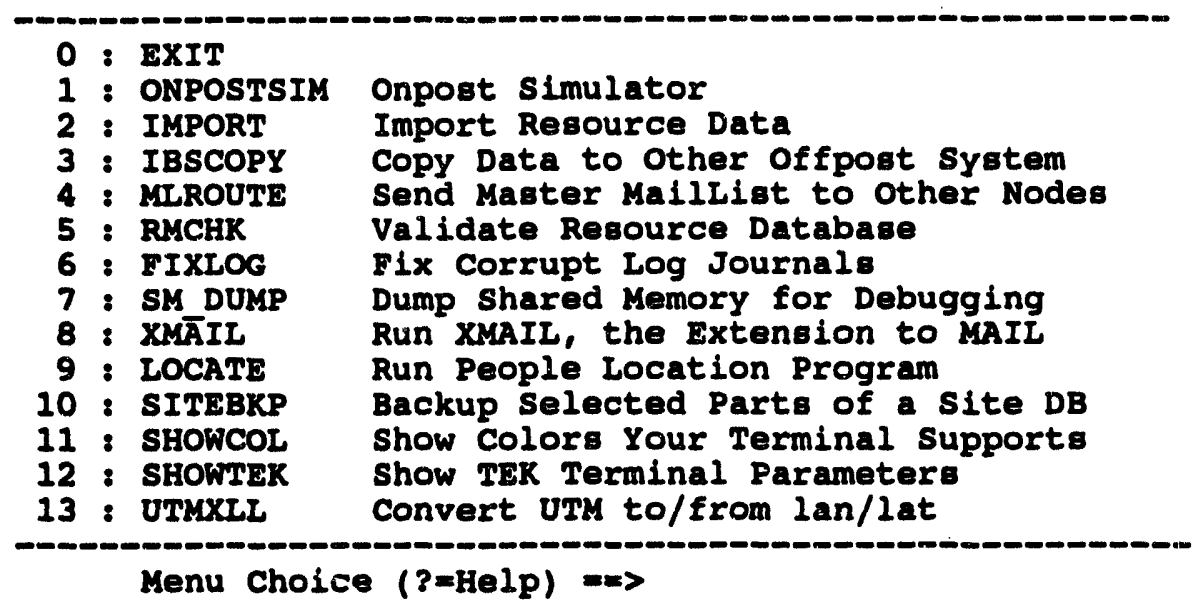

Select the LOCATE option and press the Return key. The LOCATE opening title screen will display in the same manner as described previously in this appendix. 


\section{Appendix D Onpost Simulator}

The Onpost Simulator program enables privileged IBS users to send messages that are usually sent by the Army's onpost computer system in communication with the IBS. The Onpost Simulator enables testing and exercising of IBS, independent of onpost participation. Also, if the IBS/onpost interface were inoperable, an IBS user could trigger a simulated onpost notification or other onpost-type reports.

The use of the Onpost Simulator program is restricted to authorized users, such as an IBS Information Manager.

\section{To Start the Onpost Simulator}

Enter ONPOSTSIM at the system prompt.

The Onpost Simulator copies onpost-type files to the appropriate IBS directory just as the onpost system does. You have the opportunity to modify the files before copying them. After you start the Onpost Simulator, the main menu displays as shown.

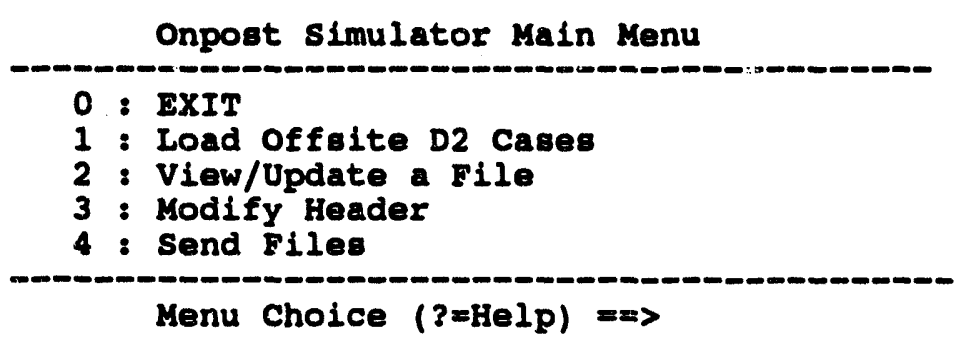

Onpost Simulator copies onpost-type files to the appropriate IBS directory just as the onpost system does. You have the opportunity to modify the files before copying them.

Option 1. The system displays the following menu.

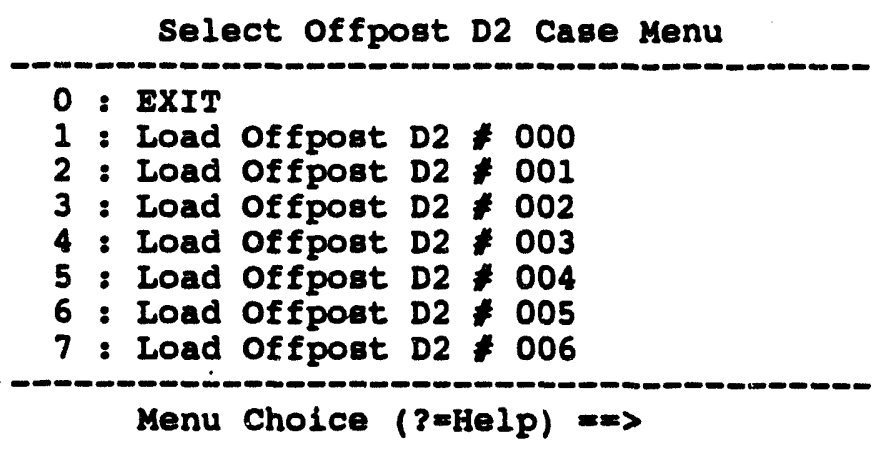


Select an offpost D2 case to be loaded. After selecting a case, press the Return key. The system will display the following message.

The offpost D2 case you specified has been copied to ONPOSTSIM. Changing the D2 files through ONPOSTSIM is not recommended. To view the files use the 'View/Update a File' option. To send the files, use the 'Send Files' option.

Press <RETURN> to continue...

Option 2. Use this option to view or update files. The system displays the following menu.

\begin{tabular}{|c|c|c|c|}
\hline $\begin{array}{r}0 \\
1 \\
2 \\
3 \\
4 \\
5 \\
6 \\
7 \\
8 \\
9 \\
10\end{array}$ & $\begin{array}{l}: \\
: \\
: \\
: \\
: \\
: \\
: \\
:\end{array}$ & $\begin{array}{l}\text { EXIT } \\
\text { View/Update } \\
\text { View/Update } \\
\text { View/Update } \\
\text { View/Update } \\
\text { View/Update } \\
\text { View/Update } \\
\text { View/Update } \\
\text { View/Update } \\
\text { View/Update } \\
\text { View/Update }\end{array}$ & $\begin{array}{l}\text { D2LOGXXXX.DAT } \\
\text { DOSAGXXXX.DAT } \\
\text { D2 INP } 2 \times x \times \text {.DAT } \\
\text { SLICEXXXX.DAT } \\
\text { WEATHER.DAT } \\
\text { WORKPLAN.DAT } \\
\text { ENVIRON.DAT } \\
\text { NOTIFY.DAT } \\
\text { CAS SUM.DAT } \\
\text { TOWERSEL.DAT }\end{array}$ \\
\hline
\end{tabular}

Select the file you want to view or update. These files are described in general in Section 2 under the heading VIEW ONPOST->IBS REPORTS and in detail Appendix $E$.

Option 3. The system displays the following messages:

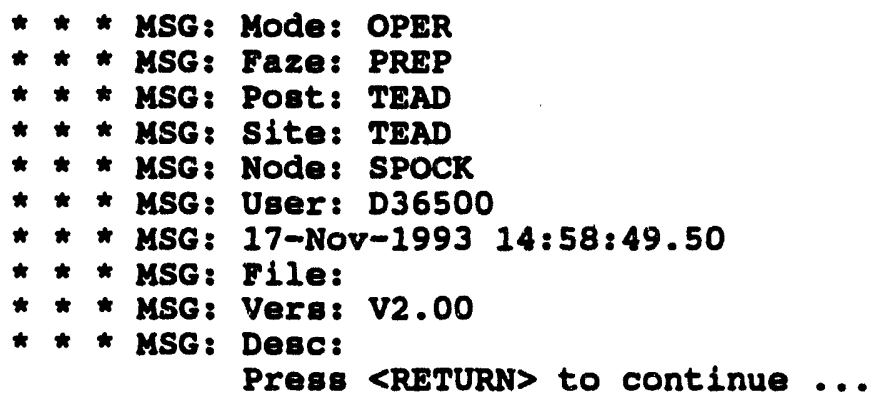

These messages are the current system headers. After viewing the messages, press the RETURN key to display the following menu.

Heàder Mode Options

\begin{tabular}{l} 
Hedier Mode Options \\
\hline $0:$ EXIT \\
$1:$ EXER \\
$2:$ OPER \\
\hline Menu Cholce $(?=\mathrm{Help})=>$
\end{tabular}


Select the number of the header mode you want to use. After you select the header mode, the system displays the following menu.

Header Phase Options
0 : EXIT
1 : PRIP
2 : EVNT
Menu Choice $(3=\mathrm{Help}=\mathrm{P}$

Select the number of the header phase you want to use. After you select the header phase, the system displays the following menu.

\begin{aligned} & Header Post Options \\ & \hdashline 0$:$ EXIT \\ & 1 ANAD \\ & 2$:$ APG \\ & 3$:$ LBAD \\ & 4$:$ NANP \\ & 5$:$ PBA \\ & 6$:$ PUDA \\ & 7$:$ TEAD \\ & 8$:$ UMDA \\ & \hline Menu Choice $($ (?=Help) $=>\end{aligned}$

Select the number of the header post you want to use. After you select the header post, the system displays the following prompt.

Enter description $=>$

Type in a description of the files you will be sending. Press the Return key after entering a description. The system will then display the updated list of headers. Your responses to these menus are used by the system to construct the header record. The header record is the first record of each file sent by the Onpost Simulator.

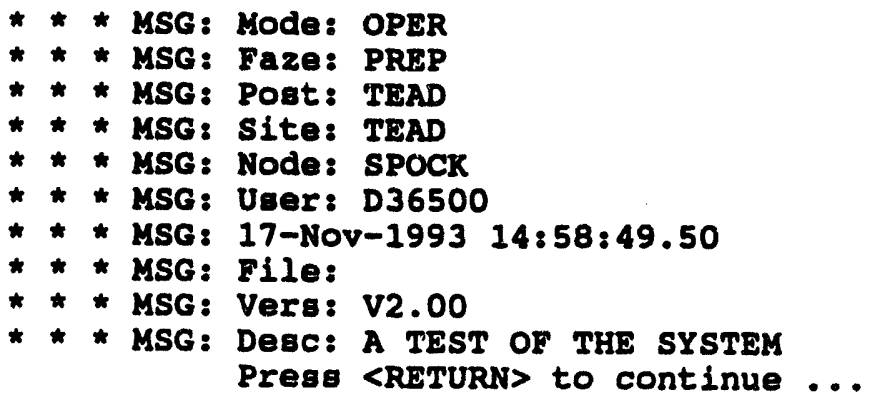


Option 4. The system displays the following menu.

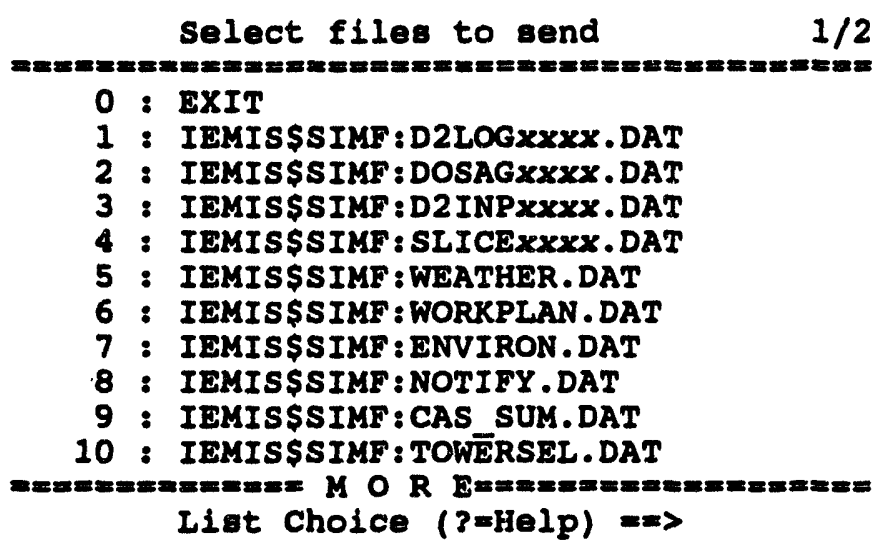

Select the number of the file you want to send. Selected files (those previously selected or reviewed/updated) will be marked with an arrow $=>$. You can select as many files as you want. After you have selected the file or files, select the 0 : EXIT option.

After you select files and exit, the system will display the report (XFERLIST.DAT) for the files to be transferred.

\begin{tabular}{|c|c|c|c|c|}
\hline XEE & ORLIST Form & $10 / 06 / 93$ & $10: 30: 00$ & 2.00 \\
\hline Type & Report Type & & File & \\
\hline$T$ & $\begin{array}{l}\text { WEATHER } \\
\text { TOWER SELECTION }\end{array}$ & $\begin{array}{l}\text { WEATI } \\
\text { TOWEI }\end{array}$ & & \\
\hline
\end{tabular}

Use the techniques described in Section 1, under the heading Conventions for Interacting with the IBS, to move around in this report.

Exit the report and send the listed files by pressing GOLD-Z. To exit the report without sending the files, press GOLD-Y. The Onpost Simulator Main Menu will display.

\section{Using IBS Shell to Run the Onpost Simulator}

You can use the IBS Shell menu system to start and run the Onpost Simulator.

Note: Running the onpost simulator through the IBS Shell will cause your system to run slower.

Enter IBSSH at the system prompt. 
Appendlx D: Onpost Simulator

This starts the IBS Shell. The IBS Shell: Main Menu will display.

IBS Shell: Main Menu

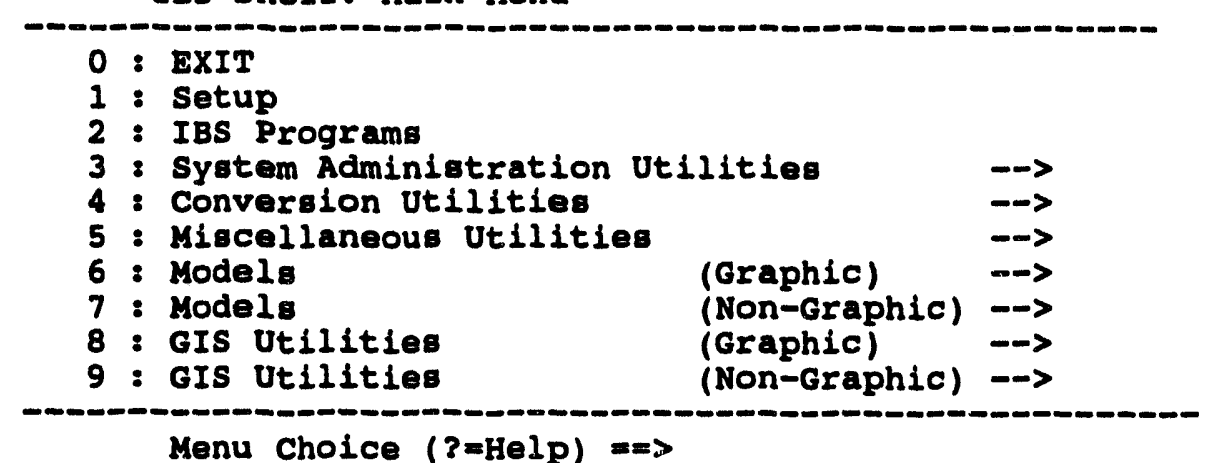

Select option 5 : Miscellaneous Utilities from the main menu and press the Return key. The Miscellaneous Utilities menu will display.

IBS Shell: Miscellaneous Utilities

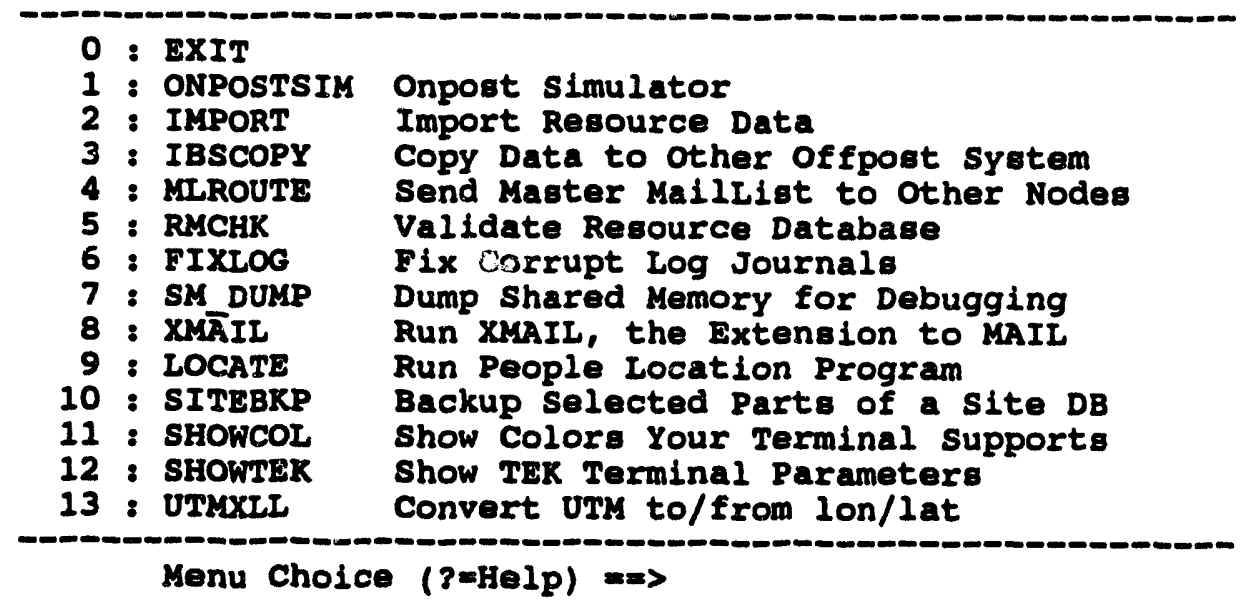

Select option 1 : ONPOSTSIM from the menu and press the Return key. The Onpost Simulator Main Menu will display as described previously in this appendix. 
Appendix E

IBS and Onpost

EOC Reports

○

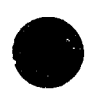




\section{Appendix $E$ \\ IBS and Onpost EOC Reports}

This appendix shows the formats of the reports exchanged between IBS and the onpost emergency operations center (EOC). These reports are accessible through options on the MESSAGE BOARD menu:

IBS MAIN MENU

MESSAGE BOARD

VAX PHONE

VAX MAIL

CREATE/EDIT MAIL UST

SEND MAIL

CHECK SENT MAIL

\begin{tabular}{ll|l} 
VIEW IBS->ONPOST RPT & $<-$ View reports sent from the IBS.
\end{tabular}

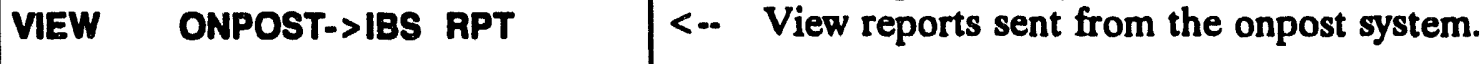

CREATE IBS->ONPOST RPT $\rightarrow<->$ Create IBS reports for the onpost system.

RESEND IBS->ONPOST RPT $\quad \rightarrow<-$ Resend an IBS report to the onpost system.

ANNOTATE LOG

CREATE COMMON LOG REPORT

CREATE PRIVATE LOG REPORT

VIEW COMMON LOG REPORT

VIEW PRIVATE LOG REPORT 


\section{Reports from the IBS}

The Create IBS $->$ Onpost Rpt and the Vlow IBS $->$ Onpost Rpt options display a menu similar to the following for creating reports (messages) transmitted from IBS to the onpost computer system. The entire menu will not display as shown, since IBS can show only 10 items at a time in a menu. To see the rest of the report types, type a $D$ (Down) at the $==>$ prompt and press the Return key.

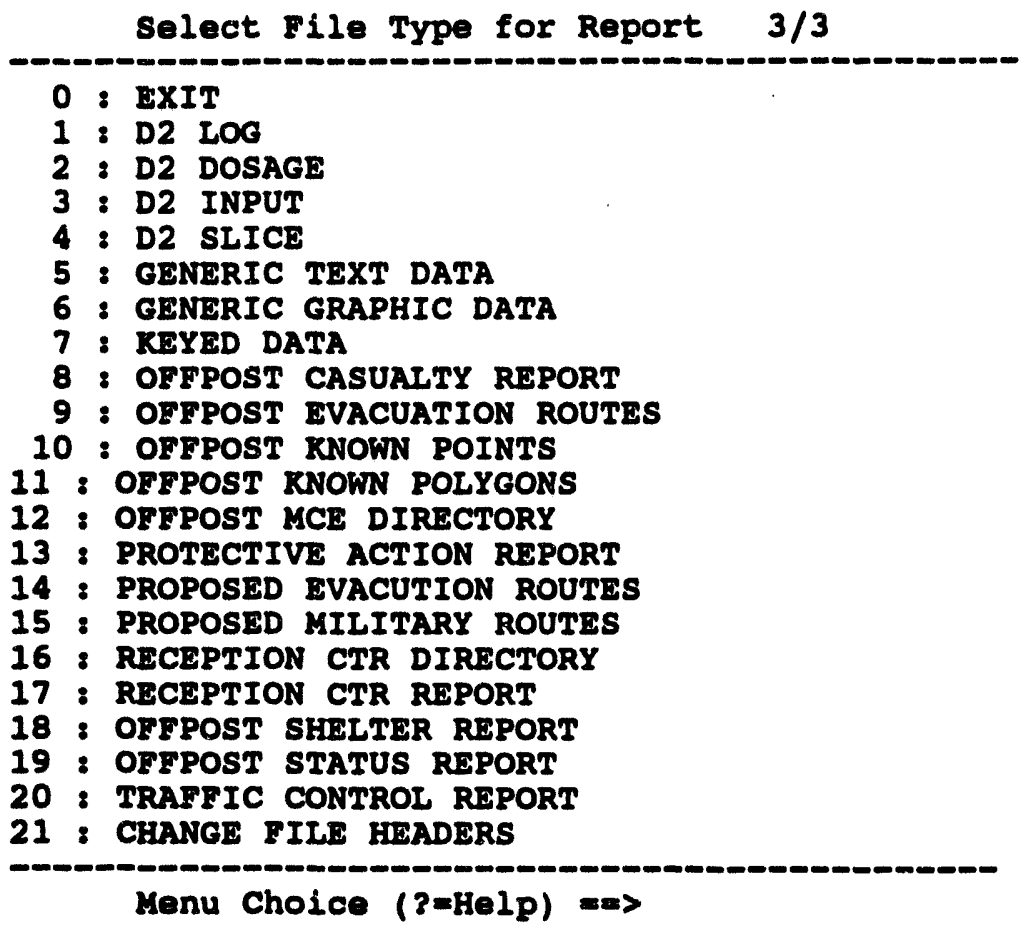

The IBS report formats are shown on the following pages in alphabetical order by menu item name. Much of the information presented in these reports is automatically calculated from data in your current site database.

For complete information on using and exiting reports, see Create IBS $\rightarrow$ Onpost Rpt in Section 2, Message Board. 


\section{CHANGE FILE HEADERS}

This option enables you to set and change the header on reports sent from IBS to the onpost system. See Section 2, Message Board, under the heading Create IBS -> Onpost Rpt for complete information on using this option. 


\section{D2 DOSAGE}

\begin{tabular}{|c|c|c|c|}
\hline Dosage Form (Page 1/2) & $8: 44: 53$ & & v2.00 \\
\hline 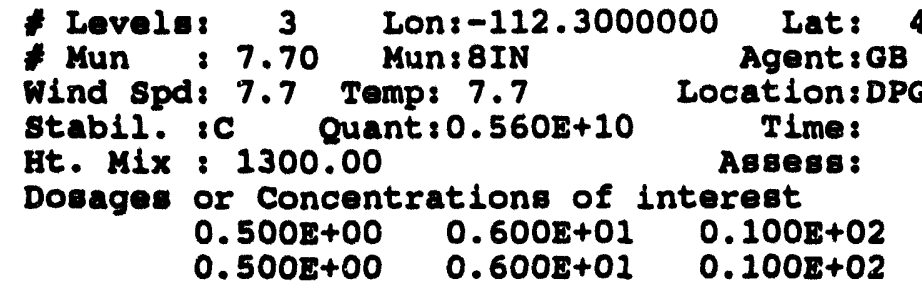 & $\begin{array}{l}40.3000000 \\
0.00 \quad \text { Rele } \\
0 \\
0.000 E+00 \\
0.000 E+00\end{array}$ & $\begin{array}{l}\text { Wind Dir: } \\
\text { ase Type: INS } \\
\text { Season: SPR } \\
\text { Source: } \\
0.000 E+00 \\
0.000 E+00\end{array}$ & $\begin{array}{l}77 \\
S_{R} \\
0.0\end{array}$ \\
\hline $\begin{array}{l}\text { Doeage or Concentration level descriptions } \\
\text { D1 } \\
\text { D2 } \\
\text { D3 }\end{array}$ & & & \\
\hline
\end{tabular}

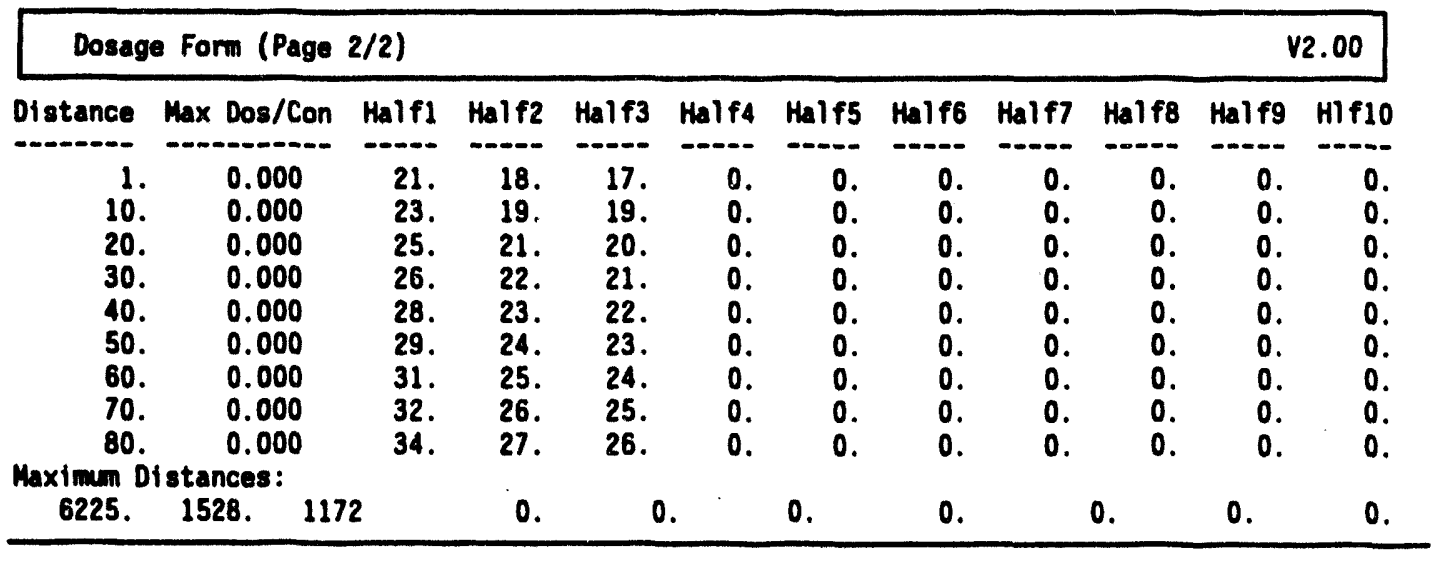

Note: The content of this report can vary if the selected D2 output was concentration rather than dosage.

You can scroll the information in this report. 


\section{D2 INPUT}

D2 STANDARD INPUT

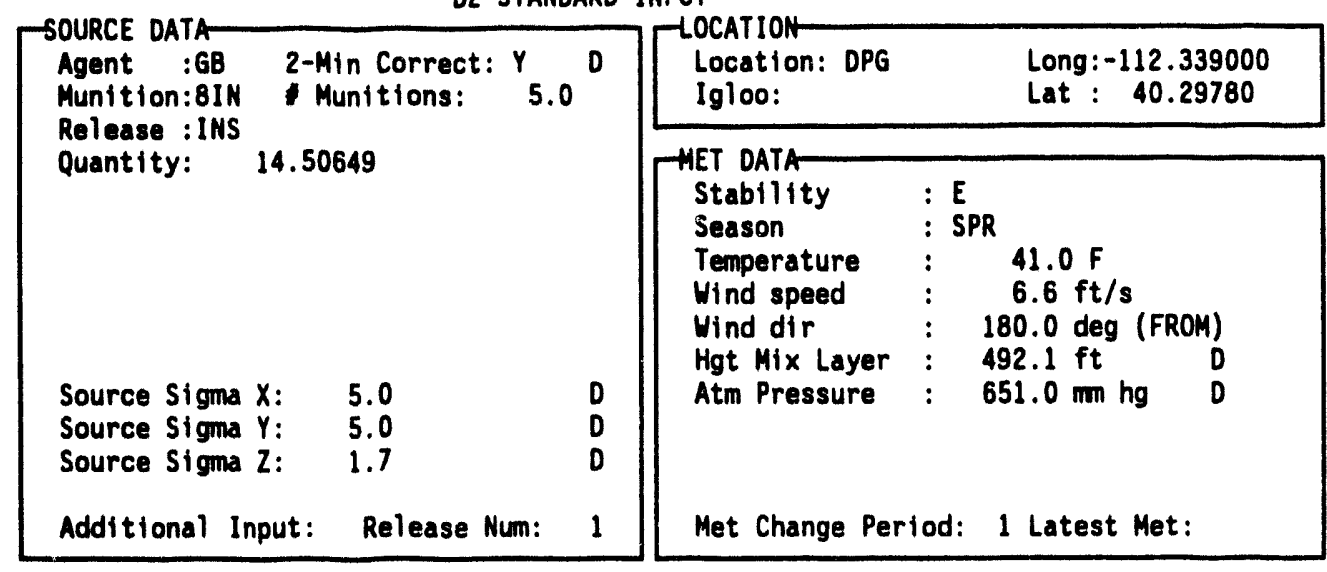




\section{D2 LOG}

The following form is an example of what you may see when you display the D2 Log. This example represents only a portion of the D2 information since the display is limited to 15 lines at a time. You can scroll the form to see all the information.

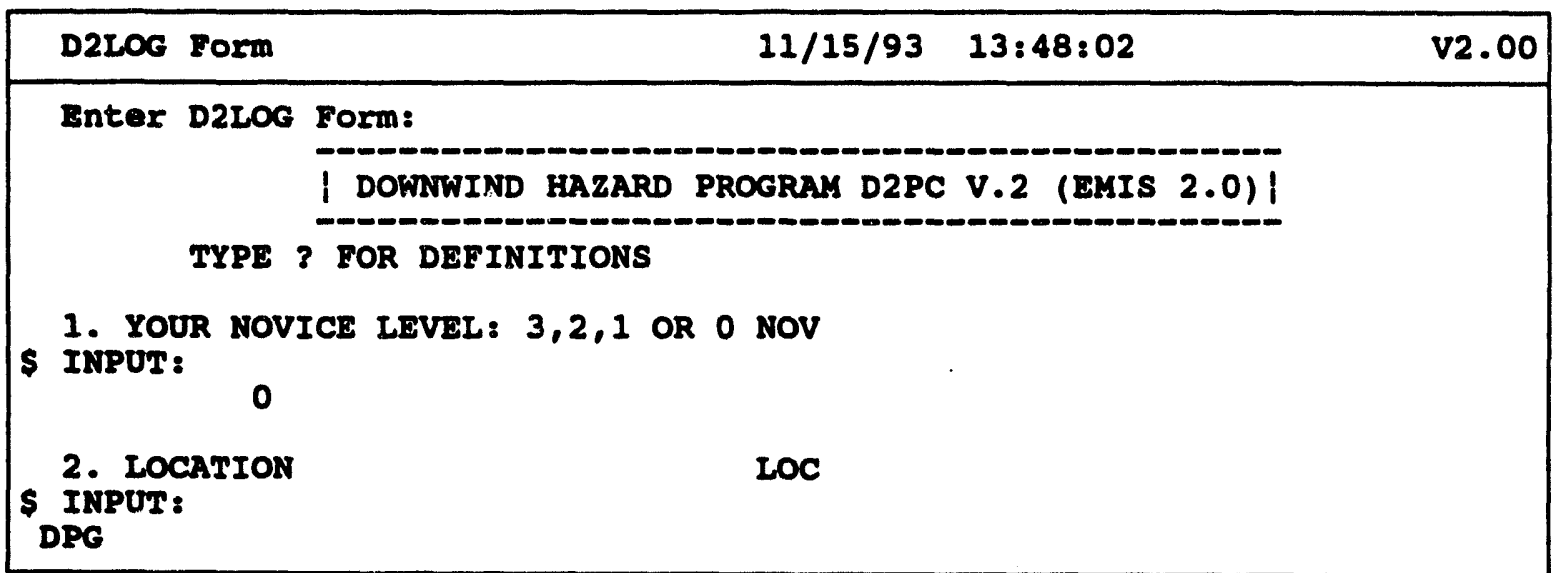

This form is presented as unformatted information. The form can be quite long. 


\section{D2 SLICE}

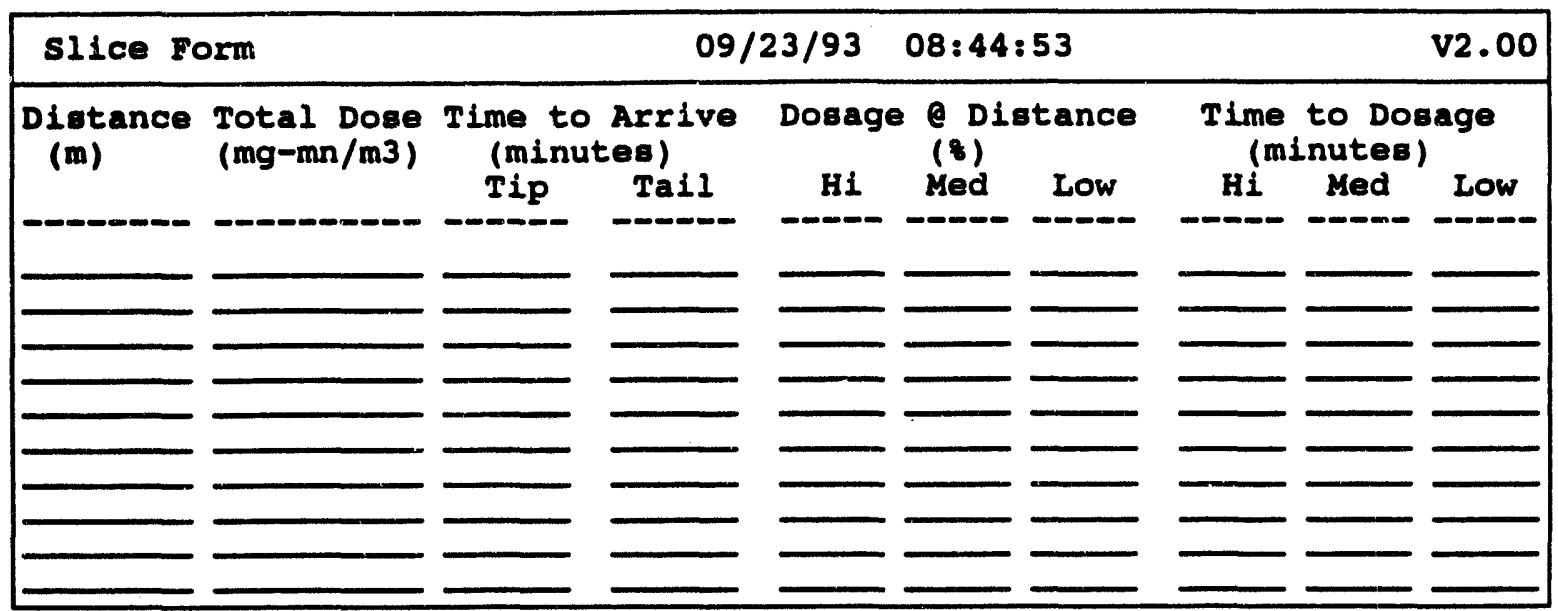




\section{GENERIC GRAPHIC DATA}

$\begin{array}{ll}\text { Generic Graphic form } & \text { v2.00 } \\ \text { Filenames for generic graphic data: } & \\ & \\ & \\ \end{array}$




\section{GENERIC TEXT DATA}

After you select Generic Text Data, the system will display the following prompt. Do you want to read info from file? $(Y / N)=\Longrightarrow$

If you type a $Y$ (Yes), the system will prompt you to enter the name of the existing data file you want to display.

If you type a $N$ (No), the system will display the following form.

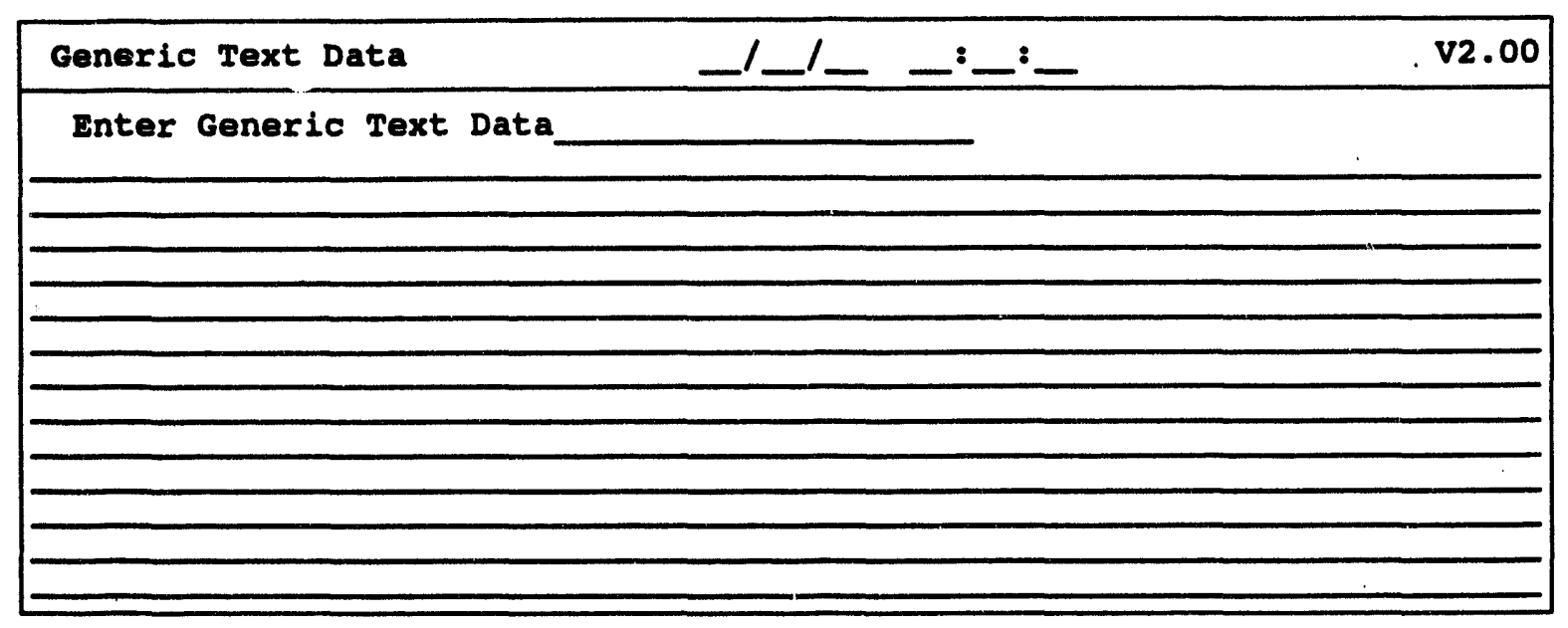

You can scroll this report. 


\section{KEYED DATA}

After you select Keyed Data, the system will display the following prompt.

Do you want to read info from file? $(Y / N) \Rightarrow$

If you type a $Y$ (Yes), the system will prompt you to enter the name of the existing data file you want to display.

If you type a $N$ (No), the system will display the following form.

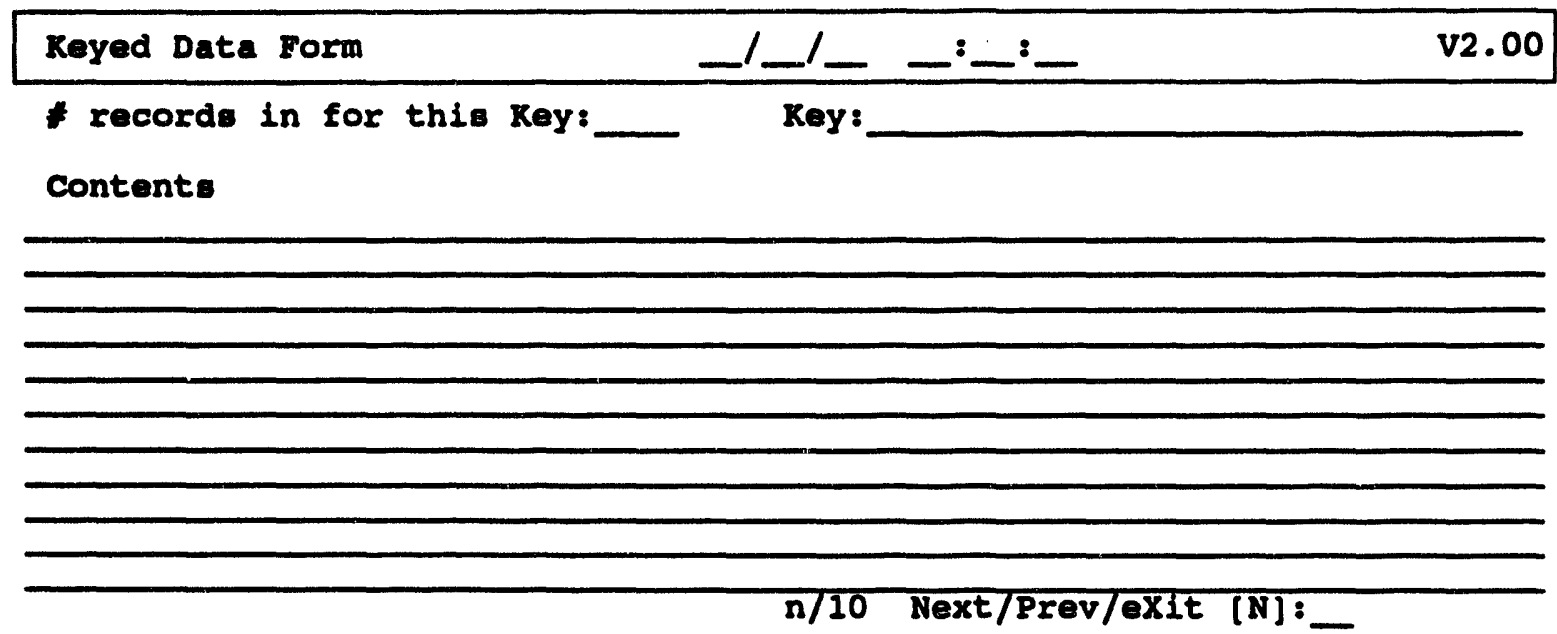

You can scroll this report. 


\section{OFFPOST CASUALTY REPORT}

Casualty Report Form $\quad$ _

Fatalities Hospital Admissions outpatient care Total casualties

:-

Chem. Agent Exposure: Fracture Anxiety reaction Total Civilian cas.

Description:

This option automatically displays casualty information that is available in the current database. 


\section{OFFPOST EVACUATION ROUTES}

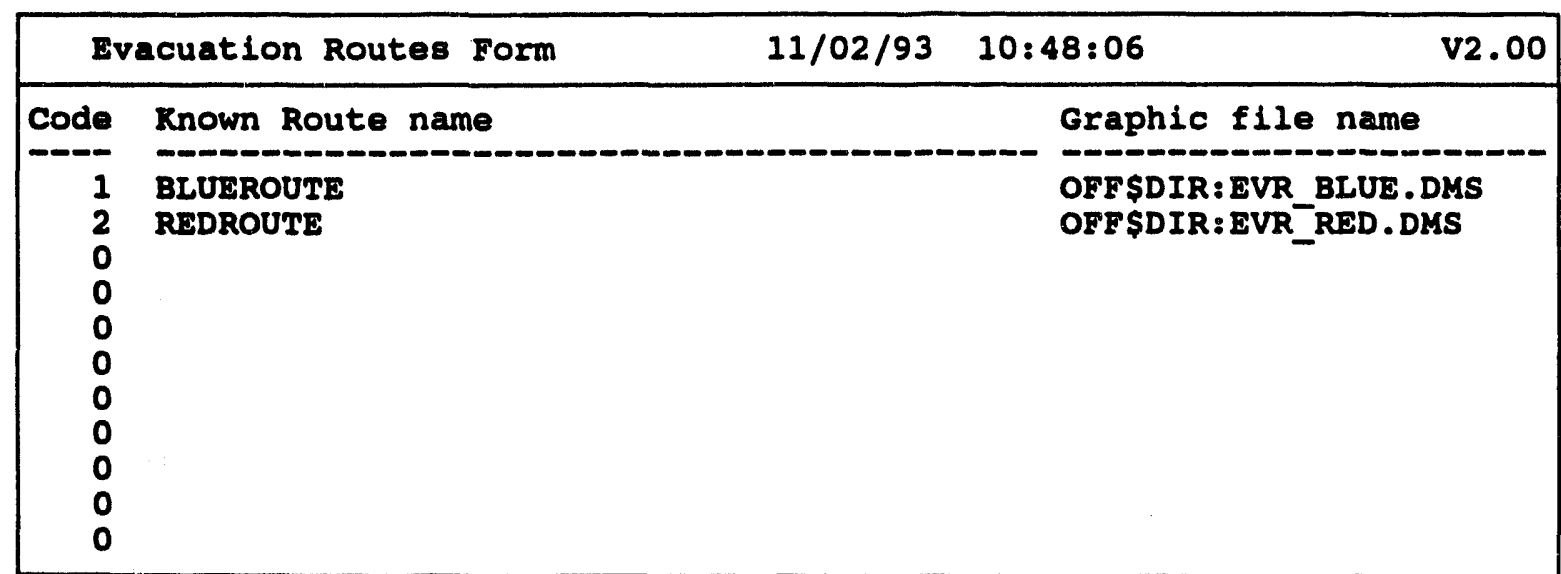

The date and time fields are filled with the system time. 


\section{OFFPOST KNOWN POINTS}

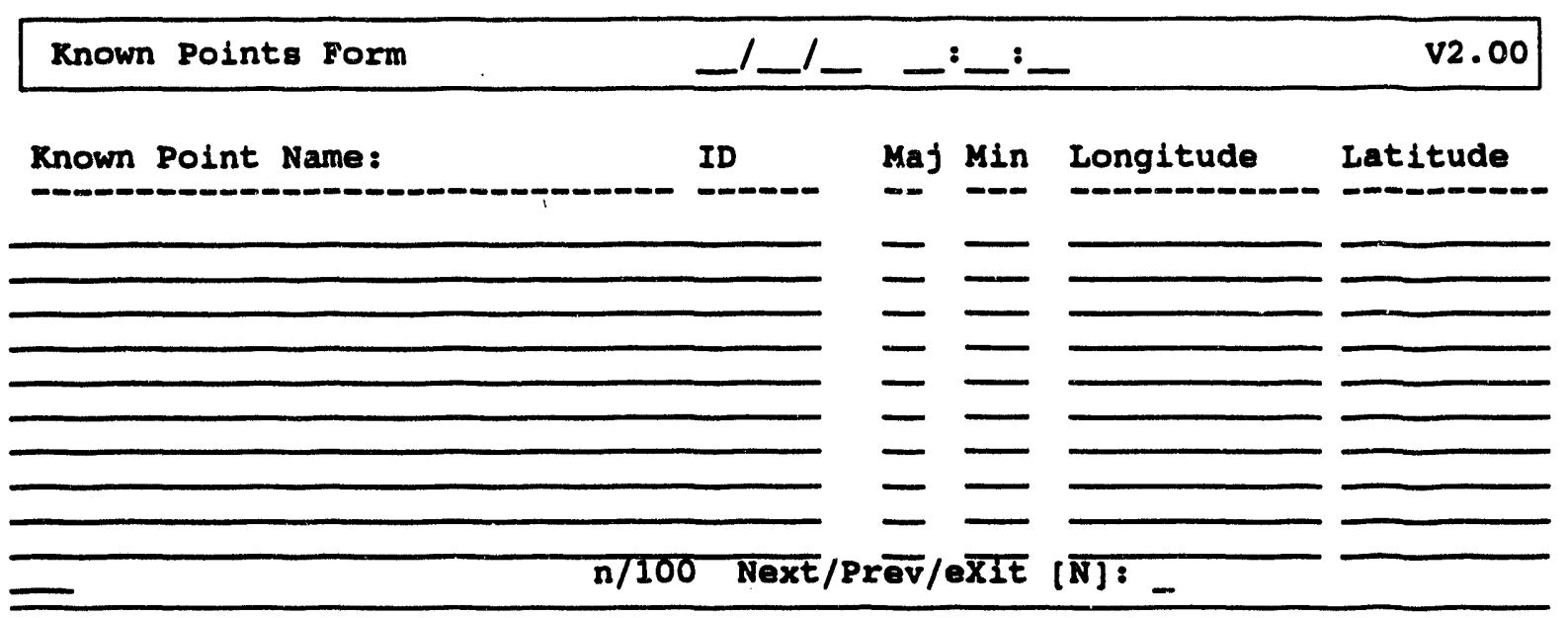




\section{OFFPOST KNOWN POLYGONS}

This option automatically displays information about the polygonal boundaries that have been created to represent specific areas. The following form lists this information in alphabetical ascending order by area code.

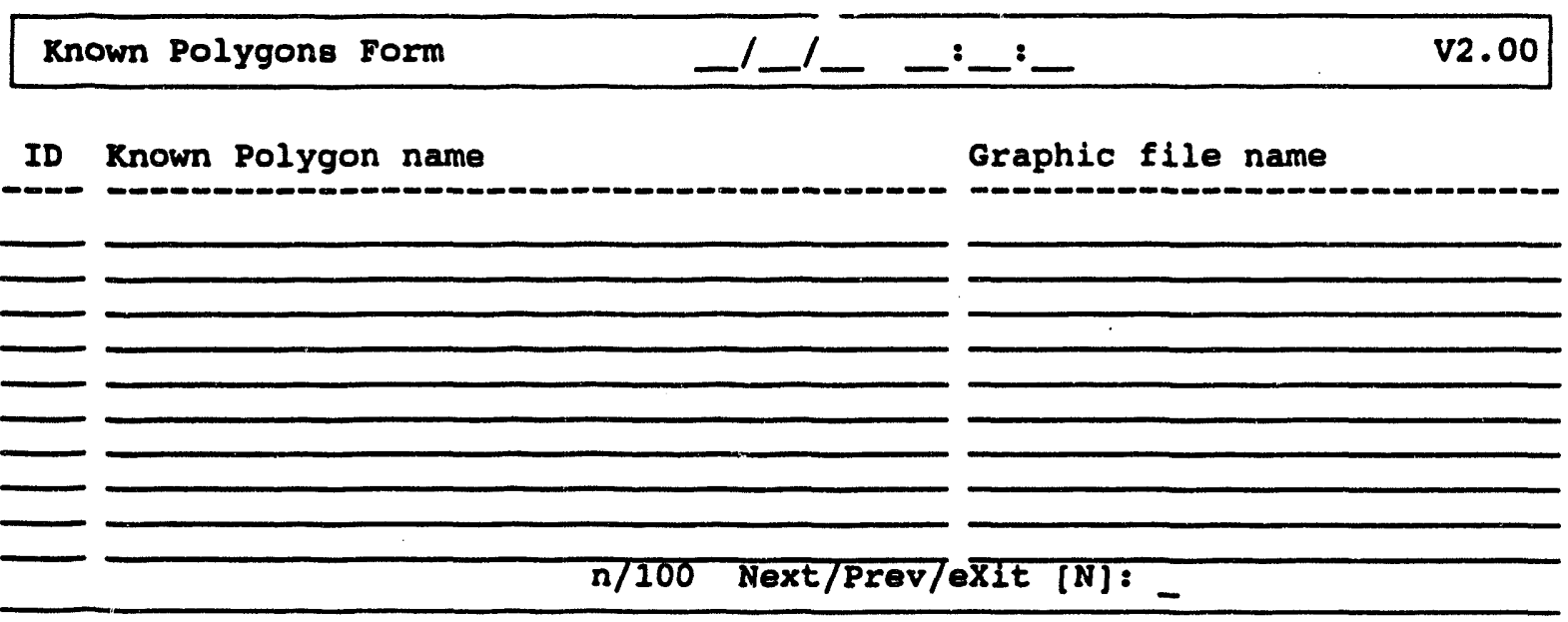

The date and time fields are filled with the current system time.

Approve and send the information (as shown under the heading, Exiting After Creating an IBS Report) or cancel it GOLD Y. 


\section{OFFPOST MCE DIRECTORY}

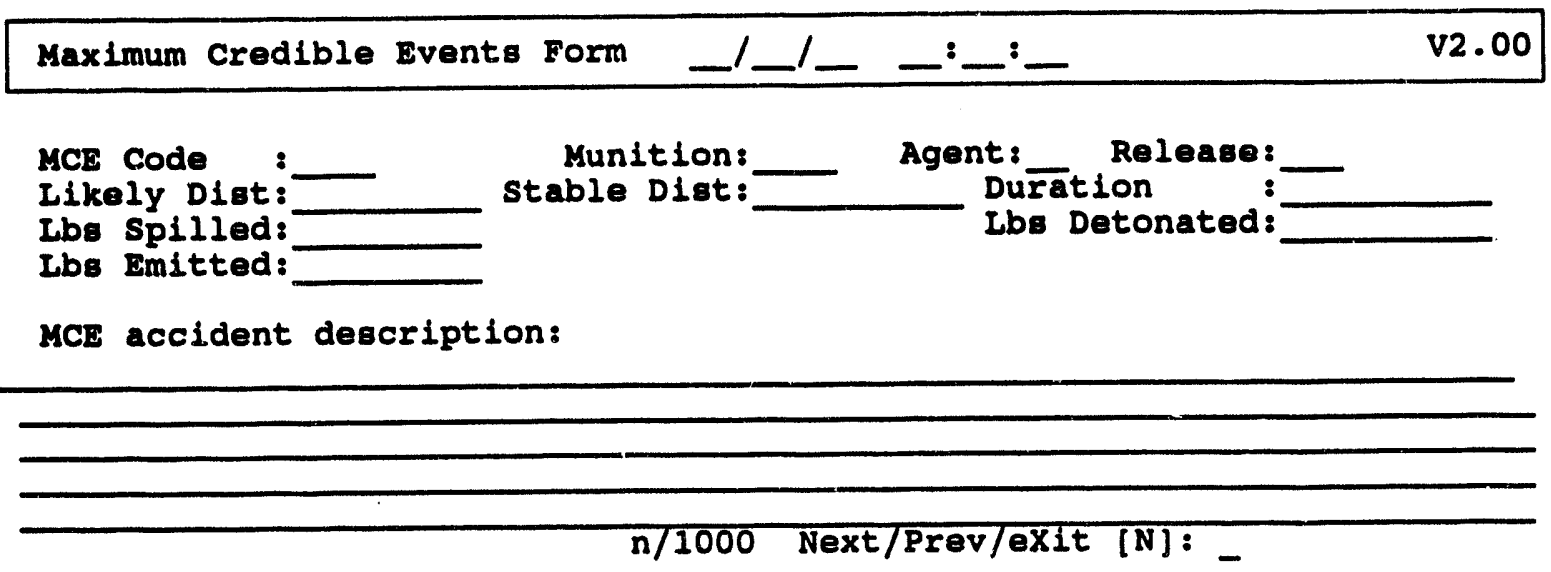

The date and time fields are filled with the current system time.

Approve and send the information (as shown under the heading, Exiting After Creating an IBS Report) or cancel it GOLD Y. 


\section{OFFPOST SHELTER REPORT}

This option enables you to enter the name of a graphic file to show shelter areas and emergency shelter information in the following form.

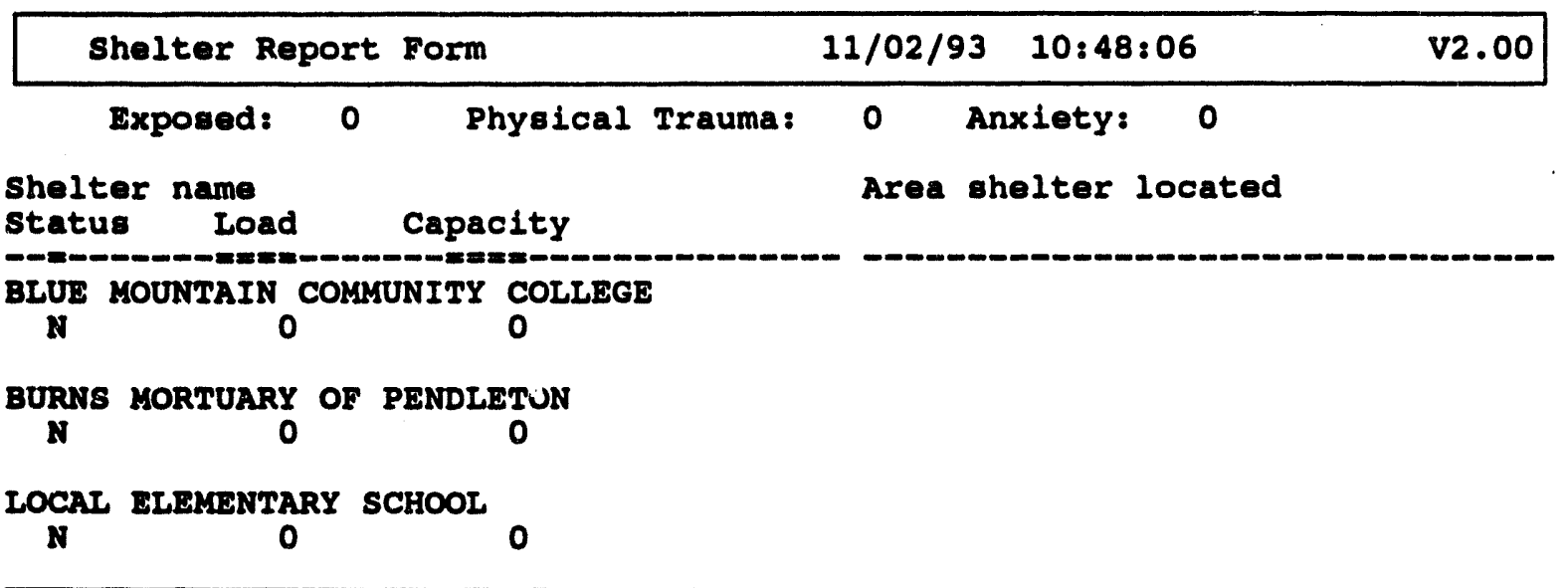

The date and time fields are filled with the current system time.

Approve and send the information (as shown under the heading, Exiting After Creating an IBS Report) or cancel it GOLD Y. 


\section{OFFPOST STATUS REPORT}

When you select this report, the system will first display the Select Person Who Chose MCE menu.

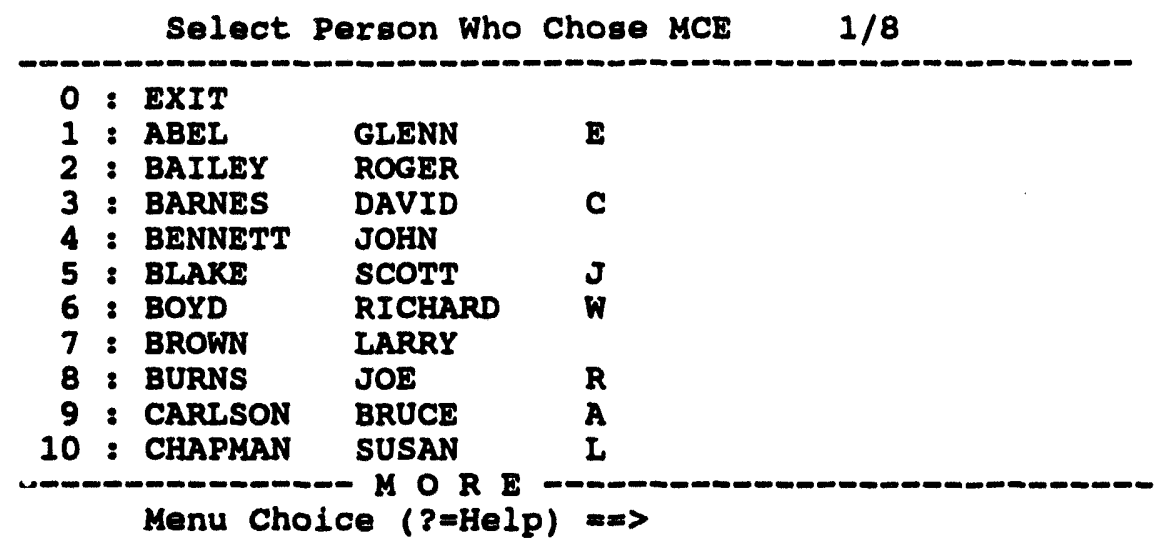

After you select a person, the system will display the Select Hospital menu.

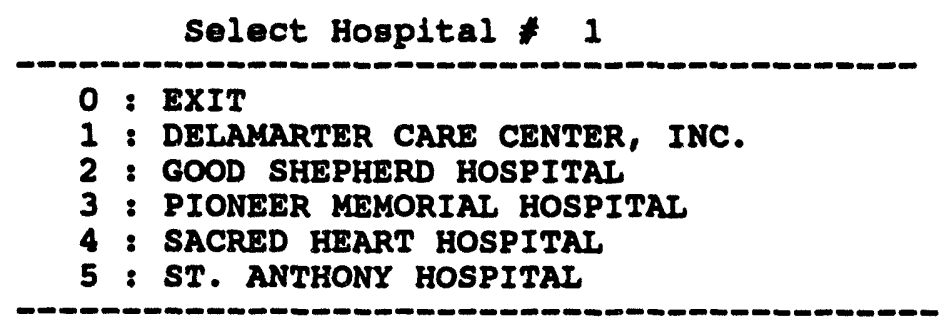

Menu Choice $(?=$ Help $)==>$

After you select the first hospital, the system will display a series of similar menus. Using these menus select Hospital 2, Hospital 3, and so on until you have ranked all the hospitals. The system will then display the Status Report form.

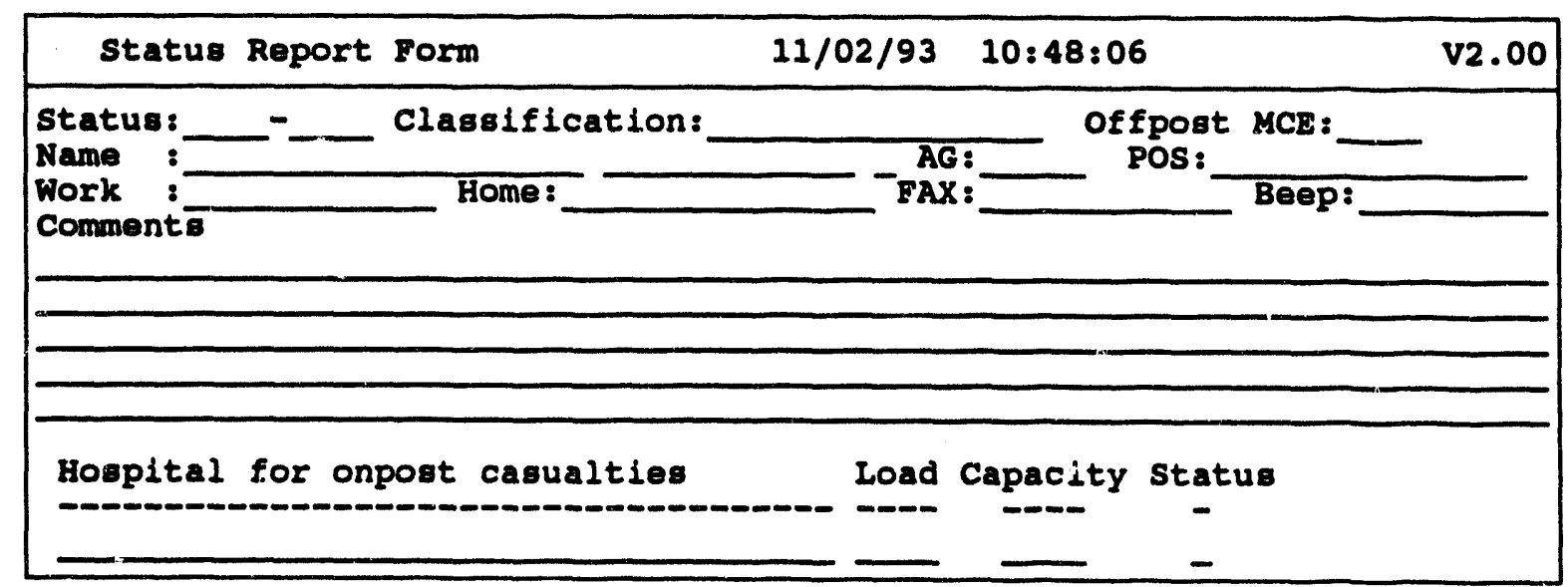


You can scroll this report.

The date and time fields are filled using the current system time. The name field is filled with the name and phone number of the person you selected from the Person Who Chose MCE menu. The hospitals you selected are listed in order.

Approve and send the information (as shown under the heading, Exiting After Creating an IBS Report) or cancel it GOLD Y. 


\section{PROTECTIVE ACTION REPORT}

When you select this report, the system will first display the Select Person Who Gave the Order menu.

\begin{tabular}{|c|c|c|c|c|}
\hline & Select & erson who & Chose $\mathrm{MCE}$ & $1 / 8$ \\
\hline 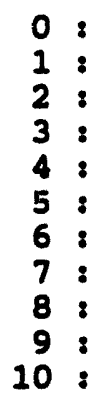 & $\begin{array}{l}\text { EXIT } \\
\text { ABEI } \\
\text { BAILEY } \\
\text { BARNES } \\
\text { BENNETT } \\
\text { BLARE } \\
\text { BOYD } \\
\text { BROWN } \\
\text { BURNS } \\
\text { CARLSON } \\
\text { CHAPMLAN }\end{array}$ & $\begin{array}{l}\text { GLENN } \\
\text { ROGER } \\
\text { DAVID } \\
\text { JOHN } \\
\text { SCOTT } \\
\text { RICHARD } \\
\text { LARRY } \\
\text { JOE } \\
\text { BRUCE } \\
\text { SUSAN }\end{array}$ & $\begin{array}{l}\mathbf{E} \\
\mathbf{C} \\
\mathrm{J} \\
\mathbf{W} \\
\mathrm{R} \\
\mathrm{A} \\
\mathrm{L}\end{array}$ & \\
\hline
\end{tabular}

After you select a person, the system will display the Select Fvacuation Route menu.

Select Evacuation Route

\begin{aligned} & 0$:$ EXIT \\ & 1$:$ BLUE \\ & 2$:$ RED \\ & 3$:$ ALTERNATE1 \\ & $4:$ ALTERNATE2 \\ & $5:$ AlO \\ & \hdashline Menu Choice $(?=H e l p)=>\end{aligned}$

After you select an evacuation route, the system will display the Select Zones to be Sheltered list.

Select Zones to be Sheltered

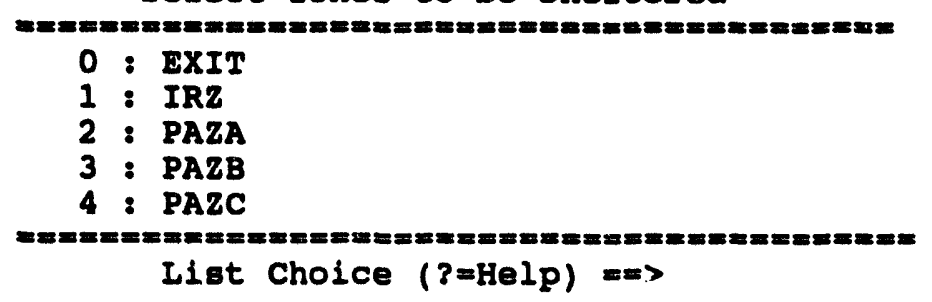


After you select a zone or zones to be sheltered, the system will display the Select Zones to be Evacuated list.

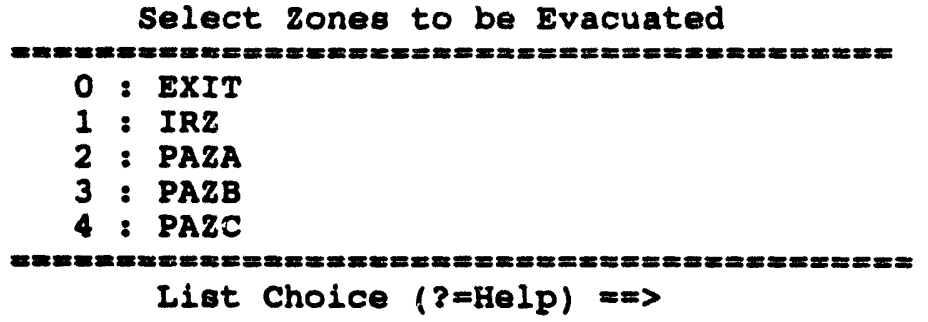

After you select a zone or zones to be evacuated, the system will display the Select Reception Centers to Use list.

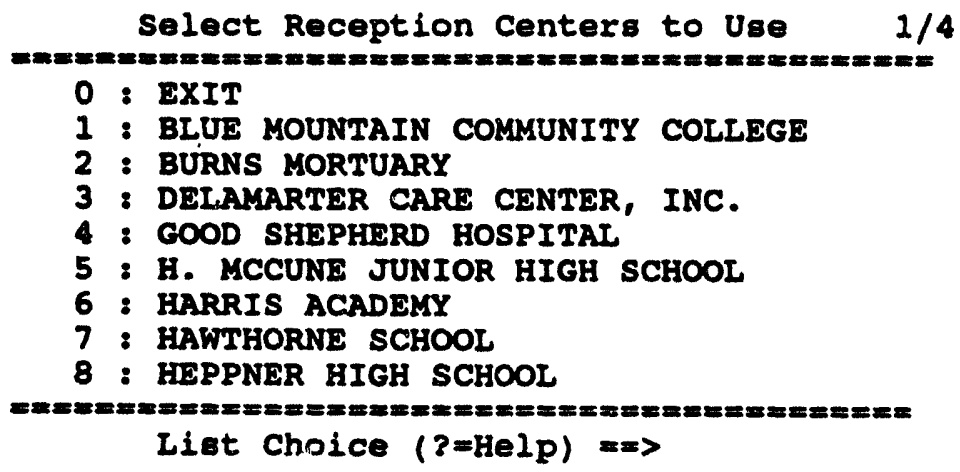

After you select the reception centers you want to use, the system displays the Protective Action Form filled with the information you selected earlier. This is a two page form, to see page two, press Gold Z.

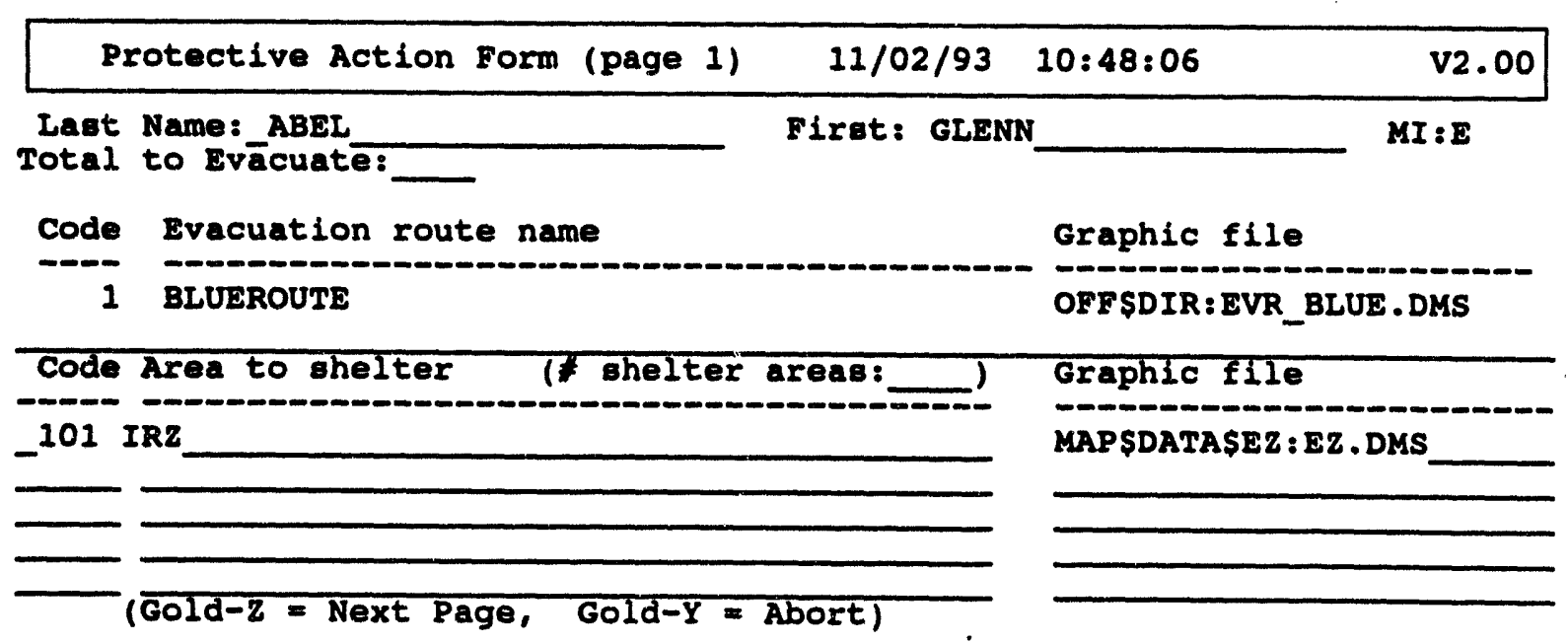




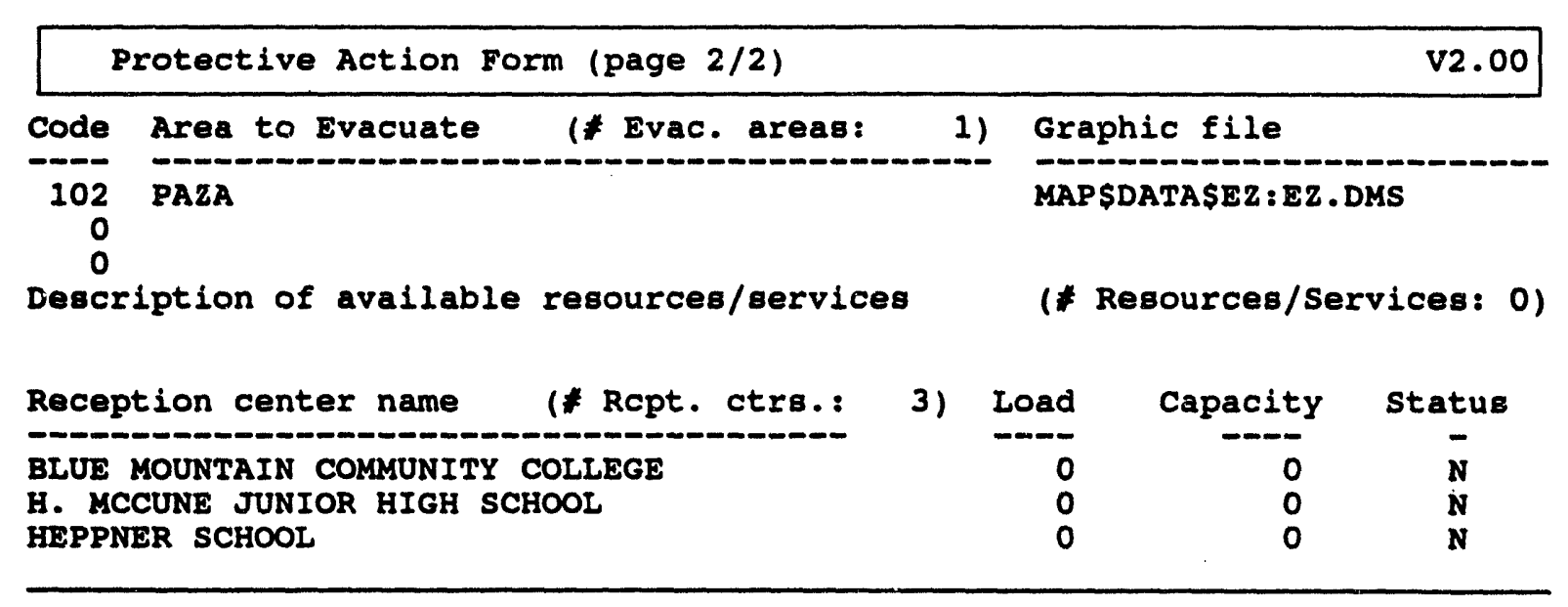




\section{PROPOSED EVACUATION ROUTES}

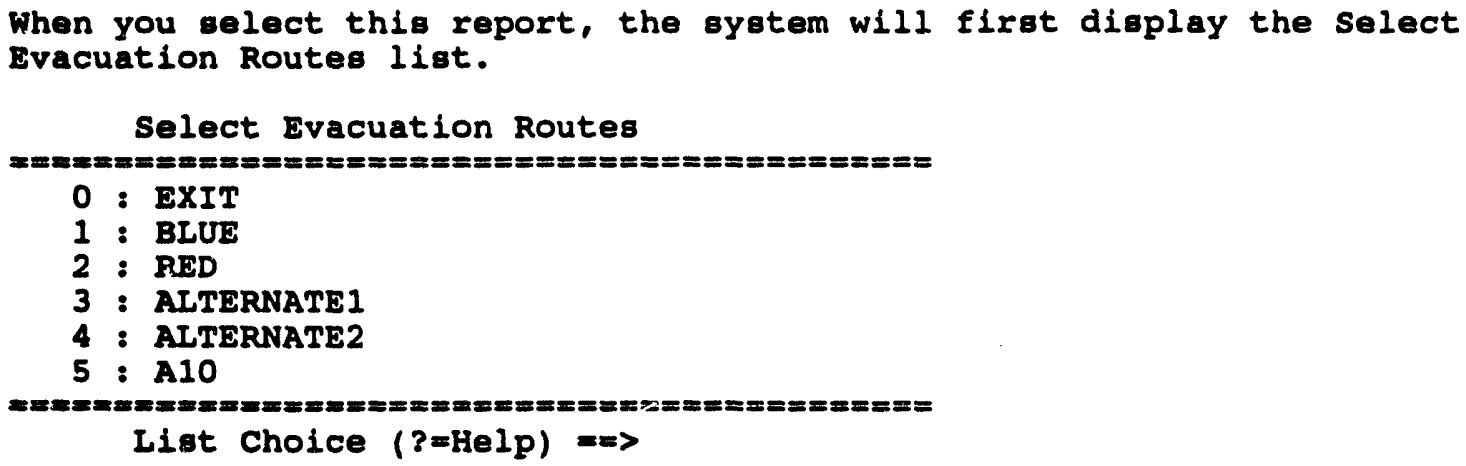

After you select an evacuation route or routes, the system will display the Evacuation Routes Form as shown in the following example.

\begin{tabular}{|lll|}
\hline Evacuation Routes Form & $11 / 02 / 93$ & $10: 48: 06$ \\
\hline Code & Known Route name & Graphic file name \\
\hline 1 & BLUEROUTE & 00 \\
2 & REDROUTE & OFF SDIR:EVR_BLUE.DMS \\
0 & & OFF \$DIR:EVR_RED.DMS \\
0 & & \\
0 & & \\
0 & & \\
0 & & \\
0 & & \\
0 & & \\
0 & & \\
\hline
\end{tabular}

The date and time fields are filled with the system time.

PROPOSED EVACUATION ROUTES automatically assembles and displays route data. The evacuation route codes and overlay labels are listed by route code in alphabetical ascending order. To look through this information, scroll it up and down on the screen with the arrow keys.

Approve and send the information (as described in Section 2, Message Board under the heading, Exiting After Creating an IBS Report) or cancel it GOLD Y. 


\section{ilD PROPOSED MILITARY ROUTES}

When you select this report, the system will first display the Select Proposed Military Route menu.

\begin{tabular}{l} 
Select Proposed Military Route \\
\hline $0:$ EXIT \\
$1:$ BLUE \\
$2:$ RED \\
$3:$ ALTERNATE1 \\
$4:$ ALTERNATE2 \\
$5:$ AlO \\
\hdashline Menu Choice $(?=H e l p)=>$
\end{tabular}

After you select a military route, the system will display the Select Destinations for Military Teams list.

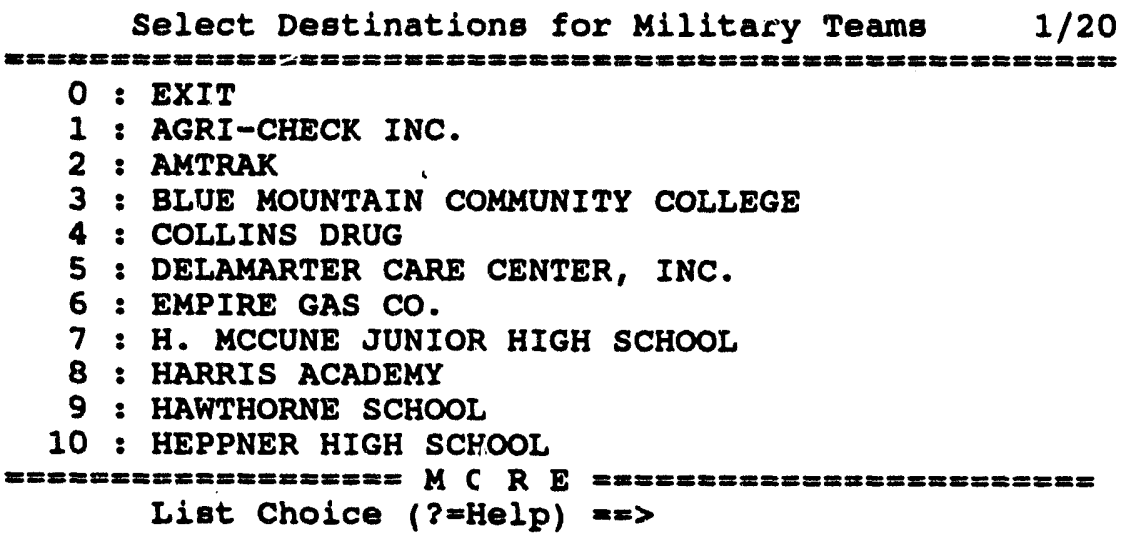

After you select the military destinations, the system displays the Incoming Military Routes Form filled with the information you selected earlier.

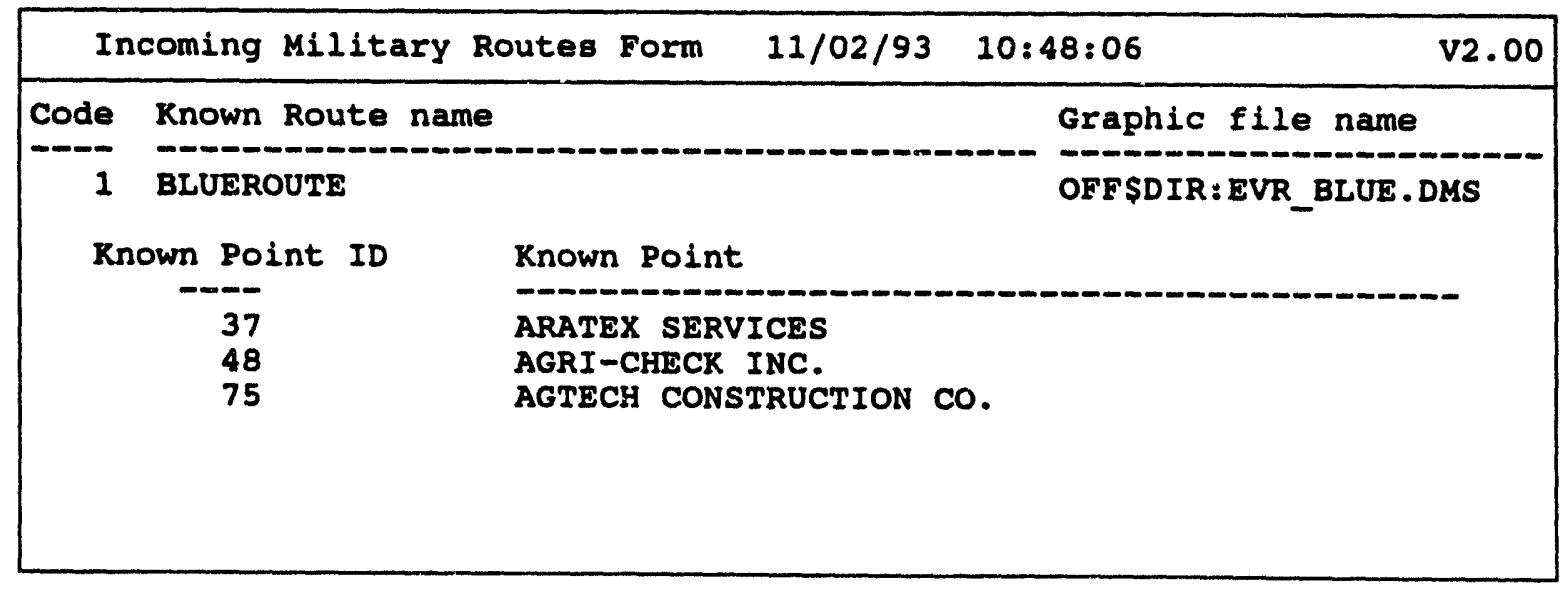


This option displays a form that describes the route(s) proposed for incoming military response teams. Each route description consists of a source, a destination, and a reference to a map overlay describing the route.

The date and time fields are filled with the system time.

Approve and send the information (as described in Section 2 under the heading, Exiting After Creating an IBS Report) or cancel it GOLD Y. 


\section{RECEPTION CTR DIRECTORY}

This option presents a scrolling form that enables you to enter descriptions of the reception centers.

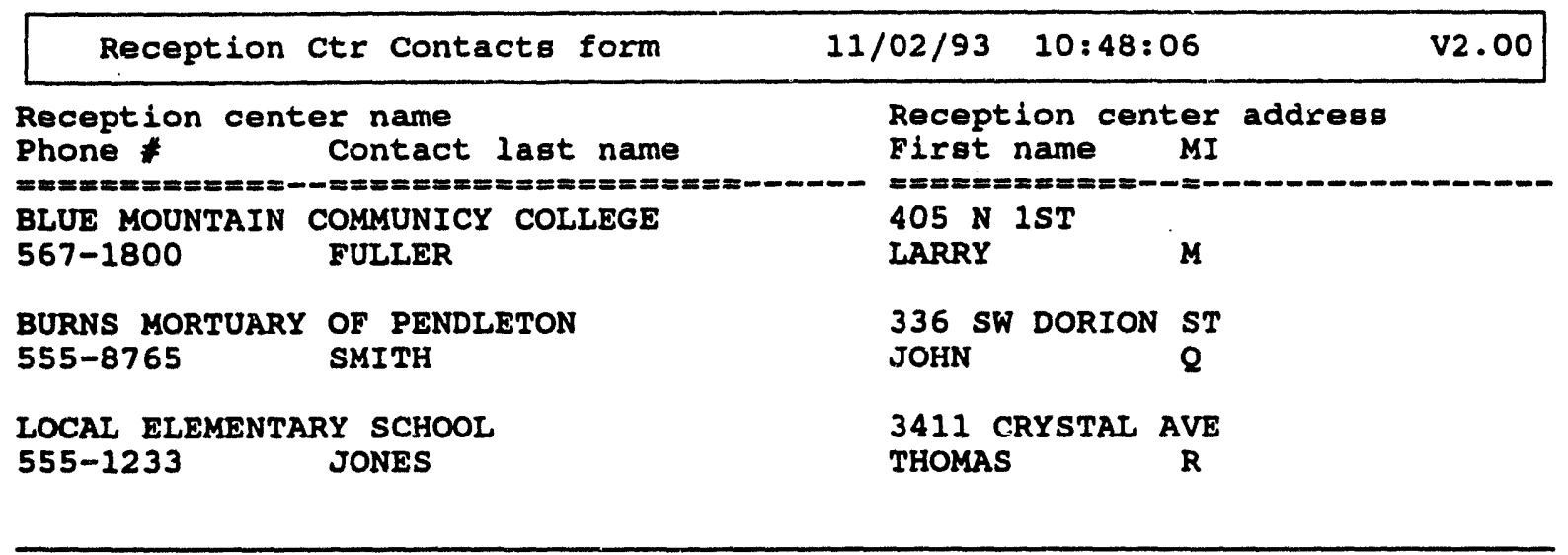




\section{RECEPTION CTR REPORT}

This option automatically displays information about reception centers in the current database.

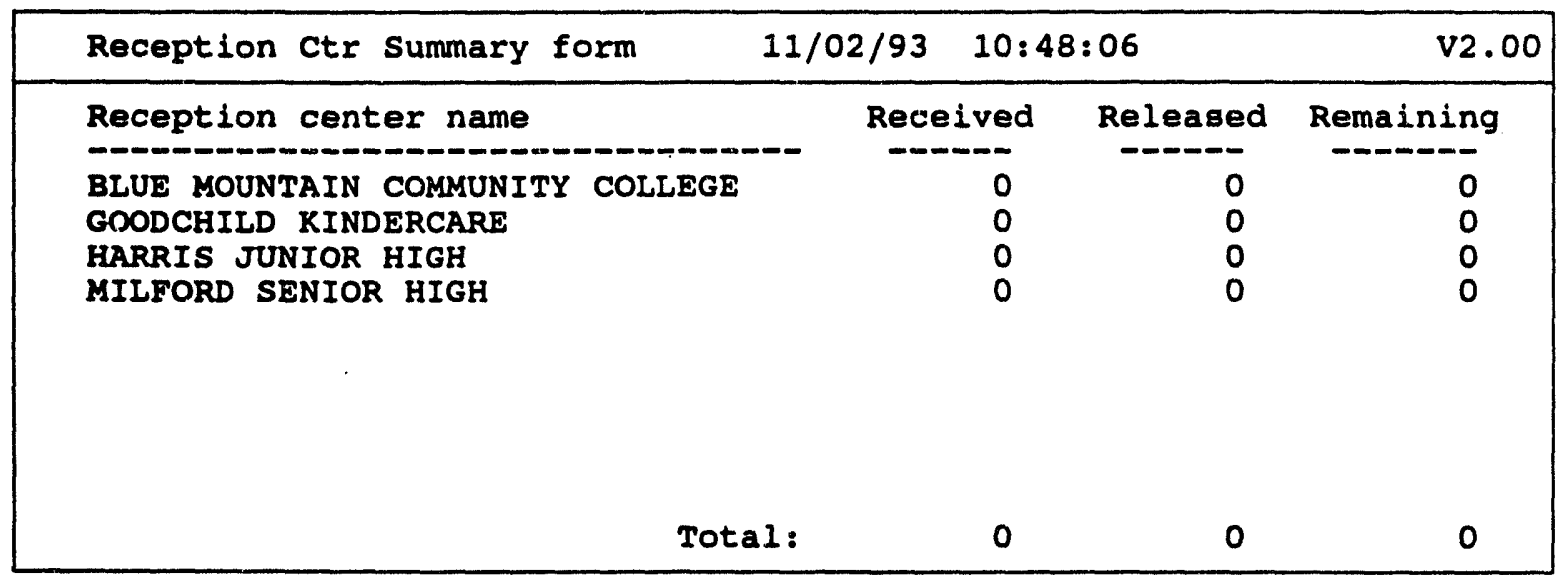

The date and time fields are filled using the current system time.

Approve and send the information (as shown under the heading, Exiting After Creating an IBS Report) or cancel it GOLD Y. 


\section{TRAFFIC CONTROL REPORT}

This option displays information from the current Law Enforcement tasks in the current Implementing Procedure and event database. The Traffic Control facilities are listed.

\begin{tabular}{|ccc|}
\hline Traffic Control Points Form & $11 / 02 / 93$ & $10: 48: 06$ \\
\hline Staffed: & Staffed Traffic Control Points \\
\hline Un-Staffed: & & \\
& & \\
\hline
\end{tabular}

The date and time fields are filled with the current system time.

Apprrve and send the information (as shown under the heading, Exiting After Cre: ng an IBS Report) or cancel it GOLD Y. 


\section{Reports from the Onpost EOC System}

VIEW ONPOST->IBS RPT displays a two page menu for reviewing reports (messages) that have been transmitted from the onpost system to IBS. Each menu item corresponds to one type of report. To see the second page, type $D$ (Down) at the Menu Choice $==>$ prompt.

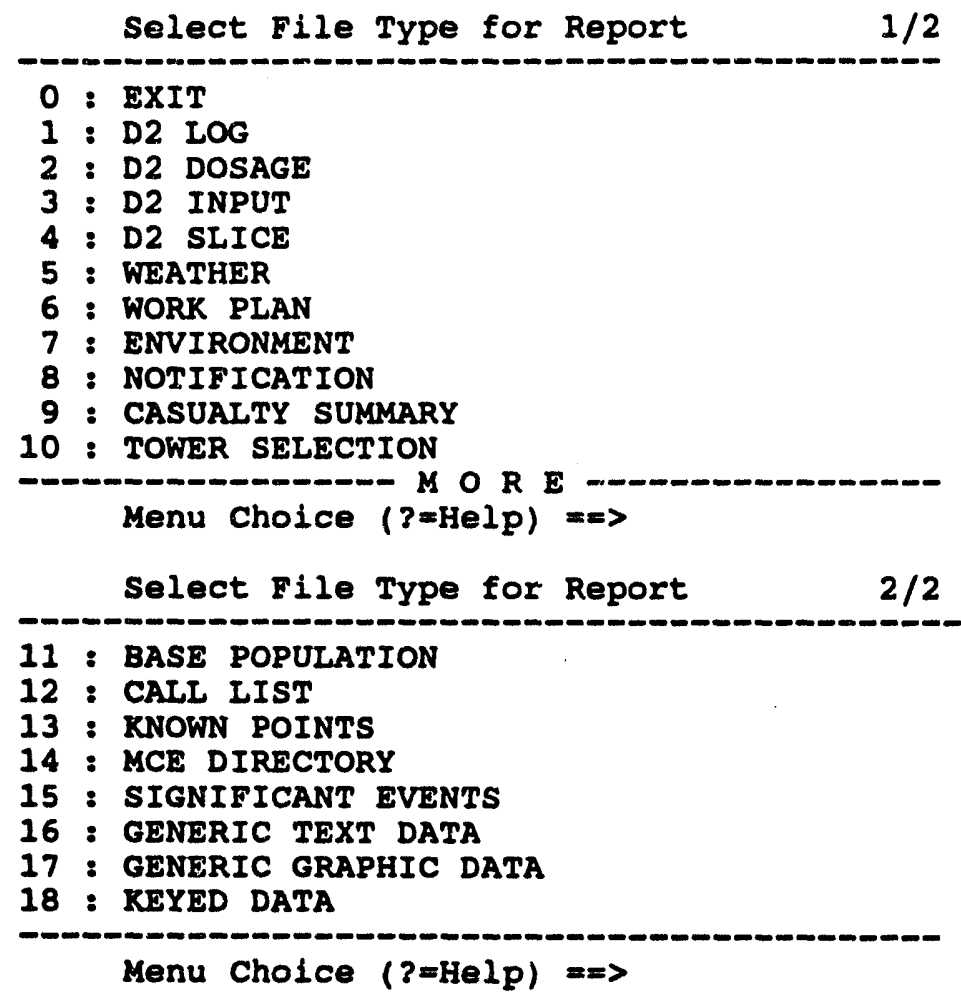

The formats for reports from the onpost system are shown on the following pages in alphabetical order by menu item name. Additional interactions with the system are also described. See the heading, Using the Report Selection Method Menu for instructions for using the Report Selection Method menu that initially displays when you select a report. 


\section{BASE POPULATION}

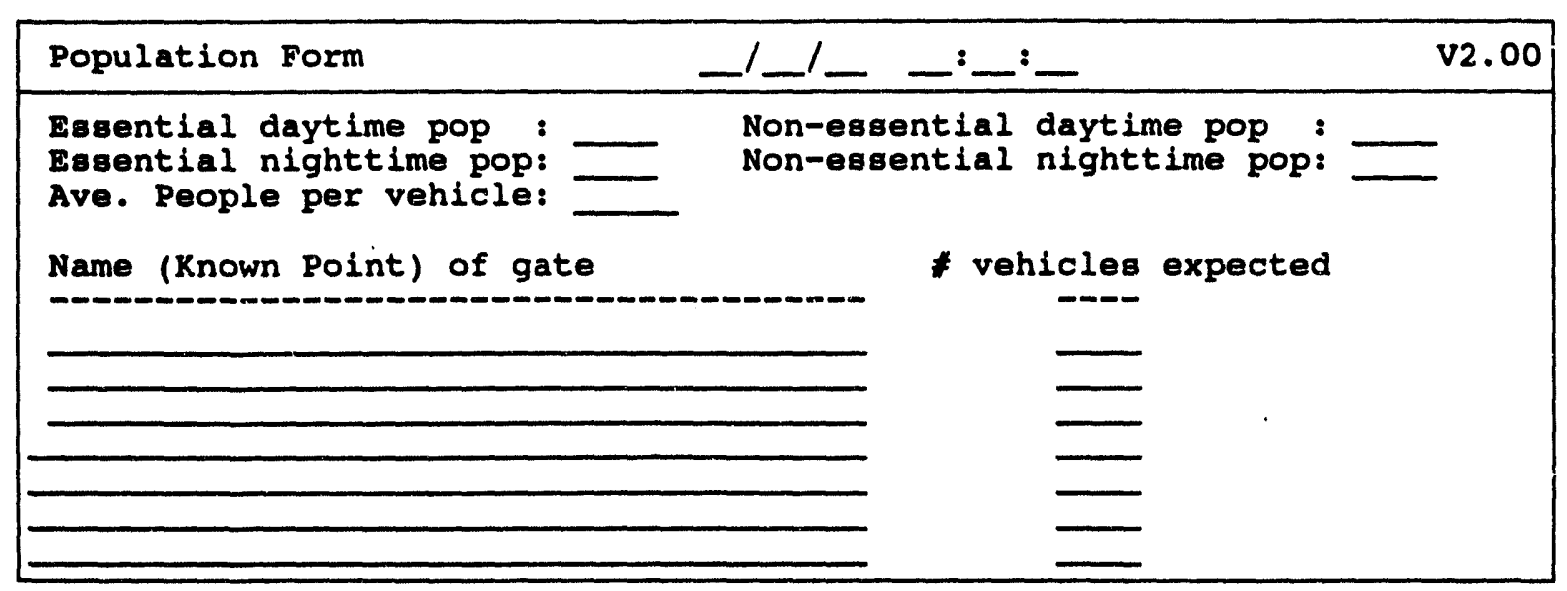


III CALL LIST

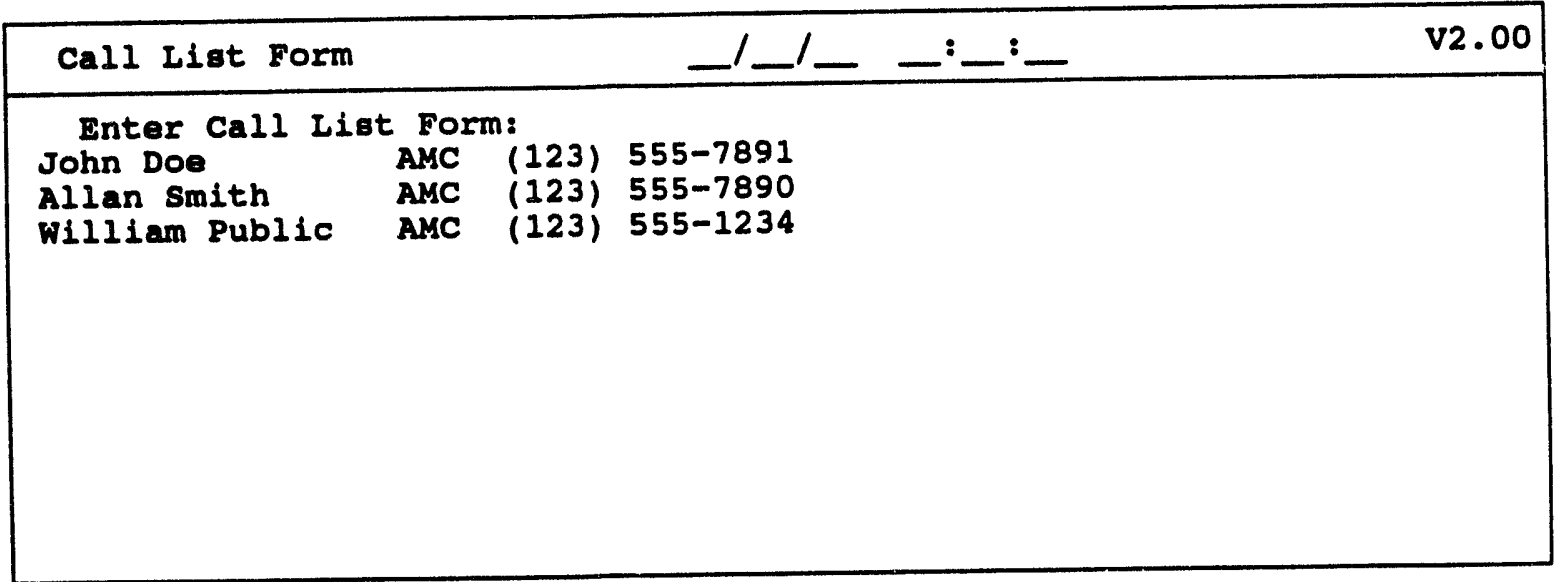




\section{CASUALTY SUMMARY}

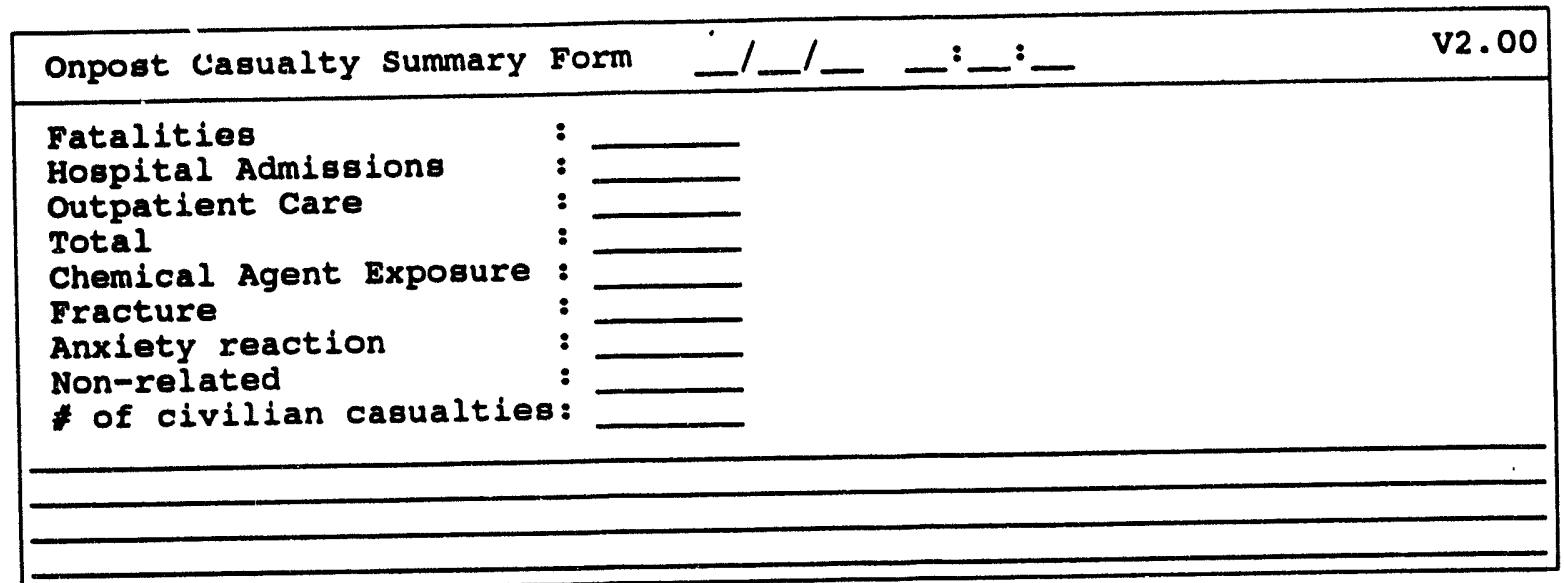




\section{D2 INPUT}

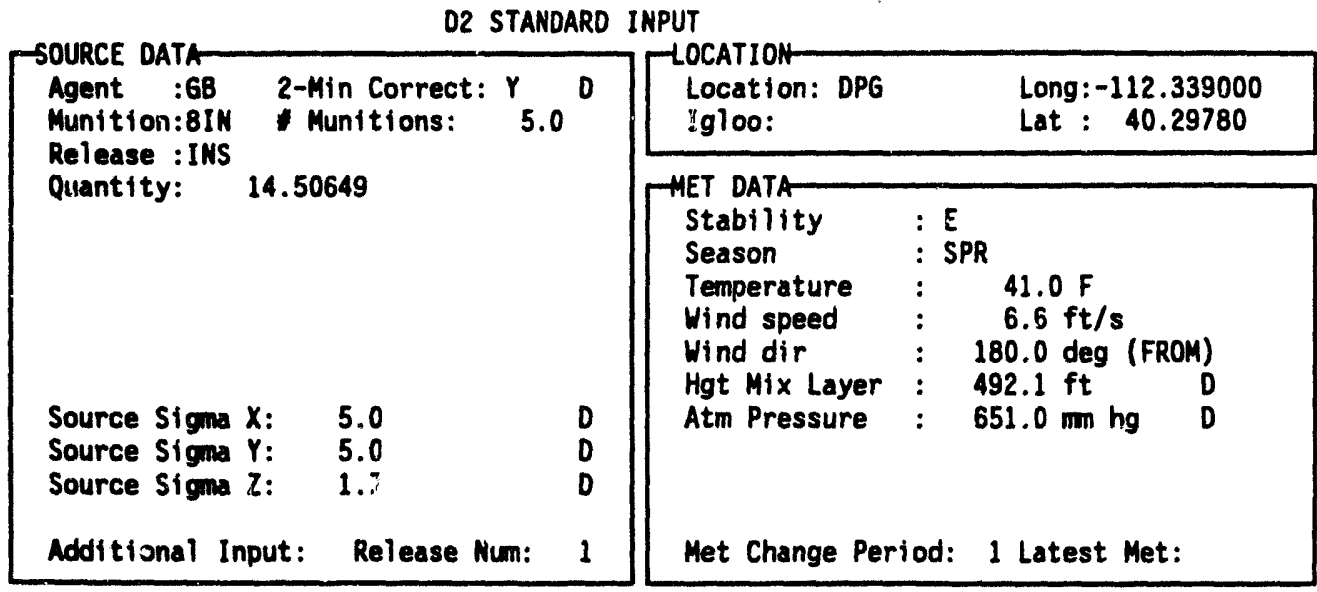




\section{D2 LOG}

The following form is an example of what you may see when you display the D2 Log. This example represents only a portion of the D2 information since the display is limited to 15 lines at a time. You can scroll the form to see all the information.

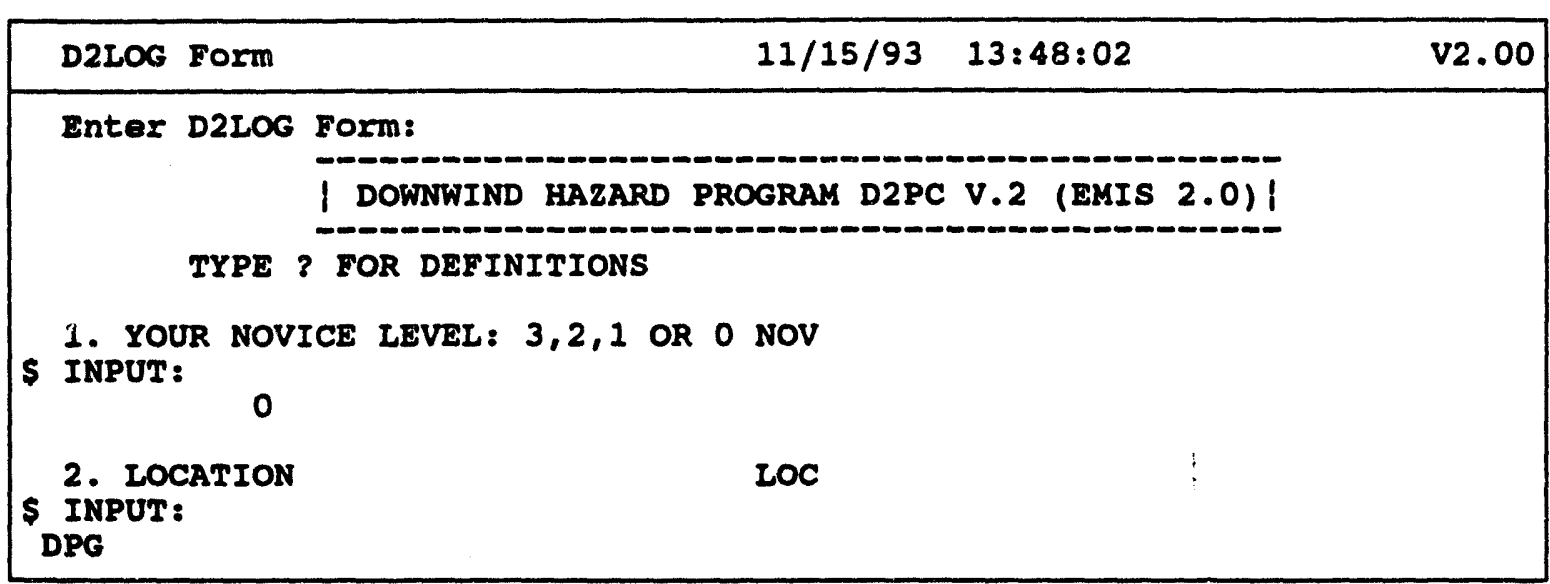

This form is presented as unformatted information. The form can be quite long. 


\section{D2 DOSAGE}

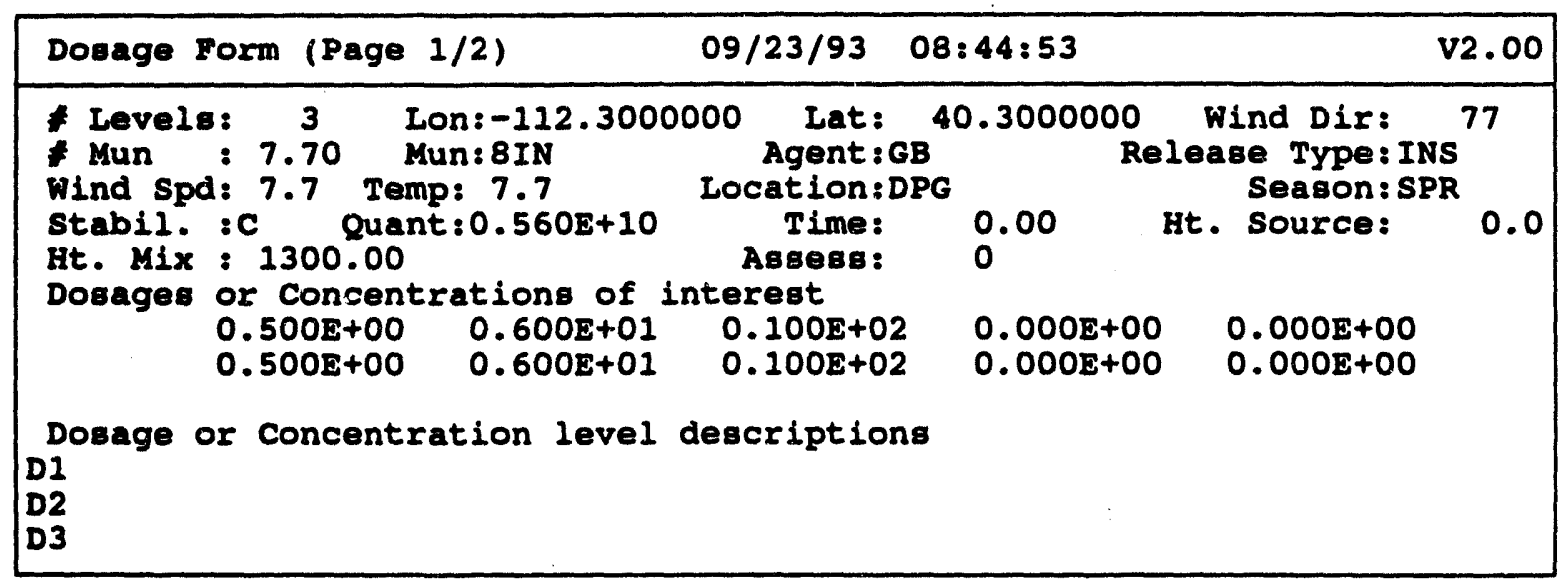

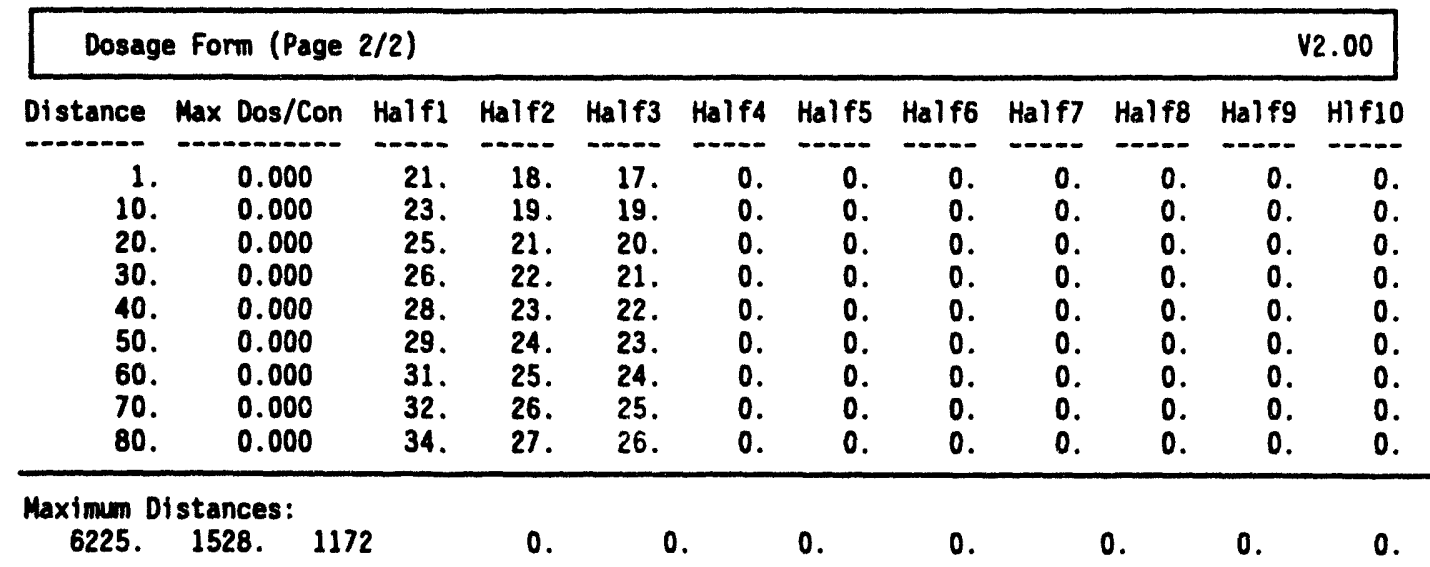

Note: The content of this report can vary if the selected D2 output was concentration rather than dosage.

You can scroll the information in this report. 


\section{D2 SLICE}

\begin{tabular}{|c|c|c|c|c|c|c|c|c|c|c|}
\hline \multicolumn{4}{|c|}{ silice Form } & $01 / 10 / 94$ & \multicolumn{3}{|c|}{$13: 52: 35$} & \multicolumn{3}{|r|}{$\mathrm{v2} .00$} \\
\hline $\begin{array}{l}\text { Number } \\
\text { A) } \\
\text { B) } \\
\text { C) } \\
\text { D) }\end{array}$ & $\begin{array}{r}\text { of Dosage L } \\
0.5 \mathrm{mg}-\mathrm{min} \\
6.0 \mathrm{mg}-\mathrm{min} \\
10.0 \mathrm{mg}-\mathrm{min} \\
0.0 \mathrm{mg}-\mathrm{min}\end{array}$ & $\begin{array}{l}\text { evels: } \\
/ \mathrm{m} 3 \\
\operatorname{lm} 3 \\
\operatorname{lm} 3 \\
/ \mathrm{m} 3\end{array}$ & $\begin{array}{l}3 \\
\text { E) } \\
\text { F) } \\
\text { G) } \\
\text { H) }\end{array}$ & \multicolumn{2}{|c|}{$\begin{array}{l}0.0 \mathrm{mg}-\mathrm{min} / \mathrm{m} 3 \\
0.0 \mathrm{mg}-\mathrm{min} / \mathrm{m} 3 \\
0.0 \mathrm{mg}-\mathrm{min} / \mathrm{m} 3 \\
0.0 \mathrm{mg}-\mathrm{min} / \mathrm{m} 3\end{array}$} & & $\begin{array}{l}\text { I) } \\
\text { J) }\end{array}$ & \multicolumn{3}{|c|}{$\begin{array}{l}0.0 \mathrm{mg}-\mathrm{min} / \mathrm{m} 3 \\
0.0 \mathrm{mg}-\mathrm{min} / \mathrm{m} 3\end{array}$} \\
\hline $\begin{array}{l}\text { DIST. } \\
\text { (m) }\end{array}$ & $\begin{array}{l}\text { TOTAL DOS } \\
(\mathrm{mg}-\mathrm{min} / \mathrm{m} 3)\end{array}$ & $\begin{array}{c}\text { TIME } \\
\text { FOR } \\
\text { TIP }\end{array}$ & $\begin{array}{l}\text { (min) } \\
\text { CLOUD } \\
\text { TAIL }\end{array}$ & $\begin{array}{c}\text { DOSAGE : } \\
(8)\end{array}$ & $\begin{array}{l}\text { TIME } \\
(\min )\end{array}$ & & $\begin{array}{l}\text { DSAGE : } \\
\text { b) (i }\end{array}$ & $\begin{array}{l}\text { TIME } \\
(\min )\end{array}$ & $\begin{array}{l}\text { DOSAGE } \\
(8)\end{array}$ & $\begin{array}{l}\operatorname{TIME} \\
(\min )\end{array}$ \\
\hline & 1. $.9627 \mathrm{E}+06$ & 0.0 & 0.2 & $\begin{array}{lr}\text { A } & 100 . \\
\text { D } & 0 . \\
\text { G } & 0 . \\
\text { A } & 100 . \\
\text { I } & 0 . \\
\text { S } & 0 . \\
\text { J } & 0 .\end{array}$ & $\begin{array}{l}0.0 \\
0.0 \\
0.0 \\
0.0 \\
0.0 \\
0.0 \\
0.0\end{array}$ & $\begin{array}{l}B \\
E \\
H \\
B \\
E \\
H\end{array}$ & $\begin{array}{r}100.0 \\
0.0 \\
0.0 \\
100.0 \\
0.0 \\
0.0\end{array}$ & $\begin{array}{ll}0 & 0.0 \\
0 & 0.0 \\
0 & 0.0 \\
0 & 0.0 \\
0 & 0.0 \\
0 & 0.0\end{array}$ & $\begin{array}{lr}\text { C } & 100.0 \\
\text { F } & 0.0 \\
I & 0.0 \\
\text { C } & 100.0 \\
F & 0.0 \\
I & 0.0\end{array}$ & $\begin{array}{l}0.0 \\
0.0 \\
0.0 \\
0.0 \\
0.0 \\
0.0\end{array}$ \\
\hline
\end{tabular}




\section{ENVIRONMENT}

Displays a summary report of information gathered from various types of on-site detectors or human observations.

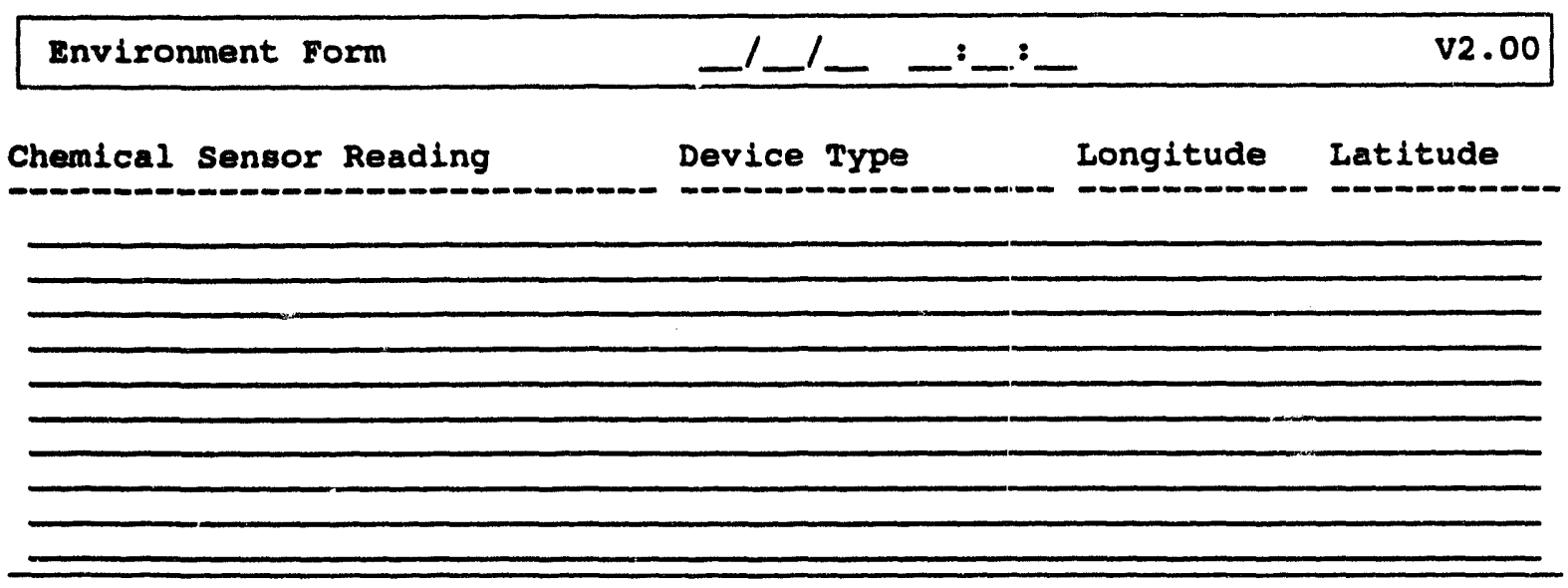




\section{GENERIC GRAPHIC DATA}

\begin{tabular}{|lr|}
\hline Generic Graphic form & v2.00 \\
\hline Filenamer for generic graphic data: & \\
& \\
& \\
\end{tabular}




\section{GENERIC TEXT DATA}

The system will display the Select Report to View: GENERIC TEXT DATA menu.

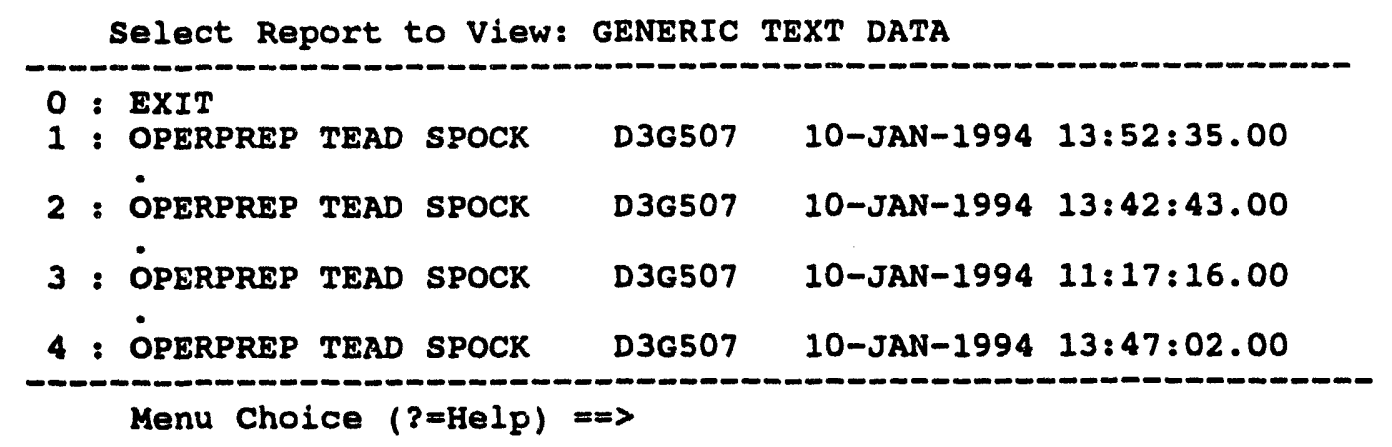

After you select a report, the system will display the report in the following format.

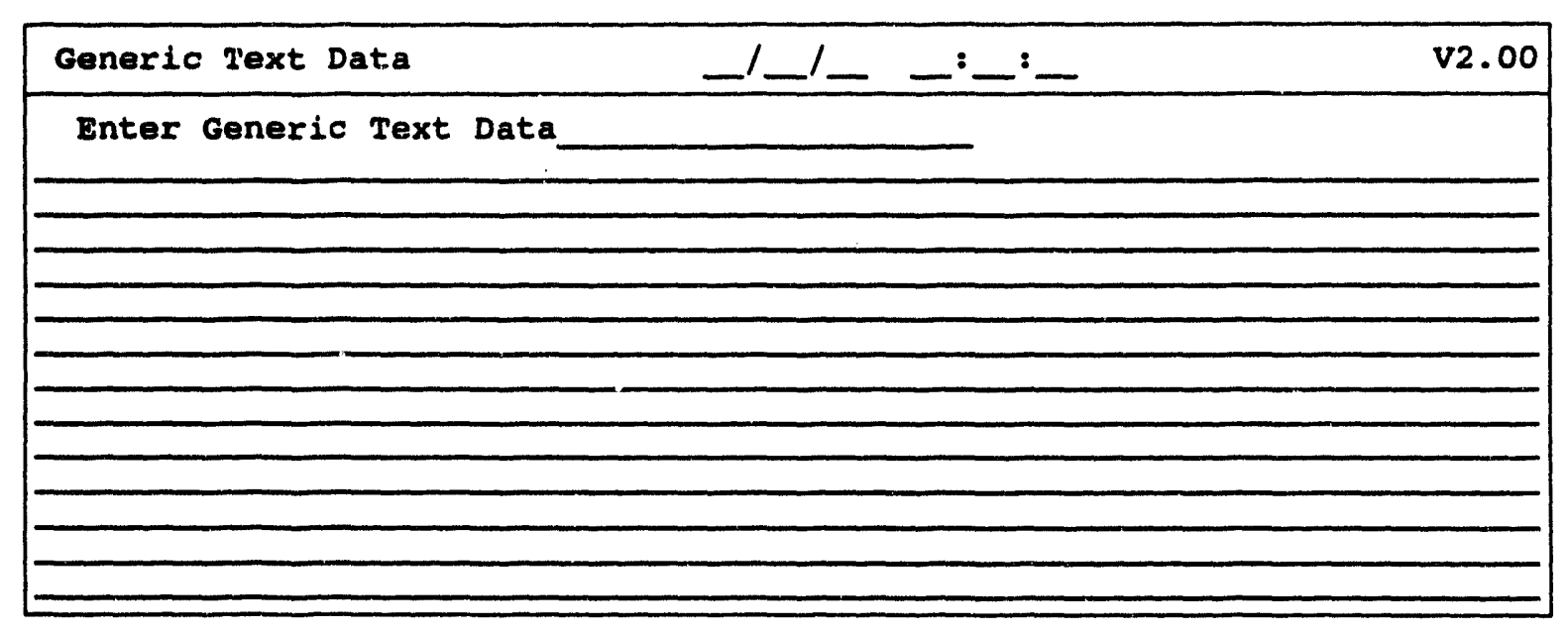

You can scroll this report. 


\section{KEYED DATA}

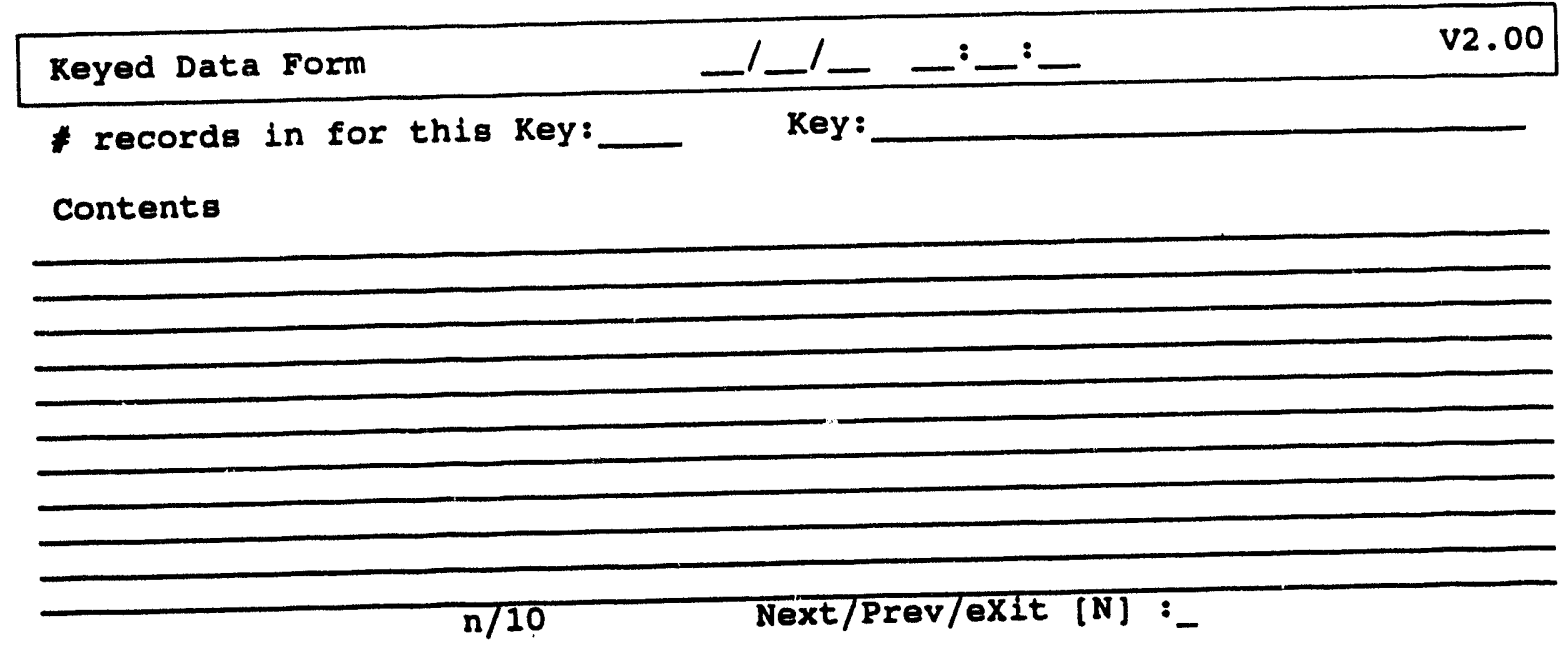

You can scroll this report. 


\section{KNOWN POINTS}

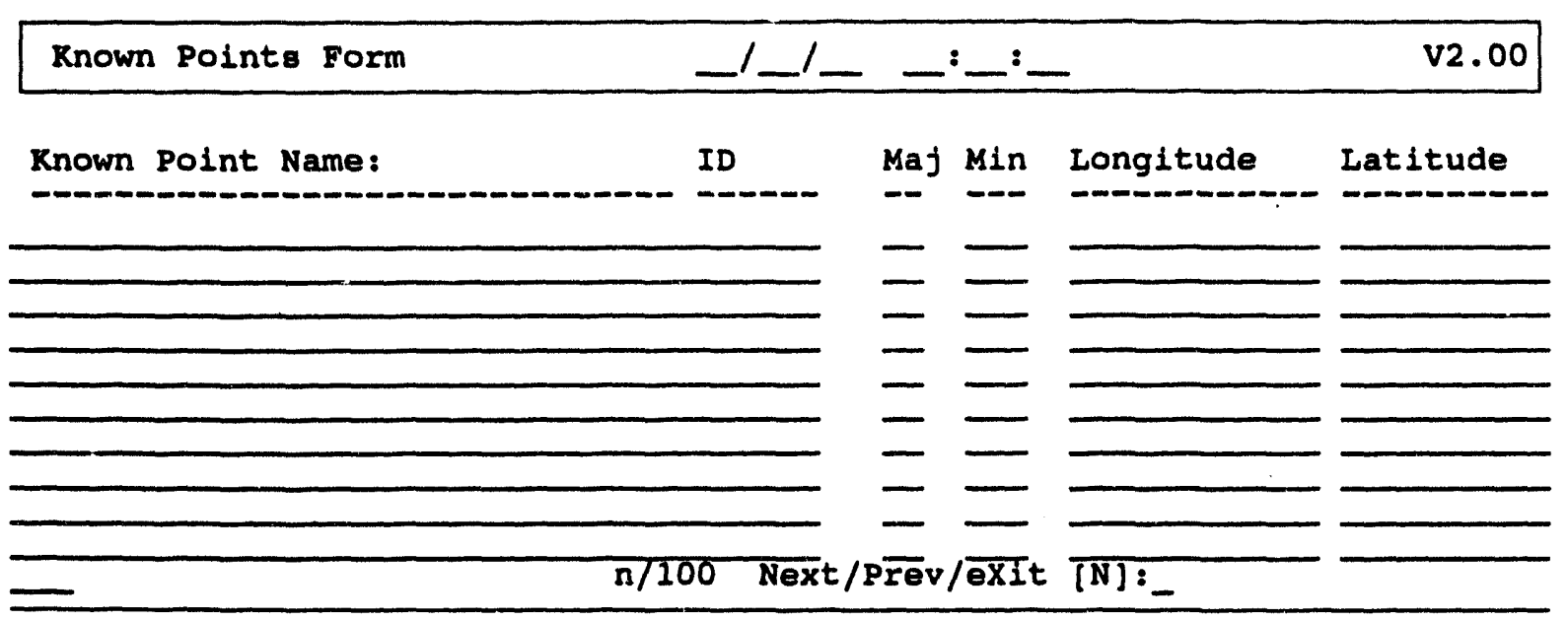




\section{MCE DIRECTORY}

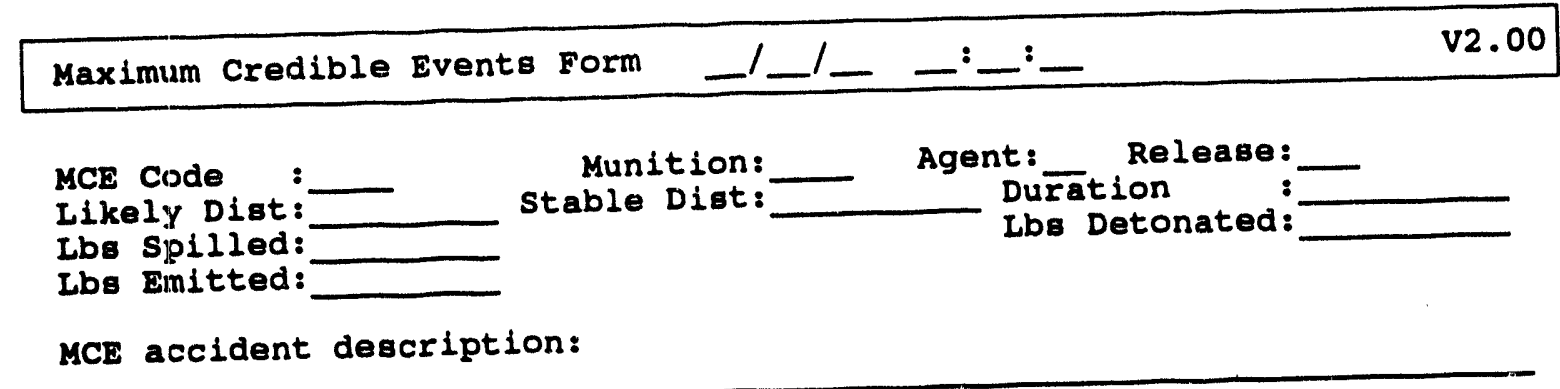

n/1000 Next/Prev/exit [N]:- 


\section{NOTIFICATION}

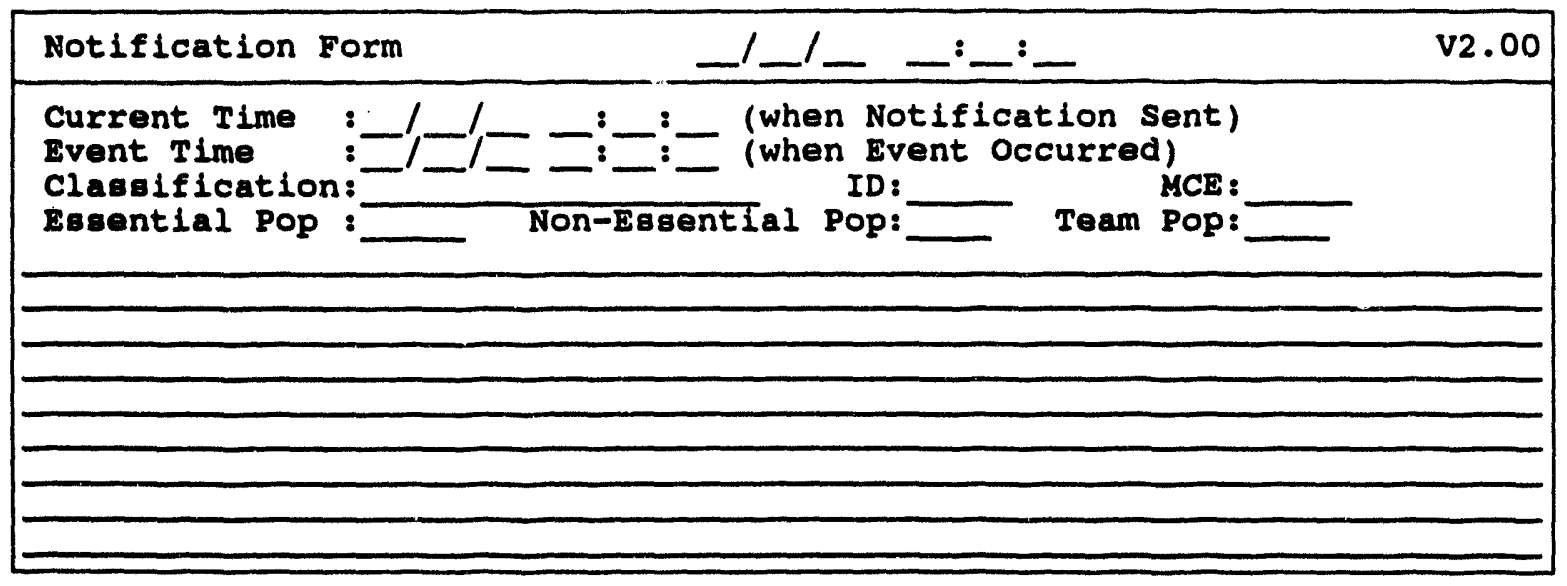

An optional free-form comments section is included on the form: onpost personnel may want to recommend a specific IBS scenario or recommend protective actions on this form. 


\section{SIGNIFICANT EVENTS}

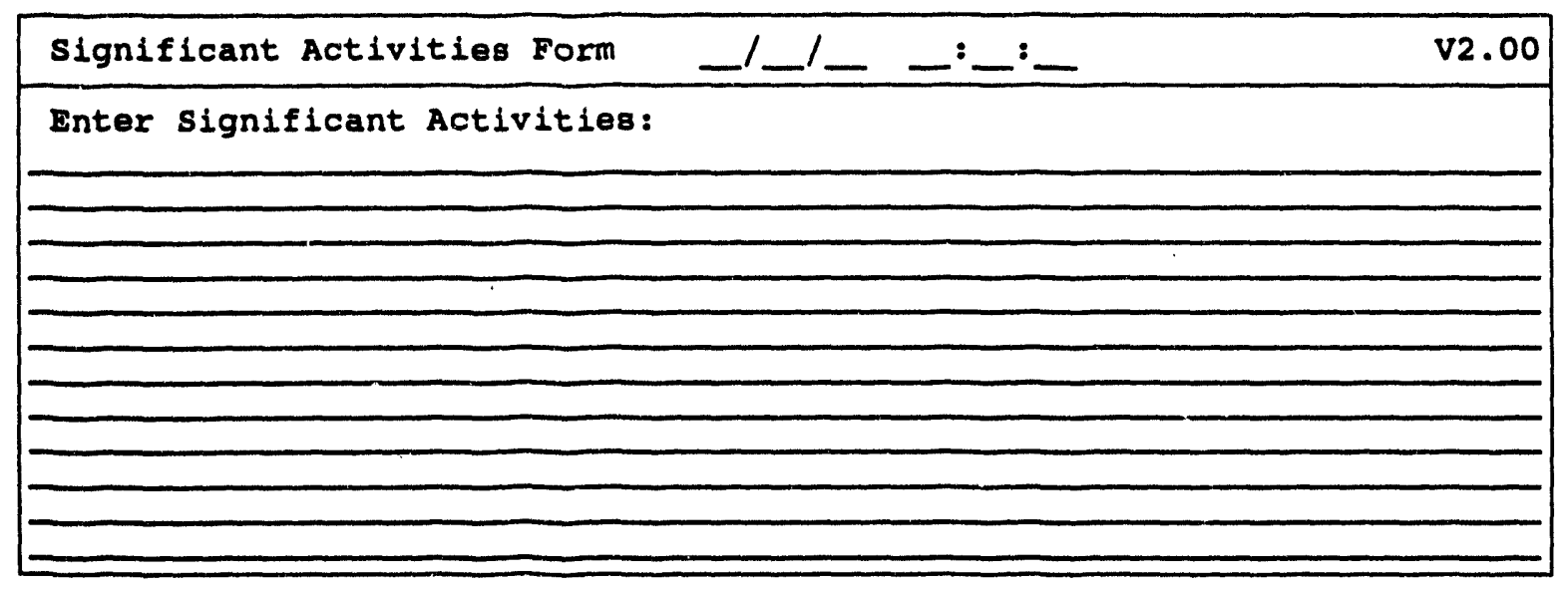




\section{TOWER SELECTION}

TOWER SELECTION displays the following report. This report identifies the meteorological data that is fed into the D2 model in JBS.

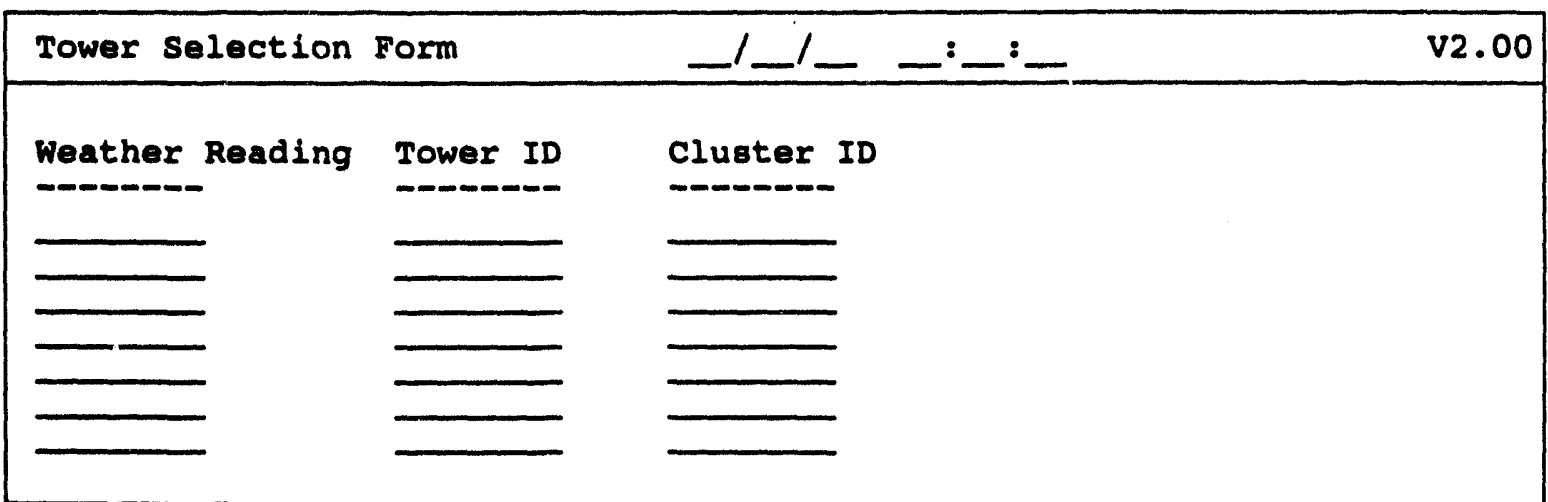




\section{WEATHER}

WEATHER displays the following report. If any values are known to be incorrect, those fields are filled with * (asterisks).

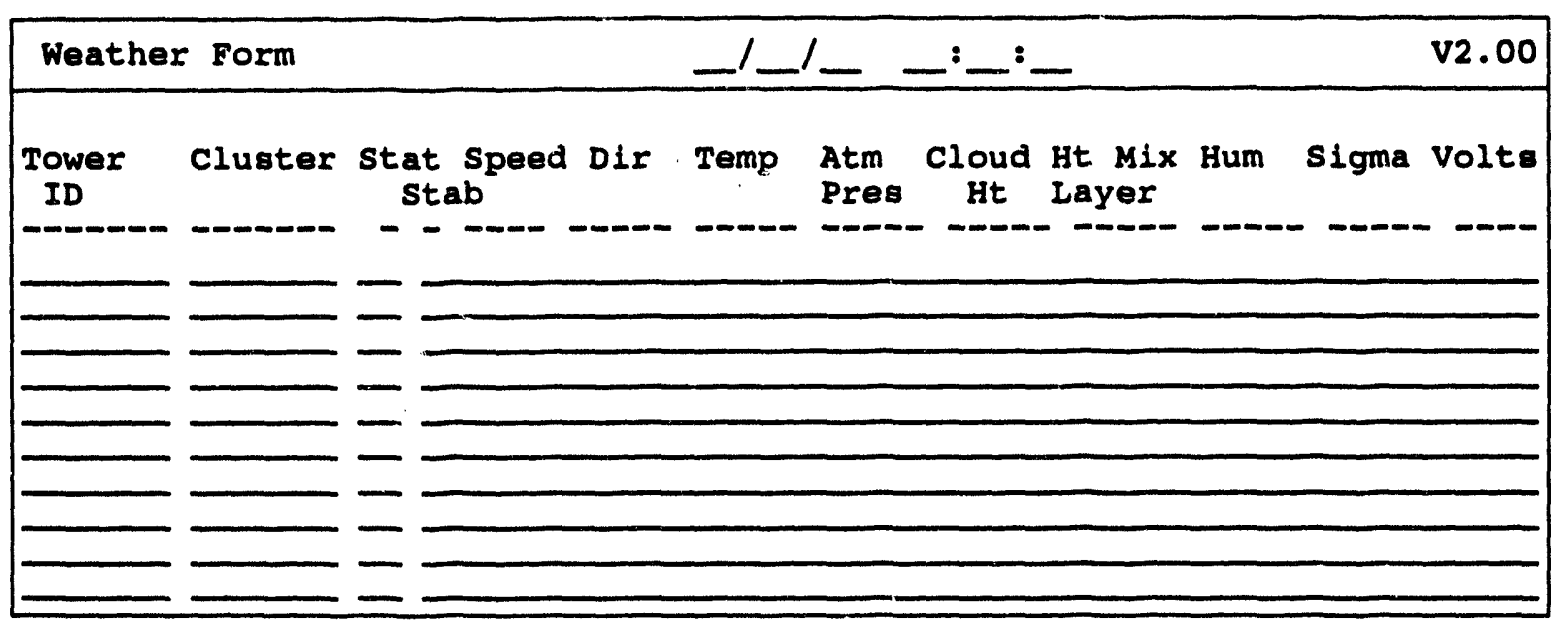




\section{WORK PLAN}

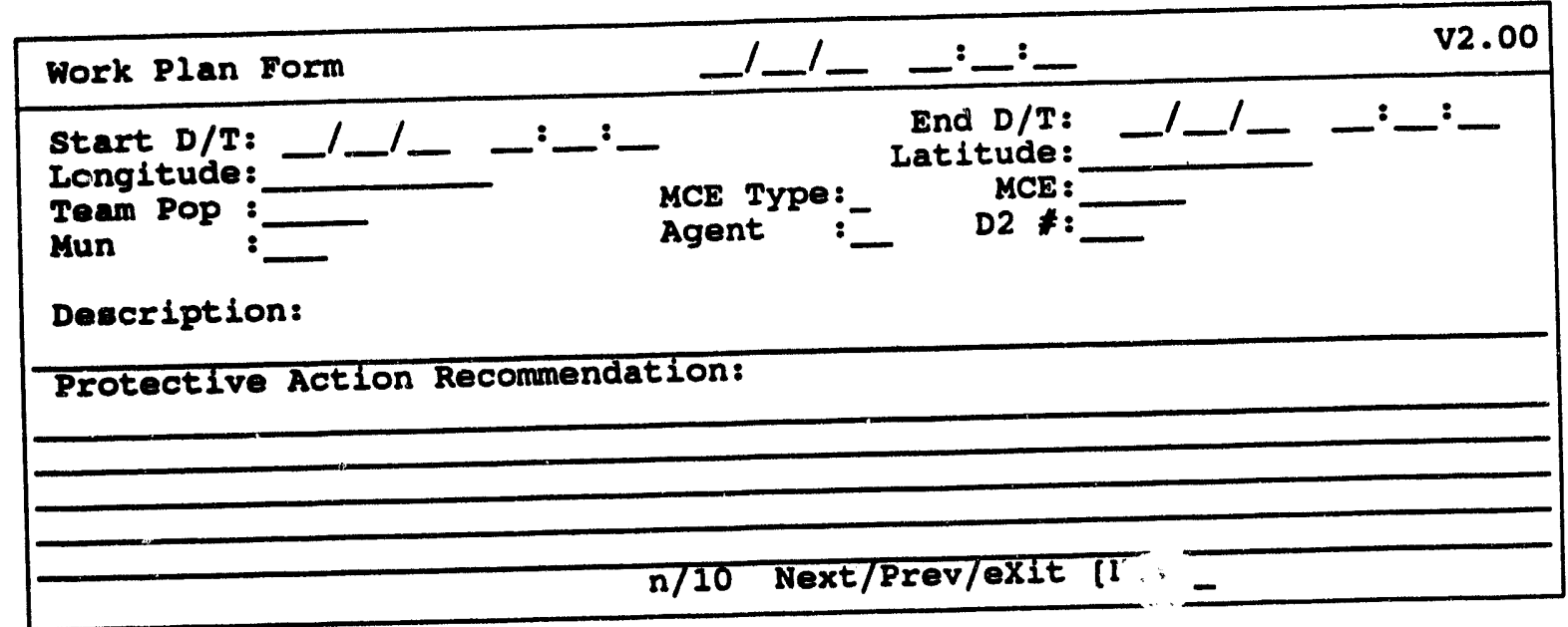


Appendlx F

IBS Icons 


\section{Appendix $F$ IBS Icons}

Icons are symbols used in the IBS to graphically depict the location and availability of features such as facilities, resources, services, and physical landmarks. Each icon is represented by a symbol which can be drawn on the topographic map display. This appendix provides a listing of the current set of icons available in IBS, together with their type.

The current set of icons has been divided into three categories within this appendix. These categories are:

- Facility Icons: Represent the location of facilities such as schools, hospitals, and shelters.

- Resource Icons: Used to depict resources at a facility, such as communication equipment, food, and medical equipment.

- Non-Facility/Resource Icons: Represent items which do not fall within the facility or resource categories. Examples of non-facility/resource icons are:
- City
- Flood
- Earthquake

The following pages contain the icon lists for the IBS. The icon listings contain two fields describing the icons. These fields are:

- Symbol: This is the graphic symbol used for displaying the icon. Because the symbols shown are drawings of the actual icons, and are not in color (some icons contain multiple colors), some minor differences in appearance may exist between the symbols and the actual icon display. Listed above each symbol in parentheses is the icon color. If the icon contains multiple colors, more than one color is listed.

- Type: This is a text field for the icon name. The icon name can be up to 8 characters in length for resource icons and up to 25 characters for all other icons.

Note: Some icons will have two names. The first (upper) name is the full name of the icon with correct spelling, the second (lower) name is the name of the icon exactly as it appears in IBS system listings. 
Resource icons are used to indicate the location of several subtypes of resources. For example, one food icon could be used to represent 100 boxes of dried fruit, 10 pounds of sugar, and 2 sacks of potatoes. The dried fruit, sugar, and potatoes are all resource subtypes; a more detailed breakdown of the resource type food. All resource types can be used to represent many resource subtypes. This is done in IBS, under Resource Management, using the privileged function Define Resources. After selecting a resource type, the user defines the subtype. The resource subtype is also called the resource description. See Section 6, Resource Management for more information on defining resources and facilities.

While it is possible to later change or even delete the subtype (description), it is not recommended. If it is changed or deleted, IP's which reference the resource will become corrupted. To prevent this, resource subtypes can be added after initial system installation but never modified or deleted. Resource subtypes can be added at any time.

The same caution is true for resource types: add them anytime, but never modify or delete them. When delivered, IBS contains some predefined resource types the specified entries in the icon control file.

To add an icon to the icon control file, perform the following procedures:

1. Create an icon using the GEDIT utility and the BLANKICON.DMS file.

2. Move the new icon (*.DMS) to the icon directory MAPSICONS:

3. Find an available major/minor code pair by looking in the ASCII version of the attribute dictionary (MAPSATTRIBDIC.BIX)

4. Add a line to the icon control file MAP\$ICONS:ICON.CTL

5. Add an entry to the attribute dictionary using the UPDATEATT utility. Dump the file using the ATTXASC utility.

In general, you will only add facility and resource icons.

Refer to the IBS Utilities Guide for more information about the GEDIT, UPDATEATT, and ATTXASC utilities. 


\section{Facility Icons}
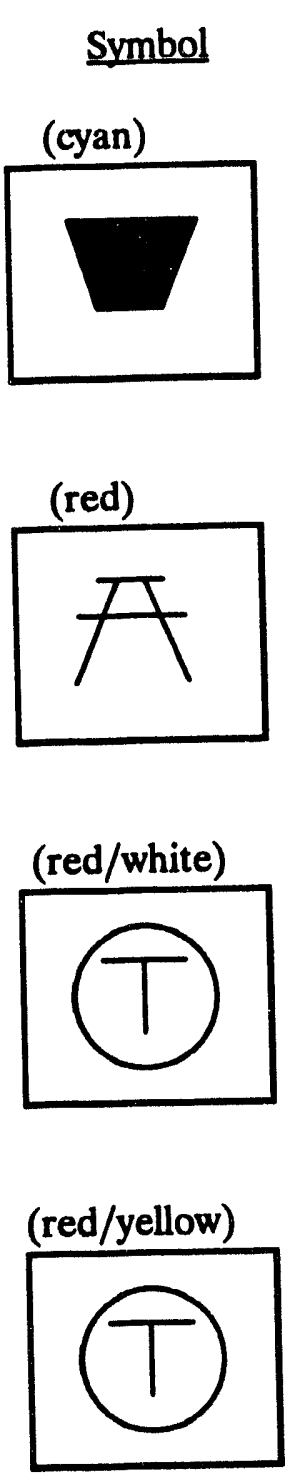

(white)

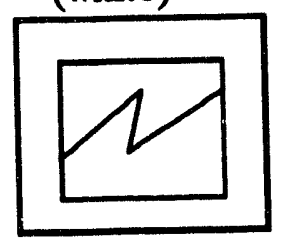

Type

Dam

Recreation Area

Traffic Control Point

Traf Ctrl Pt

Traffic Control Point (Inactive)

Traf Ctrl Pt (Inactive)

Power Station 
Symbol

(cyan/red)

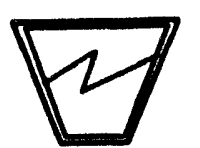

(cyan)

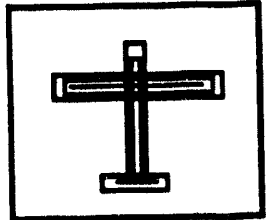

(cyan)

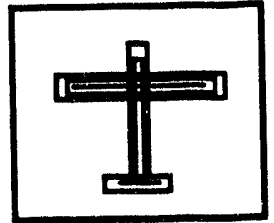

(cyan)

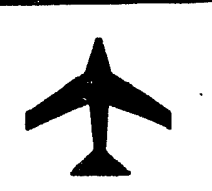

(red)

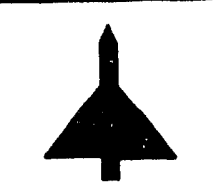

Type

Hydroelectric Plant

Civilian Airport

Airport

Civilian Air Hub

Military Airport 

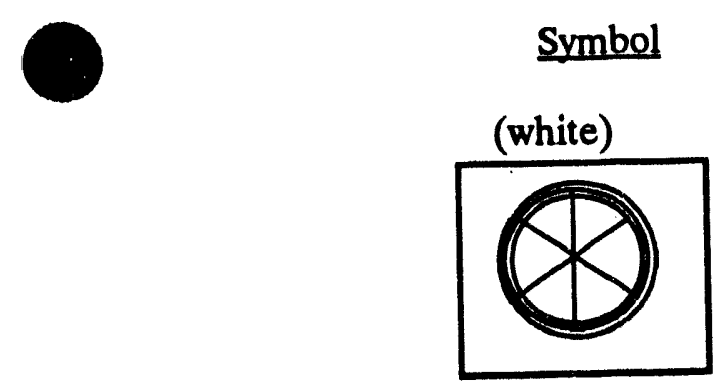

\section{Type}

Transportation facility

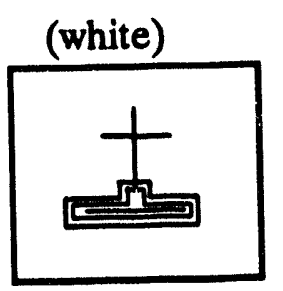

Church

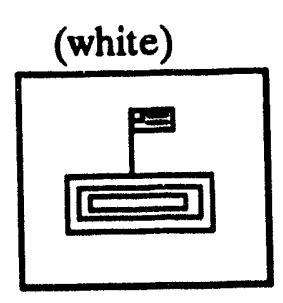

School

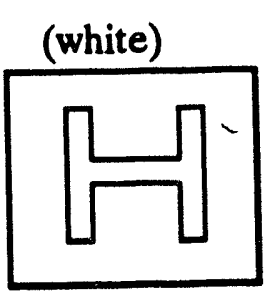

Hospital

(blue)

V.M.A.C. Hospital

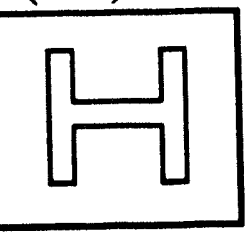

(yellow)

Hospital (Inactive) 

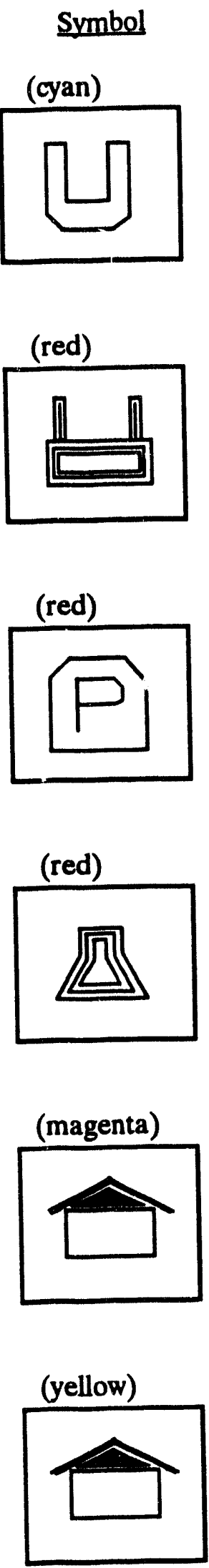

Type

Public Utility

Industrial Park

Private Business

Nuclear Plant

Shelter

Shelter (Inactive) 


\section{Symbol}
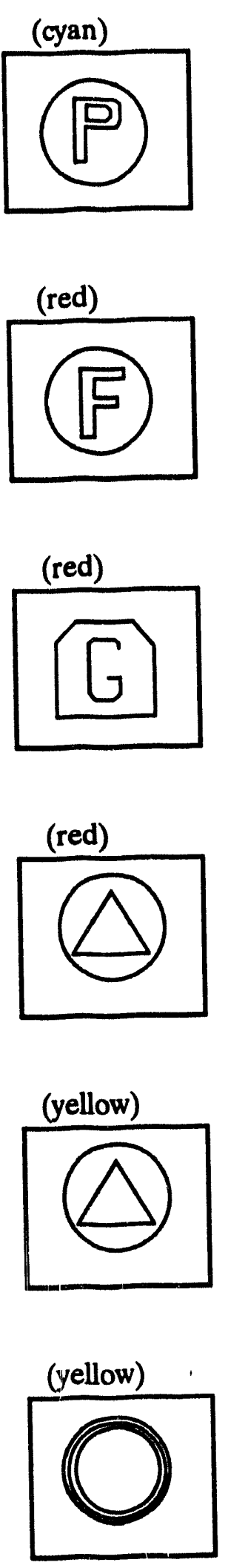

IBS Usor Guido - 1/5/94
Type

Police Station

Fire Station

Government Building

E.O.C.

E.O.C. (Inactive)

Fuel Tank Farm 
Symbol

(blue/blink white)

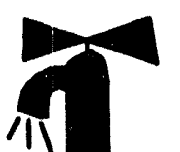

(red)

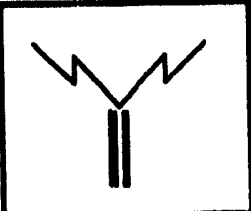

(red)

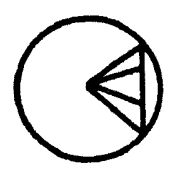

(red)

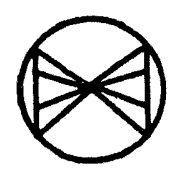

(red)

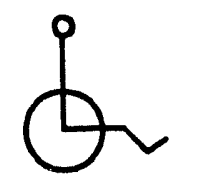

(magenta)

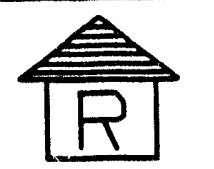

Type

Water Supply

Communications Facility

Siren - Rotating

Siren - Nonrotating

Special Population

Reception Center

Reception Ctr 


\section{Symbol}
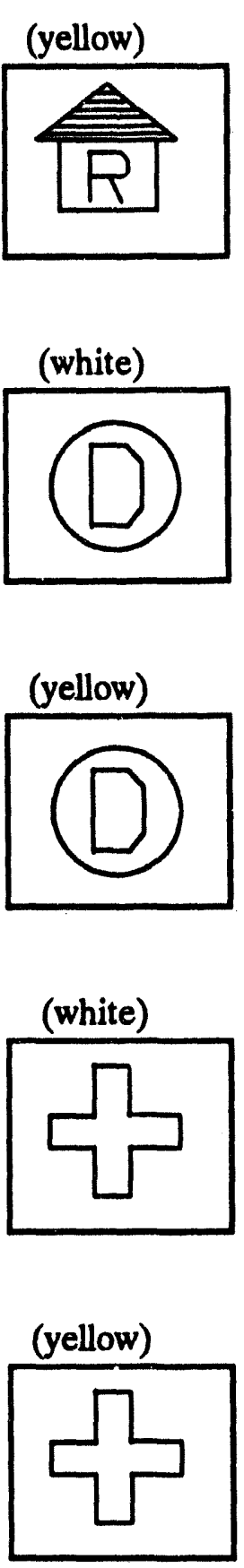

Type

Reception Center (Inactive)

Reception Ctr (Inactive)

\section{Decontamination Center Decon Center}

\section{Decontamination Center (Inactive) \\ Decon Center (Inactive)}

\section{Morgue}

Morgue (Inactive) 
Symbol

(magenta/green)

N

(white)

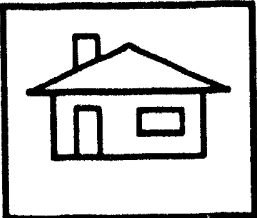

(red)

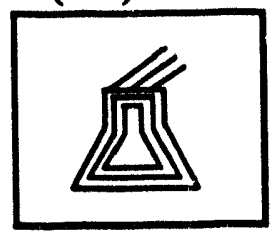

(white)

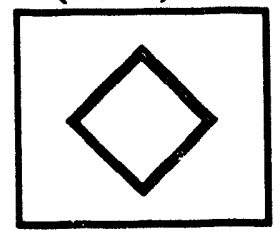

(red/white)

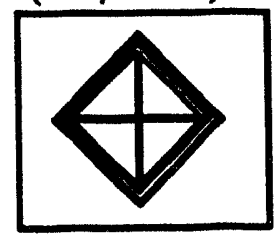

(yellow)

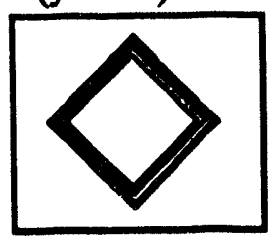

Type

Mobile Medical Unit
Private Residence

Refinery

Coal Mine

Coke Producer

Natural Gas Pressure Plant

Nat Gas Pressure Plant 
Symbol

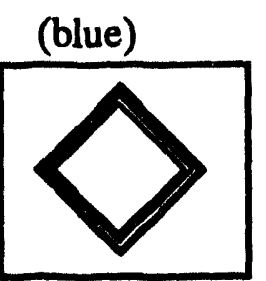

(white/yellow)

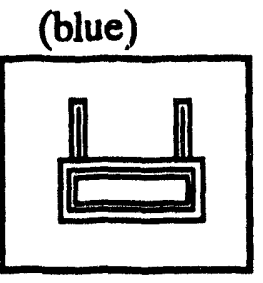

(white)<smiles>C1=C2CCC(C1)C2</smiles>

(white)

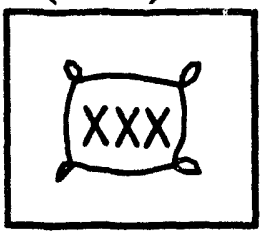

(red)

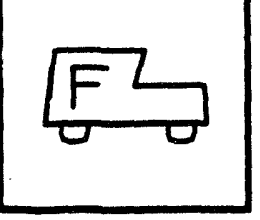

Type

Natural Gas Underground Storage

Nat Gas Underground St

\section{Petroleum Import Facility}

Petrol Import Facility

Port Facility

Grain Storage

Flour Mills

Food Distribution 


\begin{tabular}{l} 
Symbol \\
(white) \\
\hline 2 \\
\hline
\end{tabular}

Type

Poultry Production

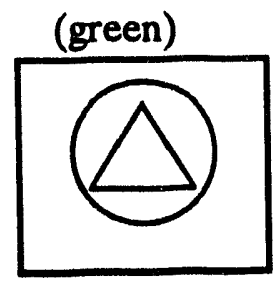

Agriculture E.O.C.

(white)

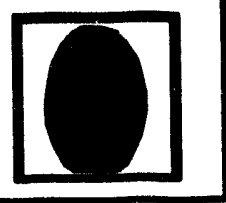

(white)

49
Food Production

Egg Producers 


\section{Resource icons}

Symbol
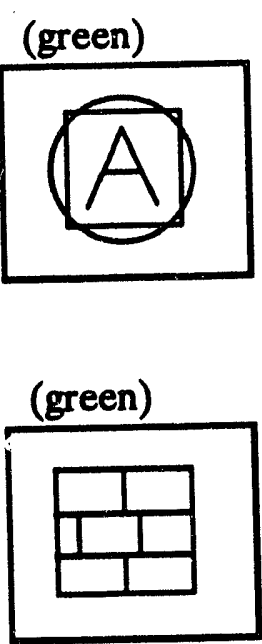

(green)

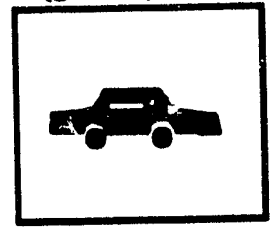

(green)

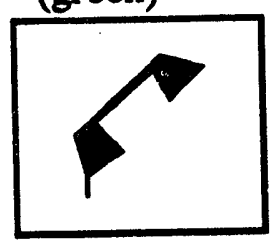

(green)

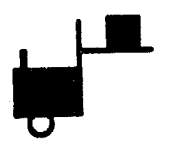

Type

1st Aid

Barricade

Barricad

Cars

Communications Equipment

Comm Eq

Construction Equipment

Const Eq 
Symbol
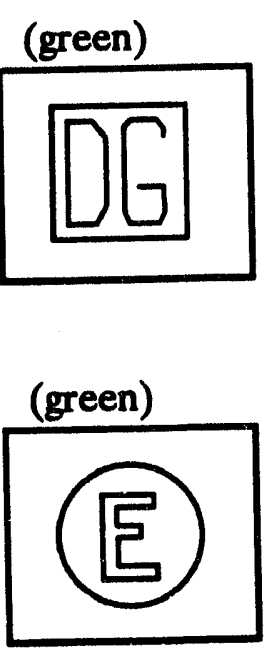

(green)

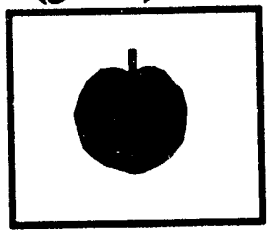

(green)

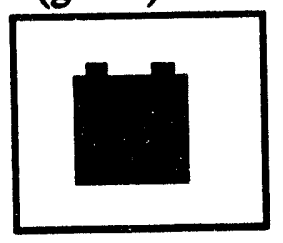

(green)

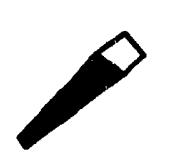

Type

Dry Goods

Dry Good

\section{Emergency Equipment}

Emerg Eq

Food

\section{Generator}

Generatr

Hand Tool

Hand $\mathrm{T}$ 


\section{Symbol}

(green)

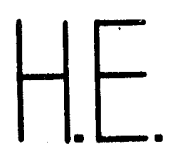

(green)

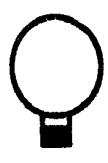

(green)

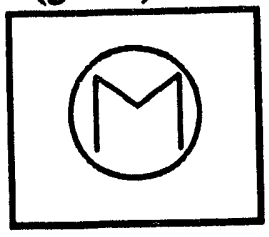

(green)

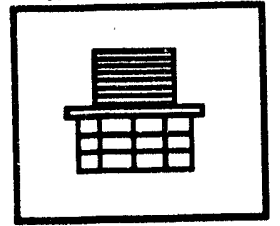

(green)

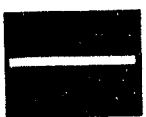

Type

Heavy Equipment

Heavy Eq

Lights

Medical Equipment Medic Eq

Office Machine

Office M

Paving Equipment

Pave Eq 


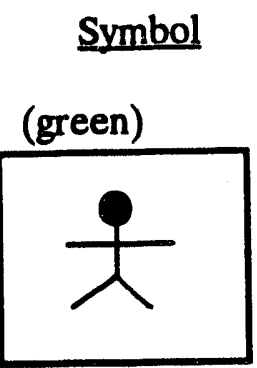

\section{Type}

People

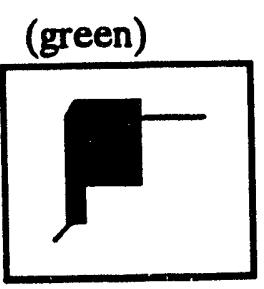

\section{Power Tool}

Power TI

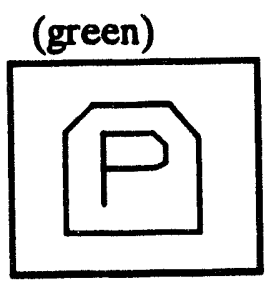

Prefabricated Building

Prefab B

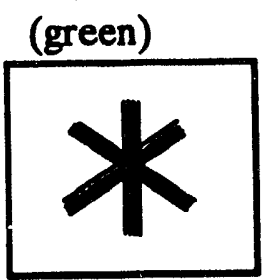

\section{Rescue Squad}

Rescue S

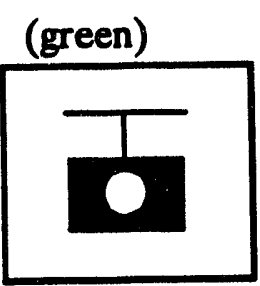

Scales 
Symbol
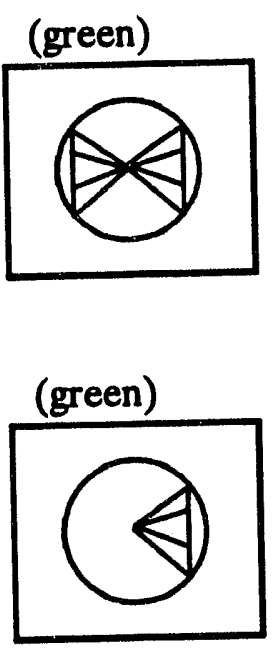

(green/white)

뭉

(green/white)

$\frac{1}{0-0}$

(green/white)

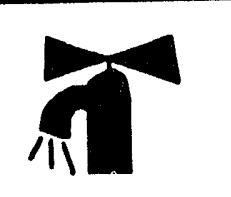

Type

Non-rotating Siren

Siren-NR

\section{Rotating Siren}

Siren-R

Transport Vehicles

Transprt

Trucks

Water 


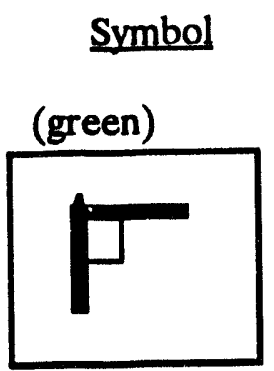

\section{Type}

Weapons 


\section{Non-Facility/Resource Icoris}

Symbol

(red)

5

(green)
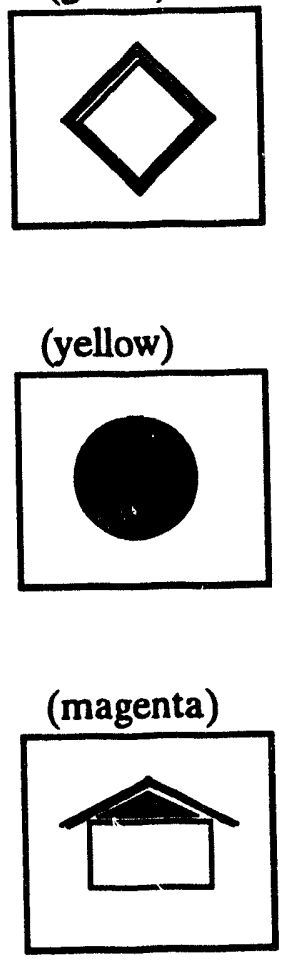

(magenta)

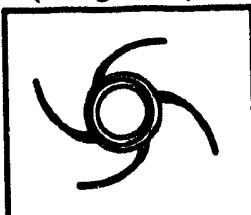

Type

Emergency Equipment

Hazmat Site

Other Control Point

Evacuation Shelter

Hurricane 
(magenta)

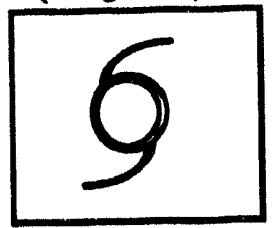

(magenta)

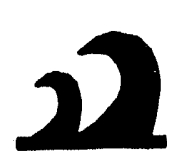

(red)

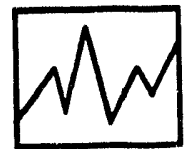

(red)

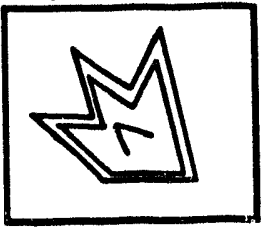

(white)

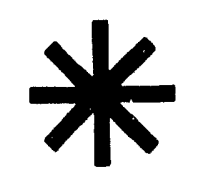

(blue)

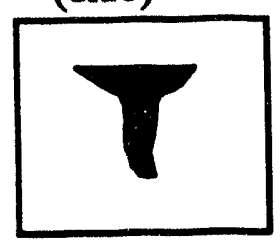

Tropical Storm

Tsunami

Earthquake

Fire

Blizzard

Tornado 

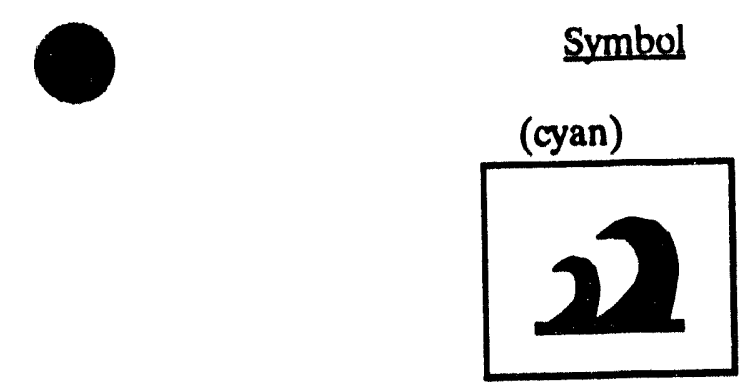

Type

Flood

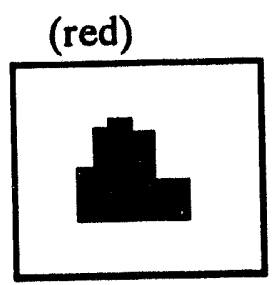

City

(red)

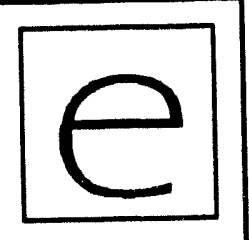

(blue/yellow)

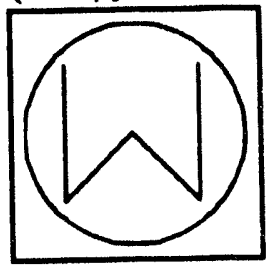

(red/blink white)

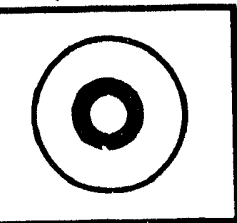

Environment Report

Weather Report

NAPB Target 
-

○

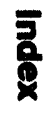

-

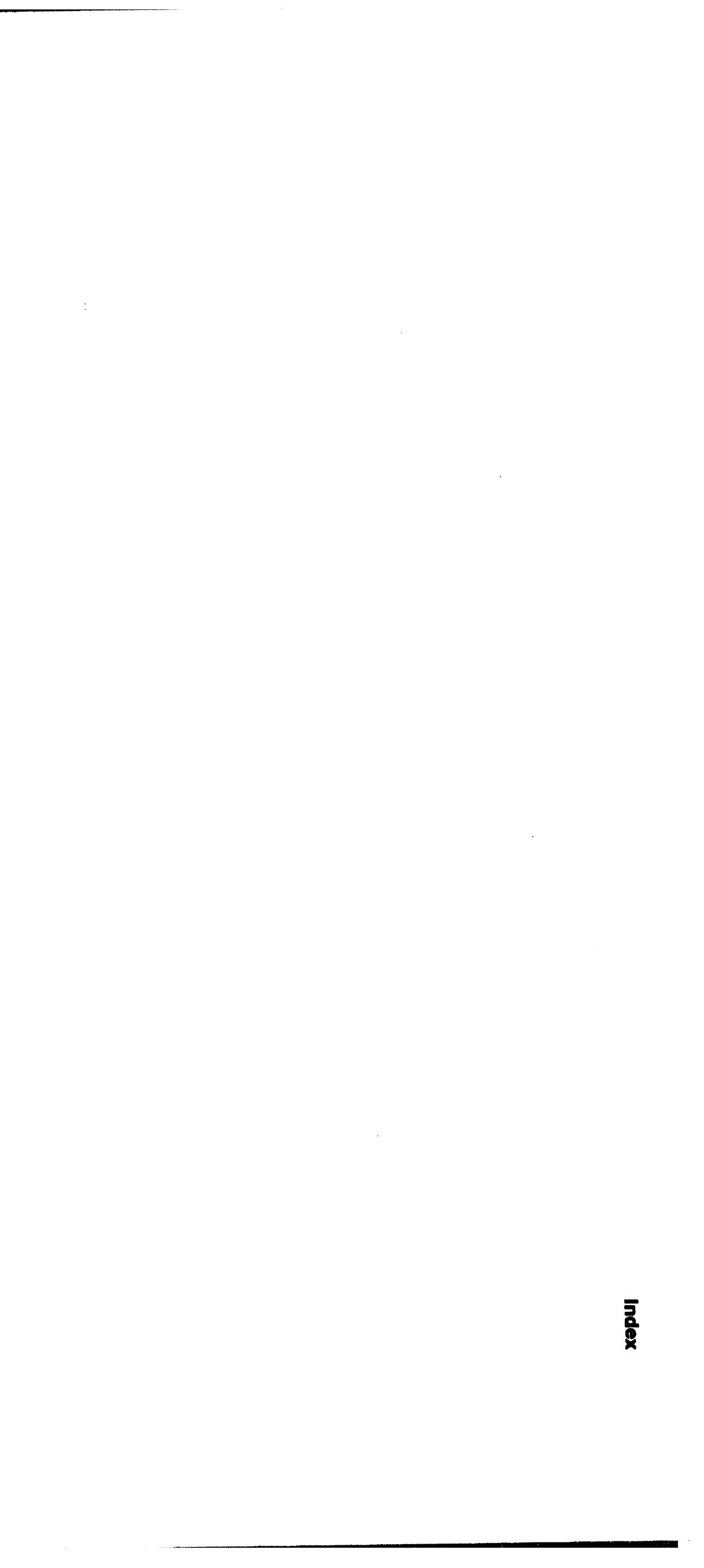


A

area

defining an area on the map screen $\mathbf{1 . 1 2}$

action notes

changing 3.27

actions

for an IP task 3.30

viewing and changing 3.25

ADD AGENCIES 4.3

ADD EP ZONE [NAME] 11.13

ADD EP ZONE [PICK] 11.13

ADD FACILITIES* 6.4, 11.59

Enter Facility Description 6.5

Enter Personnel Information 6.6

Specify Facility Location 6.4

ADD LOCATION* 11.59

ADD PEOPLE 4.7

ADD POSITIONS 4.13

agency to add, specifying 4.13

Enter a New Position Name 4.15

Specify Which Agency 4.13

ADD SPECIAL POPULATION 11.7

agency lookup table 4.2

Agency Tasks 4.2

ANALYZE TRACK 8.1

ANIMATE D2 TRACK 11.25, 40

ANIMATE D2 TRACK 8.3

ANNOTATE LOG 2.2

ARCHIVE IP OPTIONS

Archive Current IP 3.5

Reinitialize Current IP 3.5

Retrieve Archived IP to Current IP 3.5 areas/boundaries E.14

ASSIGN RESOURCES* 6.20

Resource Information, Enter 6.20

Select a Facility 6.20

asterisks in this guide 1.7

attribute description map items 5.11, 13

B

BACKUP/RESTORE SITE DATA 12.2

base case, D2 model 11.44

base map 5.14

BASE POPULATION E.29

BATCH LOG 3.41

C

CALL LIST E.30

case data

copying 12.14

case selection criteria

D2 model 3.37

D2 case, listing a 9.4

evacuation model 11.35

for selecting a D2 model case $\mathbf{9 . 2}$

casualty information E.11

CASUALTY SUMMARY E.31

centroids $\mathbf{1 1 . 2 9}$

CHANGE COMBINED REPOR'T 2.4

CHANGE D2 TRACK CASE* 9.1

CHANGE DEFAULT MAP LAYERS 12.28

CHANGE FILE HEADERS E.3

area of a region 5.2 
CHANGE ONPOST WORK PLAN 3.6

CHANGE SITE* 12.7

CHANGE TRACK CASE* 11.40

CHECK SENT MAIL 2.3

CHECK-IN IP and CHECK-OUT IP 3.9

Renumbering an IP $\mathbf{3 . 1 0}$

Choosing D2 Case by Searching for D2 Criteria 9.2

Common $\log$ Report annotating $\mathbf{2 . 2}$

COMMON LEGEND* 12.9

contamination area 11.4

contour 11.40

contour 8.2

COPY CASE OR SITE FILES 12.12, 14 FROM Another IBS User 12.17

TO Another IBS User 12.19

CREATE COMMON LOG REPORT 2.4

CREATE/EDIT MAIl LIST 2.7

CREATE IBS->ONPOST RPT 2.9, 12 changing report file headers 2.10 Data Input Forms, exiting from 2.11

CREATE NEW D2 CASE 11.44

CREATE NEW IP 3.11

CREATE PRIVATE LOG REPORT 2.4

D

D2 INPUT E.5, 32

D2 LOG E.6, 33

D2 model ANALYZE TRACK 8.1 changing the model case 9.1 description of current case $\mathbf{1 0 . 1}$ latest ONPOST track 7.1 reports 8.10

D2 model 11.39 changing the current case $\mathbf{1 1 . 4 0}$ description of current case $\mathbf{1 1 . 5 5}$ inputs 11.43 met conditions, changing 11.46 modifying standard case input $\mathbf{1 1 . 4 4}$ output reports $\mathbf{1 1 . 5 5}$ reference 11.43 running the current case 11.48 slice 11.dose file 11.48 track $\mathbf{1 1 . 3 9}$

D2 SLICE E.7, 35

D2 track animating 8.3

\section{DAMAGE ASSESSMENT 11.3}

data entry conventions $\mathbf{1 . 1 7}$

data forms 1.15

data entry conventions $\mathbf{1 . 1 7}$

Database Administration site database deletion $\mathbf{1 2 . 2 0}$

defaults

map layers 12.30

system setup 12.1

DEFINE RESOURCES* 6.22

DELETE AGENCIES 4.3

DELETE CONTAMINATION AREA* 11.4

DELETE DRAWN RISK POLYGON 11.13

DELETE EP ZONE 11.NAME 11.13

DELETE EP ZONE 11.PICK 11.13

DELETE FACILTIES* 6.8 
DELETE NATIONAL DEFENSE AREA* 11.4

DELETE PEOPLE 4.8

DELETE POSITIONS 4.15

DELETE RESOURCES* 6.24

DELETE SEARCH AREA 11.57

DESCRIBE EVACUATION POINT 11.28

DESCRIBE FACIUTIES 6.9

DESCRIBE RESOURCE 6.25

DESCRIBE TRACK 11.40

DESCRIBE TRACK 8.9

DETERMINE AREA 5.2

dialog/text display 1.15

Digital Line Graphics [DLG], conversion 2.2

Digital Mapping Structure [DMS], conversion 2.2

DIRECTION/CONTROL 11.6

DISABLE RESOURCE 6.26

DISPLAY ICONS 5.3

DISPLAY LOCATION 5.3

latitude 5.3

longitude 5.3

DISPLAY SAVED RISK AREA 11.14

DISPLAY TEXT 5.3

DOSE DETAIIS 11.39, 41

example report 11.42

DOSE DETAILS 8.9

example report 8.10

DRAW CONTAMINATION AREA* 11.4
DRAW NATIONAL DEFENSE AREA* 11.5

DRAW NEW RISK POLYGON 11.13

DRAW SEARCH AREAS 11.56

DRAW WEDGE RISK POLYGON 11.13

$\mathbf{E}$

elevation of point locations 8.11, 11.55

Emergency Activity map layers 12.28

Emergency Functions list of initial tasks $\mathbf{1 1 . 2 1}$ tasks screen 3.21, 28

Emergency Planning Zones defining risk area $\mathbf{1 1 . 5 1}$

Risk Area Analysis, planning options 11.13

EMERGENCY ACTIVITIES 11.1 overlays $\mathbf{1 1 . 1}$

ENABLE RESOURCES 6.27

ENVIRONMENT E.36

EOC ACTIVATION 11.18

EOC Reports, IBS and Onpost E.1

ESTIMATE POPULATION 11.11

ESTIMATE POPULATION 5.4, 8 facility summary [people locate] $\mathbf{5 . 6}$ population by age group [census] 5.5 population by facility [people locate] 5.5 total population [census] 5.4

EVAC ROUTE OVERLAYS 11.26

evacuation model case selection during scenario creation 11.52

case selection for scenario creation 11.51 
changing input data 11.29

changing the model case 11.33

display of results 11.38

output report 11.31

running the model 11.29

stopping the model 11.31

evacuation route code E.22

evacuation route overlay $\mathbf{1 1 . 2 6}$

EVACUATION 11.24

Delete route overlay 11.27

evacuation case, selection by criteria $\mathbf{1 1 . 3 5}$

event 1.1

event, notification of $\mathbf{2 . 2}$

event site database 1.3

changing between sites 12.7

Event Management Plan 1.3

EXECUTE D2* 11.43

EXECUTE EVAC MODEL * 11.29

exit nodes 11.29

F

facilities

deleting 6.8

description 11.61

description 6.9

facility icons $6.2,3,5,18$

modifying facility information 11.59

modifying facility information 6.13

resource listing 11.61

resource listing 6.9

Facility Tasks 6.3

ADD FACIITIES 6.3

DESCRIBE FACIIITIES 6.3

HIGHLIGHT FACILITIES 6.3

MODIFY FACILITIES 6.3

file maintenance, D2 model 11.49
G

GENERATE CALL LIST* 11.19

GENERIC TEXT DATÂ $8.9,38$

GOLD key 1.15

GRID OPTIONS 5.8

H

hardware devices 1.8

differences between 1.11, 15, 16

HARDWARE SETTINGS 12.23

HAZARD ANALYSIS 11.39

HELP

key 1.15

with text menus and forms $\mathbf{1 . 1 6}$

high-resolution map data 12.31

HIGHLIGHT DATA 5.9, 18

HIGHLIGHT FACILITIES 6.11, 18

Select Resources to Locate 6.12

Specify Area of Interest 6.11

I

icons

description of F.1

displaying 5.3

Facility F.3

Non-Facility/Resource F.19

R/source F.13

turning off 5.17

\section{IDENTIFY MAP ITEM 5.11}

Implementing Procedures 3.1, 13

Change Tasks

Editing Task Information 3.31

Information Fields, Task 3.29

Select New IP

Base Time, Set IP $\mathbf{3 . 3 5}$

D2 Cases, Identify Appropriate 3.37 
D2 Cases, Select from a List of Identified 3.38

Number, Choose IP 3.34

Operational Mode, Selecting a New IP

3.33

Plan Mode, Selecting a New IP 3.39

Retain Completed Tasks from Previous IP 3.35, 39

SEARCH FOR IP CRITERIA, Choose IP by 3.36

Change IP Notes 3.20

Change Tasks 3.28

components of 3.3

illustration 3.3

Report 3.16

report format 3.18

Select New IP 3.33

selecting an IP based on the current

Work Plan 3.6

starting a new IP 3.35

summary of options 3.15

task action list $\mathbf{3 . 3 0}$

task completion time $\mathbf{3 . 3 0}$

task resource list $\mathbf{3 . 3 0}$

task starting time 3.29

Use Tasks 3.21

Task Actions, Viewing [and Changing]

3.25

Task Resources, Viewing [and

Changing] 3.26

Task/Action/Resource Notes, Viewing

[and Changind] 3.27

Tasks by Description, Listing 3.24

Tasks, Listing Overdue 3.24

View IP Notes 3.20

INFOMANAGER ROOT

MAINTENANCE* 12.11, 13

initial tasks 11.18, 21

interaction conventions

defining an area on the map screen $\mathbf{1 . 1 2}$ graphic 1.8

textual 1.14

using data forms 1.15

using menus 1.15

IP

selecting IP for scenario record 11.51
IP Notes

changing 3.20

viewing 3.20

IP - See Implementing Procedure

ARCHIVE IP 3.5

$\mathbf{J}$

JOB ENVIRONMENT 12.10

$\mathbf{K}$

key word, specification of messages 2.5

KEYED DATA E.10, 39

known points, specifying point locations 11.59

KNOWN POINTS E.40

$\mathbf{L}$

link information 11.28

link-node diagram 11.24, 28

links 11.24, 28

LIST AGENCIES 4.6

UST FIRST TASKS 11.21

LIST PEOPLE functions 4.9

LIST POSITIONS 4.17

UST RESOURCES 6.28

LOCATE program 1.4

M

mail

VAX MAIl 2.15

mail messages 2.1

expiration time 2.15

priority 2.15

Sending 2.See Send Mail 2.1 
Mail Checker mail distribution list [See Create/Edit Mail List] 2.2

Main Menu using the 1.7

map display

highlighting items 5.9

options 5.1

text 5.3

map graphic information exchange of data 2.2

graphic map overlays, exchanged [See map graphics] 2.2

map layer

Emergency Activity overlays 11.1

RISK POLYGON 11.12

map layers

chsnging defaults 12.30

for each Emergency Activity 12.28

restricting based on display size 12.31

restricting by display size $\mathbf{1 2 . 2 9}$

map layers 5.13

MAP ANALYSIS 5.1

area and perimeter 5.2

highlighting map items 5.18

MAP LAYERS - BY ACTIVITY 12.28

MAP LAYERS - DEFAULT 12.30

MAP ZOOM 5.11

menus 1.5

picking items on menus 1.11

standard items on 1.10

using IBS menus 1.15

menus, pull-out reference A.1

MESSAGE BOARD 2.1

MISCELLANEOUS SETTINGS 12.23, 27

MODEL MANAGEMENT* 12.25
MODIFY AGENCIES 4.3

Name and Code 4.5

Specify Which Agency to Modify 4.4

MODIFY FACILITIES* 6.13, 11.9, 59

Modify Facility Description 6.13

Modify Known Point Location or Name 6.14

Select a Facility 6.13

Select Known Point 6.14

MODIFY PEOPLE 4.11

Enter New Information about the Person 4.12

Specify Which Person to Modify 4.11

MODIFY POSITIONS 4.16

Enter a New Name for the Position 4.17

Specify Which Position to Modify 4.16

MODIFY RESOURCES* 6.29

Modifying the Resource Information 6.30

Select Resource for Modifying 6.29

MODIFY SPECIAL POPULATION* 11.10

MOVE RESOURCES* 6.32

Select Destination Facility 6.33

Select Resource to Move 6.32

Specify Amount of Resource to Move 6.32

mutual aid agreement 6.6

$\mathbf{N}$

National Defense Area 11.4, 5

nodes $11.24,28$

non-graphic ibs starting B.1

using B.1

NOTIFICATION E.42

O

OFFPOST CASUALTY REPORT E.11 
OFFPOST EVACUATION ROUTES E.12

OFFPOST KNOWN POLYGONS E.14

OFFPOST MCE DIRECTORY E.15

OFFPOST SHELTER REPORT E.16

OFFPOST STATUS REPORT E.17

onpost simulator program

starting D.1

using D.2

Onpost Emergency Event Notification 3.40

ONPOST EVENT STATUS 3.40

ONPOST WORK PLAN 3.42

overlays 11.1

release 11.32

retain $\mathbf{1 1 . 3 2}$

$\mathbf{P}$

PC workstation 1.8

dialog key 1.15

GOLD key 1.16

graphic input 1.12

HELP key 1.16

people location program

starting C.1

using $\mathbf{C} .2$

People Tasks 4.6

perimeter of a region 5.2

personnel

listing options 4.9

personnel database 4.1

entering information 4.7

modifying 4.11

PERSONNEL MANAGEMENT 4.1

phone call list

emergency management personnel 11.19
PICK RISK POLYGON 11.13

point data, summarizing 5.15

population pattern 11.6, 31

during scenario creation 11.51

population, percent evacuated 11.30

position tasks 4.12

PRINT D2 REPORT 11.55

PRINT REPORT

for D2 track 8.10

privileges 1.9

problems

with graphic menus or input 1.14

with text menus or input 1.19

PROPOSED EVACUATION ROUTES E.22

PROPOSED MILITARY ROUTES E.23

PROTECTIVE ACTION REPORT E.19

pull-out menus, quick reference A.1

$\mathbf{R}$

RECEPTION CTR DIRECTORY E.25

RECEPTION CTR REPORT E.26

REFRESH SCREEN 5.13

RELEASE/RETAIN OVERLAYS 11.1, 11, 32,57

REMOVE LATEST ONPOST TRACK 7.1

REPORT CURRENT D2 DESCRIPTION 10.1

\section{REPORT CURRENT D2 DESCRIPTION} 11.55

RESEND IBS->ONPOST RPT 2.12 
resource notes

changing 3.27

Resource Form Use 6.34

Resource Tasks 6.18

ASSIGN RESOURCES 6.18

DEFINE RESOURCES 6.18

DESCRIBE RESOURCES 6.18

ENABLE RESOURCES 6.18

MODIFY RESOURCES 6.18

MOVE RESOURCES 6.18

SUMMARIZE RESOURCES 6.18

\section{RESOURCE MANAGEMENT 6.1}

resources

assigning to facilities 6.20

defining $6.22,24$

duiete 6.24

erasing resource icons 6.26

facilities with specific resources 6.11

fr $r$ an IP task 3.33

listing 6.18, 25

modifying 6.29

moving 6.32

resource icons $6.1,18,27$

resource type 6.38

summary of 6.40

type 6.1

using the resource form 6.34

RESTART [evacuation model] 11.33

RESTORE BASE MAP 5.13

risk area 11.12

during scenario creation 11.51

POPULATION SUMMARY 11.14

SAVE CURRENT 11.14, 16

risk polygon 11.12

RISK AREA ANALYSIS 11.12

RISK AREA POPULATION SUMMARY 11.14

route, evacuation route overlay $\mathbf{1 1 . 2 6}$

RUN [evacuation model] 11.33
$\mathbf{S}$

SAVE CURRENT RISK AREA 11.14, 16

scenario 11.43

creation of 11.49

deleting a scenario record $\mathbf{1 1 . 5 4}$

scenario table 11.49

modifying scenarios $11.53,54$

search criteria

for D2 cases 3.37

search criteria for evacuation cases $\mathbf{1 1 . 3 5}$

SEARCH/RESCUE 11.56

Select Message Category 2.4

SELECT IP 3.39, 11.17

SELECT MAP LAYERS 5.13

SELECT MODEL CASE* 11.33

selecting an EMP using the current Work Plan 3.7

Selecting a Facility 6.16

Selecting a Resource 6.37

Selecting a Resource Type 6.38

SELECTIVE STATUS 11.37

SEND MAIL 2.14

Mail Destination Menu 2.14

Mail Recipients, selecting 2.14

Mail Subject Form 2.14

Unread Mail [See Check Sent Mail]

2.14

SET BASE MAP 5.14

SET TIME STEP 11.38

\section{SETUP 12.1}

job environment 12.1 
shelter areas

area codes E.16

SHELTER \& CENTER SUMMARY 11.60

SHELTER OR CENTER INFO 11.61

SHELTERING 11.58

SHOW ELEVATION 11.55

SHOW ELEVATION 8.11

SHOW LATEST ONPOST TRACK 7.1

SIGNIFICANT EVENTS E.43

site data, copying 12.14

site database

deleting $\mathbf{1 2 . 2 0}$

slice file [from D2 model] 11.48

STATUS BOARD 3.1

STEP BACKWARD 11.38

STEP FORWARD 11.38

SUMMARIZE POINT DATA 5.15

SUMMARIZE RESOURCES 6.40

Select Area of Interest 6.40

Select Resource Type to be Summarized 6.41

$\mathbf{T}$

task notes $\mathbf{3 . 3 0}$

changing 3.27

viewing 3.25-27

tasks

time-stamping 3.21

tasks, list of initial tasks $\mathbf{1 1 . 2 3}$

text

displaying 5.3

erasing 5.4 turning off 5.17

text/dialog display 1.15

TOWER SELECTION E.44

track 8.1

TRAFFIC CONTROL REPORT E.27

TURN OFF ICONS 5.3, 17

TURN OFF TEXT 5.4, 17

$\mathbf{U}$

Understanding Implementing Procedures 3.2 IP Development Conditions 3.2

\section{UNHIGHIGHT DATA 5.18}

Use Tasks

Tasks, Listing Overdue 3.24

user privileges 1.4

USER ENVIRONMENT 3.41

users

types of 1.4

V

VAX MAIL 2.15

distribution lists 2.7

frequently used commands 2.15

important messages 2.4

one-time setup commands 2.16

VAX PHONE 2.17

frequently used commands 2.17

using 2.17

verification number 3.40

VIEW COMMON LOG REPORT 2.18

VIEW IBS->ONPOST RPT 2.18

VIEW ONPOST WORK PLAN 3.6 
Index

VIEW ONPOST->IBS RPT 2.20

VIEW PRIVATE LOG REPORT 2.18

$\mathbf{W}$

WEATHER E.45

Work Plan 3.6

selecting an Implementing Procedure based on the Work Plan 3.6

WORK PLAN E.46

$\mathbf{Z}$

ZOOM capabilities

MAP ZOOM 5.11

RESTORE BASE MAP 5.13

SELECT MAP LAYERS 5.13

SET BASE MAP 5.14

ZOOM IN 5.19

ZOOM OUT 5.20

ZOOM IN 5.19

ZOOM OUT 5.20 
PNL-8318

Ver. 2.0

UC-620

\section{DISTRIBUTION}

No. of

Copies

OFFSITE

2 DOE/Office of Scientific and Technical Information

COL Lawrence E. Skelly

United States Army Nuclear and Chemical Agency

7500 Backlick Road, Building 5073

Springfield, VA 22150-3198

Mr. J. Thompson

Operations Support Directorate

HQ FEMA

5321 Riggs Road

Gaithersburg, MD 20882

John Bower

Bower Software Services

104 E. 36th Place

Kennewick, WA 99337
No. of

Copies

ONSITE

DOE Richland Operations Office
R. B. Goranson
K8-50

43 Pacific Northwest Laboratory

B. M. Bailey (30)

M. J. Burford

T. R. Downing

S. W. Matsumoto (2)

S. L. Savelli

S. N. Stevens

J. R. Williams

C. Winters (2)

Publishing Coordination

Technical Report Files (3) 
$1 !$
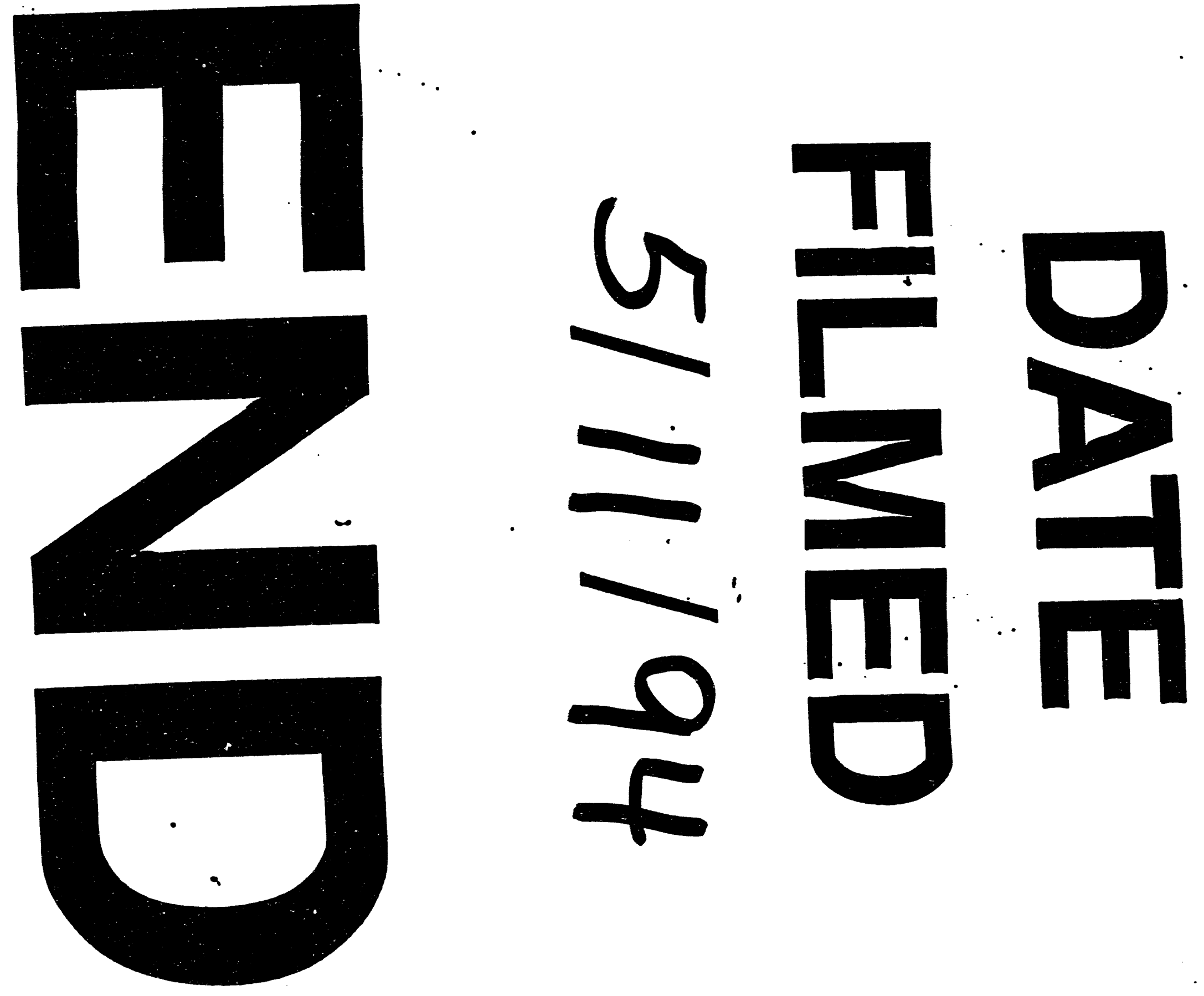


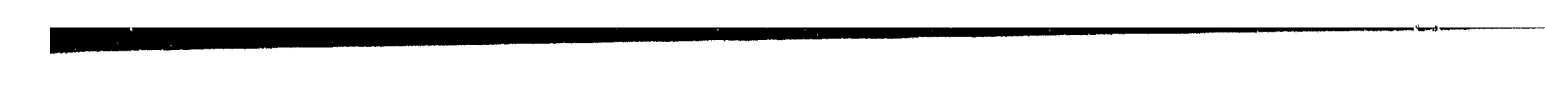

